\title{
Hydraulic Research \\ in the United States
}

1961

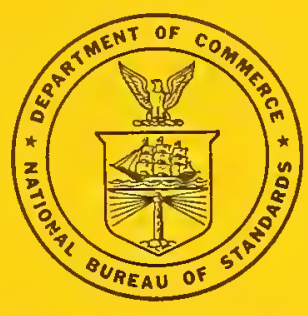

United States Department of Commerce

National Bureau of Standards

Miscellaneous Publication 238 


\section{THE NATIONAL BUREAU OF STANDARDS}

\section{Functions and Activities}

The functions of the National Bureau of Standards are set forth in the Act of Congress, March 3, 1901, as amended by Congress in Public Law 619, 1950. These include the development and maintenance of the national standards of measurement and the provision of means and methods for making measurements consistent with these standards; the determination of physical constants and properties of materials; the development of methods and instruments for testing materials, devices, and structures; advisory services to government agencies on scientific and technical problems; invention and development of devices to serve special needs of the Government; and the development of standard practices, codes, and specifications. The work includes basic and applied research, development, engineering, instrumentation, testing, cvaluation, calibration services, and various consultation and information services. Research projects are also performed for other government agencies when the work relates to and supplements the basic program of the Bureau or when the Bureau's unique competence is required. The scope of activities is suggested by the listing of divisions and sections on the inside of the back cover.

\section{Publications}

The results of the Bureau's research are published either in the Bureau's own series of publications or in the journals of professional and scientific societies. The Bureau itself publishes three periodicals available from the Government Printing Office: The Journal of Research, published in four separate sections, presents complcte scientific and technical papers; the Technical News Bullctin presents summary and preliminary reports on work in progress; and Basic Radio Propagation Predictions provides data for determining the best frequencies to use for radio communications throughout the world. There are also five series of nonperiodical publications: Monographs, Applied Mathematics Series, Handbooks, Miscellaneous Publications, and Technical Notes.

A complete listing of the Bureau's publications can be found in National Bureau of Standards Circular 460 , Publications of the National Bureau of Standards, 1901 to June 1947 (\$1.25), and the Supplement to National Bureau of Standards Circular 460, July 1947 to June 1957 (\$1.50), and Misccllaneous Publication 240, July 1957 to June 1960 (Includes Titles of Papers Published in Outside Journals 1950 to 1959) (\$2.25); available from the Superintendent of Documents, Government Printing Office, Washington 25, D.C. 


\section{Hydraulic Research in the United States}

1961

(Including Contributions from Canadian Laboratories)

Edited by Helen K. Middleton

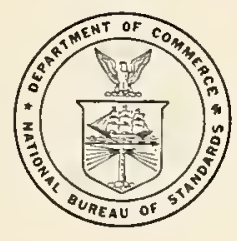

National Bureau of Standards Miscellaneous Publication 238

Issued August 15, 1961

For sale by the Superintendent of Documents, U.S. Government Printing Office, Washington 25, D.C. - Price $\$ 1.25$ 

The information contained in this publication was compiled from reports by the various hydraulic and hydrologic laboratories in the United States and Canada. The cooperation of these agencies is greatly appreciated. The National Bureau of Standards cannot assume responsibility for the completeness of this publication. We must depend upon reporting laboratories for the completeness of the coverage of their own programs, as well as upon new laboratories engaged in hydraulics to bring their activities to our attention.

Projects are numbered chronologically, and the number once assigned is repeated for identification purposes until a project is completed. Numbers commencing with 3667 refer to projects which are reported for the first time. All projects are in active state, unless otherwise noted under ( $f$ ).

The National Bureau of Standards does not maintain a file of reports or detailed information regarding the research projects reported by other organizations. Such information may be obtained from the correspondent listed under (c) or immediately following the title of the organization reporting the work. It is of course understood that any laboratory submitting reports on its work will be willing to supply information to properly qualified inquirers.

A similar bulletin, "Hydraulic Research," compiled and published by the International Association for Hydraulic Research, contains information on hydraulic research being conducted in foreign countries. This bulletin is edited by Professor H. J. Schoemaker, Director of the Hydraulic Laboratory at the Technical University of Delft, Netherlands, and Secretary of the International Association for Hydraulic Research. Copies may be obtained from the Secretary at $\$ 6.00$ each (postage included). 


\section{CONTENTSS}

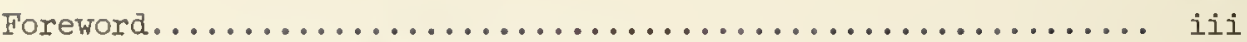

List of contributing laboratories..................... v v

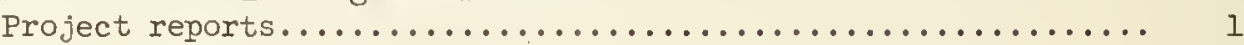

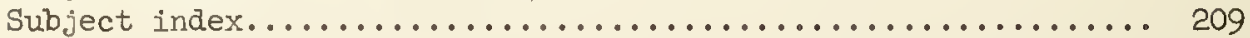

\section{Key to Projects}
(a) Number and title of project
(e) Description
(b) Project conducted for
(c) Correspondent
(f) Present status
(d) Nature of project
g) Results
(h) Publications 
ACCURATE PRODUCTS COMPANY

400 Hillside Ave., Hillside, N. J.

Dr. Peter G. Buehning, Vice Pres.

ARKANSAS, UNIVERSITY OF

Agricultural Experiment Sta., Fayetteville, Ark.

Prof. Kyle Engler, Head

Agricultural Engineering Dept.

ARKANSAS, UNIVERSITY OF

Civil Engineering Dept., Fayetteville, Ark.

Prof. L. R. Heiple, Head

BEACH EROSION BOARD (see U. S. Government)

BONNEVILIE HYDRAULIC LABORATORY (see U. S. Govt., U. S. Army Engineer District, Portland)

BROOKLYN, POLYTECHNIC INSTITUTE OF

333 Jay Street, Brooklyn 1, New York

Prof. Matthew W. Stewart, Civil Engineering

CALIFORNIA INSTITUTE OF TECHNOLOGY

Ergineering Division, Pasadena 4, Calif.

Prof. Milton S. Plesset, Applied Mechanics

CALIFORNIA INSTITUTE OF TECHNOLOGY

Hydrodynamics Laboratory, Pasadena 4, Calif.

CALIFORNIA INSTITUTE OF TECHNOLOGY

W. M. Keck Laboratory of Hydraulics and Water

Resources, Pasadena 4, California

Dr. Vito A. Vanoni, Professor of Hydraulics

CALIFORNIA, UNIVERSITY OF

College of Agriculture, Davis, California

Mr. Robert M. Hagan, Chairman, Dept. of Irrigation

CALTFORNIA, UNIVERSITY OF

College of Agriculture, Los Angeles 24, Calif.

Prof. A. F. Pillsbury, Chairman

Department of Irrigation and Soil Science

CALIFORNIA, UNIVERSITY OF

College of Engineering, Berkeley 4, Calif.

Prof. J. W. Johnson, Hydraulic Engineering

CALIFORNIA, UNIVERSITY OF

Dept. of Engineering, Los Angeles 24, Calif.

Prof. J. Morley English, Vice Chairman - Research

CALIFORNIA, UNTVERSITY OF

Dept. of Naval Architecture, Berkeley 4, Calif.

Prof. H. A. Schade, Chairman

CALIFORNIA, UNIVERSTTY OF SOUTHERN

Research Foundation for Cross-Connection Control

Los Angeles 7, California

Dr. K. C. Reynolds, Supervisor

CARNEGIE INSTITUTE OF TECHNOLOGY

Jept. of Civil Engineering, Pittsburgh 13, Penna.

r. T. E. Stelson, Head

Fivil Engineering Section, Fort Collins, Colo.

Dr. A. R. Chamberlin, Chief
COLORADO, UNIVERSITY OF

Hydraulic Lab., Dept. of Civil Engrg.;

Boulder, Colo.

Prof. R. C. Rautenstraus, Dept. Chairman

CONNECTICUT, UNIVERSITY OF

Mechanical Engrg. Dept., Box U-37, Storrs, Conn. Prof. Ronald S. Brand

1 CONNECTICUT, UNTVERSTTY OF

27

Civil Engineering Dept., Box U-37, Storrs, Conn.

Prof. Victor Scottron, Civil Engineering

CORNELL UNIVERSTTY

School of Civil Engineering

Applied Hydraulic Laboratory, Ithaca, N. Y.

Prof. Marvin Bogema, in Charge

1 DAVID TAYLOR MODEL BASIN (see U. S. Govermment)

DELAWARE, UNIVERSITY OF

Dept. of Civil Engrg., Fluids Lab., Newark, Del.

1 Dr. Kurt Frey, Directing Head

DOUGLAS AIRCRAFT COMPANY 28

El Segundo Div., 827 Lapham St., El Segundo, Calif.

FLORIDA, UNIVERSITY OF

3 The Engineering and Industrial Experiment Sta.

Coastal Engineering Laboratory, Gainesville, Fla. Dr. Per Bruun

GEORGIA INSTITUTE OF TECHNOLOGY

102 Hydraulics Laboratory, School of Civil Engrg.

Atlanta, Georgia

Prof. C. E. Kindsvater

4 HOUSTON, UNIVERSITY OF

Chemical and Petroleum Engrg. Dept.

Houston, Texas

Prof. C. V. Kirkpatrick, Director

5 HYDRONAUTICS, INCORPORATED

200 Monroe Street, Rockville, Ma.

Mr. Phillip Eisenberg, Pres.

12 IDAHO, UNIVERSITY OF

Englneering Experiment Sta., Moscow, Idaho

Dean Allen S. Janssen, Director

11 ILLINOIS STATE WATER SURVEY DIVISION

Box 232, Urbana, Illinois

Mr. William C. Ackermann, Chief

13 ILLINOIS STATE WATERWAYS DIVISION

Dept. of Public Works and Buildings

201 West Monroe st., Springfield, Ill.

Mr. Thomas B. Casey, Chief Waterway Engr.

13 ILLINOIS, UNIVERSITY OF

Dept. of Agricultural Engrg., Urbana Ill.

Dr. Frank B. Lanham, Head

14 ILLINOIS, UNIVERSITY OF

Department of Civil Engineering

Urbana, Illinois

Dr. V. T. Chow, Prof. Hydraulic Engineering 
ILLINOIS, UNIVERSITY OF

Dept. of Theoretical and Applied Mechanics

214 Talbot Laboratory, Urbana, Illinois

Prof. T. J. Dolan, Head

IOWA INSTITUTE OF HYDRAULIC RESEARCH

State University of Iowa, Iowa City, Iowa

Dr. Hunter Rouse, Director

IOWA STATE UNIVERSITY

Dept. of Agricultural Engineering, Ames, Iowa

Prof. Hobart Beresford, Head

IOWA STATE UNIVERSITY

Department of Agronomy, Ames, Iowa

Prof. William H. Pierre, Head of Dept.

IOWA STATE UNIVERSITY

Iowa City, Iowa (see Iowa Institute of

Hydraulic Research)

JOHNS HOPKINS UNIVERSITY, THE

Applied Physics Laboratory, Silver Spring, Md.

Mr. R. E. Gibson, Director

JOHNS HOPKINS UNIVERSITY, THE

School of Engineering, Baltimore 18, Maryland

Dr. John C. Geyer, Chairman

Dept. of Sanitary Engineering and Water Resources

KANSAS, UNIVERSITY OF

Dept. of Engineering Mechanics, Lawrence, Kansas

Dr. Kenneth C. Deemer, Chairman

LEHIGH UNIVERSITY

Dept. of Civil Engineering

Fritz Engineering Lab., Bethlehem, Penna.

Prof. W. J. Eney, Director and Head of Dept.

LOUISIANA STATE UNTVERSTTY AND A AND M COLLEGE

Agricultural Engineering Research,

Baton Rouge 3, La.

Mr. Harold T. Barr, Head

\section{MASSACHUSETTS INSTITUTE OF TECHNOLOGY}

Dept. of Civil and Sanitary Engineering

Cambridge 39, Massachusetts

Dr. Arthur T. Ippen, Head, Hydrodynamics Lab.

\section{MASSACHUSETTS INSTITUTE OF TECHNOLOGY}

Dept. of Mechanical Engrg., Cambridge 39, Mass.

Prof. Ascher H. Shapiro, in Charge

Fluid Mechanics Division

MASSACHUSETTS, UNIVERSITY OF

School of Engineering, Amherst, Mass.

Dean George A. Marston, Director

\section{MICHIGAN STATE UNIVERSITY}

Dept. of Civil Engineering, East Lansing, Mich. Dr. Enmett M. Laursen, Associate Professor

\section{MICHIGAN, UNIVERSITY OF}

Department of Civil Fngineering

320 West Engineering Building

Ann Arbor, Michigan

Prof. E. F. Brater

MINNESOTA, UNIVERSITY OF

Minneapolis, Minn. (see St. Anthony Falls

Hydraulic Laboratory)
St. Paul 1, Minnesota

Prof. A. J. Schwantes, Head

40 MISSOURI SCHOOL OF MINES AND METALI,URGY

Dept. of Civil Engineering, Rolla, Missouri

Dr. C. L. Wilson, Dean

44 MONTANA STATE COLTEGE

Agricultural Experiment Sta., Bozeman, Mont.

$\mathrm{Mr}$. O. W. Monson, Head

Agricultural Engineering Department

NEBRASKA, UNIVERSITY OF

Hydrodynamics Lab., Dept. of Engineering

Mechanics

Lincoln 8, Nebraska

Dr. T. Sarpkaya

NEWPORT NEWS SHIPBUILDING AND DRY DOCK CO.

45 Hydraulic Laboratory, Newport News, Virginia Mr. C. H. Hancock, Director

NEW YORK UNTVERSITY

46 Dept. of Chemical Engineering, Bronx 53, N. Y. Prof. John Happel, Chaiman

NEW YORK UNTVERSITY

College of Engineering, Dept. of Meteorology

and Oceanography

University Heights, New York 53, New York

\section{NORTH CAROLTNA STATE COLLEGE OF AGRICULTURE}

AND ENGINEERINC

University of North Carolina, Dept. of Engrg.

Research, Raleigh, North Carolina

Prof. N. W. Connor, Director, Engrg. Research

49 NORTH DAKOTA AGRICULTURAL COLIEGE

Dept. of Agricultural Engineering, Fargo, No. Dak.

Mr. W. J. Promersberger, Chairman

NORTHWESTERN UNIVERSITY

49 The Technological Institute, Evanston, Illinois

Dean Harold B. Gotaas

NOTRE DAME, UNIVERSITY OF

School of Engineering, Notre Dame, Indiana

53 Dr. H. C. Saxe, Acting Dean

OHIO STATE UNIVERSITY

Dept. of Civil Engineering, Columbus 10, Ohio

Dr. Hamilton Gray, Head

OKLAHOMA STATE UNIVERSITY

Agricultural Engineering Dept., Stillwater, Okla.

Prof. E. W. Schroeder, Head

OREGON STATE COLLEGE

Hydraulics Lab., Dept. of Civil Engineering

Corvallis, Oregon

58 Dr. Charles E. Behlke

PENNSYLVANIA STATE UNIVERSITY

Ordnance Research Lab., University Park, Penna.

Dr. John C. Johnson, Director

PURDUE UNIVERSITY

Agricultural Experiment Sta., Lafayette, Ind.

Mr. N. J. Wolk, Director 
PURDUE UNIVERSITY

School of Chemical Engineering, Lafayette, Ind.

Dr. Edward M. Camings, Head

PURDUE UNIVERSITY

Civil Engineering Dept., Lafayette, Indiana

Prof. K. B. Woods, Head

PURDUE UNIVERSITY

School of Electrical Engineering, Lafayette, Ind.

Dr. T. F. Jones, Head

PURDUE UNIVERSITY

Jet Propulsion Center, Lafayette, Indiana

Dr. Maurice J. Zucrow, Director

PURDUE UNIVERSITY

School of Mechanical Engrg., Lafayette, Ind.

Dr. P. F. Chenea, Head

PURDUE UNIVERSITY

School of Mech. Engrg., Automatic Control Lab.,

W. Lafayette, Indiana

Dr. Rufus Oldenburger, Head

REED RESEARCH, INCORPORATED

1048 Potomac St., N. W., Washington 7, D. C.

Mr. Staniey F. Reed, Pres.

ROCKY MOUNTAIN HYDRAULIC I.ABORATORY

Allenspark, Colo., Prof. C. J. Posey, Director

(Winter address: State Univ. of Iowa,

Iowa City, Iowa)

ST. ANTHONY FALLS HYDRAULIC LABORATORY

Miss. River at Third Ave., S. E., Minneapolis, Minn.

Dr. Lorenz Straub, Director

SCRIPPS INSTITUTION OF OCEANOGRAPHY

University of California, La Jolla, Calif.

The Director

SOUTHWEST RESEARCH INSTITUTE

Dept. of Applied Mechanics, San Antonio 6, Texas

Dr. H. Norman Abramson, Director

STANFORD UNIVERSITY

Dept. of Civil Engineering, Stanford, Calif.

Prof. Ray K. Linsley, Executive Head Hydraulic Lab.

STEVENS INSTITUTE OF TECHNOLOGY

Davidson Laboratory

711 Hudson St., Hoboken, New Jersey

Dr. J. P. Breslin, Director

ROBERT TAGGART INCORPORATED

400 Arlington Boulevard, Falls Church, Va.

Mr. Robert Taggart

TENNESSEE, UNIVERSITY OF

Dept. of Civil Engineering, Knoxville 16, Tenn.

$\mathrm{Dr}$. Harry H. Ambrose, Prof. of Hydraulics

TEXAS A AND M COLIEGE

Dept. of Oceanography and Meteorology

College Station, Texas

Dr. Dale F. Leipper, Head

TEXAS, UNIVERSITY OF

Dept. of Civil Engineering, Austin 12, Texas

Dr. Walter I. Moore, Directing Head
UTAH STATE UNIVERSITY

Engineering Experiment Station, Logan, Utah

Dr. Vaughn E. Hansen, Director

72 WASHINGTON STATE UNIVERSITY

96

The R. L. Albrook Hydraulic Lab., Pullman, Wash.

Dr. E. Roy Tinney, Head

73 WASHINGTON, UNIVERSITY OF

Fisheries Research Institute, Seattle 5, Wash.

Dr. William F. Royce, Director

74 WASHINGTON, UNIVERSTTY OF

Dept. of Civil Engineering, Seattle 5, Wash.

Prof. R. B. van Horn, Head

WATERWAYS EXPERIMENT STATION (see U. S. Govt.)

WISCONSIN, UNIVERSTTY OF

Hydraulic Lab., Dept. of Civil Engineering

.74 Madison, Wisconsin

Dr. Arno T. Lenz

WOODS HOIE OCEANOGRAPHIC INSTITUTION

Woods Hole, Mass.

75 Dr. Paul M. Fye, Director

WORCESTER POLYTECHNIC INSTITUTE

Alden Hydraulic Laboratory, Worcester 9, Mass.

Prof. L. J. Hooper, Director

\section{U. S. GOVERNMENT AGENCIES}

\section{DEPARTMENT OF AGRICULTURE}

AGRICULTURAL RESEARCH SERVICE

80 Soil and Water Conservation Research Division Beltsville, Maryland

Dr. C. H. Wadleigh, Chief

FOREST SERVICE

ALASKA FOREST RESEARCH CENTER

Box 740, Juneau, Alaska

Mr. R. F. Taylor

CENTRAL STATES FOREST EXPERIMENT STATION

lll Old Federal Bldg., Columbus 15, Ohio

Mr. R. D. Lane, Director

INTERMOUNTAIN FOREST AND RANGE EXP. STATION

Forest Service Building, Ogden, Utah

Mr. Reed W. Bailey, Director

LAKE STATES FOREST EXPERIMENT STATION

Univ. of Minn., St. Paul 1, Minn.

Dr. Murlyn B. Dickerman, Director

NORTHEASTERN FOREST EXPERIMENT STATION

102 Motors Ave., Upper Darby, Penna.

Dr. Ralph W. Marquis, Director

PACIFIC NORTHWEST FOREST AND RANGE EXP. STA. P. O. Box 4059, Portland 8, Oregon

Mr. R. W. Cowlin, Director

90 PACIFIC SOUTHWEST FOREST AND RANGE EXP. STA.

P. O. Box 245, Berkeley 1, California

Mr. R. Keith Arnold, Director 
ROCKY MOUNTAIN FOREST AND RANGE EXP. STA. 221 Forestry Bldg., Fort Collins, Colorado Mr. Raymond Price, Director

SOUTHEASTERN FOREST EXPERIMENT STATION

P. 0. Box 2570, Asheville, North Carolina

Mr. Joseph F. Pechanec, Director

SOUTHERN FOREST EXPERIMENT STATION

2026 St. Charles Ave., New Orleans 13, La. Mr. Philip A. Briegleb, Director

DEPARTMENT OF THE ARMY, CORPS OF ENGINEERS

BEACH EROSION BOARD

5201 Little Falls Road, N. W., Wash. 16, D. C. The President

U. S. ARMY ENGINEER DISTRICT, PORTLAIVD Bonneville Hydraulic Laboratory

628 Pittock Block, Portland 5, Oregon

The District Engineer

U. S. ARMY ENGINEER DISTRICT, ST. PAUL

1217 U. S. Postoffice and Customhouse

St. Paul 1, Minnesota

The District Engineer

U. S. ARMY ENGINEER WATERW FIS EXPERIMEIT STA. P. 0. Box 631, Vicksburg, Miss.

The Director

\section{DEPARTMENT OF COMMERCE}

BUREAU OF PUBLIC ROADS

Hydraulics Branch, Washington 25, D. C.

Mr. Carl F. Izzard, Chief

NATIONAL BUREAU OF STANDARDS

National Hydraulics Laboratory

Washington 25, D. C.

WEATHER BUREAU

Hydrologic Services, Div., Washington 25, D. C. Mr. William E. Hiatt, Chief

\section{DEPARTMENT OF THE INTERIOR}

\section{GEOLOGICAL SURVEY}

Water Resources, Div., Washington 25, D. C.

Dr. Luna B. Leopold, Chief Hydraulic Engineer

\section{BUREAU OF RECLAMATION}

Division of Engineering Laboratories

Denver Federal Center, Denver 2, Colorado

Mr. Grant Bloodgood

Asst. Commissioner and Chief Engineer

\section{DEPARTMENT OF THE NAVY}

DAVID TAYLOR MODEL BASIN

Washington 7, D. C.

The Commanding officer and Director
The Commanding officer and Director

132 U. S. NAVAL ORDNANCE TEST STATION

3202 E. Foothill Blvd.

Pasadena 8, California

The Commander

OFFICE OF NAVAL RESEARCH

F'luid Dynamics Branch

Washington 25, D. C.

Mr. Ralph D. Cooper, Head

134 TENNESSEE VALTEY AUTHORITY

Hyaraulic Data Branch, Knoxville, Tenn.

Mr. Albert S. Fry, Chief

\section{CANADIAN LABORATORIES}

H. G. ACRES AND COMPANY, LTD.

Niagara Falls, Canada

Mr. I. W. McCaig, Hydraulic Engineer

ALBERTA, UNIVERSITY OF

Department of Civil Engineering

Edmonton, Canada

Prof. T. Blench, Head

BRITISH COLUMBIA, UNIVERSITY OF

Hydraulics Lab., Vancouver 8, Canada

Prof. H. C. Gunning, Dean, Faculty of

Applied Science

158 ECOLE POLYTECHNIQUE

2500 Guyard Ave., Montreal 26, Canada

Prof. Raymond Boucher, Head

Division of Hydraulic Engineering

THE HYDRO-EIECTRIC POWER COMMISSION OF ONTARIO

620 University Ave., Toronto 2, Canada

Mr. J. B. Bryce, Hydraulic Engineer

LaSALTE HYDRAULIC LABORATORY

0250 St. Patrick St., LaSalle, P.Q., Canada

Mr. E. Pariset, Director

NATIONAL RESEARCH COUNCIL

Div. of Mechanical Engineering

Montreal Road, Ottawa 2, Canada

Dr. D. C. MacPhail, Director

ONTARIO AGRICULTURAL COLLEGE

Dept. of Engineering Science, Guelph, Canada

Prof. C. 巴. G. Downing, Head

QUEEN'S UNIVERSTTY

Hydraulics Lab., Kingston, Ontario, Canada

Prof. R. J. Kennedy, Directing Head

180 TORONTO, UNIVERSTTY OF

Dept. of Mech. Engineering, Toronto 5, Canada

Prof. G. Ross Lord, Head.
201

204

205

206

207 
UNIVERSITY OF ARKANSAS, Agricultural Experiment Station.

(2255) GROUND WATER, RESOURCES AND RECHARGE, IN THE RICE GROWING AREA OF ARKANSAS.

(b) Arkansas Agricultural Experiment Station cooperative with U. S. Geological Survey and U. S. Corps of Engineers.

(c) Prof. Kyle Engler, Head of Agricultural Engineering Dept., University of Arkansas, Fayetteville, Arkansas.

(d) Basic and applied research.

(e) The straight 26 -inch sand-packed recharge well has been tested for one year and results have not proved completely satisfactory. Main difficulties encountered arise in duplicating test condition under field situations. The sand packed well seemed to filter out plugging material but redevelopment proved more difficult than in the gravel packed well. Separan AP-30 was tried but proved unsatisfactory for conditions as encountered in this test. A slow gravel filter has been constructed and will be tested as a means of clarifying recharge water during the winter and spring of 1960-61.

(g) The project is not developed to a point for satisfactory reporting.

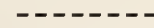

UNIVERSITY OF ARKANSAS, Civil Engineering Dept.

\section{(2741) ROCKEFELTER FILTRATION PROJECT.}

(b) Laboratory project.

(c) Prof. L. R. Heiple, Head, Civil Engineering Dept., Univ. of Arkansas, Fayetteville, Ark.

(d) Experimental and field investigation; applied research and development.

(e) This project involves a study of the removal of turbidity and bacteria from surface water supplies using coarse grained media ( $1 / 4$ to 1 inch). Laboratory model investigations and pilot field studies have been completed with the variables investigated including; (1) Depth of bed; (2) size of media; (3) shape and nature of media; (4) effect of head of water on filter bed; and (5) rate of filtration. A full-size field installation is now under construction and further statistical investigation is under way concerning the variable action of filtration.

(f) Suspended and scheduled to be reactivated,

(g) Field studies have disclosed that turbidity from normal surface waters may be substantially reduced by filtration, without prior treatment, through a coarse grained material such as pea gravel. Such a filter has a capacity for effective long range operation without development of appreciable head loss or the need for cleaning and with minimum attention. Filtration efficiency is most effective in low turbidity waters where particle size is predominately colloidal. There is substantial evidence that long range filtering action continues in cycles of loading and unloading of the filter bed before complete failure results.

(h) "Effectiveness of Coarse-Grained Media for Filtration" by Loren R. Heiple, Jour. Amer. Water Works Assn., Vol. 51, No. 6, June 1959. Reprints may be obtained by addressing $\mathrm{L}$. R. Heiple, Head, Civil Engrg. Dept., Univ. of Ark., Fayetteville. Other articles are in the process of preparation but publication data has not yet been determined.

\section{POLYTECHNIC INSTITUTE OF BROOKLYN.}

Inquiries concerning the following projects should be addressed to Prof. Matthew Stewart, Assoc. Prof. of Civil Engineering, Polytechnic Institute of Brooklyn, 333 Jay St., Brooklyn 1, New York.

\section{(3376) FLOW THROUGH CULVERTS.}

(b) Laboratory project.

(d) Experimental; for masters thesis.

(e) Experimental study to determine the nature of flow through culverts.

(g) Apparatus under construction.

(3667) DESIGN AND CALIBRATION ÓF A 90-DEGREE TRIAINGULAR WEIR.

(b) Laboratory project.

(d) Experimental; for bachelor's thesis.

(e) Design, construction and calibration of triangular weir.

(f) Completed.

(g) Thesis available for loan.

CALIFORIIA INSTITUTE OF TECHNOLOGY, Engineering Division.

\section{(1548) SPECIAL PROBLEMS IN HYDRODYNAMICS.}

(b) Office of Naval Research, Dept. of the Navy.

(c) Prof. Milton S. Plesset, Calif. Inst. of Tech., Pasadena, Calif.

(d) Theoretical and experimental; basic research.

(e) Studies of cavitating and noncavitating flow; dynamic behavior of cavitation bubbles; theoretical and experimental studies of cavitation damage.

(h) "The Theory of Rectified Diffusion of Mass into Gas Bubbles," by D. Y. Hsieh and M. S. Plesset, Calif. Inst. of Tech., Engrg. Div., Report No. 85-15, Aug. 1960. "Theory of Gas Bubble Dynamies in Oscillating Pressure Fields," by M. S. Plesset and D. Y. Hsieh, Calif. Inst. of Tech., Engrg. Div., Report No. 85-16, Aug. 1960. "On the Propagation of Sound in a Liquid Containing Gas Bubbles," by D. Y. Hsieh and M. S. Plesset, Calif. Inst. of Tech., Engrg. Div., Report No. 85-17, September 1960. 
(1816) FORCE CHARACTERISTICS OF SUBMERGED HYDROFOILS UNDER CAVITATING CONDITIONS.

(b) Bureau of Ships, Dept. of the Navy.

(c) Prof. Milton S. Plesset, California Inst. of Technology, Pasadena, California.

(d) Theoretical and experimental; basic research.

(e) Studies of hydrofoils.

(f) Completed.

(h) "Cavity Flow Past a Slender Pointed Hydrofoil," by E. Cumberbatch and T. Y. Wu, California Institute of Technology, Engineering Division Report No. 47-11, March 1960.

"Cavitating Flow Past a Large Aspect-Ratio Hydrofoil," by E. Cumberbatch, Califorria Institute of Technology, Engineering Division, Report No. 47-12, May 1960. "Accelerating, Supercavitating Flow Past a Thin Two-Dimensional Wedge," by E. Cumberbatch, California Institute of Tech., Engineering Division, Report No. 47-13, June 1960.

"Experimental Investigations of ThreeDimensional Effects on Cavitating Hydrofoils," by R. W. Kermeen, California Institute of Technology, Engineering Div., Report No. 47-14, September 1960.

\section{(3377) THEORETICAL STUDIES IN HYDRODYNAMICS.}

(b) Office of Naval Research, Dept. of the Navy.

(c) Prof. T. Y. Wu, California Institute of Technology, Pasadena, California.

(d) Theoretical; basic research.

(e) Studies of hydrodynamic flows with free surface phenomena; steady and unsteady cavity flows; principle of fish propulsion.

(h) "Swimming of a Waving Plate," by T. Y. Wu, California Institute of Technology, Fngrg. Division, Report No. 97-1, August 1960. "Some Features of Unsteady Cavity Flows," by T. Y. Wu and D. P. Wang, California Institute of Technology, Engineering Division, Report No. 97-2, in press. "A Modified Wake Hodograph for FreeStreamline Flows," by T. Y. Wu, California Institute of Technology, Engineering Division, report in preparation.

CALIFORNIA INSTITUTE OF TECHNOLOGY, Hydrodynamics Laboratory .

\section{(2502) MECHANICS OF CAVITATION DAMAGE.}

(b) National Science Foundation.

(c) Dr. A. T. Ellis, Assoc. Prof. of Applied Mechanics, California Institute of Tech., Pasadena, California.

(d) Project is both experimental and theoretical. It is primarily basic research, but it is anticipated that it will also have applications. The work has been the basis of two Doctoral Theses.

(e) The purpose of the project is to determine the detailed mechanism of mechanical damage by cavitation, and to attempt to cor- relate this with field results. The collapse of a cavitation bubble of arbitrary shape close to, or in contact with a solid boundary is being considered. Mechanical damage from bubbles not in contact with the boundary can result only from shock waves in the liquid. Preliminary work showed that these shock waves existed, but that they were too weak to be considered as a damaging mechanism. Bubbles in contact with the boundary were next considered. Experiments showed that for all but the hemispherical cavities perfect fluid theory with constant cavity pressure would yield good results concerning the change of shape of the bubble during collapse and the pressure at collapse. The high pressure is in this case generated by water hammer. It is anticipated that the infinite collapse velocities which are encountered in theoretical treatment of hemispherical cavities can be eliminated by taking into account the compression of permanent gas, and the partial compression of vapor at very high compression rates. Very little is known about this last subject, and it is anticipated that an attempt will be made to obtain some data in this field.

(g) The perfect fluid theory for collapse of non-hemispherical cavity in contact with a solid boundary has been worked out and checked experimentally.

(h) "On the Mechanism of Cavitation Damage by Non-Hemispherical Cavities Collapsing in Contact with a Solid Boundary," by Charl F. Naude and Albert T. Ellis, Calif. Inst. of Technology, Pasadena, California, Hydrodynamies Laboratory, July 1960.

(2746) HYDRODYNAMICS OF UNDERWATER BODIES.

(b) Bureau of Ordnance, Department of the Navy.

(c) Professor A. J. Acosta and T. Kiceniuk, Hydrodynamies Laboratory, California Institute of Technology, Pasadena, Calif.

(d) Experimental and theoretical investigations.

(e) Investigations of the mechanics of hydrodynamic phenomena involved in the motion of underwater bodies, including (1) studies of forces on such bodies in cavitating and non-cavitating conditions; (2) investigations of the detailed mechanics of the fluid motions giving rise to the above forces.

(g) Force measurements on supercavitating delta wings are now being made to check the theoretical results of Prof. T. Y. Wu. Measurements of apparent mass coefficients in cavity flows are also being made.

\section{（3009） CAVITATION SIMILITUDE.}

(b) Office of Naval Research, Dept. of the Navy.

(c) Professor A. J. Acosta, California Institute of Technology, Pasadena, Calif.

(d) Experimental program of basic unclassified work.

(e) To determine the effect of the various thermal properties on cavitation in a 
venturi tube. It is known that cavitation similitude parameters based upon the vapor pressure of the liquid at the bulk temperature are misleading since the pressure in the cavity may be less or may exceed this value depending on air content, speed, size, thermal conductivity, etc. To investigate this question, a simple test loop with a venturi-section made with glass windows has been constructed and run with water and Freon 113. In the future, other fluids will be used. Measurements of cavity pressure, air content, temperature, are being made.

(g) Results in water and Freon ranging in temperature from $70^{\circ}$ to $200^{\circ}$ show that the cavity pressure can depart appreciably from the value at the bulk temperature. The results are still incomplete.

(h) "Observations on the Form of Cavitation in Different Fluids," by I. R. Sarosdy, A. J. Acosta. A.S.M.E. Annual Meeting Paper No. 60-WA-83.

\section{(3378) CAVITATION IN CASCADES.}

(b) Office of Naval Research, Dept. of the Navy.

(c) Prof. A. J. Acosta, California Institute of Technology, Pasadena, California.

(d) Theoretical basic unclassified research.

(e) Study of flow through a cascade of caritating circular arc hydrofoils. Linearized theory is used to get lift and drag coefficients, cavitation numbers and burning for the case of infinitely long cavities.

(3379) EXPERTMENTAL INVESTIGATION OF CAVITY COLLAPSE PRESSURES.

(b) Bureau of Ordnance, Department of the Navy *

(c) Dr. Albert T. Fllis, Hydrodynamics Lab., California Institute of Technology, Pasadena, California.

(d) Experimental program of basic research.

(e) The purpose of the project is to experimentally investigate the pressure developed at the site of collapse of a transient cavity. Single, hemispherical spark cavities are created in water at the pressure end of a composite dural-flint glass-lead pressure bar. At the collapse of such a cavity, a transient stress pulse is propagated along the bar which is detected by an $\mathrm{x}$-cut circular disc of quartz of the same diameter as the bar and which is recorded photographically from an oscillograph. These photographic records yield information regarding the total lifetime of the cavity and the maximum amplitude and time variation of the force developed during its collapse. An ultra-high speed photographic technique permits an estimate of the peak pressure developed at the site of collapse of the cavity to be made.

(g) Cavities having maximum diameters up to $\frac{1}{2}$ inch have been studied during the course of these experiments and collapse pressures of at least 10,000 atmospheres have been observed.

(h) "An Experimental Investigation of the Collapse of Transient Cavities in Liquids," by Ieuan R. Jones, Report No. E-88, Hydrodynamics Laboratory, California Inst. of Technology, Pasadena, California, July 1960.

CALIFORNIA INSTITUIE OF TECHNOLOGY, W. M. Keck Laboratory of Hydraulics and Water Resources.

(2258) THE RESUSPENSION OF FLOCCULENT SOIIDS IN SEDIMENTATION BASINS.

(b) U. S. Public Health Service.

(c) Dr. J. E. McKee, California Institute of Technology, Pasadena, California.

(h) "The Resuspension of Flocculent Solids in Sedimentation Basins," by Alfred C. Ingersol1, Ronald T. McLaughlin, Final Report May 1960:

(2748) RELATION BETWEEN TRANSPORT OF SEDIMENT AND THE HYDRAULIC CHARACTERISTICS OF STREAMS.

(b) Agricultural Research Service, U. S. Department of Agriculture.

(c) Prof. V.A. Vanoni, Prof. N. H. Brooks, or Dr. John F. Kennedy, California Institute of Technology, Pasadena, California.

(d) Experimental and analytical basic research, including doctoral dissertation.

(e) Laboratory experiments were performed in two tilting flumes, with sand beds of $0.23 \mathrm{~mm}$ or $0.55 \mathrm{~mm}$ mean diameter. The program has been devoted primarily to the study of roughness and sediment transport in flows with antidunes and associated stationary surface waves, usually asso ciated with Froude numbers near one or slightly larger.

(f) Completed December 1960.

(g) It was found that there are several types of antidune behavior in a sand-bed stream depending on Froude number, sand size, depth, width and external disturbances. For example, surface waves may be two or three-dimensional and may break under some conditions, but not others.

The wave length of the surface and hed waves is very closely given by the relation $\lambda=2 \pi V^{2} / g$ where $V$ is mean stream velocity and $g$ is acceleration of gravity. This equation has been derived theoretically, and verified by both laboratory and field data.

(h) "Stationary Waves and Antidunes in Alluvial Channels," John F. Kennedy, Ph.D. Thesis, California Institute of Technology, 1960; also to be issued as a project report (Pub. KHWR-6), approximately January 1961. "Study of Relations Between Transport of Sediment and Hydraulic Characteristics of Streams," John F. Kennedy, Publication KHWR-7, California Institute of Tech., Pasadena, Calif.

"On the Fall Velocity of Spheres and Sand Grains," John F. Kennedy and Robert C. Y. Koh, unpublished manuscript, 1960. (A study of frequency distribution of fall velocity). 
(3668) FLOW IN OPEN CHANNELS WITH VARYING ROUGHNESS.

(b) U. S. Geological Survey.

(c) Prof. N. H. Brooks, Mr. R. Hugh Taylor, Jr. (USGS), Calif. Inst. of Tech., Pasadena, California.

(d) Thesis project, partly experimental.

(e) In natural streams, the roughness pattern (dunes, ripples, flat, etc.) is often not uniform across the bed at a given cross section. To study this problem flume experiments are being conducted with beds which are rough gravel on one side of the centerline, and smooth wood on the other side. The purpose is to analyze the velocity distribution, transverse momentum exchange, and overall fluid resistance of such a composite bed.

(3669) FLUIDIZATION OF SAND BEDS BY UPWARD FLOW.

(b) U. S. Public Health Service (Research Grant ).

(c) Prof. N. H. Brooks, Calif. Inst. of Tech., Pasadena, California.

(a) Experimental thesis project.

(e) When a bed of sand is lifted and expanded by an upward flow (the "quick" condition), it is really not an expanded porous medium, as previously described and analyzed by other investigations, but actually it becomes a thick suspension. The particles move freely, sometimes generating large overturning eddies in the fluid. These phenomena are being investigated in a one-foot square vertical lucite channel, 6-feet high. Studies of greater expansions in larger columns will lead continuously to the phenomenon known as hundred settling in dilute suspensions.

(3670) TURBULENCE AND PARTICLE ENTRAINMENT IN SজTILING TANKS.

(b) U. S. Public Health Service.

(c) Prof. Vito A. Vanoni or John F. Kennedy, Ph.D., California Institute of Technology, Pasadena, California

(d) Experimental research.

(e) The work is carried out in flumes designed for such studies. Instmumentation for measuring very low velocities is being a.3apted and developed for use in making detailed investigations of velocity fields in the proposed experiments.

(3671) EVALUATION OF FORMULAS FOR THE TRANSPORT RATE OF SEDIMENT BY ALLUVIAL STREAMS.

(b) Laboratory Project.

(c) Prof. Vito A. Vanoni, Prof. of Hydraulics, California Institute of Technology, Pasadena, California.

Analytical research using published data. The sediment discharge calculated by several well-known formulas is compared with actual measured sediment discharges in four natural streams. The results are presented as graphs of sediment discharge against water discharge. (g) Preliminary results have been reported in (h).

(h) "Lecture Notes on Sediment Transportation and Channel Stability, "Vito A. Vanoni, Norman H. Brooks, and John F. Kennedy, Publication KHWR-1, Sept. 1960.

UNIVERSITY OF CALIFORNIA, Division of Agricultural Sciences, Department of Irrigation and Soil Science.

Inquiries concerning the following projects should be addressed to Professor A. F. Pillsbury, Department of Irrigation and Soil Science, University of California, Los Angeles 24, California.

(26) DRAINAGE INVESTIGATION IN COACHELIA VALLEY.

(b) Cooperative between the Coachella Valley County Water District, Coachella, Calif., U. S. Salinity Laboratory, Riverside, Calif., U. S. Bureau of Reclamation, Boulder City, Nevada, and this laboratory.

(d) Field investigations; applied research and design.

(e) Work now concentrated on studies of drainage adequacy and of drainage yield. Change in salinity status of soil is index of drainage adequacy. Information being obtained on fluctuations of water table following irrigation, and on effect thereon of mechanically affecting soil stratification. Where drainage yield is being metered will seek to establish relationship to factors such as surface soil, crop, irrigation slope, etc.

(f) Inactive in 1960.

(27) HYDROLOGY OF WATER SUPPLIES IN CALIFORNIA.

(b) Laboratory project cooperative with Pacific Southwest Forest and Range Experiment Sta., USFS, and with College of Engrg., Univ. of Calif., Los Angeles 24; coordinated with work of Dept. of Irrigation, Univ. of Calif., Davis, Calif.

(d) Experimental; applied research.

(e) Work now concerned with (1) subsurface movement of moisture; (2) surface treatments affecting infiltration of precipitation; and (3) detention of precipitation by surface litter and effect upon infiltration.

(g) Information being accumulated in labora.tory on effect of ground litter in lengthening periods of infiltration opportunity following periods of intense rainfall.

(1058) SOIL PHYSICAL CONDITIONS IN RELATION TO IRRIGATION .

(b) Laboratory project, coordinated with work of Dept. of Soils and Plant Nutrition, Univ. of Calif. Riverside.

(d) Continuing laboratory and field studies.

(e) Present work involves (1) evaluation of use of neutron moisture probe in following the downward movement of the wetting front and use of rate of that movement to evaluate changes in soil texture and structure 
with depth; (2) effects of surface tension and fluid viscosity on hydraulic conductivity of soil; and (3) effects of salt crystals, per se, on water movement into soil.

(g) Neutron probe found to begin to detect wetting fronts when about 7 inches below such fronts in a variety of soil types.

(1303) HYDRAULIC CHARACTERISTICS OF IRRIGATION DISTRIBUTION SYSTEMS.

(b) Laboratory project, cooperative with College of Engrg., Univ. of Calif., Los Angeles 24, California.

(d) Basic and applied research.

(e) Graduate student now working with model low pressure pipe system to study hydraulic transients occurring with automatic operation.

(f) Work being summarized.

(2504) DYNAMICS OF SOIL WATER FLOW TOWARDS AND INTO SUBSURFACE DRATNAGE FACILITIES.

(b) Laboratory project, cooperative with College of Engrg., Univ. of Calif., Los Angeles 24, California.

(d) Experimental; applied research.

(e) Work now concentrated on solutions for layered soils and for wide spacing of tile.

(i) "Wetting Expansion of Draintile and Its Effects on Water Entry," A. F. Pillsbury, R. E. Pelishek and Nathan Buras. Trans. ASAE, Vol. 3, No. 1, 88-89, 1960.

"Water Table Control in Arid and Semi-Arid Regions," A. F. Pillsbury, 4th Congress, International Commission on Irrigation and Drainage $11.65-11.84$.

"Lateral Movement of Water Along a Glass Fiber Sheet Utilized as a Filter for Draintile," Nathan Buras and A. F. Pillsbury, (prepared for publication).

UNIVERSITY OF CALIFORNIA, College of Engineering, Hydraulic Laboratory.

Inquiries concerning the following projects, except when otherwise indicated, should be addressed to Prof. J. W. Johnson, Dept. of Engineering, Hydraulic Laboratory, Hesse Hall, Univ. of California, Berkeley 4, California.

(40) FLOW AND HEAT TRANSFER CHARACTERISTICS OF GAS-SOLIDS MIXTURES.

(b) Laboratory project.

(c) Prof. C. L. Tien, Asst. Prof. of Mech. Engineering, Univ. of California, Berkeley, California.

(d) Theoretical and experimental; basic and applied research.

(e) The flow and heat transfer characteristics of a gas-solids mixture (glass beads and air) have been investigated in a 0.710 inch I.D. stainless steel tube with uniform wall heat flux. Pressure drops across test section and local heat transfer coefflcient have been measured for a series of air flow rates in which the solids to air ratio is varied from 0 to 7 pounds of sollds per pound of air. The solids are introduced into the flow system through a mixing nozzle fed by a slide valve controlled weighing tank, and two different sizes of solids, 30 microns and 200 microns, have been used. Analytical studies have been made for predicting the friction factor and heat transfer coefficient.

(g) Experimental results show that the Nusselt number remains constant for solids to air ratios less than 0.5 and 1.5 and then increases. Qualitative agreement with the analytical prediction is obtained.

(h) "Heat Transfer to a Turbulently Flowing Fluid-Solids Mixture in a Pipe," by C. I. Tien, ASME Paper No. 60-HT-23, to appear in Journal of Heat Transfer.

"Heat Transfer to Flowing Gas-Solids Mixtures in a Vertical Circular Duct," by C. A. Depew, Ph.D. Thesis, 1960, Univ. of California Library, Berkeley, California.

(529) LITTORAL SEDIMENT FLOW UPON A BEACH.

(b) Beach Erosion Board, Department of Army, Washington, D. C.

(c) Field laboratory and theoretical research.

(d) The object of this project is to determine pattern of sedimert transport on beaches near San Francisco. The work of the fiscal year 1959-1960 has been the development of techniques for using a Frantz electrodynamic mineral separator to divide beach sands into size groups of essentially the same mineral composition. The object is to then measure the percentage of minerals in different size groups of samples collected along the beaches to see if these differences will yield information as to the source and manner of transport of beach sands in the San Francisco area.

\section{(1554) SEA WATER CONVERSION RESEARCH.}

(b) State of California.

(c) Prof. Everett D. Howe, Director, Sea Water Conversion Laboratory, University of Calif., 1301 South 46th Street, Richmond, Calif.

(d) Experimental, theoretical, field investigation, and pilot plant; basic research, applied research, design, and operation.

(e) The purpose of this investigation is to discover whether there is available any method for the large-scale, low-cost demineralization of sea water. The project includes a number of investigations, of which the following have been active during 1959-60: (1) multiple effect rotating evaporator; (2) evaporation by immiscible fluid heat transfer; (3) vacuum flash distillation (low temperature difference method); (4) solar distillation; (5) vapor compression tests; (6) electrodialysis tests; (7) freeze-separation; (8) ion exchange; (9) nuclear reactor studies; (10) tests on magnetic scale control unit; 
(11) biological studies; (12) underground nuclear explosions as a possible source of heat energy for the distillation of sea water; (13) capillary control of vapor transfer gaps; (14) reverse osmosis pilot plant; (15) thermodynamic and economic analysis; (16) experimental heat transfer studies; (17) properties of sea water; (18) fundamental studies of corrosion processes; (19) applications of theory of the hydrois. Investigations are being carried on both at Berkeley and at Los Angeles.

(g) Detailed results may be obtained from the progress reports and publications listed under $(h)$ below. This project has been active since 1951-52 and previous summaries have listed all reports prior to September 1959.

(h) The following reports and publications have been issued during the period since July 1959 and sunmarize the work to date: UNIVERSITY OF CALIFORIIA AT LOS ANGEIES:* "A Thermodynamic Analysis of a Low-temper. ature-difference Flash-Distillation Method of Producing Fresh Water from Sea Water," by Eldon L. Knuth, Report No. 60-11, 27 pp., February 1960.

"Sea Water Demineralization Reverse Osmosis Pilot Plant," by J. W. McCutchan, Report No. 60-19, 60 pp., March 1960.

"Sea Water Research Quarterly Progress Report October 1959-December 1959," Report No. 60-26, 70 pp., May 1960. "Sea Water Research Progress Summary," Report No. 60-70, 103 pp., June 1960. "Heat Transfer in a Single Vertical Tube Falling Film Evaporator with Dropwise Condensation," by Bruce Broker and J. W. McCutchan, Report No. 60-58, 56 pp., July 1960.

"Thermodynamic and Economic Considerations in the Preparation of Fresh Water from the Sea," by Myron Tribus et al, Report No. 59-34, September 1960.

\section{UNIVERSITY OF CALIFORNIA AT BERKELEY:**} "Progress in Saline Water Conversion," by Everett D. Howe, Journal American Water Works Association, Vol. 51, No. 10, pp. 1191-1201, October 1959.

"Solar Distillation at the University of California," by Everett D. Howe, Solar Energy, Vol. 1ll, No. 3, pp. 3l-32, October 1959.

"Performance Characteristics of Sea Water Distillation Equipment," by John T.

Chambers, IER Series 75, Issue 19, 31 pp., November 1959.

"Series Staging of Vapor Compression Distillation," by John T. Chambers and Poul S. Larsen, IER Series 75, Issue 20, 39 pp., May 1960.

"Current and Potential Methods for Demineralizing Water, " by Everett D. Howe, IER Series 75, Issue 21, 13 pp., May 1960.

"An Engineering Evaluation of Some currently Proposed Methods for Biological Conversion of Saline Waters," by William J. Oswald et al, 42 pp., February 1960.

"Ionite Membranes and Their Characteristics tics," by V. A. Klachko, Translation from the Russian by A. Kusubov, IER Series 75, Issue 22, $34 \mathrm{pp}$., August 1960.

"Berkeley Progress Report for the Year Ending June 30, 1960," IER Series 75, Issue 23, 29 pp., August 1960.

*Requests for copies should be directed to: Institute of Industrial Cooperation, Department of Engineering, University of California, Los Angeles, California. **Requests for copies should be directed to: Sea Water Conversion Laboratory, University of California, 1301 South 46th Street, Richmond, California.

(1823) THE MECHANICS OF BOTTOM SEDIMENT MOVEMENT WITH OSCILIATORY WAVES.

(b) Beach Erosion Board.

(c) Hydraulic Laboratory, Hesse Hall, Univ. of California, Berkeley, California.

(d) Experimental; basic research.

(e) To obtain experimental information on the criterion for initial and general movement of bottom sediment by wave action. Prototype conditions of the relative motion of water and bed were simulated by use of an oscillating plate in still water.

(g) A theoretical solution has been found for the turbulent boundary layer flow along an oscillating surface and was empirically checked for the smooth bottom. A solution has been found for the rough wall, but must be checked for various different types of roughness. The theoretical solution does not permit the determination of the bottom shear and may be unsatisfactory for this reason.

(2062) STRESS-STRAIN RELATIONSHIPS FOR SHEAR IN SAND-CLAY-WATER MIXIURES.

(b) Laboratory and field project.

(c) Hydraulic Laboratory, Hesse Hall, Univ. of California, Berkeley, California.

(d) Experimental; basic research.

(e) Stress-strain measurements are procured by means of plungers of given diameters, which are pressed into the sediment mixtures at a constant strain rate during which the stress is recorded by a system of strain gauges attached to a proving ring that is deformed as the plunger enters the sediment. The stress-strain relations are computed in terms of M. G. Bekker's coefficients.

(f) Experimental work to be concluded Dec. 31, 1960.

(g) The results show that for given water content strength of sediments becomes greater, (1) as base exchange capacity of clay increases, (2) as grain size decreases (i.e.) as total surface area of constituent particles increases, (3) as clay-sand ratio increases.

(2063) METHODS OF DETECTING AND TRACING THE MOVEMENT OF GROUND WATER.

(b) U. S. Bureau of Reclamation.

(c) Hydraulic Laboratory, Hesse Hall, Univ. of California, Berkeley, California. 
(d) Experimental; applied research.

(e) This study has as its objectives study of velocity variations observed in tracing the flow of liquids through porous media, development of methods and tracers for field determination of water movement underground, and application of these methods to location and measurement of seepage from canals.

(g) A field study of the use of tritium for tracing and evaluating seepage losses from a canal has been conducted. A report is in preparation.

(h) "Dispersion of a Water Tracer in Radial Laminar Flow Through Homogeneous Porous Media," by L. K. Lau, W. J. Kaufman, and D. K. Todd, Inst. of Engrg. Research Rept. 93-5, 78 pp., 1959.

\section{(2261) WAVE REFRACTION RESEARCH.}

(b) Beach Erosion Board, Department of Army, Washington, D. C.

(c) Experimental; basic research.

(e) Laboratory studies are being made of the refraction and some (diffraction and reflection) phenomena of water waves. Special attention is being given to the "Mach stem" phenomenon.

(g) In shallow water the velocity of a water gravity wave depends upon the depth of water as well as upon the length of the wave. When it travels in shoaling water it bends. This refraction changes the wave height and direction. Powerful graphical and analytical tools are available for use by the engineers; however, there is an almost complete lack of evidence as to their accuracy. The purpose of this contract has been to perform laboratory experiments to check the validity of the techniques used in practice. The first series of tests were performed in a ripple tank; these showed that the techniques were fairly reliable from a practical standpoint. A series of tests were made in a model basin $150 \mathrm{ft}$. by $64 \mathrm{ft}$. by $21 / 2 \mathrm{ft}$. deep. The results of these tests have been published. Tests have been conducted on the formation of secondary wave crests as periodic waves pass into shoal water, and the results have been found to compare favorably with theory. Studies have been made of the non-reflecting characteristics of waves incident to a steep slope, large plane angle shore, and the results presented in a report. Studies are being made of the refraction and short crested wind generated waves in the laboratory.

(h) "Experimental Study on the Solitary Wave Reflection Along a Straight Sloped Wall at Oblique Angle of Incidence" by T. C. Chen, Univ. of Calif., IER, Tech. Rept. 89-5, 29 pp., August 1960.

\section{(2265) FORCES ON ACCELERATED CYLINDERS.}

(b) Engineering Foundation and laboratory project.

(c) Prof. A. D. K. Laird, 109 Mechanics Bldg.,
University of California, Berkeley 4, California.

(d) Experimental; basic research.

(e) Measurement of drag coefficients and flow configurations about cylinders during accelerated motion in fluids as related to wave forces as cylinders.

(g) "Water Forces on Accelerated Cylinders," A. D. K. Laird, C. A. Johnson, and R. W. Walker, Journal Waterways and Harbors Div., Proc. Amer. Soc. of Civil Engr., Vol. 85, No. WWI, Mar. 1959.

"Water Eddy Forces on Oscillating Cylinders," A. D. K. Laird, C. A. Johnson, and R. W. Walker, Journal Waterways and Harbcrs Div., (in press).

\section{(2505) EFFECT OF SEDIMENT DISTRIBUTION IN STREAM} CHANNELS.

(b) University project.

(c) Hydraulic Laboratory, Hesse Hall, Univ. of California, Berkeley, California.

(d) Experimental; basic research.

(e) Alluvial flows in channels with artificially secured banks are studied systematically for their tendency to meander as expressed by the development of alternate bars. It is the aim of this study to develop criteria for stability.

(f) Experimental work concluded.

(g) The important parameters seem to be the Froude's number, the depth-width ratio and the size and uniformity of the bed sediment. The uneven distribution of friction between banks and bed is of prime importance.

(h) Ph.D. Thesis in preparation.

(2753) HYDRAULIC BREAKWATER.

(b) Office of Naval Research, Dept. of the Navy.

(d) Experimental; applied research.

(e) Determination by model tests of the mechanisms by which hydraulic breakwaters dampen water gravity waves.

(g) Three dimensional tests in a model basin show that the effect of wave refraction due to the currents generated by the hydraulic breakwater is of primary importance. For certain conditions the area in the lee of the breakwater can be made to be almost free of waves, while for other conditions the waves behind the breakwater will be higher than if there were no hydraulic breakwater in operation. A series of model sizes have been used and a definite scale effect observed. Tests have been completed in connection with the measurement of the currents generated by the jets and then the effect of the currents on the waves, the purpose being to find out in which portion of the mechanism the scale effect occurs. It was found that the scale effect occurred in the orifice. The results have been published. Tests are under way at present on the effect of hydraulic breakwaters on wind generated waves as it is believed that the short period components of such a wave system will be 
damped, allowing the long period wave components to get past the breakwater.

(h) "Wave Dissipation by Compressed Air (Pneumatic Breakwater)" by S. I. Radionov, translated by Hildegaard Arnesen, Univ. of Calif., IER, Tech. Rept. 104-9, 47 pp., April 1960.

"Verification of the Froude Modeling Law for Hydraulic Breakwater" by John A. Williams, Univ. of Calif., IER, Tech. Rept. $104-11,43 \mathrm{pp} .$, August 1960.

(2755) DEVELOPMENT OF METHODS TO TRACE SEDIMENTS USING RADIOACTIVE MATERIALS.

(b) U. S. Corps of Engineers.

(c) Prof. H. A. Einstein, Univ of Calif., Berkeley 4, California.

(d) Experimental; theoretical, and field.

(e) Radioactive materials are sought which can be permanently attached to sediment grains from the sand to the clay sizes. The instrumentation is to be developed by which these tagged sediments can be observed in prototype water courses, particularly in the San Francisco Bay.

(g) Scandium-46 and gold-198 have been found to be the best suited materials. The instrumentation for field detection of radioactivity has been developed. Four field tests in San Francisco Bay have been completed and analyzed. These tests have shown that clayey sediments are transported in salt water in general suspension only and are deposited in stable form from water flowing at less than two feet per second average velocities.

(h) "First Annual Progress Report on the Silt Transport Studies Utilizing Radioisotopes," R. B. Krone, 117 pp., Dec. 1957. Obtain from author at U.C.E.F.S. 1301 South 46th Street, Richmond, California.

"Second Annual Program Report on the Silt Transport Studies Utilizing Radioisotopes," $122 \mathrm{pp}$. Final Reports in preparation.

\section{(3019) ANALOG MODELS FOR HYDRAULIC SYSTEMS.}

(b) Laboratory project.

(c) Hydraulic Laboratory, Hesse Hall, Univ. of Calif., Berkeley, California.

(d) Experimental and theoretical; design and development.

(e) Electric analog elements to represent all major hydraulic features of a flood control project are being designed and constructed with the purpose of devising a tool enabling hydraulic engineers to optimize the design and operation of flood control systems.

(f) Completed.

\section{(3020) BOUIDARY LAYER FRICTION IN THE DOLPHIN.}

(b) Laboratory project.

(c) Hydraulic Laboratory, Hesse Hall, Univ. of California, Berkeley, California.

(d) Experimental; basic research.

(e) Purpose is to elicit whether there is an anomaly in skin friction of dolphins.

(f) Completed. (g) Observations of four large groups of dolphins suggest that they are able to swim at a sustained speed of 14 to 18 knots. The black fish are able to maintain about 22 knots and one killer whale seemed able to swim somewhat faster. This implies that the apparent coefficient of surface friction remains approximately constant for dolphins from 6 to 22 feet long, as is the case for rigid bodies; but on the basis of probable muscle power, it is only $1 / 8$ the value for rigid bodies.

(h) "Sustained Swimming Speed of Dolphins" will appear in Science during Nov. or Dec., 1960 .

\section{(3022) FLOATING BREAKWATER.}

(b) U. S. Navy Civil Engineering Laboratory.

(d) Analytical and experimental-applied research.

(e) Analytical and experimental studies of new concepts of floating breakwaters.

(g) Several new concepts have been investigated. One of these systems consisted of a series of long plastic tubes (slightly buoyant) connected side by side and filled with water. The effectiveness of the system was remarkable for wave lengths of the order of one-half the tube length, or less. Additional work has been done with large plastic bags filled with water with the same results. Small scale laboratory studies have been completed, including the measurement of forces in the mooring lines. Medium scale tests are being made in San Francisco Bay.

(h) "Transmission of Waves Past a Rigid Vertical Thin Barrier" by R. L. Wiegel, Jour. Waterways and Harbors Division, ASCE, Vol. 86, No. WWI, pp. 1-12, March 1960.

"Floating Breakwater Survey to 15 August 1959" by R. L. Wiegel, Univ. of Calif., IER, Tech. Rept. 140-2, 53 pp., August 1959.

"Floating Breakwater Survey, 15 August 1959 to 30 June 1960" by R. L. Wiegel, H. W. Shen, and O. C. Wright, Univ. of Calif., IER, Tech. Rept. 140-3, 46 pp. June 1960.

\section{(3023) PRESSURE GENERATED WATER WAVES.}

(b) National Science Foundation.

(d) Experimental; basic research.

(e) This is a study of the coupled waves generated by a pressure area moving over the water surface, both two dimensional and three dimensional; in addition, analytical studies are being made of long waves.

(f) Completed.

(g) The conoidal wave theory has been reduced to the form that rapid calculations can be made with it, using curves and tables. Laboratory tests in three dimensions have been made to determine the limit of the effect of surface tension. Tests well within the gravity wave regime have been completed.

(h) "Presentation of Conoidal Wave Theory for 
Practical Application," by R. I. Wiegel, Journal of Fluid Mechanics, Vol. 7, Part 2, pp. 273-286, 1960.

"Hurricane Storm Surge Considered as a Resonance Phenomenon," by G. Abraham, Proc. Seventh Conf. on Coastal Engrg., Council on Wave Research, The Engrg. Foundation, 1961.

"Some Aspects of Surface Water Wave Scale Effects" by G. Abraham, accepted for publication, Jour. Hydraulics Division, ASCE.

(3380) SANTA ROSA CREEK STRUCTURES.

(b) U. S. Soil Conservation Service.

(c) Hydraulic Laboratory, Hesse Hall, Univ. of California, Berkeley, California.

(d) Experimental; for design.

(e) Model tests of structures designed to regwlate the flood flows and sediment loads in Santa Rosa Creek.

(f) Concluded.

(g) The combination of a flow regulating orifice with a diversion dam and a sediment carrying tube provides a satisfactory solution.

(h) "Model Study of Santa Rosa Creek Hydraulic Structures," by G. Kalkanis, IER series No. 148, Issue 1.

(3382) FLUME STUDY ON THE TRANSPORT OF ESTUARIAL SEDIMENT.

(b) Corps of Engineers.

(c) Prof. H. A. Einstein, Univ of California, Berkeley, California.

(d) Experimental.

(e) The motion in saline water of estuarial sediments is studied under controlled laboratory conditions. Both flumes and settling vessels are used. The viscosity settling and composition of sediment-water mixtures are also studied to understand the relationships between the flow and the deposit.

(h) Final report in preparation.

(3383) EFFECT OF SURFACE ROUGHINESS ON THE FLOW OF WATER OVER ROCK SILIS.

(b) Thesis study.

(c) Prof. H. A. Einstein, Univ of California, Berkeley, California.

(d) Experimental.

(e) Smooth and rough rock sills are compared in a l-foot wide flume. The discharge coefficient is determined for free and submerged flows.

(f). Completed.

(g) Discharge coefficient is determined for a sill with 6" crest width, 6" high and 1:4 slopes upstream and downstream. This discharge coefficient is somewhat lower than that for a smooth dam of the same geometry. The downstream velocity distribution with 0.1 foot rock is very different from that on a smooth structure. The scour pattern downstream is much more favorable than for the smooth structure.

(h) M. S. Thesis by Walter M. Linder, Univ. of California, Civil Engineering 1960. Project report in preparation.

\section{(3384) SAND MOVEMENT BY WIND.}

(b) Beach Erosion Board.

(d) Experimental.

(e) To develop a trap and auxillary equipment for field measurements of the rate of sand movement by wind action. Tests on various types of traps were made in a wind tunnel to determine the trap efficiency as a function of the wind characteristics. Some field experiments also have been conducted.

(h) "Sand Movement by Wind Action on the Characteristics of Sand Traps," by K. Horikawa and H. W. Shen, Beach Erosion Board Tech. Memo. No. 119, Aug. 1960.

\section{(3385) ELECTRIC FTOOD MODEL.}

(b) U. S. Corps of Engineers, Kansas City District.

(c) Hydraulic Laboratory, Hesse Hall, Univ. of California, Berkeley, California.

(d) Experimental; design and development.

(e) Using analog model techniques a simulator for the Kansas River and its tributaries is being developed. Purpose is to provide a rapid and convenient means of estimating the effects of reservoir operation and rainfall distribution on flood stages. All pertinent hydraulic variables will be under operator's control, and a flood routing procedure completed each $1 / 60$ second.

\section{(3386) SUBSURFACE SALINITY.}

(b) Laboratory project.

(c) Hydraulic Laboratory, Hesse Hall, Univ. of California, Berkeley, California.

(d) Arlalytical and experimental; basic research.

(e) This investigation is concerned with the dynamics of the fresh-salt water interface in flow through porous media. Effects of non-steady flows and dispersion will be considered.

(g) Experimental measurements of dispersion at a fluctuating interface have been completed. other boundary conditions are being studied.

(h) "Singularity Distributions for the Analysis of Multiple Fluid Flow Through Porous Media," by G. de Josselin de Jong, Jour. Geophysical Research, November 1960.

"The Transition Zone Between Fresh and Salt Waters in Coastal Aquifers," by J. Bear and D. K. Todd, Water Resources Center Contribution No. 29, Univ. of California, Berkeley, 156 pp., 1960.

\section{(3672) WAINUT CREEK STABIIIZATION.}

(b) North Walnut Creek Emergency Flood Control District.

(c) Hydraulic Laboratory, Hesse Hall, Univ. of California, Berkeley, California.

(d) Experimental; for design.

(e) Model tests of structures to distribute evenly the flow through a compound bend with strong curvatures.

(g) A combination of low sills and lined sections will increase or decrease the roughness locally so that an even distribution of the flow will result. 
(3673) JET PUMP FOR SEDIMENT.

(b) Pacific Coast Engineering Co.

(c) Hydraulic Laboratory, Hesse Hall, Univ. of California, Berkeley, California.

(d) Experimental.

(e) The use of a jet pump as a booster pump at the end of the ladder of a suction dredge is studied.

(3674) SHEAR INTERFACE.

(b) National Science Foundation.

(c) Hydraulic Laboratory, Hesse Hall, Univ. of California, Berkeley, California.

(d) Experimental and theoretical.

(e) The frictional boundary layer along an interface is to be studied systematically with respect to shear, turbulence, stability of the interface and mixing of the fluids.

(f) Literature survey started.

(3675) CLAY TRANSPORT.

(b) National Science Foundation.

(c) Hydraulic Laboratory, Hesse Hall, and Engrg. Field Station, University of California, Berkeley, California.

(d) Experimental.

(e) A continuation and generalization of (3382) to various types of clays. The effect of flocculation and concentration of clay on flows, and the deposition and scour of these sediments are studied systematically.

(3676) ARTIFICIAL RECHARGE OF GROUND WATER.

(b) Laboratory project.

(c) Hydraulic Laboratory, Hesse Hall, Univ. of California, Berkeley, California.

(d) Analytical and experimental; basic research

(e) This investigation is concerned with the unsteady flow of water from recharge areas into homogeneous and nonhomogeneous aquifers.

(B) A solution of the general infiltration equation is being attempted by a digital computer. Results will be compared with experimental measurements.

\section{(3677) ANNULAR NOZZLE GROUND EFFECT MACHINE.}

(b) Office of Naval Research, Dept. of the Navy.

(c) Prof. R. L. Wiegel, Department of Civil Engineering, University of California, Berkeley, California.

(d) Experimental; applied research.

(e) Airborne vehicles supported by annular jets have a lift considerably in excess of that due to the jet momentum when operating in a region close to the ground. The dynamic lift, bending moment, wave resistance, base pressures, and intake pressures are being measured for such a vehicle operating over both calm water and water with surface gravity waves present.

(h) "Progress Report on Model Studies of an Annular Nozzle Type GEM" by R. L. Wiegel, D. O. Horning, W. M. Linder and G. Reichert, Univ. of Calif., IER, Field Rept. No. 55, $23 \mathrm{pp} ., 15$ June 1960 .
"Second Status Report on Model Studies of an Annular Nozzle Type GEM," by R. L. Wiegel, D. O. Horning, J. Cumming, and M. Price, Univ. of Calif., IER, Field Rept. No. 56, 52 pp., 15 Nov. 1960.

(3678) OCEAN SEWER OUTFALIS.

(b) U. S. Public Health Service.

(c) Prof. J. W. Johnson, Prof. of Hydraulic Engineering, Univ of Calif., Berkeley, California.

(d) Basic research.

(e) This study is concerned with the various phenomena involved in the diffusion of sewage at the discharge end of an ocean sewer outfall.

(g) Phases investigated to date have involved mixing resulting from jet action and surface wind waves.

(h) "Jet Diffusion in Liquid of Greater Density" by G. Abraham, Jour. Hyd. Div., ASCE, June 1960, pp. 1-13.

"The Effect of Wind and Wave Action on the Mixing and Dispersion of Wastes" by J.W. Johnson, Proc. First Int. Conf. on Waste Disposal in the Marine Environment, 1960. "Wind Waves and Swell" by R. L. Wiegel, Proc. Seventh Conf. on Coastal Engin., Council on Wave Research, Berkeley, Calif., 1961.

(3679) EFFECT OF THE STORM AND THE WATERSHED GEOMETRIES ON THE OUTFLOW HYDROGRAPH.

(b) Water Resources Center, University of California, Berkeley, California.

(c) Prof. J. Amorocho, Acting Asst. Prof. of Civil Engineering, 110 Engineering Bldg.; G. T. Orlob, Assoc. Prof. of Civil Engrg., 412 F Hesse Hall, University of California, Berkeley, California.

(d) Theoretical and experimental investigation of the outflow history from a catchment as a response function of the inflow and the catchment geometry.

(e) The objectives of the investigation include: (1) A critical evaluation of the "unit hydrograph" method with regard to its basic assumptions and to the results of its application. The criteria for this evaluation are: (a) Studies of the solutions of the fundamental equations of spacially varied unsteady flow with emphasis on their sensitivity to changes in the parameters that define the inflow pattern and the catchment characteristics. (b) Comparison between the outflow values that result from the application of the unit hydrograph method and actual measurements of outflow in fully controlled laboratoryscale catchments. (2) Development of a procedure to derive inflow-outflow relationships for catchments that may be characterized by simple geometric parameters when the inflow pattern is defined by isohyetals and by known frontal advance rates.

(g) Experiments completed to date in model catchments with and without artificial reservoir simulation indicate that the assumption of uniqueness of the basin response to 
inflow as represented by the "unit hydrograph" is not valid. The outflow rates do not vary linearly with the inflow rates during the unsteady state and the shape of the storm has a very important bearing on the shape of the hydrograph even when the average value of inflow is the same over the catchment. Evaluations of inflow gradient effects and droplet impact on the flow are being conducted.

UNIVERSITY OF CALIFORNIA, Department of Naval Architecture.

\section{(3024) STABILITY OF VESSELS IN A SEAWAY.}

(b) Society of Naval Architects and Marine Engineers.

(c) Prof. John R. Paulling, Jr., Room 224, Bldg. T-3, University of California, Berkeley, California.

(d) Experimental and theoretical; applied research.

(e) A study of the effect of the seaway on the transverse stability and capsizing of ships.

(f) Completed.

(g) It is shown that the transverse stability of a ship in head or following seas may differ appreciably from that of the same ship in calm water. Model experiments yield results which agree quite well with theoretical predictions. Charts have been devised which enable the designer to predict the loss of stability in waves.

(h) "Transverse Stability of Tuna Clippers" by J. R. Paulling. Fishing Boats of the World, II, Fishing News Ltd., London, 1960, pp 489495.

"The Transverse Stability of a Ship in a Longitudinal Seaway" by J. R. Paulling, (in preparation).

(3026) SHIP RESISTANCE IN UNTFORM WAVES AS A FUNCTION OF BLOCK COEFFICIENT AND WAVE STEEPNESS

(b) David Taylor Model Basin, Department of the Navy.

(c) Mr. 0. J. Sibul, Room 224, Bldg. T-3, Univ. of California, Berkeley, California.

(d) Experimental.

(e) A series of experiments were performed to study the effect of width (beam) and the block coefficient of the ship on the added resistance in uniform waves. The following block coefficients were used for Series 605 -foot models: $0.60 ; 0.70 ; 0.80$ and a model of DE 1006 with a block coefficient of 0.49 . For block 0.60 model two additional models were built, one with 0.75 and the other with 1.25 times the beam of the parent form. All of the models were towed in waves 5 feet long at seven different wave steepnesses between 0.0146 and 0.0684 .

(3029) REPRODUCTION OF RECORDED OCEAN WAVES IN A SHIP MODEL TOWING TANK.

(b) Natl. Sci. Foundation and Univ. of Calif. (c) Mr. 0. J. Sibul, Room 224, Bldg. T-3, Univ. of California, Berkeley, California.

(d) Basic research; applied research; design.

(e) The work undertaken under this program was the design and construction of a power and control system for the existing wave generator, such that a recorded ocean wave in a desired scale could be reproduced in the towing tank. The system utilizes a magnetic tape input to servomechanism which makes the wave-generator follow a prescribed timedistance curve.

(3684) PROPAGATION OF WAVES OVER AN OBSTACTE IN WATER OF FINITE DEPTH.

(b) Office of Naval Research, Department of the Navy .

(c) Professor J. V. Wehausen, Room 224, Bldg. T-3, University of California, Berkeley, California.

(d) Theoretical basic research, thesis for a doctoral degree.

(e) The surface waves are investigated in a channel of infinite horizontal extent with a uniform fluid depth except in a finite region, where the contour of the bottom is specified by some function, $y=b(x)$. Finally, a specific problem is worked out for a case of a bottom which is completely flat, interrupted only by a vertical barrier of vanishing thickness. Cúrves are given for the reflection coefficient as a function of wave number, with the ratio of barrier height to water depth as a parameter.

(f) Completed.

(h) "Propagation of Waves Over an Obstacle in Water of Finite Depth" by T. Francis Ogilvie, University of California, IER Series 82, Issue 14, May 1960.

(3685) SHIP SLAMMING LOADS AND HULL RESPONSES.

(b) National Academy of Sciences - National Research Council, Committee on Ship Structural Design.

(c) Professor H. A. Schade, Room 224, Bldg. T-3, University of California, Berkeley, California.

(d) Experimental and theoretical; basic and applied research.

(e) The project involves structural as well as hydrodynamic problems. Only the latter are described here. (1) It will be attempted to determine the virtual mass distribution along the length of a vibrating beam in water (forced vibration as well as impact loading). (2) A model of an element of ship bottom structure will be dropped on a free water surface. Strains, accelerations and pressures will be measured.

(3686) NON-LINEAR COUPLED SHIP MOTIONS.

(b) David Taylor Model Basin, Department of the Navy .

(c) Professor John R. Paulling, Jr., Room 224, Bldg. T-3, University of California, Berkeley, California.

(d) Theoretical with some experimental verification. 
(e) It has been shown that at certain frequencies of heave or pitch motion of a ship, a rolling motion of large amplitude may arise. This is explained in terms of instabilities of solutions of the equations of motion which include certain non-linear coupling terms.

(g) The relationships between natural frequencies in pitch and roll or heave and roll which lead to unstable rolling motion have been obtained theoretically and verified experimentally. Analog computational techniques have been used in investigating the effect of damping.

(3687) PRESSURE DISTRIBUTIONS, ADDED-MASS, AND DAMPING COEFFICIENTS FOR CYIINDERS OSCILLATING IN A FREE SURFACE.

(b) Office of Naval Research, Department of the Navy.

(c) Professor J. V. Wehausen, Room 224, BIdg. T-3, University of California, Berkeley, California.

(d) Theoretical and experimental basic research, thesis for a doctoral degree.

(e) A linearized theory is developed for the pressure distributions, added-mass and damping coefficients for horizontal cylinders oscillating vertically with small amplitude while semi-immersed in the free surface of a fluid of uniform depth. Calculated values are compared with values measured in experiments.

(f) Completed.

(g) The measured values and values based on the sample calculations show similar distinctive behavior.

(h) "Pressure Distributions, Added-Mass, and Damping Coefficients for Cylinders Oscillating in a Free Surface" by William R. Porter, University of California, IER Series 82, Issue 16, July 1960.

UNIVERSITY OF CALIFORNIA, Institute of Industrial Cooperation, Department of Engineering.

Inquiries concerning the following projects should be addressed to Prof. J. Morley English, ViceChairman, Research, Department of Engineering, Univ. of California, Los Angeles 24, California.

\section{(3680) OPTIMIZATION OF WATER RESOURCES DEVELOPMENT.}

(b) Water Resources Center, University of California.

(d) Theoretical; basic.

(e) Mathematical techniques are being developed for optimization of water resource development, including rational cost allocation using dynamic programming.

(g) An overall model has been developed. Optimum design of aqueducts and corresponding cost allocation for planning and design purposes has been analyzed.

(h) "Optimization of the Utilization of a Water Resource," W. A. Hall, Department of Engineering Report 58-15, 1958, University of California.
"Optimum Irrigation Practice Under Conditions of Short Supply", W. A. Hall and N. Buras, submitted for publication, Agricultural Engineering, 1960.

"The Dynamic Programing Approach to Water Resources Development," W. A. Hall and N. Buras, submitted for publication, Journal of Geophysical Research, 1960.

"Aqueduct Capacity Determination Under an Optimum Benefit Policy," W. A. Hall, submitted for publication, Journal A.S.C.E., 1960.

"A Method for Allocating Costs of a Water Supply Canal," W. A. Hall, submitted for publication, Journal A.S.C.E., 1960.

\section{(3681) HYDRAULICS OF SURFACE IRRIGATION.}

(b) Agricultural Experiment Station, Univ. of California, Davis, California.

(d) Theoretical and experimental; basic and design.

(e) An investigation in the hydraulic characteristics of surface irrigation with particular reference to design of surface irrigation systems.

(g) The unsuitability of Marning's equation for shallow very rough flows has been demonstrated. The general time-distance relationships for border flows have been derived for an advancing stream (unsteady). Application of these results to system design has been made.

(h) "Estimating Irrigation Border Flow," W. A. Hall, Agricultural Engineering, Vol. 37, No. 4, 1956.

"Design of Irrigation Border Checks," W. A. Hall, Agricultural Engineering, Vol. 4l, No. $7,1960$.

(3682) A STUDY OF THE INFLUENCE OF DECISION THEORY IN CIVIL AND HYDROLOGIC ENGINEERING PRACTICE.

(b) Iaboratory project.

(d) Theoretical; basic.

(e) The influence of uncertainty must be considered when designs are prepared for a water resources development. An optimum design for a particular reservoir structure must consider not only the expected, or average, value of benefits but also some measure of the aversion to (or, conversely, the propensity for) the risk inherent in an uncertain future of inflows. The effect of serial correlation in the data, and the subsequent design requirements it imposes, are considered. The study is being done, in the main, by simulation techniques.

(g) A new design method is envisioned.

(h) "Report of the Harvard Water Resources Program," (Harvard University press, Cambridge, 1961) in press, to which the author has contributed two chapters.

\section{(3683) FOUNDATIONS AND EARTH STRUCTURES IN EARTH-} QUAKES.

(b) Laboratory project.

(d) Field investigation; applied research.

(e) A rather detailed summary is included of the response of earth dams to earthquakes, 
based on a study of the earthquake literature. Approximately fourteen earth dams are treated and the structural features and damage details are given. Also treated are building foundations, bridge foundations, tunnels and landslides.

(f) Completed.

(g) Summarizing statements are included for each type of foundation and earth structure treated, indicating what is known from field experience about their behavior in earthquakes, with emphasis on failures. The earth dams and a number of the tunnels are hydraulic structures.

(h) "Foundations and Earth Structures in Earthquakes," C. Martin Duke, Proceedings Second World Conference on Earthquake Engineering, Tokyo, Japan, 1960.

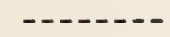

UNIVERSITY OF SOUTHERN CALIFORNIA, Research Foundation for Cross-Connection Control.

Inquiries concerning the following projects should be addressed to Dr. K. C. Reynolds, Supervisor, Research Foundation for Cross-Connection Control, University of Southern California, Los Angeles 7, California.

(49) RESEARCH FOUNDATION FOR CROSS-CONNECTION CONTROL .

(b) Laboratory project.

(d) Experimental research and field investigations; basic reaearch.

(e) To determine by proper research the relative value and protection afforded by various backflow prevention devices.

(g) Establishment of standardized laboratory and field test procedures and minimum specification requirements for backflow prevention equipment and continuous evaluation and improvement of such procedures and specifications.

(3688) MANUAL OF CROSS-CONNECTION CONTROL RECOMMENDED PRACTICE.

(b) Foundation Director was member of committee of Southern California Water Utilities Association which approved the entire manual after a draft had been prepared by a subcommittee of four.

(d) Field investigations and applied research.

(e) Manual was in preparation for six years and includes some reports of the Foundation. This is a handbook for the purveyor of a public water supply.

(f) Manual completed.

(g) The 125-page, 12-section manual provides a compendium on cross-connection control practices. A few of the section headings are: definitions, typical facilities, cross-connection control practices, specifications of devices.

(h) "Manual of Cross-Connection Control Recommended Practice" was edited and published by Research Foundation for Cross-Connection Control, University of Southern California. Price $\$ 3.90$ per copy.
CARNEGIE INSTITUTE OF TECHNOLOGY, Department of Civil Engineering.

Inquiries concerning the following projects except when otherwise indicated should be addressed to Dr. T. E. Stelson, Dept. of Civil Engineering, Carnegie Institute of Technology, Pittsburgh 13, Pennsylvania.

\section{(1834) AIR-WATER FLOW.}

(b) Laboratory project.

(d) Analytical and experimental.

(e) Study of air-binding in pipelines. Particular attention is given to the mechanism and relationships causing separation of air into pockets, re-entrainment of air at a turbulent interface and energy losses associated with the phenomenon.

(g) Experimental studies of 2-and 6-inch diameter pipes have been completed for a. variety of flow conditions.

(2064) VIRTUAL MASS.

(b) Laboratory project.

(d) Analytical and experimental.

(e) Determination of the inertia drag on bodies moving in fluids in rotational motion and under varying conditions of translati onal motion.

\section{(2275) FLOW OF LIQUID-SOLID MIXTURES.}

(b) Laboratory project.

(d) Analytical and experimental.

(e) Study of the movement of granular material carried in a fluid through closed conduits. Measurements of velocities, energy losses, concentrations and segregated conditions are made.

(2759) FLOW INTO VERTICAL SHAFTS.

(b) Laboratory project.

(d) Experimental and analytical.

(e) Evaluation of flow into vertical shafts for different conditions of geometry, gradeline, head and surface condition.

(f) Inactive.

(3203) PRESSURE SURGES IN CLOSED CONDUITS.

(b) Laboratory project - National Science Foundation Fellowship.

(d) Analytical and experimental.

(e) Determination of pipe geometry on the reflection and transmission of pressure surges in closed conduits.

(3205) FLOW OF LIQUID-SOLID MIXTURES IN INCLINED PIPES.

(b) Laboratory project.

(d) Analytical and experimental.

(e) Study of the special problems that develop when liquid-solid mixtures are carried in inclined pipes.

\section{(3390) MECHANICS OF NON-NEWTONIAN FLOWS.}


(b) Laboratory project.

(c) Dr. G. Bugliarello, Dept. of Civil Engrg., Carnegie Institute of Technology, Pittsburgh 13, Pennsylvania.

(d) Analytical and experimental.

(e) Study of energy relationships, velocities and flow structure in non-newtonian flows

(3391) VORTEX FORMATION.

(b) Laboratory project.

(c) Dr. G. Bugliarello, Dept. of Civil Engrg., Carnegie Institute of Technology, Pittsburgh 13, Pennsylvania.

(d) Analytical and experimental.

(e) Study of onset, development, stability and decay of vortex motion in free surface flows.

(3392) SEDIMENT TRANSPORT IN NATURAL STREAMS.

(b) Laboratory project.

(c) Dr. G. Bugliarello, Dept. of Civil Engrg., Carnegie Institute of Technology, Pittsburgh 13, Pennsylvania.

(d) Experimental and analytical.

(e) Studies of stream geometry, sediment load characteristics and velocities for typical natural stream conditions.

\section{(3393) EVAPORATION FROM MOVING SURFACES.}

(b) Laboratory project.

(c) Dr. G. Bugliarello, Dept. of Civil Engrg., Carnegie Institute of Technology, Pittsburgh 13, Pennsylvania.

(d) Analytical.

(e) Study of the influence of kinematic conditions at the liquid-solid interface on the evaporation process.

(f) Inactive.

(3689) PHASE SEPARATION EFFECTS IN THE FLOW OF BLOOD.

(b) National Institutes of Health.

(c) Dr. G. Bugliarello, Dept. of Civil Engrg., Carnegie Institute of Technology, Pittsburgh 13, Pennsylvania.

(d) Experimental and analytical.

(e) Study of the magnitude of the phase separation effect in the flow of blood for vessels of different sizes and configurations, both under steady and pulsating flow conditions.

\section{(3690) FLOW CHARACTERISTICS OF FOAMS.}

(b) National Institutes of Health.

(d) Experimental and analytical.

(e) Study of the flow characteristics of foams in closed conductors and open channels of varying geometry.

\section{(3691) WAVE PROPAGATION IN SOLID-LIQUTD MIXTURES.}

(b) Laboratory project.

(c) Dr. G. Bugliarello, Dept. of Civil Engrg., Carnegie Institute of Technology, Pittsburgh 13, Pennsylvania.

(d) Experimental and analytical. (e) Study of the celerity and intensity of pressure waves in solid-liquid mixtures of different characteristics flowing in pipes.

(3692) SEPARATION FLOW OF SOLID-LIQUID MIXTURES.

(b) Allegheny County Sanitary Authority.

(d) Experimental and analytical.

(e) In the separation or divergence of flowing liquid-solid mixtures unbalanced concentrations frequently occur in the different channels. Methods are being developed to predict and control the unbalance.

COLORADO STATE UNIVERSTTY, Hydraulics Laboratory, Civil Fngineering Section.

(55) SNOW COURSE MEASUREMENTS AND FORECAST ANALYSIS.

(b) Soil Conservation Service, Colorado Agrieultural Experiment Station.

(c) Mr. Jack N. Washichek, Snow Survey Supervisor, Colo. State Univ; Civil Engrg. Sect., Fort Collins, Colorado.

(d) Field investigations; applied research.

(e) Systematic measurements of depth and water content of snow at high elevations in Colorado and New Mexico mountain areas for the purpose of forecasting the runoff of the principal rivers of the state in the interest of irrigation, power, domestic supplies, and other uses. The use of electrical resistance soil moisture units is being tested to determine a factor of soil moisture deficiency for water supply forecast purposes. Most of the major basins now have 2 or more soil moisture stations installed. A period of record must follow before any degree of correlation can be accomplished.

(g) Forecasts are now being issued at forty gaging stations in Colorado and New Mexico. As forecast procedures improve, more and more vital streams will be forecasted.

(h) Colorado Agricultural Experiment Station General Series Papers - Monthly Snow Survey Reports for the Rio Grande, Colorado and Platte-Arkansas Drainage Basin.

Three small basin reports and one two-state bulletin, covering the Rio Grande, Colorado, and Platte-Arkansas drainages are issued monthly, February through May. Supplemental reports are issued January 1, May 15, and June 1 .

(821) GROUND-WATER FLUCTUATIONS AND THEIR RELATION TO PUMPING.

(b) Colorado Agricultural Experiment Station.

(c) Mr. M. M. Skinner, Assistant Civil Engineer, Civil Engineering Section, Colo. State Univ., Fort Collins, Colorado.

(d) Field investigation.

(e) The work consists of semiannual measurements of the depth to the water table in about 300 observation wells in the Arkansas and South Platte Valleys in Colorado. The observation wells, a few with continuous 
recorders, are strategically located in pumping areas. Data on power consumption are also gathered for comparison with water-table elevations. The work is coordinated with the Ground Water Branch, U.S.G.S.

(g) Water tables continue to generally decline in areas which depend entirely upon ground water for irrigation and have a small natural recharge in comparison to withdrawals. Water tables in the main stem aquifers and a areas under canals have recovered quite well following the dry period of the early $1950^{\circ} \mathrm{s}$.

(h) "Water Table Fluctuations in Eastern Colo." by W. E. Code, Colorado State University Agr. Expt. Sta. Bulletin 500-S, 34 pp., August 1958.

"The Manifold Stilling Basin," by G. R. Fiala and M. L. Albertson, Colorado State University, Civil Engineering Dept. Report No. CER58MLA35.

(1837) SEALING OF IRRIGATION CANALS BY BENTONITE SEDIMENTING.

(b) Colorado State University Experiment Station, USDA - Agricultural Research Service and Irrigation Districts and Companies.

(c) Mr. R. D. Dirmeyer, Jr., Project Leader, Engineering Research, Colorado State Univ., Fort Collins, Colorado.

(d) Applied research and development at field sites, supported by laboratory research where needed.

(e) Development work with Wyoming high-swell bentonite as a sedimenting agent in sealing ixrigation canals is essentially complete. The research and development work is now being concentrated on the use of the low-swell varieties of bentonite as a sedimenting agent for sealing irrigation canals and reservoirs.

(f) Completed.

(g) The main advantages of the low-swell bentonite over the high-swell varities are listed as follows: (1) The low-swell varieties are relatively common in many parts of the Western United States and in other areas of the world, whereas the high-swell bentonites are mainly found in Wyoming, and (2) the chemical character of the low-swell bentonites make them compatible with salty soils and hard waters whereas the highswell bentonites can undergo objectional physical changes when subjected to such conditions.

\section{(1074) HYDRAULICS OF STILLING BASINS.}

(b) U. S. Bureau of Public Roads.

(c) Mr. G. L. Smith, Assistant Civil Engineer, Civil Engineering Section, Colorado State University, Fort Collins, Colorado.

(d) Experimental; applied and fundamental.

(e) Experimental investigation was made of scour and scour control in an alluvial bed involving outflow from a cantilevered pipe. Scour control was accomplished by means of a pre-shaped basin in the alluvial bed armorplated with graded aggregate.
Quantitative tests were limited to rectangular channels with rigid vertical sides but of varying width. A qualitative investigation was scour and scour control in an alluvial channel of trapezoidal crosssection but of one width only. Outflow from the pipe was steady, uniform flow.

(f) Laboratory tests have been completed. A report covering work to date is being completed.

(g) Generalized design criteria for an armorplated, pre-shaped stilling basin have been developed. The design criteria are limited to certain flow and sediment characteristics in a rectangular channel with rigid, vertical sides and of a given width. In alluvial channels, armorplating of channel banks is essential to channel stability. In addition, decreasing the slope of the channel banks increases the effectiveness in scour control brought about by the armor plated, pre-shaped basin and banks.

(h) "Scour and Scour Control Below Cantilevered Culvert Outlets," by G. L. Smith, Colorado State University, Civil Engineering Dept. Report is now in preparation. "Sediment Sealing of Irrigation Canals," by R. D. Dirmeyer, and R. T. Shen, (Report of three-year period of 1957 through 1959), Colorado. Report No. CER60RDD33, July 1960.

(2066) STUDY OF OPEN CHANNEL CONSTRICTIONS IN A SLOPING FLUME.

(b) U. S. Bureau of Public Roads.

(c) Dr. H. K. Liu, Associate Civil Engineer, Civil Engineering Section, Colorado State University, Fort Collins, Colorado.

(d) Experimental; applied.

(e) Scour at bridge abutments of various shapes and dimensions have been investigated in the laboratory. Natural sediment having mean sizes of approximately $0.45 \mathrm{~mm}$ were used in the tests. Sediment supply of mainly bed load varied from zero to less than $1000 \mathrm{ppm}$.

(f) Laboratory tests have been completed. Data are being analyzed and compiled.

(g) Criteria for estimating the maximum depth of scour at abutments have been established. The maximum depth of scour, for given sediment size, is found to depend upon the flow depth, velocity, and abutment length and geometry .

(h) Report in preparation.

(2277) STUDY OF EVAPORATION FROM SOIL SURFACES IN TERMS OF SOIL AND MICROMETEOROLOGICAL FACTORS.

(b) Contributing project to Western Regional Project W-32 "Basic Hydrological Factors Relating to Water Conservation".

(c) Dr. Richard A. Schleusener, Assistant Research Engineer, Civil Engineering Section, Colorado State University, Fort Collins, Colorado.

(a) Experimental; basic research.

(e) The project is a study of evaporation from 
soil surfaces. During the past year experiments have been conducted to determine the effect of cyclic variation of ambient conditions of temperature, humidity and radiation on an inverse relation that sometimes exists between the rate of evaporation from a free water surface and the rate of evaporation from a soil in contact with a water table. A study is beginning to determine the effect of gradation, thickness, and soil type on the effectiveness of a gravel mulch for reduction of evaporation.

g) Under cyclic ambient conditions, the inverse relation between the rate of evaporation from a soil in contact with a water table and that from a free water surface can occur if the ambient conditions are such that the evaporation rate from a free water surface reaches a minimum value that depends on soil type, depth to water table, and may depend on the length of time these ambient conditions exist. The phenomenon does not appear to depend on order of time in which the ambient conditions occur. Preliminary studies on the characteristics of gravel mulches indicate that as much as 50 to 90 percent of the moisture lost by evaporation from a soil surface initially saturated can be conserved during the first 3 to 5 days of drying by application of a layer of gravel to the surface.

(h) "Modification of Bridge Control to Simulate Diurnal Variation of Temperatures, Humidity, and Radiation." Agric. Eng. 4I(7):450-451, July 1960, CER6ORAS25.

(2279) LABORATORY AND FIELD STUDY OF THE VORTEX TUBE SAND TRAP.

Cooperative project: Colorado Agricultural Experiment Station and Agricultural Research Srrvice. See U. S. Department of Agriculture, Agricultural Research Service, page 110.

(2513) WATER AND SEDIMENT MEASURING EQUIPMENT FOR EPHEMERAL STREAMS.

(b) Rocky Mountain Forest and Range Experiment Station, Agricultural Research Service and Colorado Agricultural Experiment Station. Mr. A. R. Robinson and Dr. A. R. Chamberlin, Colorado State Univ., Fort Collins, Colo. Experimental; applied research.

(e) The present phases of the project are to further develop measuring flumes of trapezoidal shapes for measurement of flows with steep gradients and for a large range of flows.

g) Tests of a large 1:2 model have been completed. These tests were made by correlating the results with field measurements and conditions. Upstream approach conditions and flume geometry were made to correspond to the field situation. A number of structures have been constructed and are being observed in the field.

(h) "Trapezoidal Measuring Flumes for Determining Discharges in Steep Ephemeral

Streams," by A. R. Robinson, Colorado State University Research Foundation, Civil
Engineering Section, Fort Collins, Colo., Report No. CER59ARRI.

"Model Study of a Trapezoidal Flume for Measurement of Stream Discharge," by A. R. Robinson, Colo. State Univ. Research Foundation, Civil Engineering Section, Fort Collins, Colorado, Report No. CER59ARR57.

\section{(2514) STUDY OF RESISTANCE TO FLOW AND SEDIMENT} TRANSPORT IN ALLUVIAL CHANNELS.

(b) U. S. Geological Survey.

(c) Mr. D. B. Simons, Project Chief, U. S. Geological Survey, Colorado State Univ., Fort Collins, Colorado.

(d) Experimental and theoretical; basic research (staff, doctoral and Masters).

(e) A detailed study of resistance to flow and sediment transport in alluvial channels is underway. Bed materials with median diameters of $0.19 \mathrm{~mm}, 0.28 \mathrm{~mm}, 0.45 \mathrm{~mm}$ and $0.93 \mathrm{~mm}$ are being studied.

In addition, the following related investigations are active: (1) A study of the effect of fine sediments (clay size) on flow in alluvial channels, (2) A study of the effect of temperature on flow in alluvial channels, and (3) A study of the effect of gradation size of bed material on flow in alluvial channels.

(g) Forms of bed roughness in alluvial channels have been classified. The relation of resistance to flow to forms of bed roughness has been discussed. The effect of change in form of bed roughness on depth-discharge relations for alluvial streams has been described. It has been verified that whether or not ripples form is a function of the size of bed material and that dunes will form irrespective of size of bed material, provided sufficient shear can be exerted on the bed material by the watersediment complex to cause general motion without having the Froude number equal or exceed unity. The effect of fine sediment (large concentrations of clay) on the apparent viscosity of the water-sediment complex, the fall velocity of the sediment and the effective size of the bed material have been studied. In general, the addition of fine sediment reduces the fall velocity and effective size of the bed material and can cause significant changes in form of bed roughness, resistance to flow, and bed material transport. A preliminary study of effect of temperature change. shows that a decrease in temperature will decrease the fall velocity and the effective size of the bed material sufficiently to change form of bed roughness under certain poised conditions. In a sense, the effect of reducing temperature is similar to the effects of adding fine sediment to the water only they are not as significant.

(h) "A Study of Flow in Alluvial Channels, Water Supply Paper No. 1498a - Flume Studies Using Medium Sand $(0.45 \mathrm{~mm})$ - in branch of texts," by D. B. Simons and E. V. Richardson.

"A Study of Flow in Alluvial Channels, 
Water Supply Paper No. 1498b - A Preliminary Investigation of the Effect of Fine Sediment," by D. B. Simons, E. V.

Richardson, and W. L. Haushild. Submitted for publication.

"A Study of Flow in Alluvial Channels, Water Supply Paper No. 1498c - Depth Discharge Relations," By D. B. Simons and E. V. Richardson, submitted for publication.

"Forms of Bed Roughness in Alluvial Channels," by D. B. Simons and E. V. Richardson. Submitted to ASCE for possible publication.

"A Study of Flow in Alluvial Channels, Water Supply Paper No. 1498a - The Effects of Fine Sediment on Fluid Particles, Fall Velocity and Flow Phenomenon," by W. L.

Haushild, D. B. Simons and E. V. Richardson. Submitted for publication.

"Total Sediment Transport in Alluvial Channels," by R. J. Garde, Ph. D. Thesis, Colorado State University, 1959.

"Total Sediment Transport in Alluvial Channels - Effect of Fine Sediment on the Mechanics of Flow in Alluvial Channels," by W. I. Haushild, M. S. Thesis, Colorado State University, 1959.

"Sediment Transport in Alluvial Channels Examination of Bagnold's 1956 Hypothesis," by E. V. Richardson, M. S. Thesis,

Colorado State University, 1960.

"Resistance to Flow in Alluvial Channels," by D. B. Simons and E. V. Richardson, ASCE Publication, HY5, May 1960.

(2760) METEOROLOGICAI OBSERVATIONS.

(b) Colorado Agricultural Experiment Station and U. S. Weather Bureau.

(c) Mr. Maxwell Parshall, Civil Engineering Section, Colorado State University, Fort Collins, Colorado.

(d) Field investigation.

(e) The work is being done to obtain a precise long-time record of climatological elements. The elements observed are: maximum, minimum, and current air temperature, wet and dry-bulb temperatures for dew point temperature and relative humidity, soil temperatures at $3,6,12,24$ 36 , and 72 inches, wind direction and velocity at 65 feet and 15 inches above surface, barometric pressure, evaporation from a free water surface, water temperature at surface (maximum, minimum and current), precipitation, cloud cover, dew and frost.

(g) New extreme values of temperature have been recorded recently. The long time mean temperature is increasing. Precipitation varies widely with no long time trend apparent.

(h) Sumary of 70 years' record of Meteorological data in process of publication.

(2761) A STUDY OF THE ECONOMIC EFFECT OF CONTROLLING WATER USE IN AN AREA WHERE SURFACE AND GROUND-WATER RIGHTS APPLY TO A SINGLE SUPPLY. (b) Colorado Agricultural Experiment Station and United States Department of Agriculture Regional Project W-42. (Revised)

(c) Mr. M. W. Bittinger, Assistant Civil Engineer, Civil Engineering Section, Colorado State University, Fort Collins, Colorado.

(d) Field investigation; applied research.

(e) The engineering phase of this study has as its purpose the determination of the interrelationships of ground water and surface water in an area where both are used for irrigation. An area in the South Platte Valley has been chosen for this study. The economic phase will be concerned with the implications of various types of legislative controls which may be applied to the situation.

(g) Inflow, outflow data for a reach along the main stem of the South Platte River have been obtained. Partial analysis of this data has been completed indicating where the principal sources of water entering the river occur and under what circumstances and amounts they occur. The amount of pumping of ground water in the valley near the river has been determined and its effect upon the flow estimated. Analytical methods have been developed to compare with field measurements.

(h) "Colorado Ground Water Problems - Water and the Law," by E. J. Farmer, Colorado Agricultural Experiment Station Bulletin 505-S, January 1960.

"Colorado Ground Water Problems - The Economic Picture," by I. F. Davis, Jr., Colorado Agricultural Experiment Station Bulletin 506-S, June 1960.

(2769) EVALUATION OF FLOWMETERS FOR THE MARTIN COMPANY, DENVER DIVISION.

(b) The Martin Company, Denver, Colorado.

(c) Mr. Susumu S. Karaki, Assistant Civil Engineer, Civil Engineering Section, Colorado State University, Fort Collins, Colorado.

(d) Experimental; applied research.

(e) The purpose of the project was to carry out tests on the dymamic, kinematic and general performance characteristics of various types of flow meters used in conjunction with the Titan Missile program. The flowmeters considered were the Gulton, Gentile, Tube, and Maxson ULtrasonic, impact strain gage, turbine and rotameters. The fluids under consideration were water, liquid oxygen, liquid nitrogen, JP-4, fuel, RP-I fuel and MIL-0-5606 hydraulic fluid.

(f) Completed.

(g) Accuracy and reliability of certain types of flowmeters were found to be dependent upon fluid, flow and geometric characteristics. Changes in certain properties were found to have their effects on the meter calibrations.

(h) "Influence of Elbow Location and Dynamic Viscosity on Turbine Flowmeter Calibrations," by Fred Videon and A. R. Chamberlain, Colorado State University Report No. 
CER58ARC19.

"Evaluation of the Performance Characteristics of Turbine-Type Flowmeters," by S. S. Karaki, F. Videon and F. Trelease, Colorado State University Report No. CER60SSKI 4.

"Evaluation of the Effects of Viscosity on Performance of Turbine-Type Flowmeters," by S. S. Karaki, F. Videon and F..Trelease, Colorado State University Report No. CER60SSKI9.

"The Effects of Bearing Wear and Induced Fluid Rotation on Several Flowmeters," by F. Videon and S. S. Karaki, Colorado State University Report No. CER6OSSK2O.

"Evaluation of the Performance of TurbineType Flowmeters - A Summary Report," by S. S. Karaki and F. Videon, Colorado State University Report No. CER6OSSK2l.

\section{(2770) A STUDY OF SHEAR STRESS FLUCTUATIONS AT A} LIQUID-SOLID INTERFACE BY MEASUREMENT OF THE ELECTROKTNETIC POTENTIAL FLUCTUATIONS.

(b) National Science Foundation.

(c) Dr. J. E. Cermak, Professor of Engineering Mechanics and Civil Engineering, Head, Aerodynamics Laboratory, Colorado State University, Fort Collins, Colorado.

(d) Experimental and theoretical.

(e) Electrokinetic-potential-fluctuation spectra are being measured for a range of electrode spacings and flow regimes in a glass pipe.

These data together with auto-correlation data for the electrokinetic potentials will be used to determine the character of shear stress fluctuations at the pipe wall.

(g) Preliminary electrokinetic-potentialfluctuation spectra show similar energyfrequency distributions as do turbulent velocity fluctuations measured in a turbulent flow near a solid wall.

(h) "Electrokinetic-Potential Fluctuations Produced by Turbulence at a Solid-Liquid Interface," by Gilbert Binder, Ph. D. Dissertation, Colorado State University, September 1960, 121 pp.

(2902) DEVELOPMENT IMPROVEMENT OF WATER MEASURING DEVICES.

Cooperative project; Colorado Agricultural Experiment Station and Agricultural Research Service. See U. S. Department of Agriculture, Agricultural Research Service, page 111 .

(3034) DISTRIBUTION AND CONCENTRATION OF RADIOACTIVE WASTES IN STREAMS BY FLUVIAL SEDTMENTS.

(b) U. S. Geological Survey for the Reactor Development Branch of the Atomic Energy Commission.

(c) Mr. D. W. Hubbell, Hydraulic Engineer, U. S. Geological Survey, c/o Civil Engineering Department, Colorado State University, Fort Collins, Colo.

(d) Experimental and theoretical research based on both field and laboratory experiments; applied and basic research.

(e) Natural streams provide a convenient and effective medium for the disposal of lowlevel radioactive wastes. When radionuclides are introduced in streams they become fixed on sediment particles. As a result, waste disposal depends, in part, on the transport and dispersion of the sediment. Project activity includes field and laboratory studies on the application and development of transport and dispersion theory for bed and suspended load. In addition, some phases of the dispersion of liquid contaminants are being studied.

(g) Preliminary studies of polyethylene particles released from a point source indicate that for dispersion at the water surface of an 8-foot wide alluvial channel having small dunes, transverse distribution of particles follows a normal distribution, and the coefficient of transverse diffusion, $\mathrm{K}$, in the Fickian theory increases with time and approaches a constant value asymptotically.

(3035) CONSEQUENCES OF RESTRAINT ON MOTIONS OF A MODEL SHIP.

(b) David Taylor Model Basin, Department of the Navy.

(c) Mr. E. F. Schulz, Associate Civil Engineer, Civil Engineering Section, Colorado State University, Fort Collins, Colorado.

(d) Experimental; applied research.

(e) The purpose of this project is to obtain experimental data on the influence of restraint on the model motions resulting from wave trains acting on a model ship. Initially the model motions will be restrained and the forces and moments on the model caused by the waves will be measured.

(f) Completed.

(g) A six component balance was used to measure the forces and moments on the restrained model while being towed at various speeds on different headings. Report is now being prepared.

(3036) THE LONGITUDINAL DISTRIBUTION OF FORCES AND MOMENTS ON A RESTRAINED MODEL IN WAVES.

(b) S-3 Panel of Hull Structure Committee, Society of Naval Architects and Marine Engineers.

(c) Mr. E. F. Schulz, Civil Engineering Sec., Colo. State Univ., Fort Collins, Colo.

(d) Experimental; applied research.

(e) The primary objective of this project is to impose pitching and heaving displacements (separately) varying sinusoidally in time upon a model ship and to measure the forces and moments as a function of time. The models are segmented and attached to an oscillating strongback by means of a stiff spring. The force on each end of the segment is sensed by means of an SR4 strain gage. The simultaneous records of the forces on the seven segments may be 
used to construct a longltudinal shear curve. The longitudinal bending moment is found by graphical integration.

(f) Completed.

(g) The pitching and heaving experiments on a five-foot model of a T2-SE-Al tanker have been completed. The model was oscillated at seven frequencies at rest and at three speeds of advance. The results have been analyzed and were compared with the analytical findings of Haskind.

(h) "Longitudinal Distribution of Vertical Mass, Vertical Moment of Inertia, Damping Force and Damping Moment on a Pitching and Heaving Ship," by M. R. Bottaccinri and E. F. Schulz, Colorado State University Report No. CER6OEFS32.

(3037) STUDY OF ATMOSPHERIC SURFACE LAYER PHENOMENA IN A WIND TUNNEL.

(b) National Science Foundation.

(c) Dr. J. E. Cermak, Professor Engineering Mechanics and Civil Engineering and Head Aerodynamics Laboratory, Colorado State University, Fort Collins, Colorado.

(d) Experimental and theoretical; basic research.

(e) Measurements of mean velocities and mean temperatures together with turbulence intensities and correlations have been made over a smooth, plane, heated or unheated surface. The objective of the program is to relate the turbulent boundary layer structure to the thermal stratification obtained by heating.

(g) Heating of the turbulent boundary layer at low Reynolds number has been found to produce the following effects: (1) Increase the coefficient of drag, (2) increase the eddy viscosity, (3) increase the correlation between vertical and horizontal velocity fluctuations.

(h) "Mean Velocity Profiles for Flow over a Plane, Smooth, Heated Boundary," by E. N. Earle, M. S. Thesis, Colorado State University, June 1960.

(3041) MAGNITUDE AND FREQUENCY OF FLOODS FROM SMALC WATERSHEDS IN ARID AND SEMI-ARID AREAS.

(b) U. S. Bureau of Public Roads.

(c) Dr. Richard A. Schleusener, Civil Engineering Department, Colorado State University, Fort Collins, Colorado.

(d) Applied research.

(e) A study was made of factors affecting peak rates of runoff in the semi-arid region of eastern Colorado and adjacent areas for watersheds less than 1000 square miles.

(f) Completed.

(g) It was determined from gaged watersheds that peak rates of runoff can be estimated from parameters of watershed area, channel slope, and a soil infiltration index in the region east of the Rocky Mountain foothills. Watershed area, elevation, and geographical location parameters can be used for estimates of peak rates of runoff in the Rocky Mountain foothills. Design charts and procedures are presented for determining peak rates of runoff from ungaged watersheds using the appropriate parameters.

(h) "Study of Peak Rates of Runoff in Eastern Colorado and Ad.jacent Areas," by Richard A. Schleusener, George L. Smith and Lewis o. Grant. Colorado State University Report No. CER6ORAS3l.

"Procedures for Estimating Peak Rates of Runoff in Eastern Colorado and Adjacent Areas," by Richard A. Schleusener, George L. Smith, and Lewis 0. Grant. Colorado State University Report No. CER6ORAS3O.

(3394) RESEARCH ON ARTIFICIAI AND NATURAL RECHARGE OF GROUND WATER IN COLORADO.

(b) Colorado Agricultural Experiment Station.

(c) Mr. M. W. Bittinger, Assistant Civil Engineer, Civil Engineering Section, Colorado State University, Fort Collins, Colorado.

(d) Experimental and applied research.

(e) The research under this project is being carried out in three major parts. Part I consists of an over-all analysis of the artificial recharge needs and possibilities in seven major ground-water basins in Colorado. This analysis wIll be based principally upon available information of water supply, water quality, geology, water use and other physical factors. Part II consists of the selection and establishment of field experiments on representative areas within the various ground-water basins. Part III consists of theoretical and laboratory studies to extend the information obtained under Part II.

(g) Field studies have been established at three sites in the South Platte Basin of Colorado. Studies have been completed at one of these sites, Prospect Valley. Analytical developments have been made to compare with field measurements.

(h) "The Development and Dissipation of a Ground Water Mound Beneath a Spreading Basin," by M. W. Bittinger and F. J. Trelease, presented at the 1960 winter meeting of the American Society of Agricultural Engineers, Memphis, Tennessee, December 5 - 7, 1960, Colorado State University Report No. CER6OMWB50.

(3395) FUNDAMENTAL STUDY OF A SUBMERGED THREEDIMENSIONAL JET IMPINGING UPON A NORMAL PLANE.

(b) National Science Foundation.

(c) Mr. George L. Smith, Assistant Civil Engineer, and J. E. Cermak Head of Aerodynamics Laboratory, Colorado State University, Fort Collins, Colorado.

(d) Analytical and experimental; basic research and graduate thesis.

(e) An analytical and experimental study is being made of the axisymmetrical flow 
resulting from an air jet impinging normally on a smooth flat boundary. Measurements of velocity profiles and turbulent intensities are being made in the region of the radial fully developed boundary layer. A shear meter is being designed to measure directly the wall shear stress in order to check the results obtained by means of the momentum integral equation. Experimental data will be used to describe the phenomena of the boundary layer flow.

(g) Preliminary pressure measurements in the stagnation zone follow closely the pressure aistribution as given by irrotational flow analysis. In the radial fully developed boundary layer flow, data for five runs have been obtained in which the height of the jet orifice was kept constant but the jet diameter and discharge was varied. These data indicate that the mean velocity in the outer region follows a similarity law and that in the inner region the shape of velocity profiles varies slightly with a characteristic Reynolds number.

\section{(3397) BHUMIPHOL DAM TUNNEL JUNCTION.}

(b) Engineering Consultants, Inc., Denver, Colorado.

(c) Mr. Susumu S. Karaki, Assistant Civil Engr., Civil Engineering Section, Colo. State University, Fort Collins, Colorado.

(d) Experimental; applied research.

(e) The purpose of this model study was to devise a protective structure within an unlined outlet works tunnel to protect the walls from erosion due to large velocities. Completed.

(g) A hydraulic jump stilling basin was developed in the model as a device to reduce the velocities at the tunnel bend. The basin was located immediately downstream from the outlet valves within the circular tunnel. Concrete lining was provided within the basin section to protect against erosion. At maximum discharge the jump completely filled the tunnel and positive pressures were created in the zone upstream frum the stilling basin sill.

(h) "Hydraulic Model Study of the outlet Works for Bhumiphol Dam," by Susumu Karaki. Prepared for Engineering Consultants, Inc., Denver, Colorado. Colorado State University Report No. CER60SSK5.

(3398) WIND TUNNEL MODELING OF ATMOSPHERIC DIFFUSION.

National Institutes of Health.

Dr. J. E. Cermak, Professor Engineering Mechanics and Civil Engineering, and Head Aerodynamics Laboratory, Colo. State Univ., Fort Collins, Colorado.

Experimental and theoretical.

A point source of gas (ammonia) located within a turbulent boundary layer formed. by the flow of air over a flat plate is used to create a concentration field downstream of the source. Provisions are also made to heat the boundary from below to produce a boundary layer with unstable density stratification. Sampling of the concentration field is accomplished by drawing measured volumes of gas through water. The solution is then analyzed colorimetrically to determine the methylamine concentration. The concentration fields are being studied in an attempt to determine the effects of non-isotropic boundary layer turbulence on diffusion. An attempt will be made to correlate windtunnel-diffusion phenomena to diffusion phenomena in the atmospheric surface layer.

(g) Considerable concentration field data have been obtained for the neutral boundary layer case. Systematic variations of the point-source elevation relative to the local boundary layer thickness is yielding information regarding the relative diffusion rates as a function of position within the boundary layer.

(h) "Wind Tunnel Modeling of Atmospheric Diffusion," by J. E. Cermak. Paper presented at the Third Air Pollution Research Seminar New Orleans, La. March 1960. Colorado State University Report No. CER60JEC5. Ph.D. Dissertation in preparation.

(3399) CLIMATOLOGY OF THE UPPER COLORADO RIVER BASIN.

(b) State of Colorado - Colorado Water Conservation Board.

(c) Dr. Richard A. Schleusener, Assistant Research Engineer, Civil Engineering Section, Colorado State University, Fort Collins, Colorado.

(a) Applied research.

(e) The research conducted at Colorado State University involves a study of the variability of certain meteorological parameters in the Upper Colorado River Basin, and their relation to stream flow.

The Study at Colorado State University is in cooperation with two other phases being conducted by the University of Colorado, Bureau of Economic Research, and the High Altitude Observatory, respectively. In the other phases of the study, the variability of stream flow in the Upper Colo. River Basin, and the relation of these variations to various upper atmosphere parameters is being investigated.

(g) Original weather records from 30 stations in the Upper Colorado River Basin for 1283 station-years of record have been transferred to IBM cards. The data are being reduced to storm totals, from which frequency distributions will be derived.

(3400) HYDRAULICS OF SUB-CRITICAL FLOWS IN SMALI, ROUGH CHANNNELS.

(b) Colorado Agricultural Experiment Station; U. S. Department of Agriculture, Agriculture Research Service.

(c) Mr. Norman A. Evans, Head, Department of Agricultural Engineering, Colorado State University, Fort Collins, Colorado.

(d) Experimental and field investigations; basic and applied, portions will be used for master's and doctoral theses. 
(e) This study is an experimental investigation utilizing a tilting flume in which a small channel 60-feet long is formed by natural soil which is fixed in position against movement by chemical spray. A variety of roughness forms can be created on the bed. A range of channel slope and flow depth are used. Channel shape is a variable.

(g) An equation was developed relating Chezy's resistance coefficient to the standard deviation of the bed roughness in the longitudinal direction and the Reynold's number. Although there is a clear relationship, the standard deviation is inadequate to fully characterize the bed roughness, and some additional geometrical characterization is still needed. Turbulence has been shown to develop in the shallow flows at very low Reynold's numbers and on the other hand, complete turbulence was not developed in the channel at Reynold's number in excess of 7,000 .

(3401) DRAINAGE DESIGN CRITERIA FOR IRRIGATED LANDS.

(b) Colorado Agricultural Experiment Station.

(c) Mr. Norman A. Evans, Head Agricultural Engineering Department, Colorado State University, Fort Collins, Colorado.

(d) Applied.

(e) A sand tank has been used to study the hydraulics of flow near the drain tile as well as the design criteria for gravel filters for tile drains. Hydraulic characteristics of flow through a gravelfilled mole drain will be studied later as an extension of these studies.

(3402) DEVELOPMENT OF AN ULTRASONIC STREAM BED ANALYZER.

(b) Agricultural Research Service.

(c) Mr. S. S. Karaki, Assistart Civil Engineer and Earl Gray, Instructor, Electrical Engineering, Colo. State Univ., Fort Collins, Colorado.

(d) Applied.

(e) The research was undertaken to develop an electronic instrument to simultaneously measure the water surface and stream bed profiles in alluvial streams. This instrument is to be used for research into the mechanics of water and sediment flows in alluvial streams at the Agricultural Research Service Laboratory in Oxford, Mississippi.

(f) Completed.

(g) The Dual Channel Stream Monitor, as this instrument has been named, has been successfully developed and tested in the laboratory. Water surface and bed profiles can be mapped accurately under flume conditions.

(h) "Dual Channel Stream Monitor, Final Report to Agricultural Research Service Beltsville, Maryland," by Earl E. Gray and S. S.

Karaki. Colorado State University Report No. CER6OSSKL6.

"Operational Manual for the Dual Channel Stream Monitor," by Earl F. Gray, and S.
S. Karaki.

(3403) A STUDY OF TWO-PHASE, SINC: "* COMPONENT FLOW IN A VENTURI.

(b) National Bureau of Standards, Boulder, Colorado.

(c) Mr. R. V. Smith, Assixciate Prof. of wech. Engineering, Colo. s'ate Univ., Fort Collins, Colorado.

(d) Experimental and applied.

(e) Controlled mass flows and vapor-to-liquid ratios of steam and water are run in an instrumented Venturi tube. Pressure and temperatures are recorded at staitions along the tube. These data are used in correlations and in preliminary analytical studies.

(f) Suspended.

(g) Some correlations have heen successful. Preliminary analytical ca? culations indicate the flow regime is changing through the venturi tube.

(h) "A Preliminary Study of Steam and Water Flow in Venturi Tubes, "by R. B. Smith, P. C. Wergin, J. H. Ferguson and R. B. Jacobs. Submitted to ASME Transactions for publication. Colorado State University Report No. CER6ORVS47.

(3693) THEORY OF CONSOLIDATED COMBINING PRIMARY AND SECONDARY CONSOLIDATION.-

(b) National Science Foundation.

(c) Mr. I. S. Dunn, Associate Professor, Colorado State University, Fort Collins, Colorado.

(d) Experimental and theoretical; basic research.

(e) The study consists of a mathematical analysis of the effect of viscoplastic resisance on the rate of pore pressure decrease and of an experimental program to verify the mathematical results and to investigate the effect of varied load increments on the time-consolidation relationship. The mathematical analysis will be carried out by adding visco-plastic resistance terms to the basic differential equation of consolidation developed by Terzaghi and solving the resulting equation either by standard methods or by analysis of a theoretical model. The solution of this system along with the laboratory consolidation curves will be used to produce the relationships between plastic resistance and related variables such as speed of deformation and percent of deformation.

(3694) EVALUATION OF HAIL SUPRESSION.

(b) National Science Foundation.

(c) Dr. Richard A Schleusener, Assistant Research Engineer, Colorado State Univ., Fort Collins, Colorado.

(d) Field investigation; applied research.

(e) Observations were made of the occurrence and intensity of hail in and near a commercial cloud-seeding operation conducted in northeastern Colorado during the summer of 1959 for the purpose of attempting to 
reduce hail damage. The distribution of precipitation in the same region was also studied.

(f) Completed.

(g) Simple instrumentation was developed to estimate the intensity of hail fall in terms of impact energy (foot-pounds per square foot). Comparison of impact energies from both seeded and non-seeded cases does not give a clear-cut distinction to evaluate the seeding operation, but does appear to indicate a favorable effect (reduction of hail intensity) in some cases.

Analysis of precipitation anomalies, based on a target-control analysis, shows that nine out of ten storms gave positive anomalies for the "target" stations.

(h) "An Energy Method for Relative Estimates of Hail Intensity," R. A. Schleusener, and P. C. Jennings. Bull. Amer. Meteor. Soc. 41(7):372-376, 1960. Colorado State University Report No. CER59RAS25. "A Review of Research on Hail," by R. A. Schleusener. Colorado Farm and Home Research 10(2):1-3, May-June 1960, Colo. State University Report No. CER60RAS26. "Hailstorm Damage to Crops in Northeastern Colorado, and an Analysis of Precipitation Anomalies Associated with a Cloud-Seeding Program in 1959," by R. A. Schleusener. Submitted for publication to the Journal of American Society of Sugar Beet Technologists. Colorado State University Report No. CER6ORASl.

\section{(3695) CHARACTERISTICS AND FORMATION OF HAIL.}

(b) National Science Foundation.

(c) Dr. Richard A. Schleusener, Assistant Research Engineer, Civil Engineering Department, Colorado State University, Fort Collins, Colorado.

(d) Field and laboratory investigation; basic research.

(e) The characteristics and formation of hail will be studied through the following steps: (1) Development of suitable instrumentation to determine the characteristics of the hail reaching the ground; (2) establishing a suitable network of observing stations at the ground to determine these characteristics; (3) examination of the clouds from which the hail falls, using visual, photographic, and radar observations; and (4) determining the effects of cloud modification by artificial means. The synoptic environment in which hailstorms occur will be examined.

(g) Instrumentation is being developed for the first phase of the study. A limited ground network of observing stations was established in the summer of 1960. The work will be continued and expanded in 1961.

(h) "The 1959 Hail Suppression Program in Colorado and Evidence of its Effectiveness," by Richard A. Schleusener. Submitted for publication in NUBII.A.
Colorado State University Report No. CER6ORAS41.

"The Occurrence and Variability of IceForming Nuclei During the Hail Season in Northeastern Colorado as Measured at 1l,300 ft msl at an Upwind Mountain Station," by R. A. Schleusener and L. O. Grant. Submitted for publication in NUBILA. Colorado State University Report No. CER6OLOG 42 .

(3696) EFFECTS OF CLOUD SEEDING ON SNOWFALL.

(b) Research Grant from Climax Molybdenum Company and observational assistance by the High Altitude Observatory of the University of Colorado.

(c) Mr. Lewis 0. Grant, Assistant Research Engineer, Colorado State University, Fort Collins, Colorado.

(d) Basic and applied.

(e) This research involves a study of cloud and precipitation characteristics over the Colorado Rockies under different weather situations during winter with and without the supply of artificial nuclei.

(g) Field equipment and procedures for use at high elevations in the Colorado Rockies have been developed. Observations of the daily accumulation of snowfall and snow water content have been made over a large area for seeded and unseeded days. Additional observations have included daily observations of ice nuclei concentrations; the freezing point depression of snow water samples; and photographic observations of snow water samples.

(3697) MEASUREMENT OF ATMOSPHERIC OZONE WITH THE DOBSON SPECTROPHOTOMETER.

(b) Air Force Cambridge Research Center.

(c) Dr. Richard A. Schleusener, Civil Engineering Department, Colorado State Universitv, Fort Collins, Colorado.

(d) Basic research.

(e) Measurements of the total amount and the vertical distribution of ozone with height are being made with the Dobson spectrophotometer.

(g) Observations of total ozone and the vertical distribution with height have been made on a regular basis for days when sky conditions have been clear.

(3698) COOPERATIVE RESEARCH ON PEAK RATES OF RUNOFF .

(b) Department of Highways of the State of Colorado.

(c) Dr. Richard A. Schleusener, Civil Engineering Department, Colorado State University, Fort Collins, Colorado.

(d) Applied research.

(e) The effect of soil types and slopes were investigated to determine their importance in estimating the frequency and magnitude of peak rates of runoff from small watersheds in the state of Colorado east of the Continental Divide. 
(f) Completed.

(8) Relationships between soil types and slope characteristics to peak rates of runoff were established and incorporated into design charts and procedures for determining peak rates of runoff from ungaged watersheds.

(h) "Procedures for Estimating Peak Rates of Runoff in Eastern Colorado and Adjacent Areas, " by Richard A. Schleusener, George L. Smith, and Lewis 0. Grant. Colorado State University Report No. CER6ORAS30. "Study of Peak Rates of Runoff in Eastern Colorado and Adjacent Areas," by Richard A. Schleusener, George I. Smith, and Lewis o. Grant. Colorado State University Report No. CER6ORAS3I.

(3699) ANALYTICAI STUDY OF THE MECHANICS OF SCOUR.

(b) U. S. Bureau of Public Roads.

(c) Mr. G. L. Smith, Assistant Civil Engineer, Colorado State Univ., Fort Collins, Colo.

(d) Theoretical.

(e) An analytical study was made of the mechanics of scour by both a two-dimensional and three-dimensional jet. Using the rectilinear and cylindrical coordinate system for the two cases, an equation of continuity of mass sediment transport is derived and used in describing mathematically the phenomenon of scour for various boundary conditions. Expressions for distribution of sediment transport along the bed are then derived for each condition. Jet flow impinging on a normal boundary is then analyzed by making the assumption that the Bernoulli Equation is valid in the neighborhood of the stagnation point. Plane, potential flow is considered first, followed by flow of a fluid with viscosity. For flow with viscosity from submerged and nonsubmerged outiets, expressions for the horizontal velocity and shear distribution along the normal boundary are developed using Bernoulli's theorem and the boundary layer theory of Schlichting and Truckenbrodt.

(f) Completed.

(g) Generalized equations for the depth of scour are presented for two conditions of outlets based on a law of open channel flow for sediment transport of the form given by Shields, and on the developed shear distribution along continuity equation. In particular, the variation of scour depth with respect to time and the final depth of scour are described theoretically in terms of dimensionless parameters. It is then shown that the development of the scour hole with respect to time follows the power law and the logarithmic law for the submerged and non-submerged outlets respectively before the final state is reached. The influence of the angle of the jet is analyzed also, in which expressions for the variation of the depth of scour with respect to time and the final depth of scour are also developed.

(h) "Analytical Study of the Mechanics of Scour For Three-Dimensional Jet," by Y. Iwagaki, G. L. Smith, and M. I. Albertson, Colorado
State University, Civil Engineering Department, Report No. CER6OGLS9.

"Analytical Study of the Mechanics of Scour For Two-Dimensional Jet," by L. Duckstein, Y. Iwagaki, G. L. Smith, and M. L. Albertson, Colorado State University, Civil Engrg. Department, Report No. CER6OGLSI2.

(3700) UNSTEADY FLOW IN A STORM DRAIN.

(b) U. S. Bureau of Public Roads, Division of Hydraulic Research.

(c) Dr. Vujica M. Yevdjevich, Research Hydraulic Engineer, Colorado State Univ., Fort Collins, Colorado.

(d) Theoretical; basic research.

(e) The problem is to study the hydrodynamics of unsteady flow in storm drains with the objective of developing a procedure adapted to a digital computer, verifying the procedure by hydraulic model tests and field measurements as may seem necessary. The ultimate purpose is to provide a working design method applicable to any situation where storm drains are used for removal of stormwater. With the initial and boundary conditions clearly defined for storm drains, the first phase of the research project is concerned with the analytical aspects of the problem.

(g) The analysis of varieties of initial and boundary conditions in storm drains has resulted in adoption of a generalized storm drain, with water inlet points contributing to discharge changes, and junction points contributing to discharge and water level interrelationships of the system of storm drains.

\section{(3701) DEPRESSED CURB OPENING INLET.}

(b) Bureau of Public Roads, Washington, D. C.

(c) Mr. S. S. Karaki, Assistant Civil Engineer, Civil Engineering Section, Colorado State University, Fort Collins, Colorado.

(d) Experimental; applied research.

(e) Design criteria for spacing and sizing of curb inlets on highways varies considerably throughout the country. Under-design as well as over-design is undesirable and uneconomical. Through a full scale model, criteria for efficient hydraulic design will be developed for the depressed curb opening inlets.

\section{(3702) MECHANICS OF FLOW OF SEDIMENT IN PIPES.}

(b) Colorado Agricultural Experiment Station.

(c) Mr. N. Yotsukura and S. S. Karaki, Colorado State Univ., Fort Collins, Colo.

(d) Experimental; basic research.

(e) Studies in open channel flow on the transport characteristics with bentonite in suspension have indicated that the total transport increases as the bentonite concentration in the flow increases. The mechanics of this transport phenomenon is being investigated in a closed recirculating pipe system.

(3703) FLOW CHARACTERISTICS OF LOW WEIR STRUCTURES 
I1: ALLUVIAL CHANNELS.

(b) National Science Foundation.

(c) Mr. D. B. Simons, Civil Engineering Department, Colorado State University, Fort Collins, Colorado.

(d) Experimental investigation.

(e) The flow characteristics associated with low weir structures, with sloping upstream and downstream faces, built across alluvial streams have been investigated in a two foot wide, vaiable-slope, reciruclating laboratory flume.

Two sediments have been used in an attempt to approach the problem of sediment selection for a model to simulate a prototype situation.

The effectiveness of three different sizes of triangular block energy dissipators attached to the downstream slope of the structure has been studied qualitatively.

(f) Laboratory work has been completed.

(g) The surface roughness of the model structure affects the discharge coefficient. Water surface level fluctuations, associated with dune movement at an upstream gaging station indicates the desirability of continuous recording of the elevations of the water surface. Upstream dune and ripple patterns are unaffected by the presence of the structure. Velocity of approach must be considered in discharge coefficient determination due to the changing upstream alluvial bed level. Two simulated hydrographs showed that bed configurations at any time is a function of the magnitude, slope and duration of the flood and whether considered on the rising or falling stage.

(h) Report being prepared.

(3704) DEVELOPMENT AND USE OF COLORADO BENTONITE IN SEALING IRRIGATION CANALS AND RESERVOIRS.

(b) State of Colorado.

(c) Mr. R. D. Dirmeyer, Jr., Project Leader, Colorado State University, Fort Collins, Colorado.

(d) Field investigations; applied research and development.

(e) Work consists of three stages: (1) Inventory of clay deposits in Colorado, with emphasis on those potentially useable in sealing canals and reservoirs; (2) laboratory evaluations of clays from (1) above; (3) field trials in canals and reservoirs with best clays found in (1) and (2) above, and evaluation of sealing results, (initial and with time).

(g) The results are discussed by stages as mentioned in (e) above: (I) Inventory. About 70 favorably appearing deposits have been sampled to date. (2) Laboratory evaluation. Satisfactory laboratory test procedures have been developed. Of the $70 \pm$ samples from (I) above, about 40 seem worthy of field trial testing. (3) Field trials. Preliminary results from about 40 field trials have been obtained. Sealing results range from excellent to poor. Development work is being continued.

(h) Quarterly Reports available beginning May
$1,1960$.

(3705) ANALYTICAL STUDY OF LOCAL SCOUR.

(b) U. S. Bureau of Public Roads.

(c) Dr. V. M. Yevdjevich, Research Hydraulic Engineer, Colorado State University, Fort Collins, Colorado.

(d) Basic; applied.

(e) The study includes an analysis of existing experimental model data on scour around bridge piers and abutments and at culvert outlets with respect to time. The theoretical analysis of the mechanics of scour will serve as a framework for relating model and prototype results.

(3706) FLOW CONTROL AND MEASUREMENT.

(b) International Boundary and Water Commission, United States Section.

(c) Mr. S. S. Karaki, Assistant Civil Engineer, Civil Engineering Section, Colorado State University, Fort Collins, Colorado.

(d) Experimental; applied research.

(e) Stream flow in the Rio Grande River and certain of its tributaries between Fort Quitman, Texas, and Gulf of Mexico has been difficult to measure because of the changing characteristics of the rivers. Through this study a structure is sought which will stabilize the stage-discharge relationship, specifically at the Del Rio gaging station site. The information obtained from this study should be useful also in designing structures at other stations.

(8) A braod-crested weir has been found to give varying coefficients of discharge with unit discharge and aggradation of the bed upstream from the structure. Slight alterations from the normal broad crest has been found to be beneficial in establishing a stable stage discharge relationship.

(h) "Field Investigation Report - Locating and Designing Structures to Improve Stream Gaging Accuracy in the Rio Grande River Basin," by the Field Investigation Team S. S. Karaki, A. R. Chamberlin, D. B. Simons, A. R. Robinson, and M. L. Albertson. Submitted to the International Boundary and Water Commission, El Paso, Texas. Colorado State University Report No. CER6OSSK34. "Interim Report - Hydraulic Model Studies Del Rio Site Stream Gaging Control Structure (Two Dimensional Studies)," by S. S. Karaki for International Boundary and Water Commission, United States Section. Colorado State Univ. Report No. CER6ossK62.

(3707) LOW SPEED PRECISION WIND TEST FACILITY.

(b) White Sands Missile Range, New Mexico.

(c) Dr. J. E. Cermak, Professor Mechanics and Civil Engineering, Colo. State Univ., Fort Collins, Colorado.

(d) Developmental; design.

(e) A low-speed wind tunnel is being designed for use in calibrating and standardizing wind measuring instruments. The test section will be $4 \times 4 \times 4$ ft in size and will have 
an air speed range from $1 / 2$ to $70 \mathrm{mph}$. The variation in air speed for a given setting will not vary by more then \pm 1 percent in space or time excepting within the houndary layers formed on the walls. Turbulence levels will not exceed 0.2 percent at any air speed.

(h) "A Study of Design and operation of a Low Speed Precision Wind Instrument Test Facility," by E. J. Plate and J. E. Cermak. Interim Report. Colorado State University Report No. CER60EJP58.

(3708) INVESTIGATIONS TO DEVELOP WIND TUNNEL TECHNIQUES FOR MEASURING ATMOSPHERIC GASEOUS DIFFUSION IN MODEL VEGETATIVE REGIONS.

(b) Agricultural Research Service, U. S. Department of Agriculture.

(c) Dr. J. E. Cermak, Professor Mechanics and Civil Engineering, Colorado State Univ., Fort Collins, Colorado.

(d) Experimental; basic.

(e) Diffusion of a gas (ammonia) into and out of a model vegetated plane area contributing part of a wind tunnel test section floor is to be studied. Using a test section 80 ft long and $6 \times 6$ ft in cross-section the turbulent boundary layer in which diffusion occurs will be several times thicker than the vegetation height.

Using the basic equations of fluid mechanics, an attempt will be made to establish criterion for application of the model data to prototype conditions. The criterion developed will be checked using field data being obtained at Cornell University by the Agricultural Research Service.

(3709) MICROMETEOROLOGICAL WIND TUNNEL.

(b) U. S. Army Electronic Proving Ground, Fort Huachuca, Arizona.

(c) Dr. J. E. Cermak, Professor of Mechanics and Civil Engineering, Colo. State Univ., Fort Collins, Colorado.

(d) Developmental; design.

(e) A wind tunnel is being designed and constructed which will permit control of air speed $(1-150)$, air temperature $\left(32-200^{\circ} \mathrm{F}\right)$ and relative humidity ( $5-95$ percent). The $6 \times 6$ ft square by 80 ft long test section will have provisions for heating and/or cooling about $30 \mathrm{ft}$ of the floor. The facility is being designed to permit detailed study of turbulence and turbulent diffusion under various thermal conditions.

(3710) SOME ASPECTS OF FLUCTUATIONS IN ANNUAL RUNOFF IN AND NEAR THE UPPER COLORADO RIVER BASIN.

(b) Colorado Water Conservation Board.

(c) Dr. V. M. Yevdjevich, Research Hydraulic Engineer, Colorado State Univ., Fort Collins Colorado.

(d) Basic; applied research.

(e) This study will cover: (1) Effect of overyear storage in the basin on fluctuations of annual runoff; (2) fluctuation patterns of annual runoff at some stations in the Colorado Rtver Basin and in adjacent river basins; (3) regional patterns in the sequence of annual runoff, based on the analysis of serial correlation coefficlents; (4) analysis of fluctuations by using the range (difference of previous maximum and minimum of accumulated departures from average annual runoff); and (5) physical and other explanations of patterns in fluctuations of annual runoff and effective annual precipitation. (Effective annual precipitation is defined as annual precipitation minus annual evapotranspiration for individual water years).

UNIVERSITY OF COLORADO, Department of Civil Engineering, Hydraulics Laboratory.

\section{(3405) AN EXPERIMENTAL INVESTIGATION OF THE ME-} CHANICS OF AIR ENTRAINMENT.

(b) National Science Foundation.

(c) Prof. J. Ernest Flack, Department of Civil Engrg., Univ. of Colorado, Boulder, Colo.

(d) Basic research, master's thesis.

(e) Experimental investigation of air entrainment in a liquid by agitation of the liquid in a plastic cylindrical container. A condition necessary for air entrainment is that the transverse kinetic energy due to turbulence near the surface be sufficient to overcome the stabilizing effect of surface tension. After the air is entrained in the form of bubbles, certain liquid properties such as viscosity, surface tension, and density influence the air concentration and distribution. A relationship between the air content and the fluid properties and turbulence intensity has been developed by dimensional analysis. The functional relationship of the air content with a dimensionless geometry parameter and forms of the Reynolds number, Froude number, and Weber number are presently being evaluated for air entrainment in water and ethyl alcohol.

(i) "Investigation of the Effects of Viscosity and Surface Tension on the Air Concentration of Turbulent Fluid," by John H. Nath, M. S. Thesis, University of Colorado, June 1960.

(3711) FLOW INDUCED BY A SPHERE ROTATING IN AN INFINITE ENVIRONMENT.

(b) National Science Foundation.

(c) Professor F. Kreith, Department of Mechanical Engineering, University of Colo., Boulder, Colorado.

(d) Basic research for thesis; experimental and theoretical.

(e) The flow induced by a rotating sphere is being studied experimentally and theoretically.

(g) Hotwire measurements in the three dimensional boundary layer subjected to centrifugal and coriolis forces have been taken and compared with velocity profiles 
predicted theoretically. Transition and separation have been investigated and movie pictures with smoke injection to visualize the flow are available.

(h) "Laminar Flow about a Rotating Sphere in an Infinite Environment," by J. Sullivan, Thesis, 1960, University of Colorddo.

(3712) DECAY OF A TURBULENT SWIRT IN A PIPE.

(b) National Science Foundation.

(c) Professor F. Kreith, Department of Mechanical Engineering, University of Colorado, Boulder, Colorado.

(d) Basic research for thesis; experimental.

(e) The flow characteristics of a turbulent swirl in a pipe are being studied.

(g) Pressure drop and velocity profiles in turbulent swirls have been measured. The decay characteristics are now being studied in a transparent test section.

(3713) ANALYSIS OF THE CRITICAL FLOW METER FOR MEASURING MASS FLOW RATES OF COMPRESSIBLE FLUIDS.

(b) The Martin Company, Denver, Colorado.

(c) Mr. B. T. Arnberg, Mechanical Engineering Department, University of Colorado, Boulder, Colorado.

(d) Experimental; applied research.

(e) The advantages and limitations of the critical flow meter for measuring and controlling compressible flow rates were reviewed. Operating parameters for measuring and correlating flow data were established. Design parameters and meter performance data were studied. A comparison was obtained between water, subsonic air, and critical air flow discharge coefficients.

(f) First phase of experimental work completed. Continuation of the research is contingent on sponsorship.

(g) The inlet stagnation pressure and temperature are preferred to static properties, and the throat Reynolds number is preferred to the inlet Reynolds number for the correlation of critical flow data. The elimination of the pressure differential measurement required in variable head meters simplifies the instrumentation required for measuring and controlling compressible flow rates, and also greatly increases the flow range attainable. The large pressure drop required to maintain sonic velocity at the throat is the other main limitation. Dissipative and vena contracta effects control the discharge coefficient versus Reynolds number characteristic for nozzles of varying designs. The divergent section downstream of the nozzle throat, and the throat boundary layer thickness seem to control the effect of back pressure on the critical discharge coefficient, and the unchoking characteristics of the nozzle. The method was shown to be reproducible to better than 0.1 percent. Critical discharge coefficients were within 0.3 percent of subsonic and water discharge coefficients at a
Reynolds number of $510^{5}$.

(h) "Analysis of Critical Flow Meter for measuring Mass Flow Rates of Compressible Fluids," by B. T. Arnberg, Univ. of Colo., Engr. Exp. Sta. report, zerox, 70 p., 1960.

(3714) FLOW CHARACTERISTICS AND PERFORMANCE OF BROKEN-BACK TRANSITIONS (Outlets).

(b) Bureau of Reclamation.

(c) Prof. J. Ernest Flack, Department of Civil Eng., Univ. of Colorado William A. Lidster, Bureau of Reclamation, Denver Federal Center, Denver, Colorado.

(d) Applied research; design, master's thesis.

(e) Laboratory studies were made on broken-back transitions to evaluate the characteristics and performance of this type of structure. It was found that the flow characteristics and coefficient of energy loss were influenced by the angle of divergence of the boundary with the centerline of the structure, by the upstream submergence of the inflow conduit, and by the slope of the inflow conduit.

(f) Completed.

(g) Values of the coefficient of energy loss were determined for variations in the flow characteristics and geometry listed above. The results of this study provide designers with more realistic values for energy loss through broken-back transitions.

(h) "Flow Characteristics and Performance of Broken-Back Transitions," by William A. Lidster, M. S. thesis, University of Colo., June 1960.

(3715) TRACTIVE FORCE DISTRIBUTION AROUND THE PERIMETER OF AN OPEN CHANNEL.

(b) Bureau of Reclamation.

(c) Prof. J. Ernest Flack, Department of Civil Engineering, University of Colorado, Philip F. Fnger, Bureau of Reclamation, Denver Federal Center, Denver, Colorado.

(d) Applied research, master's thesis.

(e) This study was made to investigate the possibility of using point velocities occurring in an open channel to determine the tractive force distribution on the perimeter of the channel. Velocity distributions were obtained in a straight trapezoidal channel constructed with a well graded, sand-gravel boundary. Assuming Von Karman's constant of 0.4 , the boundary shear distribution was calculated from the velocity distribution. The average of this boundary shear was determined and compared with the average obtained from the du Boys formula.

(f) This study is part of a continuing study of tractive force distribution in open channels being conducted by the Bureau of Reclamation.

(g) General agreement of the averages obtained by use of point velocity measurements and by use of the du Boys formula was found, indicating that tractive force distributions can be obtained with reasonable accuracy by use of point velocities. Considerable fluctuation of boundary shear 
values was indicated.

(h) "Tractive Force Distribution Around the Perimeter of an Open Channel by Point Velocity Measurements" by Phillip F. Enger, M.S. thesis, University of Colorado, June 1960.

(3716) A TWO-YEAR RESEARCH PROGRAM ON PAST AND PROBABLE FUTURE VARIATIONS IN STREAM FLOW IN THE UPPER COLORADO RIVER.

(b) State of Colorado, Office of the Governor.

(c) Dr. Morris Garnsey, Bureau of Economic Research and High Altitude Observatory, Department of Economics, University of Colo., Boulder, Colorado.

(a) Project is theoretical and is classified as basic and applied research.

(e) The project is an investigation of the optimum form of information regarding the seasonal and year-to-year availability of water in a specific watershed, the upper Colorado basin. The program involves three aspects: (1) A thorough statistical analysis, utilizing the latest statistical techniques, of the historical records of stream flow and precipitation. A result would be an accurate as possible expression of the probability of occurrence of various levels of precipitation and runoff, together with statistical methods of forecasting, if possible, future runoff amounts. A study of the usefulness of this form of statistical information in optimal basin operation procedures is also planned. (2) A broader study embracing correlations between stream flow and meteorological elements in an effort to learn more about hydrometeorological phenomena, and to determine to what extent better hydrometeorological knowledge can be relied upon to predict stream flow. (3) A basic research effort into specific aspects of the general circulation of the upper atmosphere, including the finding of possible relations between hemispheric atmospheric circulation patterns and specific meteorological and climatological phenomena in the basin.

(g) Enphasis to this date has been on 1 and 2 above. Statistical tests have been utilized to investigate the serial dependence of yearly stream flow and precipitation time-series. The results indicate that precipitation amounts by season or water year are indistinguisable from randon numbers, but that stream flow amounts for the larger tributaries exhibit a small but significant amount of serial interdependence. Investigations have indicated that the production of synthetic hydrologies incorporating such serial dependence enable better estimates of important statistical parameters to be made. Also the application of such statistical techniques to the problem of integrating the Glen Canyon Dam into the Colorado River complex has been attempted with promising results. Other results bearing on hydrometeorological relationships and long-period climatic changes in the Basin have been produced. For results on other phases of the project see entry under Colorado State University.

(h) "A Probability Model for Integration of Glen Canyon Dam into the Colorado River System," by M. R. Brittan, Bureau of Economic Research, University of Colorado, Boulder, Colorado, priced at $\$ 3.00$. "A Synthetic Hydrology for the Colorado River," L. Fishman and P. Julian, Proceedings of the 1960 Western Resources Conference, Boulder, Colorado, August 1960. Publication probably in March 1961, priced at $\$ 4.00$.

UNIVERSITY OF CONNECTICUT, Hydraulic Research Lab. Civil Engineering Department.

(1078) HYDROLOGIC FACTORS INFLUENCING RAINFALLRUNOFF RELATIONSHIPS ON SMALL WATERSHEDS IN EASTERN CONNECTICUT.

(b) Laboratory project, State Highway Dept.

(c) Prof. K. C. Tippy, Box U-37, University of Connecticut, Storrs, Conn.

(d) Field investigation; applied research.

(e) Rainfall and runoff measurements are being taken on small watersheds varying in size from 4 to 400 acres.

(2073) A STUDY OF SIDE FLOW INTO GUTTERS AND CHANNELS.

(b) Laboratory project.

(c) Prof. V. Scottron, Box U-37, University of Connecticut, Storrs, Conn.

(d) Experimental and analytical.

(e) Studies are being conducted on the influence of friction on the hydraulics of rectangular channels with sloping bottoms and uniform entering side flow.

(f) Some analysis still to be completed on first phase, but expect to complete a paper on this part during the coming year.

UNIVERSITY OF CONNECTICUT, School of Engineering.

(3717) PRESSURE WAVES RADIATED BY A COLLAFuING CAVITY.

(b) David Taylor Model Basin, Department of the Navy.

(c) Professor R. S. Brand, Box U-37, Univ. of Connecticut, Storrs, Connecticut.

(d) Theoretical; basic research.

(e) The velocity and pressure fields surrounding a collapsing spherical cavity are being computed numerically, with particular attention being given to the spherical shock wave which originates at the point of collapse and moves outward.

CORNELL UNIVERSTTY, School of Civil Engineering.

(2285) QUADRANT EDGE ORIFICE STUDIES.

(b) Laboratory project. 
(c) Prof. Marvin Bogema, School of Civil Engrg., Applied Hydraulic Lab., Cornell University, Ithaca, New York.

(d) Experimental.

(e) Study of the quadrant edge orifice for discharge measurements at low Reynolds numbers. Reproducibility. Effect of size and diameter ratio. Influence of pipe roughness, tap location and velocity profile. Both oil and water used.

(h) "Effect of Velocity Profiles on the Coefficient of Discharge of the Quadrant Edge Orifice Meter," M. V. Ramamoorthy, M.S. Thesis, Cornell University, Feb. 1960.

\section{(3406) CALIBRATION OF LARGE METERS.}

(b) Laboratory project.

(c) Prof. Marvin Bogema, School of Civil Engrg., Applied Hydraulic Lab., Cornell Univ., Ithaca, New York.

(d) Experimental.

(e) Facilities are available in the Cornell Applied Hydraulic Laboratory for calibration of large primary flow elements using water as the calibrating medium. Calibrations made during the past year include 14 and 24 inch turbine meters, and several 4 to 12 inch valves.

(g) Calibration reports have been submitted to sponsors.

(3407) OPEN CHANNEL FLOW IN RIGHT ANGLE BEND.

(b) Laboratory.

(c) Prof. S. Davis, School of Civil Engineering, Cornell University, Ithaca, New York.

(d) Experimental; M. S. Thesis.

(e) Study of flow conditions in right angle bends in open channels.

(f) Inactive.

(h) "Flow Round Sharp Bends," M.H.I. Salem, M.S. Thesis, Cornell University, June 1960.

(3409) EROSION ABOUT PILES DUE TO WAVE ACTION.

(b) Laboratory.

(c) Prof. M. Bogema, School of Civil Engrg. Applied Hydraulics Lab., Cornell Univ., Ithaca, New York.

(d) Experimental.

(e) Study of erosion of sand about piles in deep water due to wave action.

(f) Inactive.

(h) "The Behavior Around an Obstacle of a Flat Horizontal Beach Under the Action of Progrescive Gravity Waves," R. A. Stein, M.S. Thesis, Cornell University, Sept. 1960.

(3718) CRITICAL DEPTH FLUMES.

(b) Laboratory.

(c) Prof. S. Davis, School of Civil Engineering, Cornell Univ., Ithaca, New York.

(d) Experimental and theoretical applied research.

(e) Correlation of published data on various types of critical depth flumes.

(3719) SHARP EDGE ORIFICE STUDIES. (b) Laboratory.

(c) Prof. M. Bogema, School of Engineering, Applied Hydraulic Lab., Cornell University, Ithaca, New York.

(d) Experimental; M.S. Thesis.

(e) Study of sharp-edge orifice in 2-inch pipe with Beta ratios $0.3,0.4,0.5,0.6$, and 0.7 in the range of Reynolds number from 400 to 8000 .

UNIVERSITY OF DELAWARE, Fluids laboratory, Dept. of Civil Engineering.

\section{(3720) PROBIEMS OF FREE SURFACE FLOW.}

(b) Laboratory project.

(c) Dr. Kurt P. H. Frey, Professor, Engineering Mechanics, Department of Civil Engrg., University of Delaware, Newark, Delaware.

(d) Experimental, development, senior students project.

(e) Study on a recently constructed free surface facility. Up to $4000 \mathrm{gpm}$ water is circulated through a test cross section of largely variable sizes. The redistribution of flow for cross sectional areas up to 65 by 16 inches of the test section is of interest at the higher velocity range depending on various means of intake distribution for given geometry; a 12 inch diameter pipe is connected with tank by means of two short $90^{\circ}$ elbow diffusers (discharge cross section $65 \times 17$ inches); redistribution cone, transition to test section by nozzle; effects of guide vanes and screens under study; model for the elbow-diffuser arrangement.

(h) Facility discussed on Symposium of Flow Visualization, November 30, 1960. Winter Annual Meeting ASME, New York City, Fluid Mechanic Subcommittee of the Hydraulic Division of ASME for topic Wall Trace Techniques by Kurt Frey. No detailed description published.

\section{DOUGLAS AIRCRAFT COMPANY.}

(3721) CALCULATION OF THREE-DIMENSIONAL POTENTIAL FLOWS.

(b) David Taylor Model Basin, Dept. of the Navy.

(c) Mr. John L. Hess, Douglass Aircraft Co. EI Segundo Division, El Segundo, California.

(d) Theoretical; applied research.

(e) A machine program is being written to calculate the potential flow about arbitrary three-dimensional bodies without lift. The method used consists of replacing the surface of the body by a source distribution and solving for the distribution required to give zero normal velocity on the body. No small-disturbance approximations are made. Provision is being made to utilize any symmetry the body may possess. The immediate application is the 
calculation of pressure distributions on ships hulls, but the program can handle a variety of flow problems.

(f) Completion expected in June 1961.

UNIVERSITY OF FLORIDA, The Engineering and Industrial Experiment Station, Coastal Engineering Laboratory.

Inquiries concerning projects Nos. 2298, 3051, 3412, and 3413 should be addressed to Dr. Per Brum, Head, Coastal Engineering Laboratory, University of Florida, Gainesville, Florida.

(2298) MODEL STUDY OF DESTRUCTION OF WAVE ENERGY BY VERTICAL WALLS.

(b) National Science Foundation.

(d) Experimental and theoretical; basic research.

(e) Destruction of wave energy by vertical walls studied in Laboratory's wave tank.

(f) Completed.

(3051) BASIC STUDY ON THE RELATION BETWEEN WIND AND WATER BEHAVIOR IN COASTAL WATERS.

(b) National Science Foundation.

(d) Field and laboratory study; basic research.

(e) A combined field and laboratory research program analyzing the transfer of energy from wind to water and the effect of sloping offshore profiles as compared with bodies of water with constant depth; study of the combined setup by waves and wind for different standard profiles. Observations will be made on two platforms in the Gulf of Mexico and laboratory experiments will be carried out in the wave tank of the Coastal Engineering Laboratory.

(3410) COASTAL ENGINEERING STUDY OF BOCA RATON INLET.

(b) City of Boca Raton, Florida.

(c) City of Boca Raton, Florida.

(d) Field investigation and hydraulic-model study.

(e) Investigation of the possibilities of improving navigation conditions at Boca Raton Inlet which, because of high current velocities, are dangerous to navigation; and evaluation of the situation in regard to the inlet's condition to the erosion of the seashore on both sides of the inlet.

(f) Completed.

(3412) FLOOD TIDE STUDIES.

(b) Laboratory project.

(d) Field invsstigation; applied research.

(e) Topography of coastal areas in Florida in relation to potential flooding and statistical analysis of extreme high tides.

(3413) INLET STUDIES.

(b) Laboratory project.

(d) Field investigation; applied research. (e) Study of the stability of coastal inlets.

(e) Analysis is based on the so-called "stability shear stress" which is defined as the average shear stress in a cross-section under stable conditions. The value of this parameter is considered a function of various physical characteristics of the inlet. Suggestions are given for the design of inlets.

(h) "Natural By-Passing of Sand at Coastal Inlets," by P. Bruun and F. Gerritsen. Journal of the Waterways and Harbors Division, Proc. of the American Society of Civil Engineers, paper 2301, WW 4, Dec. 1959.

"Stability of Coastal Inlets," by P. Bruun and F. Gerritsen. North Holland Publishing Co., Amsterdam-C, 1960.

(3722) HYDRAULIC MODEL STUDY OF SARASOTA BAY.

(b) City of Sarasota and Arvida Realty Corp.

(c) City of Sarasota, Sarosota, Florida.

(a) Experimental; applied research.

(e) To study effect of fills in Sarasota Bay on the stability of New Pass and Big Sarasota Pass.

(3723) EMERALD BEACH PROJECT, PASCO COUNTY.

(b) Trustees of Emerald Beach Project.

(c) Mr. C. G. Edwards, P. 0. Box 308, Port Richey, Florida.

(d) Field invsstigation; applied research.

(e) Coastal engineering recommendations for planning of fill project.

(3724) ANALYSIS OF BEACH PROFILES AT JUPITER ISLAND.

(b) Mr. Alton A. Register.

(c) Mr. Alton A. Register.

(d) Field investigation; applied research.

(e) Recommendations for the establishment of a sea wall line.

GEORGIA INSTITUTE OF TECHNOLOGY, Hydraulics Laboratory.

Inquiries concerning the following projects should be addressed to Prof. C. E. Kindsvater, Hydraulics Laboratory, School of Civil Engineering, Georgia Institute of Technology, Atlanta Georgia, except as otherwise indicated.

(291) FLOW OF WATER OVER HIGHWAY EMBANKMENTS.

(b) Laboratory project.

(d) Experimental; partly sponsored by U. S. Geological Survey.

(e) Experimental data were obtained on the discharge characteristics of an embankment-shaped weir. Emphasis has been placed on free discharge over smooth-surfaced embankments. Data have been obtained on the influence of embankment height and tailwater submergence. Detailed velocity surveys have been made to define the boundary layer between the upstream edge of the 
upstream shoulder and the crown. Tests were made on a 1:9-scale model in a 3-foot wide fllume.

(f) Completed.

(g) It has been established that the discharge characteristics of an embankment can be related to the theoretical equation of discharge for a broad-crested weir by means of the discharge-displacement boundary-layer thickness. Data and procedures for computing the thickness of the boundary-layer at the control section have been determined as a means of generalizing the discharge equation for various shapes, sizes and roughness of embankments.

(h) Master's theses, "Dishcarge Characteristics of an Fmbankment-Shaped Weir," Gunnar Sigurdsson (1956), Sherwood P. Prawel (1959) "Influence of the Boundary Layer on Embankment-Shaped Weirs," J. Davidian (1959); available on loan from Price Gilbert Library, Georgia Institute of Technology. Summary report completed for publication in 1961.

\section{(1584) FLOW OF WATER OVER WEIRS AND SPILLWAYS.}

(b) Water Resources Division, Surface Water Branch, U. S. Geological Survey.

(d) Library search, re-analysis and correlation of published data, plus original research as required.

(e) A comprehensive study of the discharge characteristics of practical forms of weirs and spill ways, including the preparation of bibliography and the collection and analysis of experimental data from all known sources. Objectives include the publication, in generalized form, of available experimental data.

\section{(2529) UNIFORM FLOW IN OPEN CHANNELS.}

(b) Water Resources Division, Surface Water Branch, U. S. Geological Survey.

(d) Re-analysis and correlation of existing data; original experimental research and analysis; theoretical study of turbulence energy transfer and diffusion mechanisms.

(e) A fundamental investigation of the mechanics of uniform flow in open channels, with particular emphasis on the influence of channel shape on velocity distributions and wall shear-stress distributions. Experimental work is being conducted on simple and compound cross sections in a variable slope 90-foot long flume.

(1331) THE DIFFUSION OF FOREIGN PARTICLES IN A FLUID.

(b) Laboratory project; sponsored by the $\mathrm{Na}$ tional Science Foundation.

(c) Dr. M. R. Carstens, School of Civil Engrg., Georgia Institute of Technology, Atlanta, Georgia.

(a) Experimental; basic research for doctoral dissertation.

(e) The diffusion of macroscopic foreign particles is being studied in a diffusion column in order to determine the differ- ence in diffusion of the foreign particles and the fluid. The diffusion mechanism is created by a pattern of pulsing jets. The amplitude and frequency of the pulse of the jets is controlled. The foreign particles are ion-exchange resin beads to which are attached radioactive cesium molecules. Particle concentration within the column is determined by gamma-ray radiation count.

(g) The diffusion measurements with the foreign particles is complete. Dissertation in preparation.

\section{(3052) DEZ RIVER DAM SPILLWAYS.}

(b) Resources and Development Corporation.

(c) Dr. P. G. Mayer, School of Civil Engineering, Georgia Institute of Technology, Atlanta 13, Georgia.

(d) Experimental; design.

(e) Two circular shaft spillways are being investigated. The effects of short radius and long radius bends are studied. The hydraulic performance of an inclined shaft spillway is compared with a vertical shaft. The study represents a continuation of previous work.

(3414) INFLUENCE OF FREE-SURFACE DISTURBANCES ON PIEZOMETRIC MEASUREMENTS.

(b) Laboratory project.

(c) Dr. Paul G. Mayer, School of Civil Engrg., Georgia Institute of Technology, Atlanta, Georgia.

(d) Experimental and theoretical; research for master's thesis; partly supported by U. S. Geological Survey.

(e) Observations on laboratory flume (see Project 2529) revealed a discrepancy between depth measurements and piezometric-head measurements for flow conditions involving disturbed free surface. The phenomenon appears to be analogous to pressure or density variations in unsteady, compressible-fluid flows.

(g) Laboratory work completed. Thesis in preparation.

\section{(3725) SECONDARY MOTION IN ENCLOSED CONDUITS AND} OPEN CHANNELS.

(b) Laboratory project.

(c) Dr. Paul G. Mayer, School of Civil Engrg., Georgia Institute of Technology, Atlanta, Georgia.

(d) Theoretical and experimental; research for $\mathrm{Ph}$. D. thesis.

(e) A fundamental study of secondary motion in turbulent flows. Secondary motions are often superimposed upon flows in enclosed conduits and open channels. The mode of origin, development and decay is being studied to delineate the influence on the general motion pattern in straight, noncircular conduits and channels. The present phase of the study is concerned with secondary motion in turbulent, open-channel flow. 
HOUSTON UNIVERSITY, Chemical Engineering Dept.

Inquiries concerning the following projects should be addressed to Prof. A. E. Dukler, Chemical Engrg. Dept., Univ. of Houston, Houston, Texas.

(3726) ENTRATNMENT AND PRESSURE DROP IN TWO-PHASE GAS-LIQUID FLOW.

(b) Laboratory project, National Science Foundation Grant.

(d) Experimental and theoretical; basic research for doctoral thesis.

(e) A study of factors dictating the dispersion of liquid in a gas phase when both flow together in a conduit. The entrainment magnitude, its spacial distributions, size distribution and dependence on flow rates, fluid properties and conduit geometry are being explored, along with momentum and frictional effects.

(h) "Entrainment and Pressure Drop in Horizontal Two-Phase Flow of Air and Water," by M. Wicks III. M.S. Thesis, University of Houston, 1958.

"Entrainment and Pressure Drop in Horizontal Two-Phase Gas-Liquid Flow," by P.

Magiros, M.S. Thesis, University of Houston, 1958.

"Entrainment and Pressure Drop in Concurrent Gas-Liquid Flow: I. Air-Water in Horizontal Flow," M. Wicks and A. E. Duckler, AIChE J, 6, 463, 1960.

3727) ANALYSIS OF EXISTING DATA ON PRESSURE DROP IN TWO-PHASE FLOW.

(b) Sponsored jointly by American Petroleum Institute and American Gas Association.

(d) Theoretical, with both applied and basic approaches being explored.

(e) All available original source data reporting pressure drop (over 15,000 experimental points) are being collected, coded and used to prepare a bank of data on IBM cards. This bank will then be used to make definitive reliability studies of existing correlations of two-phase flow, pressure drop and flow character. New analysis and correlation will be undertaken both by data analysis using the bank and by testing of new theoretical models.

(g) Coding schemes and programs have been completed. Over 5,000 data points banked.

(3728) MOMENTUM AND HEAT TRANSFER IN THIN LIQUID FILMS UNDER TWO-PHASE FLOW.

(b) Laboratory project.

(d) Theoretical; for master's thesis.

(e) Analysis of film geometry and heat transfer based on full pipe universal velocity distributions has proved in error for thin films under shear. This study is concerned with developing suitable new relationships for velocity distribution, film thickness, temperature distribution, and heat transfer coefficients in thin films for any flow direction or fluid properties.

(h) "Flow Mechanics and Heat Transfer in Falling Film Systems," A. E. Dukler, Chemical Engi- neering Progress Symposium Series. No. $30,56,1,1960$.

(3729) EFFECT OF INTERFACIAL CHARACTER ON GAS PHASE TURBULENCE IN TWO-PHASE FLOW.

(b) Laboratory project.

(d) Theoretical and experimental; basic research for doctoral thesis.

(e) Studies are to be made to evaluate turbulence character of the gas phase in a twophase system. Studies of gas moving over wavy liquid surface, a simulated rough liquid surface, which is not moving and a simulated liquid wavy surface will be undertaken.

HYDRONAUTICS, INCORPORATED.

(3730) DYNAMTC BEHAVIOR OF GROUND EFFECT VEHICLES.

(b) David Taylor Model Basin, Bureau of Ships, Department of the Navy .

(c) Mr. Marshall P. Tulin, HYDRONAUTICS, Incorporated, 200 Monroe Street, Rockville, Md.

(d) Theoretical; basic and applied research.

(e) Research on the dynamic characteristics of ground effect vehicles with particular emphasis on development of theory for predicting motions over rough surfaces and ocean waves. Static and dynamic stability in all degrees of freedom are to be treated.

UNIVERSITY OF IDAHO, Engineering Experiment Station.

Inquiries concerning Projects Nos. 1859, 3056, 3057 , and 3416 should be addressed to Associate Director, Prof. C. C. Warnick, College of Engineering, and Projects Nos. 1862, 2786, 3417, and 3418 should be addressed to Prof. G. L. Corey, Dept. of Agri. Engrg., Univ. of Idaho, Moscow, Idaho.

(1859) INVESTIGATION OF METHODS OF CONTROLLING AND EVALUATING CANAL SEEPAGE.

(b) Laboratory project; cooperative with U. S. Bureau of Reclamation.

(d) Field investigation; basic and operationsl.

(e) Different types of canal linings are being studied and various ways of evaluating performance are being considered, especially ideas for measuring canal seepage from both lined and unlined canals.

(g) New techniques for plastic film linings have been tried as well as natural silting effects; a chemical sealant has been tested during 1959-60. Also several new techniques are being developed for measuring seepage.

(h) Annual progress report is available for limited distribution.

(1862) DETERMINATION OF ANNUAL RUNOFF FROM WATERSHED CHARACTERISTICS.

(b) Laboratory project, being carried on under Agricultural Experiment Station.

(d) Experimental; applied research. 
(e) A study of the hydrological factors affecting the Moscow Mountain Watershed as it applies to the total water use in the area.

(g) Measurement data on a small watershed is continuing to be collected.

(2786) FARM IRRIGATION EFFICIENCIES.

(b) Laboratory project; cooperative with Bureau of Reclamation under the Agricultural Experiment Station.

(d) Field investigation; basic and applied research.

(e) To evaluate irrigation efficiencies on actual farms to aid in planning of a water use on irrigation projects. To consider efficiency from aspect of farm operations and not just consumptive use of crops.

(g) Project is in third year of a 4 year program of collecting basic field data. Preliminary effeciencies are available on a few groups of farms.

(h) Annual report available on loan.

(3056) TELEMETERING HYDROLOGIC DATA FROM MOUNTAIN LOCATIONS.

(b) Laboratory project; in cooperation with federal agencies and power companies.

(d) Laboratory and field investigation; basic and applied operational research.

(e) A complete system for reporting six or more hydrologic data is being studied and basic parameters of snow are being considered for conversion into time delay circuits for transmission by radio.

(g) Circuit designs have been completed. Prototype of three measuring units is essentially completed and radio equipment has been developed for use at a field location near Moscow.

\section{(3057) CONSERVATION OF WATER FOR RANGE STOCK.}

(b) Laboratory project; cooperative with Bureau of Land Management and ranchers.

(d) Field investigation; applied operational research.

(e) Experimental stock watering ponds in desert areas will be lined and evaporation control measures supplied to see if extension of water supplies can be developed economically.

(g) Two installations have been completed and instrumentation is being installed. Soils and sites studies are in progress for additional sites and evaporation control experiments are being planned for the 1961 season.

(3416) STUDY OF METHODS FOR AUTOMATIC MEASUREMENT OF SNOW WATER CONTENT.

(b) Agricultural Research Service, U. S. Department of Agriculture.

(d) Field investigation; applied research.

(e) A study is being made of basic methods of measuring snow water content for use in telemetering data from remote mountain locations. (g) Project is being activated in November, initial survey of techniques is in progress and five field methods are being installed.

(h) A comprehensive report of feasible methods is nearing completion available only through USDA.

(3417) INFILTRATION AS AFFECTED BY FURROW PARAMETERS AND SOIL VARIABILITY.

(b) Laboratory project; under investigation in Agricultural Experiment Station.

(d) Theoretical; basic research.

(e) To determine the effect of various furrow geometric parameters and soil conditions on infiltration patterns by analogy methods.

(g) Electrical and model analogs have been constructed and methods of use have been developed.

(3418) AUTOMATIC CONTROL OF SURFACE IRRIGATI ON WATER.

(b) Laboratory project, under investigation in Agricultural Experiment Station.

(d) Experimental field investigation; applied research.

(e) To develop devices which will automatically control surface irrigation water and to field test these devices to determine their limitations.

(g) Laboratory prototypes of gates that will operate automatically have been constructed. A sensing element to activate gates is being designed and tested.

\section{ILLINOIS STATE WATER SURVEY DIVISION.}

\section{(552) SEDIMENTATION OF ILLINOIS RESERVOIRS.}

(b) Laboratory project; cooperative with Agricultural Research Service, Soil Conservation Service, and University of Illinois Agricultural Experiment Station.

(c) Mr. R. I. Corinth, Illinois State Water Survey, Box 232, Urbana, Illinois.

(d) Field investigation; applied research.

(e) For design of water-supply reservoirs, measurements of sediment accumulation in lakes in Illinois. Sediment samples are analyzed and complete surveys of watershed soil type, slopes, land use, and conservation practices are made.

(g) Results show correlation between rate of sedimentation and land use on watershed; results show six factors in explaining sediment deposition: age of lake, capacity-inflow ratio, watershed gross erosion, a watershed shape factor, the density of non-incised channels, and a watershed slope factor.

(h) State Water Survey publications: Reports of Investigation Nos. 4, 7, 8, 9, 10, 12, 15,16 , and 18; sedimentation surveys of Spring Lake, Ridge Lake, Lake Chautauqua, Carbondale Reservoir, Lake Bracken, West Frankfort Reservoir, Lake Calhoun, Lake Springfield, and Lake Carthage, respectively. 
"Water and Land Resources of Crab Orchard Lake Basin," Bulletin 42.

"Correlation of Reservoir Sedimentation and Watershed Factors, Springfield Plain, Illinois," Report of Investigation 37.

\section{(555) EVAPORATION IN ILLINOIS.}

(b) Laboratory project.

(c) Mr. W. J. Roberts, Illinois state Water Survey, Box 232, Urbana, Ill.

(d) Field invsstigation; applied research.

(e) Measurements are made of evaporation at four stations in northern, central, and southern Illinois. Evaporimeters constructed and installed adjacent to pans for year-round records.

(h) Measurements published in Climatological Data, Illinois Section.

(559) ARTIFICIAL RECHARGE OF GROUND WATER.

(b) Laboratory project.

(c) Mr. Robert H. Harmeson, Peoria Laboratory, Illinois State Water Survey, Box 717, Peoria, Illinois.

(d) Experimental; basic research.

(e) Model studies of different pit types and variations in relationship between groundwater gradients and aritficial recharge.

(g) Pilot plant pit operation by Water Survey relinquished; laboratory analysis in progress.

(h) "Artificial Ground-Water Recharge at Peoria, Illinois," Max Suter and Robert H. Harmeson, Bulletin 48, 1960, Illinois State Water Survey, Box 232, Urbana, Ill. (Report of pilot pit operations 1951 - 1959).

(560) GROUND WATER INVESTIGATION IN PEORIA, ILLINOIS, DISTRICT.

(b) Laboratory project.

(c) Mr. Robert H. Harmeson, Peoria Laboratory, Illinois State Water Survey, Box 717, Peoria, Ill.

(d) Field investigation; applied research.

(e) Continuing evaluation of ground water resources of the district. Ground water levels and temperatures are monitored in wells in key locations. Effects of artificial recharge are evaluated. Analyses for changes in composition of ground water used to trace movement of ground water and to observe for possible introduction of contaminants by articicial recharge.

(g) Ground-water conditions have improved substantially and consistently since the use of four recharge pits was initiated in two of the Peoria well fields. Artificial recharge in the North Field is practiced on a year-round demand basis. In the Central Field, articicial recharge is restricted to the seasons when surface water is cool.

(561) GROUND-WATER INVESTIGATION IN EAST ST. LOUIS AREA.

(b) Laboratory project.

(c) Mr. R. J. Schicht, Illinois State water
Survey, Box 232, Urbana, Ill.

(d) Field investigation; applied research.

(e) To evaluate the potential yield of the sand and gravel deposits beneath the American Bottoms (East St. Louis area). Ground water levels are measured in 200 observation wells, 9 of which are equipped with recording gages. Ground water pumpage, Mississippi River stages, rainfall, and quality of ground water data are continuously collected. Maps are being prepared showing the distribution and areal extent of the hydraulic properties, the thickness of the aquifer, and water-table contours. Computations are being made to determine the amount of recharge from precipitation and from induced infiltration of river water, and the amount of subsurface flow from valley walls into the American Bottoms. A geohydrologic model will be devised to simulate the complex aquifer system.

\section{(1092) HYDROLOGIC CYCLE EVALUATION.}

(b) Laboratory project; cooperative with U. S. Geological Survey.

(c) Mr. H. F. Smith, Illinois State Water Survey, Box 232, Urbana, Illinois.

(d) Field investigation; applied research.

(e) Data from rain gage networks (gathered under another project) together with information from 3 stream gaging stations and 5 ground water-level recorders were collected for use in analyzing storm rainfall-runoff relationships on small watersheds and effect of runoff on water table.

(f) Completed.

(h) "Hydrologic Budgets for Three Small Watersheds in Illinois," R. J. Schicht and W. C. Walton, State Water Survey Report of Investigation 40, in press.

\section{(1335) GROUND WATER INVESTIGATION IN THE CHICAGO} AREA.

(b) Laboratory project, in cooperation with Illinois State Geological Survey.

(c) Mr. H. F. Smith, Illinois State Water Survey, Box 232, Urbana, Ill.

(d) Field investigation; applied research.

(e) Study of variations of natural resources. Investigation of artesian well field with wells 1200 to 2200 feet deep, locally heavily pumped. Study of ground water level recession, interferences, transmissibilities, effect of additional demands.

(g) Results show the ground water resources in Chicago region are developed from four water-yielding units: glacial drift aquifers, shallow dolomite aquifers, Cambrian-Ordovician Aquifer, and Mt. Simon hquifer. The Cambrian-Ordovician has been the most highly developed source of large ground-water supplies. Pumpage in deep wells increased from $78.3 \mathrm{mgd}$ in 1958 to $88.0 \mathrm{mgd}$ in 1959. Future groundwater supplies should be taken from the shallow aquifers wherever possible.

(b) "Water Level Decline and Pumpage During 1959 in Deep Wells in the Chicage Region, 
Illinois," W. C. Walton, R. T. Sasman, and R. R. Russell, State Water Survey Circular 79, 1960.

(1865) HYDRAULIC DESIGN OF DROP-INLET SPILLWAY STRUCTURES FOR SMALL RESERVOIRS.

(b) Laboratory project, in cooperation with Agricultural Research Service, Soil Conservation Service, and Illinois Agricultural Experiment Station.

(c) Mr. H. W. Humphreys, Illinois state Water Survey, Box 232, Urbana, Iil.

(d) Experimental; generalized applied research for development and design.

(e) To determine the most desirable proportions and shapes of drop-inlet spillway structures that have uni que flow characteristics and to develop anti-vortex devices. To provide the necessary information on flow relations and discharge coefficients so that these structures may be economically designed. Initial phases of study concerned with hydruulics of square risers with free discharge. Effect of lip or crest shape and anti-vortex devices being studied. Second phase to include the complete spillway. Experimental apparatus constructed and tests are being conducted on the complete spillway. Information is being obtained on discharges, vortex effect on discharge, pressures, a flat plate anti-vortex device, and flow conditions.

(g) Hydraulics of various types of flow possible in square risers are well defined as well as some of the effects of non-square crest shape. Model tests were performed on a drop-inlet spillway to determine whether or not a metal grating deck placed above the inlet can control vortices. The results of the test show that gratings do not prevent or control strong vortices.

(2315) INTERFERENCE BETWEEN RECHARGE PITS.

(b) Laboratory project.

(c) Mr. Robert H. Harmeson, Peoria Laboratory, Illinois State Water Survey, Box 717, Peoria, Ill.

(d) Field investigation; basic research.

(e) Two recharge pits operated simultaneously for three years.

(f) Discontinued.

(g) To date no mound of interference has developed between the two recharge pits during simultaneous operation.

(h) Briefly reported in State Water Survey Bulletin 48 (see 559).

\section{(2532) EVAPORATION RETARDATION.}

(b) Laboratory project.

(c) Mr. W. J. Roberts, Illinois state Water Survey, Box 232, Urbana, Ill.

(d) Field investigation; applied research, dssign.

(e) Monomolecular chemical films to retard evaporation from water supply lakes and ponds in Illinois. Laboratory studies continuing on smaller containers.

(f) Temporarily suspended. (h) "Reducing Lake Evaporation in the Midwest," W. J. Roberts, Jour. Geophys. Res., Vol. 64, No. 10, pp. 1605-10.

"State Water Survey Technical Letter No. 2," 1959.

"Evaporation Suppression from Water Surfaces," W. J. Roberts, Trans. AGU, 38(5): $740-44,1957$.

\section{(2533) MOISTURE INF'LOW STUDY.}

(b) Laboratory project.

(c) Mr. R. G. Semonin, Illinois state Water Survey, Box 232, Urbana, Ill.

(d) Applied research.

(e) Computation of atmospheric moisture inflow of Illinois and subsequent correlation with precipitation. Moisture and wind data obtained from RAOB data.

(f) Analysis completed and report under preparation.

(h) "Artificial Precipitation Potential During Dry Periods in Illinois," Physics of Precipitation, Geophysical Monograph No. 5, AGU, 1960, pp. 424-431.

(2534) DENSE RAIN GAGE NETWORK PROJECTS.

(b) Laboratory project.

(c) Mr. G. E. Stout, Illinois State Water Survey, Box 232, Urbana, Ill.

(d) Field investigation; applied research.

(e) Data from four rain gage networks, consisting of 50 gages in 400 square miles, 10 gages in 100 square miles, 51 gages in 550 square miles, and 11 gages in 10 square miles. Studies include: 1) rainfall variability, 2) frequency of point and areal mean rainfall, 3) area-depth relations, 4) variation of point rainfall with distance, 5) areal representativeness of point rainfall, and 6) reliability of areal mean rainfall estimates.

(h) "Natural Variability of Storm, Seasonal, and Annual Precipitation," G. E. Stout, Jour. Irrigation and Drainage Division, Proc. ASCE, IRI, March 1960 (also State Water Survey Reprint Series 1960-E). "Distribution of Excessive Rainfall Amounts over an Urban Area," F. A. Huff and S. A. Changon, Jr., Jour. Geophys. Res., Vol. 65, November 1960.

\section{(2535) FILTERING THROUGH COARSE MATERIALS.}

(b) Laboratory project.

(c) Mr. Robert H. Harmeson, Peoria Laboratory, Illinois state Water Survey, Box 717 , Peoria, Ill.

(d) Experimental; basic research.

(e) Small laboratory filters containing coarse filter media to be operated at rates comparable to those achieved in field operations to determine efficiencies of filtration bacteriologically and physically.

(f) Being re-activated.

(g) Results of former field tests of various sizes of materials are reported in state Water Survey Bulletin 48.

(2788) METEOROLOGY OF FLOOD-PRODUCING STORMS. 
(b) Laboratory project.

(c) Mr. F. A. Huff, Illinois State Water Survey, Box 232, Urbana, Illinois.

(d) Applied research.

(e) Investigation of meteorological conditions associated with flood-producing storms in Illinois to obtain basic data for reliable definition of time and space distribution of such storms and for calculation of probable maximum rainfall.

(g) Continuing project; analysis progressing on storm area-depth relations, orientation of storms, seasonal and geographic distribution, synoptic weather types, topographic influences.

(3058) HYDROMETEOROLOGICAL ANALYSIS OF SEVERE RAINSTORMS.

(b) Laboratory project.

(c) Mr. F. A. Huff, Illinois State Water Survey, Box 232, Urbana, Ill.

(d) Field investigation; applied research.

(e) Field surveys and detailed analyses of severe rainstorms in Illinois. Analyses based upon radar, symoptic weather, and field survey data and include area-depthduration relations, antecedent rainfall evaluation, isohyetal maps for peak periods of storm.

(g) Analyses completed on 16 storms since 1951.

(h) Reports of Investigation Nos. 14, 24, 27, and 35 of State Water Survey. Another report, No. 42 is in preparation.

(3059) THERMAL LOADINGS AND CHARACTERISTICS OF SURFACE WATERS.

(b) Laboratory project.

(c) Mr. Robert H. Harmeson, Peoria Laboratory, Illinois State Water Survey, Box 717, Peoria, Illinois.

(d) Field investigation; applied research.

(e) A study of heat loads applied to fresh water bodies in Illinois to determine relationships between temperature and/or heat loadings, water usage, stream assets, and stream recovery capabilities.

(3419) PRECIPITATION DROUGHT CHARACTERISTICS.

(b) Laboratory project.

(c) Mr. F. A. Huff, Illinois State Water Survey, Box 232, Urbana, Illinois.

(d) Applied research.

(e) Investigation of precipitation drought frequency in Illinois, distribution in space and time of dry periods, relative severity of these periods, meteorological conditions favorable for drought in Illinois, correlation of precipitation drought with other meteorological factors such as thunderstorm frequency and atmospheric moisture distribution, and association of precipitation drought with low stream flow.

(h) "Drought Characteristics in a Continental Humid Climatic Region," F. A. Huff and S. A. Changnon, Jr., State Water Survey Reprint Series 1960-F, extract of publication No. 51, I.A.S.H. Commission of Surface Waters, pp. 22-33.
(3420) FREQUENCY AND DURATION OF LOW FLOWS.

(b) Laboratory project.

(c) Mr. John B. Stall, Illinois state Water Survey, Box 232, Urbana, Illinois.

(d) Theoretical; applied research.

(e) Analysis of the severity, frequency, and duration of low flows in Illinois streams. Study of the suitability of various theoretical distributions in explaining the occurrence of these low flow events. A partial series developed for low flow events; this series suitable for low flows from 1 month to 60 months in duration.

(g) Gumbel's Extreme Value Law found satisfactory for explaining the occurrence of independent low-flow periods from 1 month to 60 months duration for recurrence intervals from 2 years to 45 years at 20 stream gaging stations in Illinois, varying in drainage area from 550 square miles to 1310 square miles. Runoff-precipitation correlation has been utilized to extend some short period low-flow series to a recurrence interval of 50 years.

\section{(3421) PILOT DRAINAGE BASIN STUDIES IN NAPERVILLE} AREA.

(b) Laboratory project.

(c) Mr. W. C. Walton, Illinois State Water Survey, Box 232, Urbana, Ill.

(d) Field investigation; applied research.

(e) All factors of the hydrologic cycle (especially precipitation, temperature, stream flow, soil moisture, changes in surface and subsurface storage, and evaporation) to be measured and examined to obtain quantitative knowledge of the movement and storage of ground water under natural conditions in the 22-square mile basin. The annual rate of recharge to, and evapotranspiration from, the ground-water reservoir to be determined. Stream discharge hydrograph to be separated into its two components, surface runoff and groundwater runoff. Gravity yields of glacial deposits and underlying dolomite aquifer to be estimated.

(3422) STUDY OF FLOW IN SMALL WATER-DISTRIBUTION SYSTEMS.

(b) Laboratory project, in cooperation with Civil Engineering Department, University of Illinois.

(c) Dr. T. E. Larson, Illinois State Water Survey, Box 232, Urbana, Ill.

(d) Theoretical calculations and field investigation.

(e) To determine the rate of induced movement necessary to provide protection against corrosion of pipe in water distribution systems by forced movement of inhibited waters.

(f) Completed.

(h) "Circulation of Water in the Hammond Distribution System," Thurston E. Larson, John C. Guillou, and Laurel M. Henley, State Water Survey Reprint Series 1960-G (from Jour. AWWA, Vol.52, No.8, Aug. 1960.) 
(3423) QUANTITATIVE PRECIPITATION DIFFERENCES BETWEEN EXTREME SOUTHWESTERN LAKE MICHIGAN AND NEARBY LAND AREAS.

(b) Laboratory project.

(c) Mr. S. A. Changnon, Jr., Illinois State Water Survey, Box 232, Urbana, Ill.

(d) Field investigation; basic research.

(e) Monthly, seasonal, and anmual average precipitation data, based on 10 years of records obtained at water intake station located on Lake Michigan four miles east of the Chicago shore line, were compared with precipitation data from nearby land stations to get an estimate of how lake precipitation varied in relation to nearby land precipitation. Secondly, physical factors that appeared to cause differences were studied.

(f) Completed.

(g) On the average, annual precipitation at the lake-located station was $21 \%$ less than land amounts, and the greatest seasonal difference occurred in the spring and fall. Effect of lake appeared to decrease precipitation over the lake especially in summer, while lake and urban effects tend to increase precipitation over Chicago especially in winter.

(h) "Precipitation Contrasts Between Chicago Urban Area and Offshore Station in Southern Lake Michigan," S. A. Changnon, Jr., accepted for publication in Bulletin of Am. Meteor. Soc., 1960.

\section{(3731) HYDROLOGY OF DOLOMITE AQUTFERS.}

(b) Laboratory project, in cooperation with Illinois State Geological Survey.

(c) Mr. W. C. Walton, Illinois state Water Survey, Box 232, Urbana Illinois.

(d) Field investigation; applied research.

(e) Evaluation of water yielding potential from pumping test and specific capacity data is in progress. Statistical analysis of well production data is being made to determine geological controls on aquifer productivity.

\section{(3732) TRANSPIRATION RETARDATION.}

(b) Laboratory project.

(c) Mr. W. J. Roberts, Illinois State Water Survey, Box 232, Urbana, Illinois.

(d) Laboratory and field investigation.

(e) Monomolecular film-forming fatty alcohols are introduced to corn roots causing the plants to transpire less water than control plants during the growing process.

(g) Analysis in progress.

(h) Progress report in preparation.

(3733) EVALUATING WELLS AND AQUIFERS WITH ANALYTICAL METHODS.

(b) Laboratory project.

(c) Mr.W. C. Walton, Illinois State Water Survey, Box 232, Urbana, Illinois.

(d) Field investigation; applied research.

(e) Case histories of ground-water development are being studied to determine if it is possible to evaluate wells and aquifers with analytical expressions by devising approximate methods of analysis based on idealized models of aquifer situations. Geohydrologic boundaries are assumed to be straight-line demarcations and are given mathematical expression by means of the image-well theory. The hydraulic properties of the aquifer and overlying confining beds are considered mathematically by using ground-water formulas. Records of past pumpage and water levels and a digital computer are used to establish the validity of this mechanism to describe the response of aquifers to pumping.

(g) Case histories of ground-water development have been used to evaluate the practical sustained yields of three aquifers in central Illinois.

(h) "Analyzing Ground-Water Problems with Mathematical Models and a Digital Computer," W. C. Walton, International Association of Scientific Hydrology, 1960.

\section{(3734) INDUSTRIAL WATER USE IN ILLINOIS.}

(b) Laboratory project.

(c) Mr. W. J. Roberts, Illinois State Water Survey, Box 232, Urbana, Ill.

(d) Field investigation; applied research.

(e) Determine withdrawal of water by industries in Illinois, with delineation according to kinds of industry, location by area, and sources of supply.

(f) Completed.

(g) Exclusive of hydroelectric plants, 11.8 billion gallons per day was pumped by Illinois industries in 1959. This is an increase of 42.6 percent since 1950 .

(h) "Industrial Water Use in Illinois," W. J. Roberts, Proceedings of the American Power Conference, Vol. XXII, pp. 814-820, 1960 (also State Water Survey Repri.t Series 1960-D).

\section{ILLINOIS STATE WATERWAYS DIVISION, Springfield.}

(1863) EROSION CONTROL, ILLINOIS SHORE OF LAKE MICHIGAN.

(b) State of Illinois.

(c) Mr. Thomas B. Casey, Chief Waterway Engr., Div. of Waterways, Dept. of Public Works and Buildings, 201 West Monroe Street, Springfield, Illinois.

(d) Field investigation; applied research.

(e) To obtain and correlate basic data on the several forces and factors involved in erosion processes along the Illinois Shore of Lake Michigan to the end that future efforts toward the prevention of erosion might be founded upon a more definite and factual basis with a consequent greater degree of assurance that the works will serve the intended purposes.

UNIVERSITY OF ILLINOIS, SOil and Water Conservation Engineering Lab., Department of Agricultural Engrg. 
Inquiries concerning the following projects should be adaressed to Prof. B. A. Jones, 100 Agricultural Engineering, University of Illinois, Urbana, Ill.

(2316) RUNOFF FROM SMALI AGRICULTURAL AREAS IN ILLINOIS.

(b) Laboratory project cooperative with ARS, U. S. Department of Agriculture.

(d) Experimental and field investigation; basic research.

(e) To determine frequencies of peak rates and total amounts of runoff from agricultural watersheds of 25 to 1,500 acres; to determine maximum rates of runoff from agricultural watersheds in different soil association areas in Illinois; to compare runoff from agricultural watersheds under accepted soil conservation practices with watersheds cultivated without soil conservation practices. Watersheds of $45.5,63$, 82 , and 390 acres near Monticello, Illinois are covered with a rain gage network, and runoff is measured at weirs and spillway structures by water level recorders. Maximum stage recorders are installed at field structures on 8 watersheds in Champaign, Piatt, Vermillion, and Ford Counties on watersheds ranging in size from 45 to 1, 400 acres. Model studies and field calibrations are made on the field structures.

(h) "Peak Runoff and Rainfall Analyses for Two Agricultural Watersheds," by D. L.' Pigg, M. S. Thesis, University of Illinois, oct. 1959 (available on loan).

(2317) A STUDY OF DRAINAGE OF SOME ILLINOIS SOILS.

(b) Laboratory project cooperative with ARS, U. S. Department of Agriculture.

(d) Field investigation; applied research.

(e) To determine on different soil types the effect of tile spacing and depth on (I) water table as measured by drawdown wells, (2) on crop yields; to verify present tile depth and spacing formulas for soil types investigated; and to compare physical laboratory measurements with field measurements.

The rate of water table drawdown is measured in wells perpendicular to tile lines. Field permeability and laboratory permeability measurements are made as well as physical analysis of the soil type. Crop yields are determined laterally from the tile lines.

(2789) LABORATORY MODEL STUDIES OF CONSERVATION AND DRAINAGE STRUCTURES.

(b) Laboratory project.

(d) Experimental investigation in the laboratory; applied and basic research.

(e) To investigate the performance of soil and water conservation structures by means of hydraulic model studies, to study water flow patterns into surface drains and to determine the cause of failures and remedial measures of certain conservation structures under flood conditions.

(h) "The Mechanics of Square Elbow Losses,"
R. D. Black, Ph.D. Thesis, University of I.linois, Oct. 1960 (available on loan). "A Comparison of Some Filter Materials Used for Tile Drains," D. R. Sisson, M. S. Thesis, Univ. of Illinois, August 1960 (available on loan).

"A Comparison of Filter Materials for Tile Drains," D. R. Sisson and B. A. Jones Jr., paper 60-719 presented at the Winter Meeting of the Amer. Soc. of Agricultural Engineers, Dec. 1960 (available from the Executive secretary, ASAE, St. Joseph, Mich.).

"Effect of Crack Width at Tile Joints on Soil Movement into Draintile Lines,"

Benjamin A. Jones Jr., Trans. ASAE, Vol. 3, No. $1, \mathrm{pp} .33-35,41,54,1960$.

\section{(3424) A STUDY OF RAINFALI ENERGY AND SOIL EROSTON.}

(b) Laboratory project cooperative with ARS, U. S. Dept. of Agriculture.

(a) Experimental; basic research.

(e) Natural rainstorms are photographed with a raindrop camera so that the number of raindrops, their size and size distribution, and the kinetic energy of a rainstorm may be calculated. Physical measurements will be made of the soil to determine the effect of the kinetic energy of the rainstorm on soil loss. The nature and properties of rainstorms that occur in this area of IIl. will aıso be studied.

UNIVERSITY OF ILLINOIS, Civil Engineering Department.

Inquiries concerning all projects should be addressed to Dr. V. T. Chow, Prof. of Hydraulic Engineering, or for Projects Nos. 1589, 2087, 2088, 2318, 2790, 3060, 3061, and 3425, to Prof. J. C. Guillou, Dept. of Civil Engineering, University of Illinois, Urbana, Illinois.

\section{(564) HYDROLOGY OF URBAI AREAS.}

(b) Laboratory project, cooperative with Ill. State Water Survey.

(d) Experimental, theoretical, and field investigation; applied research and design.

(e) Rainfall-runoff study of an urban watershed, having an effective drainage area of 4.45 square miles and a population density of 14 persons per acre. Runoff is measured by a U. S. G. S. stream gage and precipitation by a network of fourteen rain gages strategically located in and out of the watershed. New types of evaporimeter are being developed and check results are being made.

\section{(1589) OPEN CHANNEL METER.}

(b) Laboratory project in cooperation with Theoretical and Applied Mechanics Dept.

(d) Experimental and analytical.

(e) This study is concerned with a cricical depth meter which may be economically installed in a sewer after the sewer has been placed in service. Tests using a 16-inch 
diameter pipe, with adjustable slope, has been tested using several types of obstructions.

\section{(1591) DETERMINATION OF WATERWAY AREAS.}

(b) Laboratory project, cooperative with Ill. Div. of Highways and Bureau of Public Roads.

(d) Analytical and field investigation; applied research and design.

(e) To determine the discharge of water which will reach openings of highway drainage structures, such as bridges and culverts and to provide a simple but scientific procedure for use of engineers in establishing the economical and adequate size of opening.

(g) Seven preliminary reports and two field reports have been prepared.

(h) Final report in preparation.

(2087) EFFECTIVENESS OF SUBWAY GRATINGS FOR HIGHWAY DRAINAGE.

(b) Departmental special study.

(d) Laboratory investigation; applied research.

(e) Full scale model tests of two subway rating designs have been tested in standard Ill. Division of Highways, Type II inlet frame.

(f) Suspended temporarily .

(2088) DISCHARGE CHARACTERISTICS OF RECTANGULAR TYPE INLET BOXES.

(b) Departmental study.

(d) Laboratory investigation; basic research.

(e) Scale model investigation of rectangular inlet box with long Lucite discharge pipe to verify or disprove the weir-orifice discharge theory.

(f) Suspended temporarily.

\section{(2318) FAUBER BRIDGE MODEL STUDY.}

(b) Departmental graduate study.

(d) Laboratory investigation; applied research.

(e) A design has been developed whereby a three tube culvert and an energy dissipator may replace an inadequate highway bridge. Model studies have been conducted to verify the proposed design.

(f) Final report in preparation.

(2319) FREQUENCY STUDY OF HYDROLOGIC DATA.

(b) Departmental study.

(d) Basic and applied research.

(e) Application of statistical methods and probability laws to the analysis of hydrologic data.

(g) A new concept of rainfall intensity frequency is developed and being applied to rainfall data at Urbana and Chicago, Ill.

(h) See previous issues of this publication.

\section{(2790) SIDE CHANNEL SPILLWAY STUDY.}

(b) Departmental graduate study

(d) Laboratory investigation; applied research.

(e) Model investigation of flow conditions on the apron below the spillway crest and above the spillway channel. The purpose of the investigation is to determine the geometrics of the apron and the necessity of a critical depth control at the entrance to the spillway channel.

(3060) OPERATIONAL CHARACTERISTICS OF FILTER DRAINS.

(b) Association of American Railroads.

(d) Experimental; applied research.

(e) Investigation of characteristics of flow through granular filters and perforated arain pipe. Laboratory investigations have included tests of coated and uncoated drain pipe, and permeability and filter loss studies using concrete sand as the filter material. Current laboratory investigation is toward determination of operation characteristics with compaction of filter as prime variable.

(g) Indications are that little sorting of filter material occurs at pipe perforation and that compaction of filter material is of maximum importance in controlling rate of filter migration.

(h) "First Progress Report on Performance of Filter Materials," J. C. Guillou, Bulletin 556, American Railway Engineering Assoc., February 1960.

\section{(3061) FLOW CHARACTERISTICS OF REND LAKE SPILLWAY.}

(b) Laboratory project and class problems.

(d) Model investigation of uncontrolled apron type spill way.

(e) A 1:50 scale model of approach section, spillway and energy dissipator. Tests of the original design have been completed. The spillway walls have been redesigned for more uniform distribution of flow at the hydraulic jump. The re-design has been tested and verified.

(f) Completed.

(g) "Hydraulic Model Study of Rend Lake Spillway with Design Revisions," Interlaboratory Report, Mimeo, 1960.

(3065) STUDY OF A TORNADO MODEL FOR DESIGN PURPOSES.

(b) Graduate project, doctoral thesis for Mr. G. E. Martin.

(d) Analytical and field investigations; basic research for doctoral thesis.

(e) To correlate the laws of thermodynamics, atmospheric physics, dynamic meteorology, and fluid mechanics with the available data from actual tornadoes and to construct a model tornado from these data for design purposes that are compatible with the theory. The facilities of both the Civil Engineering Department and the Illinois State Water Survey, including a weather radar, are used in this study.

(f) Completed.

(g) The results indicate: For design purposes, a severe, long path tornado represents the most serious hazard. A conservative design for tornado safety should be capable of withstanding a simultaneous pressure reduction of 3 in. Hg., a tangential wind velocity 
of $160 \mathrm{mph}$, a radial velocity of $120 \mathrm{mph}$, and a translational velocity of $60 \mathrm{mph}$. These values give a maximum combined surface wind velocity of $250 \mathrm{mph}$. This maximum velocity is invariably from a southwesterly direction in Illinois.

(h) "Quantitative Investigation of the Destructive Energy in Tornadoes," by G. E. Martin, Doctoral Thesis, Graduate College, Univ. of Illinois, 1960.

(3066) THE MECHANICS OF SQUARE ELBOW LOSSES.

(b) Graduate project, doctoral thesis for $\mathrm{Mr}$. R. D. Black.

(d) Experimental; basic research for doctoral thesis.

(e) This is a study of the factors that contribute to the loss in energy experienced by the flow of water as it passes through an abrupt angle and size reduction such as that of a plugged "tee". The study is conducted by means of hydraulic models.

(f) Completed.

(g) The results indicate that the effects upon the head loss coerficients of varying the pipe-size ratio, the deflection angle, and the plug position, at values of Reynold's number above $6 \times 10^{4}$, are all interdependent. The effects of increasing the roughness in the outlet pipe was to reduce the head loss coefficients for all of the fittings tested, and the effect of increasing the average velocity or Reynolds number as to stabilize the effects of the other variables.

(h) "The Mechanics of Square Elbow Losses" by R. D. Black, Doctoral Thesis, Graduate College, University of Illinois, 1960.

(3425) LOCKPORT SLUICEGATE STUDY.

(b) Metropolitan Sanitary District of Greater Chicago.

(d) Experimental, applied research.

(e) A l:20 scale model has been constructed and tested. The subject sluice gates will be used for supplemental control of storm water releases from the Chicago Drainage Canal. Three turbine pits in the existing powerhouse at Lockport have been modified to receive triple sluice gates. The model results will be used for calibration of the prototype structure.

(g) Report in preparation.

(3735) DESIGN AND CONSTRUCTION OF A RESISTANCE NETWORK ANALOG.

(b) Departmental study of Mr. D. C. N. Robb.

(d) Experimental; applied research.

(e) To evaluate the theory and use of a resistance network analog and to construct the analog for solving several typical problems, such as the solution for pore pressures in a zoned, rolled-fill dam.

(3736) NON-LINEAR APPROACH TO THE INSTANTANEOUS UNIT HYDROGRAPH THEORY.

(b) Graduate project, doctoral thesis for Mr. K. P. Singh. (d) Theoretical; basic research for doctoral thesis.

(e) To investigate the linearity of the theory of instantaneous unit hyarograph. A mathematical model for the instantaneous unit hydrograph is to be developed and solved by electronic computers. Application of the mathematical model will be made to observed hydrographs.

\section{(3737) HYDRODYNAMICS OF FREE-SURFACE EFFECT.}

(b) Departmental study.

(d) Theoretical; basic research.

(e) To evaluate the free-surface effect of flow in open channels.

(g) A preliminary study is being made to check the variation in roughness coefficient in circular conduits when the flow is partially full. In this study Prandtl's assumption of constant shearing stress is changed to an assumption of variable shearing stress depending on hydraulic radius. The computed variation in roughness coefficient agrees in general with the average observations.

UNIVERSITY OF ILLINOIS, Fluid Mechanies and Hydraulics Laboratory.

Inquiries concerning Project No. 2083 should be addressed to W. M. Lansford, 219 Talbot Laboratory, University of Illinois, Urbana, Ill., and for Projects Nos. 2320, 2536, 2537, and 3427 should be addressed to Prof. J. M. Robertson, 125 Talbot Laboratory, University of Illinois, Urbana, Ill.

(2083) VELOCITY DISTRIBUTION IN AN OPEN CHANNNEL HAVING A TRIANGULAR CROSS-SECTION.

(b) Research.

(d) Basic research.

(e) Data were obtained from a channel artificially roughened.

(f) Investigation reactivated, additional data being taken.

(2320) TURBULENT BOUNDARY LAYER IN A DIFFUSER.

(b) Laboratory project.

(d) Experimental and analytical; basic research.

(e) Effect of adverse pressure gradient on the development of a turbulent boundary layer is being studied in a 10 degree conical diffuser. Air is the fluid medium being used.

(f) Inactive

(2536) STUDY OF HOMOLOGOUS TURBULENCE.

(b) Laboratory project; formerly National Science Foundation.

(d) Basic research.

(e) The nature of turbulence, its production and dissipation, are to be studied in the simplest possible shear flow. This is to be produced in plane Couette flow in which the shear is constant and the turbulence homogeneous but not isotropic. Mean flow 
studies essentially complete.

(2537) WATER EXIT HYDROBALLISTICS.

(b) Office of Naval Research, Dept. of the Navy.

(d) Basic research; experimental.

(e) Information on water exit behavior of ellipsoidal bodies of fineness ratios 4 and 8 is being obtained photographically. Water is principal test liquid but glycerine and 100 percent brine solutions have also been used.

(f) Tests completed, final report in process.

(g) Effects are found to be small, velocity first increases and then decreases as body exits. Significant amounts of water are carried out with the body.

(h) "A Study of the Kinematics of Buoyant-Body Water Exit, Part II," by M. E. Clark and J. M. Robertson, TAM Dept. Repoit: 181, November 1960.

(3527) STRUCTURE OF TURBULENCE NEAR ROUGH SURFACES.

(b) Bureau of Ships Fundamental Hydromechanics Research Program.

(d) Basic research; experimental.

(e) Information on mean-flow and turbulence structure (including pressure fluctuations) near a natural roughness to be studied in 8-inch steel pipe line. Basic question is how roughness produces turbulence.

IOWA INSTITUTE OF HYDRAUIIC RESEARCH, State University of Iowa.

(66) HYDROLOGIC STUDIES, RALSTON CREEK WATERSHED.

(b) Cooperative with Department of Agriculture, U. S. Geological Survey.

(c) Prof. J.W. Howe, Department of Mechanics and Hydraulics, State University of Iowa, Iowa City, Iowa.

(d) Field investigation; applied research, and M. S. Theses.

(e) Study being made of relation between rainfall and runoff over a small area. Discharge from a 3-square-mile area measured by U. S. Geological Survey; rainfall records at five automatic recording stations collected by Soil Conservation Service. Continuous records since 1924 of precipitation, runoff, groundwater levels, and vegetal cover.

(g) Yearly records available for examination at Iowa Institute of Hydraulic Research.

(h) Reports prepared annually since 1924 available in files at the Iowa Institute of Hyaraulic Research. Summary of 33year record in piess.

(67) COOPERATIVE SURFACE-WATER INVESTIGATIONS IN IOWA.

(b) Cooperative with U. S. Geological Survey. (c) Mr. V. R. Bennion, Iowa Institute of Hydraulic Research, Iowa City, Iowa.

(d) Field investigation; collection of basic stream-flow data.

(e) Stream-flow and sediment measuring staticns maintained throughout the state of Iowa cooperatively on a continuous basis. Records collected by standard methods of U.S. Geological Survey.

(g) Records of stream flow and sediment discharge computed yearly.

(h) Records contained in Water-Supply Papers available through offices of the Geological Survey.

(68) HYDROLOGIC STUDIES, RAPID CREEK WATERSHED.

(b) Cooperative with U. S. Geological Survey.

(c) Mr. V. R. Bennion, Iowa Institute of Hydraulic Research, Iowa City, Iowa.

(d) Field investigation; applied research.

(e) Study being made of relation between rainfall and runoff over a small area. Discharge from a 25-square-mile area measured and flood runoff on main subbasins determined by U. S. Geological Survey; rainfall records at four automatic recording stations collected wy U. S. Weather Bureau. Continuous records since 1941 of precipitation, runoff, and ground-water levels.

(g) Rainfall records published in Weather Bureau Climatological Bulletins and surface runoff and ground-water levels published in Geological Survey Water-Supply Papers.

(73) MEASUREMENT OF TURBULENCE IN FLOWING WATER.

(b) Cooperative with Office of Naval Research, Department of the Navy.

(c) Dr. Philip G. Hubbard, Iowa Institute of Hydraulic Research, Iowa City, Iowa.

(d) Experimental and theoretical; basic and applied research.

(e) Instruments, primarily electrical in operation, are being developed to measure the characteristics of turbulent flow under a wide range of laboratory and field conditions. Both sensing and computing elements are involved.

(g) Techniques for cleaning hot-wire probes in place while being used to measure turbulence in water have been investigated, with encouraging results. Transistorized circuits have been aesigned for the hotwire anemometer in air, and similar circuits will be used in water.

\section{(79) CAVITATION.}

(b) Cooperative with Office of Naval Research, Department of the Navy.

(c) Dr. Hunter Rouse, Iowa Institute of $\mathrm{Hy}$ draulic Research, Iowa City, Iowa.

(d) Experimental and theoretical; basic research and graduate theses.

(e) Basic information is sought on cavitation for systematically varied boundary conditions. Studies of high-velocity submerged 
jets are being continued, with supplementary measurements of pressure fluctuations in air; instrumentation has been developed for measurement of the correlation between the velocity and pressure fluctuations to make possible prediction of the incipient cavitation index for given meanflow conditions. Previous measurements of the pressure distribution on a number of head forms at zero angle have been extended to various angles of yaw. Cavitating flow about a rotating cylinder in a normal stream has been investigated. Attention will next be given to the cavitation of disks and plates.

(81) MATHEMATICAL ANALYSIS OF PRESSURE DISTRIBUTION.

(b) Cooperative with Office of Naval Research and David Taylor Model Basin, Department of the Navy.

(c) Dr. Louis Landweber, Iowa Institute of Hydraulic Research, Iowa City, Iowa.

(d) Theoretical; basic research.

(e) A method for the determination of velocity and pressure distribution about bodies of revolution and symmetrical two-dimensional forms in arbitrary states of motion, based on solutions of integral equations of the first kind, has been programmed for the IBM 650 computer.

(g) Results of calculations of velocity and pressure distributions on a series of 30 bodies of revolution, in axial, transverse, and rotational motion, are being analyzed.

(h) "Potential Flow about Bodies of Revolution and Symmetric Two-Dimensional Forms," L. Landweber. Final report on Contract Nonr2451(00) to the David Taylor Model Basin, Dec. 1959.

(854) BOUNDARY-LAYER DEVELOPMENT ON SMOOTH AND ROUGH SURFACES.

(b) Cooperative with Office of Naval Research, Department of the Navy.

(c) Dr. Louis Landweber, Iowa Institute of Hydraulic Research, Iowa City, Iowa.

(d) Experimental and theoretical; basic research.

(e) Purpose of work is to determine the relations between boundary-layer characteristics for smooth and rough boundaries of arbitrary shape. The three-dimensional boundary layer on an ellipsoid with three unequal axes is being measured.

(h) "Three-Dimensional Turbulent Boundary Layer, " F. S. A. Pavamani, M. S. thesis, State University of Iowa, August 1960. (Available on loan.)

"Reanalysis of Boundary-Layer Data on a Flat Plate," L. Landweber, Technical Report to ONR, Nov. 1960.

\section{(1875) CHARACTERISTICS OF STABLE EDDIES.}

(b) Laboratory project, partially supported by Office of Naval Research, Dept. of the Navy.

(c) Dr. Hunter Rouse, Iowa Institute of Hydraulic Research, Iowa City, Iowa. (d) Experimental and analytical; basic rescarch.

(e) Distributions of velocity, pressure, and turbulence are being investigated throughout the vicinity of separation zones produced by abrupt changes in flow section, to the end of establishing the primary eddy characteristics as functions of the boundary geometry.

(g) Studies now being planned on flow in the wake of a circular disk and in either twodimensional or axisymmetric conduit expansions.

(h) "Distribution of Energy in Regions of Separation," Hunter Rouse, La Houille Blanche, Nos. 3 and 4, 1960.

\section{(2091) RESEARCH ON SHIP THEORY.}

(b) Cooperative with Office of Naval Research, Department of the Navy and Society of Naval Architects and Marine Engineers.

(c) Dr. Louis Landweber, Iowa Institute of Hydraulic Research, Iowa City, Iowa.

(d) Experimental and theoretical; basic research.

(e) To determine the laws governing the forces, moments, and motions of ships in smooth and disturbed sens, in order to furnish design data to the naval architect. Work is under way on the following problems: (1) Wave damping of a series of rolling (Ursell) cylinders. (2) Drag of oscillating plates of various aspect ratios, (3) Resolution of viscous and wave drag by means of measurements in the wake of a ship, (4) Effect of a free surface and boundary-layer characteristics on separation, (5) Added mass of a prolate spheroid vibrating horizontally in various modes in a free surface, (6) Treatment of vibration of spheroids and shiplike forms on the basis of a unified theory of hydroelasticity, and (7) Translation of Ship Motions (Kachka Korablia) by $\mathrm{Blagoveschensky.}$

(h) "Drag Coefficients of Flat Plates Oscillating Normally to their Planes," M. Ridjanovic, M. S. thesis, State University of Iowa, Aug. 1960. (Available on loan.) "Effect of Roughness on Ship-Model Rolling," M. Martin, C. McLeod, and I. Landweber, Schiffstechnik, April 1960.

"Added Mass of Ogival Cylinders Oscillating Horizontally in a Free Surface," L. Landweber and Chou-chen Wu, Schiffstechnik, June 1960. "Added Mass of a Rigid Prolate Spheroid Oscillating Horizontally in a Free Surface," L. Landweber and M. Macagno, Journal of Ship Research, March 1960.

\section{(2324) ANALYSIS OF FLOW PATTERNS FOR SHARP-CRESTED} WEIRS.

(b) Laboratory project, partially supported by National Science Foundation.

(c) Dr. Hunter Rouse, Iowa Institute of Hydraulic Research, Iowa City, Iowa.

(a) Analytical; basic research for doctor's degree.

(e) Determination of streamline configuration through use of digital computer for various relative heights of weir.

(f) Programing for computer essentially completed. 
(2328) INVESTIGATION OF SURFACE ROUGHNESS.

(b) Cooperative with U. S. Geological Survey, Department of the Interior.

(c) Dr. Herman J. Koloseus, Iowa Institute of Hydraulic Research, Iowa City, Iowa.

(d) Experimental; basic research.

(e) Purpose is to determine the effect of areal distribution of roughness elements on resistance in both subcritical and supercritical flow. Tests are being conducted on cubical elements cemented to the floors of a 30-foot and an 85-foot flume in varying concentrations.

(f) Data for supercritical f'low with areal concentrations of $1 / 8,1 / 32,1 / 128$, and $1 / 512$ for cubes $3 / 16$ in. on a side have been collected. Results for a $1 / 128$ density of mixed cubes, $3 / 16$ and $3 / 8$ in., have also been obtained. Subcritical flow and additional concentrations are to be investigated.

(2541) DEVELOPMENT OF INSTRUMENTS FOR USE IN ANALYZING APERIODIC SIGNALS.

(b) Cooperative with Office of Naval Research, Department of the Navy.

(c) Dr. Philip G. Hubbard, Iowa Institute of Hydraulic Research, Iowa City, Iowa.

(d) Experimental; applied research.

(e) The purpose is to improve the analysis of turbulent velocity and pressure fluctuations.

(g) A mean-product analyzer has been designed and tested for use on widely fluctuating signals. Principal features are adaptability to third-and higher-order correlations.

\section{(2791) MIXING IN STRATIFIED FLOW.}

(b) Cooperative with the office of Ordnance Research, Department of the Army.

(c) Dr. Enzo 0. Macagno, Iowa Institute of Hydraulic Research, Iowa City, Iowa.

(d) Experimental; basic research and graduate thesis.

(e) Determination of the characteristics of mixing, due to inherent instability, at the interface of stratified flow.

(f) Completed.

(g) Nondimensional shear stress at the interface and transfer of mass across it show a correlation with Froude and Reynolds numbers of the interfacial layer. Four successive regimes of flow are apparent. Paper for A. S. C. E. in preparation. As the subject for a M. S. thesis, the instability of the interface between two fluid layers in transient motion has also been investigated.

(h) "The Instability of Stratified Flow," George H. Mittendorf, M. S. thesis, State University of Iowa, Feb. 1961. (Available on loan.)

(2792) THE DECAY OF TURBUTENCE IN A ZERO-MOMENTUM WAKE.

(b) Cooperative with the Office of Naval Research, Department of the Navy.

(c) Dr. Philip G. Hubbard, Iowa Institute of
Hydraulic Research, Iowa City, Iowa.

(d) Primarily experimental; basic research.

(e) Powered models of a strut-mounted propeller and a merchant vessel are driven in a towing basin, and the wake is investigated with a Pitot rake and a hot-wire anemometer.

(g) Turbulence in the wake of a powered model has been measured, and has been found to decay more rapidly than was anticipated.

(2795) PREDICTION OF RUNOFF FREQUENCY FROM PRECIPITATION AND INFILTRATION FREQUENCIES.

(b) Laboratory project.

(c) Prof. J. W. Howe, Department of Mechanics and Hydraulics, State University of Iowa, Iowa, City, Iowa.

(d) Statistical.

(e) Exploration of possibility of estimating frequencies of rare floods based on combination of observed frequencies of precipitation and infiltration.

(f) First phase completed; continuing.

(g) Good correlation for a small, a medium, and a large watershed found in first phase.

(h) "Prediction of Runoff Frequency from Precipitation and Infiltration Frequencies," M. A. Chowdhurry, M. S. thesis, State University of Iowa, Aug. 1958. (Available on loan.)

(3068) DETERMINATION OF DYNAMIC FORCES ON FLASHBOARDS.

(b) Laboratory project.

(c) Prof. J. W. Howe, Department of Mechanics and Hydraulics, State University of Iowa, Iowa City, Iowa.

(d) Experimental; for M. S. thesis.

(e) Measurement by dynamometer of moment exerted by water flowing over flashboard.

(g) A parameter involving turning moment on flashboard related to head- and tail-water levels for typical $\mathrm{O}-\mathrm{G}$ spillway crest.

(3070) ASPIRATIVE EFFICIENCY OF VARIOUS CHIMNEY SHAPES.

(b) Graduate project.

(c) Prof. C. J. Posey, Engineering Building, Iowa City, Iowa.

(d) Experimental; applied, for M. S. thesis.

(e) Investigation of possibility of using winds to move air through pipe systems for evaporative stabilization of pavement subsoils makes it nesessary to test efficiency of "chimney" shapes.

(f) Completed.

(g) Measurements obtained for several geometries.

(h) "Effect of Wind Velocity on Draft and Discharge in Various Round Chimney Shapes," J. D. Teasdale, M. S. thesis (Dept. of Civil Engineering), State University of Iowa, June 1960.

"Aspirative Efficiency of Chimney Shapes," Mahesh C. Chaturvedi, M. S. thesis, State University of Iowa, August 1960. (Available on loan.)

(3071) MEASURING EQUIPMENT FOR SURFACE ROUGHNESS. 
(b) Graduate project.

(c) Prof. C. J. Posey, Engineering Building, Iowa City, Iowa.

(a) Developmental; applied research.

(e) Design and construction of equipment to evaluate roughness parameters for range of surface roughness of interest to hydraulic engineers .

(f) Temporarily suspended.

(3074) WAKE OF ZERO MOMENTUM FLUX.

(b) Cooperative with ONR, Dept. of the Navy.

(c) Dr. Eduard Naudaccher, Iowa Institute of Hydraulic Research, Iowa City, Iowa.

(d) Experimental; basic research.

(e) Distribution of velocity, mean and turbulent, and of pressure is being measured in the field of flow past a bluff, axisymmetric body with a centrally located jet for the particular condition of zero momentum flux.

\section{(3075) ANNULAR JETS IN GROUND PROXIMITY.}

(b) Cooperative with office of Naval Research, Department of the Navy.

(c) Dr. Hunter Rouse, Iowa Institute of Hydraulic Research, Iowa City, Iowa.

(d) Experimental and theoretical; basic research and graduate theses.

(e) The distributions of mean velocity and mean pressure in the flow and on the boundaries near an annular jet have now been studied for four cases: (1) A stationary annular jet impinging against a rigid ground plate; (2) an annular jet impinging against a rigid ground plate in the oresence of an ambient transverse flow (air-tunnel study); (3) a stationary annular jet directed against a nearby water surface; and (4) an annular jet traveling over water.

(f) Completed.

(h) "Experimental Investigation of an Annular Jet Traveling over Water," Joachim K. Malsy, M. S. thesis, State University of Iowa, August 1960. (Available on loan.)

"E-perimental Studies of an Annular Jet," Lawrence R. Mack and Joachim K. Malsy, Report to Office of Naval Research under Contract Nonr 1509(03), September 1960.

(3428) MECHANICS OF BANK SEEPAGE IN NATURAL STREAMS DURING FLOOD FLOWS.

(b) Laboratory project.

(c) Prof. J. W. Howe, Dept. of Mechanics and Hydraulics, State University of Iowa, Iowa City, Iowa.

(d) Field investigation; basic research for Ph.D. thesis.

(e) Observations taken on transverse profile of ground-water levels during rise and recession of hydrographs. Sections on Missouri, Des Moines, Boone, Iowa, and English Rivers, Clear Creek, and Rapid Creek. Permeability tests made by pumping wells.

(g) Early results indicate substantial flow into banks during period of rise, thus showing a negative groundwater contribution to the flow in this period.
(3429) JET WITH TRANSVERSE PRESSURE GRADIENT.

(b) Cooperative with Office of Naval Research, Department of the Navy.

(c) Dr. Hunter Rouse, Iowa Institute of Hydraulic Research, Iowa City, Iowa.

(d) Experimental and theoretical; basic research.

(e) In order to better understand the effect of jet mixing on an annular jet, the diffusion of a two-dimensional jet directed against a flat plate in the presence of a transverse pressure gradient is being studied.

\section{(3430) AXISYMMETRIC GRAVITY WAVES.}

(b) Cooperative with Office of Naval Research, Department of the Navy.

(c) Dr. Hunter Rouse, Iowa Institute of Hydraulic Research, Iowa City, Iowa.

(d) Theoretical; basic research.

(e) The difference between the mean potential and mean kinetic energies for periodic. finite-amplitude, axisymmetric gravity waves has been computed as a function of relative depth over the entire depth range. This difference, which is zero for infinitesimal waves, has been found to be positive for deep water but, rather surprisingly, negative for shallow water. The kinetic and potential energies have also been computed as functions of time throughout a halfperiod for both large and small relative depths.

(f) Completed.

(h) "Studies of Axisymmetric Gravity Waves of Finit? Amplitude," Lawrence R. Mack, Report to Office of Naval Research under Contract Nonr 1509(03), August 1960.

\section{(3431) SEDIMENT SORTING.}

(b) Partially supported by National Science Foundation.

(d) Dr. Lucien M. Brush, Jr., Iowa Institute of Hydraulic Research, Iowa City, Iowa.

(d) Experimental; basic research.

(e) To determine the effect of various particlesize distributions with the same means but different standard deviations on ( 1 ) totalload and suspended-load transportation, (2) bed configuration, and (3) size distribution of the total load.

(3432) ACCELERATED MOTION OF A SPHERE FALLING IN AN OSCILLATTNG FLUID.

(b) Laboratory project.

(c) Dr. Lucien M. Brush, Jr., Iowa Institute of Hydraulic Research, Iowa City, Iowa.

(d) Experimental and analytical; basic research and $\mathrm{Ph}$. D. dissertation.

(e) To determine accelerated motion of a sphere falling in an oscillating fluid.

(3433) VELOCITY DISTRIBUTION IN OPEN-CHANNEL FLOW.

(b) Graduate project.

(c) Prof. C. J. Fosey, Engineering Building, Iowa City, Iowa.

(d) Theoretical; basic, for M. S. thesis. 
(e) Analysis of velocity distribution for turbulent flow in open channels, mainly based on new data from the variable-slope flume at Allenspark, Colorado.

(f) Completed.

(g) Boundary shear distribution in triangular channel computed by different methods; integrated values compared with measured total.

(h) "Boundary Shear in a Triangular Open Channel, "Jose Jesus Mairena, M. S. thesis, State University of Iowa, August 1960. (Available on loan.)

\section{(3434) VORTEX OVER HORIZONTAL ORIFICE.}

(b) Graduate project.

(c) Prof. C. J. Posey, Engineering Building, Iowa City, Iowa.

(d) Experimental; basic research for M. S. thesis.

(e) Tests include variable head and angular momentum of inflow.

(f) Completed.

(g) For stable flow, discharge was found to vary with circulation divided by discharge per unit depth. When friction is minimized, flow may become unstable.

(h) "Vortex over a Horizontal Orifice," Kotha Koteswara Rao, M. S. thesis, State Univ. of Iowa, August 1960. (Available on loan).

\section{(3738) SEDIMENT DIFFUSION.}

(b) Laboratory project partially supported by a grant from Gulf Research and Development Co.

(c) Dr. Lucien M. Brush, Jr., Iowa Institute of Hydraulic Research, Iowa City, Iowa.

(d) Experimental; Ph. D. dissertation.

(e) To determine the sediment diffusion characteristics for small concentrations of particles in a submerged jet of water.

(3739) EDUCATIONAL FIIMS ON THE MECHANICS OF FLUIDS.

(b) National Science Foundation

(c) Dr. Hunter Rouse, Iowa Institute of HydrauIic Research, Iowa City, Iowa.

(e) Six 20-minute sound films in color are planned to cover following material: (I) An introduction to the subject, stressing its great breadth of coverage, the necessarily close tie between theory and experiment, the role of the scale model in engrg. analysis and design, and methods of flow measurement in laboratory and iield. (2) The source and significance of the fundamental principles of contiruity, momentum, and energy, and their application to typical problems in many professional fields. (3) Gravitational phenomena, including jets, nappes, channel transitions, waves, surges, and effects of density stratification. (4) Effects of viscosity, examples of laminar flow, characteristics of fluid turbulence, and problems of surface resistance. (5) Profile drag and lift, and their application to propulsion and fluid machinery. (6) Compressibility effects - water hammer, submarine signaling, gravity-wave and sound-wave analogies, and supersonic drag.

(f) First film of series now being prepared.

(3740) HYDRODYNAMICS OF FLUIDS UNDER CONDITIONS OF RAPID ACCELERATION.

(b) Rock Island Arsenal, U. S. Army.

(c) Dr. Philip G. Hubbard, Iowa Institute of Hydraulic Research, Iowa City, Iowa.

(d) Theoretical and experimental; basic research.

(e) Analytical techniques which are applicable to systems involving rapid acceleration of fluids through constrictions or of solids through fluids. Results will be expressed as lumped-constant rarameters similar to those used for steady-flow phenomena.

(g) A sharp-edged disk has been accelerated rapidly through still water, and its total drag has been measured. Equipment has been constructed to measure the discharge coefficients of various orifices and the forces which they withstand when fluid is rapidy accelerated through them.

\section{(3781) MODEL TESTS OF ROCK SAUSAGES.}

(b) Graduate project.

(c) Prof. C. J. Posey, Engineering Building, Iowa City, Iowa.

(d) Experimental; applied, for M. S. thesis.

(e) Tests of model rock sausage embankment protection at different scales to determine maximum safe heads.

(f) In progress.

IOWA STATE UNIVESSITY, Department of Agricultural Engineering.

Inquiries concerning the following projects should be addressed to Dr. H. P. Johnson, Department of Agricultural Engineering, Iowa State University, Ames, Iowa.

\section{(2330) DEPTH, SPACING AND HYDRAULICS OF TILED DRAINS.}

(b) Laboratory project.

(d) Theoretical and field investigation; basic and applied research; master's and doctor's thesis.

(e) Analytical and physical approach is being studied to detemine depth and spacing of tiled drains by analyzing soil characteristics and geometry of systems. Work is cooperative with Dr. Kirkham, Soil Physics Department of Agronomy. Studies of the relationship of hydrologic and applied hydraulic problems of field tile systems being made.

(g) No new results to report

(2331) SURFACE RUNOFF FROM AGRICULTURAL WATERSHEDS.

(b) Laboratory project.

(d) Theoretical; applied research; doctoral thesis. 
(e) The study involving the development of procedures for defining synthetic hydrographs for watersheds up to 25 square miles in area completed. Further studies involving the use of point rainfall record and synthetic hydrographs defined as mathematical function for the development of storm hydrographs for small watersheds being made.

(g) First phase completed.

(h) "Derivation of Hydrograph for Small Watershed From Measurable Physical Characteristics," D. M. Gray, Ph. D. Thesis, Iowa State University, June 1960.

(2333) IMPROVEMENT OF SURFACE DRAINS WITH TILE BLIND INLETS.

(b) Laboratory project.

(d) Field investigatinn; design.

(e) Field study is being continued to determine the effect of different tile backfill material on the flow of water into the tile drains.

(g) Results of observation made in last 5 years being summarized.

(2334) RUNOFF FROM SMALL WATERSHEDS.

(b) Laboratory project, cooperative with ARS, USDA.

(d) Field investigation; applied research design.

(e) Measurements of rainfall and surface runoff being made on seven agricultural watersheds.

(g) Bulletin summarizing ten years of record being written.

(3078) LOW FLOW CHARACTERISTICS OF STREAMS IN NORTH CENTRAI AND WESTERN IOWA.

(b) Laboratory project.

(d) Analy'ical study, master's thesis.

(e) An analysis of the frequencies of given discharges from selected streams has been completed. Theoretical functions were fitted to frequency and depletion curves.

(f) Project completed.

(g) Garma function was fitted to data describing flow in fourteen Iowa streams.

(h) "Low Flow Characteristics of Streams in North Central and Western Iowa, "P.

Tiaganides, M. S. Thesis, Iowa State Univ., March 1960 .

\section{IOWA STATE UNIVERSITY, Department of Agronomy.}

\section{(3079) MOVEMENT OF WATER IN SOIL.}

(b) Laboratory project.

(c) Prof. Don Kirkham, Soil Physics Department of Agronomy, Iowa State University, Ames, Iowa.

(d) Theoretical and applied research.

(e) Work is being done on the movement of ground water in soil, particularly in the saturated phase. Work is being continued on the use of the mass spectrometer for studying the movement of water through soil and plants using deuterium as a tracer.

THE JOHNS HOPKINS UNIVERSTTY, Applied physics Laboratory.

(2335) APPLICATION OF SWITCHING TECHIIQUES TO HYDRAULIC CONTROL SYSTEMS.

(b) Bureau of Weapons, Department of the Navy.

(d) Theoretical and experimental; applied development and design.

(e) Study the dynamic qualities of an acceleration switching hydraulic servomechanis $m$ while operating in a closed loop under the presence of various loads and environmental conditions on the transfer valve, actuator and feedback transducer.

(g) The operation of a broad bandpass servomechanism driving a low resonant frequency linkage has resulted in radical design compromises to prevent instability. Extension of acceleration switching techniques without any mechanical modifications has permitted closed loop operation with bandpasses equal to or exceeding the linkage characteristics.

(h) "Design of a Hydraulic Servo with Improved Bandpass Characteristics when Driving a. Resonant Mechanical Load," APL/JHU CM-962 by $W$. Seamone.

(3207) ACCELERATION SWITCHING HYDRAULIC SERVOMECHANISMS UNDER EXTREME ENVIRONMENTAL CONDITIONS.

(b) Bureau of Weapons, Department of the Navy.

(d) Experimental, applied development and design.

(e) Extend to regions of extreme high temperature a servomechanism capable of high performance and horsepower (up to $10 \mathrm{H}$. P.). The servo valve, actuator and feedback transducer must operate under environmental extremes while the electronic circuitry is maintained in a protected area.

(g) Tests have been conducted on hydraulic servo components under steady state temperature conditions of $700^{\circ} \mathrm{F}$ ambient and $500^{\circ} \mathrm{F}$ oil temperature. Thermal shock temperature tests have been conducted on servo packages to $400^{\circ} \mathrm{F}$ to study transient temperatures.

(3435) HYDRAULIC SUPPLY LINE CHARACTERISTICS.

(b) Bureau of Weapons, Department of the Navy.

(a) Theoretical, experimental.

(e) High performance hydraulic servomechanisms can excite the pressure and return lines into pressure oscillation. Establishment of the physical relationship which could cause pressure oscillation, as well as performance deterioration in the servo valve performance, is being investigated.

(f) Continuing low priority research study.

(g) The switching activity of an acceleration switching hydraulic servomechanism was noted to create pressure oscillation under specified conditions in length of supply lines. Analysis and experiments have shown 
that pressure oscillations occur when the acoustic frequency of the hydraulic fluid column is in specific relationship to that of the switching frequency. Where line length changes cannot be used, methods of detuning the supply lines by volume chamber or acoustic filter are developed.

\section{(3436) ADAPTIVE ELECTRO HYDRAULIC SERVOMECHANISMS.}

(b) Bureau of Weapons, Department of the Navy.

(d) Theoretical and experimental.

(e) Techniques have been developed for designing linear servomechanisms with a limit cycle instability about a relay type nonlinearity. The closed loop characteristics of this servomechanism become invariant to any pure gain changes occurring in the linear elements. This servomechanism, categorized as a self-oscillating control servomechanism, appeared to be an evolutionary improvement over the acceleration switching hydraulic servomechanism.

(g) A self-oscillating rate servomechanism has been operated with the loop closed around the valve spool position. Predictable self-oscillation frequency was achieved and dynamic performance bandpass was independent of hydraulic supply pressure between 500 and 2000 psi. A self-oscillating positional servomechanism operating with feedback from the actuator position only, achieved similar results with pressure variation between 500 and 3000 psi. The bandpass of both servomechanisms exceeded 60 cycles per second with the latter operating a complex mechanical load system.

THE JOHNS HOPKINS UNIVERSITY, The Dept. of Sanitary Engineering and Water Resources, School of Engrg.

\section{(3437) RESIDENTIAJ WATER USE RESEARCH PROJECT.}

(b) AWWA, Baltimore County, Baltimore City, Maryland State Dept. of Health, and Federal Housing Administration.

(c) Mr. Jerome B. Wolff, Research Associate, Dept. of Sanitary Engineering and Water Resources, The Johns Hopkins University, Baltimore 18, Maryland,

(d) Experimental and field investigation; applied research and design.

(e) This project is directed toward obtaining data on maximum hourly demands of residential areas having varying populations. It also is directed toward obtaining information on the effect of lawn sprinkling and other large rate water consuming devices on maximum demands in residential communities. The purpose of the project is to obtain a rational design criteria for water distribution systems.

(g) Stratification of residential areas in terms of age, ground area and social status appears to have an important effect on residential water use. Preliminary data indicates correlation between per capita demands and size of residential lots.

(h) None to date. Two progress reports have been issued dated October 26, 1959 and October 1960 which have been submitted to the contributing sponsors of the project.

(856) HYDROLOGY OF STORM DRAINAGE SYSTEMS IN URBAN AREAS.

(b) Baltimore City, Baltimore County, and the U. S. Bureau of Public Roads.

(c) Dr. John C. Geyer, Chairman, Dept. of Sanitary Engineering and Water Resources, The Johns Hopkins Univ., Baltimore, Md.

(d) Field investigation, basic resaarch, and design.

(e) Study of rainfall and runoff relationships as affected by various drainage area parameters. At present, runoff from 9 urban areas ranging in size from 10 to 400 acres are gaged 7 by stage measurements and 2 by Parshall Flumes. Three recording systems which simultaneously record rainfall and runoff from 10 inlet areas provide good opportunity for detailed study. About 9 years of rainfall records now exist for a network of 12 recording gages covering an area of about 50 square miles.

(g) A study of the Baltimore rainfall data for the period 1894-1955 shows: (1) The critical storm in the Baltimore area is the summer type cloud burst. About two-thirds of the storms - greater than 2 year frequency occur in the months of July and August. Winter storms are not important for design purposes. (2) The maximum average rainfall rate (for durations up to 60 minutes) generally occurs at the beginning of the storm. (3) Rainfall intensities (during 15, 30, and 60 minute durations) for frequencies greater than 2 yrs. are not uniform. Difference between maximum intensity and average intensity over the duration range from 30\% (for the 15 minute duration) to $75 \%$ (for the 60 minute duration). Intensities greater than those indicated by rainfall frequency curves occur during more than half the period of the 15, 30 and 60 minute durations studied. Consequently the design storm assumed in the Rational Method is unrealistic. (4) Gagings made by this project and by the Corps of Engineers indicate that where a check on the Rational Method is possible, the Rational Method produces inconsistent results. Further analyses are continuing.

(h) "Progress Report on the Storm Drainage Research Project, June 1959, "Warren Viessman, Dept. of Sanitary Engineering and Water Resources, The Johns Hopkins University, Baltimore 18, Md. A limited number of copies are available on request.

(3438) RESIDENTIAL SEWERAGE RESEARCH PROJECT.

(b) Federal Housing Administration.

(c) Dr. John C. Geyer, Chairman, Dept. of Sanitary Engrg. and Water Resources, The Johns Hopkins Univ., Baltimore 18, Md.

(d) Field investigation; operation and design.

(e) Examination of adequacy and 'tility of residential sewerage system design criteria. Determination of the effects of parameters 
of design, construction, loading and natural phenomena on operation of sewerage systems. Research includes analysis and study of representative sewerage systems throughout the country.

(f) Planning stage.

(g) Collection of data not yet begun.

UNIVERSITY OF KANSAS, Department of Engineering Mechanics.

Inquiries concerning projects Nos. 3080, 3081, 3082, and 3742 to 3744, incl., should be addressed to Dr. David W. Appel, Dept. of Engrg. Mechanics, and projects Nos. 3440 and 3745 should be addressed to Dean J. S. McNown, School of Engineering and Architecture, University of Kansas, Lawrence, Kansas.

\section{(3080) TRANSMISSION AND DISSIPATION OF SURGES IN ELASTIC TUBES.}

(b) Sohio Pipe Line Co. and Dept. of Engrg. Mech.

(d) Basic research; theoretical and experimental investigation. Also M. S. thesis.

(e) This is a basic study of speed of propagation and rate of dissipation of surges in liquidfilled elastic tubes. Field observation, on long oil pipe lines, and a M. S. thesis on celerity of surges in very elastic tubes have been completed. Further laboratory study of rate of dissipation of surges is planned.

(g) The celerity of an isolated surge in a very elastic tube has been found to be essentially independent of the velocity and direction of flow. However, a systematic variation in celerity with static pressure was found, which at low heads was due to changes in shape of the section and at higher heads was due to increase in diameter and reduction in wall thickness of the tubing.

(h) "A Study of the Transmission of Surges in Elastic Conduits," by James D. McClure, M. S. Thesis, University of Kansas, Lawrence, Kansas, June 1960.

(3081) DIFFUSION OF A JET FORMED AT AN ABRUPT ENLARGEMENT IN TWO-DIMENSIONAL FLOW.

(b) Kimberly-Clark Corp., Neenah, Wisconsin.

(d) Experimental; basic research.

(e) Development of vortices along the surface of separation at an abrupt expansion is being studied. Moving pictures taken at 3000 frames per second are being analyzed to determine characteristics of the occurrence of vortices.

(g) Cavitation has been observed to begin first in the center of vortices at ambient pressures as much as 80 percent of the dynamic pressure above the vapor pressure of the fluid. The average frequency of generation of vortices has been found to be a function of the expansion ratio.

(h) "Cavitation Along Surfaces of Separation," by David W. Appel, ASME naper 60-WA-265 presented at the Annual Meeting, November 1960. Also, a $16 \mathrm{~mm}$ sound film was prepared to accompany the above paper. The film is avail- able for loan on request.

(3082) MEASUREMENT OF LOW VELOCITIES IN WATER.

(b) Laboratory project.

(d) Development.

(e) An instrument is being developed for measuring low velocities in small hydraulic models which will utilize the known relationship between frequency of shedding of vortices in the wake of a circular cylinder and the velocity of flow.

(f) Suspended until staff is available to continue study.

\section{(3440) DRAG IN UNSTEADY FLOW PAST BLUFT BODIES.}

(b) The Sandia Corporation.

(d) Experimental and theoretical.

(e) The vorticity in the boundary layer upstream from the point of separation is related to the strength of the vortices in the wake. The force on a flat plate or a cylinder is then related to the growth, and shedding of the vortices.

(f) Terminated.

(g) Several aspects of the prediction of drag have been evaluated theoretically.

(h) "Vortex Formation and Resistance in Unsteady Motion," J. S. McNown and T.Sarpkaya, Internal report to the Sandia Corp. (5112) June 1960.

(3742) DTVERSION OF FLOW WITH SUCTION APPLIED TO SIOTS BENEATH A SHALTOW STREAM HAVING A F'REF SURFACE.

(b) Kimberly-Clark Corporation and the Dept. of Engineering Mechanics.

(d) Theoretical and experimental; basic research; also M. S. thesis.

(e) Extent of agreement between results of a momentum analysis and experimental measurements is to be determined for single, vertical, inclined and skewed slots. The experiments will be extended to multiple slots and to patterns of circular holes.

\section{(3743) STUDY OF THE MECHANICS OF DIVIDED F'LW.}

(b) National Science Foundation.

(d) Theoretical and experimental; basic research.

(e) The first part is a study of instability of divided flows both confined as at branches in pipes and semi-unconfined as at inlets and outlets. The mechanism of instability, and the dynamic characteristics of the resulting surges are to be investigated. An analytical solution for the mean flow into an inclined slot in a plain boundary of a semi-infinite flow is to be obtained and the results verified and extended experimentally. A general criterion for limits of stable division of any flow is sought.

(3744) A STUDY OF WAVE EROSION ON UNPROTECTED DIKES.

(b) Kansas Forestry, Fish and Game Commission.

(d) Experimental and field investigation; 
basic research.

(e) Information to serve as a guide toward a practical solution of wave erosion in waterfowl refuges is sought. The following aspects are being studied: (1) Wave height length and speed are being observed in a pool of uniform shallow depth of about 2 feet, with a fetch of 2.5 miles. (2)

Model tests at $1 / 4$ scale are being made of wave action on dikes composed of clay. After the operation of the model has been verified, tests will be run on embankments of various shapes with and without simulated plants and other protective devices.

\section{(3745) BASIC CHARACTERISTICS OF AN OVERLAND FLOW.}

(b) Corps of Engineers, Department of the Army, U.S.A.

(d) Theoretical; basic research.

(e) An analytical study of data from experiments on controlled surface runoff due to steady rainfali on an impervious plane surface. The objective is to provide an improved method for overland flow in the drainage of airfields and expressways.

LEHIGH UNIVERSITY, Department of Civil Engineering.

Inquiries concerning the following projects and requests for reprints and technical reports should be addressed to Professor J. B. Herbich, Chaiman, Hydraulics Division, Fritz Engineering Laboratory, Lehigh University, Bethlehem, Pennsylvania.

\section{(1602) PRESSURE DISTRIBUTION IN CONDUIT BENDS.}

(b) Laboratory project.

(d) Experimental; undergraduate special problem.

(e) Study of a rectangular bend with a central dividing wall, by means of electrical-analogy has been completed.

Inactive.

\section{(1603) BUTTERFLY VALVE STUDY.}

(b) CDC Controls Services, Inc., Hatboro, Pa.

(d) Experimental; applied research. Completed.

(2339) BUCKET-TYPE ENERGY DISSIPATOR CHARACTERISTICS.

(b) Gannett, Fleming, Cordary and Carpenter, Inc., 600 North Second Street, Harrisburg, Pennsylvania.

(d) Experimental; for general design.

Suspended.

\section{(2543) STUDY OF CONDUTT EXIT PORTAIS.}

(b) Laboratory project.

(d) Experimental; M. S. thesis.

(f) General pressure-distribution study completed.

(g) Tests of square and circular conduit with free-jet, horizontal apron, and three different wall flares, have been completed.
(3084) STUDY ON IMPROVING DESIGN OF A HOPPER DREDGE PUMP.

(b) District Engineer, U. S. Army Engineer District, Marine Division, Philadelphia, Corps of Engineers.

(d) Applied and basic research.

(e) The immediate purpose of the study is to improve design of a hopper dredge centrifugal pump for pumping silt-clay-water mixtures. The long-term objective is to determine the effect of Bingham Body-type of fluid on pumping characteristics. The project has been divided into four phases: (1) Model tests of the existing dredge pump; (2) recommendations for design changes of the dredge pump; (3) model investigation of the modified design of the dredge pump; and (4) analysis of the investigation and final recommendations. Phase I involved installation in the hydraulic laboratory of a $1: 8$ scale model of the areage pump now used on the U.S. Corps of Engineers dredge ESSAYONS. Water as well as silt-clay-water mixtures (Bingham Body-type of fluid) were pumped and complete characteristics of the pump obtained for capacity of 0 to 1200 gallons per minute, speed of 1150 to 1900 revolutions per minute, and liquid concentrations of 1000 to 1380 grams per liter. Phases 2 and 3 involve modifications in the shape of vane and changes in the exit vane angle of the impeller. Experimental tests indicate considerable improvement in pump efficiency.

(f) Phase (I) completed.

(g) Considerable improvement in pump efficiency has been achieved.

(3085) STUDY OF SCALE EFFECT BETWEEN MODEL AND PROTOTYPE SPILLWAYS.

(b) Laboratory project.

(d) Graduate students project.

(e) A 1:100 scale two-dimensional model built of Chief Joseph Dam. Prototype crest pressures compared with the data obtained on the model.

(f) Completed.

(g) Very good correlation obtained between the model and prototype.

(3086) INVESTIGATION OF DESIGN CRITERIA OF SPUR DIKES.

(b) Modjeski and Masters, Consulting Engineers, Harrisburg, Pa., Lehigh University Institute of Research.

(d) Analytical and experimental.

(e) The project has been divided into four phases: (A) Literature Survey; (B) analytical study; (C) experimental study in a fixed-bed model to determine the desired lengths and shapes of spur dikes to provide uniform velocity distribution in the waterway between bridge abutments, and (D) experimental study in a movable-bed model to verify findings in part (C). A spur dike has been defined as a projection extending upstream from the bridge abutment. 
(f) Phases (A) and (C) completed, phases (B) and (D) active.

(g) Preliminary investigation indicates that a properly designed spur dike can produce a fairly uniform velocity distribution between the abutments.

(h) "The Effect of Spur Dikes on Flood Flows Through Bridge Constrictions," John B. Herbich. Paper presented to the ASCE at Boston, Mass. on Oct. 14, 1960, $37 \mathrm{pp}$. (A limited number of pre-prints available.)

(3441) STUDY OF SCALE EFEECT BETWEEN MODEL AND PROTOTYPE $270^{\circ}$ BENDS FOR FLOW OF SILTCLAY-WATER MIXTURES.

(b) Laboratory project.

(d) M. S. thesis.

(e) Four-, six-, and eight-inch diameter $90^{\circ}$ elbows assembled to form $270^{\circ}$ bends. Head loss measurements obtained for various flows and concentrations of silt-clay-water mixtures. Prediction equations have been investigated.

(g) Evidence of scale effect present.

(h) "Scale Effect on $270^{\circ}$ Pipe Bends for Bingham Body Fluid," J. B. Herbich and P. L. Brach. Memo. No. M-10, F. L. Report No. 277-M-10, June 1960, 40 pp., (copies available).

(3442) SUGGESTED DESIGN CHANGES FOR A CENTRIFUGAL PUMP IMPELEER HANDLING DREDGED MUD.

(b) Research report requirement of M.S. degree.

(d) Theoretical.

(e) Design changes in centrifugal pump impeller for handling mud are suggested on basis of past research and theoretical considerations.

(f) Completed.

(h) "Suggested Design Changes for a Centrifugal Pump Impeller Handling Dredged Mud," W. I. Weiss, Graduate Student Report, Nov. 1959, 20 pages, (copies available).

(3746) ANALYSIS OF FLOW PATTERN IN VOLUTE OF A CENTRIFUGAL PUMP.

(b) Research report requirement of M. S. degree.

(d) Experimental.

(e) High-speed movies of flow taken through a transparent plexiglas volute casing were analyzed. Velocity distribution as well as distribution of the exit angle between the impeller vanes as fluid leaves the impeller were determined.

(f) Suspended.

(h) "Analysis of High-Speed Movies of a Model Pump," J. B. Herbich and W. M. Waddington, Fritz Lab. Report No. 277-M-11, June 1960, 36 pages, (copies available).

(3747) FRICTION LOSSES IN PIPES FOR BINGHAM-BODY FLUIDS.

(b) Laboratory project.

(e) The project has been divided into three phases: (a) Literature survey; (b) analytical study; (c) experimental study.
Agricultural Engineering Department.

(2800) HEAD LOSS DUE TO QUTCK COUPLERS IN ALUMINUM IRRIGATION PIPE.

(b) Laboratory project.

(c) Mr. William F. Lytle, Agr. Engr. Dept., La. State Univ., Baton Rouge, La.

(d) Experimental; applied research.

(e) To determine the head loss caused by quick couplers manufactured by various companies in 3-, 4-, 5-, and 6-inch sizes of aluminum irrigation pipe. Each coupler is tested in alined position and at maximum angle of misalinement.

(g) Fifty-five couplers of the bolt-on type have been tested. In the near future "factory installed" couplers will be tested and new manufacturers who were not in business in 1956 will be contacted.

(h) "Analysis of Head Loss in Irrigation Pipe Couplers," by W. F. Lytle and J. E. Wimberly, Paper 60-727 available from ASAE, St. Joseph, Michigan.

MASSACHUSETTS INSTITUTE OF TECHNOLOGY, Dept. of Civil and Sanitary Engineering, Hydrodynamics Lab.

Requests for reprints and Technical Reports should be addressed to Dr. Arthur T. Ippen, Professor of Hydraulics, Hydrodynamics Laboratory, Mass. Inst. of Technology, Cambridge 39, Mass.

\section{(307) MECHANICS OF STRATIFIED FLOW.}

(b) Laboratory project.

(c) Prof. D. R. F. Harleman, Mass. Inst. of Technology, Cambridge 39, Mass.

(d) Theoretical and experimental; graduate research.

(e) A general study of the characteristics of flows in which vertical density gradients are present. Density differences may be due to temperature, chemical composition or solids in suspension. Two topics are currently under investigation: (1) Characteristics of the saline wedge in an estuary, and (2) induced circulation in stratified fluids.

(g) An equation for the shape of the arrested saline wedge in an estuary is obtained from the one-dimensional equations of motion and continuity for a two-layer nonuniform, stratified flow. Knowledge of the total intrusion length permits calculation of the mean interfacial shear. The experimental results of others show good agreement with the theory. The effect of the river densimetric Froude number is shown to have only a small effect on the dimensionless shape of the saline wedge. Circulation and mixing is induced in a stratified reservoir $\left(30^{\prime} \times 3^{\prime} \times 4^{\prime}\right)$ by means of vertical jets of fluid from a manifold. Reservoir fluid is recirculated through the manifold by means of a pump. An evaluation of the mixing efficiency is made by comparing the change in potential energy of the reservoir to the kinetic energy input at the jets. Additional investigations are 
underway .

(h) "Characteristics of the Saline Wedge in an Estuary," S. B. Thesis, Course I, MTT, F. Malouf and P. Mehlhorn, June 1960.

"Forced Convection in Vertically Stratified Fluids," S. M. Thesis, R. A. Farmer, J. P. Franklin, and D. E. Wheeler, January 1961.

(1609) EXPERIMENTAL STUDY OF THE SORTING OF BEACH SEDIMENTS BY WAVE ACTION.

(b) Beach Erosion Board, U. S. Army Corps of Engineers .

(c) Prof. P. S. Eagleson, Hydrodynamics Lab., Mass. Inst. of Tech., Cambridge 39, Mass.

(d) Experimental; basic research.

(e) Quantitative study of the mechanics of beach sediment movement by shallow water waves.

(g) The applicability of previously derived relations for prediction of the equilibrium profile of sand beaches and the sorting of their constituent sediments has been inyestigated in the laboratory.

Current experiments are investigating the mechanics of generation of longshore currents on a straight, plane impermeable beach.

(h) "Equilibrium Characteristics of Sand Beaches in the Offshore Zone," S. M. Thesis, MIT, Hydrodynamics Laboratory, January 1961.

\section{(2546) CHARACTERISTICS OF FLOW WITH DILUTE FIBER} SUSPENSIONS.

(b) Technical Association of Pulp and Paper Industries.

(c) Prof. A. T. Ippen and Prof. J. W. Daily, Hydrodynamics Lab., Mass. Inst. of Tech., Cambridge 39, Massachusetts.

(d) Experimental and analytical; básic research.

(d) Basic investigation of hydrodynamics of dilute suspensions.

(g) Previous investigations of the hydrodynamics of flowing paper fiber suspensions emphasized the dual role of fiber interlocking and turbulence in the transfer of momentum and shear with such suspensions. The present studies are investigating the role of the suspended medium in modifying the turbulence structure in the absence of particle entanglement and interlocking. Near neutrally buoyant rigid particles are being used. Energy dissipation, velocity profiles and turbulence characteristics are being studied experimentally and analytically.

\section{(2548) TURBULENT DIFFUSION IN STRATIFIED FLUIDS.}

U. S. Public Health Service.

(c) Prof. A. T. Ippen, Prof. D. R. F. Harleman, Hydrodynamics Lab., Mass. Inst. of Tech., Cambridge 39, Massachusetts.

(d) Theoretical and experimental; basic research (doctoral thesis).

(e) An investigation of various turbulent diffusion processes for application to salinity intrusion and waste dispnsal in partially or well mixed tidal estuaries.

(g) The experimental equipment is a 32 foot channel in which turbulence is generated mechanically by means of a stack of ex- panded aluminum sheets oscillating vertically with amplitudes up to one-half inch and frequencies up to four cycles per second.

Concentrations are measured and recorded at various stations by means of probes sensitive to the changes in conductivity. The turbulence level is specified in terms of the measured rate of energy dissipation within the liquid. The effects of gravity convection due to density differences between the diffusant and receiving fluids are separated from turbulent diffusion effects by a series of control tests with zero density difference.

Experiments are being made to determine the longitudinal distribution of salinity in a uniform estuary with fresh water inflow at one end and a constant ocean salinity maintained at the other end. Salinity distributions are determined for various fresh water inflow rates and turbulence levels in the flume.

The one-dimensional salinity distribution is found to be correlated with a stratification parameter expressing the ratio of energy dissipation to the gain in potential energy of the flow in the estuary. Present studies are concerned with the two. dimensional salinity distributions and the relationship of the vertical salinity gradients to the vertical velocity distributions. The reversal of the bottom velocities which is characteristic of estuaries is also shown to be related to the stratification parameter described above.

(h) "The Turbulent Diffusion and Convection of Saline Water in an Idealized Estuary," D. R. F. Harleman and A. T. Ippen, Publication No. 51 (International Association of Scientific Hydrology), Proccedings of the Helsinki Congress of the International Union of Geodesy and Geophysics, August 1960.

"Liquid Diffusion and Convection in Homogeneous Turbulence," S. M. Thesis, MIT, D. W. Mc Dougall, Course I, August 1960.

(2801) INTERACTION OF WAVES WITH FLOATING BODIES.

(b) Office of Naval Research, Dept. of the Navy.

(c) Prof. A. T. Ippen, Hydrodynamics Lab., Mass. Inst. of Tech., Cambridge 39, Mass.

(d) Theoretical and experimental; basic research for doctoral thesis.

(e) Analytical and experimental investigation of interaction of surface waves with basic shapes. Purpose of the study is to develop a feasible prototype floating or moored breakwater structure.

(g) Two problems have been completed. The theoretical portion of each of these problems is based on small amplitude classical wave mechanics. The numerical solutions were obtained on an IBM 704 digital computer. (1) Theoretical and experimental investigation of the interaction of a fixed, semi-immersed circular cylinder with a train of surface waves. The theory 
was developed for the case of deep-water; however, the experiments covered both deep and shallow-water waves. The theory predicts reflection and transmission coefficients and force components on the cylinder which are in good agreement, except that an energy loss of approximately $10 \%$ occurred in the reflection-transmission process. (2) Theoretical and experimental investigation of a semi-immersed circular cylinder which is oscillating vertically about the mean water surface. The theory was developed for a fluid of arbitrary depth and predicts the amplitude of the generated waves and also the force on the cylinder. The theory shows that if the ratio of water depth to cylinder radius is greater than 10 there is no effect of water depth. Present studies are concerned with (1) moored cylinders in a tandem arrangement which is designed to reduce mooring forces and (2) effects of channel geometry on wave transmission. It is desired to investigate the effect on reflection and transmission coefficients of a linear change of depth with distance.

(h) "Interaction of a Fixed, Semi-Immersed Circular Cylinder with a Train of Surface Waves," R. G. Dean and F. Ursell, Technical Report No. 37, MIT Hydrodynamics Laboratory, September 1959.

"Surface Waves Generated by an Oscillating Circular Cylinder in Shallow Water," Y. S. Yu and F. Ursell, Technical Report No. 40, MIT Hydrodynamics Laboratory, January 1960 .

"Forced Small-Amplitude Water Waves: A Comparison of Theory and Experiment, Journal of Fluid Mechanics," Vol. 7, Part 1, pp. 33-52, April 1959.

\section{(2802) EXPERIMENTAL STUDY OF WAKE MECHANICS.}

(b) Office of Naval Research, David Taylor Model Basin, Dept. of the Navy.

(c) Prof. J. W. Daily, Prof. P. S. Eagleson, Hydrodynamics Lab. Mass. Inst. of Tech., Cambridge 39, Massachusetts.

(d) Experimental; basic research (doctoral theses).

(e) A study of the effect of trailing edge geometry on the charccteristics of the wake of a thin flat plate with particular emphasis on transverse plate vibrations. Tests are carried out in a $7-1 / 2 \times 9$ inch water tunnel test section capable of speeds to $40 \mathrm{ft} / \mathrm{sec}$.

(g) Measurements of the turbulent structure of the early wake behind a stationary thin flat plate have beon made in water for a given trailing edge geometry. Other trailing edges are being investigated.

The transfer of energy between plate and fluid is being investigated under the condition of externally forced vibrations of the plate.

(h) "The Hyoroelastic Behavior of Flat Plates as Influenced by Trailing Edge Geometry," A. T. Ippen, G. H. Toebes, and P.S. Eagleson, Technical Report No. 36, МIT Hydrodynamics Laboratory, April 1960.
"The Early Wake of a Fixed, Flat Plate," C. J. Huval, S. M. Thesis, MIT, Course I, 1961.

(3089) FXPERIMENTAL STUDY OF EROSION IN CURVED CHANNELS.

(b) Agricultural Research Service, U. S. Dept. of Agriculture S.W.C. Watershed Technology Research Branch.

(c) Professor A. T. Ippen, P. A. Drinker, Geologist, WTRB, Mass. Inst. of Tech., Cambridge 39, Massachusetts.

(d) Experimental; basic research (doctoral thesis).

(e) Investigation of boundary shear stress distribution and magnitude in curved, open channels to determine location and extent of protection required in natural streams. of interest is the variation of boundary shear with selected conditions of flow and channel geometry.

(g) The magnitude and distribution of boundary shear stress have been studied in a $60^{\circ}$ curve for varied conditions of flow. The test channel is trapezoidal with a hydraulically smooth surface, and sides sloping 2 horizontal to 1 vertical. The width: depth ratios have been varied from 8 to 12 , with a variation in radius width ratio of 1.75 to 2.17 . For the conditions tested, the Froude numbers are in the range 0.38 to 0.55 . Tests were first conducted in the single curve with straight, uniform approach flows. Following this, the velocity distribution in the approach channel was artificially distorted to simulate the varied effects of upstream channel alignment. Flows were thus studied in U- and S- bend stream patterns. Tests are now being conducted to determine the effect of bed roughness on the shear distribution. Following this series, the channel will be modified to give radius-width ratios of about 4; further tests will be made to determine the influence of the parameter $r / w$ on the shear distribution. The boundary shear stress is determined by maans of round surface Pitot tubes; a modified Pitot tube has been calibrated for the measurement of shear stress on a test surface of uniform roughness.

(h) "Velocity and Boundary Shear Distributions in an Open Channel Bend," G. K. Noutsopoulos, S. M. Thesis, MIT, May 1960.

"The Distribution of Boundary Shear Stresses in Curved Trapezoidal Channels," A. T. Ippen, P. A. Drinker, W. R. Jobin, and G. K. Noutsopoulos, MIT Hydrodynamics Laboratory Technical Report No. 43, January 1961.

(3090) MODEL OF PUMPING PLANT FOR CHARLES RIVER BASIN (BOSTON) DRAINAGE CONTROL.

(b) Commonwealth of Massachusetts, Metropolitan District Commission.

(c) Prof. D.R.F. Harleman, Hydradynamics Lab., Mass. Inst. of Tech., Cambridge 39, Mass.

(d) Experimental.

(e) Model studies to determine forebay and pump suction intake geometry for high capacity, low head axial flow pumps. 
(f) Completed.

(g) A model study of a pumping station site one-half mile downstream of the Charles River Dam was made to investigate the effect of existing briage piers on the flow geometry in the pump intake basin. A deflector wall $600 \mathrm{ft}$. upstream of the intakes was employed to change the direction of the main stream to avoid having the intakes fall in the wake of a large bridge pier.

(h) "Model Study of a Flood Control Pumping Station for the Charles River Basin at the Warren Avenue Bridge," D.R.F. Harleman, Hubal, and T. K. Chu, MIT Hydrodynamics ratory Technical Report No. 39, December 195.

\section{(3443) COMPUTEF STIL: OF POWER PLANT TRANSIENTS.}

(b) Misi River Division, Corps of Engineers.

(c) Prcf. $\because$ Ippen, Prof. P. S. Eagleson, Hydrodynaricis Lab. Mass. Inst. of Tech., Carr. ridge 39, Mass.

(d) Tho-retical, field measurements; applied research.

(e) Development of a comprehensive digital computer program for the solution and investigation of the complete transient problem in hydropower installations.

(g) The problem of load rejection has been programmed for the IJM 709 computer. The problem of load acceptance and surge tank stability is being formulated. Plans have been completed for a comprehensive field test of two Corps of Engineers power plants involving measurement of all pertinent mechanical, electrical and hydraulic variables under contitions of acceptance, rejection, and uscillation of load.

(h) "Hydropower Plant Transients, Part I Design of a Comprehensive Field Test Program," A. T. Ippen, F. E. Perkins, and P. S. Eagleson, MIT Hydrodynamics Lahoratory Technical Note No. 7, January 1961.

(3444) EFFECTS OF BASIN GEOMETRY AND VISCOUS DAMPING ON THE AMPLITUDE OF RESONANT OSCILLATIONS IN HARBORS.

(b) Office of Naval Research, Dept. of the Navy. Professor A. T. Ippen, Hydrndynamics Lab., Mass. Inst. of Tech., Cambriage, Mass. Theoretical and experimental; basic research (doctoral theses).

Investigation of the response of a harbor to waves incident on the harbor opening. Initial experimental phase dealt with a circular harbor ( $2 \mathrm{ft}$. in dia.) having a $5^{\circ}$ opening and commuicating with the main wave basin by means of an entrance channel. The characteristics of the response of this harbor in the vicinity of the lowest symmetrical resonant mode of oscillation were stridied; (1) With resonance defined as the maximum of the ratio of the amplitide at the center of the harbor to the incident wave amplitude, the theoretical value of the period of oscillation at resonance based on closed basin theory was $T=0.566$ sec. and the observed period was in exact agreement. (2) The harbor appeared to act essentially as a closed basin at resonance as shown by measurements of the phase angle between the incident and reflected wave in the approach channel. (3) In the vicinity of resonance the water surface configuration within the harbor was in good agreement with the theoretically predicted configuration of a Bessel Function of the first kind.

In order to fulfill one of the basic objectives of this program, that of the resonance problem for large entrance gaps, a small rectangular harbor situated in the main basin is under study. Due to the simple geometry this configuration lends itself more readily than the circular harbor to an analytic solution for the prediction of surface configuration and resonant period. Initial experimental and theoretical agreement is good for this basic coupled basin system for a large gap opening. It is hoped that methods of approach used will be amenable to extensions to internally coupled harbor systems and harbors of irregular planform.

\section{(3445) CHARACTERISTICS OF CROSS WAVES.}

(b) Office of Naval Research, Dept. of the Navy.

(c) Prof. A. T. Ippen, Prof. L. Howard (Math.) Mass. Inst. of Tech., Cambridge 39, Mass.

(d) Theoretical and experimental; (doctoral thesis).

(e) An investigation of the stability of twodimensional standing waves which lead to the development of three-dimensional cross (or edge) waves.

(g) The phenomenon of cross waves occurs when a wave generator is operated at high frequencies. Standing cross waves having crests perpendicular to the wave generator may then be observed.

A theory of cross waves in a closed tank has been developed. The amplitudes of the various modes of the free surface as functions of the width to length ratio add the amount by which the critical wave amplitude is exceeded by the driving amplitude can be caluulated. Experimental measurements have essentially verified the theory.

(h) "Characteristics of Cross Waves," J. D. Lin, Sc.D. Thesis, MIT Hydrodynamics Laboratory, August 1960 .

(3446) EFFECT OF PARTTCLES ON TURBULENCE AND RESISTANCE IN FREE SURFACE FLOW.

(b) Laboratory project.

(c) Prof. A. T. Ippen, Hydrodynamics Lab. Mass. Inst. of Tech., Cambridge 39, Mass.

(d) Theoretical and experimental (doctoral thesis).

(e) An investigation of the effect of neutrally bouyant particle suspensions on the resistance coefficient and shape of the velocity profile. Measurements of the intensity and spectrum of the velocity fluctuations in the direction of mean flow are made to study changes in the turbulence structure. The purpose of the first phase is to 
eliminate the buoyant weight of the particles as a suspension parameter and to develop a phenomenological model to desscribe the observed effects.

(g) The change in shape of the velocity profiles was found to be similar to that obtained in studies with silt and sand suspensions. The turbulence intensity was found to increase with increasing concentration. The results for one particular particle size are correlated against concentration.

It was concluded that the buoyant weight of the suspended particles has no primary effect on the flow characteristics.

(h) "The Dynamics of Open Channel Flow with Suspensions of Neutrally Buoyant Particles," C. Elata, Sc.D. Thesis, MTT, Course I, January 1961.

\section{(3748) DISPERSION IN POROUS MEDIA.}

(b) U. S. Public Health Service.

(c) Prof. D.R.F. Harleman, Hydrodynamics Lab., Mass. Inst. of Tech., Cambridge 39, Mass.

(d) Theoretical and experimental; basic research (doctoral thesis).

(e) Investigation of the mechanism of dispersion in porous media. Experimental program will study saline water intrusion in coastal aquifers.

(8) Present phase is concerned with one-dimensional dispersion phenomena in an attempt to correlate the dispersion coefficient with media properties, permeability, mean velocity and rate of energy dissipation. Plastic spheres are being used in the experimental equipment. Additional equipment is being designed to investigate the dispersion of an interface between salt and fresh water under a tidal rise and fall of the ocean level.

(3749) RESISTANCE OF ENCLOSED ROTATING DISKS.

(b) Office of Ordnance Research, U.S. Dept. of the Army.

(c) Prof. J.W. Daily, Hydrodynamics Lab., Mass. Inst. of Tech., Cambridge 39, Mass.

(d) Experimental and analytical; basic research.

(e) Effect of superposed through-flows on boundary layers, secondary motion and surface resistance of enclosed rotating disks.

(g) An exploratory study to survey the main features of the flow phenomena using flow visualization techniques as well as quantitative measurements is to be followed by detailed studies in the significant range of variables.

(3750) WAVE FORCES ON SUBMERGED, MOORED OBJECTS.

(b) Laboratory project.

(c) Prof. D.R.F. Harleman, Hydradynamics Lab., Mass. Inst. of Tech., Cambridge 39, Mass.

(d) Theoretical and experimental; basic research.

(e) Investigation of the dynamic behavior and mooring forces on a submerged, buoyant body whose motion is induced by a train of oscillatory surface waves. The objective is to develop a method of predicting amplitudes of motion and mooring forces.

(g) Two shapes, an ellipsoid of revolution and a sphere, have been tested at various depths of submergence. Objects are moored by a simple cable system so that the motion is that of an inverted pendulum. The controlling parameter is the ratio of the natural frequency of the moored object to the frequency of the surface wave motion. Conditions leading to resonance must be avoided if mooring forces are to be small.

(h) "Effect of Shape and Depth on Wave Forced Oscillations of Submerged, Moored Objects," E. G. Verrett, S. M. Thesis, $1 v I T$, August 1960 .

\section{(3751) ANALYSIS OF TIDAL MOTION IN ESTUARIES.}

(b) Laboratory project.

(c) Prof.A. T. Ippen, Prof. D.R.F. Harleman, Hydrodynamics Lab., Mass. Inst. of Tech., Cambridge 39, Mass.

(d) Theoretical; basic research.

(e) Formulation of mathematical models for the analysis of the dynamic behavior of tidal estuaries. For a particular estuary in which the tidal amplitudes are known it is desired to predict tidal velocities, phase lags and rates of energy dissipation. These quantities are necessary for the enalysis of salinity intrusion phenomena.

(g) Two estuaries have been studied; the Bay of Fundy and the Delaware. In each case computed tidal velocities are in close agreement with observed values. Method does not depend on segmentation of the estuary hence analytical tidal velocity expressions can be determined which are applicable over the entire length. The analysis of energy dissipation rates is currently under way.

(h) "Determination of the Tidal Characteristics in the Delaware Estuary by a Mathematical Model," S. M. Thesis, MIT, M. F. Meador, June 1960.

MASSACHUSETTS INSTITUTE OF TECHNOLOGY, Department of Mechanical Engineering.

(3092) JWT-PIPE VALVE.

(b) Various sponsors including U.S. Air Force, Chandler-Evans Corp.

(c) Prof. S. Y. Lee, Mass. Inst. of Tech., Cambridge 39, Mass.

(d) Basic and applied research.

(e) Experimental and theoretical study of pressure and flow transfer characteristics of a high velocity jet of compressible or incompressible fluid impinging on one or more receivers. The configuration is useful in the fluid power control field when fluid power is transferred between parts having relative movement. The power amplifying properties of this configuration are also very useful and important.

(g) The pressure-flow transfer characteristics 
of jet-pipes of several different designs have been studied. Of particular interest is the relationship of these characteristics and the various geometrical dimensions. The forces and dynamic stability are also studied.

(h) "Optimum Design Parameters of a Pneumatic Jet-Pipe Valve," by K. N. Reid, Jr., presented at the First International Congress of the International Federation of Automatic Control, Moscow, U.S.S.R. 1960.

Published by Butterworths Scientific Publications, London, 1960, Vol. 1, Pp. 387-392, of preprints of papers presented at the International Federation of Automatic Control Congress, Moscow, 27 June - 7 July, 1960 .

"Power Transfer Characteristics for Compressible Flow from a Nozzle to a Detached Receiver," by C. K. Wang, Dynamic Analysis and Control Laboratory memorandum M-8090-5, Mass. Inst. of Technology, Cambridge, Mass., 1960.

"Some Aspects of the Pneumatic Jet-Pipe as a Valve and Coupling Device," by E. J. Schuler, 1960 SM Thesis, M. E. Dept., Mass. Inst. of Technology, Cambridge, Mass. "A Study of Pressure-Flow Characteristics of a Pneumatic Jet-Pipe Valve," by P. G. Nicoletti, 1959 S. B. Thesis, M.E. Dept., Mass. Inst. of Tech., Cambridge, Mass.

\section{(3447) REACTION-JET SERVOMOTOR.}

(b) U. S. Air Force.

(c) Prof. S. Y. Lee, Mass. Inst. of Tech., Cambridge 39, Mass.

(d) Analytical and experimental.

(e) Study the feasibility of using dynamic type fluid motor in servo applications where hot gas is used as a medium.

(g) (1) Steady-state torque-speed characteristics, (2) dynamic response, (3) performance of position-control servo systems using the reaction-jet motor, and (4) hot gas applications.

(h) "Development of a Gas Operated ReactionJet Servomotor," by Robert S. Scher, presented at the Symposium on Recent Mechanical Engineering Developments in Automatic Control, The Institution of Mechanical Engineers in London, England, January 5-7, 1960.

"Steady State Performance of Reaction Jet Servomotor for Several Different Designs," by Cheng K. Weng, $1960 \mathrm{M}$. S. Thesis, M. E. Dept., Mass. Inst. of Tech., Cambridge, Mass .

"An Investigation of Some of the Characteristics of a Pneumatic Servomotor," by Louis H. Bangert, 1958 S. B. Thesis, M. E. Dept., Mass. Inst. of Tech., Cambridge, Mass .

"The Effect of Friction on Compressible Flow in Small Diameter Tubes as a Function of Tube Geometry," by Edward A. Bulanowski, $\mathrm{Jr}$., and Andrew J. Deraney, 1960 S. B. Thesis, M. 巴. Dept., Mass. Inst. of Tech., Cambridge, Mass.

"Dynamic Analysis of a Jet Reaction Servomotor," by Charles E. Roden, 1959 S. B.
Thesis, M. E. Dept., Mass. Inst. of Tech., Cambridge, Mass.

"Investigation of Thrust as a Function of the Fluid Temperature in a Sonic Nozzle," by Lawrence G. Clawson, 1959 S. B. Thesis, M. E. Dept., Mass. Inst. of Tech., Cambridge, Mass.

\section{(3448) FLOW THROUGH CONTROL VALVE ORIFICES.}

(b) U. S. Air Force, Chandler-Evans Corp., Hamilton Standard (Div. of United Aircraft).

(c) Prof. J. L. Shearer, Mass. Inst. of Tech., Cambridge 39, Mass.

(d) Applied research.

(e) Experimental investigation of the characteristics of flow through fixed area and variable area orifices with emphasis on resistance to fluid flow and the factors that lead to being able to predict the resistance characteristics over a wide range of Reynolds Numbers.

(g) Actual size and large scale models have been studied for hydraulic and pneumatic flows with special emphasis on low Reynold Number flows. Small amounts of rounding of the entrance corners have a very great effect on discharge coefficients at low and intermediate Reynolds Numbers with hydraulic flow. Pneumatic flows have demonstrated bistable flow conditions accompanied by hysteresis. A basic investigation is underway of the causes of bistable flows which occur in flapper-nozzle valves. Unsteady flow in poppet valves is also being investigated experimentally.

(h) "Resistance Characteristics of ControlValve Orifices," J. L. Shearer, Proceedings of the Symposium on Recent Mechanical Engineering Developments in Automatic Control, London, Jan. 1960. Published by British I. Mech. E., I Birdcage Walk, London, England.

"A Pneumatic Flapper Valve Study," R. E. Norwood, Proceedings of the First Congress of the International Federation for Automatic Control, Moscow, June 1960, published by Butterworths, London, England.

"The Force on the Flapper of a Pneumatic Flapper Valve," R. E. Norwood, NEREM Record 1960, published by Boston Section of IRE, 313 Washington st., Newton, Mass.

(3452) INTERACTIONS AMONG BURNING FUEL DROPLETS AND THEIR EFFECTS ON COMBUSTION STABILITY AND ROUGHNESS.

(b) Office of Scientific Research, U. S. Air Force.

(c) Prof. T. Y. Toong, Mass. Inst. of Technology, Cambridge 39, Massachusetts.

(d) Theoretical and experimental; basic research for master's and doctoral theses.

(e) Theoretical and experimental investigations of interactions among burning fuel droplets in a steady and oscillating flow field. The main objective is to further an understanding of the general problem of combustion instability.

(g) Theoretical and experimental studies of the 
interactions between two burning fuel cylinders were carried out. Predicted results of burning rate agree well with the measured ones.

(h) "Interactions Among Burning Fuel Droplets, (I) A Single Fuel Plate", by T. Y. Toong, AFOSR TN 60-516, 1960.

"Interactions Among Burning Fuel Droplets, (II) Two Parallel Fuel Plates" by T. Y. Toong, AFOSR TN 60-517, 1960.

\section{(3455) SECONDARY FLOWS IN RECTANGULAR DUCTS.}

(b) Office of Ordnance Research, Dept. of the Army.

(c) Prof. A. H. Shapiro, M.I.T., Cambridge, Mass.

(d) Theoretical and experimental; basic research, Sc.D. thesis.

(e) The secondary flows associated with fullydeveloped turbulent flow in long, straight, rectangular ducts have been measured and interpreted. The generation of secondary vorticity and its magnitude are the main items of interest.

(f) Completed.

(g) See below.

(h) "Fully Developed Turbulent Flow in Straight Rectangular Ducts - Secondary Flow, its Cause and Effect on the Primary Flow," by L. C. Hoagland, Technical Report No. 2 M.I.T., Sept., 1960.

(3456) FLAME PROPAGATION AND STABILIZATION IN BOUNDARY LAYERS.

(b) National Science Foundation.

(c) Prof. T. Y. Toong, Mass. Inst. of Tech., Cambridge 39, Mass.

(d) Theoretical and experimental; basic research for doctoral and master's theses.

(e) Basic study of mechanisms of flame propagation and stabilization in a laminar boundary layer adjacent to a heated plate.

(g) Theoretical and experimental investigation of the structure and propagation of laminar flames near a heat sink were carried out. Experiments were conducted in a two-dimensional tunnel under sub-atmospheric pressures. Predicted burning-velocity variations agree well with the measured ones.

(h) "Structure and Propagation of Laminar Flames Near a Heat Sink," by T. N. Chen and T. Y. Toong, Combustion and Flame, Vol. 4, No. 3, 1960.

\section{(3457) JET MIXING WITH CHEMICAL REACTION.}

(b) Laboratory project.

(c) Prof. T. Y. Toong, Mass. Inst. of Tech., Cambridge 39, Mass.

(d) Theoretical and experimental; basic research for doctoral and master's theses.

(e) Theoretical and experimental investigations of the effects of chemical reaction on transport of mass, momentum and energy.

(g) Development of combustion in the mixing zone of two concentric gas streams of different composition, temperature and velocity were studied experimentally. Highspeed streak photographs show the propa- gation of kernels ignited at a short distance downstream of the initial contact point between the two streams.

(3463) BEHAVIOR OF WAKES IN ADVERSE PRESSURE GRADIENTS.

(b) Office of Naval Research, Dept. of the Navy,

(c) Mr. Uwe Schuab, Gas Turbine Lab., Mass. Inst. of Technology, Cambridge, Mass.

(d) Experimental and theoretical; basic research (for masters thesis).

(e) A number of cases of wake growth due to pressure gradients have been measured and the data are being used to establish a theoretical method of calculation.

\section{(3752) VORTEX EFFECTS IN PIPE FLOW.}

(b) General Electric Co. and Westinghouse Electric Corp.

(c) Prof. P. G. Hill, Mass. Inst. of Tech., Cambridge, Mass.

(d) Experimental; basic research, master's thesis.

(e) The decay of a strong vortex motion in pipe flow can affect the axial flow markedly by changes in the pressure field. The effect was studied experimentally.

(f) Completed.

(g) Changes in the axial velocity distribution are shown to be a consequence of the vortex. Decay. The shape of the vortex velocity distribution is however almost independent of the axial motion.

(3753) EFFECT OF CORIOLIS FORCES ON THE TURBULENT BOUNDARY LAYER.

(b) National Science Foundation.

(c) Prof. P. G. Hill, Gas Turbine Lab., Mass. Inst. of Tech., Cambridge, Mass.

(d) Experimental and theoretical; basic research.

(e) The purpose of this work is to examine the consequences of a Coriolis generated instability on the flow in a turbulent boundary layer particularly with respect to momentum and mass transfer.

(3754) BLADE FORCES DUE TO WAKE IMPINGEMENT.

(b) General Electric Co. and Westinghouse Electric Corp.

(c) Mr. Malcolm Lefcort, Gas Turbine Lab., Mass. Inst. of Tech., Cambridge, Mass.

(d) Experimental; basic research for Doctor's thesis.

(e) In a turbomachine the blades are excited by wakes shed from preceding blade rows. A water table representation of the phenomenon is being constructed and experimental measurements of the transient pressure forces will be made.

\section{(3755) TRANSITION FROM BUBBLE TO SLUG FLOW.}

(b) Office of Naval Research, Dept. of the Navy.

(c) Prof. R. Moissis, Department of Mechanical Engineering, Mass. Inst. of Tech., Cambridge, Mass. 
(d) Experimental and theoretical; basic research for S.M. thesis.

(e) To determine the criteria which govern the transition from the bubble regime to a developing slug flow when a gas-liquid mixture flows upwards in a vertical tube. The establishment of these criteria is essential to the accurate calculation of pressure drop in riser section of nuclear reactors, steam generator, etc.

(g) Two stages have been distinguished in the process of transitions. First, the small bubbles come together and form a group whose outline is the same as that of a Taylor bubble. Second, the interfaces between the small bubbles ccllapse and a single bubble is formed.

\section{(3756) ENTRANCE EFFECT IN A TWO PHASE SLUG FLOW.}

(b) Office of Naval Research, Dept. of the Navy.

(c) Prof. R. Moissis, Department of Mechanical Engineering, Mass. Inst. of Tech., Cambridge, Mass.

(d) Experimental and theoretical; basic research for Sc.D. thesis.

(e) Study of the kinetics of a G. I. Taylor bubble as it rises in a vertical tube behind a series of other bubbles in a gasliquid slug flow. The purpose is to determine the mean density in a developing slug flow.

(f) Completed.

(g) A theoretical expression for the velocity distribution in the walls behind a Taylor bubble has been derived. The rise velocity of a boiling bubble is expressed as a function of separation distance from the bubble ahead of it. The density distribution in a developing two-phase slug flow is a function of flow rates, of distance frcul the tube inlet, and of initial bubble size. "Entrance Effects in a Developing Slug Flow," R. Moissis and P. Griffith, MIT DSR Report No. 18, June 1960.

\section{(3757) THREE DIMENSIONAL BOUNDARY LAYERS ON RO-} TATING BLADES.

(b) General Electric Co. and Westinghouse Electric Corp.

Mr. Erik Olsson, Gas Turbine Lab., Mass. Inst. of Tech., Cambridge, Mass.

(d) Experimental and theoretical; basic research for doctors thesis.

The purpcses of this work are to examine the usefulness of momentum integral methods in predicting crossflow near blade surfaces and to examine the whole flow field in the blade passages.

(3758) FORCED CONVECTION FILM BOILING INSIDE OF VERTICAL AND HORIZONPAL TUBES.

National Science Foundation.

Mr. W. M. Rohsenow, Mass. Inst. of Tech., Cambridge, Mass.

(d) Experimental and analytical.

(e) Test section consists of electrically heated stainless steel tuke for obtaining test data and an electrically heated coated glass tube (Corning) for flow visualization. Test data to be taken on Freon in film hoiling.

(g) First test results expected in November 1960.

(3759) THE THREE DIMENSIONAL BOUNDARY LAYER IN THE VICINITY OF A WEDGE.

(b) Office of Naval Research, Dept. of the Navy.

(c) Mr. Richard G. Schwind, Gas Turbine Lab., Mass. Inst. of Tech., Cambridge, Mass.

(d) Experimental and theoretical; basic research for doctoral thesis.

(e) A study of the boundary layer flow near a wedge corner when the stream is laminar, with particular emphasis on separating flow.

(3760) PROPULSION THROUGH CHANGES OF BODY SHAPE.

(b) Laboratory project.

(c) Prof. A. H. Shapiro, M.I.T., Cambridge, Mass.

(d) Theoretical and experimental; basic research, Sc.D. thesis.

(e) Through what kinds of periodic changes in body shape can propulsive thrust be obtained? Is the thrust large enough to be interesting?

\section{(3761) SECONDARY FLOWS IN ROTATING FLUTDS.}

(b) Laboratory project.

(c) Prof. A. H. Shapiro, M.I.T., Cambridge, Mass.

(d) Experimental.

(e) Secondary flows were observed in a cylindrical tank with a turning rotor in the base, with different viscosities, speeds and depths.

(i) Temporarily discontinued.

(b) An amazing variety of secondary flow patterns, with isolated regions, were observed.

(h) "Some New Observations of Rotating Liquids," by C. F. Young, S.M. Thesis, Dept. of Mech. Engineering, M.I.T., 1960.

(3762) COMPUTER REPRESENTATIONS OF HYDRAULIC TURBINE CHARACTERISTICS.

(b) Woodward Governor Company.

(c) Mr. David R. Vaughan, Teaching Assistant, Room 3-447, Mass. Inst. of Tech., Cambridge, Mass.

(d) Experimental; applied research.

(e) A large amount of Holyoke Turbine Test Data is being used as a basis for computing parameters for a functional representation of turbine characteristics. This functional representation will appreciably reduce the cost of simulating a turbine over its entire operating range. By predicting the parameters from machine specific speed with detailed machine tests, preliminary system studies will be possible.

(3763) COMPARATIVE STUDY OF TURBINE AND COMPRESSOR TIP CLEARANCES.

(b) General Electric Co., and Westinghouse Electric Corp.

(c) Mr. Eiji Yokoyama, Gas Turbine Lab., Mass. Inst. of Tech., Cambridge, Mass.

(d) Experimental; basic research for master's 
thesis.

(e) A cascade wind tunnel is being used to establish the relative effects of tip clearances in turbines and compressors by studying the flow in the region of a slot of variable width.

(3764) VISUAL STUDY OF TWO-PHASE, ONE-COMPONENT FLOW WITH HEAT ADDITION.

(b) National Science Foundation, NSF Grant G11355.

(c) Mr. S. William Gouse, Jr. Assistant Prof. of Mechanical Engineering, Mass. Inst. of Tech., Cambridge, Mass.

(d) Experimental and theoretical investigation; basic research.

(e) Investigate two-phase flow in a vertical tube with heat addition in a transparent electric resistance film heated test section. Make measurements of pressure drop, temperature distribution, void fraction distribution and heat transfer rates. Make visual observations by means of high speed. photography.

UNIVERSTTY OF MASSACHUSETTS, School of Engineering.

Inquiries concerning the following projects should be addressed to Dr. Charles E. Carver, Jr., Assoc. Prof. of Fluid Mechanics, Dept. of Civil Engineering, University of Massachusetts, Amherst, Mass.

\section{(2561) HYDROLOGY STUDIES IN WESTERN MASSACHUSETTS.}

(b) Cooperative with the U.S. Soil Conservation Service, U.S. Weather Bureau and U. S. Geological Survey. Student assistance has been financed by faculty research grants.

(d) Experimental - field and laboratory; for design of watershed yield, flood peak reduction, and general information.

(e) Mass curve studies for reservoir and watershed yield have been completed for selected drainage areas in western Mass. An extension of these data combined with an expansion of some field work with regard to runoff characteristics of small drainage areas is planned.

(3467) THE EFFECT OF HEADER GEOMETRY UPON FLUID FLOW CHARACTERISTTCS IN NUCLEAR REACTORS AND HEAT EXCHANGERS.

(b) Laboratory project; student assistance financed by Teacher's Research Grant.

(d) Experimental; applied research, M.S. thesis.

(e) To determine the relationships between such variables as core and tube diameter, tube lattice and spacing, header height, etc., upon the individual flow per tube for a pressure vessel in which fluid is introduced through a single radial line placed at the base of the header.

(g) Total flow through header correlated with number of tubes mathematically; flow deviation among tubes increases as number of tubes decreases.
(3765) MATNTENANCE OF A LAMINAR BOUNDARY LAYER ON A POROUS FLAT PLATE AT ZERO INCIDENCE BY AREA SUCTION.

(b) Laboratory project.

(d) Experimental, basic research, master's thesis.

(e) A porous flat stainless steel plate was installed in a closed conduit past which a flow at $10 \mathrm{ft} / \mathrm{sec}$ streamed. Suction was applied to the plate and attempts made to visually detect the existence of a laminar boundary layer by means of dye and small thread streamers.

(f) Suspended.

(g) Laminar boundary layer was not observed with dye or threads. Displacement thickness when suction applied only about 8 to 12 mils. If laminar boundary layer did in fact exist, it was concluded that it would have to be detected indirectly by measurement of drag reduction on the plate as dye methods failed.

(h) "Maintenance of a Laminar Boundary Layer on a Flat Plate By Area Suction," M. S. thesis by Howard. B. Pritz, Dept. of Mech. Eng., Univ. of Mass., Amherst, Mass.

(3766) AN EXPERIMENTAL STUDY OF THE STABILITY OF STANDING (TRAPPED-RING) VORTICES IN TWO-DIMENSIONAL INCOMPRESSIBLE FLOW.

(b) Laboratory project - financed by Teacher's Research Grant.

(d) Experimental; basic research.

(e) Project just being initiated; it is planned to study standing vortices in a Hele-Shaw apparatus.

MICHIGAN STATE UNIVERSITY, Department of Civil Engineering.

(2125) SEDIMENT TRANSPORT IN RUNOFF WATER FROM SMALL AGRICULTURAL WATERSHEDS.

(b) Michigan Agricultural Experiment Station.

(c) Prof. R.Z. Wheaton, Agricultural Engineering Dept., Michigan State University, East Lansing, Michigan.

(d) Field investigation; for design.

(e) Samples of runoff water are collected at periodic intervals and more frequent intervals during flood flow to determine the concentration of sediment being transported. Runoff gaging stations serviced by USGS. Dense network of 22 recording raingages for 25 square mile area in two watersheds.

(g) Sediment content of runoff is low.

(2126) SURFACE AND SUBSURFACE DRAINAGE.

(b) Michigan Agricultural Experiment Station.

(c) Prof. E. H. Kidder, Agricultural Engineering Dept., Michigan State University, East Lansing, Mi chigan.

(d) Experimental; field investigation, applied research.

(e) To study the effect of bedding, bedding 
and moling, bedding and tile, and tile drainage on crop yields in a submarginal farming area. Crop yields in a graingrain hay-hay rotation are measured in increments away from the drainage feature.

(g) Two rod tile lateral spacing has given the highest crop yields. A 60-foot tile spacing ranks second.

(2127) AN INVESTIGATION OF THE STABILITY AND DURABILITY OF SUBSURFACE DRAINS PLACED IN MUCK.

(b) Michigan Agricultural Experiment Station.

(c) Prof. E. H. Kidder, Agricultural Engineering Dept., Michigan State University, East Lansing, Michigan.

(d) Experimental; field investigation; applied research.

(e) Four lateral underdrains were placed in muck (ph6.5). Concrete and clay tile in one-and two-foot lengths, perforated steel pipe in eight-foot lengths and perforated fiber pipe in six-foot lengths were install ed.in 1952. Elevations of the ground surface and the underdrains are taken annually. Quality of the material is checked at fouryear intervals.

(g) The soil surface subsided 0.8 to 0.9 feet the first year, with little subsidence since. The underdrains settled 0.3 feet the first year, negligible since. Concrete drain tile from three manufacturers deteriorated by acid action. Considerable rusting was noted on galvanized steel. Hay blinding material was in excellent condition.

\section{(3102) WATER REQUIREMENTS OF PLANTS.}

(b) Michigan Agricultural Experiment Station.

(c) Prof. R. Z. Wheaton, Agricultural Engineering Dept., Michigan State University, East Lansing, Michigan.

(d) Experimental, field investigation; applied research.

(e) Four areas are protected against natural rainfall during the cropping season. Precision irrigation is practiced to maintain four levels of available water in the soil. Meteorological, evapotranspiration and evaporation data are also collected.

(g) The highest level of available water (range between 70 and $100 \%$ in the surface foot) gives the highest yield of potatoes. Consumptive use peak rate of 0.18 inches per day.

\section{(3104) SPRINKLER IRRIGATION FOR FROST PROTECTION} OF PLANTS.

(b) Michigan Agricultural Experiment Station.

(c) Prof. E. H. Kidder, Agricultural Engineering Station, Michigan State Univ., East Lansing, Michigan.

(d) Experimental, laboratory and field investigation; applied research.

(e) To determine the application rates and repeat frequency of water application to give effective protection to plants against frost damage. (g) Applications rates of 0.1 inch per hour, repeat frequency of 12 to 20 seconds has protected truck crops against minimum temperature of $19^{\circ} \mathrm{F}$.

(3105) SHEAR AND PRESSURE DISTRIBUTTON ON DUNESHAPED BOUNDARIES.

(b) National Science Foundation.

(c) Dr. E. M. Laursen, Dept. of Civil Engineering, Michigan State University, East Lansing, Mi chigan.

(d) Experimental, basic research.

(e) Since the bed of an alluvial stream commonly consists of dunes and ripples, the distribution of shear and pressure over these roughness elements is of interest in regard to both sediment transportation and resistance to flow. A 44-foot Lucite conduit with schematic triangular dunes and air as the fluid is being used in the experimental investigation.

(3767) SYNTHESIS OF SEDIMENT-TRANSPORTING CHARACTERISTICS OF STREAMS.

(b) Laboratory project.

(c) Dr. E. M. Laursen, Dept. of Civil Engineering, Michigan State University, East Lansing, Michigan.

(d) Analytical; applied research, for M.S. thesis

(e) The assumption is made in this investigation that the variability of sediment load for a given discharge of a natural stream can be explained by a temporary change in the bed material of the stream due to the addition of fine material during surface runoff. Field data of the U.S.G.S. at several locations is being used to test this hypothesis.

(3768) SPILLWAY PROFILES FOR DESIGNATED UNDERPRESSURE.

(b) Laboratory project.

(c) Dr. E. M. Laursen, Dept. of Civil Engineering, Michigan State University, East Lansing, Michigan.

(d) Experimental; applied research, for M.S. thesis.

(e) The characteristics of two model spillways will be compared. The profile of one is based on the fully-ventilated, sharp-crested weir at $3 / 4$ design head. The profile of the other is based on a partially-ventilated, sharp-crested weir at full design head. The feasibility of the latter design will be assessed by comparison of discharge coefficients and pressure aistribution at various heads with the standard design.

UNIVERSITY OF MICHIGAN, Department of Civil Engineering.

\section{(3469) SMAIL BOAT HARBOR STUDY.}

(b) Dept. of Port Control, Cleveland, Ohio.

(c) Prof. E. F. Brater, 320 West Engineering Bldg., Univ. of Michigan, Ann Arbor, Mich.

(d) Experimental; applied research. 
(e) Determination of a procedure for reducing wave action in the mo ring area.

(f) Experimental work completed.

(g) Two methods were developed for reducing wave heights in the harbor area.

(h) Copies of report can be obtained from Dept. of Civil Engrg.

(3769) WAVE REFRACTION IN A TRAPEZOIDAL CHANNEL.

(b) Laboratory project.

(c) Prof. E. F. Brater, Professor of Hydraulic Engineering, Dept. of Civil Engrg., College of Engrg., Univ. of Mich., Ann Arbor, Mich.

(d) Theoretical and experimental. Basic research for doctoral thesis.

(e) Investigation of the refraction of waves which enter a trapezoidal channel from deeper water.

(3770) ROLL WAVES.

(b) Laboratory project.

(c) Prof. E. F. Brater, Professor of Hydraulic Engineering, Dept. of Civil Engrg., College of Engrg., Univ. of Mich., Ann Arbor, Mich.

(d) Theoretical and experimental. Basic research for doctoral thesis.

(e) Investigation of the characteristics of a wave generated by a disturbance at the entrance to a channel.

(3771) WATER HAMMER.

(b) Laboratory project.

(c) Prof. V. L. Streeter, Prof. of Hydraulics, Dept. of Civil Engrg., College of Engrg., Univ. of Mich., Ann Arbor, Mich.

(d) Theoretical and experimental; basic research for doctoral thesis.

(e) Investigation of friction effects on water hammer attenuation, by introducing friction losses in the differential equations, solving them by different methods using a high speed computer. Experimental study of water hammer under conditions of high friction.

UNIVERSITY OF MTNNESOTA, Agricultural Experiment Station.

\section{(1929) DRAIN TIIE JUNCTION LOSSES.}

Cooperative with St. Anthony Falls Hydraulic Laboratory. See page 76.

(2350) DRAINAGE OF AGRICULTURAL LAND BY PUMPING.

(b) Laboratory project.

(c) Prof. Curtis L. Larson, Dept. of Agricultural Engineering, Univ. of Minnesota, St. Paul 1, Minnesota.

(d) Theoretical and field investigations; applied research.

(e) The project has three phases: (1) The development of basic relations for planning pump drainage systems, (2) the study of rates of drainage, and (3) the study of factors affecting the efficiency.

(g) Tests of a propeller pump with various rates of cycling and with various suction conditions have been completed and a report is being prepared.

(h) "Evaporation Losses from Standard NonRecording Rain Gages," A.S.A.E. Trans., Vol. 3, No. 1, pp. 82-83, 1960.

(2576) CONSTRUCTION, DEVELOPMENT, AND PUMPING OF SHALIOW WELLS FOR IRRIGATION.

(b) Field project.

(c) Prof. Evan B. Allred, Dept. of Agricultural Engineering, Univ. of Minn., St. Paul 1, Minn.

(d) Field investigation; applied research and development.

(e) The objectives of the project are: (1) To study and develop inexpensive methods for construction of shallow irrigation wells, (2) determine hydraulic permeability and characteristics of various aquifers, and (3) to survey and determine extent and availability of shallow ground water sources for irrigation in Minnesota.

(3470) HYDRAULIC PERFORMANCE OF IRRIGATION BOOMSPRINKIERS.

(b) Field and laboratory project.

(c) Prof. Evan R. Allred, Dept. of Agricultural Engineering, Univ. of Minn., St. Paul 1, Minn.

(d) Primarily field investigation; applied research.

(e) The objective of the project is to determine the effect of wind velocity, nozzle arrangement, rotation speed and operating pressure on the distribution from irrigation boom-sprinklers.

IISSOURI SCHOOL OF MINES AND METALLURGY, Dept. of Civil Engineering.

\section{(319) WEIR STUDIES.}

(b) Laboratory Project.

(c) Prof. E. W. Carlton, Civil Engrg. Dept., Missouri School of Mines and Metallurgy, Rolla, Mo.

(d) Experimental; basic research for masters thesis.

(e) Tests on rectangular weirs were made to determine effect of velocity of approach on the relation between crest depth and critical depth of an imaginary open channel having same dimensions as the weir opening.

(g) Study produced a simple, accurate, and quick solution for plotting of $M$ function. Relationship between the $M$ function and the critical depth is logarithmic. This greatly simplifies determination of critical flow where the critical depth is known or vice versa. A relationship exists between $M$ function of channels of same shape but different dimensions. The velocity of approach does not affect the relationship between physical depth and crest depth.

(h) "Calibration of Weirs by Means of Critica $\perp$ 
Flow and Specific Energy," R. A. Rapp, M. S. Thesis, Missouri School of Mines, 1950. (Available on loan).

(2578) CORRELATION OF WEIR CREST DEPTH AND WEIR FLOW CHARACTERISTICS.

(b) Laboratory project.

(c) Prof. Clifford D. Muir, Associate Professor of Civil Engineering, Missouri School of Mines and Metallurgy, Rolla, Mo.

(d) Experimental.

(e) Tests on several cipoletti weirs were made in order to determine the effect of weir thickness, H/P ratio, and Froude's Number on the ratio of crest depths to the critical depth of an imaginary open channel having the same dimensions as the weir flow section.

(g) This study indicated a definite relationship between the crest depth to critical depth ratio and the Froude Number of the imaginary channel. However, the ratio tended to become constant at either high or low Froude Numbers. The $\mathrm{H} / \mathrm{P}$ ratio had no noticeable effect on this relationship. A continuation of this study indicates probable superiority of crest depth flow relationships, when weirs having a narrow width with respect to head are being used.

(h) "Correlation of Weir Crest Depth Froude Number, H/P Ratio, and Weir Thickness," Paul Harrawood, Master's Thesis, Missouri School of Mines, 1956. (Available on loan).

(3471) REGULATION OF RIVER BANK DEVELOPMENT THROUGH FLOOD PLAIN ZONING.

(b) Laboratory project.

(c) Prof. E. W. Carlton, Prof. of Civil Engrg., C. E. Department, Missouri School of Mines and Metallurgy, Rolla, Mo.

(d) Field investigation; applied research.

(e) The basic concepts for establishing an effective flood plain zoning program were investigated from three aspects: (1) Establishment of frequency and magnitude of design flood; (2) translation of design flood to zoning limits on the ground through hydraulic computations; and (3) establishment of a sensible adjustment of land use to flood hazard.

(f) Suspended.

(g) In addition a recommended zoning program has been established for a flood plain in Missouri with applications for the entire state and for most regions of the United States. A complete summary of the status of flood plain zoning in the United States has been tabulated.

(h) "Regulation of River Bank Development Through Flood Plain Zoning," William J. O'Neill, Master's Thesis, Missouri School of Mines, 1959. (Available on loan).

\section{(3772) CULVERT INLETS WITH SKIMMING HOODS.}

(b) Laboratory project.

(c) Prof. C. D. Muir, Associate Professor of Civil Engineering, Missouri School of Mines, Rolla, Missouri.

(d) Experimental; basic research for master's thesis.

(e) Model tests are being conducted on culvert inlets with several types of skimming hoods in order to study their efficiency and possible application to sanitary lagoons.

(3773) PIPE FRICTION WHEN PUMPING FLUID-SOLID MIXTURES.

(b) Laboratory project.

(c) Prof. C. D. Muir, Associate Professor of Civil Engineering, Missouri School of Mines and Metallurgy, Rolla, Missouri.

(d) Experimental; basic research for master's thesis.

(e) Tests were run pumping various mixtures of water and sand through a $3 / 4$ " pipe in order to study friction factors when solid transport was part of the flow.

(g) Preliminary results indicate a relationship exists between friction factor and solids percentage. However, this relationship becomes difficult to obtain for solid percentages above 40 percent.

\section{(3774) CULVERT INLET STUDIES.}

(b) Laboratory project.

(c) Prof. C. D. Muir, Associate Professor of Civil Engineering, Missouri School of Mines and Metallurgy, Rolla, Mo.

(a) Experimental; basic research for master's thesis.

(e) Model tests for a culvert were conducted to study culvert efficiency at partial flow and the formation of critical depth at the inlet. These tests were limited to a circular inlet.

(g) Results of study indicated a need for culvert entrance configuration study.

(h) "A Study of the Inlet Characteristics and Entrance Losses of a Pipe Culvert with A Flush Mounted Sharp-Edged Inlet," Luke L. Callaway, Jr., Master's Thesis, Missouri School of Mines, 1960. (Available on loan).

(3775) VERTICAL WATER JET IMPACTING UPON A STILLING BASIN.

(b) Laboratory project.

(c) Prof. V. A. C. Gevecker, Civil Engineering Department, Missouri School of Mines and Metallurgy, Rolla, Missouri.

(d) Experimental; bssic research for master's thesis.

(e) Tests being conducted on the terminal effect of a $3 / 8^{\prime \prime}$ water jet on a cylindrical stilling basin to determine side and bottom pressures, velocities, and energy dissipated.

MONTANA STATE COLLEGE, Agricultural Experiment Station.

\section{(3108) STREAMFLOW FORECASTING IN MONTANA BASED} ON SNOW SURVEYS.

(b) Agricultural Engineering Department, Mont. Experiment Station; Soil Conservation Service. 
(c) Mr. Lynn F. Johnson, Montana State College, Bozeman, Montana.

(d) Experimental; statistical analysis of snow survey and runoff data.

(e) Adaptation of the electronic digital computer to the development of forecast formulas.

(f) Active project approaching completion. Will probably be continued on a service basis.

(g) Technical bulletin in preparation.

(3109) IMPROVING THE EFFICIENCY OF IRRIGATION APPLICATION BY BORDER IRRIGATION.

(b) Agricultural Engineering Department, Agricultural Experiment Station; U. S. Bureau of Reclamation cooperating.

(c) Professor Charles C. Bowman, Montana Agricultural Experiment Station, Montana State College, Bozeman, Montana.

(d) Experimental and basic research.

(e) Laboratory studies of basic principles which govern the flow of water at a shallow depth over rough ground under various densities of crop growth. Supplemented by field experiments and tests.

(f) Project has been in progress several years. Laboratory equipment added recently .

(g) Annual reports of progress have been made to the Director and to the Bureau of Reclamation.

\section{(3472) INTERCEPTION AND ITS EFFECT ON PRECIPI-} TATION DISPOSAL.

(b) Agricultural Engineering Department, Mont. Agricultural Experiment Station.

(c) Mr. Lynn F. Johnson, Montana State College, Bozeman, Montana.

(d) Basic research in field of hydrology.

(e) Development of instrumentation to measure transpiration and evaporation under coniferous canopies on mountain watersheds.

\section{- - - - - -}

UNIVERSITY OF NEBRASKA, Hydrodynamics Laboratory, Dept. of Engineering Mechanics.

(3776) VORTEX FORMATION AND DRAG IN UNSTEADY FLOW PAST BLUFF BODIES.

(b) National Science Foundation.

(c) Prof. T. Sarpkaya, Dept. of Engireering Mechanics, Bancroft Hall 219, University of Nebraska, Lincoln 8, Nebraska.

(d) Experimental and theoretical study of drag and inertia in unsteady flow. Basic research for master's and Ph.D. thesis.

(e) Primary objects of the rssearch are: To determine the growth and motion of vortices behind two dimensional bluff bodies subjected to unsteady flow; to determine the basic characteristics of the corresponding resistance; and to correlate a particular vortex configuration with the instantaneous resistance.

(g) The forces predicted on the basis of the moving and growing singularities are comparable in magnitude to forces which are observed.

(3777) TORQUE AND CAVITATION CHARACTERISTICS OF BUTTERFLY VALVES.

(b) Laboratory project.

(c) Prof. T. Sarpkaya, Bancroft Hall 219, Univ. of Nebraska.

(d) Theoretical and experimental; applied research.

(e) Free streamline theory is used to determine the contraction coefficients and the hydrodynamic torque. Theoretical results obtained for two-dimensional case are compared with the ones obtained experimentally. Results are extended to axially symmetrical butterfly valves. Inception of cavitation determined theoretically. Results obtained from experiments and those calculated from theory are excellent.

(f) Completed.

(g) For a free discharge valve the maximum value of the torque coefficient is about 0.03 , and occurs at about $20^{\circ}$ from the full open position.

(h) "Oblique Impact of a Bounded Stream on a Plane Lamina", T. Sarpkaya, Journal of the Franklin Institute, Vol. 267, No. 3, pp: 229-242, March 1959. May be obtained from The Franklin Institute.

"Torque and Cavitation Characteristics of Butterfly Valves, "T. Sarpkaya, Journal of Applied Mechanics, Paper No. 60-WA-105, pp: 1-8. ASME Winter Annual Meeting, N. Y., Dec. 1, 1960. May be obtained from ASME.

(3778) REFLECTION, TRANSMISSION, AND ATTENUATION OF PULSE WAVES IN BIFURCATTNG ELASTIC CONDUTTS.

(b) Cardiovascular Research Center, Medical School, University of Nebraska. Laboratory Project.

(c) Mr. Randolph M. Clark, Bancroft Hall 219, University of Nebraska, Lincoln 8, Nebr.

(d) Theoretical and experimental; applied research for master's thesis.

(e) The purpose of the project: To determine the effect of the conduit resistance on the magnitude of the maximum pressure created by elastic wave propagation; the rate of damping of the elastic wave pressure; the transmission and reflection coefficients; and to correlate the results obtained from this research with the propagation of pulse waves in arterial system.

(g) Wave velocity is not equal to a simple superposition of celerity and mean velocity of flow.

(h) "Pulse Waves in Elastic Conduits," M. S. Thesis by R. Clark, August 1960. May be obtained from the Department of Engineering Mechanics, University of Nebraska.

(3779) VIRTUAL MASS.

(b) Laboratory project.

(c) Prof. T. Sarpkaya, Bancroft Hall 219, University of Nebraska, Lincoln 8, Nebr.

(d) Experimental and basic research.

(e) Study of the added mass of lens-shaped 
bodies, two parallel square plates, and two parallel, infinitely long rectangular plates of various thicknesses.

(f) Completed.

(g) The added masses were determined from a mass-frequency relationship obtained by immersing the objects in water and accelerating them in oscillatory motion. The experimental results are in good agreement with the analytical studies of corresponding potential flows.

(h) "Added Mass of Lenses and Parallel Plates," T. Sarpkaya, ASCE EM3, No. 2511, pp: 141152, June 1960.

(3780) MECHANISM OF TURBUTENCE GENERATION IN PULSATING VISCOUS FLOW.

(b) Laboratory project.

(c) Prof. T. Sarpkaya, Bancroft Hall 219, Univ. of Nebraska.

(d) Experimental and theoretical basic research, for master's thesis.

(e) To understand the mechanism of generation of turbulence in pulsating viscous flow superposed on the steady and initially laminar fllow.

(g) When the amplitude ratio of the pulsating pressure gradient to steady one is not large, the maximum dissipation occurs at the wall. However, with the increase of the amplitude ratio the position of the maximum dissipation moves into the flowing fluid and its distance varies with time.

(3781) FLOW OF NON-NEWTONIAN FLUIDS IN A MAGNETIC FIELD.

(b) Laboratory project.

(c) Prof. T. Sarpkaya, Bancroft Hall 219, University of Nebraska, Lincoln 8, Nebr.

(d) Theoretical; basic research.

(e) The analytical solution to the equation of motion is given for the steady laminar flow of a uniformly conducting incompressible non-Newtonian fluid, (Bingham plastic and Ostwald and de Waele type fluid) between two parallel planes.

(f) Completed.

(h) "Flow of Non-Newtonian Fluids in a Magnetic Field," T. Sarpkaya, presented at the $43 \mathrm{rd}$ national meeting of AIChE, Tulsa, Oklahoma, Sept. 25, 1960, pending publication. Preprints may be obtained from AIChE. Priced at 50 cents.

\section{(3782) INDUCED MASS OF CONE'INED FLUIDS.}

(b) Laboratory project.

(c) Prof. T. Sarpkaya, Bancroft Hall 219, University of Nebraska, Lincoln 8, Nebr.

(d) Theoretical basic research for master's thesis.

(e) When a confined fluid is sudfenly accelerated through an opening initial acceleration is determined by the induced mass of the fluid. This mass could be determined from the streamline pattern of a corresponding steady flow. If this mass is ignored initial acceleration turns out to be unrealistically large.
NEWPORT NEWS SHIPBUIIDING AND DRY DOCK COMPANY.

Inquiries concerning the following projects should be addressed to Mr. C. H. Hancock, Hydraulic Lab., Newport News Shipbuilding and Dry Dock Company, Newport News, Virginia.

\section{(123) HYDRAULIC TURBINE TESTS.}

(b) Laboratory project.

(d) Experimental; for design data.

(e) Scale model turbines, using either Francis or propeller type runners, are tested for power and efficiency at various speeds.

\section{(124) METER CALIBRATION TESTS.}

(b) Laboratory project.

(d) Experimental.

(e) To establish calibration curve for determining correction for various rates of flow. Meters are tested at various rates of flow by weighing tank method. Time is recorded electronically by decade counters.

(896) VANE MOMENT TESTS ON ADJUSTABLE BLADE RUNNERS.

(b) Laboratory project.

(d) Experimental; for design data.

(e) Tests are to determine vane moments at various gate openings, blade positions and speeds. The turbine load is applied by an electric dynamometer and speed is me asured with a decade counter. The blades are held in position by an amplidyne control system on a spider rod through the shaft. The blade moments are obtained from a proving ring by means of electric strain gages.

\section{(901) SHIP MODEL RESISTANCE TESTS.}

(b) Laboratory project.

(d) Experimental; for design data.

(e) Scale ship models are towed to determine effective horsepower, bare hull, required by the ship. Because of their small size, several models may be towed in a short period of time thus allowing much preliminary work to be done on the choice of lines. Final lines are checked by David Taylor Model Basin. To eliminate a large portion of this preliminary testing, a schedule of systematic models was arranged in which the beam-draft ratio, the displacementlength ratio, and the prismatic coefficient are varied over a wide range. Towing this set of models is continuing and when completed will provide design data for a standard offset series covering a wide range.

\section{(1132) HYDRAULIC PUMP TESTS.}

(b) Laboratory project.

(d) Experimental; for design data.

(e) Scale model pumps, centrifugal and propeller types, are tested at constant speeds for head developed, power consumption, and efficiency at various rates of discharge. Cavitation tests are sometimes conducted 
by lowering the suction head to a point where the developed head and efficiency break down. Blade moments are measured by installing electric resistance strain gages on the turbine blade roof. Shear strains are transmitted from the turbine via a slip ring.

(1133) CAVITATION TESTS OF HYDRAULIC TURBINE MODELS.

(b) Laboratory project.

(d) Experimental; for design data.

(e) Scale model turbines are tested on cavitation stand to determine sigma at which cavitation starts. By the use of a plexiglas throat ring and a strobulux light synchronized with the shaft rotation, visual observations are made to determine the location on the blade where cavitation starts. Tests were run to determine runaway speeds at low sigma values.

(2582) AIR TESTS ON HYDRAULIC TURBINE MODEL.

(b) Laboratory project.

(d) Experimental; for design data.

(e) Plexiglas hydraulic turbine model is tested with air. Smoke and tufts are used in the flow visualization studies. Velocity and pressure distribution studies are made using a sensitive differential manometer. The gate moments obtained from the pressure distribution will be checked with a strain gage dynamometer.

(f) Suspended.

(3111) PUMP-TURBINE TESIS.

(b) Laboratory project.

(d) Experimental; for design data.

(e) Pump-turbine models are tested either as a pump or turbine on this test stand. Cavitation as well as performance tests on pump, turbine or pump-turbine models can be made on this facility. Provision has been made to perform vane moment tests on adjustableblade turbine runners at the same time as performance tests.

(3783) AIR CONTENT CAVITATION OF TURBINES.

(b) Laboratory project.

(d) Experimental; applied research.

(e) Study of cavitation of hydraulic turbines as affected by the air quantity contained in the tunnel.

\section{(3784) PITOT TUBE CALIBRATION.}

(b) Laboratory project.

(d) Experimental.

(e) Calibration of a small 3-hole cylinarical search tube to determine accuracy as affected by blockage, pipe wall, angularity, discharge and fabrication.

(g) Results within $\pm 1 / 2$ percent can be attained for velocity. The angle can be determined to within 0.1 degree.

(3785) VELOCITY PROFIIE IN TURBINE MODEL. (b) Laboratory project.

(d) Experimental; applied research and development.

(e) Determination of velocity distribution through a two-dimensional turbine effected by entrance angle, hub configuration, and distributor height.

(3786) FLOW STRATGHTENERS.

(b) Laboratory project.

(d) Experimental and theoretical; applied research.

(e) Testing of different shapes for the straightening of flow in short pipes.

(3787) ADDED MASS OF TURBINES.

(b) Laboratory project.

(d) Experimental and theoretical; applied research.

(e) Determination of the effects of added mass of a propeller on the efficiency and blade moment step-up formulas from model to prototype.

NEW YORK UNIVERSITY, Department of Chemical Engrg.

Inquiries concerning the following projects should be addressed to Professor J. Happel, Department of Chemical Engineering, New York University, Univ. Heights, New York 53, New York.

(2583) EFFECT OF PARTICLE CONCENTRATION ON PRESSURE DROP AND SEDIMENTATION VELOCITY IN DILUTE BEDS OF PARTICLES.

(b) Grants from Texas Company and American Chemical Society; laboratory project.

(d) Theoretical; basic research for doctoral thesis.

(e) The slow translational motion of dilute beds of particles settling through viscous fluids subjected to the influence of cylindrical boundaries is being studied. This will ultimately enable a theoretical prediction of the effect of particle concentration on pressure drop and sedimentation velocity in beds of particles.

(g) The fluid velocity for a large number of field points within a cylindrical container has been computed for a spherical particle settling at six evenly spaced locations along the cylinder radius. The velocity field for all locations has also been obtained from the computed points by interpolation. These findings are applied to multi-particle systems.

(3474) HEAT TRANSFER AND CHEMICAL REACTION RELATIVE TO BEDS OF SPHERICAL PARTICLES.

(b) Laboratory project.

(d) Theoretical; basic research for doctoral thesis.

(e) An analytical solution is developed by assuming a model where fluid is flowing between two concentric spheres which are maintained at different temperatures. The 
partial differential equations applicable are solved by assuming power series solutions in temperature and in spherical coordinate $\theta$. The results will be compared to existing data on heat and mass transfer in packed and fluidized beds.

(3788) BOUNDARY LAYER MASS TRANSFER WITH HETEROGENEOUS CATALYSIS.

(b) Grants from American Chemical Society and National Science Foundation; Laboratory project.

(d) Theoretical; basic research for doctoral thesis.

(e) This work includes a study of the rate of gas-solid catalytic reactions in multiparticle systems. Using boundary layer theory in conjunction with a model consisting of a solid sphere inside a freesurface spherical cell, the relationship between rates of diffusion and rates of surface-catalyzed reactions is developed.

(g) Theoretical results for chemically dilute systems correlate existing mass transfer data reasonably well. It was found that molar convective transport to or from the surface affects the mass transfer rate and may give appreciably different results than those obtained from film theory or the dilute solution equation. A simple criterion is set up to determine when the dilute solution correlations can be used.

NEW YORK UNIVERSITY, Department of Meteorology and Oceanography .

\section{(2356) SHIP MOTIONS PROJECT.}

(b) David Taylor Model Basin, Dept. of the Navy.

(c) Prof. Willard J. Pierson Jr., Assoc. Prof. of Meteorology, New York Univ., University Heights, New York 53, New York.

(d) Theoretical and experimental; basic and applied research.

(e) Studies of the theory of a stationary Gausian process as applied to the motions of ships in waves; experimental and theoretical determination of co-spectra and quadrature spectra.

(g) Theoretical studies of cross spectra and bi-quadratic spectra, and theoretical papers on wave theory and ship motion theory.

(h) "The Apparent Loss of Coherency in Vector Gaussian Processes Due to Computational Procedures with Application to Ship Motions anù Random Seas," by W. J. Pierson, Jr., and John F. Dalzell. (In preparation.)

\section{(2357) WAVE PROJECT.}

(b) Bureau of Ships, Dept. of the Navy.

(c) Prof. Willard J. Pierson, Jr., Associate Professor of Meteorology, New York University, University Heights, New York 53, New York.

(d) Theoretical and experimental; and basic and applied research. (e) Attempts to solve various probabilistic problems in connection with stationary Gaussian noise.

(g) Work is continuing on the joint density of amplitude and half period and on improved zero and ordinate crossing techniques.

(3120) OFFICE OF NAVAL RESEARCH ATMOSPHERE INTERACTION AND WAVE PROJECT.

(b) Geophysics Branch, Office of Naval Research, Department of the Navy.

(c) Prof. Gerhard Neumann, Prof. of Oceanography and Professor Willard J. Pierson, Jr., Associate Professor of Meteorology, New York University, New York 53, New York.

(d) Experimental and theoretical; basic and applied research.

(e) Study of wave generation and propagation in deep water; non-linear properties of capillary and gravity waves. Observations of temperature and humidity and wind over the sea surface. Albedo measurements. Wind stress on water surfaces and the oceanic circulation. A study of the large scale oceanic circulation has just been completed and a report is in preparation.

(g) It has been shown that wave spectra cannot form a nested family of waves for fully developed seas. Non-linear effects were not too pronounced in project SWOP and a revised version of the report has been published as described in the references below.

(h) "On the Dymamical structure of the Gulf Stream as an Equivalent-Barotropic Flow," by G. Neumann. Journal of Geophysical Research, volume 65, No. 1, January 1960, pp. 239-247.

"Evidence for an Equatorial Undercurrent in the Atlantic Ocean," by G. Neumann. Deep Sea Research, 1960, Volume 6, pages 328334, Pergamon Press, Limited, London, England.

"Some Meteorologically Important Relationships Between the Ocean and Atmosphere," by G. Neumann. Transactions of the New York Academy of Science, Ser. II, Vol. 22, No. 8, 615-633, 1960.

"Ocean Waves," by $\mathrm{F}_{\mathrm{T}}$. Neumann and $\mathrm{W}$. J. Pierson, Jr. In McGraw-Hill Encylcopedia of Science and Technology, 1960 Edition. "Some Non-linear Properties of LongCrested Periodic Waves with Lengths Near 2.44 Centimeters," by W. J. Pierson and Paul Fife. To be published in the Journal of Geophysical Research, January 1961:

"Surface Waves," by W. J. Pierson, Jr. In United States National Report 1957 1960, Twelfth General Assembly, International Union of Geodesy and Geophysics, Leason H. Adams, Editor. Helsinki, Finland, July 25 - Aug. 6, 1960, p 261.

"The Directional Spectrum of a Wind Generated Sea as Determined from Data Obtained by the Stereo Wave Observation Project," by L. J. Cote, J. David, W. Marks, E. Mehr, R. MeGough, W. J. Pierson, Jr., F. C. Ronne, J. Ropek, G. Stephenson, R. C. Vetter, and R. G. Walden, Meteor. Papers, Vol. 2 
No. 6, June 1960 .

NORTH CAROLINA STATE COLLEGE OF AGRICULTURE AND ENGINEERING OF THE UNIVERSITY OF NORTH CAROLINA, Department of Engineering Research.

(1636) RAINFALL, INTENSITY, DURATION, FREQUENCY, CURVES FOR NORTH CAROLINA.

(b) Laboratory project.

(c) Prof. Charles Smallwood, Dept. of Civil Engineering, North Carolina State College, Raleigh, North Carolina.

(d) The collection and analysis of data pertaining to intensity, duration and frequency of rainfall in North Carolina.

(e) Since work is continuing, no conclusive results are available at this time.

NORTH DAKOTA AGRICULTURAL, COLTEGE, Department of Agricultural Engineering.

\section{(3475) SURFACE DRAINAGE.}

(b) Laboratory project.

(c) Mr. W. J. Promersberger, Chairman, Agricultural Engineering Department, North Dakota Agricultural College, Fargo, N. D.

(d) Field investigation; applied research, masters thesis.

(e) To study the effect of parallel ditch spacing, land forming and smoothing on crop yields in the Red River Valley. To determine the feasibility of using farm sized equipment to perform the work.

(g) On fields which have a uniform slope, a forty rod spacing of field ditches will give adequate drainage. Closer spacing may be necessary on very flat or nonuniform slopes. Proper aisposal of spoil and land smoothing between ditches will improve effectiveness of drains.

(h) "Land Forming for Improved Surface Drainage," E. W. French, W. J. Promersberger, and H. Frank Hughes, North Dakota Farm Research, Vol. 21, Nov. 8, Nov.-Dec. 1960. "Installation of an Open Ditch Drainage System in Flat Heavy Clay Soils," H. Frank Hughes. Unpublished M. S. Thesis, North Dakota Agricultural College, Febmary 1960.

NORTHWESTERN UNIVERSITY, The Technological Inst.

(2586) DISPERSION OF FLUID IN POROUS MEDIA.

(b) Laboratory project; Pure Oil Company.

(c) Professor Robert B. Banks, Department of Civil Engineering, Northwestern University, Evanston, Illinois.

(d) Theoretical, experimental; masters thesis of Mr. Bernard Lef'kowitz and Mr. Robert Owston.

(e) Packed column apparatus permits sampling of fluid flow to determine effects of dispersion, diffusion and convection on the change in solute concentration. Onedimensional studies have been resumed and experiments on radial and spherical flow are beginning. A wide range of Reynolds number will be covered; effects of adsorption will be investigated. Attempts will be made to correlate the Darcy friction factor and the longitudinal dispersion coefficient.

(f) Continuing.

(g) A theoretical analysis of the problem indicates that the phenomena is described by an equation similar to the heat conduction equation. It has been found that the longitudinal dispersion coefficient is proportional to the product of the fluid velocity and the grain diametr.

\section{(3476) FLOOD WAVE ROUTING.}

(b) Northwestern Technological Institute.

(c) Professor W. S. Hamilton, Dept. of Civil Engineering, Northwestern University.

(d) Theoretical and analytical for doctoral and masters theses.

(e) The purpose is to calculate the movement of flood waves in prismatic and natural channels. Finite difference equations based on (a) method of characteristics and (b) basic equations of momentum and continuity are to be programmed separately for solution or a digital computer.

(f) Continuing.

(g) A general method using finite differences along characteristic curves and requiring trial solution has been set up.

(3477) THE EFFECT OF JET MIXING ON SEDIMENTATION EFFICIENCY.

(b) Laboratory project.

(c) Prof. Robert B. Banks, Department of Civil Engineering, Northwestern University, Evanston, Illinois.

(d) Theoretical and experimental; doctoral thesis of $\mathrm{Mr}$. Robert Kersten.

(e) The study is concerned with the effect of mixing, caused by a two-dimensional jet, on the percentage of particles removed in a rectangular sedimentation basin. Liquid flow, transporting solid particles, is introduced through a slot at the entrance of a long channel. Slot opening and elevation can be varied. The amount of solid particle removal, as well as the distribution of particles on the bottom, is measured.

(f) Continuing.

(g) Utilizing the generalized transport equation and employing the eddy diffusivity and velocity distribution of the two-dimensional turbulent jet, one is able to compute concentration distributions and removal ratios by relaxation solution methods. Results obtained to date indicate very good agreement, between theory and experiment.

(3478) EFFECTS OF TEMPERATURE DISTRIBUTION WITHIN OILFILMS OF BEARINGS.

(c) Professor 0. C. Zienkiewicz, Dept. of 
Civil Engineering, Northwestern University, Evanston, Illinois.

(d) Theoretical.

(e) Numerical solution of energy and heat dissipation equations and a study of the effects of viscosity variation across and along the oilfilms on the build up at lifting pressures.

( 1 ) Completed.

(g) The importance of the temperature variation across lubricant film is of a sufficient magnitude to invalidate the conventional theory in many instances.

(3480) THE FLOW OF NEWTONIAN AND OF NON-NEWTONIAN FLUIDS IN THE ENTRANCE OF A TUBE.

(b) Laboratory project.

(c) Professor John C. Slattery, Department of Chemical Engineering, Technological Inst., Northwestern University, Evanston, Illinois.

(d) Theoretical basic research for thesis.

(e) Boundary layer analysis is being applied to calculate pressure and velocity distributions.

(g) Improved velocity distribution obtained for laminar Newtonian flow.

\section{( 3481 ) BOUNDARY-IAYER FLOW PAST SUBMERGED BODIES.}

(b) Laboratory project.

(c) Professor John C. Slattery, Department of Chemical Engineering, Technological Inst., Northwestern University, Evanston Illinois.

(d) Theoretical, basic research for thesis.

(e) Boundary layer analysis is being applied to flow past a circular cylinder and past a sphere. The object of these calculations will be to estimate the pressure distribution, form drag, and total drag in each of these cases. Both Newtonian and nonNewtonian flluids are being considered.

(3482) NON-NEWTONIAN FLOW THROUGH AN ANNULUS.

(b) Laboratory project.

(c) Professor John C. Slattery, Dept. of Chemical Engineering, Northwestern Univ., Evanston, Illinois.

(a) Theoretical; basic research for thesis.

(e) The flow of non-Newtonian fluids through a thin annulus (the ratio of the inner diameter to the outer diameter greater than 0.6) is being studied; the results will be extended to annuli with rotating cores.

\section{(3483) GROUND EFHECT PHENOMENA.}

(b) Laboratory project.

(c) Professor A. A. Kovitz, Dept. of Mechanical Engineering, Northwestern University, Evanston, Illinois.

(d) Theoretical; basic research.

(e) To study the thrust augmentation capabilities of jet devices near surfaces, including both rigid and deformable surfaces.

(3484) MIXING AND REACTION KINETICS IN FIOWS.

(b) Laboratory project. (c) Professor A. A. Kovitz, Dept. of Mech. Engineering, Northwestern Univ., Evanston, Illinois.

(d) Theoretical.

(e) To study the flow of real gases in high speed, high temperature phenomena including non-equilibrium effects.

(g) Study completed of mixing of dissociated undissociated gas using simplified rate law. Obtained closed form solution describing approach to equilibrium in boundary layer type mixing. Study initiated on the mixing of gases including the effects of ionization.

(h) "Memorandum on Flow with Recombination Behind an Oblique Shock Wave," Memo No. III-1 Contract AF 40(600)-748.

"Non-Equilibrium Effects in Parallel Stream Mixing," Memo No. III-2, Contract AF 40(600)-748.

"A Solution for laminar, Parallel Stream Mixing with Dissociation and Recombination," with R. F. Hoglund, Phys. of Fluids, vol. 3, 436, May-June 1960.

(3789) THE HYDROMECHANICS OF A HIGH VEIOCITY GAS JET PENETRATING A LIQUID SURFACE.

(b) Laboratory project; Bureau of Ships, Department of the Navy.

(c) Professor Robert B. Banks, Department of Civil Engineering, Northwestern University, Evanston, Illinois.

(d) Theoretical, experimental; research investigations of Mr. D. V. Chandrasekhara and Mr. Frank Collins.

(e) A jet of air flowing downwards from a nozzle located above a liquid surface, deforms the otherwise level surface. The research objective is to obtain quantitative information regarding the shape and stability of the depressed region and cavity. Information on pressure and velocity distributions will be obtained.

(3790) TURBULENCE CHARACTERISTICS OF A SUBMERGED IIQUID JET.

(b) Laboratory project.

(c) Prof. S. G. Bankoff and J. E. Sunderland, The Technological Institute, Northwestern University, Evanston, Illinois.

(d) Basic experimental research, doctoral thesis.

(e) Using the recently developed Hubbard-Iing hot-film anemometer, the time-average velocity profiles and the correlation coefficients will be measured for a submerged, round, free liquid jet.

\section{(3791) ZERO-GRAVITY, TWO-PHASE FLUID MECHANICS.}

(b) Laboratory project.

(c) Prof. S. G. Bankoff, Technological Inst., Northwestern Univ., Evanston, Illinois.

(d) Basic experimental research; doctoral thesis.

(e) The development of the two-phase boundary layer in the flow of a liquid past a porous plate through which a second immiscible liquid is injected is studied. Electrical 
resistance probes are used for determination of the position of the region boundaries. This stimulates zero-gravity boiling heat transfer from a flat plate.

(3792) RESPONSE OF A BOILING CHANNEL TO INPUT FLUCTUATIONS.

(b) Laboratory project.

(c) Prof. S. G. Bankoff, Technological Inst., Northwestern Univ., Evanston, Illinois.

(d) Basic theoretical research; doctoral thesis.

(e) A recently presented variable-density, single-fluid model for two-phase flow in pipes and channels under steady-state conditions is adapted to the study of the response of a channel to fluctuations of input power or flow.

(3793) VOID FRACTION PROFILES IN TWO-PHASE MERCURYGAS FLOW.

(b) Argonne National Laboratory.

(c) Prof. S. G. Bankoff, Technological Inst., Northwestern Univ., Evanston, Illinois.

(d) Experimental basic research; doctoral thesis.

(e) Measurement of isothermal steady-state void fraction profiles in concurrent flow of mercury and air by means of electrical resistance probe.

(3794) CREEPING FLOW PAST A SPHERE OF A NONNEWTONIAN FLUID.

(b) Laboratory project.

(c) Professor John C. Slattery, Department of Chemical Engineering, Technological Inst., Northwestern University, Evanston, Ill.

(a) Theoretical; basic research for thesis.

(e) Recently proposed Variational principle is used to obtain a solution.

(3795) THE EFFECT OF VIBRATIONS ON BOILING HEAT TRANSFER.

(b) Laboratory project.

(c) Dr. J. E. Sunderland, Technological Inst., Northwestern University, Evanston, Ill.

(d) Experimental; basic research, M.S. thesis.

(e) A study has been carried out to determine the effect of mechanical vibrations on boiling heat transfer.

(f) Completed.

(g) Results show that the rate of heat transfer at the burnout point is substantially increased by mechanical vibrations.

(h) A publication is in preparation.

(3796) AN INVESGITATION INTO THE MECHANISM OF FREEZE DRYING.

(b) Quartermaster Corps, U. S. Army.

(c) Dr. J. E. Sunderland, Technological Inst., Northwestern University, Evanston, Ill.

(d) Experimental and theoretical; basic research on M.S. and Ph.D. level.

(e) This is a study of heat and mass transfer problems encountered with freeze drying. One problem is to determine the conditions for the flow through the dried substance to be due to a concentration gradient, or else a total pressure gradient. In other words, is the flow of vapor due to diffusion, or hydrodynamic type flow.

(g) Several progress reports are available and may be obtained from the correspondent.

(3797) HEAT CONDUCTION AND CONVECTION PROBLEMS ASSOCIATED WITH MELTING.

(b) Laboratory project.

(c) Dr. J. E. Sunderland, Technological Inst., Northvestern University, Evanston, IIl.

(d) Theoretical; basic research; Ph.D. thesis.

(e) A study is being carried out to determine the velocity and temperature distribution in the melted layer of a melting body.

\section{(3798) BOUNDARY LAYER TURBULENCE.}

(c) Mrs. George G. Lamb, The Technological Inst., Northwestern University, Evanston, Illinois.

(d) To develop model for quantitative predictions of turbulence in boundary layers.

(e) To develop model based on origin of turbulence in boundary layers that may be extended to permit quantitative understanding of momentum transfer and velocity profiles in turbulent boundary layers.

\section{(3799) VELOCITY PROFILES IN A SEDIMENT-LADEN} BOUNDARY LAYER.

(b) Northwestern Technological Institute.

(c) Professor W. S. Hamilton, Dept. of Civil Engineering, Northwestern University, Evanston, Illinois.

(d) Thenretical and experimental; for doctoral thesis.

(e) The purpose is to determine semi-theoretically the effect of a density gradient, caused by sediment concentration profiles, on the velocity distribution in the boundary layer along a plane surface, and to check the results with measured data.

(3800) THE EFFECT OF PRE-COMBUSTION ON DETONATION WAVE STRUCTURE.

(b) Laboratory project.

(c) Professor A. A. Kovitz, Dept. of Mechanical Engineering, Northwestern University, Evanston, Illinois.

(d) Theoretical.

(e) To study the effect of initial gas composition on the temperature, pressure, and composition distributions through a detonation wave.

(3801) THE DETERMINATION OF FORM DRAG AND SKIN FRICTION FACTORS IN THE FLOW OF GASES THROUGH EXPANDED FIXED BEDS OF SPHERICAL PARTICLES.

(b) Doctoral dissertation (C. A. Wentz).

(c) Professor George Thodos, Department of Chemical Engineering, Northwestern Univ., Evanston, Illinois.

(d) Experimental.

(e) Expanded fixed beds have been prepared by 
attaching phenolic spheres ( $d=1.25$ inches) with rigid fine wires in order to produce a composite structure having different void fractions. A test sphere is located in the center of this structure. This sphere is provided with means for obtaining the static pressure distribution around the spherical surface. With this experimental information, the form drag can be accounted for and when subtracted from the total drag, the shear drag is obtained.

UNIVERSITY OF NOTRE DAME, Department of Civil Engineering.

\section{(1643) BIBLIOGRAPHY OF HYDROMETRY.}

(b) Research work with a grant from the Naiional Science Foundation.

(c) Dr. S. Kolupaila, Dept. of Civil Engrg. Notre Dame, Ind.

(d) Bibliographical research.

(e) Chapters: historical development; compendiums, handbooks, textbooks, manuals; waterstage observations; water stage computations; runoff determination; hydrometric instruments; rating of hydrometric instruments; equipment of hydrometric stations; area-velocity method; velocity method in conduits; tracer methods; the Gibson method; volumetric measurements; orifices and nozzles; orifice plates and nozzles in pipes; venturimeters; weirs and flumes; modern physical methods of flow measurement; mechanical water meters; slope-area method; depth measurements; tidal waters; sediment measurements; precipitation and evaporation; density measurement; source material.

(f) Completed.

(g) About 7500 papers in 30 languages are indexed and annotated.

(h) "Bibliography of Hydrometry," S. Kolupaila. Published by Univ. of Notre Dame and may be ordered from the Notre Dame Press, Notre Dame, Ind., priced at $\$ 10.00$.

(3124) HISTORY OF HYDROMETRY IN THE UNITED STATES.

(c) Dr. S. Kolupaila, Dept. of Civil Engrg., Notre Dame, Ind.

(g) The first part is published, the second, Modern History of Hydrometry in the United States, is being prepared for publication.

(h) "Early History of Hydrometry in the United States," by S. Kolupaila, Proceedings of ASCE, 86(1960), Journal of the Hydraulics Division, No. HY 1, Jan., 51 pp.

\section{(3802) COMPONENT RUNNNER FOR THE CURRENT METER.}

(b) Laboratnry project, continuation of the itern (2827).

(c) Dr. S. Kolupaila, Dept. of Civil Engrg., Notre Dame, Ind.

(d) Applied research.

(e) A runner (impeller) of the screw type current meter of a special design follows the cosine law. This is important when oblique currents are to be measured. (g) Significance of the component runner for measurements in closed conduits, especially in locations at a short distance from inlets and at close proximity to the conduit walls is emphasized.

(h) "Significance of a Component Runner for the Current-Meter Method of Flow Measurement in Closed Conduits," by S. Kolupaila, Symposium on Flow Measurement in Closed Conduits, Paper A-1, pp. 1-8, National Engineering Laboratory, East Kilbride, Glasgow, 1960. To be published in the Proceedings of the Symposium, Edinburgh, H. M. Stationary office, 1960.

(3803) POTENTIAL ANALOG SIMULTTION OF DEFORMABLE HYDRODYNAMIC BOUNDARIES.

(b) National Science Foundation.

(c) Dr. A. G. Strandhagen, Univ. of Notre Dame, Notre Dame, Indiana.

(d) Project is both experimental and theoretical, and is of a basic research type. Two master's degree candidates and one doctoral candidate are active in this investigation.

(e) Two-dimensional conducting sheet is used to simulate the flow around submerged bodies moving below a free surface. Flow past cavitating hydrofoils, flat-plate hydrofoils, and shaped hydrofoils are under investigation.

(g) Flow past vortex and a flat plate have been completed. Results indicate that potential analog simulation is accurate. Extensions to solution of difficult mathematical cases appear promising.

(h) "Potential Analog Studies of Hydrodynamic Deformable Boundaries," by Brother C. Albert Welsh, a doctoral dissertation.

OHIO STATE UNIVERSITY, Department of Civil Engrg.

(3030) TRANSIENT FLOW THROUGH POROUS INCOMPRESSIBLE MEDIA WITH VARIOUS BOUNDARY CONDITIONS.

(b) Experimental part was supported by the National Research Council of Canada.

(c) Prof. B. S. Browzin, Ohio State Univ., 2036 Neil Avenue, Columbus 10, Ohio.

(d) Experimental and theoretical; basic research

(e) The unsteady laminar flow was reproduced by a highly viscous liquid flowing between closely spaced translucid plates on a number of models with geometric boundaries representing various types of earth dams on impervious foundations and earth massives crossed by open channels, wher boundary conditions are of transient character with respect to the time.

(g) Experimental part concerning earth dams and earth massives on impervious foundations completed. The theoretical part of the research completed for the case of rapid drawdown in homogeneous dams. The theoretical research of cases of gradual drawdown, of non-homogeneous dams, of tailwater condition, and the drawdown in canals is progressing.

An approximate function relating, by 
dimensionless parameters, the shape and the position of free surface of flow through an earth dam, following rapid reservoir drawdown, to the geometry of the dam was obtained theoretically and confirmed by experiments.

(h) "Transient Flow Through Earth Dams on Impervious Foundations After Rapid Drawdown of the Reservoir," Submitted for publication in the Proceedings of the Fifth International Congress on Soil Mechanics.

(3031) THE VARIATION OF HYDROLOGIC FACTORS AND THEIR INFLUENCE ON RIVER REGIMES IN THE GREAT LAKES-ST. LAWRENCE DRAINAGE AREA.

(b) Laboratory project.

(d) Basic research.

(e) Research is based on long range flow and meteorologic record. Flow and precipitation data on U. S. and Canada stations were statistically investigated in order to obtain river regime characteristics. other climatic, geologic and botanic data, will be included, depending on availability.

(g) Classified discharges and precipitation for long range gauging and meteorologic stations are calculated. Characteristic parameters for river classification of the area are obtained.

OKLAHOMA STATE UNIVERSITY, Agricultural Engineering Department.

\section{(2365) HYDROLOGIC STUDIES ON SMALL GRASS-COVERED WATERSHEDS.}

(b) Agricultural Experiment Station cooperative with Agricultural Research Service.

(c) Prof.F.R. Crow, Okla. State Univ., Dept. of Agricultural Engrg., Stillwater, Okla.

(d) Field investigation; applied research.

(e) Measurements are being made to provide hydrologic data on total watershed runoff and peak rates of runoff from three small grass-covered watersheds ( 17 to 206 acres) in north central oklahoma. Highway culverts, modified by the addition of weir sills, are being used as runoff measuring devices.

(g) Intensive model tests of culverts equipped with weir sills completed. Eight year data on precipitation and runoff completed.

(h) "Runoff from Small watersheds in the Reddish Prairie Grasslands of Oklahoma," W. O. Ree and F. R. Crow, Oklahoma Agricultural Experiment Station Technical Bulletin.

(2828) THE EFFECTIVENESS OF MONOMOLECULAR FILMS FOR REDUCING EVAPORATION FROM RESERVOIRS.

(b) Oklahoma Agricultural Experiment Station.

(c) Prof. F. R. Crow, Oklahoma State Univ., Dept. of Agr. Engrg., Stillwater, Okla.

(d) Experimental; applied research.

(e) Studies are being made on plastic lined experimental evaporation reservoirs to develop methods of application and determination of effectiveness of hexadecanol and octadecanol films for reducing eva- poration. Effect of wind on stability of monolayers is being studied in low-speed laboratory wind tunnel.

(g) Evaporation reductions of 25 to $40 \%$ have been obtained using a slurry method of applying film to experimental pond. Curves have been developed relating wind speed and required film application rate.

(h) "Reduction of Reservoir Evaporation Losses by the Application of Surface Film of Hexadecanol, "F. R. Crow, Oklahoma Agricultural Experiment Station. Presented before the ASAE 1960 winter meeting, Memphis, Tenn.

(3804) THE HYDRAULICS OF CONSERVATION CHANNELS.

(b) Agricultural Research Service, U. S. Department of Agriculture in cooperation with the Oklahoma Agricultural Experiment Station.

(c) Mr. W. O. Ree, Agr. Research Service, Soil and Water Conservation Research Div. Watershed Tech. Research Branch, Stillwater, Okla.

(d) Experimental; applied research.

(e) Vegetation lined waterways of the kind used to convey short duration flood flows from small watersheds are constructed full size on the grounds of an outdoor hydraulic laboratory. Flow tests are made on these experimental channels to determine the protective ability of various grasses and to evaluate the flow friction factors under different conditions of growth. Perennial grasses for permanent protection and annual grasses for the temporary protection of newly constructed earth waterways are both considered in these studies. Temporary liners of various fibers including jute, paper, and glass are also testsd.

(g) Manning's $n$ values have been determined for various grass species. The physical characteristics of the vegetation and the flow character both influence the flow retardance factor so special design diagrams have been prepared to aid in solving flow problems under these conditions.

(h) "The Establishment of Vegetation-Lined Waterways," W. O. Ree, Agricultural Research Service. Presented before the Nineteenth Short Course on Roadside Development, Columbus, Ohio 1960.

OREGON STATE COLIEGE, Hydraulics Laboratory.

OPEN CHANNEL JUNCTIONS FOR SUPERCRITICAL FLOW.

(b) Laboratory project.

(c) Dr. C. E. Behlke, Dept. of Civil Engrg., Oregon State College, Corvallis, Oregon.

(d) Experimental theoretical; basic research.

(e) Diagonal wave action produced by the junction of two supercritical streams of water in rectangular channels is being studied analytically and experimentally.

\section{(3806) TWO DIMENSIONAL MANIFOLDS.}

(b) Laboratory project.

(c) Dr. C. E. Behlke, Dept. of Civil Engrg., 
Oregon State College, Corvallis, Oregon.

(d) Experimental and theoretical for master's thesis.

(e) Geometry of fllow from a multi-slotted conduit into the atmosphere will be measured and the geometry will be computed by the free-streamline, hodograph method.

THE PENNSYLVANIA STATE UNIVERSITY, Ordnance Research Laboratory, College of Engineering and Architecture. Work done under Dr. G. F. Wislicenus, Director of the Garfield Thomas Water Tunnel.

(2832) MEASUREMENT OF FORCES ON A MODEL IN A WATER TUNNEL.

(b) Laboratory project.

(c) Messrs. G. B. Gurney and T. E. Peirce, Ord. Research Lab., Univ. Park, Pennsylvania.

(d) Experimental; developmental.

(e) The problem concerns the measurement or forces on models in a water tunnel over a velocity range up to $80 \mathrm{fps}$, pressure ranges of 3 to 60 psia.

(g) Two four component (lift, axial force, pitching and rolling moment) balances for use in water tunnels utilizing strain gaged pre-tensioned flexure beams as the force sensing devices have been in successful operation for two years. Development of a dynamic balance is now underway. The same principles will be employed with an improvement in that the model dead weight no longer is absorbed by the force sensing elements.

(2833) EXCITATION OF CAVITY RESONANCE BY WATER FLOW.

(b) Laboratory project sponsored by the Bureau of Ships.

(c) Mr. R. E. Bland, Dr. E. J. Skudrzyk, Ord. Research Laboratory, University Park, Penna.

(d) Primarily experimental, some theoretical; basic research.

(e) Experiments involving the excitation of cavity resonance by water flow past an opening or cavity, i.e., trapped water on one side of the opening and flowing water on the other side.

(f) Completed.

(h) Summary Technical Memorandurn available.

\section{(3143) REDUCTION OF SKIN FRICTION DRAG.}

(b) Joint program of investigation with the General Electric Company and with the United States Rubber Co. sponsored by the Bureau of Naval Weapons.

(c) Dr. John Lumley and Mr. A. F. Lehman, Ordnance Research Lab., University Park, Pennsylvania.

(d) Experimental; applied research.

(e) Investigations into the application of boundary layer control through suction and compliant surfaces for underwater bodies.

(g) Successful probe and associated electronic gear developed.
(3486) TURBULENCE MEASUREMENTS IN WATER.

(b) Laboratory project sponsored by the Bureau of Naval Weapons.

(c) Dr. John Lumley, Ordnance Research Lab., University Park, Pennsylvania.

(d) Experimental.

(e) Using a constant temperature probe, some turbulent flows at high Reynolds numbers will be investigated with particular attention to homogeneous grid-produced turbulence and turbulent dispersion in a shear flow.

(g) Measurements have been taken in a small water tunnel settling section determining the effect of various screens and honeycombs on turbulence.

\section{(3487) FLOW DISTORTION FEEDING INTO A PROPELLER.}

(b) Laboratory project sponsored by the Bureau of Naval Weapons.

(c) Mr. J. J. Eisenhuth, Ordnance Research Lab., Univ. Park, Pennsylvania.

(d) Theoretical and experimental.

(e) This is a study of the interaction effects between control surfaces and a propeller when the surfaces are located in front of the propeller and feed a distorted flow into it. The primary goal is to determine how effectively the propeller cancels the forces produced by the control surfaces.

(3488) FLOW OVER A BODY OF REVOLUTION WITH STABILIZING SURFACES.

(b) Laboratory project sponsored by the Bureau of Naval Weapons.

(c) Mr. E. J. Rodgers, Ordnance Research Lab., University Park, Pennsylvania.

(d) Theoretical and experimental.

(e) This study is directed toward the understanding of the flow conditions, around a body of revolution with stabilizing fins under conditions of pitch and/or yaw. The eventual goal is to be able to predict more precisely the hydrodynamic coefficients of such a body by virtue of a better understanding of the flow conditions.

(3807) INVESTIGATION OF THE CAVITATION CHARACTERISTICS OF A FEW SIMPLE LIQUIDS.

(b) Natl. Aeronautics and Space Administration.

(c) Mr. A. F. Lehman, Ordnance Research Lab., University Park, Pennsylvania.

(d) Experimental, analytical, basic research.

(e) To investigate experimentally the cavitation characteristics of a few simple (as regards to vapor pressure and handling) liquids under conditions occurring in space and aircraf't pumping machinery, and analyze the results so that a reliable basis for theory applicable to these conditions can be formulated.

PURDUE UNIVERSITY, Agricultural Experiment Station. 
(2596) THE USE OF A RAINFALL SIMULATOR FOR SOIL AND WATER MANAGEMENT STUDIES.

(b) Agricultural Research Service, SWC, ESW, USDA and Purdue University.

(c) Mr. L. Donald Meyer, ARS, Agricultural Engineering Building, Purdue University, Lafayette, Indiana.

(d) Field investigation; applied research.

(e) The rainfall simulator is used on runoff plots for comparison of treatments which effect erosion and infiltration. Research includes studies of tillage methods, crop residue management, slope, soil type, crop rotations, and intensity histograms.

(h) "Use of the Rainulator for Runoff Plot Research," by L. Donald Meyer. Soil Sci. Soc. Am. Proc. 24, 319-322, 1960.

"Soil and Water Conservation Research with the Rainulator," by Donald Meyer and J. V. Mannering. Seventh Int. Soil Sci. Soc. Congress Proc. August 1960.

(2597) THE EFEECTS OF TILLAGE ON RUNOFF AND EROSION.

(b) Laboratory project.

(c) Mr. W. D. Lembke, Agricultural Engineering Department, Purdue University, Lafayette, Indiana.

(d) Field investigation; applied research.

(e) Runoff is measured from 15 watersheds in five different tillage systems. These systems involve two surface soil treatments and three subsoil treatments, including subsoil fertilization and vertical mulching. Hydrologic analyses of these small watersheds are used to evaluate the effects of tillage on soil moisture, crop gwowth and yield, and runoff.

(2835) PRELIMTNARY INVESTIGATION OF WATER TABLE IN SANDY SOIL.

(b) Laboratory project.

(c) Mr. W. D. Lembke, Agricultural Engineering Department, Purdue Univ. Lafayette, Ind.

(d) Field investigation; applied research.

(e) The water table in an adjacent sandy field is controlled from a supply ditch in which the water level is kept high. The depths to the water table are continuously measured during the growing season at various distances from the ditch. Crop yield data are collected and correlated with the depths to the controlled water table.

(2837) TREATMENT OF SURFACE WATERS FOR DOMESTIC USE ON THE FARM.

(b) Laboratory project.

(c) Prof. E. J. Monke, Agricultural Engineering Department, Purdue Univ., Lafayette, Ind.

(d) Field investigation; applied research.

(e) The treatment of pond water through slow sand and diatomaceous earth filters is being evaluated.

(h) "Diatomaceous Earth and Cartridge Type Filters Evaluated for Application in a Pond Water Treatment System" by L. G. Laudenschlager, M. S. thesis, Purdue Univ.,
1960.

"Farm Pond Water - Safe to Drink" by Laudenschlager et al. Agricultural Extension Service, Purdue University. 1960.

(3490) INVESTIGATION OF FLOW CHARACTERISTICS IN DRAIN TILE AND THE RELATIONSHIP OF THESE FLOW CHARACTERISTICS TO SEDIMENTATION.

(b) Laboratory project.

(c) Prof. E. J. Monke, Agricultural Engineering Department, Purdue Univ. Lafayette, Ind.

(d) Laboratory investigation; basic and applied research.

(e) Flow of water through a transparent drain is being observed on steep slopes. Three regimes of flow below a hydraulic jump which is made to occur on these slopes are being studied to determine their effect on the design of tile drains.

(h) "The Hydraulics of Pipe Outlets for Tile Drains," by W. D. Lembke, Agricultural Engineering, Vol. 41, June 1960.

(3808) DEVELOPMENT AND REFINEMENT OF METHODS FOR ESTIMATING FIELD RUNOFF AND SOIL LCSS.

(b) Agricultural Research Service, U. S. Dept. of Agriculture, in cooperation with Purdue Agricultural Experiment station.

(c) Mr. Walter H. Wischmeier, ARS-SWC, Agr. Engr. Dept., Purdue Univ., Lafayette, Ind.

(d) Experimental; development.

(e) The relationships of numerous rainstorm. characteristics, topographic features, soil characteristics and surface conditions to field runoff and soil erosion are being evaluated from plot data obtained under natural rainfall. Basic plot and small watershed data on an individual storm basis have been assembled in an ARS central runoff and soil-loss data laboratory at Purdue University from 22 states. The data represent results of cooperative research studies over the past 32 years at 39 locations.

(g) A rainfall-erosion index has been derived which evaluates numerically the capacity of specific combinations nf rainstorm. characteristics to erode soil from farm fields. About 200 station rainfall records in the contiguous United States were analyzed to obtain probability values of the erosion index by geographic areas. Iso-erodent maps were prepared from these data. A soil-loss prediction procedure was developed which provides guide lines for conservation farm planning. Derivation of information needed for localized evaluations of the factors in the soil-loss equation is continuing.

(h) "Rainfall Energy and its Relationshin to Soil Loss," W. H. Wischmeier and D. D. Smith, Trans. Amer. Geo. Un. 39(2): 285-291 (1958).

"Evaluation of Factors in the Soil-Loss Equation," W. H. Wischmeier, D. D. Smith, and R. E. Uhland, Agr. Engin. 39(8): 458462 (1958).

"A Rainfall Erosion Index for a Universal Soil-Loss Equation," W. H. Wischmeier, Soil 
Sci. Soc. Proc. 23: 246-249 (1959).

"Cropping-Management Factor Evaluations for a Universal Soil-Loss Equation,"W. H. Wischmeier, Soil Sci. Soc. Proc. 24: 322326 (1960).

"A Universal Soil-Loss Equation to Guide Conservation Farm Planning," W. H. Wischmeier and D. D. Smith. Trans. VIIth Internat. Congress of Soil Science.

PURDUE UNIVERSITY, Chemical Engineering Department.

(3809) HEAT AND MASS TRANSFER TO VISCOUS LIQUTD FILMS.

(b) Purdue Research Foundation.

(c) Mr. W. H. Tucker, Chemical and Metallurgical Building, Purdue Univessity, Lafayette, Indiana.

(d) Experimental; design and applied research, master's and doctoral theses.

(e) (1) Concurrent flow systems (gas and liquid primarily). (2) Effect of surface tension on transfer of shear from high velocity gas to a liquid surface. (3) Liquid distribution in a packed bed in concurrent flow of gas and liquid. (4) Spinning disk liquid-gas contactor. (5) High velocity liquid for liquid-gas contacting.

(g) Surface tension shown to be very important in the transfer of shear from gas to liquid.

(h) One article is being prepared for publication.

(3810) HEAT AND MOMENTUM TRANSFER IN FLOW OVER ROUGHENED SURFACE.

(b) National Science Foundation.

(c) Mr. J. E. Myers, School of Chemical Engrg., Purdue University, Lafayette, Indiana.

(d) (1) Experimental and theoretical; basic and applied for doctoral theses.

(e) (1) The theoretical part is an investigation of solutions of the energy and momentum equations for flow over smooth and roughened flat plates. (2) The experimental part is a study of the relation between form drag, skin friction, and heat transfer on circular fins inside a pipe.

(g) A number of mathematical solutions have been found to the theoretical problems being investigated.

(h) Doctoral theses currently being prepared.

PURDUE UNIVERSITY, School of Civil Engineering.

(2839) HYDRAULICS OF RIVER FLOW UNDER ARCH BRIDGES.

(b) State Highway Department of Indiana and Bureau of Public Roads.

(c) Dr. J.W. Delleur, School of Civil Engrg., Purdue University, Lafayette, Indiana.

(d) Experimental; for design, for master's theses.

(e) The purpose of the research is to study systematically the hydraulic efficiency of waterways under arch bridges, to provide a criterion for determining the proper clear span of arch bridges so as to compensate for the loss of efficiency at high flows, and to provide a method for computing the backwater upstream of arch bridges.

(g) Preliminary small scale model investigation has been completed. Large scale testing of two and three dimensional semi-circular models in both smooth and rough boundaries without eccentricity, skew or entrance rounding is complete. The large scale tests were conducted in a tilting flume $5 \mathrm{ft}$. wide and $64 \mathrm{ft}$. long.

(h) "Design and Construction of Hydraulic Flume and Backwater Effects of Semi-Circular Constrictions in a Smooth Channel, " H. J. Owen, M. S. Thesis, January 1960. "Hydraulics of River Flow Under Arch Bridges, Progress Report No. 3, "P. F. Biery and J. W. Delleur, Joint Highway Research Project, Purdue University, Sept. $21,1960$.

"Hydraulics of River Flow Under Arch Bridges, "P. F. Biery and J. W. Delleur, A technical report given to A.S.C.E., Annual Convention, Boston, October 1960. "Hydraulies of Single Span Arch Bridge Constrictions," P. F. Biery, Master's Thesis, Purdue University, January 1961.

(2840) MECHANISM OF TURBULENCE IN FREE SURFACE FLOW.

(b) Purdue Research Foundation.

(c) Dr. J. W. Delleur, School of Civil Engrg., Purdue University, Lafayette, Indiana.

(d) Theoretical and experimental; for Ph.D. theses.

(e) Analytical and experimental investigation of the mechanism of turbulence in free surface flow. The analytical part of the project will investigate important flow characteristics such as the spectrum of turbulence, correlation of velocities in the turbulent field, degree of isotropy, and the various velocity functions in submerged jet and open channel flow. The experimental portion of the pagram will make tests coincident with theoretical studies.

(g) Precision test flume designed. The flume has variable longitudinal slope and the changeable cross section. The cross section may be rectangular or trapezoidal with different side slopes. Hot wire anemometer in progress.

(2841) STUDY OF RUNOFF FROM SMALL WATERSHEDS FOR HIGHWAY DRAINAGE DESIGN IN INDIANA.

(b) State Highway Department of Indiana.

(c) Dr. J.W. Delleur, School of Civil Engrg., Purdue University, Lafayette, Indiana.

(d) Analysis and statistical investigation for $\mathrm{Ph} . \mathrm{D}$. thesis.

(e) The purpose of the research is to study the hydrology of watersheds less than $200 \mathrm{sq}$. miles throughout the state of Indiana, to improve the existing methods 
for estimating the runoff from small watersheds, and to improve the present methods of design of highway drainage structures servicing small watersheds.

(g) Runoff and rainfall data are being collected, and runoff statistical and geomorphological analysis has been completed.

(3146) HYDROMECHANICS OF FLUID COLLECTOR SYSTEM IN POROUS MEDIA.

(b) Purdue Research Foundation.

(c) Dr. G. H. Toebes, School of Civil Engineering, Purdue University, Lafayette, Indiana.

(d) Theoretical, and experimental; for Ph.D. thesis.

(e) Analytical and experimental investigations of the flow domain around horizontal collector walls. Theoretical investigation includes development of the method of rigorous solution in three dimensions and solution of related two dimensional problems. Theoretical results will be supplemented by experimental data. Experiments will be made on hydraulic and electrolytic tank models.

(g) Review of related literature is completed. Method of rigouous theoretical solution and two dimensional solution of free surface flow toward an infinite horizontal sink strip are developed. Experiments on a preliminary hydraulic model are completed. New hydraulic model equipped with electric free surface probe is built.

\section{（3147） GEOHYDRAULICS.}

(b) Laboratory project.

(c) Messrs. J. W. Delleur and A. L. Simon, Hydraulic Laboratory, School of Civil Engrg., Purdue University, Lafayette, Indiana.

(d) Theoretical; basic research.

(e) Geohydraulic theory is being developed as a science based on Fluid Mechanics and Hydrogeology. Quantitative analyses are developed. A bibliography includes principal works of European scientists and others.

(f) Inactive.

(3491) NUMERICAL METHODS IN ANALYSIS OF HYDROMECHANICS PROBL.EM.

(b) Engineering Experiment Station, Purdue University .

(c) Dr. G. H. Toebes, Hydraulic Laboratory, School of Civil Engineering, Purdue Univ., Lafayette, Indiana.

(d) Analytical and applied research for $\mathrm{Ph} . \mathrm{D}$. thesis.

(e) The purpose of the research is to make available to the hydraulic engineers the mathematical tools which are normally beyond his competence. The techniques of solving numerically flood routing problems is in progress. The emphasis will be on methods making use of electric desk calculators, digital and analog computers.

(3492) TRAISIENT FLOW OF GROUND WATER WITH FREE SURFACE THROUGH INCLINED LAYERED SYSTEM. (b) Purdue Research Foundation.

(c) Dr. M. E. Harr, School of Civil Engrg., Department of Soil Mechanics, Purdue University, Lafayette, Indiana.

(d) Theoretical for Ph.D. thesis.

(e) The study is aimed at the development of a rational treatment of the "rapid drawdown" condition for the analysis of sloping core type earth and rockfill dams.

\section{(3493) SEEPAGE INTO SHEETED EXCAVATION.}

(c) Dr. M. E. Harr, School of Civil Engineering, Department of Soil Mechanics, Purdue Univ., Lafayette, Indiana.

(d) Theoretical.

(e) The closed form solution of the problem for the factor of safety with respect to heaving of the bsse of sheeted excavation and the quantity of seepage.

(f) Completed.

(g) A nomographic chart for solution of the equations reduces the results into a form directly applicable for design.

(h) Report submitted for publication to A.S.C.E. Soil Mechanies Division.

(3811) UNSTEADY FLOW OF GROUNDWATER INTO SURFACE RESERVOIR.

(c) Dr. M. E. Harr, School of Civil Engineering, Department of Soil Mechanics, Purdue Univ., Lafayette, Indiana.

(d) Discussion of published paper entitled as above by William Haushild and Gordon Kruse.

(h) Discussion to "Unsteady Flow of Groundwater into Surface Reservoir," by William Haushild and Gordon Kruse, Joumal Hydraulies Division, A. S. C. E., Vol. 86, No. HY 7, p. 13, July 1960.

PURDUE UNTVERSTIY, School of Electrical Engineering.

(3494) AN INVESTIGATION OF THE FFASIBILITY OF A MAGNETICALLY CONTROLIEDD POPPET VALVE HYDRAULIC SERVOMECHANTSM.

(b) Laboratory project.

(c) Dr. J. E. Gibson, School of Electrical Engineering, Purdue University, West Lafayette, Indiana.

(d) Experimental and analytical; basic research for master's thesis.

(e) This project includes the design, analysis and experimental testing of a method of controlling a hydraulic - mechanical energy converter by means of a time varying pressure source and two electro-magnetic poppet valves.

(f) Suspended

(g) Method has proved feasible to a limited degree.

(h) "An Investigation of an Electromagnetically Controlled Poppet Valve for Use in Pulse Length Modulated Hydraulic Automatic Control Systems," David E. Boddy, Master's thesis, Purdue University, Lafayette, Indiana, 109 pages, August 1960. 
PURDUE UNIVERSITY, Jet Propulsion Center.

(2374) THE MECHANISM OF TWO PHASE FLOW OF ANNULAR LIQUID FILMS IN A VERTICAL TUBE.

(b) Office nf Naval Research, Dept. of the Navy.

(c) Dr. M. J. Zucrow, Jet Propulsion Center, Purdue University, West Lafayette, Indiana.

(d) Experimental and theoretical; basic research for doctoral and masters theses.

(e) This problem is concerned with the analytical and experimental study of the mechanism of the downward flow of a liquid film on the inside wall of a vertical circular tube with co-current gas flow in the core of the tube. Systematic experiments were conducted for determining the effect of the rates of air and liquid upon the mean thickness of the liquid film and the pressure gradient in the gas stream.

(g) The effect of the viscosity of the liquia film upon film thickness was determined experimentally employing water and a 54\% glycerol water solution. For a given air velocity it was concluded that increasing the viscosity of the liquid forming the films increased the mean liquid film thickness for the same liquid flow rate. Correlating the data by plotting the thickness parameter vs. liquid Reynolds number was found to be reasonably satisfactory for large changes in the viscosity of the liquid. It was also observed that increasing the viscosity of the liquid in the film improved the film stability.

(h) "Viscosity Effects in Two Phase Annular Flow, "Hans H. Ammann, Thesis, M. E. School, Purdue University, Lafayette, Indiana, August 1960.

PURDUE UNIVERSIIY, School of Mechanical Engineering.

(3495) CONTROL OF TURBULENCE BY MEANS OF SCREENS.

(b) Laboratory project.

(c) Prof. J. B. Jones, School of Mechanical Engineering, Purdue University, Lafayette, Indiana.

(d) Experimental; basic research for master's thesis.

(e) This investigation concerns the control of turbulence intensity by means of screens without flow channel contraction. Variables considered are screen mesh, screen solidity, and the number of screens in series.

(f) Completed.

(g) Within the ranges of variables investigated (screen mesh $3 \times 3$ to $40 \times 40$, solidity ratio 0.29 to 0.51 , air velocity 22 fps to 66 fps) it was found that the minimum value of turbulence intensity obtained downstream of a series of screens depends on only the screen solidity ratio, with higher solidity ratios giving lower minimum turbulence values, and that the number of screens required to obtain the minimum value decreases with increasing solidity ratios.
(3812) TURBUI.ENI FLOW ALONG A CORNER.

(b) Laboratory project.

(c) Prof. J. B. Jones, School of Mech. Engrg., Purdue University, Lafayette, Indiana.

(d) Experimental; basic research for master's and doctoral theses.

(e) The purpose of this research is to gain an understanding of the mechanism of secondary flow in turbulent flow along a corner. Measurements will include directional turbulence intensities and turbulent shear quantities needed to evaluate current hypotheses on the cause of secondary flows.

(g) For boundary layers developing along a corner with zero pressure gradient, the isotach patterns (i.e., lines of constant velocity as shown on planes normal to the mean flow direction) are independent of free stream turbulence intensity in the range of 0.8 to 2.5 percent. Directional measurements of turbulence intensity show that the ratio of turbulence intensity parallel to an isotach to that normal to an isotach is always greater than unity and in the corner region increases with increasing isotach curvature.

(3813) TURBULENCE STRUCTURE IN DEVELOPING PIPE FLOW.

(b) Laboratory project.

(c) Prof. J. B. Jones, School of Mech. Engrg., Purdue University, Lafayette, Indiana.

(d) Experimental and analytical; basic research for doctoral theses.

(e) The structure of turbulent shear flow is being studied by investigating developing boundary layers in pipes. One phase of the research is a study of the flow in the inlet region of a smooth pipe. Another is a study of the changing boundary layer between fully developed turbulent flow in a smooth pipe and fully developed flow in an artificially roughened section of the pipe.

(3814) DISPLACEMENT EFFECTS OF TRANSVERSE CYLINDRICAL TOTAL PRESSURE PROBES.

(b) Laboratory project.

(c) Prof. J. B. Jones, School of Mech. Engrg., Purdue University, Lafayette, Indiana.

(d) Experimental; applied research for master's thesis.

(e) The purpose of this research is to determine the characteristics of small cylindrical total pressure probes for measurements in steep gradients very close to a wall.

PURDUE UNIVERSITY, Automatic Control Laboratory, School of Mechanical Engineering.

(3815) EXPERIMENTAL AND THEORETICAL STUDIES OF HYDRAULIC LINES AND COMPONENTS.

(b) Natl. Aeronautics and Space Administration.

(c) Dr. Rufus Oldenburger, Head, Automatic 
Control Lab., School of Mech. Engineering, Purdue University, W. Lafayette, Ind.

(d) Applied research.

(e) This investigation is concerned with the study of dynamic behavior of hydraulic lines, accumulators, valves, etc. High frequency flow inputs to small hydraulic lines and analysis of pressure and flow phenomenon along the line with various boundary conditions is the initial work being started. The effects of friction and turbulence are being considered. Theoretical studies are being undertaken for the dynamic behavior of other hydraulic components as well as the small lines. It is planned within the next year to start experimental work on other hydraulic components in addition to lines.

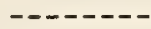

REED RESEARCH FOUNDATION.

(3148) THE STREAMING OF BLOOD IN VEINS AND ARTERIES OF LIVING ANTMALS.

(b) National Heart Institute, under Grants $\mathrm{H}-2402$ ( c 3) and $\mathrm{H}-2263$ ( c 3).

(c) Mr. Johann Martinek, Reed Research Foundation, 1048 Potomac Street, N. W., Wash., D. C.

(d) Theoretical; basic research.

(e) Steady and non-steady flow of viscous liquid in rigid and elastic tubes.

(g) The mathematical nature of the tube walls has been partly established in Part I. In the present study (continuation of Part I), the possible physical interpretations of the tube walls based on the mathematical forms obtained lead to vortex lines of helical shapes forming a cylindrical sheet concentric with the tube axis. These, and additional singularities, providing for a simply connected domain (the tube being assumed as multiconnected region, like anchor ring) have been found necessary to render uniquely the fluid resistance in the tube. Numerical computations are now being performed to establish amount of slip and drag. Preliminary results indicate with specific physical data used in particular relation to the nature of blood, that slip on walls is of smaller order of magnitude than maximum fluid velocity at pipe center, hence beyond detection by fluid dynamical experimentation.

(h) "On the Streaming of Blood in Rigid Tubes," by Johann Martinek, to be submitted to the Bulletin of Mathematical Biophysics 1960.

\section{ROCKY MOUNTAIN HYDRAULIC LABORATORY.}

(2140) EVALUATION OF OPEN-CHANNEL FRICTION LOSSES.

(b) National Science Foundation, Water Resources Division of the U. S. Geological Survey, and the State University of Iowa cooperating.

(c) Prof. C. J. Posey, Allenspark, Colorado (summer); State Univ. of Iowa, Engineering
Building, Iowa City, Iowa (winter).

(d) Experimental; basic.

(e) Variable-slope flume long enough to permit accurate evaluation of open-channel friction losses is being tested at slopes into the steep range, determining normal depth and velocity distribution for batten and rolled natural-type roughnesses in triangular and trapezoidal cross-sections.

(f) Active experimentation during summers.

(h) "Water Surface Profiles and Velocity Distributions for Flow in a Long Uniform Channel," R. W. Powell and C. J. Posey. R.M.H.L. Report No. 25 (in press).

"Boundary Shear in a Triangular Open Channel," J. J. Mairena. M. S. Thesis, State University of Iowa, August, 1960, (available on loan).

\section{(3496) TESTS OF RIPRAP SCOUR PROTECTION.}

(b) Standard Oil Company of Texas.

(c) Prof. C. J. Posey, Allenspark, Colorado (sumer). State Univ. of Iowa, Engineering Building, Iowa City, Iowa (winter).

(d) Experimental; design development.

(e) To find economical design of riprap to protect offshore drilling structure from underscour.

(f) Active experimentation during summers.

(g) Model-prototype similitude for unusual type of erosion achieved by the use of Gilsonite.

\section{ST. ANTHONY FALLS HYDRAULIC LABORATORY, UNIVERSITY} OF MINNESOTA.

Inquiries concerning project Nos. 2144, 3152, 3153, $3156,3158,3160,3161,3164,3497,3499,3501$, $3502,3503,3504$, and 3816 to 3824 should be addressed to Dr. Lorenz G. Straub, Director, St. Anthony Falls Hydraulic Laboratory, Mississippi River at Third Avenue S. E., Minneapolis 14, Minn.

Inquiries concerning project Nos. 111, 1168, and 2386, which are conducted in cooperation with the Agricultural Research Service, should be addressed to Mr. Fred W. Blaisdell, Project Superviosr, Watershed Technology Research Branch, Soil and Water Conservation Research Division, Agricultural Research Service, St. Anthony Falls Hydraulic Laboratory, Minneapolis 14, Minnesota.

Inquiries concerning Project No. 194, which is conducted in cooperation with the Corps of Engineers and the U. S. Geological Survey, should be addressed to Engineer in Charge, Byrnon Colby, Federal InterAgency Sedimentation Project, St. Anthony Falls Hydraulic Laboratory, Mississippi River at Third Ave., Minneapolis 14, Minnesota.

\section{(11l) CLOSED CONDUIT SPILLWAY.}

(b) Agricultural Research Service, U. S. Department of Agriculture in cooperation with the Minnesota Agricultural Experiment Station and the St. Anthony Falls Hydraulic Laboratory.

(a) Experimental; generalized applied research for development and design. 
(e) A two-sided drop inlet having a width equal to the pipe diameter and a variable length is currently being tested. The anti-vortex device consists of a horizontal plate supported by end piers above the crest of the arop inlet. The characteristics, performance, losses, and pressures in the drop inlet and on the anti-vortex plate are being determined for various combinations of drop inlet length, and height and overhang of the anti-vortex plate. Water is used as the model fluid to determine the performance characteristics, and head-discharge relationships during flows of waterair mixtures. For full flow, air is used as the model fluid to determine the various energy loss coefficients and the pressure coefficients.

(g) The theory of closed conduit spillways has been developed, verified, and published. Resurts of tests on many forms of the closed conduit spillway entrance have been published. Pipe culverts laid on steep slopes may flow completely full even trough the outlet, discharges freely. Generalized methods for analysis and reporting of the results have been developed. The use of air as the model fluid has been verified by comparing test results with those obtained using water as the model fluid. The arop inlet with the horizontal anti-vortex device causes the spillway to act as a self-regulating siphon when the headpool level approximates the anti-vortex plate elevation. The height of the anti-vortex plate above the drof inlet crest and the overhang of the anti-vortex plate determine the effectiveness of the plate as an antivortex device.

(h) "Hood Inlet for Closed Conduit Spillways," by Fred W. Blaisdell, American Society of Civil Engineers Proceedings Volume 86 No. HY 5, pp. 7-31, May 1960.

\section{(I168) A STUDY OF CANTILEVERED OUTLETS.}

(b) Agricultural Research Service, U. S. Department of Agriculture, in cooperation with the Minnesota Agricultural Experiment Station and the St. Anthony Falls Hydraulic Laboratory.

(d) Experimental; generalized applied research for design.

(e) Pipe outlet conduits for small spillways are frequently cantilevered beyond the toe of the earth dam. Attempts will be made to determine quantitatively the size of the scour hole to be expected under various field conditions.

(f) Suspended.

\section{(1929) DRAIN TILE JUNCTION LOSSES.}

(b) Minnesota Agricultural Experiment Station in cooperation with the Agricultural Research Service, U. S. Department of Agriculture and the St. Anthony Falls Hydraulic Laboratory.

(c) Prof. Philip W. Manson, University of Minn., St. Paul Campus, St. Paul, Minnesota.

(d) Experimental; generalized applied research for design.

(e) The junction losses in arain tile flowing full are determined for laterals of different sizes entering mains of different sizes at various angles. The laterals enter the main at the center line. Additional tests have been made with the crowns (or inverts) of both main and lateral in the same plane.

(f) Completed.

(g) Tests have been completed on sharp edge junctions entering the main at angles varying in 15 degree increments from 15 degrees to 165 degrees. Both the lateral and the main are completely full. The tests cover all possible combinations of discharge in the lateral and the main. Laterals having areas $1 / 1,1 / 2,1 / 4,1 / 7$, and $1 / 16$ that of the main have been tested. The data are being analyzed and a comprehensive report is in preparation. A color motion picture film entitled "Energy Losses at Converging Pipe Junctions" has been completed and is available. The $16 \mathrm{~mm}$ film is 800 feet long.

(h) "Loss of Energy at Sharp-Edged Pipe Junctions" by Fred W. Blaisdell and Philip W. Manson. Submitted for publication.

(2144) EXPERIMENTAL AND ANALYTICAL STUDIES OF HYDROFOILS.

(b) Office of Naval Research, Dept. of the Navy.

(d) Experimental and analytical; basic research.

(e) Investigation of the quantity of air required to create and sustain an inflated cavity on a submerged hydrofoil of finite span.

(g) Experimental investigations utilizing TulinBurkart supercavitaiing sections submerged below a horizontal free-surface have indicated that by introducing air to the foil a small cavitation number can be obtained at relatively low velocities. For small air flows supplied to the cavity, the resulting cavitation number is roughly proportional to the air flow. A reentrant jet was observed for these conditions. As the air flow was increased, the reentrant jet, disappeared and the cavity appeared to vibrate. From this point, an increase in air flow resulted in very little reduction of the cavitation number. The actual mechanism by which air leaves the cavity is being investigated. Lift force measurements made for these sections extrapolated to zero cavitation number agree satisfactorily with theory.

(2386) GENERALIZED DESIGN OF TRANSITIONS FOR SUPERCRITICAL VELOCITIES.

(b) Agricultural. Research Service, U. S. Dept. of Agriculture, in cooperation with the Minnesota Agricultural Experiment Station and the St. Anthony Falls Hydraulic Lab.

(d) Experimental; generalized applied research for development and design.

(e) Studies will be made to develop a transition and to determine the rules for its design. The transition will be used to 
change the flow cross section from clrcular to rectangular when the velocities are supercritical.

(f) Suspended.

(3152) KARADJ REREGULATING SPILLWAY MODEI, STUDIES.

(b) Harza Engineering Company, Chicago, Ill.; Governemnt of Iran.

(d) Experimental; design and operation.

(e) A l:60 scale model of Karadj Reregulating Dam and Spillway to study the operation of the spillway. A $1: 180$ pilot model and a 1:78 scale section model were also used.

(f) Tests completed.

(g) Recommendation of a deeply submerged flip bucket to replace ski jump design proposed.

(3153) FLOW ABOUT BODIES AT SMALL CAVITATION NUMBERS.

(b) Office of Naval Research, Department of the Navy.

(d) Experimental and analytical; basic research.

(e) Current interest is in unsteady supercavities and in a cavity noise. Both natural and ventilated cavities are understudy.

(3156) WANAPUM SPILLWAY STUDIES.

(b) Harza Engineering Company, Chicago; Public Utility District of Grant County, Ephrata, Washington.

(d) Experimental; design and operation.

(e) A 1:144 scale partial comprehenslve model for Wanapum Power Project on Columbia River to arrive at optimum alignment of the earth fill dam and optimum exterior geometry for fish passing facilities.

(3158) FLOATING BREAKWATERS.

(b) U. S. Naval Civil Engineering Laboratory, Department of the Navy, Eleventh Naval District.

(d) Experimental and analytical.

(e) Primarily a study whose objective is to develop new ideas for floating type devices intended to attenuate ocean type incident waves.

(f) Completed.

(g) Tests indicate that immersed bags of suitable form fill, and position can effectively attenuate waves.

(h) "An Experimental Study of Flexible Floating Breakwaters," by John F. Ripken, St. Anthony Falls Hydraulic Laboratory, Univ. of Minnesota, Technical Paper No. 31-B, 40 pages, October 1960.

(3160) MISSION DAM SPILLWAY MODEL STUDIES.

(b) B. C. Engineering Company, Vancouver, B. C., Canada.

(d) Experimental; design and operation.

(e) A 1:80 scale comprehensive model of the flip bucket spillway for the Mission Dam on the Bridge River in British Columbia to study the operation of the spillway.

(f) Tests completed.

(g) Recommendation of a non-symmetrical flip bucket deflector giving a high degree of dispersion.

\section{(3161) HYDRAULICS OF SEWER DROPSHAFTS.}

(b) City of St. Paul, Minnesota.

(d) Experimental; applied.

(e) Investigate relative merits of sewer drop structures for discharges up to $1000 \mathrm{cfs}$ and drops up to about 100 feet.

(f) Test work completed.

(g) Impact type energy dissipator developed to stabilize flow and eliminate air from lower interceptor line. Report in progress.

(3164) SCOUR AROUND BRIDGE PIERS.

(b) Laboratory project.

(d) Experimental and analytical; Ph.D. thesis.

(e) Prediction and measurements of ultmmate depths of scour around known shape and size of pier.

\section{(3497) WANAPUM FISH FACILITIES STUDIES.}

(b) Harza Engineering Company, Chicago, Ill.; Public Unility District of Grant County, Ephrata, Washington.

(d) Experimental; design and operation.

(e) Two 1:36 scale models of right bank attraction water flow system and orifice and weir fish entrances for design verification and comparison of effectiveness of orifice versus weir entrances.

(f) Test work completed.

(3499) STUDIES OF HYDROFOIL CONFTGURATIONS IN REGULAR WAVES.

(b) David Taylor Model Basin, Department of the Navy.

(d) Experimental.

(e) Experimental investigation of the longitudinal stability (heave and pitch) of a tandem " $V$ " foil hydrofoil configuration for regular head and following seas to verify existing non-linear theory.

(g) Satisfactory agreement has been obtained between experimental heave and pitch responses of a tandem " $\mathrm{V}$ " foil configuration and solutions of non-linear differential equations developed by Ogilvie for head and following seas and craft velocities of 5 and 10 fps. For small wave amplitudes, the linearized equations adequately describe the heave and pitch responses. The solutions to the nonlinear equations indicate a steady-downward heave component that tends to cause the craft to crash, particularly in following seas. This component has been observed experimentally, although the actual magnitude has not been satisfactorily determined.

\section{(3501) PEARL RIVER RESERVOIR SPILLWAY STUDIES.}

(b) Harza Engineering Company, Chicago; Horace B. Lester, Engineer, Jackson, Mississippi; Pearl River Valley Water Supply District.

(d) Experimental; design and operation.

(e) A 1:60 spillway section model to arrive at optimum design of the 10 gate low head 
spillway. A 1:72 comprehensive model to study the overall hydraulics of the spillway.

(f) Project completed.

(g) Incorporation of a flat apron with staggered chute blocks and baffle blocks based on the SAF type design was recommended. Data was obtained on discharge rating for the crest with the tainter gates open and partly open.

\section{(3502) MANGLA SPILLWAY STUDIES.}

(b) Harza Engineering Company, Chicago; Binnie, Deacon, and Gourley, London; Government of Pakistan.

(d) Experimental; design and operation.

(e) A 1:300 scale spillway model of two stage stilling basin energy dissipator, a comprehensive study of all important hydraulic features. A 1:216 scale section model consisting of two control structure gates, a study of pressures on gate and gate calibration. Typical dimensions of earth fill dam spillway include a drop in water level of 330 feet and a design discharge of $1,100,000 \mathrm{cfs}$.

\section{(3503) ARKANSAS RIVER DEVELOPMENT SEDIMENT STUDIES.}

(b) U. S. Army Engineer District, Little Rock.

(d) Experimental; design.

(e) To investigate the feasibility of constructing an armor layer on the bed of a stream to stabilize the bed and prevent degradation.

(g) Results suggest that the armor material will stabilize the bed under certain conditions.

(3504) EXPERIMENTAL DETERMTNATION OF UNSTEADY LIFT AND DRAG FORCES ON DIHEDRAL HYDROFOILS IN WAVES.

(b) David Taylor Model Basin, Department of the Navy.

(d) Experimental, basic research.

(e) General investigation of the forces on dihedral, surface-piercing hyorrofoils in regular waves. This includes a study of the forces on a hydrofoil placed in the wake of another, as would be the case in a tandem configuration.

\section{(3816) NECUIMA RIVER DIVERSION STUDIES.}

(b) Corporacion Venezolana De Fomento, Caracas, Venezuela.

(d) Experimental; design and operation.

(e) Study of schemes for river diversion for Necuima storage dam on Caroni River, Venezuela, based on tests on a 1:200 scale, rigid bed model of one projected site.

Section model tests of closure by friction control were also made.

(f) Completed.

(g) Data on the feasibility of closure by friction control was obtained.

(3817) BROKOPONDO SPILLWAY STUDIES. (b) Suriname Aluminum Company, Suriname; Harza Engineering Company, Chicago.

(d) Experimental; design and operation.

(e) 1:164 scale spillway section model and a 1:100 scale comprehensive model of the site for the Brokopondo hydroelectric Project on the Suriname River to check the hydraulics of the spillway and associated features during diversion as well as full pool operation.

(f) Completed.

(g) Recommended reduction in height of side walls of the sloping spillway apron in interest of economy. Provided rating curves for the ogee crest with tainter gates open and partly open.

\section{(3818) EVALUATION TESTS OF WAVE ABSORBERS.}

(b) U. S. Rubber Company.

(d) Experimental.

(e) Experimental evaluation of wave height attenuation and mooring force characteristics of floating wave absorbers of flow resisting structure.

(f) Completed.

(g) Tests establish effective attenuation characteristics of material and provide data for prototype design.

(h) "Evaluation Studies of the U. S. Rubber Company Wave Blanket and Wave Trap" by John F. Ripken, St. Anthony Falls Hydraulic Laboratory, University of Minnesota, Project Report No. 62, 40 pages, October 1960.

(3819) DESIGN STUDIES FOR SOUTH SASKATCHEWAN RIVER PROJECT.

(b) Canada Department of Agriculture, Prairie Farm Rehabilitation Administration, Regina, Saskatchewan.

(d) Experimental; applied research.

(e) Experimental studies of the preliminary design of components of the diversion tunnel system and spillway system of South Saskatchewan River Project.

(g) Preliminary tests of the diversion system showed good agreement between computed and measured curves relating pool elevation and discharge.

(3820) MODEL STUDIES OF CHUTE NO. 2 AT ST. ANTHONY FALLS.

(b) Northern States Power Company, Minneapolis.

(d) Experimental; applied.

(e) Experimental study of various methods for reduction of bed scour below existing Chute No. 2.

(g) A stilling basin of the SAF type was developed and tested; erosion was materially reduced. Other proposals are also being tested, including a horizontal segment of chute located at the water surface and fitted with terminal blocks.

(3821) STRUT INTERFERENCE EFFECTS ON HYDROFOIL SYSTEMS.

(b) Office of Naval Research, Bureau of Ships. 
(d) Experimental; applied research.

(e) Investigation of the interference effects of supporting struts on the lift and drag forces of typical hydrofoil configurations.

\section{(3822) FLOW OVER VIBRATING PLATES.}

(b) Office of Naval Research, Dept. of the Navy.

(d) Experimental; applied research.

(e) Studies in a partly closed high velocity channel equipped with a plate which can be vibrated as a beam with several different resonant frequencies to determine if vibrations have an effect on boundary layer development.

(3823) SIMILAR AND QUASI-SIMILAR SOLUTIONS OF THE BOUNDARY LAYER EQUATIONS FOR TWODIMENSIONAL INCOMPRESSIBLE FLOWS.

(b) Laboratory project.

(d) Theoretical and experimental, for Ph.D. thesis.

(e) Similar velocity profile solutions of the boundary layer equation were studied in the $(x, y)$ and $(x, x)$ planes. Special attention was given to two-component flow problems. Experimental work necessary to support theoretical results was also conducted.

(f) Completed.

(g) It was found that similar solutions of the boundary layer equations in $(x, y)$ plane are also similar in the $(x, x)$ plane. Following problems were solved as examples in $(x, x)$ plane: (1) Laminar jet, (2) flat plate boundary layer and (3) laminar flow at the interface of two fluids of different viscosity and density. Experimental data were also obtained confirming the solution to the last problem. The existence of similar perturbation velocity profiles in the $(x, y)$ plane were also investigated and applied to the problem of the laminar wake and to the problem of laminar flow at the interface of two fluids.

(h) "Similar and Quasi-Similar Solution of the Boundary Layer Equations for Two-Dimensional Incompressible Flows" by Chieh-Shyang Song, a thesis submitted to the faculty of the University of. Minnesota in partial fulfillment of the requirements for the Ph.D. degree.

(3824) SURFACE CHARACTERISTIC OF ATR ENTRATNED FLOW IN STEEP CHANNELS.

(b) Laboratory project.

(d) Experimental and theoretical investigation of the wrinkling of the free surface of flow in steep channel and its influence on air concentration and velocity distribution. Thesis for $\mathrm{Ph} . \mathrm{D}$.

(e) Experimental investigation is being carried out on the SAF high velocity channel for slopes up to $53^{\circ}$. Velocities are measured by means of a pitot tube and high speed photography. Air concentration is measured by the SAF concentration meter. The surface elevation is measured by a device which measures the avarage time the surface is above a given elevation.

INTER-AGENCY SEDIMENTATION PROJECT IN COOPERATION WITH ST. ANTHONY FALLS HYDRAULIC LABORATORY.

\section{(194) A STUDY OF METHODS USED IN MEASUREMENT AND} ANALYSIS OF SEDIMENT LOAD IN STREAMS.

(b) Subcomittee on Sedimentation, Inter-Agency Committee on Water Resources. Personnel of the U. S. Army Corps of Engineers and the U. S. Geological Survey are actively engaged on the project.

(c) Engineer in Charge, Bymon C. Colby, Federal Inter-Agency Sedimentation Project, St. Anthony Falls Hydraulic Laboratory, Mississippi River at Third Avenue S. E., Minneapolis 14, Minnesota.

(d) Experimental; applied research and development.

(e) Drawings and specifications to facilitate the manufacture of suspended-sediment and bed-material sampler, particle-size analyzers and associated laboratory apparatus are available. Approved designs of suspended-sediment samplers include a singlestage sampler, a 4-pound hand sampler, a 22-pound hand-line sampler, a 62-pound medium weight sampler, and electrically operated samplers weighing 100 and 300 pounds. Bed-material samplers include a piston type hand-operated sampler, a 30pound hand-line sampler, and a 100-pound sampler for cable suspension. Other instruments developed include a sediment sample splitter, a bottom-withdrawal sedimentation tube for size analyses, and a visual-accumulation sedimentation tube with recording equipment for particle size analyses of sands. The primary objective of the current program is the development of an instrument to automatically record suspended-sediment concentrations in flowing streams.

(g) A final report is being prepared on the single-stage suspended-sediment sampler developed for ephemeral type streams. Samplers of this type have been installed at several experimental sites. Prototype tests were continued on an intermittent pumping and settling type sediment sampler, and results are favorable. Field tests were continued on the nuclear sediment density probe and scaler unit but dependable operation has not yet been attained. Laboratory tests were continued on equipment using the diffusion of light as a measure of solids in suspended sediment samples. Preliminary tests were made on an electronic sensing instrument. Particles suspended in a mild electrolyte interrupt a fixed impedance as they pass through a small orifice producing voltage fluctuations proportional to particle size. These pulsations are electronically scaled and counted

(h) "Intermittent Pumping - Type Sampler," Report N, February 1960.

"Instructions for Sampling with US D-49 Suspended-Sediment Samplers," Report 0, 6 pages, March 1960. 
SCRIPPS INSTITUTION OF OCEANOGRAPHY, University of California.

\section{(3825) GENERATION AND PROPAGATION OF INTERNAL WAVES.}

(b) Laboratory project.

(c) Mr. Charles Cox, Scripps Institution of Oceanography, La Jolla, California.

(d) Experimental and theoretical basic research.

(e) Observations of temperature fluctuations as functions of depth from surface to bottom of the sea are made at an array of automatically recording stations. Analysis in terms of internal waves of various modes within a spectrum of frequencies at each station permits estimation of pattern of radiation of internal waves. Theoretical studies suggest the importance of conversion of tidal energy into internal motions by interaction with a rough sea bottom. Experimental investigation of this process will permit estimation of the flow of energy between wave modes and its ultimate fate.

(g) Theoretical results suggest that a moderate fraction of tidal energy can be converted into internal motions in one tidal cycle.

(h) "Coupling of surface and internal tides," C. S. Cox, Preprints, International Oceanographic Congress, pp. 399-400, 1959.
(DTMB technical supervision).

(c) Dr. H. N. Abramson, Director, Department of Applied Mechanics, Southwest Research Institute, 8500 Culebra Road, San Antonio 6, Texas.

(d) Experimental, theoretical; applied research.

(e) Present work includes the design, construction, and testing of flexible hydrofoil models to obtain data on unsteady hydrodynamic lift and moment for a variety of operating conditions.

(h) "Hydroelasticity: A New Naval Science," S. R. Heller and H. N. Abramson, Jour. Am. Soc. Naval Engrs., 71, 205-209, May 1959. "Effect of the Free Surface on the Flutter of Submerged Hydrofoils," by W. H. Chu and H. N. Abramson, Jour. Ship Research, 3, 20-27, June 1959.

"An Alternative Formulation of the Problem of Flutter in Real Fluids," by W. H. Chu and H. N. Abramson, Jour. Aero/Space Sci., 26, 683-684, October 1959,

"A Discussion of the Flutter of Submerged Hydrofoils," by H. N. Abramson and W. H. Chu, Jour. Ship Research, 3, 5-13, October 1959.

"Disturbance of Rudder-Excited Hull Vibration on U.S.S. Forrest Sherman - A Problem in Hydroelasticity," by H. N. Abramson, Trans. SNAME, 67, 362-365, 1959.
SOUTHWEST RESEARCH INSTITUTE, Department of Applied Mechanics.

\section{(3826) HYDRODYNAMICS OF SHIP SLAMMING.}

(b) Bureau of Ships, Department of the Navy (DTMB technical supervision).

(c) Dr. H. N. Abramson, Director, Department of Applied Mechanics, Southwest Research Institute, 8500 Culebra Road, San Antonio, Texas.

(d) Theoretical; applied research.

(e) Study of pressure distribution on bodies of arbitrary cross-section entering a plane water surface.

(h) Three SwRI technical reports.

(3827) STUDTES OF TURBULENT FLOW.

(b) Laboratory project.

(c) Mr. William Squire, Senior Research Engr., Department of Applied Mechanics, Southwest Research Institute, 8500 Culebra Road, San Antonio 6, Texas.

(d) Theoretical; basic research.

(e) Studies of several classical problems by means of a new generalized theory of turbulent flow.

(f) Completed.

(h) "A Unified Theory of Turbulent Flow. I. Formulation of the Theory," by W. Squire, App. Sci. Res., A 8, 158, 1959.

"A Unified Theory of Turbulent Flow. II. Plane Couette Flow," by W. Squire, App. Sci. Res., A9, 393-410, 1960.

\section{(3828) STUDIES IN HYDROELASTICITY.}

(b) Bureau of Ships, Department of the Navy
STANFORD UNIVERSITY, Department of Civil Engineering.

(1944) STUDY OF METHODS OF ESTIMATING RESERVOIR EVAPORATION.

(b) U. S. Weather Bureau.

(c) Prof. Joseph B. Franzini, Dept. of Civil Engineering, Stanford University, Stanford California.

(d) Field investigation; applied research.

(e) An attempt is being made to develop a simple rugged radiation integrator for use in estimating reservoir evaporation. Three small-scale radiation integrators patterned after Curming's model have been tested and the data have been analyzed.

(g) Preliminary results indicate that use of energy budget approach to small insulated evaporation pans shows promise for the measurement of net radiation.

(h) "Progress Report on Radiation Integrator Research," by Joseph B. Franzini and Walter F. Rowland, Dept. of Civil Fingineering, Stanford University, May 1960.

\section{(1946) SYNTHESIS OF HYDROGRAPHS FOR SMALL AREAS.}

(b) National Science Foundation.

(c) Prof. Ray K. Linsley, Dept. of Civil Engrg., Stanford University, Stanford, California.

(d) Theoretical and field investigation; basic and applied research; Ph.D. thesis.

(e) An attempt to develop a universal method for estimating the runoff hydrographs from small areas.

(f) A simplified theory for non-equilibrium conditions has been compared with experimental results taken under controlled 
laboratory conditions. A statistical analysis of data from several typical basins has been started. A mathematical analysis of the non-equilibrium flow in a simple channel with lateral inflow has been completed. The later work is being extended to more complex conditions via digital computing methods. Statistical and computer methods are being explored to develop a basis for reliable estimates of runoff frequency.

(h) "Computation of a Synthetic Streamflow Record on a Digital Computer," by Ray $\mathrm{K}$. Linsley and Norman H. Crawford, Publication No. 51, International Assoc. of Scientific Hyårology, pp. 526-538, 1960.

(2151) MODEL STUDY OF PETERS DAM CHUTE SPILLWAY.

(b) Laboratory project.

(c) Prof. John K. Vennard, Dept. of Civil Engineering, Stanford University.

(d) Experimental; engineer thesis.

(e) Comparison of spillway performance and design predictions.

(g) Experimental work completed; thesis being written.

(2614) PIPE FRICTION IN UNSTEADY FLOW.

(b) Laboratory project.

(c) Prof. John K. Vennard, Dept. of Civil Engineering, Stanford University.

(d) Experimental and analytical; Ph.D. thesis.

(e) Comparison of friction processes for steady and unsteady states.

(g) Experimental work completed and analyzed; thesis being written.

(2863) FLOW THROUGH POROUS MEDIA.

(b) National Science Foundation.

(c) Prof. Byrne Perry, Dept. of Civil Engineering, Stanford University, Stanford, Calif.

(d) Theoretical and experimental, basic research.

(e) New analytical methods are being developed for ussteady seepage flow with a free surface, e.g., the seepage through an earth dam. The effect of non-rectilinear boundaries is also being considered.

(g) Theoretical work in progress.

(h) "Unsteady Flow Through an Underdrained Earth Dam," by Roger J. M. DeWiest, J. Fluid Mechanics, Vol. 8, pt. 1, pp. 1-9, 1960 .

(3166) HYDRODYNAMLCS OF FLOW INTO CURB INLETS.

(b) U. S. Bureau of Public Roads.

(c) Prof. John K. Vennard and Prof. Byrne Perry, Dept. of Civil Engineering, Stanford University, Stanford, California.

(d) Experimental and analytical; Ph.D. thesis.

(e) A hydrodynamic theory has been developed for predicting the flow from a smooth, undepressed gutter into a curb opening inlet which intercepts $100 \%$ of the flow. Experimental confirmation is given.

(f) Completed.

(h) "Hydrodynamics of Flow into Curb-Opening
Inlets," by Richard J. Wasley, Tech. Report No. 6, Dept. of Civil Engineering, Stanford University, November 1960.

\section{(3507) STUDY OF INFILTRATION.}

(b) Graduate research; doctoral thesis.

(c) Prof. Joseph B. Franzini, Dept. of Civil Engineering, Stanford University, Stanford, California.

(d) Theoretical investigation; laboratory and field studies.

(e) An attempt will be made to develop analytically relations between soil parameters, precipitation rates and duration, and infiltration capacities. The analytical work will be supplemented by laboratory and field studies.

(f) Project is underway.

\section{(3508) EVAPORATION SUPPRESSION.}

(b). U. S. Public Health Service.

(c) Prof. Joseph B. Franzini, Dept. of Civil Engineering, Stanford University, Stanford California.

(d) Laboratory and field investigations; engineer thesis.

(e) Project currently consists of: (1) Laboratory studies using Langmuir tray to find the monomolecular film with optimum healing properties. (2) Field studies using Class A evaporation pans and smaller containers to evaluate the evaporation reduction capabilities and biological attrition resistances of the various monomolecular films tested in (1). (3) Development of a practical method for the application of a monomolecular film to the surface of a reservoir. In later stages of the project the effect of a monomolecular film on the biota in a 45 acre lake will be evaluated.

(g) Furl scale field tests using hexadecanol on the 45 acre lake during the summer of 1960 gave an evaporation reduction of 18 percent.

STEVENS INSTITUTE OF TECHNOEOGY, Davidson Laboratory.

\section{(2154) INVESTIGATION OF SHIP MOTTONS.}

(b) Office of Naval Research, Department of the Navy.

(c) Prof. Edward V. Lewis, Davidson Laboratory, Stevens Institute of Technology, 711 Hudson Street, Hoboken, New Jersey.

(d) Theoretical and experimental; basic research.

(e) The development of a method of calculation for predicting ship motions caused by head or following seas. Towing tank tests of ship forms differing widely from the forms currently used in practice, in search of corsiderable improvement in seakeeping qualities of ships.

(g) Towing tank tests of seni-submerged vessel for high-speed operation in waves have been completed. Towing tank tests of a slender 
craft fitted with large bulbs under the keel at bow and stern have been made in calm water and in irregular head and following seas. Analog computer studies have been made of the calm water stability characteristics of a craft similar to a shallowrunning submarine with a fixed surfacepiercing strut at intermediate and extreme speeds. Studies of other unusual hull types are planned.

(h) "Preliminary Evaluation of a Semi-Submerged Ship for High-Speed Operation in Rough Seas," E. V. Lewis and C. Odenbrett, Journal of Ship Research, Vol. 3, No. 4, March 1960.

"High Speed Supercritical Ships in Rough Seas," E. V. Lewis and P. R. Van Mater, Proceedings of Third Summer Seminar on Ship Behavior at Sea, Stevens Institute of Technology, June 1960.

"Semi-Submerged Ships for High Speed Operation in Rough Seas," E. V. Lewis and J. P. Breslin, Proceedings of Third Symposium on Naval Hydrodynamics, Office of Naval Research - Netherlands Ship Model Basin, Scheveningen, The Netherlands, Sept., 1960.

(2155) SEAKEEPING QUALITIES OF SHIPS AT ALL HEADINGS TO WAVES.

(b) Bureau of Ships, Department of the Navy (DTMB Technical Supervision).

(c) Prof. Edward V. Lewis, Davidson Laboratory, Stevens Institute of Technology, 711 Hudson Street, Hoboken, N. J.

(d) Theoretical and experimental; basic research.

(e) To investigate the coupled responses of ship models at all headings to waves in order to assist in the prediction of seakeeping qualities and to evaluate means of reducing or controlling ship motions so as to increase sea speeds. A selfpropelled and rudder-controlled ship model is being tested at various headings to both regular and irregular long-crested waves. Coupled motion responses are being measured and parallel analytic studies are being made of equations of motion for ships with six degrees of freedom. Stability and control are also being studied.

(g) In oblique seas pitching and heaving motions follow a predictable pattern with no perceptible effect from rolling or yawing. In irregular seas having a broad spectrum the head sea condition is the most serious for pitching. Large leeway angles are encountered at certain headings to short waves and irregularities in rolling occur when the natural period is approximately double the encounter period.

(h) "Ship Motions in Oblique Seas," E. V. Lewis and E. Numata, Transactions of the Society of Naval Architects and Marine Engineers, Vol. $68,1960$.

\section{(2387) BENDING MOMENT OF SHIPS IN WAVES.}

(b) Society of Naval Architects and Marine Engineers.

(c) Prof. Edward V. Lewis, Davidson Laboratory,
Stevens Institute of Technology, 711 Hudson Street, Hoboken, N. J.

(d) Experimental and analytical; applied research.

(e) Calculation of bending moments in waves, taking into account dynamic effects of ships motions and forward speed, for romparison with experimentally determined bending moments. Prediction of bending moments in irregular waves and comperison with irregular tank wave results. Extension to measurements of model bending moments at a range of headings to long-crested regular waves.

(f) Completed.

(g) Fairly good agreement has been obtained between calculated and observed bending moments in head seas, giving theoretical confirmation of reduction of moments under dynamic conditions of forward speed and pitching and heaving motions. Tests at oblique headings to waves have shown that horizontal bending moment can become large in relation to vertical bending moment while torsional moments are relatively small.

(h) "Longitudinal Bending and Torsional Moments Acting on a Ship Model at Oblique Headings to Waves, "E. Numata, Journal of Ship Research, Vol. 4, No. 1, June 1960.

(2390) CONTROILED FINS FOR REDUCING SHIP PITCHING.

(b) Bureau of Ships, Department of the Navy (DTMB Technical Supervision).

(c) Mr. Wilbur Marks, Davidson Laboratory, Stevens Institute of Technology, 711 Hudson Street, Hoboken, N. J.

(d) Experimental and analytical; applied research.

(e) To determine the most desirable action of controllable fins at the bow or stern of a ship to reduce pitching in regular and irregular head seas.

(g) Analytical studies indicate that a combination of fixed fins at the bow and oscillating fins at the stern seems most promising in reducing ship pitching motions; model experiments have verified these findings.

(h) "Research on the Reduction of Pitching Motion of Ships by Means of Controllable Fins," P. G. Spens, Preliminary Report, Davidson Laboratory, Report No. 708.

(2393) MOTIONS AND BENDING MOMENTS OF SHIPS IN WAVES.

(b) Bureau of Ships, Department of the Navy (DTMB Technical Supervision).

(c) Mr. Wilbur Marks, Davidson Laboratory, Stevens Institute of Technology, 711 Hudson Street, Hoboken, N. J.

(d) Experimental and analytical; applied research.

(e) Measurements of motions and external bending moments and shear of a jointed model of a high-speed naval vessel underway in irregular head waves in a towing tank. Results will he analyzed by cross-spectral techniques to deter mine frequency response functions.

(g) Pilot studies indicate that when crossspectral techniques are applied to the analysis of moderate irregular wave data, the 
resulting frequency response functions show good agreement with response functions obtained from regular wave tests.

(h) "Theory and Experiment in the Evaluation of Bending Moments Acting on a Ship in Waves, "W. R. Jacobs and J. F. Dalzell, Davidson Laboratory Report 797, May 1960. "The Apparent Loss of Coherency in Vector Gaussian Processes Due to Computational Procedures with Application to Ship Motions," W. J. Pierson, Jr., and J. F. Dalzell. Submitted to Journal of Ship Research.

(2615) FORCES AND MOMENTS ON SUBMERGED BODIES BELOW WAVES.

(b) David Taylor Model Basin, Bureau of Ships, Navy Department

(c) Dr. M. Martin, with Mr. Charles Henry, Davidson Laboratory, Stevens Institute of Technology, 711 Hudson Street, Hoboken, New Jersey.

(d) Experimental and theoretical; basic and applied research.

(e) To measure the forcss and moments acting on submerged bodies moving obliquely to the crests of regular waves, and to compare the results with available theory.

(f) Completed.

(g) Slender-body theory has been applied to determine the forces and moments due to the waves acting on a submerged body while moving under regular waves at various headings relative to the wave crests. The forces have also been found on body-appendage combinations by the same theory. Experiments have been carried out using a long slender, axially-symmetric model with and without a conning tower. The wave length-body length ratio tas varied from 0.5 to 2.5 . Tests were made at headings of $0^{\circ}$ (head seas), $30^{\circ}, 60^{\circ}$ and $90^{\circ}$ (beam seas) and speeds of $0,2,4$, and 6 feet per second. A comparison of theoretical and experimental results was made. The data show reasonably good agreement with theory.

(2616) THE BLADE-FREQUENCY FORCE GENERATED BY A PROPELLER ON A BODY OF REVOLUTION.

(b) David Taylor Model Basin, Bureau of Ships, Department of the Navy.

(c) Dr. J. P. Breslin, Director and Dr. S. Tsakonas, Head of Fluid Dynamic Division, Davidson Laboratory, Stevens Institute of Technology, 711 Hudson Street, Hoboken, New Jersey.

(d) Theoretical; applied research.

(e) The purpose is to evaluate the importance of the pulsating near field of the propeller in generating vibratory forces on ships and to determine the attenuation of these forces with tip clearance and number of blades. Expressions for the vibratory pressure generated by a marine propeller operating in a wake which has been derived in project (3512) are being used for the evaluation of the lateral, longitudinal and vertical components of force and moment.

(2865) EFFECT OF SPEED AND FULLNESS ON HULL BENDINC MOMENTS IN WAVES.

(b) American Bureau of Shipping.

(c) Mr. Wilbur Marks, Davidson Laboratory, Stevens Institute of Technology, 711 Hudson Street, Hoboken, New Jersey.

(d) Experimental; applied research.

(e) To determine to what extent, if any, different longitudinal strength standards should be adopted for ships of different fullness and service speeds. The hull midship bending moments of three models with block coefficients ranging from 0.68 and 0.80 were measured in regular and irregular head and following seas. Work is continuing in oblique waves.

(g) Experimental results show that dynamic midship hull bending moments in regular model length waves vary with fullness at low speeds according to the trend predicted by standard static calaulations.

(2866) AN ANALYTIC STUDY OF THE PRESSURE FIELD NEAR COUNTER-ROTATING PROPELLERS.

(b) David Taylor Model Basin, Bureau of Ships, Navy Department.

(c) Dr. J. P. Breslin, Director and Dr. S. Tsakonas, Head of Fluid Dynamics Division, Davidson Laboratory, Stevens Institute of Technology, 711 Hudson Street, Hoboken, New Jersey.

(d) Theoretical; applied research.

(e) To compare the characteristics of counterrotating propellers with those of single propeller with regard to the magnitude of the oscillatory pressures produced at nearby points in the field. The study is divided into two parts. In the first, the pressure signal is calaulated according to referencel by superposition of the individual propeller fields as though they were independent. In the second, an approximate treatment of the effect of blade interaction is considered by the method given in reference?.

(f) Completed. Preliminary report in preparation.

(g) The performance of the counter-rotating propeller does not seem to justify its generally accepted superiority over the conventional propeller. The mechanical complications of the counter-rotating propeller are not counterbalanced by any advantage in thrust-producing effects. Calculations of the blade interference effects on the oscillatory pressure field indicate that their contribution is almost $15 \%$ of the corresponding two-dimensional vibratory pressure signal. Furthermore it is seen that the blade-blade interferrence is a local phenomenon whose effect decays rapidly beyond two or three chords from the propeller plane.

\section{(3169) WAKE FORMS BEHIND HIGH SPEED PLANING SURFACES.}

(b) Bureau of Aeronautics, Department of the Navy.

(c) Mr. Robert L. Van Dyck, Davidson Laboratory, Stevens Institute of Technology, 711 Hudson 
Street, Hoboken, New Jersey.

(d) Experimental; kasic research.

(e) A study was conducted in order to determine the surface contours of the wake shapes developed by planing forms associated with high-speed water-based aircraft. This work was undertaken because of the lack of accurate information concerning the wakes of planing forms operated at high speeds, high angles of attack, and heavy loadings. The effects of vee-bottom angle, chine flare, and step shape are evaluated in addition to the above-mentioned parameters.

(f) Completed.

(g) The wake results are presented in nondimensionalized graphical form to enable wake-shapes to be predicted for a wide variety of runing conditions and planing forms: It was found that an essentially two-dimensional approach can be used to represent the expanding and filling-in of any cross-section of a trough with time. The mechanism of wake formation was found to be determined by the basic initial geometric and kinematic planing conditions.

(h) "Final Engineering Report on Wake-Shapes of Planing Forms Associated with HighSpeed Waterbased Aircraft," by Robert L. Van Dyck, Davidson Laboratory Report R-768, October 1960.

(3171) ANALYTICAL STUDY OF THE THRUST DEDUCTION OF A SINGIE-SCREW THIN SHIP.

(b) David Taylor Model Basin, Bureau of Ships, Navy Dept.

(c) Dr. S. Tsakonas, Head of Fluid Dynamies Division and W. Jacobs, Senior Research Engineer, Davidson Laboratory, Stevens Institute of Technology, 711 Hudson St., Hoboken, Jew Jersey.

(d) Theoretical; applied research.

(e) An analytical study for the evaluation of the potential part of thrust deduction for thin ships similar to Haskind's type, with varying coefficients of vertical and horizontal fullness, is undertaken in order to reveal the functional dependence on the geometry of the propeller-hull configuration and propeller performance characteristics. Completed. Preliminary report is in preparation.

(8) Expressions have been evolved for the thrust deduction of a thin ship due to propeller and free surface effects when the center of the propeller is located 1) at the maximum submergence at the stern, 2) at any arbitrary position. It has been found that while finning both sections and waterplane of conventional ships lowers the thrust deduction, the section coefficient is more effective than the waterplane coefficient. Furthermore axial displacement of the propellar is more effective in mitigating the arag augmentation than is vertical displacement. The free surface effect is an important contributor in most cases of practical interest. Furthermore the analysis strengthens the belief that the frictional part of the thrust deduction is of equal weight with the potential.

(3173) HYDROELASTIC INSTABILITIES OF SUPERCAVITATING HYDROFOILS.

(b) David Taylor Model Basin, Bureau of Ships, Navy Department.

(c) Mr. Charles J. Henry, Davidson Laboratory, Stevens Institute of Technology, 711 Hudson Street, Hoboken, N. J.

(d) Theoretical; basic research.

(e) Theoretical analysis of the conditions for the occurrence of hydroelastic instabilities (i.e. divergence and flutter) of supercavitating hydrofoils in two dimensions as functions of cavitation number, point of separation, elastic axis location, center of gravity location and elastic spring constant.

(f) Completed.

(g) A two-dimensional analysis of the static and dynamic stability of rigid super-cavitating hydrofoil sections supported elastically showed that the instabilities commonly called divergence and flutter in aeroelastic literature are quite likely to occur in typical supercavitating hydrofoil installations. The analysis indicated that the speed at which divergence will occur is increased by increasing the radius of gyration, moving the elastic axis forward, decreasing the cavitation number or moving the point of separation forward. It is found that the region of dynamic stahility will increase when the radius of gyration is increased, the elastic axis is moved forward, the center of gravity is moved forward and/or the ratio of the stiffiness in translation to the stiffness in rotation is increased.

(h) To be published as a Davidson Laboratory Technical Note.

(3174) UNSTLEADY LIFT AND MOMENT ON FULLY CAVITATIVG HYDROFOILS AT ZERO CAVITATION NUMBER.

(b) Office of Naval Research, Department of the Navy.

(c) Dr. M. Martin, Davidson Laboratory, Stevens Institute of Technology, 711 Hudson St., Hoboken, N. J.

(d) Theoretical; basic research.

(e) Analytical studies of the forces and moments acting on a thin, supercavitating hydrofoil performing arbitrary oscillations is pursued on the basis of the acceleration potential method.

(f) Completed.

(g) Expressions for the lift and moment coefficients of a thin, upercavitating plate performing arbitrary oscillations are developed in terms of the coefficients of a power series describing the chord-wise amplitude distribution. General expressions are applied to the case of a foil moving through a stationary sinusoidal vertical gust and to that of a rigid foil performing heaving and rotational oscillations. Comparison is made with Sear's results for a fully wetted foil in a sinusoidal gust and Parkin's in the case 
of pure heaving motion. General conclusions as to the effect of the various parameters have been drawn.

(h) Final report in preparation.

(3176) THEORY OF LATERAL MOTIONS OF SHIPS IN WAVES.

(b) David Taylor Model Basin, Bureau of Ships, Navy Department.

(c) Dr. Pung Nien Hu, Davidson Laboratory, Stevens Institute of Technology, 711 Hudson Street, Hoboken, N. J.

(d) Theoretical; basic research.

(e) Analytical study of the lateral motions of surface ships with three degrees of freedom in oblique waves. The virtual mass, damping and dynamic coupling of a surface ship in oscillatory motion, as well as the hydrodynamic excitation forces and moments due to oblique waves have been evaluated. The free surface influence on the hydrodynamic forces have been included in the above. Further work on determining lateral ship motions is continuing.

(h) A Davidson Laboratory report on the completed portion of the work described in (e) is in preparation.

(3509) THEORETICAL CALCULATIONS OF THE VIBRATORY THRUST PRODUCED BY A SHIP PROPELIER OPERATING IN THE WAKE OF A HULL.

(b) David Taylor Model Basin, Bureau of Ships, Navy Department.

(c) Dr. S. Tsakonas, Staff Scientist, and Winnifred R. Jacobs, Senior Research Engr., Davidson Laboratory, Stevens Institute of Technology, 711 Hudson Street, Hoboken, N. J.

(d) Theoretical; applied research.

(e) Computational work is carried out to test the validity of the theory developed by Ritger and Breslin, "On the Quasi-steady and Unsteady Thrust and Torque of a Propeller in a Ship Wake," Comparison is made with the experimental results.

(g) (1) Theoretical computations are compared with the results obtained during ship trials and from 1/25-scale model tests of the single-screw ship $A E 21$. It is shown that the theoretical thrust is on the average $8 \%$ lower than the model test data. Also the alternating, unsteady theoretical thrust is about the average of the ship trial results while the quasi-steady computation gives an alternating thrust three times the magnitude which is close to the model test results. (2) Theoretical computations have also been made of the vibratory thrust produced by an 8-inch propeller (TMB No. 2406) operating in the wake of a symmetrical airfoil strut placed at $35^{\circ}$ and $25^{\circ}$ to the direction of flow. This is for comparison with the results published in DTMB report no. 1107 of tests conducted in the 12" Variable Pressure Water Tunnel at ITMB. In this case it has been found that the unsteady theoretical results are lower than the experimental while the quasi-steady theoretical results are higher and not as close to the test values.

(h) A detailed description of the computational procedure and also certain improvements of the basic theory have been written up in preliminary form. The final report will be published as soon as (2) under (g) above is complete.

(3511) STUDIES OF THE SOUND PRESSURE FIELD GENERATED BY A MARINE PROPELLER OPERATING IN A WAKE.

(b) United Aircraft Corporation, Research Department.

(c) Dr. S. Tsakonas, Head of Fluid Dynamics Division, Davidson Laboratory, Stevens Irstitute of Technology, 711 Hudson Street, Hoboken, IN. J.

(d) Theoretical, applied research.

(e) The sound pressure field of a rotating propeller in rectilinear motion is obtained by replacing the normal pressure distribution over the propeller by a distribution of acoustic pressure doublets acting at the propeller disc. The strength of this acoustic doublet distribution is obtained from unsteady aerodynamic theory in conjunction with Burrill's correction factors.

(f) Near completion. Preliminary report in preparation.

(g) General. expressions for the sound pressure contributed by the thrust and torque have been derived in terms of the harmonic constituent of the unsteady inflow velocity field. Corresponding expression of the pressure signal for the hydrodynamic field, near acoustic field and far acoustic field. have been deduced from the general formulee. Closed-form expressions for the near and far-acoustic fields have been developed in terms of complete elliptic integrals. Computations for the far acoustic field indicate that the pressure signal attributed to the variable loading is more persistent in the field than is so in the uniform inflow case.

(h) Preliminary report in preparation.

(3512) BLADE FREQUENCY PRESSURE NEAR AN OPERATING MARINE PROPELLER IN A WAKE.

(b) David Taylor Model Basin, Bureau of Ships, Navy Department.

(c) Dr. J. P. Breslin, Director and Dr. S. Tsakonas, Head of Fluid Dynamics Division, Davidson Laboratory, Stevens Institute of Technology, 711 Hudson Street, Hoboken, New Jersey.

(d) Theoretical, applied research.

(e) The purpose is to provide more realistic information than is at present available on the exciting forces generated by the transient flow produced by a marine propeller operating in the vicinity of a hull and its appendages. This information is essential for a study of the vibration of the hull as a whole as well as the hydroelastic behavior of plating and control surfaces. The linearized pressure is determined as the solution of a Dirichlet problem within the frame of Karman and Sear's non-stationary airfoil theory. 
(g) General expressions for the vibratory pressure signal generated by the propeller have been derived in terms of LipschitzHankel functions.

(3514) THEORETICAL AND EXPERIMENTAL INVESTIGATION OF FLUTTER OF FULLY-WETTED HYDROFOILS.

(b) Davia Taylor Model Basin, Office of Naval Research, Navy Department.

(c) Mr. Charles J. Henry, Davidson Laboratory, Stevens Institute of Technology, 711 Hudson Street, Hoboken, N. J.

(d) Theoretical and experimental; basic research.

(e) Previous flutter investigations have shown disagreement between experimental results and theoretical predictions of the critical flutter speed of hydrofoils (see Henry, Dugundji, Ashley, "Aeroelastic Instabilities of Lifting Surfaces in High Density Media,, Journal of Ship Research, Vol. 2, No. 4, March 1959). Experiments will be carried out at several combinations of the parameters involved and the results will be compared with theoretical predictions. Several modifications of the present theory will be investigated in order to achieve good agreement between theory and experiment.

\section{(3515) HYDRODYNAMICS OF HIGH SPEED SHIPS.}

(b) U. S. Maritime Administration.

(c) Prof. Edward V. Lewis, Davidson Laboratory, Stevens Institute of Technology, 711 Hudson Street, Hoboken, N. J.

(d) Experimental developmental research.

(e) Tests covering resistance in calm water and motions in irregular long-crested waves and series of models of surface merchant ships suitable for a speed range of 30 to 50 knots with displacements from 20,000 to 80,000 tons, beam-draft ratios of 2.25 and 3.75, and displacement-length ratios from 60 to 150 .

(f) Completed.

(g) Trends of resistance, effective horsepower and running trim vs. speed in calm water are presented, with displacement-length ratio as a parameter. Trends of effective horsepower, bow acceleration, bow immersion, and incidence of slamming in irregular head seas are presented as functions of speed and displacement-length ratio.

(h) "Hydrodynamics of High Speed Ships: Part I - Smooth Water Resistance; Part II Rough Water Performance," P.R. Van Mater, $\mathrm{Jr}$. and R. B. Zubaly, Davidson Laboratory Report 789, July 1960.

(3516) INVESTIGATION OF HULL BENDING MOMENTS IN WAVES OF EXTREME STEEPNESS.

(b) Ship Structure Committee.

Mr. Wilbur Marks, Davidson Laboratory, Stevens Institute of Technology, 711 Hudson Street, Hoboken, N. J.

(d) Experimental, applied research.

(e) Model tests are to be carried out on a jointed model of a typical merchant ship to determine midship bending moments in very steep waves. Objective is to determine upper physical iimit of wave bending moments.

(g) Bending moment is found to be linear in waves of small and moderate steepness. Nonlinearity in bending moment appears with high waves and its nature varies with wave length. Bending moment is greatest for waves 1.5 times the length of the ship.

(h) "Investigation of the Upper Physical Limit of Longitudinal Seaway Bending Moments, " by J. F. Dalzell, Internal Report.

(3517) SHIPS OF MINIMUM WAVE RESISTANCE.

(b) Office of Naval Research, Department of the Navy.

(c) Dr. Milton Martin and Mr. James White, Davidson Laboratory, Stevens Institute of Technology, 711 Hudson Street, Hoboken, N. J.

(d) Theoretical and experimental; basic research.

(e) An investigation is underway to evaluate the agreement between computed and measured wave resistance of ship models of minimum wave resistance at high Froude numbers as determined from Weinblum's tables, in which the lines are modified to compensate for the boundary layer displacement thickness. Comparison will be made with the thin ship theory calculations and calculations satisfying the boundary conditions on the wetted hull surface to be made on the NORC.

(g) Computations based on Weinblum's Tables have been made of minimum wave resistance forms for a large Froude number range, of ships of length-draft ratio 33.3 and prismatics between 0.56 and 0.74 . A model of minimum wave resistance at a Froude number of 0.5 , whose principal proportions are those of a destroyer, has been constructed and is at present being tested at several drafts. Estimates of the boundary layer displacement thickness have been made. These estimates are now being used to modify the lines of the model for a second series of tests.

(3518) THE EFFECT OF HIGH SPEED ON LATERAL SHIP STABILITY.

(b) David Taylor Model Basin, Bureau of Ships, Department of the Navy.

(c) Dr. Pung Nien Hu, Davidson Laboratory, Stevens Institute of Technology, 711 Hudson Street, Hoboken, N. J.

(d) Theoretical; basic research.

(e) Conduct theoretical study of the effect of high speed on surface ship stability and maneuverability, including determination of lateral stability derivatives, stability irlices and variations, and steady-state turning diameters.

(h) A Davidson Laboratory report of the work described in (e) is in preparation.

(3829) DEVELOPMENT OF SONIC WAVE PROBE FOR USE ON SHIPS.

(b) Hydromechanics Laboratory, David Taylor Model Basin.

(c) Mr. Wilbur Marks, Davidson Laboratory, 
Stevens Institute of Technology, 711 Hudson Street, Hoboken, N. J.

(d) Experimental; development.

(e) Determine the feasibility of using a sonic probe in conjunction with an accelerometer to measure the waves encountered by a moving ship when the system is mounted at the bow. The influence of the wave field projected by the ship must be determined. The effect of tilting the sonic probe and accelerometer on the recorded wave motion must be studied.

(3830) RADIATION OF A MARINE PROPELLER PRESSURE WAVE FROM ELASTIC PLATE AND CYLINDER.

(b) David Taylor Model Basin, Bureau of Ships, Navy Department.

(c) Dr. S. Tsakonas, Head of Fluid Dynamics Division, Davidson Laboratory, Stevens Institute of Technology, 711 Hudson Street, Hoboken, N. J.

(d) Theoretical; applied research.

(e) The purpose is to evaluate the sound pressure field radiated from the pulsating boundary of an elastic plate and shell when these are subjected to vibratory pressures generated by a marine propeller. This study will determine the extent of the contribution of the elastic boundary in amplifying the sound level generated by a propeller.

(g) This project is in the formative stage.

(3831) CORRELATION OF THEORETICAL RESULTS WITH EXPERIMENTS ON VIBRATORY THRUST AND PRESSURE.

(b) David Taylor Model Basin, Bureau of Ships, Navy Department.

(c) Miss Winnifred R. Jacobs, Senior Research Engineer, Davidson Laboratory, Stevens Institute of Technology, 711 Hudson Street, Hoboken, N. J.

(a) Applied research.

(e) Experimental vibratory thrust and pressure results for various single-screw ship forms obtained at National Physics Laboratory, Hamburgische Schiffoau-Versuchsanstalt Gesellschaft, Netherlands Ship Model Basin and David Taylor Model Basin are to be correlated with theoretical results obtained on the bssis of the work done in References 1 and 2. If the correlation is close, charts will be constructed for use by naval architects in determining the pressure field and thrust fluctuations for proposed single-screw ship configurations.

(g) The project is in its initial state.

(h) "A Theory for the Quasi-steady and Unsteady Thrust and Torque of a Propeller in a Ship Wake," P. Ritger and J. P. Breslin.

"Marine Propeller Pressure Field Due to Loading and Thickness Effects," J. P. Breslin and S. Tsakonas.

(3832) FORMULATION OF EQUATIONS FOR SUBMARINE TRAJECTORIES WITH SIX DEGREES OF FREEDOM.

(b) David Tayıor Model Basin, Department of the Navy.

(c) Mr. James White, Daviason Laboratory,
Stevens Institute of Technology, 711 Hudson Street, Hoboken, N. J.

(d) Theoretical; applied research.

(e) Equations of a very general nature are being formulated to study the transient and steady state turning motion of deeply submerged submarines.

(g) Paxtial differential equations for the motion of a deeply submerged submarine with six degrees of freedom are being written in accordance with the SNAME, "Nomenclature for Treating the Motion of a Submerged Body Through a Fluid." The hydrodynamic forces and moments will be expressed in terms of third order Taylor series expansions which contain all of the cross-coupling terms. Particular emphasis is being placed on the terms expressing roll instability due to yaw and pitch. The thrust exerted on the submarine is to be expressed as a function of speed of advance and propeller R. P. M. The effects of the interaction of bow planes on stern planes, the effect of propellex R.P.M. on stern plane effectiveness, and the effect or changes in ballast are also included. Representative estimates of all parameters will be made.

(3833) EXPERIMENTAL AND ANALYTICAL STUDY OF FLUTTER OF SUBMERGED HYDROFOILS.

(b) David Taylor Model Basin, Office of Naval Research, Navy Dept.

(c) Mr. Charles J. Henry, Research Engineer, Davidson Laboratory, Stevens Institute of Technology, Hoboken, N. J.

(a) Experimental and theoretical; basic research.

(e) To determine experimentally the conditions for flutter of submerged hydrofoils and to provide correlation of theory and experiment.

(3834) A STUDY OF THE HYDROELASTIC INSTABILITIES OF SUPERCAVITATING HYDROFOILS.

(b) David Taylor Model Basin, Bureau of Ships, Navy Dept.

(c) Mr. Charles J. Henry, Research Engineer, Davidson Laboratory, Stevens Institute of Technology, Hoboken, N. J.

(d) Theoretical; basic research.

(e) To determine theoretically, the conditions necessary for flutter and divergence instabilities of a rigid, two dimensional supercavitating hydrofoil supported elastically in two degrees of freedom.

(f) Completed.

(g) A two dimensional theory is used to define the unsteady hydrodynamic force and moment acting on an oscjllating hydrofoil, which is assumed to be elastically restrained in translation normal to the free stream direction and in rotation about a prescribed axis which is normal to the plane of flow. The effects of variations in the elastic and inertial properties, as well as the effect of varying the position of the upper surface flow separation point of the possibilities of either form of instability are determined. The theory predicts that static instability (divergence) is possible for 
typical supercavitating hydrofoils and that dynamic instability is also very likely. This latter result is contrary to the results for flutter of fully wetted hydrofoils with identical configurations, where it has been shown that flutter is unlikely for fully wetted hydrofoil operation.

(h) "A Study of the Hydroelastic Instability of Supercavitating Hydrofoils, " Paul Kaplan and C. J. Henry, Journal of Ship Research, to be published.

\section{ROBERT TAGGART INCORPORATED.}

\section{(3835) HYDROPHONE SELF-NOISE RESEARCH.}

(b) Office of Naval Research, Department of the Navy.

(c) Mr. Robert Taggart, Robert Taggart Incorporated, 400 Arlington Boulevard, Falls Church, Virginia.

(d) Experimental; development.

(e) Flow tests were carried out with hydrophones in the test section of a specially designed quiet flow facility whose ambient noise characteristics are known. These tests were preliminary to self-noise measurements on a dummy flexible line hose hydrophone.

(f) Discontinued.

(g) During experimentation a hydrophone was examined which, when later tested at sea, was found to have exceptionally low selfnoise characteristics.

(h) Progress reports to Office of Naval Research dated 1 October 1958, 1 January 1959, and 1 April 1959.

(2836) ACOUSTIC EXCITATION OF FLAT PLATES IN A TURBUTENT BOUNDARY LAYER.

(b) David Taylor Model Basin, Department of the Navy.

(c) Mr. Robert Taggart, Robert Taggart Ircorporated, 400 Arlington Boulevara, Falls

Church, Virginia.

(d) Experimental; applied research.

(e) 10 study the excitation of rigid and flexible flat plates due to the pressure fluctuations in a turbulent boundary layer. Various flat plates will be mounted flush in the test-section of a gravity-fed water tunnel which is specially designed for low ambient noise, over a mean velocity range of 0 to 20 feet per second. It is intended to measure the response characteristics with and without damping, of the flexible plate in order to provide information for use in the design of sonar domes and shell plate panels.

UNIVERSTTY OF TENNESSE Department of Civil Engineering.

Inquiries concerning the following projects should be addressed to Dr. Harry H. Ambrose, Department of Civil Engineering, University of Tennessee, Knoxville 16, Tennessee.

(2159) DISCHARGE COEFFICIENTS FOR TAINTOR GATES ON SPILLWAYS.

(b) Cooperative with the Tennessee Valley Authority.

(d) Experimental; basic research.

(e) A generalized model of a taintor gate on a spillway crest was investigated for the head-discharge relatiorship. The effect of the trunnion location as well as that of relative head and relative gate opening was considered.

(f) Experimental work completed. Correlation of data temporarily suspended.

(2619) BOUNDARY ROUGHNESS EFFECTS UPON TURBULENT FLOW.

(b) Laboratory project.

(d) Experimental; basic research.

(e) Continuation of extended study of specific effects of certain characteristics of roughness-element geometry on turbulent flow over rough surfaces. Velocity distributions and piezometric gradients have been measured in artificially roughened pipes.

(f) Suspended pending expansion of facilities.

(g) Measurements have been made and results have been summarized for 35 patterns of artificial roughness. Of particular interest is the critical roughness-element spacing for maximum resistance.

(3839) CHARACTERISTICS OF FLOW THROUGH A BOTTOM GRID.

(b) Laboratory project.

(d) Experimental; for master's thesis.

(e) The effects of velocity, depth, slope, and gria conformation on discharge through a grid in the bottom of an open channel will be investigated.

(f) The facility is under construction.

(3840) BOUNDARY PRESSURES ON CONDUTT ENTRANCES OF OPTIMUM DESIGN.

(b) Laboratory project.

(d) Experimental; for master's thesis.

(e) The relative pressure distribution will be determined for the boundaries of square and rectangular conduit entrances which are designed to avoid cavitation.

(f) Test facility almost complete.

(3841) EXPANDING FLOW ON A SLOPING APRON.

(b) Laboratory project.

(a) Experimental; basic research for master's thesis.

(e) The characteristics of flow from an abrupt expansion onto a sloping apron will be investigated to determine the effect of the slope on the pattern of subcritical and supercritical expansion.

(f) Test facility and equipment is being developed. 
TEXAS A AND M COLLEGE, Department of Oceanography and Meteorology.

(2868) INVESTIGATION OF STORM SURGES ALONG THE SOUTH SHORE OF NEW ENGLAND.

(b) Beach Erosion Board, Corps of Engineers, U. S. Arny, Contract DA-49-055-civ. eng. $-56-4$.

(c) Profeesor Robert 0. Reid, Project Supervisor, Texas $A$ and $M$ College, College Station, Texas.

(c) Numerical analysis; applied research.

(e) Numerical and graphical procedures are utilized in the evaluation of storm surge behavior in schematic (mathematical) models Narragansett Bay, Long Island Sound, and Buzzards Bay, particular attention being devoted to Narragansett Bay. The numerical work is being carried out using an IBM 704 computer. Numerical studies of astronomical tides in Narragansett Bay are also being carried out.

(g) A numerical procedure for computation of water level changes in coastal bays and estuaries due to moving storm systems has been developed and tested for several different occurrences of hurricane surges for Narragansett Bay, Rhode Island. The numerical calculations are based upon the finite difference counterparts of the equations of motion and of contimuity for a network of channels. The method involves a marching procedure of computation leading to the estimated water level hydrographs (versus time) at different key points in the channel system. Astronomical tides and variable wind effect are jointly included in the computing system. The system of calculation gives good agreement for the astronomical tide regime and gives a fair prediction for the peak surges in the aforementioned bay for three different hurricane conditions which have been simulated in respect to wind field. One drawback of the system is that it does not allow for the two-dimensional aspects of the storm surge on the continental shelf outside the bay mouth.

(h) "Numerical Evaluation of Surges and Tides in Narragansett Bay," Appendix A - Detailed Listings of Surge - Tide Problems, R. 0 . Reid, Ref. 60-12, Texas A and M Res. Fdn., Aug. $1960,133 \mathrm{pp}$.

(2870) MODEL STUDY OF SURGE ACTION IN A PORT.

(b) Office of Naval. Research, U. S. Navy Project NR 08j-036, Contract N7 onr 48702 .

(c) Dr. B. W. Wilson, Principal investigator, Texas A and $\mathrm{M}$ College, College Station, Texas.

(d) Experimental; basic and applied research.

(e) To collate results and conclusions from a model study of long period wave action in Table Bay Harbor, Cape Town, South Africa.

(f) Initiated 1957; completed 1960.

(g) The nature of the surge phenomenon has been uncovered. Its reproduction in an engineering model and experiments to control it are described. It is shown that effects on shipping can be brought under control by suitably containing the existing harbor within an outer basin of tight mole construction.

(h) "Model Study of Surge Action in a Port," B. W. Wilson, Tech. Report No. 24-(57), Texas $A$ and $M$ Research Foundation, Dec. $1960,61 \mathrm{pp}$.

(2873) COMPUTATION OF DESIGN STORM-TIDE FOR THE NEW YORK BAY AREA.

(b) Beach Erosion Board, Corps of Engineers, U. S. Army and New York District, Corps of Engineers, Contract DA-49-055-civ-eng58-9.

(c) Dr. B. W. Wilson, Project Supervisor, Texas $\mathrm{A}$ and $\mathrm{M}$ College, College Station, Texas.

(d) Numerical analysis; applied research.

(e) This project concerns the correlation of observed effects in New York Bay with the characteristics of known storms and its application to the prediction of storm-tides for a design hudricane.

(f) Initiated Nov. 1957; completed Oct. 1960.

(g) Least squares multiple regression correlation of known storm-tide elevation at the mouth of New York Bay with antecedent storm characteristics (wind stress and pressure gradient) at a number of offshore stations has been undertaken with data for four storms, tabulated at $20 \mathrm{~min}$. intervals. The derived coefficients of correlation have been used in the prediction formula to predict the time-sequences of water level change at the bay-mouth for each of the four storms as a check on the validity of the formula. The formula has then been applied to the case of a design hurricane travelling on a given path at six possible speeds. High speed digital computer techniques have been used for this study. In an extension of this work predictions have been made for a more severe design-hurricane in three combinations of size and speed and finally for a Probable Maximum Hurricane. An application of the method has been made in predicting the effects of hurricane Hazel of Oct., 1954. The comparison of results with the known storm-induced water levels is generally good and establishes the reliability of the method.

(h) "The Prediction of Hurricane Storm-Tides in New York Bay, " by B. W. Wilson, Tech. Memo No. 120, Beach Erosion Board, Corps of Engrs., U. S. Army, Aug. 1960, 122 pp.

"Hurricane Tide Prediction for New York Bay," B. W. Wilson, Proc. VIIth Coast. Eng. Conf", (Scheveningen, Holland, Aug. 1960): Council Wave Research, Berkeley (publication pending, 1961).

"Discussions on the Prediction of Hurricane Storm-Tides in New York Bay," D. L. Harris and B. W. Wilson; Bulletin Beach Erosion Board, Corps of Engrs., U. S. Army (publication pending, 1961 ).

(3519) DEEP-SEA MOORING OF SHIPS IN WAVES AND CURRENTS.

(b) David Taylor Model Basin, U. S. Dept. of 
the Navy, Contract No. Nonr-2119 (02).

(c) Dr. B. W. Wilson, Project Supervisor, Texas $\mathrm{A}$ and $\mathrm{M}$ College, College Station, Texas.

(d) Theoretical; basic research.

(e) To determine the mooring line tensions arising from hydrodynamic forces of waves and currents acting on a ship and mooring cable(s) in deep water.

(g) Following a literature survey of work previously done on this and allied studies, the first problem posed for solution has been concerned with the configuration of a negatively buoyant mooring cable used to anchor a ship in a uniform horizontal current prevailing over full water depth in the absence of waves. The steady state configuration of a deep-sea cable is then being integrated from the solution of the above case applied to variable vertical distributions of horizontal steady current, conforming to realsitic ocean patterns. Facilities of a high speed digital computer are being used for evaluating sets of cable parameters applicable to a wide variety of possible mooring line situations. Further research will be involved with the transient effects of waves and fluctuating wind.

(h) "A Study of the Movement of Moored Ships Subjected to Wave Action," B. W. Wilson (Discussion), Proc. Inst. C. E. (London), v. 15, April 1960, pp. 444-448.

"Characteristics of Anchor Cables in uniform Ocean Currents," B. W. Wilson, Tech. Report No. 204-1, Texas A and M Research Foundation, April, 1960, $154 \mathrm{pp}$.

"Mooring of Ships Exposed to Waves," B. W. Wilson, Tech. Report No. 204-2, Texas A and M Research Foundation, Nov. 1960, 65 $\mathrm{pp}$.

"A Case of Critical Surging of a Moored Ship," B. W. Wilson (closure to discussion), Proc. ASCE v. 86 (WW4), Nov. 1960, pp. 99103.

(3520) FORECASTING OF OCEAN WAVES GENERATED BY MOVABLE VARIABLE WIND SYSTEMS IN DEEP AND SHALLOW WATER.

(b) Engineering Foundation, New York; SoconyMobil Oil Co., Dallas; Humble Oil and Refining Co., Houston; Office of Naval Research, U. S. Navy, Contract N7 onr 48702 (Project No. NR 083-036).

(c) Dr. B. W. Wilson, Project Supervisor, Texas $A$ and $M$ College, College Station, Texas.

(d) Theoretical and empirical; basic and applied research.

(e) To verify a moving fetch variable-wind graphical forecasting procedure by direct comparison of results with wave observations at one or more offshore stations. Thence to investigate the possibility of extending the method to rapid forecasting of wave conditions in near-shore environments where water depth, friction and refraction are complicating factors in wave generation.

(g) Analysis is being made of the sea conditions induced by hurricane "Audrey" of June, 1957. Complete synoptic maxs for the Gulf of Mexico area have been prepared, showing the surface pressure patterns wind distributions and circulations at intervals of 3 hours from June 25 to June 28. From these space-time wind-fields for five different lines of approach to the Louisiana coastline have been obtained. The original graphical wave forecast method for dealing with moving wind systems over deep water has been adapted to a high speed digital procedure which can be processed on an IBM 704 or 709 computer. Application to the hurricane "Audrey" windfields is proceeding and the method is being further adapted to shallow water. A re-analysis of basic observational wave data has been undertaken to improve wave forecasting accuracy if possible.

(h) "Note on Surface Wind Stress over Water at Low and High Wind Speeds," B. W. Wilson, Jour. Geophys. Research, v. 65 (10) Oct. 1960, pp. 3377-3382.

"Deep Water Wave Generation by Moving Fetches of Variable Wind," B. W. Wilson, Tech. Report No. 206-1, Texas A and M Research Foundation, Nov. 1960, 35 pp.

\section{UNIVERSITY OF TEXAS, Department of Civil Engineering.}

Inquiries concerning Projects Nos. 2162, 2396, 2397, 2629 , 2874, and 3524 should be addressed to Dr. Walter L. Moore, Dept. of Civil Engineering, Univ., of Texas, Austin 12, Texas.

(2161) CHARACTERISTICS OF A HYDRAULIC JUMP AT AN ABRUPT CHANGE IN BOTTOM ELEVATION.

(b) University of Texas Resaarch Institute and Bureau of Engineering Research.

(c) Dr. Carl W. Morgan, Associate Professor of Civil Engineering, Univ. of Texas, Austin, Texas.

(d) Experimental.

(e) Experimental determinations are made of the flow characteristics at two-dimensional channel drops and rises. The velocity distribution and surface profile will be determined throughout the length of the jump for various relative changes in bottom elevation. The longitudinal location of the jump in relation to the change in bottom elevation will be varied over a broad range in distinction to previous related investigations in which relative location of the jump was held constant.

(g) Results for the abrupt drop are complete and have been published. For a given entering Froude number lying between 2 and 8 three types of jump may form, the type and its longitudinal location depending only on the relative downstream depth. The velocities near the bottom below the drop are always less than the mean velocity in the downstream channel for the jump type of maximum height. Experimental measurements have been made on the related investigation for an abrupt rise and report is being prepared.

(h) "The Hydraulic Jump at an Abrupt Drop," by W. L. Moore and C. W. Morgan, Transactions A. S. C. E. Vol. 124, pp. 507-524, 1959. 
records to predict the annual runoff of the

(b) Cooperative with U. S. Geological Survey.

(d) Field investigation; applied research.

(e) Measurements of rainfall and runoff for a 4 sq. mile and a $2 \mathrm{sq}$. mile portion of the Waller Creek watershed are being made to provide basic information for estimating runoff from small urban watersheds in the Southwest area. Two stream flow stations and a rain gage net are in operation. Studies of the correlation beteeen runoff, rainfall, and the characteristics of the drainage basin are being made by various proposed methods to serve as a base for comparison with the data as it is collected from the stream.

(g) Careful estimates of the peak discharges at the gaging station were made by various proposed methods based on measurable characteristics of the basin. These results will be of interest to compare with observed peak discharges in later years when the record is long enough to be significant.

(2396) RESISTANCE OF PIERS IN FREE SURFACE FLOW.

(b) Laboratory project.

(d) Theoretical and experimental (thesis).

(e) An investigation is being made of the drag resistance of piers as a function of shape, relative submergence, spacing, and Froude numbers. The pier resistance is being correlated with the head loss for flow in a channel.

(g) A phase of the investigation has been completed for Froude numbers less than 0.5 with cylindrical piers at various submergence and spacing. An investigation of the resistance of $H$ section piers at various orientations and longitudinal spacings has been completed. Another phase has been completed which demonstrates that the velocity gradient along a cylindrical pier affects the drag coefficient. The local drag coefficient decreases along the pier in the direction toward the end of the pier where the velocity is high. The reduction in drag coefficient is related to a dimensionless measure of the velocity gradient along the cylinder.

(2397) EFFECT OF UPSTREAM DEVELOPMENT ON THE RUNOFF FROM SMALL WATERSHEDS IN THE SOUTHWEST.

(b) Laboratory project.

(d) Field investigation (thesis).

(e) For a selected watershed rainfall and runoff relations before the period of upstream development are being analyzed. The relations obtained for this period will be applied to the rainfall records after the upstream development and the predicted runoff compared with the actual runoff.

(g) Sources of data have been located. The available information tabulated, and a method of evaluating the runoff devised that appears to be reasonable. Multiple correlation diagrams have been developed which may be used with storm rainfall

(h) "The Effect of Watershed Development on Surface Runoff in Central Texas," James K. Ferrill, M. S. Thesis, June 1960.

(2629) A MECHANICAL TURBULENCE INDICATOR FOR LIQUIDS.

(b) Bureau of Engineering Research, University of Texas.

(d) Experimental instrument developemnt.

(e) There is need for a relatively simple device to give a quantitative measure of the degree of turbulence in a flowing fluid. Electrical instruments commonly measure the root mean square of the turbulent fluctuations as an indication of the intensity. The instrument being developed measures the maximum turbulent fluctiation as an indication of the intensity. The instrument is similar to a $1 / 2$ inch diameter Prandtl velocity tube except that it has two stagnation openings; the conventional one which gives the mean stagnation head and an additional one which leads through a sensitive check valve and accumulator to a manometer tube. The check valve and accumulator elements are located in the tube less than $3 / 8$ of an inch from the stagnation opening to minimize inertia effects.

(g) The instrument has been built and calibrated. Measurements have been made to evaluate the operation of the instrument in the turbulent field of a hydraulic jump. A report is being prepared describing the instrument, the calibration technique and the results in the hydraulic jump.

(2874) AN INVESTIGATION OF THE SCOUR RESISTANCE OF COHESIVE SEDIMENTS.

(b) Bureau of Engineering Research, University of Texas, Austin, Texas.

(d) Analytical and experimental (laboratory).

(e) Exploratory tests have been made with two different schemes, one with radially outward flow between a circular disc and the soil sample, and one with a submerged vertical circular jet impinging on a horizontal soil surface. With the first scheme it was not possible to obtain the necessary precision of measurement at low scour rates, but with the second scheme satisfactory measurements were obtained. A correlation based on dimensional analysis gave consistent results in evaluating the rel ative scour resistance of several materials. Apparatus is being fabricated for a new test which is expected to permit direct evaluation of the shear stress at the soil surface. In this test a cylindrical soil sample is submerged in a transparent concentric cylinder which can be rotated at a controlled speed to generate a shear stress on the soil surface. An attempt will be made to relate the scour resistance to other measurable soil properties, and finally to interpret the results in relation to field otservations. 
(g) The apparatus to determine shear stress at the soil surface has been constructed and calibrated, and preliminary tests have been conducted on a soil sample.

\section{(3522) LONG TIME FLUCTUATIONS IN STREAM RUNOFF.}

(b) Laboratory project.

(c) Dr. Carl W. Morgan, Dept. of Civil Engineering, Univ. of Texas, Austin 12, Texas.

(d) Analytical and field study.

(e) Values of runoff from selected drainage areas in the lower Mississippi River Basin and in basins of the rivers emptying directly into the Gulf of Mexico were studied. Variations in the runoff values for each stream were considered and these trends compared with solar variations. The relative sunspot numbers were used as the measure of solar variations and were correlated with the mean annial runoff. Further correlations are being made with different "lag" periods between solar activity and surface runoff.

(g) The gradual shifting of the centers of runoff excess and deficiency is consistent rather than random and appears to represent a gradual cyclic change in the runoff pattern. It appears that the locations of the centers of runoff deficiency is following roughly the same path that it did some 22 to 24 years previously. Correlation coefficients of t0.2 to t0.5 are obtained for selected rivers in Mississippi, Alabama, Georgia, and Arkansas when sunspot numbers in the ll-year sunspot cycle are correlated with runoff. Texas streams do not give significant correlation with the ll-year sunspot cycle but give better correlation if runoff is compared with the double sunspot cycle in which sunspot numbers are assumed as negative in alternate cycles.

(3524) GROUND WATER FLOW AND SEEPAGE IN NONHOMOGENEOUS, NON-ISOTROPIC SEDIMENTS.

(b) Laboratory project.

(d) Theoretical, hasic.

(e) A relaxation solution for the Laplace equation has been developed which is applicable across a boundary between two regions of different permeabilities. It is believed that the method can be expanded to apply to any specified non-homogeneous and non-isotropic condition. It is intended that the solution be set up for computation on an electronic computer and that selected numerical solutions be checked against those from an electrolytic tank.

- n.....

UTAH STATE UNIVERSITY, Engineering Experiment Station.

\section{(3183) DYNAMICS OF FLOW IN STEEP, ROUGH, OPEN ChANNELS.}

\section{(3185) FYDRAULICS OF SURFACE IRRIGATION.}

(c) Dr. Dean F. Peterson, Dean of Engineering, Utah State University, Logan, Utah.

(d) Experimental theoretical field investigation; basic research for doctoral thesis.

(e) A basic study of parameters involved in flow in steep, rough channels where the roughness is relatively an appreciative part of the depth, and where channels are sufficiently steep that super critical flow can occur in connection with contractions caused by the roughnesses. The work is basic, however, it could have application to steep mountain streams and to hydraulic structures. Basic over-all parameters have been investigated for simple cases. The continuing project will study the effect of a single roughness inducing super critical flow and acting as a control. The interaction of roughnesses and the effect of roughnesses of distributed sizes will be studied in a sloping flume during this year.

(g) Flow regimes have been classified into three major regimes and seven sub-regimes. Parameters delineating the regimes for very simple roughness cases have been suggested. In the tumbling regime the rough channel acts as a continuing critical depth control, thus a reach of tumbling flow channel may be considered as a "virtual" weir.

(h) "Flume Studies of Flow in Steep, Rough, Open Channels," P. K. Mohenty and Dean F. Peterson presented at meeting of Hydraulics Division, American Society of Civil Engineers, Fort Collins, Colorado, July 1, 1959. Published Journal of the Hydraulics Division, Proc. of the Amer. Soc. of Civil Engrs., Nov, 1960, Vol 86, p. 55.

(3184) FLOW TO PARTIALIY PENETRATING WELL IN AN UNCONFINED AQUIFER.

(b) Laboratory project.

(c) Dr. Dean F. Peterson, Dean of Engineering, Utah State University, Logan, Utah.

(a) Experimental; basic research for doctoral thesis.

(e) The effect of drawdown relative to depth of penetration, well diameter, and relative thickness of aquifer on flow into an ideal partially-penetrating, unconfined well system was studied using a combination electrical and membrane analogue, and an electrical resistance analogue computer. Functional relationships between the geometrical and the flow parameters are proposed based on dimensional considerations and experimental results.

(f) Completed.

(g) The effect of partial penetration for a well of the unconfined type is thoroughly treated.

(h) "Discharge to Partially-Penetrating Wells in Unconfined Aquifers," by Mostafa M. Soliman and Dean F. Peterson. Manuscript still being revised for the Hydraulics Division, Am. Soc. of Civil Engineers.

(b) Laboratory research. 
(c) Dr. Vaughn E. Hansen, Director, Engineering Experiment Station, Utah State University, Logan, Utah.

(d) Experimental; theoretical; basic research.

(e) Hydrodynamic study for movement of water over a porous surface when intake varies with time. Free surface and the rate of advance are defined.

(8) A paper has been completed for publication. It contains the results of basic mathematical developments defining the free surface and the rate of advance. A resulting differential equation must be solved by approximation. Solutions of this equation have been obtained to compare with field measurements of the rate of advance. The results are within ten percent of field observations. Additional studies are now being planned to utilize high speed computers to obtain sufficient typical solutions to permit the development of characteristic of parametric curves so that solutions can be obtained more readily from the complex differential equations.

(h) "Mathematical Relationships Expressing the Hydraulics of Surface Irrigation" paper presented at Agriculture Research Service Meetings March 25, 1960, publication pending.

(3186) EVALUATION OF GROUND WATER IN A NONHOMOGENEOUS, ANISOTROPIC MEDIA.

(b) Laboratory project.

(c) Dr. Vaughn E. Hansen, Director Engineering Experiment Station, Utah State University, Logan, Utah.

(d) Experimental, theoretical; basic research. Two master's theses have been completed.

(e) A variable resistance network has been developed wherein problems of non-homogeneous anisotropic flow can be evaluated. This network has been used to establish the procedure, validity and accuracy of solutions which can be expected from this approach. Boundary conditions necessary for unique solutions and the method of application of boundary conditions have been studied.

(3187) INVESTIGATION OF THE HYDRAULIC AND MECHANICAL CHARACTERISTICS OF SPRINKLERS.

(b) Laboratory project.

(c) Dr. Vaughn E. Hansen, Director, Engineering Experiment Station, Utah State University, Logan, Utah.

(d) Experimental; field investigation.

(e) The basic criterion in the study was to reduce the turbulence in mechanical sprinklers in order to improve the range.

(f) Completed.

(g) Several rather simple modifications in the commercial product could be modified to materially increase the range.

(3188) STEADY FLOW TOWARD AN UNCONFINED WELL.

(b) Laboratory project.

(c) Dr. Vaughn E. Hansen, Director, Engineering
Experiment Station, Utah State University, Logan, Utah.

(d) Theoretical; doctoral thesis.

(e) Unconfined flow toward a well is extremely complex because of the existence of a free surface. The object of this project is to arrive at a more sound mathematical evaluation of the flow by using better boundary conditions when solving the equations. The unsteady flow case is also analyzed. New boundary conditions are evaluated.

(f) Completed.

(g) Boundary conditions have been clarified and equations have developed utilizing the improved boundary conditions. The results have been compared with other methods of computing the free surface shape for flow toward a well. An equation for unsteady flow has also been developed.

(3525) MEASUREMENT OF FLOW FROM HORIZONTAL PIPE BY THE COORDINATE METHOD.

(b) Laboratory project.

(c) Dr. Vaughn E. Hansen, Director, Engineering Experiment Station, Utah State University, Logan, Utah.

(d) Experimental, theoretical; applied research.

(g) The error involved in the conventional method of measurement is shown to be large. The coefficient has been defined and parameters ieveloped so that more accurate measurements can be obtained in a quick, easy method of water measurement.

(h) "Discharge Coefficient in the Coordinate Method of Measuring Pipe Flow," D. L. Bassett, Master's Thesis, Civil Engineering Department, Utah State University, 1952 - a bulletin outlining field procedure to be followed with the methods is now being prepared.

\section{(3526) QUICK COUPLING FOR FLEXIBIE PIPE.}

(b) Laboratory project.

(c) Dr. Vaughn E. Hansen, Director, Engineering Experiment Station, Utah State University, Logan, Utah.

(d) Experimental; design and development.

(e) A coupling which can be light and flexible and also permit ease of coupling and disconnecting flexible pipe in the field is being developed.

(f) Completed.

(g) A coupler has been developed which dces permit ready use in the field.

(3527) DEVELOPMENT OF LOW COST WATER LEVEL RECORDER.

(b) Laboratory project.

(c) Dr. Vaughn E. Hansen, Director, Engineering Experiment Station, Utah State University, Logan, Utah.

(d) Experimental, development.

(e) In general, the available instrumentation for measuring fluctuation in water level is costly. Most equipment is designed for a wide range of application. However many areas require only a limited 
fluctuation in water level. This particularly true in irrigation practice. Objective of the project is to develop a low-cost recorder which will fit these needs and thereby permit a more extensive use.

(g) A water level recorder has been developed which does meet the requirements and is now being modified and adapted for commercial production.

\section{(3528) THE EFFECT OF SEDIMENT PROPERTIES ON THE} ATTENUATION OF AN ULTRASONIC PLANE WAVE.

(b) Laboratory project.

(c) Dr. Gordon H. Flammer, Associate Professor, Civil and Irrigation Engineering Department, Utah State University, Logan, Utah.

(d) Theoretical and experimental; basic research.

(e) The attenuation of an ultrasonic plane wave passing through a homogeneous suspension has been the subject of several theoretical and experimental investigations from which theoretical relations have been obtained. Experimental results cover only part of the range of ratios of sound wave length to particle circumference. Theoretical relations for the range not covered by experimental results ignore sediment properties other than sphericity. Recent experimental work indicates that other sediment properties need to be considered as well. These results were incidental in the study of a measurement technique and hence, were of a preliminary nature. There remains considerable basic research on the effect on the attenuation relation of various sedisphericity, sonic refractive index, absorption, and transparency.

(g) A paper has been written on the "Use of Ultrasonics in the Measurement of Suspended Sediment Size Distribution and Concentration," this paper touches only lightly on the subject of interest here.

\section{(3529) DEVELOPMENT OF LOW COST IRRIGATION WATER} METER.

(b) Cooperative with Irrigation Dept., Univ. of California, Davis, California.

(c) Mr. Jerry E. Christiansen, Professor of Civil and Irrigation Engineering, Utah State University, Iogan, Utah.

(d) Experimental; applied research-development.

(e) Tests on the use of a domestic type water meter as a by-pass meter for irrigation service were conducted on three types of primary head producing divisions for use with water meter.

(f) Experimental work completed. Manuscript in preparation.

(g) Resurts indicate that a small domestic type of water meter can be employed as a by-pass meter for measuring large flows in pipe lines with a fair degree of accuracy.

\section{(3530) WATER REQUIREMENTS OF WILDLIFE AREAS.}

(b) Utah State Fish and Game Department, Salt Lake City, Utah.

(c) Mr. Jerald E. Christiansen, Professor Civil and Irrigation Engineering, Utah State University, Logan, Utah.

(d) Field investigation; applied research.

(e) Large areas of marshy lands adjacent to Great Salt Lake have been developed and improved by the State Fish and Game Department, and the Federal Wildlife Service, as Migratory Bird Refuges. Available stream flow from several of the major streams flowing into these areas where the water is impounded behind dikes to create habitat suitable for nesting, feeding and resting of water fowl. Millions of ducks and geese utilize this area each year during their migratory flights.

(g) The basic purpose of the study is to determine the quantities of water necessary for this area in order to maintain them in a productive state.

(h) "Water Requirements of Water Fowl Refuges in Utah," J. E. Christiansen, J. B. Low, and M. C. Tsai.

\section{(3842) DEVELOPMENT OF LOW COST IRRIGATION STRUCTURES}

(b) United States Steel.

(c) Dr. Vaughn E. Hansen, Director Engineering Experiment Station, Utah State University, Logan, Utah.

(d) Experimental and field investigation for operation.

(e) This project has been conducted to develop a low-cost prefabricated irrigation structure that can be easily installed by unskilled workmen, and can be adapted to many sizes and shapes of ditches. It will be versatile in that it can be used as a division box, turnout, check, drop, gate, etc., Measuring devices are being developed to add to its many uses. Sizes, shapes, thickness of material to be fabricated, and fastening devices are being determined. Effects of frost and ditchbank stresses are also being studied.

(g) The results will benefit farmers, ranchers and garoners throughout the nation in that it answers a great need in irrigation hydraulics.

(3843) A SHAPE AND FRICTION FACTOR RELATIONSHIP BETWEEN SMOOTH, RECTANGULAR, AND CIRCULAR CHANNELS.

(b) Laboratory project.

(c) Dr. Vaughn E. Hansen, Director Engineering Experiment Station, Utah State University, Logan, Utah.

(d) Theoretical; basic research for master's thesis.

(e) This study is to determine a shape factor relationship so that the friction factors (Moody curves) for circular pipes can be used with rectangular shaped channels. To accomplish this, head loss data will be taken, through a wide range of Reynold's numbérs, from a number of rectangular channels varying from approximately a square to a channel approximately $3 / 8$ inches $\times 4$ inches.

Only one material will be used in constructing the channels and the narrow 
dimension of the channel will be held constant. Friction factor values for circular pipe have often been used for shapes other than circular; and for shapes that are not too far from a circle, the error isn't appreciable; however, for channels that are far removed from a circle.

(g) It is anticipated that this study will result in more realistic friction factors for rectangular channels.

(h) Publication pending master's thesis.

(3844) THE REMOVAL OF HIGH TURBIDITY WITH RAPID SAND FILTERS.

(b) Laboratory project.

(c) Dr. Vaughn E. Hansen, Director, Engineering Experiment Station, Utah State University, Logan, Utah.

(d) Experimental; theoretical, basic research for a master's thesis.

(e) A study of the efficiency of rapid sand. filtration is conducted under conditions of varying initial turbidity and application rate. The turbidity ranges from 50 to 400 parts per million and the flow rate from 2.5 to $5.5 \mathrm{gal} / \mathrm{min} / \mathrm{ft}^{2}$ of filter area. The same sand $0.505 \mathrm{~mm}$ mean diameter, is used in all the tests; and its depth is held constant at 30 inches. The filter is constructed from a plastic tube, $31 / 2$ inches in diameter to minimize wall effects, and is equipped with an overflow so a constant head of 44 inches can be maintained above the sand.

(g) By studying the realtionships between initial turbidity, flow rate, the final turbidity, it is hoped that a system can be obtained whereby rapid sand filters can be utilized in the removal of high turbidity without prior sedimentation. This kind of filtration would be useful in a pressure-irrigation system where the finished product need not be so highly polished as in a culinary system.

(h) Publication pending master's thesis.

\section{(3845) WATERSHED MODEL STUDIES.}

(b) Agricultural Research Service, U. S. Department of Agriculture.

(c) Dr. Vaughn E. Hansen, Director Engineering Experiment Station, Utah State University, Logan, Utah.

(d) Experimental; for master's thesis.

(e) A study of the simulation of the run-off hydrograph (the graphical representation of the discharge versus time relationship for a given point in the stream channel) shape for a typical small southwestern arid watershed.

For this study, a small watershed will be modeled in size, shape, and topography encompassing provisions for varying the permeability of the model's surface. Water to represent precipitation in various patterns will be applied over the model watershed.

By the nature of the proposed study, the dominant factors influencing the characteristic shape of the run-off hydrography are: (1) Watershed shape, (2) Rainfall intensity, (3) Rainfall duration, (4) Time element being a function of a composition roughness factor.

The study is divided into two phases. In the first phase, the object is to simulate the run-off hydrography using a physical model with an impervious surface. Thus, it is known that the simulated hydrography will be distorted volumetrically. The second phase has the same objective as the first, except refining the simulation by removing the distortion of run-off volume. The second phase has the added objective of an investigation of the relationship between infiltration and run-off.

(g) A better understanding of the parameters influencing the rainfall-run-off relationship of arid southwestern watershed will be obtained. Ultimately, this will result in better design of structures built to contain, convey, or bridge the run-off water of this area.

(3846) CONSTRUCTION OF AN INTERSTATE HIGHWAY ACROSS THE SALT FLATS NEAR WENDOVER, UTAH.

(b) Utah State Road Commission

(c) Jerry E. Christiansen, Professor, Civil and Irrigation Fngineering, Utah State Univ., Logan, Utah.

(d) Field investigation for design and development of Interstate highway.

(e) The design and construction of an interstate highway across the salt flats near Wendover, Utah, poses a number of problems that require solutions. This is one of the few places in the world where a highway must be built over a salt bed. The maintenance of the present highway and railway that traverses these salt flats has been difficult. It is hoped that a better understanding of the problem, based on extensive field and laboratory investigations of materials on which the highway will be built, will result in a design that will be relatively free of maintenance problems. The objective, therefore, is to fully determine the characteristics of the salt bed and the underlying soil materials to considerable depth. The work completed to date has been concerned primarily with the permeability of the subsoil materials to the flow of water. Surprisingly, it has been found there are very permeable strata underlying the salt. These are of considerable concern because of the movement of partially saturated solutions through these permeable zones which tends to dissolve and remove salt, resulting in uneven settlement of the roadway.

(g) A sound and economic design depends opon a complete knowledge of the materials involved. Investigations should be of definite practical value in determining the basic requirements for the design and construction of the multimillion dollar highway, which will be built within the next few years. Economies in design should result from the studies being undertaken.

(h) "Pumping Tests on Salt Flats" progress report by J. E. Christiansen, Derle Thorpe, 
Terrell Tovey, B. B. Patil and Will Morin, October, 1960.

WASHINGTON STATE UNIVERSITY, The R. L. Albrook Hydraulic Laboratory.

Inquiries concerning the following projects should be addressed to Dr. E. Roy Tinney, Head, The R. L. Albrook Hydraulic Laboratory, Division of Industrial Research, Washington State University, Pullman, Washington.

\section{(1689) STUDY OF FLUID FLOW IN PIPE NETWORKS.}

(b) Personnel responsible for the design and/or operation of water and gas distribution systems.

(d) Analyses by analogue and digital computers.

(e) Flow distributions have been made with the McIlroy Analyzer for over forty cities, several gas systems, an air system, a generator cooling system, and several other unique systems. Losses throughout the system are obtained. Engineers use the analogue to design system pumps, tanks, and piping additions or revisions. A program has been prepared whereby some of the problens not readily solvable by the McIlroy Analyzer can be analyzed on an IBM digital computer.

(2165) THE INFLUENCE OF LOGGING OPERATIONS ON RUN-OFF FROM PRECIPITATION.

(b) Laboratory project.

(d) Analytical with field investigation.

(e) Analysis of the run-off from watersheds on which extensive logging has been done was conducted to determine the correlation between run-off and logging in regions where the rainfall is heavy and regrowth rapid.

(f) Completed.

(h) Paper submitted for publication.

(2631) ROCKY REACH HYDROELECTRIC DEVELOPMENT.

(b) Chelan County Public Utility District No. 1 .

(d) Experimental; design.

(e) A 1:75 model 109 feet by 40 feet has been constructed of 7500 feet of the Columbia River to study construction phases and the operation of the complete development of the Rocky Reach site. Studies have been completed on the cofferdam layouts and tests are now underway on the operation of the spillway and fishway entrances. In addition, a $1: 44.9$ scale model of two bays of the spillway has been constructed and installed in a large glass-sided flume to determine specifically the design of baffles on the apron and nappe deflectors on the ogee. A 1:45 model of four bays of the truncated spillway has been built and tested to determine causes of and remedial measures for apron erosion by the diverted flow. A 1:45 model of seven bays of the spillway has been built and is being testen to determine the limits for non-unifurm uperation of the gates which might be detrimental to the baffle system.

(g) Erosion that occurred during diversion stages has been traced to upstream gravel collecting in eddies on the apron. The eddies moved the rock over the concrete surfaces and ground holes in the apron.

(h) Status reports to the client. Final reports in preparation.

(2632) PRIEST RAPIDS PENSTOCK GATE STUDIES.

(b) Pacific Coast Engineering Company.

(d) Experimental; design.

(e) A 1:18 model of fixed wheel intake gates for the Priest Rapids Hydroelectric Project has been constructed to determine the hydraulic downpull for several lip designs. A generalized study has also been made to investigate various designs of intake gates with a view toward a more economical design of gates and gantry cranes.

(f) Completed.

(h) Fi:lal report to client.

(2878) HYDRODYNAMICAI STUDIES.

(b) Laboratory project.

(d) Theoretical and experimental.

(e) A mathematical analysis of segmental flip buckets has been developed using free streamline theory. Analysis gives the relation between the dimensions of the bucket, the thickness of the nappe, the face angle of the dam, and the exit angle of the jet. Evaluation of the integrals arising from the conformal transformation has been made using an IBM 650 digital computer. Experimental testing to confirm theoretical analysis has been completed.

(h) Master's Thesis at Washington State Univ., "Laboratory Investigations of Trajectories from Segmental Flip Buckets," by Howard Copp. Paper submitted for publication.

\section{(2879) HYDRAULICS OF LEVEL IRRICATION.}

(b) Laboratory project cooperative with the Department of Agricultural Engineering, Washington State University.

(d) Theoretical and experimental.

(e) Analysis is being developed to define rate of advance and recession of the water front on a level irrigation border taking into account the infiltration. A tilting flume 75 feet long, 3 feet wide and 2 feet deep has been erected. A mechanical apparatus to simulate infiltration is being installed.

(g) Theoretical and experimental results agree well.

(h) Paper submitted for publication.

(3192) ADVANCE OF A SHALLOW LIQUID FRONT DOWN A DRY CHANNEL.

(b) National Science Foundation Grant.

(d) Theoretical and experimental; basic research. 
(e) Mathematical analysis of equations is being conducted. Experiments will be conducted in a tilting flume to supplement and verify the theoretical approach. A glass-lined tilting flume has been completed and tests with oil are underway.

(g) Theoretical analysis is confirmed by results from ( $2 \varepsilon 79$ ) above.

(h) Paper on mechanics of advance of liquid front to be presented at Phoenix convention ASCE, April 1961.

\section{(3531) WANAPUM MODEL.}

(b) Harza Engineering Company.

(d) Experimental; design.

(e) A l:20 scale comprehensive model has been constructed of the Wanapum Project on the Columbia River. Cofferdam studies have been completed. Further tests have been concerned with velocity patterns and magnitudes in the vicinities of the fish ladders and spillway apron.

(h) Status reports to the client.

(3532) DIAMOND NATIONAL MODEL.

(b) Diamond National Corporation.

(d) Experimental; design.

(e) A distorted model, 1:150 horizontal scale 1:60 vertical scale, has been built of the Pend Oreille River downstream of Albeni Falls Dam. This model has been used to study the formation and growth of a sediment bar in the log booming area and with corrective and preventive measures to insure adequate depth for booming operation in slack water. Sediment samples have been collected and analyzed to determine the origin of bar deposits.

(f) Completed.

(h) Reports to the client.

(3533) NOXON MODEL.

(b) Ebasco Services.

(d) Experimentar; design.

(e) A flume model to a scale of 1:50 has been constructed and tested to determine methods of preventing excessive erosion of the baffle teeth. An additional 1:50 scale model has been built and is being tested to determine the non-uniform gate openings permissible without detrimental results to the baffles.

( $\mathrm{g})$ Reshaping of the baffle teeth and nappe deflectors on the spillway indicate good energy dissipation without serious erosion of the structure or river bed and without low pressures.

(h) Report to client.

(3534) WELLS MODEL.

(b) Bechtel Corporation.

(d) Experimental; design.

(e) A 1:45 flume model of the spillway for the proposed Wells Dam was built and tested. These tests of the preliminary design were made to insure a satisfactory design from the standpoints of bed erosion, pressures on spillway and pier, and discharge rating of the spillway. Additional tests have also been made on a unique spillway design that is essentially a hollow shell stabilized with anchored piers.

(f) Completed.

(h) Report to client.

\section{(3847) CHUNGJU HYDROELECTRIC PROJECT.}

(b) Bechtel Corporation, San Francisco, Calif.

(d) Experimental; design.

(e) Two models for the Chungju project have been built and tested. A 1:50 flume model of two full and two half bays of the spillway was used to evaluate energy dissipators. A l:100 comprehensive model was used to study flow pattern in powerhouse tailrace and general spillway flows.

(h) Final report to client.

\section{(3848) CALIBRATION OF FLOW METERING FLUMES.}

(b) Agricultural Research Service, Boise, Idaho.

(d) Experimental; design.

(e) Metering flumes are being placed on several watersheds in southern Idaho. Models of these flumes are to be tested to determine the desirable shape, location of head measuring taps, orientation, and elevation of invert. The effect of flow rate, upstream and downstream topography, and sediment will be considered. One model to a scale of 1:30 has been built and the tests are nearly completed.

(h) Status reports to client.

\section{(3849) NON-CIRCULAR CONDUITS.}

(b) Laboratory project supported in part by Nat. Acad. Sciences grant to Dr. Jamil Malaika.

(d) Theoretical and experimental.

(e) The effect of hydraulic radius on friction loss in fully turbulent region will be studied by using circular, elliptical, rectangular, and rhombic cross-sectional shapes for the conduit.

\section{(3850) OXBOW FUSE PLUG.}

(b) Idaho Power Company, Boise, Idaho.

(d) Theoretical and experimental design.

(e) Since one spillway at Oxbow Dam will carry the flood of record, a small rock fill structure called a fuse plug was used in lieu of gates for the second spillway. Tests on $1: 40$ and $1: 20$ scale models were conducted to determine the mechanics of washout. A half-scale model approximately 14 feet high and 60 feet long was built at the dam site. This model was washed out by diverting the Snake River. Erosion rates were recorded in several ways to indicate the nature of the washout process and the effect of the type of embankment material on washout rates.

(f) Completed.

(g) Good correlation between laboratory models results and theory. Field model indicated 
the regularity of the washout process and the initial breaching action.

(h) "The Mechanics of Washout of an Erodible Fuse Plug" by E. Roy Tinney and H. Y. Hsu, paper presented at ASCE Boston Convention October 1960, and later submitted for publication.

UNIVERSITY OF WASHINGTON, Fisheries Research Institute.

(3535) EFFECTS OF LOGGING ON PRODUCTIVITYY OF PINK SALMON STREAMS IN ALASKA.

(b) Bureau of Commercial Fisheries, U. S. Fish and Wildlife Service, Juneau, Alaska, is contracting agency. Co-operating agency is Alaska Forest Research Center, U. S. Forest Service, Juneau, Alaska.

(c) Mr. Robert L. Burgner, Assistant Director, Fisheries Research Institute, University of Washington, Seattle 5, Washington.

(d) Experimental, theoretical, and field investigation; basic and applied research, including master's and doctoral thesis research.

(e) Objectives of the research program are: (1) To identify environmental factors causing mortality of pink salmon embryos, (2) to gain a more complete understanding of irterrelationships among spawning behavior, physical and biological attributes of the stream and spawning bed, and mortality of embryos, (3) to determine how the quality of the spawning-bed environment as it pertains to growth, development, and mortality of embryos is affected by logging, and (4) to determine criteria for the improvement of natural spawning areas to increase production of juvenile salmon. Included among active routine studies are hydrological conditions, intragravel water quality, spawning bed quality, and channel debris evaluation. Included among active basic studies are composition and source of suspended sediment and bed load, relationship between gravel composition and permeability, exchange between surface and intragravel water, and sources of intragravel water.

(g) Methods have been developed for routine field measurement of dissolved oxygen content of intragravel water, gravel composition, and mortality of salmon embryos. Gravel shift has been identified as an important natural cause of embryonic mortality. A theoretical model of fáctors controlling interchange between stream and intragravel water has been proposed and tested qualitatively.

(h) "Logging and Salmon," Staff. Fisheries Research Institute Circular No. 105, 12 pp. Sept. 1959.

"Interchange of Flowing Stream and Intragravel Water," Walter G. Vaux and William. L. Sheridan, Fisheries Research Inst.

Circular No. 115, 4 pp. mimeo, Feb. 1960. "Measurement of Gravel Composition of Salmon Streambeds," W. J. McNeil and W. H. Ahnell, Fisheries Res. Inst. Cir. No. 120,
6 pp. mimeo, April 1960.

"A Hyaraulic Sampler for Collecting Salmon Embryos in Spawning Beds," W. J. McNeil, Fisheries Res. Inst. Cir. No. 128, 8 pp. mimeo., Nov. 1960.

UNIVERSITY OF WASHINGTON, Charles W. Harris Hydraulics Laboratory.

(3536) A MODEL STUDY OF DOWNSTREAM MIGRANT COLLECTION FACILITIES ON MAYFIELD DAM, COWLITZ RIVER.

(b) City Light Company, Tacoma, Washington.

(c) Prof. E. P. Richey, 201 More Hall, Univ. of Washington, Seattle 5, Washington.

(d) Experimental investigation; design verification and/or correction.

(e) Primary separation by Louvre screens in power channel; fish bypassed through cascade of vanes in pier and conducted to secondary separator basin and separated by overflow weir.

(f) Completed.

(g) Louvre design verified. Operating characteristics of vane separator determined Design of secondary separating basin has been determined and operating characteristics verified.

(h) Report to Department of Public Works, Major Projects Division, Tacoma, Washington. Contact this agency for copy of report.

\section{(3537) FLOW VISUALIZATION ABOUT A SALMON.}

(b) Salmon Fatigue Laboratory, University of Washington, Seattle 5, Washington. In cooperation with the U. S. Department of Navy, Naval Ordnance Test Station, China Lake, California.

(c) Dr. Joseph Kent, University of Washington, Seattle 5, Washington, and Mr. Wallace Allen, NoTS, China Lake, California.

(d) Basic research.

(e) To photograph the pattern of turbulence created by a fish swimming in still or moving water with use of plastic beads and dye. To determine magnitude of drag for the flexible fish in comparison to solid bodies.

(3851) A STUDY OF THE RESISTANCE OF AN 18-INCH PLAIN CONCRETE PIPE AND AN 18-INCH HONED CONCRETE PIPE.

(b) United Concrete Pipe Corporation, Baldwin Park, California.

(c) Professor H. S. Strausser, 201 More Hall, University of Washington, Seattle 5, Wash.

(d) Experimental investigation; design.

(e) To determine the resistance of a plain 18-inch concrete pipe and the same pipe after honing. Hazen-Williams, Seabeg, Manning and Nikuradse roughness determined.

(f) Completed.

(g) Results for various resistance coefficients were determined for large Reynolds Numbers.

(h) Report submitted to United Concrete Pipe Corporation, Baldwin Park, California. Contact this company for copy of report. 
(3852) A STUDY OF THE USE OF GUIDE VANES IN A $90^{\circ}$ UNSYMMETRTCAL MITERED BEND.

(b) Laboratory project.

(c) Prof. H. S. Strausser, 201 More Hall, Univ. of Washington, Seattle 5, Washington.

(d) Experimental and theoretical investigation; M. S. Thesis .

(e) To study the geometry of guide vanes necessary to produce uniform velocity distribution downstream from a $90^{\circ}$ mitered bend where entrance and exit areas are different, open channel approach, conduit discharge.

\section{(3853) FLOW THROUGH AN ARRAY OF CYLINDERS.}

(b) Laboratory project.

(c) Prof. Ronald E. Nece, Department of Civil Engineering, University of Washington, Seattle 5, Washington.

(d) Experimental; M. S. Thesis.

(e) Hydrodynamic forcss are to be determined on one of a row of circular cylinders oriented obliquely with respect to a uniform approach flow. Cylinder spacing and angular orientation of the single row are to be varied. This is an initial step in a study of flow through oblique louver systems.

UNIVERSITY OF WISCONSIN, Hydraulics Laboratory.

(149) THE EFFECT OF SUBMERGENCE ON FLOW CHARACTERISTICS OF HYDRAULIC STRUCTURES.

(b) Laboratory project.

(c) Prof. J. R. Villemonte, Hydraulics Lab., Univ. of Wisconsin, Madison 6, Wisconsin.

(d) Theoretical and experimental; basic and applied research for M.S. degree.

(e) The effects of submergence on discharge of large circular thin-plate weirs and orifices and broad-crested weirs are being studied.

(g) General correlation equations have been developed for all thin-plate weirs Parshall Flumes, and one type of Ogee spillway.

(368) DEVELOPMENT OF A FLOOD FORECASTING PROCEDURE FOR THE WISCONSIN RIVER.

(b) Laboratory project.

(c) Dr. A. T. Lenz, Chairman of Dept. of Civil Engineering, University of Wisconsin.

(d) Experimental; M.S. thesis.

(e) Fundamental studies of rainfall-runoff relations were made to estimate runoff values to be used in flood forecasting by the unit hydrograph method.

(f) Suspended.

(g) Six M.S. and two Ph.D. theses have been completed and are available on loan.

(956) ENERGY LOSS IN LIQUID FLOW IN PIPES AND FITTINGS UNDER HIGH PRESSURE.

(b) Laboratory project in cooperation with the Ladish Company, Cudahy, Wisconsin, and the Wisconsin Alumni Research Foundation. (c) Prof. J. R. Villemonte, Hydrauiics Laboratory, Univ. of Wisconsin, Madison 6, Wis.

(d) Theoretical and experimental; applied research and design for B.S., M.S. and Ph.D. theses.

(e) Energy loss measurements in straight pipes and fittings have been completed on sizes $1 / 4$ inch to 2 inches. Pressure range 0-2500 psi, temperature range 60 to $120^{\circ} \mathrm{F}$. Reynolds number range 50 to 150,000 .

(f) Suspended.

(g) If viscosity, density, and temperature relations are known, the standard pipe friction theory applies at high pressures. The fitting loss constants for laminar flow are about 3 times those for turbulent flow when $\mathrm{N}_{\mathrm{R}}=2000$. The loss gradually reduces to zero at $\mathrm{N}_{\mathrm{R}}=150$.

\section{(957) THE THERMODYNAMICS OF LIQUIDS.}

(b) Laboratory project cooperative with the Dynex Corporation, Milwaukee, Wisconsin.

(c) Prof. J.R. Villemonte, Hydraulics Laboratory, Univ. of Wisconsin, Madison 6, Wis .

(d) Theoretical and experimental; basic and applied research for Ph.D. thesis.

(e) New equipment has been assembled to increase the pressure range to 10,000 psi. The viscosity-pressure-temperature relation ships for several petroleum oils will be studied using the Gunaji high-pressure falling sphere viscometer.

(f) Suspended.

(g) A general correlation has been developed for the viscosity-pressure-temperature relationships for five industrial petroleum oils. Pressure range 0-2000 psi, temperature range $60-120^{\circ} \mathrm{F}$.

(959) HYDROLOGIC INVESTIGATION OF LAKE MENDOTA DRATNAGE BASTN.

(b) Part of a larger project entitled "Origin and Quantities of Algal Fertilizers Tributary to Lake Mendota." Cooperative study sponsored by University of Wisconsin.

(c) Dr. A. T. Lenz, Chairman of Department of Civil Engineering, University of Wisconsin, Madison 6, Wisconsin.

(d) Field investigation; applied research for Ph.D., M.S. theses.

(e) Five stream gaging stations have been installed to measure tributary inflow to Lake Mendota and Yahara River outflow. Precipitation records are being obtained from fourteen recording rain gages. Current efforts are concentrating on publication of summary of resuits to date.

(f) Suspended.

(g) Three M.S. and six B.S. and two Ph.D. theses completed, (available on loan).

(1181) VORTEX FLOW FROM HORIZONTAL THIN-PLATE ORIFICES.

(b) Wisconsin Alumni Res. Foundation and J.C. Stevens, Consulting Engr., Portland, Oregon.

(c) Prof. J.R. Villemonte, Hydraulics Laboratory, University of Wisconsin, Madison 6, Wis .

(d) Theoretical and experimental; basic research 
for M.S. and Ph.D. theses.

(e) The effects of vorticity on orifice discharge were studied over a wide range of vorticity, head, and orifice size.

(g) A new parameter, the vortex number, was developed as the ratio of inertial and centrifugal forces. A general correlation procedure was also developed for estimating discharge rates through orifices with varying degrees of vorticity.

\section{(1707) PROBLEMS OF SCOUR AT BRIDGE AND CJLVERT} OPENINGS.

(b) Consolidated's Civic Foundation, Inc.

(c) Dr. A. T. Lenz, Chairman, Dept. of Civil Engineering, Univ. of Wis., Madison 6, Wis .

(d) Experimental; for M.S. and B.S. theses.

(e) Hydraulic model studies were made to determine methods of estimating probable scour pattern for a proposed structure having certain physical site characteristics and conditions of flow. Remedial methods were studied at existing structures so scour will be reduced or eliminated.

(f) Completed.

(g) Causes of scour at one location were correlated with topography and water levels. Study of the design of training walls to get better flow under the bridge structures was completed.

(h) Three M.S. theses are available on loan.

(1709) CALIBRATION OF V-NOTCH WEIRS AT ENDS OF CULVERTS.

(b) Wisconsin Culvert Co.

(c) Dr. A.T. Lenz, Chairman, Dept. of Civil Engineering, Univ. of Wis., Madison 6, Wis.

(d) Experimental; for M.S. and B.S. theses.

(e) A $90^{\circ} \mathrm{V}$-notch was installed in a rectangular flume and was used as a control for flows up to and above the top of the weir plate.

(f) Completed.

(g) Mathematical interpretation of the flows as the summation of $\mathrm{V}$-notch and rectangular weir flows was made and coefficients determined to express the total flow as a function of the head above the bottom of the V-notch.

(h) One B.S. thesis available on loan.

\section{(3538) ANALOG MODELS OF GROUNDWATER FLOW.}

(b) Marathon Paper Co., Wasusu, Wisconsin.

(c) Dr. A.T. Lenz, Chairman of Dept. of Civil Engineering, Univ. of Wis., Madison 6, Wis.

(d) Experimental; M.S. thesis.

(e) This problem deals with the movement of two miscible fluids of different densities in an aquifer - one is water and the other is a waste product from the manufacture of paper.

The problem is analyzed by utilizing an electric analog plotter and by a two-dimensional hydraulic model.

(g) One M.S. thesis is available on loan.

(3539) THE EFFECT OT BOUNDARY ROUGHINESS AND CONFIGURATION ON TURBULENCE LEVEI AND VELOCITY DISTRIBUTION . (b) Wisconsin Alumni Res. Foundation

(c) Prof. J. R. Villemonte, Hydraulics Laboratory, Univ. of Wisconsin, Madison 6, Wis.

(d) Theoretical and experimental; basic research for M.S. and $\mathrm{Ph} . \mathrm{D}$. theses.

(e) New instrumentation has been developed to measure turbulence levels in pipes and ducts. The effects of boundary roughnesses on the decay of extra turbulence caused by a variety of boundary configurations is being studied.

(3540) MODEL STUDIES OF PUMP INLET STRUCTURES.

(b) Wisconsin Alumni Res. Foundation in cooperation with the Government of West Bengal, India.

(c) Prof. J. R. Villemonte, Hydraulic Laboratory, University of Wisconsin, Madison 6, Wis .

(d) Experimental; design for M. S. thesis.

(e) A 1/16-scale model of the inlet structure for one of four axial flow pumps at the Uttarbhag Pumping Station (Sonarpur, India) has been made. Studies of inlet flow patterns and pressure coefficients for a wide variety of flow situations are being made for the purpose of reducing the cavitation threshold.

(3541) HYDRAULIC CHARACTERISTICS OF CIRCULAR SEDIMENTATION BASINS.

(b) National Institute of Health, Washington, D. C.

(c) Prof. G. A. Rohlich and Prof. H. R. Villemonte, Hydraulics Laboratory, Univ. of Wisconsin, Madison 6, Wisconsin.

(d) Experimental; basic research and design for M.S. and Ph.D. theses.

(e) A versatile, transparent, 6-ft dia. cylindrical basin has been constructed which will permit model studies at depth to diameter ratios of 0.67 to 0.083 . Flow patterns and dispersion characteristics will be otserved over a wide range of overflow rates. New instrumentrtion for measuring small velocities and dispersion functions are being developed.

\section{(3542) RESEARCH ON FLOW IN CULVERTS.}

(b) Laboratory project.

(c) Dr. J. G. Woodburn, Prof. of Civil Engineering, Univ. of Wisconsin, Madison 6, Wis .

(d) Theoretical and experimental; design; M. S. and $\mathrm{Ph} . \mathrm{D}$. theses.

(e) Hydraulic characteristics of a variety of culvert models will be studied, with particular attention to the location of critical depth under various conditions of inlet and discharge control.

(3854) REACTION JET INLET FOR OIL-WATER SEPARATORS.

(b) The American Petroleum Institute.

(c) Professor G. A. Rohlich and Professor James R. Villemonte, Hydraulic and Sanitary Lab., College of Engineering, Univ. of Wisconsin, Madison, Wis.

(d) Experimental; basic research and design for master's and doctoral theses. 
(e) A transparent basin 5 feet wide, 10 feet long, and 3 feet deep has been constructed. Investigations will be made using various sizes and spacings of the stengel reaction jets at the entrance to the basin to determine the effects of jet inflow on the hyaraulic characteristics.

WOODS HOLE OCEANOGRAPHIC INSTITUTION.

\section{(3855) DIRECTIONAL SPECTRUM OF A WIND GENERATED SEA.}

(b) U. S. Navy Bureau of Ships, Davia Taylor Model Basin; Office of Naval Research and NSF.

(c) Mr. Raymond G. Stevens, Woods Hole Oceanographic Institution, Woods Hole, Mass.

(a) An experimental observational program of ocean waves in their natural state considered as a program in basic research.

(e) Wave heights as a function of time will be observed at six points on a linear array. Various methods of data analysis will be employed in order to determine the directional spectrum of the wind generated waves. A comparison will be made of locally generated wave spectra with waves generated in a large oceanic basin. The ultimate purpose of this research is to investigate the possibility of scaling open ocean waves to those encountered in a semi-sheltered basin, with the view of using natural basins and bays as ship model testing basins.

(f) Observations of wind generated waves for various wind velocities have been made using a six point linear array. Observations have been conducted at Buzzards Bay and Panama City, Florida. Preliminary data processing is underway.

(h) See "Ocean Wave Slope Measurement"

(3856) OCEAN WAVE SLOPE MEASUREMENT.

(b) National Science Foundation and office of Naval Research, Dept. of the Navy.

(c) Mr. Harlow G. Farmer, Jr., Research Associate in Hydraulics, Woods Hole Oceanographic Institution, Woods Hole, Mass.

(d) An experimental observation program of ocean waves in their natural state considered as a program in basic research.

(e) Observations of wave slopes were made by measurement of the height difference at three closely spaced points. The observing device consisted of three resistance wires suspended vertically from a fixed frame. The resistance at each wire is proportional to the wave height; the difference between the resistance of adjoining pairs is taken to be the wave slope.

(f) The observational phase of this work is completed and slope frequency distributions have been analyzed.

(h) The instrumentation employed in this work was described at the Seventh Conference on Coastal Engineering held at the Hague, Netherlands in August 1960 and will appear in the proceedings of that conference as
"An instrumentation system for wave measurements recording and analysis" Harlow G.

Farmer, and David D. Ketchum, Proceedings of Seventh Conference on Coastal Engineering in preparation.

WORCESTER POLYTECHNIC INSTITUTE, Alden Hydraulic Laboratory.

Inquiries concerning the following projects should be addressed to Prof. I. J. Hooper, Director, Alden Hydraulic Laboratory, Worcester Polytechnic Institute, Worcester 9, Mass.

\section{(1963) METER CALIBRATION.}

(b) Foxboro Company, Foxboro, Mass.

(d) Experimental; for design.

(e) Calibration of various sizes from $1^{\text {" to }} 36^{\text {" }}$ diameter magnetic flow meters.

(3544) SWING CHECK VALVES.

(b) Atwood and Morrill Co.

(d) Experimental; for design.

(e) Tests including determination of pressure drop, leakage, disc orientation were conducted on a variety of valves varying in nominal size from 2 " to $16^{\prime \prime}$.

(g) Tests in progress.

\section{(3545) HYDRAULIC CYCLONE.}

(b) Bird Machine Co.

(d) Experimental; for design.

(e) Evaluation of the percentage break up of the flow between accepts and rejects in a cyclone type separator were determined. Character of flow in three different flow sections also analyzed.

(g) Tests in progress.

(3546) SUN OIL CO. - SINCLAIR REFINING CO.

(d) Experimental; for design.

(e) A l/100 horizontal scale and 1/50 vertical scale model of a section of the Delaware River was constructed to study the flow pattern in the river area adjacent to structures owned and operated by Sun Oil Co. and Sinclair Refining Co.

(f) Tests completed.

(3547) TRONERAS PROJECT.

(b) Gannett, Fleming, Cordary and Carpenter, Inc.

(d) Experimental; for design.

(e) A $1 / 43$ scale model of a diversion tunnel intake was constructed along with a section of the Guadalupe River upstream of the intake. The flow pattern for a range of expected flows was studied. In addition flow studies and pressure measurements in the intake were made.

(f) Tests completed.

(3548) OTISCO DAM.

(b) O'Brien and Gere. 
(d) Experimental for design.

(e) A $1 / 20$ scale model of a section of the river bed including the old, new and rebuilt spiliways have been constructed. It is proposed to study the flow pattern over the new spillway plus emergency channels with a view to locating guide walls, gate structures, spilling pool boundaries and a section of highway.

(g) Tests in progress.

\section{(3857) METER CAIIBRATION.}

(b) General Controls Co., Foster Div.

(d) Experimental; for design.

(e) Laboratory calibration of various meters from 2" to 24 " diameter.

(3858) METER CALIBRATION.

(b) B-I-F Industries Inc.

(d) Experimental; for design.

(e) Calibration of open flow nozzles and venturi meters up to $48^{\prime \prime}$.

\section{(3859) NIAGARA POWER PROJECT.}

(b) Unl, Hall and Rich.

(d) Experimental; for design.

(e) A l/25 scale model of one section of power conduit plus gate structure has been installed in a $3 \mathrm{ft}$. glass sided flume. A model gate and stop logs have been fabricated. Tests will be conducted of the planned conduit filling operation during which the dynamic forces on the stop logs will be measured.

(g) Test in progress.

\section{(3860) SMITH MOUNTAIN HYDROELECTRIC DEVELOPMENT.}

(b) Ebasco Services, Inc.

(d) Experimentzl; for design.

(e) A l/60 scale model of a section of the Roanoke River was duplicated including the arch dam, spillways, and chutes, powerhouse, and penstocks. Studies included spillway performance, energy dissipation in river below spillway chutes, powerhouse penstock and tailrace flow conditions and the second stage diversion schemes.

(f) Tests in progress.

\section{(3861) SMITH MOUNTAIN PROJECT.}

(b) Sollitt Construction Co.

(d) Experimental; for design.

(e) A 1/60 scale model of the river bed at the construction site was constructed. The model included various structures necessary for stream diversion during the first phase of construction. Details studied on the model included upstream and downstream cofferdams, retaining walls, bed excavation and location of construction bridge piers.

(f) Tests in progress.

(3862) RENCA THERMAL PLANT.

(b) Ebasco International.

(d) Experimental; for design. (e) A $1 / 6$ scale model of the supply flume and suction piping to each of two condenser coolant pumps was constructed of plexiglass. Flow conditions in the approaches, pump bell section and reducing elbow are to be studied.

(f) Tests in progress.

(3863) STABILITY OF HOLLOW NOSE BULLETS.

(b) Laboratory project.

(d) Theoretical and experimental; basic research for M.S. thesis.

(e) The stability and flight characteristics of the hollow point bullet were studied and compared with other more common shapes. Experimental work performed on a flow table was used to supplement theoretical analysis.

(f) Completed.

(g) The hollow point used in studies was found to have definite advantages as to stability when compared with ogive noses.

(h) "The Stability Characteristics of a Hollow Point Burlet," M.S. Thesis at Worcester Polytechnic Institute.

\section{(3864) CAVITATION ON AN ACCELERATING BODY.}

(b) Laboratory project.

(d) Theoretical and experimental; basic research for M.S. thesis.

(e) Development of cavitation on the surface of a rapidly accelerating disc was studied. Data taken photographically using equipment set up for work under Bureau of Ordnance development contract.

(f) Completed.

(h) "An Experimental Investigation of Cavitation Growth Behind a Sharp Edged $45^{\circ}$ Beveled Disk caused by Motion Imparted by Impact," M.S. Thesis at Worcester Polytechnic Inst.

\section{ACCURATE PRODUCTS COMPANY.}

\section{(3865) DUCTED PROPELLERS.}

(b) Office of Naval Research, Department of the Navy.

(c) Dr. Peter G. Buehning, 400 Hillside Avenue, Hillside, New Jersey.

(d) Theoretical; basic research.

(e) Investigation of the effect of propeller diameter and rpm on efficiency of ducted propellers with and without guide vanes taking into account friction on blading and enclosure. Analysis of flow pattern and development of design procedures.

(8) The ducted propeller with guide vanes has been analyzed; curves have been obtained permitting matching of propeller diameter and rpm for optimum overall efficiency of the unit.

UNIVERSITY OF CALIFORNIA, College of Agriculture, Department of Irrigation.

(21) THE MECHANICS OF WATER DROPLET AND SPRAY 
FORMATION FROM SPRINKLER NOZZLES.

(b) California Agricultural Experiment Station.

(c) Dr. J.R. Davis, Department of Irrigation, University of California, Davis, Calif.

(d) Experimental; theoretical and laboratory investigation.

(e) Investigations to evaluate the causes of wave formation of the jet, to evaluate the nature of the wave system, and to determine the relation between turbulence in the nozzle and the formation of discontinuous water arops.

(g) Results include the development of the electric needle technique for describing the frequency, amplitude and wave length of the wave system.

(23) HYDROLOGY OF IRRIGATION SUPPLIES IN CALIFORNIA.

(b) California Agricultural Experiment Station.

(c) Prof. R. H. Burgy and W. D. McMillan, Department of Irrigation, University of Calif. Davis, California.

(d) Experimental and field investigation; applied research.

(e) Evaluation of the hydrologic effects of various watershed management practices is under study on several upland drainages. Diamond drilling equipment was used to install piezometers and access tubes in one mountain watershed for evaluation of the groundwater component of water yield. Lysimeters and meteorological equipment installed in an adjacent area provide continuous measurements of evapotranspiration and potential evapotranspiration.

(h) "Hydrologic Effects of Vegetation Conversion," Report presented to the Control Burning Com., Sportsman's Council of the Redwood Emp. 15 pp., 1960, W. D. McMillan. "Interception Loss From Grass," W. D. McMillan and R. H. Burgy, Jour. Geophys. Fes. 65:2389-2394. 1960 .

(24) MEASUREMENT OF IRRIGATION WATER AND IMPROVEMENT IN FARM IRRIGATION STRUCTURES.

(b) California Agricultural Experiment Station.

(c) Doctors V. H. Scott and J. R. Davis, Dept. of Irrigation, University of California, Davis, California.

(d) Experimental; design.

(e) A study was conducted on the flow characteristics of circular weirs. A discharge formula was developed based on the equation of continuity. The area involved in this equation was expressed in terms of head and weir radius. The velocity was considered to be a function of several factors including head, weir radius, boundary conditions, and fluid properties. The most important of these was considered to be end and bottom contractions, head and weir radius. The equation developed for the velocity included a coefficient of discharge which was defined as a function of end and bottom contractions, head and radius.

(g) The results obtained show that the effect of boundary conditions on the coefficient discharge become zero when the values of the end and bottom contractions are greater than two or three times the weir diameter. When the contractions are greater than this amount, the coefficient of discharge becomes a function of head and radius only. Results obtained in this study indicate that a satisfactory relationship can be developed for the effect of radius on the discharge coefficient. However, experimental data for more than three sizes of weirs would be required in order to describe this relationship satisfactorily. "Flow Characteristics of Circular Weirs," M. Moayeri, M. S. thesis in Irrigation Science. January 1961.

(25) PHYSICAL AND CHEMICAL FACTORS AFFECTING SOIL INFILTRATION RATES.

(b) California Agricultural Experiment Station.

(c) Doctors L. D. Doneen, D. W. Henderson, J. W. Biggar and G. R. Dutt, University of California, Davis, California.

(d) Theoretical and basic laboratory studies and field applied research.

(e) Water management practices for various soils have been continued in the laboratory and field. In addition, emphasis has been placed on the chemical nature of the water by establishing 60 ring infiltrometers with growing crops.

(g) The concentration and the type of mineral constituents in the waters influence the permeability of soils, particularly when changing from one quality to another, which had a marked influonce on infiltration and hydraulic conductivity.

(h) "Boron Adsorption and Release by Soils," J. W. Biggar, and Milton Fireman, Soil Sci. Soc. Amer. Proc. 24(2):115-120. 1960. "Field Infiltration Studies With Green Manures and Crop Residues," W. A. Williams, and L. D. Doneen, Soil Sci. Proc. 24:58-61, 1960 .

\section{(1819) DRAINAGE IN RELATION TO IRRIGATION.}

(b) California Agricultural Experiment Station.

(c) Doctors J. N. Luthin and V. H. Scott, Department of Irrigation, University of Calif., Davis, California.

(d) Experimental and field investigation; basic and applied research.

(e) (1) Drainage of artesian water. An analog solution to the problem of tile drainage of artesian water was presented in an earlier report (1957). In the past year ar analytical solution has been obtained for the same boundary condition. A note has been submitted to Agricultural Engrg. describing the solution and comparing it to other analyses of the artesian problem. (2) Physics of flow towards drains as studied in a drainage laboratory. A drainage tank (50 feet long, 10 feet high, and 3 feet wide) is under construction on the Davis Campus. It will be filled with Oso Flaco sand and should be in operation in the near future. 
(3) Measurement of soil hydraulic conductivity. A method of measuring the soil hydraulic conductivity in the absence of a water table is needed. The procedure which is under development involves the use of a lined well. A $2^{\prime \prime}$ pipe is driven into an auger hole. A cavity is left open at the end of the pipe. The cavity is filled with sand and water is added to the pipe. The rate of flow of water out of the pipe is used in conjunction with some soil moisture measurements to calculate the soil hydraulic conductivity. This method is currently under development. A sector tank equipped with tensiometers has been constructed to make measurements of the flow and to check the theory.

(4) Solution of problems on the voltage analyzer. Additional analyses have been made of flow of water toward tile lines in stratified or layered soils. In particular the movement of the water table in such soils has been examined for nonsteady state conditions. The application of the soil-moisture characteristic curve to non-steady state conditions has been examined and the limitations of this approach pointed out.

(h) "Predicted and Experimental Water Table Drawdown During Tile Drainage," W.

Brutsaert, G. S. Taylor and J. N. Luthin, Manuscript submitted to Hilgardia.

"Ponded Flow Through Layered Soils," G. S. Taylor, R. V. Worstell and J. N. Luthin, VII International Cong. Soil Sci. (in press). "Criteria for Tile Drain Spacings in Artesian Areas," C. Argyriadis and J. N. Luthin, Trans. A.S.A.E. 3:87-89, 1960. "The Falling Water Table in Tile Drainage. II. Proposed Criteria for Spacing Tile Drains," J. N. Luthin, Trans. A.S.A.E. $2: 14-45,1960$.

"The Falling Water Table in Tile Drainage.
III. Factors Affecting the Rate of Fall, " J. N. Luthin and R. V. Worstell. Trans. A.S.A.E. 2:45-48, 1960.

(3866) HYDRAULICS OF SURFACE IRRIGATION SYSTEMS.

(b) California Agricultural Experiment Station.

(c) Dr. J.R. Davis, Department of Irrigation, University of California, Davis, Calif.

(d) Experimental; laboratory and field investigation.

(e) Rational approaches to defining the flow of water in vegetative channels, dimensional analyses and model studies of rate of water advance in borders. Evaluations of criteria for design of tail water return systems, measurement of flow in small irrigation streams, and evaluation of irrigation efficiency concepts.

(g) A method of determining flow rates in irrigation furrows with simple, inexpensive equipment was found to be fairly accurate but additional refinements are necessary. The flume studies of hydraulic roughness using artificial plants has been completed, and showed that the exponent of hydraulic radius in Manning's equation differs significantly from the commonly used value.

(h) "Concepts on Design of Border Irrigation Systems," John R. Davis, Presented at ARSSCS Research Application Workshor on Hydraulics of Surface Irrigation, February $9-10,1960$.

"Estimating Rate of Advance for Irrigation Furrows," John R. Drvis, Presented at ARSSCS Research Application Workshop on Hyaraulies of Surface Irrigation, February 9 - 10, 1960.

"Design of Irrigation Border Checks," W. A. Hall, Agr. Engin., 41:439-442, 1960. "Performance Parameters of Irrigation Systems," W. A. Hall, Trans. A. S. A. E. 3(1):75-76, 81, 1960 . 
U. S. DEPARTMENT OF AGRICUIIURE, AGRICULTURAI RESFARCH SERVICE, Soil and Water Conservation Research Division.

\section{EASTTERN SOIL AND WATER MANAGEMENT RESEARCH BRANCH.}

(1966) IMPROVED SYSTEMS FOR CONIROL OF RUNOFF AND EROSION.

(b) Cooperative with the following state Agricultural Experiment Stations and other agencies for use throughout the thirty-one Eastern States: Georgia, Illinois, Indiana, Iowa, Maine, Minnesota, Mississippi, Missouri, New Hampshire, New York, Wisconsin. Some studies under this project are reported in more detail as cooperative research under the respective states.

(c) Mr. T. W. Edminster, Chief, Eastern Soil and Water Management Research Branch, Plant Industry Station, Beltsville, Maryland.

(d) Experimental and field investigations, both basic and applied for development and design.

(e) The purpose of these studies is to obtain fundamental information on the mechanics of rainfall, runoff and erosion, to determine the effects of the basic factors-climatic, topographic, soil and cover on runoff and soil loss, and to develop and evaluate the runoff and erosion control effectiveness of various soil and water management and supporting conservation practices. The relationships and evaluations are combined into equations or graphs for estimating soil loss from individual fields in conservation farm planning and in determining probable sediment production in watersed protection programs. The work is carried on in laboratory and fractional acre plot studies with natural and simulated rainfall and on primary unit watersheds. Both meteorological and hydrological measurements are made. The basic data are assembled in a central statistical laboratory for placement on punch cards for machine and graphical correlation analysis.

(g) Work continued on evaluation of factors in a universal soil loss prediction equation. Rainfall erosion indices and their monthly distribution curves have been computed for 181 locations in the U. S. from which an iso-erodent map is being prepared. Crop-management factors for use in the equation have been published for 100 crop cover-management combinations. Slope and soil erodibility factors are being re-evaluated. Research was started on the hydraulics of water movement as sheet flow and as channel flow in individual crop rows and terrace channels under natural and simulated rainfall conditions. The mechanics of soil detachment and transport by raindrop splash and in the phases of water flow outlined above are included in the studies.

(h) "Erosion Characteristics of Rainfal1," G. R. Free, Agr. Engin., Vol. 41, No. 7, pp. 447-449, 455, (July 1960).

"Use of Field Plot Rainfall Simulator for
Runoff Plot Research," L. D. Meyer, Soil Sei. Soc. Amer. Proc., Vol. 24, No. 4, pp. 319-322, (July-Aug. 1960).

"Current Concepts and Developments in Rainfall Erosion Research in the United States," D. D. Smith and W. H. Wischmeier, Trans. of the Fifth International Congress of Agr。 Engin. 1958, Brussels, Belgium, Vol. I, pp. 458-467, (1960).

"Cropping-Management Factor Evaluations for a Universal Soil-Loss Equation," W. H. Wischmeier, Soil Sei. Soc. Amer. Proc., Vol. 24, No. 4, pp. 322-326, (July-August 1960).

"Erosion from Corn After Meadow Depends on Quality of Meadow," W. H. Wischmeier, Crops and Soils, Vol. 12, No. 6, pp. 225226, (March 1960).

"Soil and Water Losses and Infiltration Rates on Ida Silt Loam as Influenced by Cropping Systems, Tillage Practices and Rainfall Characteristics," W. C. Moldenhaver and W. H. Wischmeier, Soil Sci. Soc. Amer. Proc., Vol. 24, No. 5, pp. 409-413, (Sept.-Oct. 1960).

\section{(3867) IRRIGATION AND DRAINAGE FACIIITIES.}

(b) Cooperative with the following state Agricultural Experiment Stations and other agencies for use throughout the thirty-one Eastern States: Alabama, Florida, Louisiana, Minnesota, Missouri, New York, Ohio, Virginia, and Vermont.

(c) Mr. T. W. Edminster, Chief, Eastern Soil and Water Management Research Branch, Plant Industry Station, Beltsville, Md.

(d) Experimental and field investigations, both basic and applied for development and design.

(e) The purpose of these investigations is to develop engineering techniques that will provide maximum effective control and management of water onto and off farm land consistent with maximum conservation of soil and water resources. Techniques are developed for managing surface water flow through land forming, surface drainage systems and soil conditioning through crop and cultural practices that improve internal soil drainage. Methods are studied for effectively collecting and storing excess surface runoff for later farm use. Tile, mole and other subsurface drainage systems are developed and their effectiveness determined. The hydraulics of surface water management for irrigation and drainage is studied. The work is carried on in laboratory and field studies. Both meteorological and hydrological measurements are made.

(g) Work is continuing on land forming and the development of improved surface drainage systems, the effectiveness of field diversions, improved plastic mole drainage techniques and the effectiveness of other subsurface drainage systems. The hydrology and hydraulics of surface water management for drainage and of irrigation water flow in crop row channels is receiving increased attention. 
(h) "Field Experiences in Measuring Hydraulic Conductivity for Drainage Design--Soil Core Method in Virginia," a symposium, W. W. Donna, Phelps Walker, et al. Agr. Engin., Vol. 40, No. 5, pp. 270-273, 280, (May 1960).

"Irrigation Systems for Grasslend," T. W. Edminster, Grasslands, Amer. Assoc. Adv. Sci., Vol. 53, pp. 15l-157, (1950).

"Land Forming--A New Water Management Practice," Lee F. Hermsmeier and Curtis L. Larson, Minnesota Farm and. Home Sci., Vol. 17, No. 1, pp. 8-9, (Oct. 1959).

"Land Forming for Drainage," I. L. Saveson, Agr. Engin., Vol. 40, No. 4, pp. 208-209, 213, (April 1959).

"Land Forming--An Accepted Drainage

Practice," Phelps Walker and J. H. Lillard, Agr. Engin., Vol. 41, No. 1, pp. 24-27, (Jan. 1960).

\section{U. S. SAIINITY IABORATORY.}

\section{(3868) A STUDY OF THE MECHANISMS AND MATHEMATICS} OF WATER MOVEMENT IN UNSATURATED SOIL.

(b) Laboratory project.

(c) Dr. W. R. Gardner, U. S. Salinity Laboratory, P. 0. Box 672, Riverside, Calif.

(d) Experimental and theoretical; basic research.

(e) Experimental techniques are being devised to measure the water-transmitting properties of unsaturated soils as a function of other soil properties. Methods are being devised to obtain solutions of various unsaturated-flow problems.

(g) Several methods have been devised for measuring the capillary conductivity of soils, including a method for in situ measurements in the field in the tensiometer range. Solutions have been obtained. for the movement of water to a plant root and for the drainage of a vertical soil column.

(h) "Diffusivity of Soil Water During Sorption as Affected by Temperature," W. R. Gardner, Soil Sci. Soc. Amer. Proc. 23: 406-407, 1959.

"The Effect of an Electrolyte Concentration and Exchangeable Sodium on the Diffusivity of Water in Soil," W. R. Gardner, M. S. Mayhugh, J. O. Goertzen, and C. A. Bower. Soil Sci. 88: 270-274, 1959.

"Measurement of Capillary Conductivity and Diffusivity with a Tensiometer," by W. R. Garäner. Trans. VII Cong. Internatl. Soil Sci. Soc. (in press).

\section{WATERSHED TECHNOLOGY RESEARCH BRANCH.}

\section{(150) HYDROLOGIC RESEARCH ON AGRICUTTURAL WATER-} SHEDS.

(b) Cooperative with State Agricultural Exp. Stations, Soil Conservation Service, U. S. Bureau of Reclamation, University of Iowa, University of Mississippi, Central and Southern Florida Flood Control District, and the Wisconsin Valley Improvement Co.

(c) Mr. H. N. Holtan, Watershed Technology
Research Branch, Plant Industry Station, Beltsville, Maryland.

(d) Experimental; field and laboratory; for planning and design of-watershed protection and flood prevention projects, upstream structures, and farm water disposal systems.

(e) The purpose of the studies is to develop an understanding of the hydrologic processes of procedures for predicting flood runoff and water yield from agricultural watersheds. Research is carried out on watersheds ranging in size from 1 to 75,000 acres, including measurements of rainfall, runoff, evapotranspiration, moisture storage and the accretion, and movement of groundwater. Hydrologic records are being obtained on 199 watersheds in 21 state, as follows: Safford and Tombstone, Arizona; Ft. Lauderdale and Vero Beach, Florida; Watkinsville, Georgia; Monticello, Illinois; Iowa City, Iowa; College Park and Hagerstown, Md.; East Lansing, Michigan; Oxford, Mississippi; McCredie, Missouri; Hastings, Nebraska; High Point, N. Carolina; Newell, S. Dakota; Albuquerque and Santa Rosa, N. Mex.: Cohocton and Dutchess County, New York; Coshocton, Ohio; Stillwater, Oklahoma; Riesel (Waco), Texas; Blacksburg, Va.; Moorefield, West Virginia; Colby, Fennimore and La Crosse, Wis.: Montpelier, Vermont. Other studies include analysis and interpretation of accumulated records and the Cooperative Water Yield Procedures Study at Lincoln, Nebraska by Soil Conservation Service, Bureau of Reclamation and Agricultural Research Service to develop methods for estimating the effect of watershed treatment upon yields of stream flow.

(g) Hydraulics investigations under this project include the principles of surface and porous-media flow essential to an understanding of the hydrologic performance of the watershed and its underlying aquifers.

(h) Monthly summaries of rainfall and runoff, maximum volumes of flow for selected periods of time, and detailed data for selected runoff events are brought up-todate every few years. Interpretative studies are reported in Departmental media and in the journals of technical societies.

(1723) THE HYDRAULICS OF CONSERVATION STRUCTURES.

See St. Anthony Falls Hydraulic Laboratory Projects Nos. 111, 1168, 1929, 2386, and 2860. See also Illinois State Water Survey Division Project No. 1865

(b) Cooperative with the Oklahoma and Minnesota Agricultural Experiment Stations, with St. Anthony Falls Hydraulic Laboratory, and Illinois State Water Survey, Urbana, Ill.

(c) Mr. L. L. Kelly, Watershed Technology Research Branch, Plant Industry Station, Beltsville, Maryland.

(d) Experimental; applied research for development and design.

(e) Research dealing with the design, construction, and testing of structures for controlling and conserving soil and water are carried out under this project. Field 
studies are made to determine the causes of deterioration of drainage ditches, terrace outlets, and hydraulic structures that have failed in service. Laboratory experiments in methods of preventing such deterioration are supplemented by field tests of those measures or devices that appear promising. At the Stillwater, Oklahoma Outdoor Hydraulic Laboratory the hydraulics of trash racks on drop spillways are under study, and studies are being continued on devices for measuring flow rates. At the St. Anthony Falls Hydraulic Laboratory studies were continued on the capacity and performance of the hood inlet to the closed conduit spillway and on the hydraulic design characteristics of anti-vortex devices for drop spillways. Cooperative studies on drop inlets were continued with the Illinois State Water Survey at Urbana, Illinois.

(g) Model tests at Minneapolis, Minn. showed that smaller drop inlets can be used with the non-projecting hood than with the projecting hood. Model tests were run on 62 variations of the two-sided-entry table-top anti-vortex plate for drop inlets. Analyses of these data are not yet completed. At Stillwater, Oklahoma model tests of trash racks continued using hemp rope treated with a sulfuric acid solution to simulate trash action usual to a reservoir. Model tests indicated that if a top orifice plate is used to reduce flow through the drop inlet (a common practice where oversized pipe is dictated by needs for structural strength and the needs for clean-out facility) a negative pressure may develop inside the drop inlet. Under these conditions pipe flow rather than orifice flow governs throughout. Tests showed that it would be necessary to vent the drop inlet to maintain orifice control.

(h) "The SAF Stilling Basin. A Structure to Dissipate the Destructive Energy in HighVelocity Flow from Spillways," Fred W. Blaisde1l. U. S. Dept. Agr., Agr. Handbk. 156: $16 \mathrm{pp}$. (1959).

Letter to the Editor of Civil Engineering Magazine regarding "Improved Culvert Performance Through Design and Research

studies," by William J. Bauer, May 1959.

Fred W. Blaisdell.

"The Virginia V-Notch Weir," W. O. Ree and W. R. Gwinn, U. S. Dept. Agr. ARS 41-10: 7 pp. (1959).

"Head Loss in Quick-Coupled Aluminum Pipe Used for Sprinkler Irrigation Systems," W. O. Ree, U. S. Dept. Agr., Agr. Handbk. 147: $20 \mathrm{pp}$. (1959).

"Discussion of Some Experiments with Emergency Siphon Spillways," by Warren B. Mc-

Birney. Fred W. Blaisdell and Harold W. Humphreys. Amer. Soc. Civil Engin. Proc. HY4 86:103-108 (1959).

"A Closure on Eisenhower and Grass River Lock Models," Martin E. Nelson and Harvey J. Johnson. Amer. Soc. Civil Engin. Proc. (HY7) 85: 145 (1959).

"Discussion of Pressure Changes at Open Junctions in Conduits," by W. M. Sangster,
Horace W. Wood, Ernest T. Smerdon and Herbert G. Bossy. Fred W. Blaisdell. Amer. Soc. Civil Engin. Proc. (HYll) 85: 153 (1959).

"Testing Debris Guards for Pipe Spillways," W. R. Gwinn and W. O. Ree. USDA Soil Conserv. 25: 227-229 (1960).

"The Hood Inlet for Closed Conduit Spillways," Fred W. Blaisde11. Amer. Soc. Civil Engin. Proc. (HY5) 86: 7-31 (1960). "Report of Preliminary Tests of a Fine Mesh Jute Channel Liner," W. O. Ree. WTRB Research Report 331, July 1960.

"Let's Demonstrate Hydraulic Phenomena," Elaine D. Foss and F. W. Blaisdell. Unnumbered ARS Pub. July 1960.

\section{(2175) SEDTMENT HYDRALUICS.}

See also California Institute of Technology (Project No. 2748, page 3), Massachusetts Institute of Technology (Project No. 3089, page 5), Colorado State University (Project No. 3402, page 16), and ARS Sedimentation Laboratory (Project Nos. 3869, 3870, and 3871, page

(b) Cooperative with State Agricultural Experiment Stations in Mississippi, Oklahoma, Wisconsin and New York, Soil Conservation Service, University of Arizona, University of Mississippi and Massachusetts Institute of Technology.

(c) Mr. Carl R. Miller, Watershed Technology Research Branch, Plant Industry Station, Beltsville, Maryland.

(d) Experimental; field and laboratory development of concepts procedures, guides, and criteria for use in planning, design, construction, and maintenance of programs and measures for soil and water conservation, and the protection and development of agricultural watersheds.

(e) Experiments, investigations, and analytical studies to determine fundamentals and principles of entrainment, transportation and deposition of sediment, and the morphology of stream channel systems in agricultural watersheds. The investigations include studies: channel geometry, stream bank erosion, shear stresses exerted by flowing water on channel periphery materials of various textures and types, resistance to flow as related to bed configuration, sediment transport and composition, and development of means and methods for stream channel stabilization andccontrol. Development of specialized instruments is an integral part of the investigations. Investigations are carried on from headquarters at Oxford, Miss.; Stillwater, Okla.; East Aurora, New York; and Madison, Wis.

(g) Field data analysis and studies in Miss. have established the existence of discontinuity in the stage discharge relationship for certain sand-bedded streams. Discontinuity results from the interaction of sediment transport conditions, stream hydraulic factors, and the channel resistance to flow as related to bed configuration. This conforms with laboratory experiment findings at the California Institute of Technology. 
Studies in New York have resulted in development of relationships between channel bend geometry and maximum points of shear stress and scour for certain stream types. Preliminary mathematical relationships between requisite riprap size and flood flow hydraulic parameters in stream bends have been developed. Concurrent laboratory studies at the Massachusetts Institute of Technology are establishing shear stress patterns in a bend under idealized conditions. In oklahoma, studies indicate erosion resistant abilities of various type channel liners to protect newly emergent vegetation in grassed waterways. At Colorado State University a unique ultra sonic device was developed for use in laboratory and field to simultaneously measure stream bed and water surface profiles (ARS Contract).

(h) "Effects of Flood Flow on Channel Boundaries," by D. A. Parsons, Journal of Hydraulics Division, ASCE, Vol. 86, April 1960.

"Discontinuous Rating Curves for Pigeon Roost and Cuffawa Creeks in Northern Mississippi," ARS 41-36, USDA, April 1960. "Lecture Notes on Sedimentation Tranportation and Channel Stability," by Vito A. Vanoni, Norman H. Brooks, and John F. Kennedy, Publication No. KHWR-1, Sept. 1960, (Contract 2206-ARS-61).

"Dual Channel Stream Monitor," Earl E. Gray and S. S. Karaki, Colo. State Univ., CER60SSK46, August 1960 (ARS Contract). "Report of Preliminary Tests of a Fine Mesh Jute Channel Liner," by W. O. Ree, ARS Research Report No. 331, July 29, 1960. "A Critique on Stable Channels in Cohesive Materials and a Research Proposal," by C. R. Miller, ARS Research Report No. 333, August 18, 1960.

"Average Scour and Fill in Sand-Bed Streams," by Bruce R. Colby, ARS Research Report No. 336, October 25, 1960.

\section{Sedimentation Laboratory}

\section{(3869) FLUVIAL MORPHOLOGY.}

(b) Laboratory project; cooperative with Miss. State University and University of Miss.

(c) Mr. Russell Woodburn, Director, Sedimentation Laboratory, Univ. of Mississippi, Oxford, Miss.

(d) A field investigation project; applied research.

(e) Field studies on selected natural watersheds in the Yazoo River Basin of Miss. are made to delineate the variables of stream geometry and stream hydraulics in terms of sediment discharge characteristics. These watersheds vary in area from 115 acres to 75,000 acres. Acquired data are studied for adherence to existing regime equations, tractive force concepts, and bed load formulae and to develop new or improved relationships. Development of methods to determine total sediment discharge are an integral part of the investigations. Measurement of channel scour and fill and the forces affecting these bed elevation changes are also being studied.

(g) Studies have established the existence of a discontinuity in the stage-discharge relation at several locations in the project area. Changes in channel efficiency, occasioned by changes in bed configuration, have allowed water discharges to vary more than 100\% for given water stages. Variations in Manning's roughness factor from .035 to .015 during the course of a storm have occurred and for a given water discharge on separate occasions the " $n$ " value has been known to double. Froude numbers for flood over plane beds or antidunes in the field are less than Froude numbers computed from comparable flows in laboratory flumes; this difference in Froude numbers is believed to be partly a function of depth.

(h) "Average Scour and Fill in Sand Bed Streams," by Bruce R. Colby, WIRB, SWCRD, ARS Research Report No. 336, October 25, 1960.

"Discontinuous Rating Curves for Pigeon Roost and Cuffawa Creeks in Northern Miss.," by Bruce R. Colby, ARS 41-36, USDA, April 1960.

\section{(3870) AGGRADATION AND DEGRADATION AS RELATED TO} CHANNEL STRUCIURES.

(b) Laboratory project in cooperation with Miss. State Univ and the Univ of Mississippi.

(c) Mr. Russell Woodburn, Director, Sedimentation Laboratory, University of Miss., Oxford, Mississippi.

(d) Field investigation; applied research.

(e) It is necessary for proper planning and design of agricultural watershed conservation work to have a knowledge of the extent of aggradation or degradation that is likely to occur with placement of structures in alluvial channels. Studies of 17 structures in three separate watersheds of north Miss. are underway to develop procedures and criteria useful in predicting channel adjustments with structural installations and accompanying changes in sediment transport and flow pattern.

(g) The degree of channel cutting and channel erosion rates have been determined for one reservoir on East Goose Creek, Lafayette County, Miss., for the 5-year period, 19531958, and for six structures on Little Rock Creek, Carroll County, for the 3-year period, 1956-1959.

\section{(3871) LABORATORY STUDIES OF SEDIMENT TRANSPORT.}

(b) Laboratory project in cooperation with Miss. State Univ. and the Univ. of Mississippi.

(c) Mr. Russell Woodburn, Director, Sedimentation Laboratory; Univ. of Mississippi, Oxford, Miss.

(d) Experimental; basic and applied research.

(e) To more fully explain by laboratory flume experiments the relationships between stream hydraulics and sediment transport which generally occur in natural channels. Work includes the testing and development of sediment transport equations and the 
determination of the relation between "unmeasured" and total bed material discharge. An additional objective is the determination of changes in bed configuration with changing flow and the effect upon flow resistance and the transport of sands.

WESTERN SOIL AND WATER MANAGEMENT RESEARCH BRANCH

\section{(151) LINING OF IRRIGATION CANALS AND RESERVOIRS.}

(b) Laboratory project, Agricultural Research Service, Utah State University, and Bureau of Reclamation cooperating.

(c) Dr. C. W. Lauritzen, Soil Scientist, Agricultural Research Service, Utah State University, 101 Engineering Building, Logan, Utah.

(d) Experimental; basic and applied research.

(e) Linings for irrigation canals and reservoirs are being tested to develop more effective and lower cost methods of reducing seepage losses in irrigation systems. The investigation includes: (1) Evaluation of physical properties of lining materials; (2) model testing of linings in an outdoor laboratory; and (3) field testing at selected sites to determine relative durability under varying subgrade and climatic conditions.

(g) Development work on our asphalt-coated jute liner continued. Some changes were made in the asphalt coating, and a 12-ounce burlap was substituted for the 15-ounce sacking. This resulted in a liner that was more uniformly coated and the coating less subject to cracking on flexing at sharp angles. To provide a built-in protective coating, slate granules were imbedded in the top of the liner. Test installations of last year were extended to include a section of the improved material. It appears now that the material is reasonably satisfactory, and although development work is continuing, it has been released for test marketing in the Denver, Colorado, area.

(h) "Asphalt-Coated Jute Liner Developed for Canals and Reservoirs," C. W. Lauritzen, Farm and Home Science, 24:1, 12-13, 28-29, March 1960.

"Linings for Irrigation Canals," C. W. Lauritzen, Irrigation, Engineering, and Maintenance, 9:13, 10-11, December 1959, first part, 10:1, 12-13, January 1960, second part.

(2177) WATER REQUTREMMENTS IN IRRIGATED ARFAS.

(b) Field project in cooperation with state and Federal agencies.

(c) Mr. Harry F. Blaney, Irrigation Engineer, Agricultural Research Service, 1131 Bartlett Building, 215 West 7 th St., Los Angeles 14, Calif., or Dr. Howard R. Haise, Investigations Leader, Irrigation Practices and Requirements, ARS, P. 0. Box 758, Fort Collins, Colorado.

(d) Field experiments and office analysis.

(e) (I) To determine the consumptive use of water by agricultural crops, native vegetation, and water requirements for irrigated crops; (2) to compile and prepare for publication available data relating to irrigation requirements and consumptive use as determined by field experiments; and (3) to estimate water requirements from climatological and other data.

(g) Monthly coefficients (k) have been developed for irrigated crops and phreatophytes in the Blaney-Cridale formula, $u=k f=$ consumptive use, where " $\mathrm{k}$ " is a monthly coefficient based on experimental measurements, and " $f$ " is a factor determined from mean monthly temperatures and percent of daytime hours. Reports are being prepared on "Determining Consumptive Use and Irrigation Requirements," and "Monthly Consumptive Use by Irrigated Crops in Western United States."

(h) "Determining Irrigation Requirements from Consumptive Use Water Rates," Harry F. Blaney, Trans. Vth International Congress of Agricultural Engineering, 1: 292-304, Brussels, 1960.

"Relationship of Pan Evaporation to Evapotranspiration by Phreatophytes and Hydrophytes," Harry F. Blaney, Symposium on Phreatophytes, May 1958.

"Progress Report on Water-Consuming Areas Along the Santa Ynez River Channel, Santa Barbara County, California," Harry F. Blaney, Paul Nixon, et al, Soil and Water Conservation Research Division, USDA, 1960.

(2179) EVAPORATION AND CONSUMPTIVE USE OF WATER IVVESTIGATIONS IN THE SAN FRANCISCO BAY AND ADJACENT AREA.

(b) Laboratory project, cooperative with Div. of Water Resources, State of California; and the Corps of Fngineers, San Francisco Bay District, U. S. Army.

(c) Mr. Dean C. Muckel, Irrigation Engineer, P. 0. Box 180, Berkeley, California.

(d) Field investigation.

(e) To determine rates of evaporation from fresh water surfaces, the consumptive use of fresh water by marshland vegetation (tules and cattails), and the consumptive use of water by salt grass at varying depths to water table in the San Francisco Bay and adjacent areas.

(f) Completed.

(h) "Estimated Evaporation and Evapotranspiration Losses under Various Proposed Barrier Plans of the San Francisco Bay System, California," Dean C. Muckel, December 1959, final report (distribution restricted).

(2180) EVAPORATION LOSSES FROM RESERVOIRS AND IAKES.

(b) Field project of Western Soil and Water Management and Research Branch, ARS-SWC, USDA, in cooperation with State of Calif., Counties and other agencies.

(c) Mr. Harry F. Blaney, Irrigation Engineer, Agricultural Research Service, 1131 Bartlett Bldg., 215 West 7th St., Los Angeles 14, Calif.

(e) Experimental; compilation and analysis 
of data.

(e) To determine evaporation losses from reservoirs and lakes and develop empirical formulas from climatological data for computing monthly evaporation. Cooperative field measurements are being made of pan evaporation on 15 stations ranging from 240 feet below sea level at Salton Sea to 9194 foot elevation at Kaiser Pass in the SierraNevada Mountains.

(g) Results of monthly pan evaporation, temperature, humidity, wind movement and precipitation measurements have been compiled and published in California State Bulletin No. 54-B and Bulletin No. 73, "Evaporation from Water Surfaces in California," by Harry F. Blaney and Dean C. Muckel. A Progress Report on "Evaporation at High Elevations in San Joaquin River Basin California," at six stations has been prepared by Ieonard $I_{\text {. }}$. Longacre and Harry F. Blaney for period 1946-1959. Regression equations for computing monthly evaporation at elevations ranging from 400 to 9200 feet have been developed from pan evaporation and climatological data.

(h) "Evaporation from Free Surfaces at High Altitudes," Harry F. Blaney, Bulletin No. 17, Association Internationale d'Hydrologic Scientifique, Louvain, Belgium, March 1960.

(2181) STORAGE OF WATER UNDERGROUND FOR IRRIGATION IN CALTFORNIA.

(b) Laboratory and field project.

(c) Mr. Leonard Schiff, Hydraulic Engineer, ARS, 4816 East Shields Ave., Fresno 3, Calif.

(d) Experimental; laboratory and field investigations, applied research.

(e) To efficiently store and use underground water in quantity and of a quality needed in various locations. The objectives are: (1) To determine the physical and chemical characteristics of surface soil and substrata on selected sites and to relate these characteristics to infiltration and percolation rates and to lateral flow; (2) to determine the feasibility of recharge irrigation (deep percolation by sufficient irrigation of crops) as a means of storing water underground; (3) to determine the effect of recharge on the quality of water reaching the groundwater table under selected site conditions and on the quality of the ground water; and (4) to prepare a recharge guide which permits the evaluation of a site for recharge, suggests methods and systems of recharge to be used and indicates the quality of ground water that may be expected as a result of recharge.

(2279) IABORATORY AND FIELD STUDY OF THE VORTEX TUBE SAND TRAP.

(b) Agricultural Research Service, U. S. Dept. of Agriculture and Colo. Agricultural Experiment Station.

(c) Mr. A. R. Robinson, Agricultural Engineer, Hydraulics Laboratory, Colo. State Univ., Fort Collins, Colo.

(d) Experimental; applied research. (e) The study is being made to develop generalized criteria for the design of the vortex tube sand trap. The sand trap will be used in irrigation and power canals for removal of bed load material.

(f) Completed.

(g) Tests indicate that with the proper design, the vortex tube sand trap is very effective in the removal of bed load material for sizes greater than $0.3 \mathrm{~mm}$. The efficiency of trapping varies with the velocity of flow across the tube and the size of material. High efficiencies can be maintained even though the amount of flow removed by the tube is reduced from 15 to 5 percent. Tubes of different shapes seem to operate equally well. However, the cross-sectional area and length of tube seem to be critical points of design.

(h) "Vortex Tube Sand Trap," A. R. Robinson, Proceedings ASCE, Jourmal of the Irrigation and Drainage Division, November 1960.

(2650) EFFECT OF WATER TABLE DEPTH ON IRRIGATION REQUIREMEINIS AND YIELD OF LAHONTAN ALFALFA.

(b) U. S. Dept. of Agriculture, Agricultural Research Service, Soil and Water Conservation Research Division.

(c) Mr. Rhys Tovey, Agricultural Engineer, ARS, Box 9186 University Station, Reno, Nev • (d) Experimental; applied research.

(e) To determine surface-irrigation requirements of Iahontan alfalfa grown on three soil textures with constant water tables at various depths, and on well-drained soil in the absence of a water table; to determine the effect of plant growth stage on the rate of water use by Lahontan alfalfa; to determine the relation between the use of water by alfalfa under various water table conditions, evaporation from porous atmometer bulbs, and evaporation from a Weather Bureau evaporation pan; and to evaluate the effects of a fluctuating water table on the yield and growth rate of alfalfa.

(g) The seasonal values indicate that: (1) The consumptive use and yield of alfalfa for the non-irrigated treatments decreased as the depth to water table increased; (2) the non-irrigated lysimeters show a lower consumptive use and yield than the irrigated lysimeters in most instances; (3) the consumptive use and yield of the drained irrigated treatments are comparable to the values measured for the eight-foot water table, non-irrigated treatment; and (4) the differences due to water table depth are less for the irrigated than for the nonirrigated treatments.

(h) "Equipment for Controlled Water Table Investigations," Rhys Tovey and W. C. Bianchi, submitted to the American Society of Agricultural Engineers Journal for publication.

(2651) DRATINAGE INVESTIGATIONS IN THE NORTH SHORE AREA OF CARSON LAKE, INEVADA.

(b) U. S. Department of Agriculture, ARS, Soil 
and Water Conservation Research Division.

(c) Mr. Victor I. Myers, Agricultural Engineer, and Mr. Anthony S. Dylla, Agricultural

Engineer, ARS, Box 9186 University Station, Reno, Nevada.

(d) Field and applied research.

(e) To determine the causes for drainage problems in the study area, to develop equipment and techniques suited to conditions in the study area which will permit determining qualitative and, if possible quantitative relationships between causes for drainage problems in the study area and in other similar areas; to develop physically and economically feasible methods of correcting or alleviating problems in the study area and in other similar areas.

(g) Canal seepage measurements are being analyzed for relationship high water table build-up. Investigative borings are being compiled for determination of corrective drainage measures. Hydraulic conductivity and specific yield determinations are being compiled for design of corrective drainage measures. Plastic lined mole drains are being studied as a possible economical drainage problem. Well, piezometer, and irrigation efficiency data are being compiled for analyzing the cause for drainage problems.

(h) "Procedures for Evaluating Drainage Project Feasibility," Victor I. Myers, Trans. of Fourth Congress, International Cormission on Irrigation and Drainage, Madrid, Spain, June 1960.

(2652) UIITIZATION OF AVAILABLE WATPR SUPPLIES IN THE COLORADO RIVER BASIN OF NEVADA.

(f) Suspended.

(2653) CONSUMPTIVE USE, WATER SUPPLY AND IRRIGATION STUDIES IN SANTA BARRARA COUNTY, CALIFORNIA.

(b) Laboratory project in cooperation with Santa Barbara County Water Agency, U. S. Geological Survey, Califormia State Dept. of Water Resources and U. S. Bureau of Reclamation.

(c) Mr. Paul R. Nixon, Agricultural Engineer, USDA Agricultural Research Service, P. 0 . Box "E", 7th and Chestnut Streets, Lompoc, California.

(d) Basic and applied research.

(e) Soil moisture and soil suction measurements are made in agricultural crops in coastal and intermediate environments. From these and other data, evapotranspiration is computed. Evapotranspiration values are compared with observations made at five climate stations of USWB Class A type. Objectives include providing information of value for local water inventories and refinement of present methods of computing evapotranspiration from climatological data. Some work is done to determine water application efficiencies and amounts of deep percolation and to collect irrigation data for development of improved management techniques for conservation of water.

Soil moisture measurements (made with neutron scattering moisture meters to depths of 10 to 28 feet) together with measurements of precipitation and other climatological factors are being made to determine how much, if any, of the rainfall in certain ground water recharge areas penetrates beyond the root zone. The 13 sites being studied represent various cover, soil, and topographic condition. From the data. collected evapotranspiration rates are determined. A study is made of movement of water in various soil to help determine net contribution to ground water recharge by deeply penetrating rainwater.

(g) Rather marked increase in evapotranspiration rates observed as distance increases from 4 to 28 miles from the ocean. Downward translocation of moisture has been observed to continue during the dry season following winter precipitation. This migration of moisture in unsaturated soil was observed in all soils studied but was most pronounced in sandy soil.

(h) "Translocation of Moisture with Time in Unsaturated Soil Profiles," Journal Geoph. Res. 65: 655-661, 1960.

(2902) DEVELOPMENT AND TMPROVEMENT OF WATER MEASURING DEVICES.

(b) Agricultural Research Service, U. S. Dept. of Agriculture and Colo. Agricultural Experiment Station.

(c) Mr. A. R. Robinson, Agricultural Engineer, Hydraulies Laboratory, Colorado State University, Fort Collins, Colorado.

(d) Experimental; applied research.

(e) The purpose of this project is to develop new water measuring devices and to improve existing ones for the measurement of irrigation water. Present phases of the project are concerned with development of trapezoidal measuring flumes and evaluation of vane type flow meters and modified Hall flow tubes.

(g) Tests have been made of trapezoidal flumes for a variety of sizes and capacities. The capacities range from $0.02-60.0$ cfs. In general, the trapezoidal shaped flumes have been found to be superior to rectangular ones from an operational standpoint. Vane-type meters have been studied and their relative accuracy determined over a range of operating conditions.

(h) "Trapezoidal Flumes for Open Channel Flow Measurement," A. R. Robinson and A. R. Chamberlain, American Society of Agricultural Engineers Transactions, 3:2, 1960.

(3209) CONSUMPTIVE USE OF WATER BY CROPS IN ARIZONA.

(b) Cooperative with the Arizona Agricultural Experiment Station.

(c) Mr. Leonard J. Erie, Irrigation Engineer, Southwest Water Conservation Laboratory, Box 816-A, Rt. No. 2, Tempe, Ariz., and Mr. Karl Harris, Civil Engineer, ARS, 
Arizona Savings Building (Room 420), Phoenix, Arizona.

(d) Experimental; field research.

(e) The objectives of this project are to: (1) To determine consumptive use of new crops; (2) keep consumptive use measurements up to date as varieties and production changes take place and; (3) develop better information on peak period uses and to obtain soil moisture tensions at certain stages of plant development.

(3211) THE RATE OF ADVANCE OF IRRIGATION WATER IV FURROWS AS A FUNCTION OF MEASURABLE PHYSICAL FACTORS.

(b) Laboratory project.

(c) Mr. Hollis Shull, Agricultural Engineer, Southwestern Irrigation Field Station, P. 0. Box 1339, Brawley, California.

(d) Field investigation, applied research.

(e) The knowledge of the nature of the flow of irrigation water in furrows is necessary in designing new irrigation systems and in operating existing irrigation systems. This project is a field study of the hydraulics of flow of irrigation water in furrows. It includes the nature of flow of water in furrow channels, the infiltration of water in furrows, the rate of inflow to furrows, the furrow shape and bottom slope, and the relationships between these factors and the rate at which water advances down furrows.

(g) The general relationships between inflow to a furrow and the disposition of the inflow in the furrow can be expressed in the form of a continuity equation. The specific relationships necessary to develop a workable rate of advance equation have not been determined. It is not possible to determine the nature of the infiltration of irrigation water in furrows with sufficient accuracy for prediction purposes. The nature of the flow of water in the furrow channel has not been determined and the effect of furrow shape, slope and roughness has not been determined. Present efforts are being directed to the problem of infiltration in furrows.

\section{(3212) THE HYDRAULICS OF CYLINDER INFILTROMETERS.}

(b) Laboratory project.

(c) Mr. Charles T. Bourns, Agricultural Engineer, Agricultural Research Service, Irrigation Building (Room 215), University of California, Davis, California.

(d) Experimental; basic research and developmental.

(e) This is a three-dimension model study of the hydraulics of cylinder type infiltrometers to determine the flow regime of this device, the necessity for buffer cylinders, the effect of diameter on its function, the effect of methods and depths of placement on results, the effect of location of less permeable soil strata in relation to depth of placement of infiltrometer, and the effect of various operational techniques on reliability of results.

(3213) DEVELOPMENT OF A DEVICE FOR FIELD MEASUREMENT OF HYDRAULIC CONDUCTIVITY OF SOIL STRATA.

(b) This is a cooperative project with the Soil Conservation Service.

(c) Mr. William W. Donnan, Agricultural Engineer, P. 0. Box 629, Pomona, Calif.

(d) Field investigation; applied research.

(e) The objectives of this study are to develop a relatively simple device for use in measuring hydraulic conductivity rates of soil strata beneath the water table.

(g) Laboratory studies of various devices have been completed. A field well point called "The Pomona Well Point," which can be duplicated in any shop has been developed and tested in the laboratory. The appurtenant field equipment is being developed prior to testing the apparatus in the field.

(h) "Well Point Device for Measuring Hydraulic Conductivity of Sand Strata," W. W. Donnan, Journal Irrigation and Drainage Division, ASCE, (in press).

(3215) DETERMINATION OF THE QUANTITY AND EFFECTS OF PLAYA IAKE SEDIMENTS RETAINED IN MULTIPIE PURPOSE WELIS USED FOR GROUND WATER RECHARGE AND IRRIGATION IN THE HIGH PLAINS OF TEXAS.

(b) Laboratory project; cooperating with the High Plains Underground Water District No. 1, the Texas Agricultural Experiment Station, and the Soil Conservation Service.

(c) Mr. Wayme Clyma, Agricultural Engineer, Agricultural Research Service, Southwestern Great Plains Field Station, Bushland, Texas.

(d) Field investigation; applied research.

(e) The primary objectives of the study are: (1) To determine the quantity of sand, silt and clay entering recharge wells during the recharge operation from Playa Lakes; (2) to determine the quantity of sand, silt, and clay pumped from multiplepurpose wells during the pumping cycle of a recharge operation; and (3) to determine the changes in specific yield of study wells resulting from retained sediments.

(g) Additional data collected during 1960.

(h) Report in preparation.

\section{(3216) PERFORMANCE OF SUBSURFACE DRAINAGE} INSTALLATIONS IN THE LOWER RTO GRANDE VALILEY OF TEXXS.

(b) Cooperative with the Texas Agricultural Experiment Station, Soil Conservation Service and the Lower Rio Grande Valley Soil Conservation Districts.

(c) Mr. L. R. Ussery, ARS, P. O. Box 157, Weslaco, Texas.

(d) Experimental; field research.

(e) The purpose of the study is to measure the influence of drains on depths to and fluctuation of ground water tables. Actual field data will be related to present design criteria and empirical drain spacing formulas. 
(3217) HYDROLOGIC STUDIES OF GROUND WATER IN THE RED RIVER VALIEY OF NORTH DAKOTA.

(b) Project cooperative with North Dakota. Agricultural Experiment Station.

(c) Mr. Leo C. Benz, Agricultural Engineer, USDA-ARS-SWC, P. O. Box 806, Grand Forks, North Dakota.

(d) Field investigation; applied research.

(e) The project covers a rectangular area of approximately 200 square miles. This area is gridded with observation wells and piezometer batteries to evaluate artesian conditions, water table gradients and fluctuations, and ground water quality. The purpose of the project is to conserve soil and water on approximately 400,000 acres of salt-affected soils in the Red River Valley of North Dakota.

(g) The data indicate that rainfall is a major contributor to high water tables. Piezometer batteries show upward gradients but pressures are dissipated at depths of 10 to 30 feet. Salt sources are the deep artesian aquifers.

(h) "Jetting Equipment and Techniques used in a Drainage and Salinity Study," R. H. Michelson, L. C. Benz, C. W. Carlson and F. M. Sandoval. Submitted for publication in Agricultural Engineering.

"Groundwater Investigations in a Saline Area of the Red River Valley, North Dak.," L. C. Benz, R. H. Mickelson, F'. M. Sandoval and C. W. Carlson, submitted for publication in Journal of Geophysical Research.

(3218) SOIL EROSION AND ROUGHIESS CHARACTERISTICS UNDER FURROW IRRIGATION.

(b) Project cooperative with the Washington Agricultural Experiment Station.

(c) Mr. S. J. Mech, Agricultural Engineer, Agricultural Research Service, Irrigation

Experiment Station, Prosser, Washington.

(d) Field research.

(e) The influence of soil management and water intake on erosion under furrow irrigation is being studied. Some of the variables being considered are cropping practices, moisture levels and slope. The variation of the roughness coefficient (Manning $n$ ) is being studied.

(f) Completed.

(h) "Soil Erosion and its Control Under Furrow Irrigation in the Arid West," Stephen J. Mech, USDA Agric. Information Bul. No. 184, pp. 1-6, August 1959.

(3550) THE EFFECT OF SPRINKIER PATPHERN VARIATION ON IRRIGATION FFFICIENCY.

(b) Laboratory project.

(c) Mr. Claude H. Pair, Irrigation Engineer, Agricultural Research Service, P. O. Box 835, Boise, Idaho.

(d) Experimental; applied research and design.

(e) To determine the effect of sprinkler pattern on field irrigation efficiency and to develop a method for calculation of field irrigation efficiency for a sprinkler system from sprinkler pattern, wind velocity, humidity, temperature, irrigation period, and related factors. Work is continuing to: (1) Obtain more precise information for the design, layout, installation, and operation of sprinkler irrigation systems on various soil types, slopes, and crops under various weather condttions; and (2) determine the effect of sprinkling upon various soils and crops.

(h) "Sprinkler System Mechanization," Claude H. Pair, (in press).

"Sprinkler Irrigation," Claude H. Pair, USDA Leaflet No. 476, July 1960.

\section{(3552) HYDRAULICS OF SURFACE IRRIGATION.}

(b) Laboratory project.

(c) Mr. James A. Bondurant, Agricultural Engineer, Agricultural Research Service, P. 0 . Box 835, Boise, Idaho.

(d) Experimental; field investigation, basic research.

(e) To investigate the factors that influence the advance and recession of water in an irrigation border strip.

\section{(3553) MECHANIZATION OF SURFACE IRRIGATION.}

(b) Laboratory project.

(c) Mr. James A. Bondurant, Agricultural Engineer, Agricultural Research Service, P. O. Box 835, Boise, Idaho.

(d) Experimental; design and development.

(e) To develop completely mechanized control systems for surface irrigation.

(3554) DEVELOPMEIN OF AN ECONOMICAL FILIER SYSTEM FOR FILTERIING THE SEDTMENTS FROM PLAYA LAKE WATER DURING RECHARGE OPFRATIONS WITH MULTIPIE PURPOSE WEIIS.

(b) Laboratory project; cooperating with the High Plains Underground Water Conservation District No. 1, Texas Agricultural Experiment Station, and the Soil Conservation Service.

(c) Mr. Wayne Clyma, Agricultural Engineer, Agricultural Research Service, Southwestern Great Plains Field Station, Bushland, Tex.

(d) Experimental; applied research.

(e) Development of an economical method of removing sediments from playa lake water, used for ground water recharge, by the use of flocculating agents alone or flocculating agents in conjunction with a sand filter.

(g) Tests conducted to present indicate that from 43 to 93 percent of the silt and clay sediments in lake water available for artificial ground water recharge may be flocculated and settled with the use of a flocculent alone.

(h) "Flocculent Used to Remove Sediments From Playa Lake Water Used for Ground Water Recharge," W. Clyma and M. E. Jensen, Texas Agri. Exp. Sta. Prog. Rept. 2144, May 1960. "Clarification of Playa Lake Water by Aerial Application of a Flocculating Agent," W. Clyma and W. I. Broadhurst.

(3555) FEASIBILITY OF LOW-COST SUB-SURFACE PLASTIC DRAINS FOR IRRIGATED AREAS. 
(b) This is a cooperative project with the Caterpillar Tractor Co., Union Carbide Plastics Corp., the Soil Conservation Service and the Agricultural Experiment Stations.

(c) Mr. William W. Donnan, Agricultural Engineer, P. 0. Box 629, Pomona, California.

(d) Field investigation, applied research.

(e) The objectives of this project are: (1) To determine the applicability of shallow depth drainage to specific drainage problems; (2) to evaluate installation problems of plastic drains; and (3) to determine the effectiveness of this practice in a leaching program.

\section{(3556) FARM CONVEYANCE AND WATER APPLICATIONS.}

(b) Laboratory project, Agricultural Research Service and Utah State Univ. cooperating.

(c) Dr. C. W. Lauritzen, Soil Scientist, Agricultural Research Service, Utah State Univ., 101 Engineering Bldg., Logan, Utah.

(d) Experimental; basic and applied research.

(e) New methods and equipment for conveying and applying irrigation water are being developed. The hydraulic properties of lay-flat tubing are being studied and new materials are being evaluated to determine their use in conveyance structures.

(g) Most lay-flat tubing is designed for low pressures. A butyl-coated nylon tubing developed a few years ago withstood reasonably high pressures but elongated when heads above about 10 feet of water were applied. This resulted in snaking and kinking to the point where it was not satisfactory for higher heads. During the past year the design of this tubing has been improved and beginning next year a tubing is expected to be on the market which will withstand 50 feet of hydrostatic head in the 8-inch size without any elongation. A tubing such as this should find many uses.

(h) "Shape Factors for Hydraulic Design of LayFlat Irrigation Tubing," Allan S. Humpherys and C. W. Lauritzen, Journal Amer. Soc. Agric. Eng. (in press).

(3557) THE DEVELOPMENT OF TECHNIQUES AND PROCEDURES FOR INVESTIGATING THE DRAINAGE PROBLEMS ON AN ALIUVIAL FLOOD PLAIN.

(b) Laboratory project.

(c) Mr. Victor I. Myers, Agricultural Engineer, Agricultural Research Service, Box 9186 University Station, Reno, Nevada.

(d) Applied research.

(e) Techniques, procedures, and equipment are being developed to aid in the investigation of drainage problems on an alluvial flood plain. Soil conservation surveys are utilized as a basis for the studies. In addition, deep stratum surveys are being made, hydraulic conductivity measurements taken, canal seepage measured, farm irrigation efficiencies measured, plastic tile evaluated, and other data collected.

(g) A drainage classification system has been established to relate soil conservation surveys to drainage problems and problem areas. The system is designed for use in most areas of the United States. A map of the Newlands Reclamation Project of Nevada has been constructed showing locations of canals and drains in relation to drainage categories. An improved seepage meter has been fabricated and tested.

(h) "The Physical and Economic Consideration for Drainage Project Feasibility," Victor I. Myers, Lucine N. Langan, and Russell D. Lloyd, approved for publication in Agric. Engineering.

(3558) LABORATORY MODEL STUDIES OF THE SEDTMENT SEALING PROCESS.

(b) U. S. Dept. of Agriculture, Agricultural Research Service, Soil and Water Conservation Research Divlsion.

(c) Mr. Myron B. Rollins, Soil Scientist, Agricultural Research Service, Box 9186, University Station, Reno, Nevada.

(d) Experimental; applied research.

(e) To determine factors influencing sediment penetration and retention involved with sealing irrigation canals or reservoirs with seepage transported bentonite, and to develop procedures to obtain effective seals. Experimentation is being done with sands placed in lucite cylinders 3 inches in diameter and 2 feet long. Bentonite is applied by dispersing it in the water, percolation carries the bentonite down into the sand provile. Numerous aspects concerning the chemical, physical and mineralogical properties of the bentonites, waters, and sands will be evaluated.

(g) Preliminary investigations suggest that effective seals can be obtained within certain unknown limitations.

(h) "The Apparent Swelling Behavior of Some Moderately Dispersed Bentonites, "Myron B. Rollins, Merrill J. Hallam, and Victor I. Myers. To be published in Soil Science Society of America, Proceedings.

(3559) HYDRAULIC CHARACTERISTICS OF SURFACE RUNOFF FLOWS FROM SIMULATED RAINFALL ON LEVEL AND GRADED FURROW AND BORDER STRIP IRRIGATION SYSTEMS.

(b) Nebraska Agricultural Experiment Station and Agricultural Research Service.

(c) Mr. Norris P. Swanson, Agricultural Engineer, Agricultural Research Service, Agricultural Engineering Building, Room 201, University of Nebraska, Lincoln 3, Nebraska.

(d) Field investigation; findings will be used for design purposes.

(e) Simulated rainfall is applied to plots several hundred feet long on selected sites with growing crops. In the case of row crops, the application of the simulated rainfall is such that each furrow becomes an individual watershed subject to a different rainfall intensity. Timed initial and antecedent moisture condition storms are applied. Instrumentation provides for measurement of furrow runoff flows and 
depth of flow by stations. Furrow stream velocities are measured by salt injection. Cross sections of representative furrows are recorded by stations prior to each storm and after the last. Erosion measurements are obtained and soil particle size distributions obtained.

(g) Furrow cross sections change significantly with storm runoff and enlarge at downstream stations. Furrow runoff stream velocities tend to be constant along the length of a furrow with a given storm intensity.

(h) "Proceedings of the ARS-SCS Workshop on Fydraulics of Surface Irrigation," ARS 41-43, September 1960.

(3560) EVAPOTRANSPIRATION OF HUMBOLDT MEADOW VEGETATION AS MEASURED WITH LYSTMETERS:

(b) U. S. Dept. of Agriculture, Agricultural Research Service, Soil and Water Conservation Research Division.

(c) Mr. Rhys Tovey, Agricultural Engineer, Agricultural Research Service, Box 9186 University Station, Reno, Nevada.

(d) Experimental; applied research.

(e) Objectives: (1) To measure the evapotranspiration of native meadow vegetation with lysimeters under controlled water table conditions. (2) To relate measured climatic factors to evapotranspiration rates. Nine plastic lysimeters have been installed on the flood plains of the Humboldt River near Winnemucca, Nevada. Stands of native meadow vegetation are being established in the lysimeters. A complete Class "A" weather station has been set up at the experimental site. Other instrumentation to measure radiation, soil temperatures, water table fluctuation, etc., will be installed.

(3872) DINAMIC STMILARITY IN PIPE ELBOW FLOW METHRS.

(b) Laboratory project.

(c) Mr. Lloyd E. Mvers, Director, Southwest Water Conservation Iaboratory, Route 2, Box 816-A, Tempe, Arizona.

(d) Experimental; applied research.

(e) The objective of the study is the development of means for obtaining dynamic similarity in pipe elbow flow meters to permit the use of standard rating curves. Magnitudes of errors caused by various flow disturbing elements in pipe systems will be determined and various methods for reducing or eljminating these disturbances will be tested.

(3873) GROUND COVERS AIVD OTHER STRUCTURES FOR COLTECTING AND STORING PRECIPITATION.

(b) Field and laboratory project, Agricultural Research Service and Utah State University cooperating.

(c) Dr. C. W. Lauritzen, Soil Scientist, Agricultural Research Service, Utah State University, 101 Engineering Building, Logan, Utah.

(d) Experimental and applied research.

(e) There are areas in many regions where water for livestock and even culinary uses is scarce or nonexistent, yet considerable water in the form of precipitation falls each year. As an example, the precipitation on one acre of land in an 8-inch rainfall area amounts to 217,248 gallons. This is enough to supply water to more than 200 head of cattle for 100 days. This study includes the development and testing of materials for ground covers and storage facilities to be used for the collection and storage of water in low rainfall areas together with the design and operation of these facilities.

(g) During the past several years work has been done on the development and testing of materials which would be suitable for low cost ground covers and storage facilities. Among these have been asphalt membranes, including prefabricated asphalt structures, plastic film and butyl sheeting. Of these, butyl sheeting and an asphalt-coated jute structure look most promising for ground covers. Any of the common water storage facilities can be used, such as lined reservoirs and tanks, provided they are watertight and preferably closed to prevent evaporation. A collapsible butyl-coated nylon bag has been developed which looks promising for low cost storage.

(h) "Ground Covers for Collecting Precipitation," C. W. Lauritzen, Farm and Home Science, 21:3, 66, 67, 87, September 1960.

(3874) INFLUEINCE OF COIORADO RIVER WATER UPON IRRIGATION AND DRATNAGE IN SAN JACINIO BASIN.

(b) This is a cooperative project with the Soil Conservation Service and the Eastern Municipal Water District, Riverside County, California.

(c) Mr. V. S. Aronovici, Soil Scientist, Agricultural Research Service, P. 0. Box 629, Pomona, California.

(d) Field investigation; applied research.

(e) The purpose of this project is to observe the accumulation of salts, if any, within the profiles of soils irrigated with Colorado River water.

\section{(3875) A STUDY OF THE INTERNAL MOISTURE STRESS} WITHTN PLANTS.

(b) Laboratory project.

(c) Mr. I. N. Namken, Soil Scientist, USDA, ARS, SWC, P. O. Box 157, Weslaco, Texas.

(d) Experimental; development investigation.

(e) This study provides information on the possible use of the relative turgidity and plant stem resistance methods as simple tools for use in soil-water-plant relationship studies and predicting when to irrigate.

(g) The two methods of measuring internal moisture stress of cotton plants under investigation, plant stem resistance and relative turgidity, show promise for practical application as tools for better understanding water relations in plants as well as for predicting when to irrigate. Highly significant correlations were obtained among plant stem resistance relative 
turgidity and soil moisture tension. However, the sensitivity or reliability of the methods cannot be fully determined until more detailed studies are conducted on the effect climatic variations at sampling time have on the measurements.

(h) "Field Studies of Internal Moisture Relations of the Corn Plant," L. N. Namken and E. R. Lemon, Agronomy Journal, (in press).

"Measurement of Plant Moisture Stress," I. N. Namken, Progress in Soil and Water Conservation Research, a quarterly report, SWCRD-ARS-USDA, (in press).

(3876) SOIL-WATER-PIANP RELATIONSHIPS OF COTMON AS AFFECTED BY SOII MOISTURE REGIME.

(b) Laboratory project.

(c) Mr. L. N. Namken, Soil Scientist, USDA, ARS, SWC, P. O. Box 157, Weslaco, Texas.

(d) Field investigation; applied.

(e) This study provides information on the rate, amount, and pattern of soil moisture depletion by cotton as affected by the stage of plant growth, the amount of available moisture in the profile and the soil type. Various methods of soil moisture measurement are being compared (Neutron scattering, gravimetric and tensiometric methods).

(g) There was a characteristic parabolic relationship between the rate of soil moisture depletion by cotton and stage of plant growth, reaching its peak during the early blooming stage and continuing at this peak rate during the next $5-6$ weeks, the period of boll development, considered to be the critical period in the development of the cottom plant insofar as its demand for moisture is concerned. Following this period there was a gradual decline in the rate of moisture depletion as the plant matured. High moisture conditions delayed maturity and extended the period of peak moisture depletion.

Good agreement was found between soil moisture values obtained gavimetrically and those obtained by means of the neutron probe, at all soil depths under consideration.

(h) "An Economical "Go Cart" for a Neutron Probe and Scaler," M. Amemiya and I. N. Namken, Soil Sci. Soc. Amer. Proc., (in press).

\section{(3877) SOIL MOISTURE REQUIREMENTS FOR COTTON.}

(b) Laboratory project.

(c) Mr. P. Earl Ross, Agricultural Engineer, USDA, ARS, SWC, P. O. Box 157, Weslaco, Texas.

(d) Field investigation; applied research.

(e) A study to determine the most effective use of a variable and limited supply of irrigation water for cotton production.

(g) It has been found that soil moisture may be reduced to 10 percent field capacity in the upper 2 feet with no significant reduction in yield of cotton.

(3878) EFHECT OF WINTER OATS AND PEREINIIAL
RHODESGRASS ON SUBSEQUENT REMOVAL AND UIILIZATION OF SOIL MOISTURE BY COTTON.

(b) Laboratory project.

(c) Mr. P. Earl Ross, Agricultural Engineer, USDA, ARS, SWC, P. O. Box 157, Weslaco, Texas.

(d) Field investigation; applied research.

(e) A study of the effect of different soil physical conditions on soil moisture use anc requirement by cotton and the effects of the grass crops on cotton production.

(3879) CHARACTPERIZATION OF THE "HOT SPOT" PROBLAM IN THE IOWER RIO GRANDE VAITEY OF THEXAS.

(b) Laboratory project.

(c) Mr. I. Roy Ussery, Agricultural Engineer, USDA, ARS, SWC, P. O. Box 157, Weslaco, Texas.

(d) Experimental and field investigation; applied research.

(e) Purpose of this study is to define the causes of salt accumulation in soil profiles in the nonirrigated area of the Lower Rio Grande Valley of Texas. Investigations include studies of ground surface and water-table topography, physical and chemical characteristics of soil profiles, soil management practices and climatic conditions, as related to occurrence of soil salinity.

(g) An Extensive sand formation underlies the nonirrigated area under study and adjacent irrigated and rangelands areas. Extreme fluctuations of a saline water table saturating the sands occur with local rainfall of high intensity. Pumping tests show the sand has hydraulic conductivity of approximately 400 gallons per square foot per day. Residual salt deposits in the 6 to 12 foot depth of the soil profile are probably of marine origin.

(h) "Drainage and Salinity Problems in the Nonirrigated Area of the Lower Rio Grande Valley of Texas," L. Roy Ussery. Paper presented at Winter Meeting, ASAE, Memphis, Tenn., December 5-8, 1960.

(3880) THE MICRODYNAMICS OF UNSATURATEDD MOISTURE FLOW.

(b) Laboratory project.

(c) Mr. Craig I. Wiegand, Soil Scientist (Physics), USDA, ARS, SWC, P. O. Box 157, Weslaco, Texas.

(d) Experimental and theoretical; basic research.

(e) The study is being conducted to obtain information on the microdynamics of unsaturated moisture flow. Specific objectives are aimed at (a) determining whether the activation energy for unsaturated flow is a function of soil moisture content, (b) obtaining evidence on the generality of the parabolic moisture distribution with respect to the extracting interface, and (c) interpreting unsaturated flow in terms of molecular level mechanisms of flow. To this end various systems for inducing unsaturated flow are being set up and the 
temperature dependence of the flux and the moisture distribution resulting from flow are being measured.

(3881) FACTORS AFFECTING THE EVAPORATION OF FREE WATER.

(b) Laboratory project.

(c) Mr. Craig L. Wiegand, Soil Scientist (Physics), USDA, ARS, SWC, P. O. Box 157, Weslaco, Texas.

(d) Experimental; applied research.

(e) The experiment is being conducted to obtain quantitative information on the rate of evaporation of free water over a wide range of different combinations of water surface temperature, air temperature, and ambient relative humidity. The experiment is being conducted in a controlled environment laboratory.

(g) The rate of evaporation follows the vapor pressure of water quite closely. It is indicated that temperature of the evaporating surface should be incorporated into empirical equations expressing evaporation from lakes, reservoirs, and wet soil profiles.

\section{$m-m-m-n$}

U. S. DEPARTMENT OF AGRICULTURE, FOREST SERVICE, Alaska Forest Research Center.

(2654) EHFECT OF LOGGING ON PHYSICAL CHARACTERISTICS OF SALMON STREAMS IN SOUTHEAST ALASKA.

(b) Laboratory project.

(c) Mr. A. E. Helmers, Acting Forester in Charge, Alaska Forest Research Center, P. O. Box 740, Juneau, Alaska.

(d) Field investigation; applied research.

(e) This work attacks the vital problem of maintaining the fish-producing potential of Southeast Alaska streams, while logging their watersheds. Work is concentrated on 4 streams lying 40 miles west of Ketchikan. Three study-streams are being logged under Forest Service supervision and the fourth stream is used as an unlogged control.

Study is directed toward factors which may exert a major influence on pink and chum salmon development and survival in a logged stream. Factors selected are: Streamflow pattern; (b) stream water temperature and $\mathrm{pH}$; (c) character of sediment movement in streams; (d) composition of streambed riffle areas; (e) movement of streambed materials in riffles; (f) shift of stream channels; and $(g)$ occurrence of stream debris.

(g) A field laboratory for determination of suspended sediment levels (p.p.m.) has been constructed and now operates during the field season at Hollis, Alaska. Samples during summer-fall 1960 expanded investigations of (a) general suspended sediment character of 4 Kasaan streams, (b) relation of suspended sediment in logged and unlogged streams to stream discharge levels, (c) effects of logging dis- turbances on suspended sediment concentrations and on the organic/inorganic character of the sediment.

A study of stream channel shift and debris movement associated with logging is being converted from a hand-mapped project to an annual helicopter photo coverage.

U. S. DEPARTMENT OF AGRICULTURE, FOREST SERVICE, Central States Forest Experiment Station.

Inquiries concerning the following projects should be addressed to Mr. R. D. Lane, 111 Old Federal Building, Columbus 15, Ohio.

\section{(3561) WATERSHED PREDICTION METHODS.}

(b) Laboratory project.

(d) Experimental and field investigation; basic and applied research.

(e) An analysis of records to determine the relation of precipitation to runoff in hardwood forest types in the 30-45 inch rainfall belt of the Central United States.

(f) Completed.

(g) Precipitation and runoff records for three small watersheds near Rolla, Missouri were analyzed. The three watersheds differ in size, shape, land use, and cover type. The smallest covers 0.6 square mile and is open land. The middle one had approximately 2.1 square miles of oak forest and 4.3 square miles of grain crops and pasture. The largest contains approximately 9.3 square miles of oak forest and 4.7 square miles of grain crops and pasture. In the seven year period 1948 to 1955 the annual precipitation varied widely - from 18 to 65 inches - and averaged 38 inches.

In these Ozark watersheds effective ground water storage areas occurred in the lower reaches - the branch bottoms - where soils were deeper and hydraulic gradients were rather low. The smaller watersheds had smaller water yields, probably because more water seeped to lower ground levels. For predicting annual water yields from annual precipitation a water year commencing June 1 and ending May 31 gave the best correlation. Since ample soil moisture was not always available, total amount of evapotranspiration increased as growing season precipitation increased. Further analyses of the hydrographs showed that only 22 storms were recorded in an average year. This contrasts sharply with 68 at Coshocton, Ohio and 128 at Coweeta, near Franklin, North Carolina. The period May-July had the largest number of storms and highest storm flows and the period September-December the lowest number of storms and smallest storm peak discharges. Generally, storm peaks were higher and more generous on small watersheds than on larger watersheds because the frequency and magnitude of storm peaks usually vary inversely with watershed size. In the 7-year period studied here the smallest watershed had 96 peak flows exceeding 40 c.s.m. (cubic feet per second per square mile) while the 
middle sized had 65 such peaks and the largest only 44. The smaller watershed had more storms in the higher peak classes with one maximum of $2800 \mathrm{c.s.m}$. The majority of peaks occurred during the growing season.

(h) "Annual Water Yields From Small Watersheds in the Ozarks." Presented by R. Z. Whipkey at a combined A.R.S., S.C.S., F.S. workshop, New Orleans, La., Oct. 1960.

(3562) RESTORTNG DEPIETED SLOPES, COSHOCTON HYDROLOGIC LABORATORY, OHIO.

(b) Laboratory project.

(d) Field investigation; basic and applied research.

(e) An evaluation of hydrologic changes that occur in a broomsedge, poverty-grass covered watershed after it is rehabilitated by planting tree seedlings.

(f) Completed.

(g) Prior to the installation of a gaging station in 1938, two-thirds of a 43.6 acre watershed had a stand of grass and brush and the other one-third had a stand of uneven-aged hardwoods. In 1938 and 1939 three small parts of the non-forested area were planted with black locust and the balance was planted with white, red, pitch, Scotch and Virginia pine. In late 1958 the residual hardwood stand had a total of 126 square feet of basal area per acre, the pine plantations had 78 , and the locust plantations had 143. Hydrograph analyses showed: (1) In the average year streamflow equalled or exceeded 0.18 cubic feet per second per square mile for 182.5 days and was zero for 84 days. When precipitation was low the stream was dry as many as 225 days a year and exceeded flows of 0.5 c.s.m as little as 10 percent of the time. Streamflow was continuous in 1950 when precipitation totaled 43.6 inches. (2) Conversion of the watershed to complete forest cover decreased the ground water depletion time by 7 days, from 30 days in 1939-1945 to 23 days in 1952-1957. (3) Average annual base flow for the ll-year period 1939-45 and 1952-57 was 8.88 inches (4/5 of the total annual flow). It was greatest, 5.5 inches, during the ground water recharge period and least, $0.89 \mathrm{in.}$ during the soil moisture recharge period. (4) The 1l-year average annual stormflow yield was 2.2 inches ( $1 / 5$ of total annual flow). It was greatest, 1.16 inches, during the ground water recharge period and least, 0.15 inches, during the soil moisture recharge period. (5) Converting the watershed to complete forest cover did not change the proportion of baseflow and storm water yield, but did decrease the quantity of each. Baseflow was decreased by 4.4 inches and stormflow by 1.4 inches. The greatest changes in each occurred during the period of ground water recharge and the least during the period of maximum evapotranspiration. (6) a 53 percent re. duction in the occurrence of stormflows equal to or greater than $20 \mathrm{c.s.m}$. was discovered in a comparison of stormflows at plantation ages of 1-6 with those of 13-17 years. A reduction of 80 percent was found in the occurrence of flows with a peak equal to or greater than 60 c.s.m.

(h) "Forest Plantation Development Influences Streamflow." Presented by L. W. Hill at the Society of American Foresters Annual Meeting, Washington, D. C., November 1960.

(3563) SUBSOIL WATHER MANAGFMENT ON NORTHERN HARDWOOD FOREST AREAS.

(b) Laboratory project.

(d) Experimental and field investigations; basic and applied research.

(e) Movement of subsoil water will be studied in various geologic and soil types to: (1) Develop techniques for quantitatively measuring subsurface water movement from small plots; (2) to learn the effect of artificial rainfall on quantity and timing of subsurface water movement; and (3) to develop a flow equation, including coefficients for the significant variables affecting that flow. This information will aid watershed technicians in making land management decisions on areas that have lots of subsurface stormflow.

(g) Measuring water level changes in smalldiameter, piezometric wells is a standard technique for studying the build-up and depletion of ground water. This technique is used widely in ground water research especially in studies of drainage of agricultural lands. No measurable changes in water level can occur, however, unless an impenetrable layer occurs in some form that will cause back pressure in the ground water. This condition was found not to exist, and the piezometer technique was found to be unsatisfactory in our studies of subsoil water movement through the permeable soils on the sloping forest land in eastern Ohio. One technique that has given encouraging results is to isolate a block of soil and route the subsurface flow through porous material into collector troughs. Accumulated volumes of subsurface flow from several depths plus increases in the volume of soil moisture as measured by the neutron soil moisture meter have agreed reasonably well with the total rainfall amounts that were sprinkled on the plots.

Though workable, the technique is being refined to give greater portability and economy. The ultimate aim is to find a way to obtain accurate quantitative measurements on enough small plots that the flow from a whole watershed during wet periods can be predicted reliably.

(3882) INTERCEPTION OF PRECIPITATION BY THE CANOPY AND FLOOR OF A HARDWOOD FOREST.

(b) Laboratory project.

(d) Experimental and field investigation; basic and applied research.

(e) A recent, 3-month long, late summer study in Butler County, Missouri, shows the amount of rainfall intercepted by, retained 
by, evaporated from, and infiltrated through the forest floor of a uniform, well-stocked, 40-year-old stand of black oak, post oak, and hickory. Samples of the forest floor were carefully transferred onto wire mesh screens inside platform mounted trays. A 4-foot long by 3-inch wide trough-type rain gage was attached to each side of specially constructed 4-foot by l-foot trays. Water caught in each trough was collected and weighed in 5gallon containers. Water filtering through the forest floor samples was collected and weighed in other containers connected to the main trays.

Three trays (with their contained forest floor samples) were placed near the stem of each of two trees and three were placed under the edge of the crown of each of these sample trees. Three trays were placed under a small canopy opening and three were placed in a large opening. Each tray was weighed daily and the water caught by the trough rain gages was weighed after each of the 21 storms that occurred during the study period.

(f) Completed.

(g) The live tree canopy and the decaying, organic forest floor were found to extract and lose back into the atmosphere 27.1 percent (2.94 inches) of the 10.84 inches of gross precipitation. Interception by the tree canopy, which averaged 14.3 percent ( 1.55 inches) of the gross precipitation, accounted for slightly more than one-half the total loss. Generally it was greatest near the stems and least under the forest openings. The additional 12.8 percent ( 1.39 inches) of loss was a result of evaporation from the forest floor. It occurred in three stages. Initial evaporation during and immediately after rainstorms amounted to 6.0 percent $(0.65 \mathrm{in.)}$. Approximately 3.8 percent (.41 inch) was evaporated within 5 to 10 days after saturation. The remaining 3.0 percent ( 0.33 inches) was lost during the next 10 20 day period.

The amount of gross precipitation that was left to percolate through the forest floor was 72.9 percent ( 7.90 inches).

The weight of the forest floor averaged 4 tons per acre. Its decomposed fraction held more moisture on a volume weight basis than did either the undecomposed leaf litter or the mineral soil.

(h) "Interception of Precipitation by a Hardwood Forest Floor in the Missouri Ozarks," William T. Semago, Master of Science in Forestry Thesis, 137 pp., June 1960.

U. S. DEPARTMENT OF AGRICULTURF, FOREST SERVICE, Intermountain Forest and Range Experiment Station.

Inquiries concerning the following projects should be addressed to Dr. Reed W. Bailey, Director, Intermountain Forest and Range Experiment Station, Ogden, Utah.
(2908) METHODS OF REHABILTTAATING FLOOD AND SEDTMENT SOURCE AREAS ON DAMAGED FOREST, BRUSH, AND RELATED RANGE LANDS.

(b) Laboratory project.

(d) Experimental and field investigations; basic and applied research.

(e) Studies to develop and evaluate methods and techniques of controlling excessive overland flow and erosion, and their effects on streamflow from depleted or inadequately protected sloping forest, brush, and related range lands.

(g) The effects of two moderate intensity summer rainstorms in eroding soil from ten 1/50acre plots on the Gallatin elk range were analyzed in relation to ground cover and soil bulk density. Each of these storms produced about 0.5 inches of rainfall and had a maximum 5-minute intensity of 1.5 inches per hour. The least amount of soil eroded--2l pounds per acre per storm--was from sites having a ground cover of $100 \%$ in combination with a soil bulk density of 0.70 . Very little more soil was eroded where the ground cover density was only 70 percent. As ground cover density decreased below 70 percent, the amount of soil eroded increased at a rapidly accelerated rate. Thus, a ground cover density of 70 percent is one requisite for preventing accelerated erosion on heavily trampled south-facing range sites.

As soil bulk density increased above 0.70 , the amount of soil eroded increased irrespective of ground cover density. These increases were lowest on sites with a complete ground cover, but increased greatly as ground cover became less. There appears to be no range of soil bulk density values, similar to the range of 70 to 100 percent ground cover, over which essentially equal control of soil erosion is provided. Of the range sites studied, those having ground cover densities of less than 70 percent were usually associated with soil bulk densities greater than 1.00. Conversely, sites supporting ground cover densities of 70 percent or more are usually associated with soil bulk densities of 1.00 or less. The most effective degree of erosion control to be expected on these sites appears to be provided by ground cover densities of 70 percent or more in combination with soil bulk densities of 1.00 or less. Under these conditions, no more than 50 pounds of eroded soil per acre should be expected from storms described above. In about 94 percent of cases, these range plant cover and soil conditions are expected to produce no more than 100 pounds per acre of eroded soil per storm.

The long-term effects of restoration of plant cover on flood-source areas by seeding, contour trenching, and exclusion of grazing were analyzed. Twenty-two years of records (1937-58) provide a basis for comparing streamflow from two adjacent watersheds of contrasting use history in northern Utah. Centerville watershed has no history of 
plant cover depletion or floods. The adjacent Parrish watershed, severely damaged by overgrazing and burning, produced four disastrous mud-rock floods in 1930. A time-trend analysis of discharges of Parrish Creek compared with those of Centerville Creek, shows that Parrish Creek streamflow decreased 2.70 inches over the 22-year period for an annual decrease of 0.12 inch. Similar time-trend analyses for the first and last 1l-year period show that 83 percent of the total decrease in streamflow occurred in the first 11 years (1937-1947) and that no significant decrease has occurred during the last 11 years. The largest decreases in streamflow in Parrish Creek by months occurred in March, April, and May, the period when demands for water are not so great. The trend of decreased annual discharge from the restored Parrish Creek watershed has been accompanied by a delay in the date of maximum daily discharge. During the early period of record, Parrish Creek tended to reach its maximum daily discharge about 3 days earlier than Centerville Creek. In the later years the maximum discharges have occurred about 3 days later than Centerville Creek.

A major effect that resulted from rehabilitation of Parrish watershed is the virtual elimination of sedimentation. In 1930, the four mud-rock floods from the damaged

Parrish watershed produced sediment amounting to 153 acre feet per square mile. Rehabilitation has so effectively reduced sedimentation that streamflow from Parrish Creek is now diverted directly into water systems.

(h) "Low Flow Discharges and Plant Cover Relations on Two Mountain Watersheds in Utah," Reed W. Bailey and Otis I. Copeland, Jr., I.A.S.H. No. 51, pp. 267-278, 1960.

"Watershed Restoration," Otis I. Copeland. Jour. of Soil and Water Cons. 15 (3): 105$120,1960$.

(3883) SOIL DETACHMENT AND TRANSPORT BY SUMMER RAINS.

(b) Laboratory project.

(d) Experimental and field investigations; basic and applied research.

(e) The objective is to determine the amount and variation of soil particle size classes detached and transported under the impact of summer storms on a bare plot of soil in northern Utah.

(g) Samples of sediment eroded from the plot during the past 11 summers were analyzed for particle size distribution. Analysis of the data in relation to depth, duration, and intensity of storms is underway.

(3884) STUDIES OF HYDROIOGIC PROCESSES ON FOREST LANDS IN NORTHERN IDAHO.

(b) Laboratory project.

(d) Experimental and field investigations; basic and applied research.

(e) Study of factors affecting water content, accumulation, and melting of snow on forested lands.

(f) Completed.

(g) An analysis of relations between maximum snow water content and elevation, aspect, and forest canopy density included variable reflecting differences in snowfall from year to year, and six interaction variables involving all of the possible linear interaction combinations of differences in years, elevation, aspect, and forest canopy density. Throughout its range from 2,700 to 5,500 feet, elevation accounted for an increase of 30.1 inches of water content in the average snowfall year. The effects of aspect varied with elevation. The aspect having the minimum water content was 165 degrees and that having the maximum water content was 11 degrees (measured as azimuths from north). Water content was affected uniformly by changes in the forest canopy regardless of elevation, aspect, or magnitude of snowfall. An equation describing these relations was developed.

(h) "Some Terrain and Forest Effects on Maximum Snow Accumulation in a Western White Pine Forest," Paul E. Packer. Western Snow Conf. Proc., pp. 63-66, 1960.

U. S. DEPARTMENT OF AGRICUITURE, FOREST SERVICE, Lake States Forest Experiment Station.

Inquiries concerning the following projects should be addressed to the Director, Lake States Forest Experiment Station, St. Paul Campus, University of Minnesota, St. Paul 1, Minn., unless indicated otherwise.

\section{(3885) PROBLEM ATALIYSIS OF FOREST WATERSHED PROBLEMS AND RESEARCH NEEDS IN THE LAKE STATES.}

(b) Cooperative project with Forestry Dept., State University of Minn., E. Lansing, Mich.

(d) Field investigation and literature review as program guide.

(e) A survey was made of the forest watershed management conditions and needs in the three Lake States--Michigan, Wisconsin, and Minnesota--as a preliminary research program guide.

(f) Completed.

(g) The survey revealed the existence of several distinct forest watershed problem areas in the Lake States. It outlines a general program of research for each. One area is concerned with the hydrology of forested bogs in the northern forest spruce zone, another is an erosion and rehabilitation area in southwest Wisconsin and southeastern Minnesota, and a third deals with the problem of ground-water movement and behavior in the sandy soils of Michigan. The research program outlined also emphasizes the need for fundamental research on cover changes and management practices to determine their effect on individual processes.

(h) "Watershed Management Research Needs in the Forests of the Lake States," by Robert E. Dils, Michigan State University Agriculture 
Experiment Station, Spec. Bul. 416, 35 pp., illus., 1957.

(3886) THE CLASSIFICATION AND NOMENCLATURE OF NATURAL UPLAND FOREST HUMUS TYPES IN THE NORTHERN LAKE STATES.

(b) A regional cooperative project with the Dept. of Forestry, Mich. State University, East Lansing, Mich.

(c) Dr. D. P. White, Dept. of Forestry, Michigan (3888) State Univ., East Lansing, Mich.

(d) Field investigation; basic and applied research.

(e) The various types of humus layers in Michigan, Wisconsin, and Minnesota forests are to be classified and checked against the existing humus classification by Lunt and Hoover.

\section{(3887) WATERSHED MAINAGEMEINT RESEARCH IN NORPHERN} MINNESOTA.

(b) Laboratory project.

(d) Experimental and field investigations; basic and applied research.

(e) Tests the influence of forested bogs on streamflow and ground-water behavior. Two major projects have been undertaken to date: (1) Studies of the effect of forest cover conditions on individual hydrologic processes. This has included the impact of soil-cover types on snow accumulation and melt, soil f'reezing, and moisture regime. (2) studies of forest bog hydrology on small forested swamp watersheds. Present instrumentation includes a recording well and a series of 9 to 12 nonrecording wells in each of 3 swamps. Two watersheds have been equipped with stream-gaging stations and rain gages, and the third swamp will be instrumented in the near future.

(g) Forest cover retarded spring snowmelt, conifers retained snow longer than hardwoods, conifers intercepted more snow than broadleaf types, there was less water content in the snowpack in dense than in thin stands, strip cutting of timber increased snow accumulation, humus type and depth affect the kind and depth of frost penetration in soil. There was less soil freezing under broadleaf than conifer stands, and in spite of soil freezing, forest soils of a sandy nature and rather low moisture content had a considerable infiltration rate.

(h) "Occurrence and Depth of Frozen Soil," by Roger R. Bay, Jour. Soil and water Conserv. 13: 232-233, illus., 1958.

"Forest Type Affects Snowpack," by Roger R. Bay, Jour. Soil and Water Conserv. 13: 129130, illus., 1958.

"Cutting Methods Affect Snow Accumulation and Melt in Black Spruce Stands," by Roger R. Bay, Lake States Forest Exp. Sta., Tech. Note 523, 2 pp., illus., 1958.

"An Inexpensive Soil Tube Jack," by Roger R. Bay, Soil Sci. 88: 303-304, illus., 1959.

"Snow Behavior in Forests of Northern Minn. and its Management Implications," by Sidney Weitzman and Roger R. Bay, Lake States Forest Experiment Station, Station Paper 69,
18 pp., illus., 1959.

"Soil Freezing Observations After Changes in Forest Cover," by Roger R. Bay, Lake States Forest Experiment Station, Tech. Note 576, 2 pp., 1960.

"Infiltration Rates in Frozen Soils in Northern Minnesota,: by J. H. Stoeckeler and Sidney Weitzman, Soil Sci. Soc. Am. Proc. 24(2): 137-139, 1960.

SOIL MOISTURE REGIME, SNOW BEHAVIOR, AND SOIL FREEZING IN SEVERAL COVER TYPES IN NORTHERN WISCONSTN.

(b) Cooperative project with Waterways Exp. Station, Corps of Engineers, Dept. of the Army, Vicksburg, Miss.

(d) Field investigation; basic and applied.

(e) The project which was initiated to get soilmoisture and soil-freezing data involved daily observations of soil moisture content using Colman fibreglass units in an open and forested silt loan and on two forested sandy soils with rather shallow permanent water table at 2 feet and 5 feet respectively. Snow depth and depth of soil freezing were observed in winter on four sites and soil temperatures recorded.

(g) Higher soil moisture content was observed in surface layers of silt loan in open hay land compared with hardwood timber. The latter used more moisture. Soil freezing was negligible most of the winter under an undisturbed snowpack of 0.5 to 1.0 foot in both situations. Shallow water tables in sands increased surface soil moisture very appreciably due to capillary rise, and it in turn improved growth rate of quaking aspen, but not appreciable in the jack pine, comparing 2- versus 5-foot-depth water tables.

(h) "Soil Moisture Regime in some Forest and Nonforest Sites in Northern Wisconsin," by John L. Thames, Joseph H. Stoeckeler, and Robert Tobiaski, Soil Sci. Soc. Amer. Proc. 19(3): 381-384, illus., 1955.

"Properties of 160 Soils of Four North Central States," by John L. Thames and Edmond I. Swensen, Lake States Forest Exp. Sta., Station Paper 38, 15 pp., illus. 1956. "The Iake States Penetrometer for Measuring Depth of Soil Freezing," by J. H. Stoeckeler and John L. Thames, Soil Sci. 85: 47-50, illus., 1958.

(3889) WATERSHED MANAGEMEIT RESEARCH IN THE DRIFTLESS AREA OF SOUTHWESTERN WISCONSIN.

(b) Laboratory project, with some aspects in cooperation with Wisconsin Conservation Department.

(d) Field investigations; basic and applied research.

(e) Major emphasis is given to methods of controlling runoff and erosion, including gully stabilization through reforestation, and manipulation of land use and treatments. Studies of infiltration, soil-moisture movement and storage on loessal soils under the impact of grazing and other uses are underway. The effect of land use and land 
treatments on springflow is also being investigated. Two $90^{\circ} \mathrm{V}$-notch weirs have been installed in springs and two modified 2-foot San Dimas flumes have been installed on small watersheds. Part of the study involves computation, analysis, and publication of some older file data on lysimeters, needed as background material for the overall aim of the project.

(g) Markedly better soil-moisture conditions were found on north as compared with south slopes, on lower slopes as compared with upper slope positions, and in broadleaf stands as compared with conifers. Growth rate of conifers was 3.5 times greater than broadleaf species on comparable south slopes. Livestock trampling reduced infiltration rate in the single cylinder method by 93 percent.

A 563-foot-long meandering spring channel, mostly in an open pasture, was shortened 67 percent by rerouting the water through a new ditch made with a small bulldozer through a willow-shaded location to speed flow of water and reduce water temperature at mouth of the spring channel where it met the trout stream. Water temperature was reduced by $10^{\circ}$ to $11^{\circ} \mathrm{F}$ by shortening the spring channel.

A cover of litter on bare soil improved its infiltration capacity and ability to produce percolation water through a 4-foot profile. A layer of gravel was outstanding in this respect. A cover of planted trees was better than the usual farm crops. Layers of litter from 2 to 3 inches deep absorbed and held most of the precipitation in light rains under 0.5 inch, but only about 11 percent of rainfall of over 1 in.

(h) "A Lysimeter Installation for studying Forest Influence Problems," by Harold F. Scholz and J. H. Stoeckeler, Jour. Forestry 38: 256-260, illus., 1940. "Trampling by Livestock Drastically Reduces Infiltration Rate of Soil in Oak and Pine Woods in Southwestern Wisconsin," by J. H. Stoeckeler, Lake States Forest Exp. Sta., Tech. Note 556, 2 pp., illus., 1959.

"Water Temperature Reduction in Shortened Spring Channels of Southwestern Wisconsin Trout Streams," by J. H. Stoeckeler and Glenn $J$. Voskuil, Trans. Amer. Fisheries Soc. 88: 286-288, illus., 1959. "Moisture Storage by Leaf Litter," by Willie R. Curtis, Lake States Forest Exp. Sta., Tech. Note 577, 2 pp., 1960.

"An Automatic Trigger Device for use in FW-1 Water Level Recorders," by Willie R. Curtis, Jour. Forestry 58: 819-820, illus. 1960 .

"Forests and Erosion in the Driftless Area," by Richard S. Sartz, Wis. Conserv. Bul. 25(3): 21-24, illus., 1960.

"Soil Moisture Regime in Southwestern Wisconsin as Affected by Aspect and Forest Type," by J.H. Stoeckeler and Willie Curtis, Jour. Forestry. In press.

(3890) WATERSHED MANAGEMENT RESEARCH IN LOWER MICH.

(b) Cooperative project with Fish Division, (h)

Michigan Department of Conservation, Lansing, Michigan.

(d) Field investigation; applied research.

(e) A major objective of this study is to determine the hydrology of ground-water recharge and uses in deep sandy soils of the Udell Hills area in Michigan. Installations to date include a series of ground-water wells in deep morainal areas and adjoining outwash plains. After the calibration period, the effect of cover manipulation--especially plantation establishment and harvesting methods--on ground-water recharge and use will be established. A second major study is concerned with streambank stabilization and the sediment problem in streams flowing through these sandy areas.

(g) Red pine plantations had the least snow accumulation on the ground and the greatest depth of frost penetration in the soil. In spring the snowpack and soil frost persisted longer than on the broadleaf types. Snow disappeared faster in oak stands than in the other forest types, and there was very little soil frost. Soil freezing was least in northern hardwoods. Thinned stands of red pine accumulated more snow than dense unthinned stands.

Soil-moisture samplings to a depth of $7 \mathrm{ft}$. in dense 25-year-old red pine plantations and 60- and 70-year natural scrub oak stands showed red pine started to use soil moisture earlier in spring than oak. Both plots started at field capacity in early April. In late June and early July, rate of moisture depletion was more rapid in scrub oak than pine, and by the end of July the moisture status of both cover types was similar and continued to be similar until the last sampling in mid-October when field capacity of 5.78 inches was again nearly attained. Northern hardwoods showed more total soil moisture than the conifer areas. Calculated ground-water recharge in sandy outwash plains in the period April-October 1958 was 4.18 inches for open, wild grassland; 3.27 inches for scrub oak; and 1.51 inches for dense red pine plantations. These were based on soil-moisture samplings and calculation of a daily soil-moisture budget. More research is planned in this area of investigation, with an attempt to have the studies on a 12-month basis. A survey was made of 228 streambanks in 4 separate watersheds in Lower Michigan, of which 115 had been stabilized, usually by rock on the lower slope, and grass and mill chaff seedings on the upper portion, to determine effectiveness of the man-made stabilization efforts compared with untreated banks where volunteer vegetation was the only stabilizing action. The streambank stabilization efforts are considered quite successful. Serious erosion on treated versus untreated banks was 7 versus 47 percent respectively. Waterlines of treated banks were 93 percent stabilized versus 28 percent on untreated banks.

"Snow Accumulation Under Red Pine of Different Stand Densities in Lower Michigan," by Robert E. Dils and John L. Arend, Lake States 
Forest Experiment Station, Tech. Note 460, 2 pp., illus., 1956.

"Effects of Forest Cover on Soil Freezing in Northern Lower Michigan," by W. D. Striffler, Lake States Forest Experiment Station, Station Paper 76, 16 pp., illus., 1959.

"Pattern of Soil Moisture Depletion Varies Between Red Pine and Oak Stands in Mich.," by Dean H. Urie, Lake States Forest Exp. Station, Tech. Note 564, 2 pp., illus., 1959.

"Streambank Stabilization in Michigan--A Survey," by W. D. Striffler, Lake States Forest Experiment Station, Station Paper 84, 14 pp., illus., 1960.

U. S. DEPARTMEIVT OF AGRICUTIURE, FOREST SERVICE, Northeastern Forest Experiment Station.

Inquiries concerning the following projects should be addressed to Dr. Ralph W. Marquis, Director, Northeastern Forest Experiment Station, 102 Motors Avenue, Upper Darby, Pennsylvania.

(656) WATERSHED MANAGEMENT RESEARCH, DELAWARELEHIGH-EXXPRTMENTAL FOREST, PENNSYLVANIA .

(b) Laboratory project; in cooperation with the Pennsylvania Dept. of Forests and Waters and U. S. Geological Survey.

(d) Field investigation; basic and applied research.

(e) A study was started in 1948 on the DelawareLehigh Experimental Forest, Monroe County, $\mathrm{Pa}$., to determine the water economy for a 1,530-acre watershed covered with scrub oak. The cover is now being converted by planting and fire protection to conifers and the effect on water relations will be measured.

(f) Suspended.

(g) The watershed was calibrated on the basis of the first six year's daily climatic and streamflow record by relating monthly, seasonal, and annual discharge to rainfall and air temperature. About 300 acres have been planted; further planting depends on results of seed-spot tests. Stream gaging and climatic research were discontinued December 31, 1958 until such time vegetation has changed sufficiently to warrant further gaging to determine the effect of the change on streamflow.

(966) WATERSHED MANAGEMFNT RESEARCH, POCONO EXPERTMEETAL, FOREST, PENNSYLVAINIA.

(b) Laboratory project.

(d) Field investigation; basic and applied research.

(e) Studies have been started on the Pocono Experimental Forest, Wayne County, Pa., to determine effects of forest management practices and logging operations upon the quantity and quality of water yielded by a small watershed. Installations have been established to measure precipitation, streamflow and rainfall interception. (f) Suspended.

(g) Stream-gaging was stopped December 31, 1958, after 6 years of record, and will be started when the watershed is subjected to a forest treatment.

(1188) WATERSHED MANAGEMENT RESEARCH, FERNOW EXPERIMENIAL FOREST, WEST VIRGINIA.

(b) Laboratory project.

(d) Field investigation; basic and applied research.

(e) Studies were started in 1951 on the Fernow Experimental Forest, Tucker County, W. Va., to determine the effect of different levels of cutting practices, different logging methods, and different forest uses upon water quantity and quality. Nine watersheds have been equipped with streamgaging stations and raingages.

(g) Following six years of record taking, and analysis for calibration, treatment of one group of five watersheds was started in May 1957 and completed in 1958. Records are being continued to determine treatment effects on streamflow.

(h) "A Simple Filter for Small Streams," K. G. Reinhart, Northeastern Forest Expt. Sta. Note 167,4 pp., 1960.

(2419) WATTERSHED MANAGEMENT RESEARCH, HUBBARD BROOK FIXPERIMENTAL FOREST, IEW HAMPSHIRE.

(b) Laboratory project.

(d) F ield investigation; basic and applied research.

(e) The objective is to determine the effect of forest type, condition, and treatment on quantity and quality of streamflow. Studies are conducted in plots and experimental watersheds on the 7500-acre experimental forest in the White Mountains at West Thornton, New Hampshire.

(g) Four weirs have been built and climatic stations established.

(h) "Prospects in the Northeast for Affecting the Quantity and Timing of Water Yield Through Snowpack Management," Howard W. Lull and Robert S. Pierce. Proceedings of the Western Snow Conference, 54-62, 1960.

(2910) WATERSHED MANAGEMENT RESEARCH, LFADING RIDGE WATERSHED, PENITSYLVANIA.

(b) Laboratory project, in cooperation with the School of Forestry, Pennsylvania State University and the Pennsylvania Dept. of Forests and Waters.

(d) Field investigation; basic and applied research.

(e) A cooperative study was started in 1957 to determine the effect of forest cover and treatment on quantity and quality of streamflow in the oak-hickory type in Pennsylvania, and to study associated and basic soil-water relationships.

(g) Three experimental watersheds have been selected, weirs constructed, and a climatic station established.

(3567) WATERSHED MANAGEMENT RESEARCH, BAITIMORE 
WATERSHEDS, BATITMORE, MARYIAND.

(b) Laboratory project in cooperation with the Baltimore Bureau of Water Supply.

(d) Field investigation; basic and applied research.

(e) A cooperative study started in 1958 to determine effect of growth of 7oblolly and white pine in plantations on streamflow, and to compare streamflow from watersheds in conifer plantations with streamflow from a hardwood-forest watershed.

(g) Streamflow of three experimental watersheds is being measured and a climatic station has been established.

(h) "The Baltimore Watershed--An Example of Good Management," Irvin C. Reigner and Walter C. Sushko. Public Works 91: 85-88, 1960.

(3568) WATERSHED MANAGEMENT RESEARCH, NEWARK WATERSHEDS, NEWFOUNDIAND, N. J.

(b) Laboratory project in cooperation with the Division of Water Supply of the City of Newark, N. J., and Newfoundland, N. J.

(d) Field investigation; basic and applied research.

(e) A cooperative study to determine the influence of selected treatments of forested municipal watersheds on water supply.

(g) Weirs on 3 experimental watersheds were built in the fall of 1958 and stream gaging and climatic measurements were started in the spring of 1959.

U. S. DEPARTMENT OF AGRICUTIURE, FOREST SERVICE, Pacific Northwest Forest and Range Experiment Station.

Inquiries concerning the following projects should be addressed to Mr. R. W. Cowlin, Director, Pacific Northwest Forest and Range Experiment Station, P. 0. Box 4059, Portland 8, Oregon.

(969) EFFECT OF LOGGING, CLFARCUTTING AND OIHER FOREST OPERATIONS ON STREAMFIOW.

(b) Laboratory project.

(d) Field investigation; applied research.

(e) H. J. Andrews Experimental Forest, McKenzie River drainage, west central Oregon.

Streamflow from three small experimental watersheds in virgin Douglas-fir has been measured for seven years by means of trapezoidal flume stream gages. These observations provide a pretreatment calibration which will be carried on for three years or more. Planned treatments will test effect of two systems of timber cutting on water yield and erosion.

In 1959 logging roads were constructed in one of the three watersheds to supply information on sediment yields.

Bull Run watershed in cooperation with City of Portland Water Bureau. Pretreatment calibration measurements now being taken on three small watersheds within the Bull Run watershed, source of Portland's water supply. Cover is virgin Douglas-fir. Streamflow is being measured by trapezoidal flumes. Results of this study will help determine the future management policy on the watershed.

Entiat River drainage. Three small watersheds in granodiorite soils of northcentral Washington are being studied. Streamflow is measured through 120-degree $V$-notch weirs, one completed in October 1959 and the remaining two in October 1960. Coyote Creek drainage. Two small watersheds in southwestern Oregon are being studied. Streamflow is measured through 120-degree $\mathrm{V}$-notch weirs completed in September 1960.

(g) Road construction in one of the watersheds in the H. J. Andrews forest exposed 6.2 percent of the watershed, and during the first year following construction, roads were correlated with an increase in low flows and in suspended sediments.

(h) "Pacific Northwest Forest and Range Expt. Station Annual Report for 1959."

\section{(2187) EFFECT OF CATTIE GRAZING ON EROSION.}

(b) Laboratory project.

(d) Field investigation; applied research.

(e) Starkey Experimental Forest and Range, northeast Oregon. Study to determine the effect of heavy, moderate and light grazing on erosion, sediment production and runoff. Sediment catchment basins have been constructed in small drainages, one in each of six pastures in which are tested three rates of grazing and two systems of management: deferred-rotation and season-long use. Major effect on erosion will be determined by volume of sediment accumulated in the basins. Study now in its sixth year.

(2911) INFLUENCE OF FOREST COVER ON INTERCEPTION OF PRECIPITATION.

(b) Laboratory project.

(d) Field investigation; applied research.

(e) H. J. Andrews Experimental Forest. A study of interception in old-growth Douglasfir was begun in the summer of 1957. Net precipitation is measured by moving rain gages located at six representative sites; measurements of gross precipitation are being made in adjoining cutover areas.

\section{(2912) EFHECT OF LOGGING ON EROSION.}

(b) Laboratory project.

(d) Field investigation; basic and applied research.

(e) Wenatchee River drainage, central Washington. Soils derived from three major parent materials were sampled and are being analyzed to determine their basic physical and chemical characteristics. Parent materials are Swauk sandstone, basalt and granite.

North-Central Washington. Soil disturbance was measured on two logged areas to determine relative effects of logging by two methods: yarding by tractor and Wyssen 
Skyline Crane.

(8) Measurable soil disturbance was found on 22.2 percent of the area logged by tractors while only 5.4 percent of the area logged by Wyssen Skyline Crane was disturbed.

(h) "Watershed Disturbance from Tractor and Skyline Crane Logging," by David D. Wooldridge. Jour. Forestry 58:369-372, May 1960.

(3221) EROSION FROM TRACTOR SKIDROADS.

(b) Laboratory project.

(d) Field investigation; applied research.

(e) A study in southwest Oregon to relate erosion and runoff from tractor skidroads in logged forests to several soil, physiographic and climatic variables. The essential purpose of the study is to determine under what conditions tractor logging results in excessive erosion.

(I) Discontinued.

U. S. DEPARTMENT OF AGRICULTURE, FOREST SERVICE, Pacific Southwest Forest and Range Experiment Station.

\section{(261) WATTERSHED MANAGEMENT RESEARCH, SOUTHERN} CATTFORNIA.

(b) Iaboratory project.

(c) Dr. R. Keith Arnold, Director, Pacific Southwest Forest and Range Experiment Station, P. 0. Box 245, Berkeley 1, Calif.

(d) Experimental; field investigations; basic and applied research.

(e) Purposes are (1) to determine how watersheds runction; what happens to the precipitation, and how water and soil movement are influenced by conditions of vegetation, soil, geology, and topography; and (2) to develop methods of watershed management, including treatment of areas denuded by fire, to insure maximum yield of usable water and satisfactory flood runoff and soil erosion control.

Principal work center is the 17,000-acre San Dimas Experimental Forest situated in the San Gabriel Mountains. A fire started by lightning in July 1960 consumed the vegetation, mostly brush, on 90 percent of the area and destroyed or damaged many of the research installations. Immediately after the fire a major emergency research program was started to test the effectiveness of various measures used to reduce flood runoff and erosion on the denuded watersheds. These rehabilitation measures include seeding grasses and mustard singly and in combination with physical treatments such as wattling, channel barriers and contour terraces. The tests are being made on 37 watersheds of 3 to 30 acres each, equipped to measure rainfall intensity, peak discharge and suspended sediment. Twenty-five have basins to measure bedload. Studies of hydrologic processes and tests of applied management methods to increase water yield through vegetative type conversion in progress before the fire are being continued.

(g) Streamflow was increased by the clearing of 38 acres of woodland-riparian trees and shrubs from the main channel of 875-acre Monroe Canyon. Effects of the clearing were determined by comparing the flow from Monroe Canyon with that from adjacent and comparable Volfe Canyon for years of similar rainfall before and after treatment. The first year after treatment, following a very wet winter, Monroe Canyon flow was 70 acre-feet or 30 feet more than predicted had the Canyon bottom trees not been removed. During the dry part of the second year after treatment, following a winter of very low rainfall, streamflow from Monroe was increased 14 acre-feet, compared to 17 feet during the dry part of the first year. Seventy percent of the total streamflow the second year was delivered during the dry summer and fall seasons when water shortages are greatest. Before the clearing, Monroe Canyon had ceased flowing during similar drought periods.

In another test, streamflow was increased by deadening the brush on 40 acres of side slopes with deep soil in 100-acre Bell Watershed No. 2. The brush was sprayed with herbicides each spring for three years starting in April 1958. During a 16-month period (June 1958 through Sept. 1959), the expected streamflow without treatment would have been $3 \frac{1}{2}$ acre-feet. Actual streamflow was 9-1/4--an increase of nearly 6 acre-feet. Before treatment the stream in Bell No. 2 dried up during the summer and fall seasons, but flow has been continuous since the first spraying. In contrast, the stream in adjacent unsprayed Bell Watershed No. 3, the control, was dry for 8 of the 16 months. Soil moisture measurements show that evapotranspiration during the rainy season October 22, 1950 to May 10, 1960 averaged 10 inches from unsprayed brush sites, but only about $6 \frac{1}{2}$ inches from sprayed sites.

The movement of soil, rock and organic debris on slopes in Arroyo Seco Canyon (Los Angeles River drainage) was greatly increased after the brush and tree cover was burned in October 1959. Material caught in contour troughs on seven slopes ranged from 2.2 to 24.7 tons per acre during the first year after the fire. South-facing slopes flanking geologically rejuvenated stream channels yielded the most material, 10 times the pre-burn rate. Nearly 89 percent of this eroded material came during the dry season. North rejuvenated slopes showed a post-burn rate of 4.3 tons per acre per year, or an increase of about 17 times the unburned average. Material from north non-rejuvenated sites increased 16 times and from south non-rejuvenated sites only 4 -fold after the fire. Dry-season debris movement exceeded wet-season movement at all but one site. However, precipitation was below normal during the post-fire winter. 
(h) "Vegetation Types of the San Bernardino Mountains," by Jerome S. Horton, Pacific Southwest Forest and Range Experiment Station, Tech. Paper. No. 44, 29 pp., illus., April 1960.

"Watershed Management in Action in the Pacific Southwest, " by Walt Hopkins and J. D. Sinclair, Soc. Amer. Foresters Proc., 1960.

"Moisture Sampling in Wildland Soils with a Newtron Probe," by Robert A. Merriam, Iowa State Jour. of Science, Vol. 34, No. 4, pp. 641-648, May 15, 1960.

"Watershed Management Research in Southern California's Brush-Covered Mountains," by J. D. Sinclair, Jour. of Forestry (4): 226-268, 1960.

\section{(2415) WATERSHED MAITAGEMENT RESEARCH, INORTHERN} CAIIFORNIA.

(b) Laboratory project.

(c) Dr. R. Keith Arnold, Director, Pacific Southwest Forest and Range Experiment Station, P. 0. Box 245, Berkeley 1, Calif.

(d) Experimental; field investigation; basic and applied research.

(e) The aim is to develop a hydrologic base for land management decisions. The hydrologic effects of wildfires, of attempts at conversion of brushlands to grass, and of logging and other land uses are to be evaluated. Present studies emphasize development of methods of management of high elevation snowpacks for maximum control and yield of water.

Major work center is in Berkeley with 18 studies being conducted throughout northern California in the headwaters of the Kings, American, Yuba, Truckee, and Feather rivers. At the Teakettle watersheds in the headwaters of the Kings River Basin, five small watersheds are under calibration for evaluation of streamflow and sedimentation. In the Onion Creek watersheds in the headwaters of the American River Basin, five streams are being gaged and sediment measured. Snow accumulation and soil molsture are being measured in logged and unlogged forest and in brush areas, at both Onion Creek and Castle Creek. Castle Creek in the Yuba River Basin is being gaged, suspended sediment measured, and basic snow physics studies are underway. Daily meteorological measurements are being taken at three stations, and radiation and snow physics at the headquarters station. At Sagehen Creek in the Truckee River Basin, sediment and streamflow and their effects on fishlife are being studied in cooperation with the Department of Zoology, University of California. Also the effects of conversion of brushfields to forest are being studied.

At Swain Mountain Experimental Forest in the Feather River Basin, snow and soil moisture are being measured where forests were cut in strips and blocks and where logging slash was treated and untreated. In all, snow accumulation is being measured at 91 special snow courses, soil moisture at some 300 points.

(g) Measurements of snow accumulation on different slopes in openings and in surrounding forest were made at 90 sites at the Central Sierra Snow Laboratory. Snow water in the maximum snowpack on north slopes averaged 63.5 inches in 1958 and 54.3 inches in 1959 compared to 28.1 and 18.9 inches during the same years on south slopes. The lower water content of the snowpack on south slopes ( 9.2 inches each year) is a clear indication of winter melt. Openings had 2.2 to 8.4 inches more snow water than the surrounding forest at the time of maximum pack, with only the south and west slopes showing significantly less difference in the "ary year" of 1959 than in the very "wet year" of 1958.

The size of trees (small 15-60 feet) to large (greater than 100 feet) had little effect upon the average snow water left in the spring (June 1, 1958) in openings and in adjacent forest on east and west slopes and on level areas. Small tree sites averaged 29.5 inches of snow water compared to 29.0 inches for medium and large trees. One square mile of 4 square mile Castle Creek basin was selectively logged in the summer of 1958. Water yielded as streamflow was apparently increased the first year after logging--374 acre-feet more water was delivered than would have been expected without the logging. This increase was equivalent to 1.75 inches of yield over the entire watershed, or 7.0 inches in the logged area. Sediment production from the castle Creek watershed also increased after logging. Computed average long-term suspended sediment production, assuming that normal streamflow occurred each year, was 234 tons per sq. mi. per year before logging (1957-58). Production increased to 1,286 tons the first year (1958-59) after logging, then decreased to 455 tons per sq. mi. the second year (1959-60) despite some relogging in the watersheds.

Evaporation from snow and wind at 1 foot above the snow was measured in forest openings, varying in size from $\frac{1}{2}$ to 1 times as wide as the tree heights to greater than 4 tree heights across. Evaporation was closely related to wind. During a day with steady wind, evaporation was 0.015 inch and wind travel 39 miles in the smallest openings compared to 0.030 inch evaporation and 115 miles wind travel in the largest openings. Evaporation for a 10-day period in March 1960 averaged 0.020 inch per day in the forest openings. Summer evapotranspiration losses during 1958 and 1959 were measured at 37 sites representing various forest stand conditions near the Central Sierra Snow Laboratory. Moisture losses from the top 4 feet of soil varied widely with forest conditions as follows: from bare soil 2.0 inches; low density red fir 5.2 inches; forest opening with reproduction 5.6 inches; wind sunflower 7.6 inches; dense old growth and young red fir, and opening with reproduction 7.6 in.; 
and from very dense reproduction 10.4 in. Additional losses of 2.0 inches of summer precipitation occurred at each site. Analyses have been made of the relation of erodibility indexes of California wlldland soils to geology vegetation, elevation and geographic zone. Geologic rock type was by far the most important source of differences in soil erodibility. Soil differences associated with vegetation showed grassland soils least erodible, forest-land soils next and brushland soils most erodible. Although erodibility was well indexed by these variables, still erodibility was highest in the Central coast zone, next erodible in the Sierra and least erodible in the North Coast.

(h) "Managing Our Snow for a Better Water Supply, "anonymous Pac. Sw For. and Range Expt. Sta. and State Dept. of Water Res., 17 pp. illus., 1959.

"Research in Management of Snowpack Watersheds for Water Yield Control," H. W. Anderson, Jour. Forestry 58(4): 282-284, 1960.

"Three Years of Progress in 'Operation WetBlanket '," H. W. Anderson, Abstract Jour. Geophys. Res. 65(5):1632, 1960.

"Effects of Logging and Brush Removal in Snow Water Runoff," H. W. Anderson and Clark H. Gleason, Internat. Assoc. Sci. Hydrol, Publ. No. 5, pp. 478-489, 1960. "Prospects for Affecting the Quantity and Timing of Water Yield Through Snowpack Management in California," H. W. Anderson, 28th Ann. Western Snow Conference Proc., 1960.

"Third Progress Report, 1959-1960, Cooperative Snow Management Research," H. W. Anderson, and Lucille G. Richards. Pacific Southwest Forest and Range Experiment Station, pp. 95-140, June 1960.

"Proposed Program for Watershed Management Research in the Lower Conifer Zone of California," H. W. Anderson. Pacific Southwest Forest and Range Experiment Station, Tech. Paper No. 46, 21 pp., April 1960.

U. S. DEPARTMENT OF AGRICULIURE, FOREST SERVICE, Rocky Mountain Forest and Range Experiment Station.

Inquiries concerning the following projects should be addressed to Mr. Raymond Price, Director, Rocky Mountain Forest and Range Experiment Station, Room 221 Forestry Building, Fort Collins, Colorado.

(377) WATERSHED MANAGEMENT RESEARCH, FRASER HYDROLOGIC IABORATORY.

(b) Laboratory project.

(d) Field investigations; applied research.

(e) To determine influence of lodgepole pine and spruce-fir forests and of the management of these forests for wood products on factors associated with the yield of water, largely from stored snow. The purpose is to solve problems in the management of forested watersheds of the high altitude zone of the Rocky Mountains for maximum yields of usable water. To determine what part of the ablation from summer snow fields was due to evaporation.

(g) The estimated increase in water yield from the Fool Creek watershed due to tImber harvesting has been:

\begin{tabular}{lc} 
Year & Acre-feet \\
\cline { 2 - 2 } 1956 & 254 \\
1957 & 200 \\
1958 & 125 \\
1959 & 186
\end{tabular}

Net gain of moisture at snow surface was measured during the first half of July 1957--a net loss during the first half of August 1958. Diurnal trend was for condensation during nights, evaporation in mornings, and either evaporation or condensation in afternoons, depending on weather conditions. Shading decreased snowmelt during daylight hours but increased melt during the night. Poor agreement was found between measured moisture exchange and that computed from Sverdrup's equation.

(h) "The Fraser Experimental Forest--Its Work and Aims," L. D. Love. Rocky Mountain Forest and Range Experiment Station, Station Paper 8, revised June 1960, 16 pp. "Moisture Exchange Between the Atmosphere and Alpine Snow Surfaces Under Summer Conditions (Preliminary results)," M. Martinelli Jr., Journal of Meteorology, Vol. 17, No. 2, pp. 227-231, April 1960. "Annual Report for 1959, Rocky Mountain Forest and Range Experiment Station," U. S. Forest Service, Fort Collins, Colo.

(657) WATERSHED MANAGEMENT RESEARCH, TEMPE, ARIZONA.

(b) Laboratory project.

(d) Experimental; basic and applied research.

(e) To study the disposition of rainfall as influenced by watershed vegetation; (2) to determine the influence of various types of forest and grassland vegetation as well as vegetation modified by cultural treatment such as grazing and timber harvest, on streamflow, water use, water loss, and erosion and sediment yield; (3) to determine for phreatophytic vegetation (water-loving plants) the amount of water used, methods for reducing water use by phreatophytes or for replacing them with more useful plants; and for mixed conifer and chaparral types of vegetation to determine the hydrologic characteristics of natural watersheds and the effect of cover modification upon water yields, soil stability and other resource values. At Sierra Ancha Experimental Watersheds in central Arizona, rainfall, runoff, and erosion are measured on three watersheds in the pine-fir vegetation type at high elevation, on two watersheds in the ponderosa-chaparral type, and from four watersheds in the grassland-chaparral type at intermediate elevations, and on nine small watersheds in the semidesertchaparral type at low elevations. Water 
use by different types of plants in various soils is studied on eleven large lysimeters. Three watersheds have also been established in the pure ponderosa pine type and two in the mixed conifer type to test the effects of logging practices upon water yield and soil stability. Gaging stations for four watersheds in the pure chaparral type are also available to evaluate watershed-game interrelations. One cluster of two watersheds and another cluster of three watersheds are available for testing the effect of manipulating chaparral cover. Supplemental studies are determining the proper use of chemicals, fire, and mechanical treatment for manipulating shrub in the type.

Interception, moisture use, and factors affecting water yield are being tested in Utah and alligator juniper forests on the Beaver Creek Project, south of Flagstaff, Arizona.

Ecology of Tamarix pentandra and other phreatophytes is under investigation. Germination, seedling survival, and rate of spread. studies were continued. A field apparatus employing the infrared analyzer for detecting moisture has been used for detailed measurements of evapotranspiration of phreatophytes.

(g) In the pine-fir forests on the North Fork of Workman Creek, streamflow increased. during the first two years, after replacing 80 acres of forest vegetation with perennial grass. During the first water year (October 1958 through September 1959), the increase was 0.5 inches, although not statistically significant; during the second year there was a statistically significant increase of 2.0 inches. Comparative soil moisture determinations using the neutron scattering method showed aspen to use more moisture than grass or conifer from April through September 1960.

On chaparral watersheds burned by wildfire in June 1959, number and size of peak flows and duration of base flows were increased by destruction of plant cover. On two watersheds prior to the fire flow extended from November to June; thereafter to date, flows have been continuous or nearly so. Increased water yields have been accompanied by high sediment yields. On three watersheds where negligible quantities of sediment were measured during the three prefire years, sediment yields during the period August 1959 to March 1960 have ranged from 18 to 56 thousand tons per square mile.

Seed of the most aggressive phreatophyte, five-stamen tamarisk, will germinate readily when moistened, but seedlings require saturated soil for several weeks for survival. Tamarisk sprouts readily from cut portions of fresh stem, but these severed portions dry out and die in a few hours in the sun. Severed roots do not sprout. Therefore, rootplowing mature tamarisk stands when soil is dry and weather warm is an effective method of mechanical control.

In the pinyon-juniper type, stemflow of Utah and alligator juniper amounts to about one percent of annual gross precipitation, and increases with storm size greater than 0.25 inch. Throughfall can be predicted with the equation: $Y=.05+.84 X_{1}$ . $21 \mathrm{X}_{2}$, where $\mathrm{X}_{1}$ is gross precipitation and $\mathrm{X}_{2}$ is foliage density. The canopy camera gave a good index of foliage density and values obtained with it were used for $\mathrm{X}_{2}$. Moisture differences were compared in two feet of soil between cleared and natural stands of juniper by travimetric sampling on 10 pairs of plots. No difference between cleared and natural stands has been detected over two spring-to-fall periods.

(h) "Transpirational Surges in Tamarix and Eucalyptus as Measured with an Infrared Gas Analyzer," John P. Decker and Janet D. Wien, Plant Physiol., 35 (3), 340-343, 1960.

"Utilization of Five-Stream Tamarisk by Cattle," Howard L. Gary. Rocky Mt. Forest and Range Expt. Sta., Res. Note 51, Illus., 1960.

"The Problem of Phraetophytes," J.S. Horton. Symp. Hannoversch-Munden, Internat'l Sci. Hydrol. Assoc. Pub. 48, $1: 76-83,1959$.

"Use of Root Plot in Clearing Tamarisk Stands, "Rocky Mt. For. and Range Expt. Sta. Res. Note 50, illus., 1960. "Seed Germination and Seedling Establishment of Phreatophyte Species," F. C. Mounts and J. M. Kraft. Rocky Mt. For. and Range Expt. Sta., Station Paper 48, illus., 1960.

(1969) WATERSHED MANAGEMENT RESEARCH, ALBUQUERQUE, NEW MEXICO.

(b) Cooperative study with Bureau of Land Management and Geological Survey.

(d) Applied research.

(e) Evaluation of range-watershed conditions on small watersheds in the San Luis drainage of the Rio Puerco. Three contiguous watersheds, ranging from 338 to 555 acres located about 8 miles north of the San Luis community and west of the Rio Puerco main channel provide the study area. Water and sediment inflow are measured in small reservoirs formed by earthen dams. Precipitation rates and amounts of vegetation changes are periodically measured over the watersheds. Five years of data have been collected under continued cattle grazing during the six month overwinter period (November 1 to May 1). Soil elevation measurements have been obtained on the three watersheds for purposes of determining soil losses from the alluvial soils. Rising stage sediment samplers have been installed on the three watersheds.

(g) Grazing use has averaged 50\% on the key species alkali sacaton. Galleta is less preferred by cattle and use has averaged only $40 \%$ on this species. Fencing of individual watersheds in proximity to available water in the reservoirs has had a pronounced effect on the grazing pattern. Remeasurement of soil elevation transect grids one year after establishment indicates 
an appreciable rate of aggradation on the alluvium near the bluffs.

(h) "The Rio Puerco - Past, Present, and Future," E. J. Dortignac, 5 th Annual Water Conference, Las Cruces, New Mexico, 1960.

"Annual Report for 1959, Rocky Mountain

Forest and Range Experiment Station, U. S. Forest Service," Fort Collins, Colo.

(2188) WATERSHED MANAGEMENT RESEARCH, ALBUQUERQUE, NEW MEXICO.

(b) Laboratory project.

(d) Field investigation.

(e) Coleman soil electrical units were installed at 3-inch depth intervals from the $1-1 \frac{1}{2}$ inch soil depth to bedrock or to a depth beyond any anticipated moisture penetration. Recording and standard gages were used to measure precipitation. Moist pinyon-juniper zone (17-inch annual precipitation). A record of precipitation and soil moisture was maintained under three ground-cover conditions; under pinyon trees and in a woodland opening; in grassland; and in a bared area kept free of vegetation by chemical spraying. Dry pinyonjuniper-sagebrush zone (13-inch annual precipitation). A record of precipitation and soil moisture was maintained under four conditions: native sagebrush under protection from livestock grazing; and in crested wheatgrass under 25 percent utilization, under 75 percent utilization and under full protection from cattle grazing.

(f) Field study terminated.

(g) At Pine Flat (7340') in the Manzano Mountains southeast of Albuquerque, 5 years of soil moisture measurements have shown that summer rainfall was insufficient to replenish soil moisture throughout the 30 inch soil profile under blue grama grass or pinyon trees. In contrast, maximum soil moisture conditions were recorded with much less precipitation during the winter-spring period. On the basis of this study it was concluded that for similar conditions, soil water discharge to ground water could be expected to occur during the spring on the average once every 4 or 5 years. Pine Flat represents the more moist pinyon-juniper situations.

(h) "Water Yield from Pinyon-Juniper Woodland," 36 th Annual Meeting $S$ outhwest $R$ ocky Mountain Division of the Association for the Advancement of Science, Alpine, Texas, 1960 .

(2420) WATERSHED MANAGEMENT RESEARCH, GRAND JUNCTION, COLORADO.

(b) Laboratory project.

(d) Field investigation; applied research.

(e) To compare the amount of soil moisture withdrawal under aspen, spruce and mixed grass-weed type.

(f) Discontinued.

(g) Soil moisture was measured in the spring and fall of 1955, 1957, and 1958 on Black Mesa. The study plots were located on selected sites where the soil was deep enough to permit gravimctric sampling to a depth of 8 feet. Water usc was considered to be the difference betwen the amount of soll moisture in the spring and fall, adjusted for summer precipitation. Water use was significantly different amone the three vegetation types. However, because the amount of spring soil moisture was significantly different among types, and because spring moisture was correlated with water use in aspen and spruce types, it was impossible to attribute water use differences solely to the type of vegetation.

(h) "Relative Water Use by Aspen, Spruce, and Grassland in Western Colorado," H. E. Brown and J. R. Thompson. Manuscript being prepared for publication.

(2657) WATERSHED MANAGEMENT RESEARCH, GRAND JUNCTION, COLORADO.

(b) Laboratory project.

(d) Field investigation; applied research.

(e) To determine the effect of range conditions and related factors on sediment production and runoff on three mountain grassland watersheds in western Colorado. Range condition is being measured by means of 20 or more 3step transects on each watershed. Ninety degree $V$-notch weirs are used to gage the watersheds which vary in size from 86 to 272 acres. Water samples are taken several times daily during snowmelt and periods of storm runoff for determination of suspended sediment; bed load is measured in the weir ponds.

(2658) WATERSHED MANAGPMENT RESEARCH, RAPID CITY, SOUPH DAKOTA.

(b) Laboratory project.

(d) Experimental; basic and applied research.

(e) To determine how heavy grazing of bluegrass range in the $\mathrm{Black} \mathrm{Hills}$ has influenced soil structure. Involves measurement of bulk density and pore space of soil inside and outside livestock exclosures. Study of basic soil-water relationships under dense ponderosa pine in the Black Hills to determine how thinning influences amount of water available for streamflow. Involves measurement of precipitation under thinned. and unthinned pine, stemflow, and soil moisture. Runoff and soil erosion on the Deadwood Burn in relation to the re-establishment of vegetation.

(g) In a dry year thinned ponderosa pine used more water than unthinned pine. Both stands used virtually all precipitation during the year. In addition the thinned stand drew on holdover storage from the previous year. There was no holdover storage available for use by the unthinned stand.

(h) "Soil Porosity and Bulk Density on Grazed and Protected Kentucky Bluegrass Range in the Black Hills, "Howard K. Orr, Journal of Range Management, 13(2): 80-86, 1960. "Annual Report for 1959, Rocky Mountain Forest and Range Experiment Station," U. S. Forest Service, Fort Collins, Colorado. 
(2913) BEAVER CREFK WATERSHED PROJECT.

(b) Laboratory project, cooperative with Coconino National Forest, Flagstaff, Ariz.

(d) Field investigation; basic research.

(e) Calibration of 12 small watersheds, 6 in ponderosa pine type, 3 in alligator juniper type, and 3 in Utah juniper type. A newly designed modified trapezoidal Venturi flume is being used to measure discharge from these steep ephemeral streams. Precipitation measurements are being taken.

(g) Rating curves for the flume based on model tests and field measurements have been prepared for the Beaver Creek flumes. Two rating curves have been prepared, one based on head measured above the floor of the throat section, the other based on head in a 120-degree V-notch which can be bolted to the end of the flume. Ratings go up to $300 \mathrm{cfs}$ for the natural flume and 200 cfs for the flume with $V$-notch attached.

(3222) BEAVER CREEK WATERSHED PROJECT.

(b) Iaboratory project, cooperative with Coconino National Forest, Flagstaff, Arizona.

(d) Field investigation; basic research.

(e) Study of the disposition of precipitation in the Utah juniper type, including measurements of precipitation, interception, surface runoff, and soil moisture budget by stand density class.

(f) Discontinued.

(3223) WATERSHED MANAGEMENT RESEARCH, FORT COLIINS, COLORADO.

(b) Laboratory project.

(d) Field investigation; applied research.

(e) A physical evaluation of mechanical erosion control practices established on the Trout Creek Watershed, Salida District, San Isabel National Forest, Colorado. Evaluation of mechanical erosion control practices on depleted lands in the Colo. Front Range. The following soil associations are represented: Edloe-Stecum association derived from granite, ChubbaLaporte (limestone), Trout Creek-ganoHeath (shale and sandstone), Buena VistaRods-Outcrop (Trachyte).

(f) Completed.

(g) Gullies were classified into discontinuous and continuous systems. In these systems critical locations were determined that are the result of the mechanics of gullying. Structures will be most effective if installed at these locations. To be successful simple check dams shall accomodate the highest peak flow that is estimated to occur during the designed life time of the structure.

(h) "Annual Report, 1959, Rocky Mountain Forest and Range Experiment Station," U. S. Forest Service, Fort Collins, Colo.

"An Evaluation of Gul.ly Control Structures on the Pike and San Isabel National Forests in Colorado," Burchard H. Heede, in press.
(3224) BEAVER CREEK WATERSHED PROJECT.

(b) Laboratory project, cooperative with Coconino National Forest, Flagstaff, Ariz.

(d) Fleld investigation; basic research.

(e) Rainfall interception by nine densities of pole-size ponderosa pine.

(f) Discontinued.

(3569) WATERSHED MANAGEMENT RESEARCH, IARAMTE, WYOMING .

(b) Iaboratory project.

(d) Field investigation; applied research

(e) The objectives of the study are to determine the effects of big sagebrush on total runoff from snownelt, snow accumulation and storage pattern. In addition, the study offers opportunity to determine how natural stands of big sagebrush affect cloudburst storm runoff and rate of sediment movement. Three high elevation sagebrush watersheds, 60 to 106 acres, in western Wyoming provide the study area. V-notch weirs gage the runoff, and suspended sediment samples are taken periodically. Snowpack is sampled along permanent transects and at random points. Summer precipitation is sampled by a network of recording and non-recording gages, while winter precipitation is sampled by a single standpipe snow accumulation gage.

(g) Total runoff from these drainages in 1959 averaged 2.98 inches and suspended sediment loads ranged from 3 ppm at low flows to $139 \mathrm{ppm}$ near peak flow. Average runoff in 1960 was 1.33 inches and suspended sediment ranged from 4 ppm to $53 \mathrm{ppm}$.

(3570) WATERSHED MANAGEMENT RESEARCH, ALBUQUERQUE, NEW MEXICO.

(b) Iaboratory project.

(d) Field investigation; exploratory.

(e) Appraise snowpack conditions, including accumulation and melt at several locations in the Sangre de Cristo Range as a basis for conducting future basic research in snowpack management.

(f) Completed.

(g) Data undergoing analysis.

(3571) WATERSHED MANAGEMENT RESEARCH, ALBUQUERQUE, NEW MEXICO.

(b) Laboratory project.

(d) Field investigation; exploratory.

(e) Determine for Engelmann spruce, Douglasfir, ponderosa pine, and aspen on north and south aspects: (1) Periods of soil moisture deficit and surplus, (2) relative soil moisture and temperature variations during growth and dormant season, (3) occurrence and depth of soll freezing. Basis for fundamental research.

(3572) WATERSHED-RANGE MANAGEMENT RESEARCH, ALBUQUERQUE, NEW MEXICO.

(b) Study in cooperation with the Bureau of 
Land Management.

(d) Applied research.

(e) Evaluation of soil pitting (Calkins pitter) on surface runoff, erosion and vegetation. Surface runoff plots (20), $10^{\prime}$ by $30^{\prime}$, are installed on 3 slope aspects, representing different soil conditions, in the Rio Jemez drainage. Precipitation, runoff, sediment and changes in vegetation are measured.

(g) Reduction in surface runoff caused by pitting during the first rainy season averaged $10 \%$ and $26 \%$ for the south and north exposures, respectively.

(h) "The Rio Puerco--Past, Present and Future," E. J. Dortignac, 5th Annual Water Conference, Las Cruces, New Mexico, 1960.

(3573) WATERSHED-RANGE MANAGEMENT RESEARCH, AIBUQUERQUE, NEW MEXICO.

(b) Cooperative study with Bureau of Land Management.

(d) Applied research.

(e) Evaluation of soil ripping (Jayhawker) on surface runoff, erosion and vegetation. Surface runoff plots (62), 10' by $30^{\prime}$, are installed on a north and south aspect and upper and lower slopes representing different soil conditions in the Rio Jemez drainage. Seeding grass (alkali sacaton) and browse (chamiza) and protection from livestock and rabbits is also evaluated. Precipitation, runoff, sediment, and changes in vegetation are measured.

(g) Soil ripping with the Jayhawker resulted in about $98 \%$ reduction in surface runoff during the first rainy season.

(h) "The Rio Puerco--Past, Present and Future," by E.J. Dortignac, 5th Annual Water Conference, Las Cruces, New Mexico, 1960.

(3891) WATERSHED MANAGEMENT RESEARCH, LARAMIE, WYOMING .

(b) Laboratory project.

(d) Field investigation; basic research.

(e) The objectives of this study are to investigate the length, depth and configuration of big sagebrush growing at high elevations in Wyoming and to determine how the rooting characteristics of this important plant are affected by site.

(3892) WATERSHED MANAGEMEIT RESEARCH, LARAMIE, WYOMINIG .

(b) Laboratory project.

(d) Field investigation; applied research.

(e) This study will evaluate the comparative efficiencies, in terms of water stored in accumulated snow, of tandem 4-ft slatted snowfences erected at three different spacing intervals on open windswept slopes in southeast Wyoming.

(3893) WATERSHED MANAGEMENT RESEARCH, LARAMTE, WYOMING .

(b) Laboratory project.

(d) Field investigation; applied research.

(e) This study will evaluate the influence of opening size and effect of exposure on snow accumulation and disappearance from cutover forests of lodgepole pine in the Big Horn Mountains of Wyoming. Clearcut blocks of 5 , 10, and 20 acres on several exposures have been selected for study. Uncut conditions on each exposure will also be studied.

(3894) PRELIMINARY GAGING OF STREAMFLOW AND PRECIPITATION IN THE SANTA FE EXPERTMENTAL WATERSHEDS.

(b) Laboratory project.

(d) Field investigation; exploratory.

(e) To obtain: (1) Preliminary information on streamflow characteristics for correlation with snowpack ablation and summer rainfall; (2) information on relative water yields from several vegetation zones in high altitude watersheds in New Mexico; (3) information on the amount and occurrence of precipitation received in study areas; and (4) information on the range of flows to be expected so that suitable equipment can be designed and installed for more permanent stream gaging.

Portable waterstage recorders and crest gages have been placed on selected streams at culvert locations. Precipitation storage gages are located on the selected experimental watersheds in the Sangre de Cristo range in New Mexico.

(3895) WIND TRAITSPORT AND DEPOSITION OF SNOW.

(b) Laboratory project.

(d) Field investigations; basic research.

(e) The purpose is: (1) To correlate snow drift intensity with meteorological and terrain features; (2) to measure the amount and vertical distribution of snow carried by the wind in an area of moderately rough terrain; (3) to determine important features associated with the deposition of snow; (4) to determine the effect of slat and wire fencing on the accumulation of snow in selected natural catchments in the alpine portion of Loveland Basin, Colo. and to test the relative effectiveness of this type of fence at two locations in the same general area; and (5) to test several methods of erecting slat and wire snow fences on exposed sites.

(3896) THE VEGETATION AND MICROCLTMATIC TREATMENIS FOR WATERSHED REHABILITATION IV THE SOUTHERN ROCKY MOUNTAJINS.

(b) Laboratory project.

(d) Field investigations; applied research.

(e) Research to find the most suitable plants for establishment on difficult and badly eroding sites, the best methods of establishing them on various sites, and the influences of mechanical watershed rehabilitation measures on the microclimate and other site factors in the southern Rocky Mountains.

(g) Exploratory studies just initiated show microclimatic changes due to mechanical 
treatment in watershed rehabilitation. Surface soil temperatures and soil moisture regimes are affected by contour trenching. Steepness of slope and type of equipment used in building trenches can greatly affect the percentages of total area in which the microclimate is made more favorable and more unfavorable for plants.

U. S. DEPARTMENT OF AGRICULTURE, FOREST SERVICE, Southeastern Forest Experiment Station.

\section{(380) WATER RESOURCE AND WATTERSHED MANAGEMENT} RESEARCH.

(b) Laboratory project. For general public use and information.

(c) Mr. J. F. Pechanec, Dir., Southeastern For. Expt. Sta., P. O. Box 2570, Asheville, N.C.

(d) General investigations of forest influences in the southeastern United States, with primary emphasis on fundamental hydrologic research on watershed processes and related applications in watershed management.

(e) Basic research into forest hydrologic processes from the precipitation of water over an area until it leaves the watershed as streamflow or evapotranspiration. Demonstrations of several cover types and land management practices and their effect upon water yield, quality and flow characteristics. Development of watershed management methods pertinent to the region and cooperative trials and demonstrations of these methods. Most of the experimentation and hydrologic data collection is on the 5600-acre Coweeta Hydrologic Laboratory located in the zone of maximum precipitation for the eastern United States (Nantahala Range of the Southern Appalachians). Eighteen individual and two multiple watersheds are currently active and along with an additional 13 standby watersheds whose streamflow has been gaged for over 25 years provide the locale for the experimental program. Over 650 cumulative years of streamflow records are available for drainages ranging from 4 acres to 8 square miles. One F-P analog-todigital water level recorder is in trial installation; all ther weirs are serviced by chart-trace recorders. The Laboratory has 8 recording and 68 non-recording (standard) rain gages, a raindrop camera in cooperation with the Univ. of Ill., I recording ground water well, 5 recording hygrothermographs, 6 recording soil or water thermographs, 1 metering anemometer, 1 recording anemometer and wind vane, 1 evaporation pan and 2 recording pyrheliometers. Water samples are collected from selected watersheds for quality analysis on a storm period basis. Soil moisture is measured in the field with portable neutron scattering devices. A small laboratory equipped for soil physical analysis and instrument repair is on the area. Data reduction from chart trace to punched card is accomplished locally through an Oscar-K chart reader. Basic related research in plant-soil-moisture relations is emphasized at the Union Research Center. Current soil moisture studies include development of field measurement techniques for moisture investigations by the neutron method, comparative water use requirements of cover types, moisture recharge and depletion investigations, and depth of moisture withdrawal by representative cover types. Secondary studies deal with hydrologic properties of forest soils. The center has laboratory facilities for analysis of foliage and physical and chemical properties of soils, a portable neutron scattering device for measuring soil moisture, 4 gaged watersheds, three recording and 7 standard raingages, one recording ground water well, and a standard Weather Bureau weather station.

All projects are to be carried to completion through analysis of data, preparation of reports and publication of technical articles. Research studies (Coweeta and Union) include: (1) Evapotranspiration from forest land, hydrologic effects of reducing basal area; (2) rehabilitation treatment of experimental watersheds formerly used in studies of mountain farming, woodland grazing and exploitive mountain logging; (3) evapotranspiration and water yield from different types of forest cover; (4) study of the soil-water balance as related to recharge, drainage and evapotranspiration; (5) application of hydrologic concepts to small forested watersheds; (6) demonstrating the application of principles of hydrology on forested watersheds; (7) studies of energy balance, precipitation and evapotranspiration on slopes and how modified by cover and physiography; and (8) recharge, drainage, storage, and depletion of soil moisture in relation to vegetative cover and other environmental factors.

(g) Early demonstrations of good and poor watershed management practices and necessary rehabilitation methods have been of great educational value to the public and have helped document recommendations for proper land practices on public and private lands. Removal of vegetation from selected watersheds by several different cutting patterns produced increased annual water yields in the order of 3 to 16 inches without detectable changes in stormflow or soil stability. Currently established typeconversions from existing hardwood cover to white pine and to grass are to demonstrate differential water use, if any, by varying cover types. Several studies of soil moisture storage and movement are in progress. The annual range in moisture storage flux for the top 7 feet of a mountain slope profile is 7 to 12 inches of water. Subsoil moisture content shows promise as a predictor of nonstorm streamflow. Soil moisture accretion and depletion in weil-watered terrain may be a poor measure of evapotranspiration because of confusion with long term slow drainage. 
Field and model studies designed to determine the dynamics of moisture storage on steep slopes suggest that much of the base flow in mountain streams is from soil moisture in the zone of aeration rather than from saturated aquifers. Computations of solar energy theoretically available to mountain slopes indicate that energy differences between various slopes may be small during the growing season, quite large during the dormant. A raindrop camera is now maintained in cooperation with the University of Illinois. Studies of hydrologic constants commonly in use indicate that conventional flood estimation methods are not adaptable to small mountain watersheds. While the unit hydrograph method is applicable to channel precipitation, it is inappropriate for subsurface flow and weak for overland flow. Stormflow on a small watershed is being diverted into a sprinkling system on deep-soiled slopes in an effort to increase baseflow at the expense of storm runoff.

Moisture depletion rates and recharge were found to vary by cover types and soil depth over a 7-year period. No noticeable difference in depletion between pine and pinehardwood cover types was observed although forest and grass cover differed in their water use particularly below 30-inch depths. Rehabilitation of a small eroded watershed greatly reduced peak discharge and erosion from the watershed. Methodology studies have provided valuable guides for efficient use of the neutron method in field moisture studies.

(h) "Watershed Management Research in the Southeast," by J. D. Hewlett and I. J. Metz. Journal of Forestry 58(4): 269-271, April 1960.

"Watershed Management Research-Challenging Career for Young Scientists," by H. G. Meginnis. The Ames Forester 47: 20-24, 1960 .

"Effect of Altering Forest Vegetation on Low Flows of small Streams," by $\mathrm{k}$. A. Johnson and H. G. Meginnis. Paper presented at the l2th Gen. Assembly Internatl. Union Geodesy and Ceophysics, Internatl. Assoc. Sci. Hydrol., Helsinki, Finland, July 25-August 6, 1960. Extract of publication No. 51 of the I.A.S.H., Commission of Surface Waters, pp. 257-266.

"Hydrologic Properties of Southern Forest Soils," by L. J. Metz. Southern Forest Soils, 8th Forestry Symposium, Louisiana State University, 1959.

"Soil Moisture Distribution Between Trees in a Thinned Loblolly Pine Plantation," by J. E. Douglass. Journal of Forestry, 58:221-222, 1960.

"Increasing Water Yields by Cutting Forest Vegetation," by H. G. Meginnis. Trans. of Meeting of the International Association of Scientific Hydrology, Int. Union of Geodesy and Geophysics. Symposium, HanoverMunden, 8-13 Sept. 1959. Pub. No. 48, Water and Woodlands, Vol. I, 59-68.

"The Effect of Mountain Topography on Solar Energy Theoretically Available for Evapo- transpiration," by L.W. Swift, Jr. Manuscript in preparation.

"A Method for Calculating Error of Soil Moisture Volumes in Gravimetric Sampling," by J. D. Hewlett and J. E. Douglass. Submitted to Forest Science.

U. S. DEPARTMENT OF AGRICUETURE, FOREST SERVICE, Southern Forest Experiment Station.

Inquiries concerning the following projects should be addressed to Mr. P. A. Briegleb, Director, Southern Forest Experiment Station, 2026 St. Charles Avenue, New Orleans 13, Louisiana.

(2914) WATERSHED MANAGEMENT RESEARCH, OXFORD RESEARCH CENIFER, OXFORD, MISSISSIPPI.

(b) Laboratory project, in cooperation with Soil Conservation Service, Agricultural Research Service, University of Mississippi.

(d) Field investigation of runoff and erosion from small experimental watersheds on forest and potential forest lands; basic and applied research.

(e) Twelve small natural headwater catchments, two to four acres each, were installed in batteries of three to determine runoff and erosion from old fields, depleted upland hardwoods, pine plantations, and mature upland pine-hardwoods. Treatments are deferred until after a suitable calibration period. Related studies include restoration of depleted watersheds and plant-soil-water relationships.

(g) Watershed studies. Results indicate that surface runoff is strongly correlated with storage opportunity in the upper 6 inches of soil. Runoff predictions using the 0-6 inch soil moisture storage index were most accurate for winter precipitation and least accurate for high-intensity summer storms. Surface runoff and peak flows were greatest from abandoned fields, intermediate from depleted upland hardwoods, and least from 20-year-old loblolly pine plantations. The soils are silt loams of loessial origin and Coastal Plain sandy loams. Surface runoff from each of the three types of vegetation cover increased directly with the proportion of loessial soil. Presence of a shallow fragipan more than doubled the amount of surface runoff and increased peak flows.

(h) "Runoff as a Function of Moisture-Storage Capacity," J. L. Thames and S. J. Ursic. Jour. Geophys. Research 65(2): 651-654, 1960 .

"Effect of Cover Types and Soils on Runoff in Northern Mississippi," S. J. Ursic and J. L. Thames. Jour. Geophys. Research $65(2): 663-667,1960$.

(3225) WATERSHED MANAGEMETIT RESEARCH, HARRISON RESEARCH CENTER, HARRISON, ARKANSAS.

(b) Laboratory project, in cooperation with Soil Conservation Service and University of Arkansas. 
(d) Field investigation of hydrologic effects of conversion of mountain hardwood forests to range, and of forest management practios on soil moisture regime; applied research.

(e) Runoff plots $12 \times 100$ feet were installed on woodland and on woodland converted to range by aerial spraying, with grazing treatments; plots were also installed to measure effects of prescribed burning for tree seedbed preparation on runoff and sedimentation.

(g) Soil moisture in woodland areas was found to be usually less than in areas converted to range. In 1958-59, the grass areas were near or above field capacity during much of the dormant season, but the woodland areas rarely reached field capacity. On these highly porous, cherty soils, storage capacity of the soil may prove an important factor in protection from excessive runoff during heavy winter and spring rains.

(h) Annual Report Southern Forest Experiment Station.

(3226) SOIL MOISTURE RESEARCH, VICKSBURG RESEARCH CENIER, VICKSBURG, MISSISSIPPI.

(b) Waterways Experiment Station, Corps of Engineers, U. S. Army.

(d) Field and laboratory investigations, basic and applied research on factors affecting soil moisture.

(e) Project aims to develop and improve a soil-moisture prediction method based on field studies throughout the USA.

(g) Very small changes in elevation caused significant changes in moisture and bulk density of soils 6 to 12 inches below the surface.

A method was developed for sampling wet soils by freezing with liquid nitrogen.

(h) "Liquid Nitrogen for Sampling Wet Soils and Calibrating Wet-Soil Sampling Devices," H. D. Burke, A. W. Krumbach, and E. S. Rush. U. S. Army Engineers Misc. Paper No. 4-371, January 1960.

"Effects of Microrelief on Soil Moisture and Bulk Density Distribution," A. W. Krumbach. Jour. Geophys. Research 64(10): 1587-1590, 1959.

U. S. ARMY, CORPS OF ENGINEERS, Beach Erosion Board.

Inquiries concerning the following projects should be addressed to the President, Beach Erosion Board, 5201 Little Falls Road, N. W., Washington 16, D. C.

(181) EQUILIBRIUM PROFILE OF BEACHES AND STUDY OF MODEL SCALE EFFECTS.

(b) Laboratory project.

(d) Experimental.

(e) Equilibrium beach profiles will be determined experimentally for waves up to 6 feet in height in a prototype tank; the waves will be modeled at a 1 to 10 scale in small laboratory tanks for various median diameter and specific gravity sedi- ments to determine scale effect.

(g) Additional tests were made using crushed coal of average specific gravity 1.5 (modeled by the settling velocity relationship to give corresponding characteris. tics of material tested in the large tank). observed material movement and profile changes corresponded much more nearly to the large scale results in the prototype tank, although the coal slope deteriorated somewhat faster. A partial explanation for differences is the wide range of specific gravities of individual coal particles.

\section{(660) OBSERVED WAVE CHARACTERISTICS.}

(b) Laboratory and field project.

(d) Field investigation; basic research.

(e) To secure a more thorough knowledge of the characteristics of ocean waves. A number of electrical recording wave gages have been installed in coastal waters and these records are analyzed for significant height and period.

(g) The new type plastic wave gage sections have proven superior to the neoprene coated aluminum channel type and have been installed at all Beach Erosion Board wave gage installations. Anti-fouling paint has been applied to several of the gages and has proved very effective in reducing the marine growth on the gages, depending upon location. The wave spectrum analyzer utilizing a revolving tape head is now in the testing stage. Experimental records obtained with a tape recorder at Atlantic City, N. J., are being analyzed for comparison with analysis by hand and by other automatic analyses. An improved staff type wave gage is being fabricated for the New Orleans District for use in Lake Pontchartrain, La. This gage is unique in that it is designed to operate in water with salinity changes ranging from fresh water to sea water. Operation of the new gage at New Orleans was very good--3 additional gages of this type have been fabricated, two for New Orleans and one for Vicksburg which is being installed in Hawaii.

\section{(975) METHODS OF BY-PASSING SAND PAST INLETS.}

(b) Laboratory project.

(d) Field investigation; applied research.

(e) To study methods and requirements for pumping sand past inlets and to determine the applicability of the methods in stabilization of beaches adjacent to inlets. Data are being procured on the effect to the shoreline of a sand by-passing operation at Port Hueneme, Calif., and Lake Worth, Fla., and on the effect to the shoreline of a new harbor being constructed at Ventura, Calif. This latter project involves an offshore detached breakwater along with entrance jetties to the new harbor. Data at the three locations include periodic hydrographic surveys south and north of the inlet, wave data, sand 
samples, detailed records of pumping operations, and detailed records of er.trance channel maintenance. A general study is being made of the possibility of adapting commercial instruments utilizing a radioactive source to the discharge line to measure quantity of material pumped in by-passing operations.

(976) ESTABLISHMENT OF CRITERIA FOR CONSTRUCTION OF ARTIFICIAL BFACHES.

(b) Laboratory project.

(d) Theoretical; applied research.

(e) To develop criteria for construction of beaches by artificial means. The present continuing phase of this general study involves the measurement of a natural beach slope and attempts to determine its response to the forces normally incident upon the shore such as wave height and period, angle of wave approach, tide, and direction and magnitude of littoral current. By statistical methods the relative importance of the forces or combinations of forces may be evaluated. A complementary study relating grain size distribution parameters to the direction of littoral drift and zones of accretion or erosion and wave height and period is continuing. Trend surface techniques are being applied to such size distribution parameters as the mean, standard deviation, skewness and kurtosis.

(g) Computing machine techniques are being applied to the statistical evaluation of the importance of the forces and of the parameters. Preliminary results indicate that wave height and wave period are more important in the general study and that the mean and the standard deviation are important in the trend surfaces.

(977) DEVEIOPMENT OF WAVE HEIGHT AND WAVE DIRECTION GAGES.

(b) Laboratory project.

(d) Experimental; development.

(e) To develop wave height and wave direction gages for use in securing accurate records of wave characteristics. (See also Project 660).

(f) Project was Inactive during 1960.

(g) Parts for a new type wave direction gage have been placed under procurement. Laboratory tests of this gage are expected in the next six months.

(2190) STUDY OF EFHECT OF A GROIN SYSTFM ON THE RATE OF LITTORAL MOVEMENT.

(b) Laboratory project.

(d) Experimental; basic research.

(e) To study the effect of groins on the rate of littoral drift passing a groin system. Initial tests consist of waves generated at a 30-degree angle to the sand beach. Measurement of material movement is being made at the down beach end. The tests planned for the immediate future, as have the current season tests, will continue to emphasize the task of establishing sound calibration data relative to littoral transport and wave characteristics. This is now considered a prerequisite to attempting more detailed study and testing on the effects of groins on the rate of littoral drift.

(g) The new series of littoral transport tests on an initial 1 on 10 beach slope and beach lengths of 30 feet or less begun last season have been continued through the present 1960 test season. A total of 7 littoral transport tests have been completed. The seven ( 7 ) tests completed cover a wave steepness range of 0.003 Ho/Lo 0.038. A littoral transport rate of approximately $16,000 \mathrm{lbs} / \mathrm{hr}$ (dry weight of sand) was measured for one test (No. 5-60) where the average wave period was $3.00 \mathrm{sec}$. and wave heights averaged as high as $0.66 \mathrm{ft}$.

(2192) REGIONAL STUDIES OF THE SOUPH SHORE OF LONG ISLAND, NEW YORK; ATLANTIC COAST OF NEW JERSEY; AIND THE DELAWARE-MARYIAINDVIRGINIA SHORE LINE FROM CAPE HENLOPEN TO CAPE CHARLES.

(b) Laboratory project.

(d) Field investigations; basic research.

(e) To compile all existing data pertinent to shore processes on a regional scale. Report to consist of four chapters; geomorphology and shore line histories, littoral forces, littoral materials, and summary and conclusions. Subject matter to include physiography geological development of the shore region, sources of littoral material, waves, tides or water level fluctuations, current physical characteristics of the littoral materials, interrelation of sedimentary properties, relation of properties of littoral materials to position in the littoral zone, and changes in shore line configuration.

(g) All chapters for New Jersey completed except for editing. Geomorphology and shore line history of the south shore of long Island have been completed and submitted for publication. The littoral materials chapter is nearing completion and the littoral forces chapter is essentially complete.

\section{(2193) SHORE PROTECTION PLANNING AND DESIGN.}

(b) Laboratory project.

(d) Design.

(e) The purpose of this project is to supplement and revise the Beach Erosion Board's Technical Report No. 4, "Shore Protection Planning and Design" as new data and techniques are developed for use in the solution of coastal engineering problems.

(g) Second addenda sheets to this report are being prepared for publication early in 1961. A second edition of the entire report, which will include the two addenda to the first edition, is also being prepared. It will include recent data on forces on piles, rubble breakwater design, 
sand by-passing plants, beach fill design, and dune stabilization.

\section{(2195) RE-EXAMTINATION OF ARTIFICIALLY NOURISHED} AND CONSTRUCTED BFACHES.

(b) Laboratory project.

(d) Field investigation; applied research.

(e) To. study the behavior of beach fills placed to restore or nourish a beach sector and the effect of the fill on adjacent shores. A selected number of beach fills are being re-examined.

(g) Survey and sand sample data have been taken at Prospect Beach, Connecticut. A beach fill was placed along this beach in 1957, the fill material being obtained from the offshore zone by conventional pipeline dredge. Preliminary analysis of data indicates that, in the three year period since placement of fill, wave action has transported a measurable quantity of the fill material from the beach zone to the offshore zone and that profile adjustment of the fill material is still in progress.

\section{(2659) LARGE SCALE TESTS OF WAVE FORCES ON PILING.}

(b) Laboratory project.

(d) Experimental; applied research, design.

(e) To determine the nature and magnitude of forces on piles caused by breaking and nonbreaking waves.

(g) A synchronized record of forces on the pile, the water elevation (changing with the wave cycle) and the horizontal water velocity for waves of several periods and heights have been prepared.

(2660) WAVE TANK STUDY OF QUANTITY OF SEDTMENTT IN SUSPENSION IN THE SURF ZONE (INCLUDING TEMPERATURE EFFECTS).

(b) Laboratory project.

(d) Experimental; basic research.

(e) A vacuum pump-type suspended sediment sampler has been used to collect suspended sand samples under various laboratory conditions of waves, water temperature, and sand. The purpose of the study is to determine the relationship between wave, water, and sand characteristics, and the amount of material maintained in suspension and hence available for longshore transport by currents.

(g) A limited number of suspended samples has been collected in conjunction with the littoral transport in the SPTB (see Project No. 2190). Suspended coal samples have been collected in conjunction with the study; "Equilibrium Profile of Beaches and Study of Model Scale Effects." Data from the analysis of these two suspended sediment collections, one sand and the other coal, will be used to augment the analysis of the respective projects. As model scale effect studies using coal are repeated, suspended coal samples will likewise be repeated to aid detection of any changes in specific gravity or size distribution of pulverized.coal.
(2661) WAVE RUN-UP ON SHORE STRUCTURES.

(b) Laboratory project.

(d) Experimental; design.

(e) Wave run-up is determined experimentally by various waves for different types of shore structures. Effect of both structure roughness and permeability is being investigated.

(g) Relatively large scale data have been taken on a 1 on $1 \frac{1}{2}$ slope structure having a single layer of riprap, 3 layers of riprap, and a permeable rubble mound structure. These results indicate the probable existence of a scale effect for rubble structures (as has been previously indicated for smooth slopes).

(h) Discussion by Thorndike Saville, Jr. of article "Laboratory Investigation of Rubble Mound Breakwater" Journal, Waterways and Harbors Division, American Society of Civil Engineers, September 1960.

(2916) WAVE AND SURGE FORECASTING RELATIONSHIPS AND TECHNIQUES.

(b) Laboratory project.

(d) Theoretical; basic research.

(e) To determine methods of predicting wave and storm surge characteristics.

(g) Studies and investigations of methods and application of methods for hurricane surge predictions have been continued. Work has begun on relating wave height and period to the wave spectrum. A few paper chart wave records have been analyzed to obtain wave heights and periods, from which wave spectra are computed and an attempt is being made to correlate these records with those analyzed for the same period by use of the wave spectrum analyzer.

(h) "Hurricane Surge Prediction for Delaware Bay," Charles L. Bretschneider, Beach Erosion Board Misc. Paper No. 3. "A. Theory for Waves of Finite Height," presented at VIIth Conference on Coastal Engineering, the Hague, August 1960.

(3227) DEVELOPMENT OF INPLACE SEDIMENT DENSITY GAGE .

(b) Laboratory project.

(d) Field, development.

(e) To develop an inplace gage to determine density of material under water in shoal areas (navigation channels, reservoirs, etc.).

(f) Completed.

(g) The probe has been field-tested. These tests indicated that the enlargement of the probe casing at the top made it unduly difficult to push the probe into the shoal materials. The probe has been recased to a uniform diameter of $1 \frac{1}{2}$ inches to overcome this fault. The final report has been published and distributed. The published report indicates that the probe is a reliable instrument and fills the need for which it was designed.

(h) "Development and Tests of a Radioactive Sediment Density Probe," by J. M. Caldwell, 
Beach Erosion Board Technical Memorandum No. 121, 29 pages, September 1960.

(3228) MODEL TESTS OF WAVE SET-UP ON BEACHES.

(b) Laboratory project.

(d) Experimental.

(e) To relate increase in water level at the shore due to wave action alone to the incident wave characteristics and shore hydrography.

(g) Additional tests have been made on a 1 on 15 slope and indicate a wave set-up of the same order as, or at slightly larger than for the 1 on 30 slope. Small scale laboratory data also indicate addition of a submerged of. ore barrier may radically increase the wave set-up at the shore.

(3574) PNEUMATIC BREAKWATER.

(b) Laboratory project.

(d) Theoretical, basic research.

(e) To determine methods of predicting wave and storm surge characteristics.

(f) Tests were discontinued due to lack of funds. However, the analysis of the data has been made by the U. S. Army Transportation Corps and a report will be prepared at that office. A separate analysis of the same data has also been made by this office, and it is planned that some type of a discussion report will be made, but with considerably less detail than the report planned by the U. S. Army Transportation Corps.

(3897) RADIOACTIVE TRACERS FOR BEACH STUDIES.

(b) Laboratory project.

(d) Experimental; research.

(e) A natural or simulated sediment on or in which a radioisotope has been incorporated is to be placed at predetermined points along a sandy beach in the Shore Processes Test Basin. Wave induced currents will transport these labelled particles and periodically, the beach and offshore zone will be monitored with appropriate detection instmuments. In this manner a time-space history of the labelled particles will be determined. From the timespace history and other data it is hoped to develop further information concerning the mechanics of particle and littoral movement. Experience gained from the laboratory testing program will be utilized when field testing is undertaken.

(3898) SCOUR CAUSED BY WAVES STRIKING SEAWALLS OR BULKHEADS.

(b) Laboratory project.

(d) Applied research.

(e) The effect of waves acting against a vertical bulkhead on a sand beach in eroding or building up the beach.

(g) A total of five (5) preliminary tests were run during the current 1960 season. These tests cover a total of five separate wave and/or beach conditions.

U. S. ARMY ENGINEER DISTRICT, CORPS OF ENGINEERS, Portland, Bonneville Hydraulic Laboratory.

Inquiries concerning Projects Nos. 401, 2662, 2919, $2921,3229,3575,3576,3577,3578,3899$ and 3900 , should be addressed to the District Engineer, U. S. Army Engineer District, Walla Walla, Building 602, City-County Airport, Walla Walla, Washington.

(401) MODEL STUDY OF MCNARY DAM FISH LADDER, COLUMBIA RIVER, OREGON AND WASHINGTON.

(b) U. S. Army Engineer District, Walla Walla, Corps of Engineers, Walla Walla, Washington.

(d) Experimental; for design.

(e) The 1:16-scale model reproduced a section of the Washington fish ladder that included the 180-degree bend, the 12 pools upstream therefrom, and the 6 pools downstream therefrom. Subsequently, the upper leg was revised to include three of the tilting weirs which will maintain satisfactory flow conditions in the horizontal section between the fixed-type weirs and the automatic regulating gates upstream. Various ladder widths, slopes, and orifice sizes were studied to determine the effects thereof on flow conditions in typical pools between the weirs.

(f) Tests have been completed.

(g) Based on these tests, a 30-ft-wide fish ladder sloped 1 on 20, with 20-ft spacing between successive weirs having two 2l- by 23-inch orifices per weir, was selected for final construction.

(h) "Flsh Facilities for McNary Dam, Columbia River, Oregon and Washington," U. S. Army Engineer Bonneville Hydraulic Laboratory Tech. Rpt. No. 30-1, June 1960. (Available on loan.) This report summarizes the test results from seven hydraulic models that were used to determine probable effects of original and adopted structures on anadromous fish.

(2662) GENERAL MODEL STUDY OF JOHN DAY LOCK AND DAM, COLUMBIA RIVER, OREGON AND WASHINGTON.

(b) U. S. Army Engineer District, Walla Walla, Corps of Engineers, Walla, Washington

(d) Experimental; for design.

(e) A fixed-bed model constructed to an undistorted scale of 1:80 reproduces the Columbia River bed from Mile 213.7 to 216.8. The dam axis is at Mile 215.6. The original structures layout consists of a straight, 20-bay, gravity-type spillway controlled by 50 - by 58.5-ft tainter gates, a powerhouse for 20 Kaplan turbines (initial installation 10 units), an 86 - by 675 -ft navigation lock having a maximum lift of $113 \mathrm{ft}$, a concrete nonoverflow section, rock-fill abutments, and facilities for passing anadromous fish over the dam. Cofferdams having steel cells in the river legs and earth-and-rock shore connections are designed to withstand river flows to 
$700,000 \mathrm{cfs}$ during first-and second-stage construction periods and 300,000 cfs during third-stage diversion. Purposes of the model study are to check the structures alignment and flow conditions affecting power generation, cofferdam placement, and fish passage.

(g) Results of tests indicated the first-step cofferdam was satisfactory after minor revisions, whereas numerous changes in the alignment and height of the second-step cofferdam cells were necessary. Although flow patterns adjacent to the main structures were fairly satisfactory, realignment of the downstream approach channel improved conditions for navigation and extension of a training wall between the spillway and powerhouse reduced a possible hazard for fish migrating upstream. Detalled studies of alternative locations for the south fish entrance and pumphouse that will supply auxiliary attraction water for the powerhouse fish collection system and of tailrace alignments are in progress.

(2918) MODEL -STUDY OF SIDE-CHANNEL SPILLWAY NORTH HARTLAND DAM, OTTAUQUECHEE RIVER, VERMONT.

(b) U. S. Army Engineer Division, New England, Corps of Engineers, Boston, Massachusetts.

(c) Div. Engr., U. S. Army Engr. Div., New England, 150 Causeway St., Boston 14, Mass.

(d) Experimental; for design.

(e) A 1:50-scale, fixed-bed model reproduced a portion of the 185-ft-high, 1520-ft-long earth embankment dam, sufficient forebay area and topography to simulate prototype flow conditions, and the 450-ft-long spillway crest and 50-ft-wide trapezoidal side channel through the left abutment of the dam. The spillway is designed to pass a maximum flood of 160,900 cfs under a head of $20.3 \mathrm{ft}$. The study was necessary to insure that the adopted spillway will be economical to construct and will perform satisfactorily.

(f) Tests completed.

(g) Although the straight crest of original design was satisfactory, tests showed that an L-shaped crest 485 ft long would be adequate and would require less rock excavation.

(h) "Side-Channel Spillway, North Hartland Dam, Ottauquechee River, Vermont," U. S. Army Engineer Bonneville Hydraulic Laboratory Technical Report No. 86-1, December 1959. (Available on loan.)

(2919) MODEL STUDY OF CHANNEL IMPROVEMENT PLANS, PALOUSE RIVER, COLFAX, WASHINGTON.

(b) U. S. Army Engineer District, Walla Walla, Corps of Engineers, Walla Walla, Washington.

(d) Experimental; for design.

(e) A 1:40-scale flume model was used to determine the extent of channel enlargement and modification, levees, flood walls, and revetments necessary to protect the town of Colfax, Washington, from higher-thanrecord discharges: 14,500 cfs in the South Fork, 16,800 cfs in the Palouse River above the mouth of the South Fork, and 28,000 cfs in Palouse River below the mouth of the South Fork. Space limitations require sharply curved channels of varying cross section which are further restricted by existing bridge piers at several locations. Owing to the scale ratio used, the model surfaces (enameled plywood) were too rough to reproduce the prototype concrete surfaces, "n" $=0.014$. Similitude was obtained through use of a slope correction factor in determining model gradients.

(f) Tests completed.

(g) Test results showed the need for revision of several transitions and addition of streamlined pier nose extensions to railroad and highway bridges on both North and South Forks. Studies were made to determine channel invert slopes and wall alignments that will create and maintain a hydraulic jump at desired locations in each channel.

(h) Final report is in preparation.

(2921) MODEL STUDY OF ICE HARBOR SPILLWAY STOP LOG, SNAKE RIVER, WASHINGTON.

(b) U. S. Army Engineer District, Walla Walla, Corps of Engineers, Walla Walla, Washington.

(d) Experimental; for design.

(e) A 1:20-scale model of a single bay of Ice Harbor spillway dam will be installed in an existing laboratory flume. Structural features of stop log will be reproduced and facilities will be provided for direct measurement of hydraulic load on a stop log as it is lowered into place in highvelocity flow.

(f') The proposed tests have been cancelled.

(3229) MODEI STUDY OF SPILLWAY FOR JOHN DAY DAM, COLUMBIA RIVER, OREGON AND WASHINGTON.

(b) U. S. Army Engineer District, Walla Walla, Corps of Engineers, Walla Walla, Washington.

(d) Experimental; for design.

(e) A 1:41.14-scale model of three bays of the spillway dam was used to determine the hydraulic characteristics of the proposed spillway and stilling basin and to develop revisions in design that would improve performance or reduce construction costs.

(f) Tests completed.

(g) Satisfactory design of spillway and stilling basin, and determination of pressure data and discharge rating curves for free and gated flows were accomplished. The tests led to selection of revised designs for the crest pier noses, stop-log slots, stilling basin, and end sill. Additional tests were made to determine the best helght and location for: (1) sill that will be placed on the basin floor in Bay 1 in order to maintain downstream flow at adjacent fishway entrances; and (2) baffles adjacent to Pier 1 and the wall between the spillway and powerhouse to prevent entry of fish into operating section of spillway.

(h) Final report in preparation.

(3230) MODEL STUDY OF NAVIGATION CHANNEI IMPROVEMENT AT BONNEVILLE DAM, COLUMBIA RIVER, OREGON AND WASHINGTON. 
(b) U. S. Army Engineer District, Portland, Corps of Engineers, Portland, Oregon.

(c) District Engineer, U. S. Army Engineer District, Portland, 628 Pittock Block, Portland 5, Oregon.

(d) Experimental; for design.

(e) A 1:130-scale, undistorted, fixed-bed model reproduces 5.6 miles of the Columbia River adjacent to the dam site. The original layout includes existing structures and river bed (survey made in summer and fall of 1958). The purpose of the model is to study methods for improving navigation conditions in the approaches to Bonneville lock for seagoing vessels. A remotelycontrolled model of a $\mathrm{C}-2$ freighter is used to assist evaluation of flow conditions in the navigation channel.

(f) Inactive. Tests of downstream approach have been completed.

(g) After verification for existing conditions (1958), tests were made to determine effects of 1959 dredge cuts in the lock approach, together with alternative improvement plans (rock-fill or concrete groins, permeable guard walls or dykes, and partial revision of the lock approach). None of the preliminary plans was satisfactory, and approximately 15 major channel revisions were tested singly or in combinations in efforts to provide the most practical and economical solution to the problems involved. The most desirable plan will include approximately 900,000 cu yd of excavation along the Washington shore, $86,000 \mathrm{cu}$ yd of excavation at the downstream end of Bradford Island 180,000 cu yd along the Oregon shore, and $100,000 \mathrm{cu}$ yd of excavation at the north side of the lock approach.

(3575) MODEL STUDY OF JOHN DAY NAVIGATION LOCK, COLUMBIA RIVER, OREGON AND WASHINGTON.

(b) U. S. Army Engineer District, Walla Walla, Corps of Engineers, Walla Walla, Wash.

(d) Experimental; for design.

(e) A 1:25-scale model reproduced the 86-by 675-ft lock chamber, split lateral filling and emptying systems, river outlet for emptying system, and portion of the upstream and downstream approach channels. Sufficient upstream approach area was simulated to permit investigation of vortex action over intake manifolds.

(g) Tests of the original design filling and emptying systems were completed. Vortex action over intake manifolds was eliminated for model forebay conditions by reversing the left intake manifold so as to draw flow from spillway side of lock wall. Possible cavitation in emptying culvert bends was precluded by locating the emptying valves downstream from the bends. Various lateral culvert roof designs were studied. A design with a small roof overhang, tentatively adopted for design, provided a filling time of $11.7 \mathrm{~min}$ and a maximum longitudinal hawser force on an 11,070-ton ( 8 barge) tow of about 6 tons with an initial head of 113 ft and a 4.0-min valve schedule. The lock emptied in 13.8 min with a 2.2-min valve schedule and developed maximum hawser forces of approximately 2.5 tons. Tests to refine lateral culvert design are continuing.

(3576) MODEL STUDY OF NORTH FISH LADDER DIFFUSERS, JOHN DAY DAM, COLUMBIA RIVER, OREGON AND WASHINGTON.

(b) U. S. Army Engineer District, Walla Walla, Corps of Engineers, Walla Walla, Washington.

(d) Experimental; for design.

(e) A 1:8-scale model reproduces diffusers 3 through 6, ladder welrs 155 through 163 , and a section of the auxiliary water-supply conduit. A constant flow of $100 \mathrm{cfs}$ will pass down the 24-ft-wide, 1-on-10 sloped north fish ladder, but discharge in the water-supply conduit will vary from 600 to $1300 \mathrm{cfs}$. Provision was made in the model for measurement of outflows from the ladder, the water-supply conduit, and individual diffusers. The model is constructed so that dimensions or other details of the weirs, orifices, and diffuser wells can be altered to improve their hydraulic characteristics if necessary.

(g) Several diffusion chamber designs were studied, and the size and location of orifices to provide scheduled diffuser flows for range of tallwater fluctuations within the fish ladder were determined.

(3577) GENERAL MODEL STUDY OF LOWER MONUMENTAL DAM, SNAKE RIVER, WASHINGTON.

(c) District Engineer, U. S. Army Engineer District, Walla Walla, Building 602, CityCounty Airport, Walla Walla, Washington.

(d) Experimental; for design.

(e) A l:100-scale, undistorted, fixed-bed model reproduces approximately 2.4 miles of Snake River bed and overbank topography at the dam site. The dam axis is at River Mile 41.5, about 60 miles from the city of Pasco, Washington. Studies will be made to determine flow conditions during various construction stages and after proposed structures have been installed.

(g) Verification of the model and studies of the first construction stage were completed. The test results indicated that proposed limits for excavation along the right bank were inadequate and that several revisions in alignment and height of the cofferdam were needed. Problems concerning fish passage adjacent to the upstream comer of the cofferdam and bottom erosion within the diversion channel were solved during the course of the model studies made this year. Tests on the second-stage cofferdam and first-step structures are in progress.

(3578) MODEL STUDY OF FISH LADDERS FOR JOHN DAY DAM, COLUNBIA RIVER, OREGON AND WASHINGTON.

(b) U. S. Army Engineer District, Walla Walla, Corps of Engineers, Walla Walla, Washington.

(d) Experimental; for design.

(e) An existing 1:10-scale fish ladder model was revised to reproduce 32 pools of $24-\mathrm{ft}$ wide ladder sloped 1 on 10. Tests were being made to develop a design which will provide flow conditions comparable to those 
in a 1-on-16 slope, 24-ft-wide ladder after which model will be revised to study the orifice-controlled regulating section of fish ladder.

(g) Velocities, flow patterns, and surge characteristics were determined for fixedweir sections of several alternative designs (12-in. head on weirs).

(3899) MODEL STUDY OF SPILIWAY FOR LOWER MONUMENTAT DAM, SNAKE RIVER, WASHINGTON.

(b) U. S. Army Engineer District, Walla Walla, Corps of Engineers, Walla Walla, Washington.

(d) Experimental; for design.

(e) The 1:42.47-scale model includes a 3-bay section of the 8-bay spillway and stilling basin. Tests are being made to evaluate hydraulic performance of the proposed spillway and, if necessary or desirable, to develop revisions in design that will increase performance or reduce construction and maintenance costs.

(g) Design and construction of the model were completed during the year. Tests have included measurements of discharge, pressures, and water-surface profiles over the crest without piers.

(3900) MODEL STUDY OF DOWNPULL FORCES ON EMERGENTCY CLOSURE GATES.

(b) Office of the Chief of Engineers, Dept. of the Army, Washington, D. C.

(c) District Engineer, U. S. Army Engineer District, Portland, 628 Pittock Block, Portland 5, Oregon.

(d) Experimental; applied research.

(e) This is a general study of various sluice coaster gate bottom and lip shapes, and includes downpull and discharge measurements as affected by angle of gate bottom, length of gate lip extension, control valve opening, number of control valves operated, and condition of air vents (open or closed). A I:25-scale model reproduces a level approach to an intake tower with vertical headwall normal to intake center line, two three-sided bellmouth intakes, a 20-ft-wide by 22-ft-high emergency gate (tractor type), two 10-ft-wide by 15-ft-high control valves (tainter), and a 22-ft-diam. outlet tunnel. Hydraulic downpull forces are computed from pressures at 21 critical locations on the emergency gate.

(8) Tests on a gate having a 30-degree bottom and a 2 1/4-in. extension of the downstream skin plate have been completed. With one intake open, maximum downpull forces on the emergency gate always occurred just before control of the outflow shifted from the tainter gate to the tractor gate and ranged from 46 kips at a 50 -ft head to $340 \mathrm{kips}$ when the head was $300 \mathrm{ft}$.

(3901) MODEL STUDY OF LOW-BAY SPILLWAY FOR JOHN DAY DAM, COLUMBIA RIVER, OREGON AND WASH.

(b) U. S. Army Engineer District, Walla Walla, Corps of Engineers, Walla Walla, Washington.

(d) Experimental; for design. (e) The 1:24-scale model includes two low spillway bays and stilling basin for John Day Dam. Tests were made to determine a design for the downstream lip of low bay that would eliminate scouring during second-stage diversion. Tests will also be made to determine scouring conditions for several low-bay elevations to assist in low-bay design for other projects.

(g) During tests simulating second-stage diversion through the low bays of John Day Dam, scouring action was minimized by terminating the low bays with a vertical strip extending approximately 7.5 ft downward to the spillway bucket. The tests are being extended to several low-bay elevations to determine the influence of tallwater depth and discharge on scouring action within the stilling basin and spillway bucket.

\section{U. S. ARMY ENGINEER DISTRICT, CORPS OF ENGINEERS,} St. Paul.

\section{(194) A STUDY OF METHODS USED IN MEASUREMENT} AND ANALYSIS OF SEDIMENT LOADS IN STREAMS.

U. S. Army Engineer District, St. Paul and U. S. Geological Survey, in cooperation with St. Anthony Falls Hydraulic Laboratory. See St. Anthony Falls Hydraulic Laboratory, page 75 .

\section{U. S. ARMY ENGINEER WATERWAYS EXPERIMENT STATION,} CORPS OF ENGINEERS.

\section{(236) MISSISSIPPI BASIN MODEL.}

(b) Office of the Chief of Engineers, Dept. of the Army, Washington, D. C.

(d) Experimental; for design.

(e) The project provides for construction and operation of a model of the Mississippi. River Basin including the Mississippi, Ohio, Missouri, and Arkansas Rivers, and their principal tributaries. All existing and proposed flood-control reservoirs, dikes, floodwalls, and other pertinent works will be reproduced. The model area comprises 200 acres, and measures 4,500 feet east and west, and 3,900 feet north and south. Completed construction consists of the Upper Mississippi River from Hannibal, Missouri, to Vicksburg, Mississippi; the Missouri River from Sioux City, Iowa to the mouth; the Arkansas River from Blackburn Dam Site, Oklahoma, to Pine Bluff, Arkansas; the Ohio River from Louisville, Kentucky, to the mouth; the Cumberland River from old Hickory Dam, Tennessee, to the mouth; and the Tennessee River from Pickwick Dam to the mouth. The topography of the streams and flood plains are being reproduced to a horizontal scale of $1: 2,000$ and vertical scale of 1:100. Water-surface elevations are measured by electrically operated stage devices with the recorders located in 
central control buildings. Stream flow is introduced and controlled by automatic instruments called inflow controllers. The model was designed to ald in the development of coordinated basinwide plans for flood control and operation of floodcontrol structures.

(g) The extent of model operation each year is determined by the testing programs directed by the Mississippi Basin Model Board and Chief of Engineers and requested by Divisions and Districts that have operable sections on the model. The model was operated as an integrated unit for comprehensive (basinwide) tests; tests were conducted of the 1937, 1943, 1945, and 1950 floods using the actual floods with present-day conditions and the same floods without reservoir modification. Tests were conducted during the current year by the following U. S. Army Engineer Divisions: Missouri River, Ohio River, and Lower Mississippi Valley. Verification tests were conducted on the Missouri, Ohio, and Mississippi Rivers. Special tests were made to determine: stages and discharges that would result from the Hypothetical Flood OR-1 on the Ohio River, which is a combination of the 1937 and 1950 floods; stages and discharges that would result from the Hypothetical Flood 52-A on the Mississippi River, and the roughness conditions that will exist on the Cumberland River after the completion of Barkley and Cheatham Dams.

(h) "Tests for Re-evaluation of Missouri River Agricultural Ievees in the Kansas City District," Mississippi Basin Model Report 32-2, (December 1959).

"Proposed Alignments for Columbia Bottoms Levee, St. Louis Industrial Park, "Miss. Basin Model Report 31-3, (January 1960). "Tests for Re-evaluation of Missouri River Agricultural Ievees in the Omaha District," Mississippi Basin Model Report 32-3, (June 1960).

(425) COMPREHENSIVE MODEL STUDY, DELAWARE RIVER, PENNSYLVANIA.

(b) District Engineer, U. S. Army Engineer District, Philadelphia, Corps of Engineers, Philadelphia, Pennsylvania.

(d) Experimental; for design.

(e) To develop and test plans for reduction of shoaling in several ranges of the navigation channel, the entire Delaware River estuary from the Atlantic Ocean to Trenton is reproduced in the model which is of the fixed-bed, silt-injection type, with scale ratios of $1: 1,000$ horizontally and $1: 100$ vertically. Tides and tidal currents are reproduced by automatic tide generators. Observed prototype salinities are reproduced in the Delaware Bay portion of the model, and provisions made for the injection of silt, and for measuring silt deposits. Studies are also made of salinity intrusion and the dispersion and dilution of wastes discharged into the estuary.

\section{(993) CAVITATION RESEARCH.}

(b) Office of the Chief of Engineers, Department of the Army, Washington, D. C.

(d) Experimental; applied research.

(e) The cavitation characteristics of such elements as baffle piers, steps in stilling basins, spillway and conduft gage slots, and offset joints are studied in either a vacuum tank or a variable-pressure, closedjet water tunnel. The investigation includes a review of literature to evaluate the many variables that affect cavitation results. A high-velocity water facility is being constructed to study resistance of protective coatings on cavitation-damaged concrete specimens.

(994) EFFECTS OF MODEL DISTORTION.

(b) Office of the Chief of Engineers, Department of the Army, Washington, D. C.

(d) Experimental; applied research.

(e) This is a general study to determine the hydraulic effects of various types and degrees of model scale distortion on velocity distribution and other hydraulic conditions, with the ultimate aim of establishing limits of permissible distortion for the various types of models. Tests are in progress of a rectangular flume having a 90-degree bend with provisions for changing the vertical scale to provide a distortion of 0 to 10 .

\section{(999) STABILITY OF RUBBLE-MOUND BREAKWATERS.}

(b) Office of the Chief of Engineers, Dept. of the Army, Washington, D. C.

(d) Experimental; applied research.

(e) Rubble-mound structures are studied in a 5- by 4- by 119 foot wave tank to develop formulas, supported by experimental data, from which the design of safe and economical breakwaters can be determined. In addition to quarrystone, tetrapods, tetrahedrons, tribars, and other specially molded armor units are being studied.

(g) The results of stability tests on pell-mellplaced protective cover layers of quarrystone, tetrapod, tribar, hexapod, modifled cube, and tetrahedron armor units are represented with very good accuracy by the formula

$$
W_{r}=\frac{\gamma_{r} H^{3}}{K_{\Delta}\left(S_{r}-1\right)^{3} \cot \alpha}
$$

where $W_{r}$ is weight of individual armor units, $\gamma_{r}$ is the specific weight of the armor units, $H$ is height of selected design wave, $S_{r}$ is the specific gravity of armor units relative to the fluid in which the structure is located $\left(\gamma_{r} / \gamma_{W}\right), \alpha$ is the angle of the breakwater face, measured from the horizontal, and $K_{\Delta}$ is a dimensionless coefficient.

(h) "Design of Quadripod Cover Layers for 
Rubble-Mound Breakwaters; Hydraulic Model Investigation," U. S. Army Engineer Waterways Experiment Station Miscellaneous Paper No. 2-372, January 1960. (Avallable on loan. )

(1002) EFFECTS OF SCALE AND OPERATING TTECHNIQUES ON HARBOR WAVE ACTION MODELS.

(b) Office of the Chief of Englneers, Dept. of the Army, Washington, D. C.

(d) Experimental; applied research.

(e) Tests are conducted in flumes and harbor model basins to obtain information that will allow more accurate determination of optimum scales for wave models, and the effects of different scale and operating techniques on the accuracy of model results. The efficlency of flexible-element wave fllters is belng investigated to facllitate continuous operation of wave flumes.

Resonant chambers for harbor entrances and attenuation of waves in a three-dimensional model are being studied.

\section{(1004) INSTRUMENTATION.}

(b) Office of the Chief of Engineers, Department of the Army, Washington, D. C.

(d) Experimental; development.

(e) Various types of measurement and control equipment for use in hydraulic studies are being developed. These include equipment for measuring subsurface currents and for operation of a model boat by remote control. The development of miscellaneous model and field measuring instruments was continued as the need arose.

(1211) MODEL STUDY OF HOOSIC RIVER, NORTH ADAMS, MASSACHUSETTS.

(b) Distrlct Engineer, U. S. Army Engineer Dist., New York, Corps of Engineers, New York, N.Y.

(d) Experimental; for design.

(e) A 1:30 model was used to verify the hydraulic design for improvement of certain sections of the North and South Branches of Hoosic River in North Adams, Massachusetts, and to determine whether changes should be made for safety, increased efficiency, or economy. The flow in the major portion of these channels will be below critical depth. The model was used to check such design features as channel alignment, transitions, superelevation in bends, characteristics of weirs, stllling basins, arop structures, the treatment of intakes and outlets, wall helghts, and elevations of bridges.

(f) Final report in preparation.

(g) Uneven energy content of the flow entering the stilling basin at the end of the $1 \mathrm{~m}$ provement works resulted in unsatisfactory flow conditions in the basin of original design. Satisfactory flow conditions were obtained by dividing the stilling basin into two sections and deslgning each section to provide for only that portion of flow entering that particular section. Tests of the junction section indicated that flow conditions could be improved slightly by realignment of the outside walls. On the North Branch a satisfactory design for the entrance of Hunterfield Brook was developed. On the South Branch a storm-drain outlet was moved downstream so as to give satisfactory free board of the $B$ and $M$ RR bridge.

(1212) MODEL STUDIES OF OUTLET WORKS, OAHE DAM, MISSOURI RIVER, SOUTH DAKOTA.

(b) District Engineer, U. S. Army Engineer District, Omaha, Corps of Engineers, Omaha Nebraska.

(d) Experimental; for design.

(e) Hydraulic performance of the outlet works for Oahe Dam was studied on three models: a 1:60 model reproducing the downstream ends of the six 18.25-foot-diameter outlet tunnels, the stilling basin, and portions of the discharge and pilot channels; a 1:25 model of one central control shaft, the portion of the tunnel upstream of the control shaft, including the intake and a 1:25 model of one of the control shafts, containing tandem vertical-lift gates, and the tunnel downstream therefrom including the outlet transition.

(f) Completed.

(g) A satisfactory double-stage stilling basin was developed. In general, the model provided the means for developing effective stilling basin and tunnel transition structures of minimum size. In addition, the model demonstrated that closing the bulkhead slot in the tunnel intake would minimize the possibility of cavitation and produce optimum hydraulic efficiency.

(h) "Outlet Works, Oahe Dam, Missouri River, South Dakota; Hydraulic Model Investigation," U. S. Army Engineer Waterways Experiment Station Technical Report No. 2-557, Sept. 1960. (Available on loan.)

(1467) ANALYSIS OF HYDRAULIC EXPERIMENTAL DATA (MODEL AND PROTOTYPE) AND DEVELOPMENT OF DESIGN CRITERIA.

(b) Office of the Chief of Engineers, Dept. of the Army, Washington, D. C.

(d) Analytical (model and prototype) and field investigations; for design.

(e) A general study to develop, analyze and disseminate to Corps of Engineers establishments hydraulic design criteria to insure adequate capacity, economy of construction, and safe and satisfactory operation. Criteria are developed from model and prototype tests relating to the design of spillways, outlet works, gates and valves, channels, and navigation structures. Program also includes prototype tests in cooperation with other Corps of Engineers establishments.

(g) "Hydraulic Design Criteria" charts have been prepared on the fluid properties of water, spillway abutment contraction coefficlents, wave pressures on crest gates, effects of gate seat location on spillway crest pressures, discharge coefficients for conduit and open channel tainter gates, 
and head losses for flap gates. Prototype measurements were made of surface profiles and vertical velocity profiles in the chute spillway at Fort Randall Dam for discharges giving uniform flow depths of 1.5 to 2.3 feet and velocities of 20 to 37 feet per second.

(h) "Hydraulic Design Criteria" Issue No. 10 (available for purchase in limited quantities).

"Hydraulic Prototype Tests of Tainter Valve, McNary Lock, Columbia River, Washington," U. S. Army Engineer Waterways Experiment Station Technical Report No. 2-552, June 19 1960 .

1474) OPERATING FORCES OF MITER-TYPE LOCK GATES.

(b) Office of the Chief of Engineers, Dept. of the Army, Washington, D. C.

(d) Experimental; applied research.

(e) A general study to collect basic data on operating forces of miter-type lock gates and to determine the effect of various elements upon these forces was conducted in a 1:20 model. A lock chamber 110 feet wide was reproduced with provisions for varying the length up to 600 feet on each side of the gate. Forces required for operation of miter gates were measured for variations of the following elements: gate leaves, speeds and accelerations of operation, submerged depths, recess shapes, bottom clearances, chamber lengths, and nonsynchronous operation of gate leaves. Variations in the type linkage driving the gate were also investigated.

(f) Final report in preparation.

(g) Peak hydraulic resistance to operation of the miter gate occurred as the leaves entered the mitered position. The maximum torque of the Ohio River type linkage exceeded those of the Panama and the modified Ohio River type linkages for the same operating conditions, as was expected since there is angularity between the strut and sector arms of the Ohio River linkage and, therefore, a greater velocity of the gate leaves as they entered the mitered position. An increase in the submergence of the gate leaves, speed of operation, length of lock chamber, or decrease in the bottom clearance serves to increase the hydraulic forces resisting gate movement. The presence of barges in the lock chamber and nonsynchronous gate operation do not appreciably affect torque values.

(1475) SIPHON ACTION AT PUMPING PLANTS.

(b) Office of the Chief of Engineers, Dept. of the Army, Washington, D. C.

(d) Experimental; applied research.

(e) This study was conducted to aid in developing design criteria for pumping plants that depend on development of siphonic action in the discharge side of the pumps in order to yield the required discharge. Full-size models of a 6-inch and 12-inch plastic discharge line were tested. Variables investigated during the tests were: rates of flow, water levels in the discharge side of the pumps, slope and length of the riverward leg, and venting condttions at the crown.

(f) Final report in preparation.

(1738) MODEL STUDY OF SPILLWAY AND STILLING BASIN, GREENUP LOCKS AND DAM, OHIO RIVER.

(b) District Engineer, U. S. Army Engineer District, Huntington, Corps of Engineers, Huntington, West Virginia.

(d) Experimental; for design.

(e) A 1:25 section model reproducing 400 feet of the approach area, a portion of the spillway crest and stilling basin, and 800 feet of the exit area was used to examine hydraulic performance of the spillway and stilling basin. A second phase of the study involved the measurements of hydraulic forces acting on a submergible-type spillway gate.

(f) Final report in preparation.

(g) The stilling basin recommended for construction consists of a horizontal apron 74 feet long at elevation 470, with a single row of 6-foot-high baffle piers and a 4-foot-high stepped end sill. Bottom velocities in the exit area at or near normal tailwater did not exceed 4 feet per second. The submergible gate was stable for all conditions investigated and the maximum water load did not exceed $54 \mathrm{kips}$ per hoist.

(1739) MODEL STUDY OF GATE AND STILIING BASIN, MARKLAND LOCKS AND DAM, OHIO RIVER.

(b) District Engineer, U. S. Army Engineer District, Louisville, Corps of Engineers, Louisville, Kentucky.

(d) Experimental; for design.

(e) A 1:25 section model reproducing 400 feet of the approach area, a portion of the spillway crest and stilling basin, and 800 feet of the exit area was used to examine the hydraulic performance of the spillway weir and stilling basin, and a 1:4 model of the gate sill reproducing the flared downstream face of the sill was also used to study the performance of the submergible spillway gate. A second phase of the study involving measurements of hydraulic forces acting on a submergibletype spillway tainter gate was conducted in the 1:25 model.

(f) Final report in preparation.

(g) Tests of the original design stilling basin revealed satisfactory performance as regards energy dissipation; however, the proximity of the baffle piers to the submergible gate caused considerable turbulence in the vicinity of the submerged gate bottom for certain flow condtions. This was corrected by placing the first row of baffle piers a minimum of 45 feet below the gate sill. The performance of the submergible gate was satisfactory. The gate was stable throughout its range of travel and the maximum water load on the gate was about 56 kips per hoist. Tests on the 1:4 gate and gate sill model with a 2-inch 
to 3 -inch sill flare revealed positive pressures in the area between the gate and sill. Tests of the inflatable-type gate seal revealed rapid flutter of the seal for most submerged positions of the gate. Pressure fluctuations in the flared area while the seal was fluttering were in the range of 17 to 27 feet of water. Based on these unsatisfactory results the inflatable type seal was eliminated from prototype use. Emergency or temporary sealing of the submergible gates will be accomplished with tubing or pipes.

\section{(1986) SALT WATER INTRUSION AND RELATED PHENOMENA.}

(b) Committee on Tidal Hydraulics, Corps of Engineers (correspondence should be addressed to Mr. C. F. Wicker, Chairman, Committee on Tidal Hydraulics, U. S. Army Engineer District, Philadelphia, Corps of Engineers, Philadelphia, Pennsylvania).

(d) Experimental; applied research.

(e) To determine the effects of salinity and related phenomena on the vertical distribution of currents and shoaling characteristics in estuaries, tests are being made in a lucite flume 327 feet long, 1.5 feet deep, and 0.75 foot wide. One end of the flume is connected to a 25-foot-square tidal basin in which any desired tide may be produced and in which the salinity may be controlled. The opposite end is connected to a fresh-water source. Combinations of tidal range, tidal period, source salinity, mean depth, and fresh-water inflow are studied. A total of about 10 tests were made during the year. The results are belng analyzed; however, no conclusions have been reached at this time.

(1987) RIPRAP PROTECTION AT HYDRAULIC STRUCTURES (FORMERLY MODEL REPRODUCTION OF PROTOTYPE EROSION BELOW STILLING BASINS).

(b) Office of the Chief of Engineers, Dept. of the Army, Washington, D. C.

(d) Experimental; applied research.

(e) The study of erosion characteristics of various sizes of riprap and gravel material is being performed with a view to securing adequate protection at minimum cost.

Measurements of velocity and turbulence at which movement of materlal begins will be made. At present, tests are being conducted on various sizes of riprap below a high structure and a low, navigation-type structure to determine the fllow characteristics'at which movement occurs.

(1988) WATER TEMPERATURE EFFECTS ON BED FORMS AND ROUGHNESS.

(b) Office of the Chief of Engineers, Dept. of the Army, Washington, D. C.

(d) Experimental; applied research.

(e) A laboratory flume, in which water temperatures can be varied to simulate normally experienced sumer and winter temperatures, is being used to investigate the effects of water temperature on streambed forms and roughness of various types of bed materials.

(2428) MODEL STUDY OF SAVANNAH HARBOR, GEORGIA.

(b) District Engineer, U. S. Army Engineer District, Savannah, Corps of Engineers, Savannah, Georgia.

(d) Experimental; for design.

(e) The investigation was conducted in a model which reproduced the following: (1) that portion of the Atlantic Ocean, adjacent to the harbor entrance, from Calibogue Sound on the north to Wassaw Sound on the south; (2) the Savannah River and its flood plain to the head of tide at Ebenezer landing; and (3) that portion of the Intracoastal Waterway which crosses the area included in the model. The model was of fixed-bed construction with scale ratios, model to prototype, of $1: 800$ horizontally and $1: 80$ vertically. Automatic tide generators were used to reproduce tides and tidal currents throughout the harbor, and salt water was used in the model ocean to reproduce the effects of density difference on current velocities and distributions. Shoaling studies were made by injecting finely ground gilsonite into the model to reproduce the patterns of shoaling as observed in the prototype, following which the effects of proposed improvement plans on shoaling patterns were observed and evaluated Studies were also made of the effects of proposed improvement plans on dispersion and dilution of contaminants discharged into the harbor. Refinements of plans for reducing and locallzing shoaling were tested.

(f) Tests completed; preparation of final report in progress.

(g) The results of model tests indicate that the cost of maintenance dredging in Savannah Harbor can be reduced most effectively by a combination of (1) completely diking all dredge spoil areas, and (2) construction of a sediment trap and tide gate in lower Back River.

(2429) MODEL STUDIES OF THE CORNWALL ISLAND AND BARNHART ISLAND-LAKE ST. FRANCIS REACHES, ST. LAWREINCE RIVER.

(b) District Engineer, U. S. Army Engineer Dist. Buffalo, Corps of Englneers, Buffalo, N. Y.

(d) Experimental; for design.

(e) Two fixed-bed models were used to study plans for navigation improvement in the lower portion of the International Rapids section of the St. Lawrence River. A 1:100 model of the Cornwall Island Reach reproduced all features of the river from just below the tailrace of the proposed Barnhart Island powerhouse to about the mid-point of Cornwall Island, and included portions of both the north and south Cornwall Island channels, Polly's Gut, and the entrance to Grass River locks. A model of the Barnhart Island-Lake St. Francis Reach, built to scales of $1: 300$ horizontally and $1: 100$ vertically, reproduced a greater area upstream and downstream of Cornwall Island. 
Both models were used to study navigation conditions in the approach to the Grass River locks, proposed plans for excavations in both Cornwall Island channels to effect navigation improvement in South Channel, and to determine conditions that will be encountered by navigation during the construction of the project features in the Cornwall Island Reach.

(f) Preparation of final report in progress.

(2673) MODEL STUDIES OF BARKLEY LOCK AND DAM, CUNBERLAND RIVER, TENNESSEE.

(b) District Engineer, U. S. Army Engineer District, Nashville, Corps of Engineers, Nashville, Tennessee.

(d) Experimental; for design.

(e) A I:120 model, reproducing the Cumberland River from mile 29.4 to 32.2 , the lock, dam, and powerhouse, was used to investigate flow characteristics in the approaches to the lock. A 1:36 model, reproducing the riverward downstream lock wall including the culvert manifold which discharges into the spillway stilling basin, a discharge manifold discharging through the stilling basin, five spillway bays, 324 feet of approach channel, and 596 feet of exit channel, was used to investigate flow characteristics in the stilling basin and exit channel. The proposed design for the lock filling and emptying system was tested in a 1:33 model simulating the upper approach channel, intake manifolds in both walls serving culverts 16 feet square, lateral culvert diffusers in the lock chamber floor, and port manifolds in the spillway stilling basin for discharging flow from both culverts. The emergency lock gate was studied in a 1:25 model which reproduced the gate, gate sill, and portions of the upstream lock approach and the lock chamber downstream from the gate. This model was used to determine: (1) hydraulic forces on and stability of the gate under various flows including free flow over the lock miter sill; (2) hydrostatic forces on the gate in various positions; (3) gate wheel reactions and sill roller reactions at given positions; and (4) head loss through the bridge decking.

(f) Tests completed; final report in preparation.

(2675) MODEL STUDIES OF DARDANELIE LOCK AND DAM, ARKAIVSAS RIVER, ARKAIVSAS.

(b) District Engineer, U. S. Army Engineer District, Little Rock, Corps of Engineers, Iittle Rock, Arkansas.

(d) Experimental; for design.

(e) Three models were used for the investigation. A 1:120 model reproduced the structures and 4,000 feet of approach channel and 8,000 feet of exit channel. The approach channel was molded in concrete to overburden contours while the exit channel was molded in concrete to bedrock contours with the overburden topography molded in pea gravel to facilitate revision of the channel configuration. This model was used to determine relative merits of several possible arrangements of the structures constituting the control section of the dam. Alternate lock guide-wall designs were also tested on this model, and a short series of tests was made to evaluate the effectiveness of floating guide booms in the reservoir for collecting and passing drift. A 1:50 section model reproducing one full and two adjacent half bays of the spillway and stilling basin was utilized for studies of the adequacy of the weir and stilling basin design. This model had a glass side so that flow patterns could be observed directly. The section model was also used to test a revised crest pier design with wider gate bays which will be incorporated. A 1:25 model reproducing 700 feet of upstream lock approach channel, the guide wall, the lock culvert intakes, the lock culverts through the filling valves, and three adjacent spillway bays (the downstream portions of the lock culvert and lock chamber are reproduced schematically) was used to develop a satisfactory lock intake system and approach channel. Provisions were made for mechanical operation of the culvert valves and automatic recording of pertinent data.

(f) Tests completed, and report on 1:120 model and $1: 50$ section model tests completed; preparation of final report on 1:25 model in progress.

(g) Tests on the 1:120 model provided information on the best arrangement of structures and effects of downstream channel degradation, and indicated the desirability of having the longer lock wall on the riverside at both upstream and downstream entrances. The floating guide booms in the upper pool did not appear practicable. As a result of the 1:50 section model tests, the crest pier nose shape was changed and the end sill height was lowered slightly.

(h) "Dardanelle Lock and Dam, Arkansas River, Arkansas; Hydraulic Model Investigation," U. S. Army Engineer Weterways Experiment Station Technical Report No. 2-558, Nov. 1960. (Available on loan).

(2678) MODEL STUDY OF LOCKS AND DAM NO. 41, LOUISVILLE, KENTUCKY.

(b) District Engineer, U. S. Army Engineer District, Louisville, Corps of Engineers, Louisville, Kentucky.

(d) Experimental; for design.

(e) A fixed-bed, 1:120 model reproduces a sixmile reach of the Ohio River including adjacent overbank areas, the locks and dam structures, and all bridges and other structures that might affect flow conditions. Purposes of the model study are to: determine the effects of location, size, and alignment of the dam on stages and currents in the upper pool; determine the effects of location, size, and alignment of a new approach channel on navigation and surge conditions; determine the best location for a new navigable span on the 
Pennsylvania Railroad bridge; determine a method of operating the dam for optimum navigation conditions; study navigation conditions in the lower approach as affected by flow through dam, powerhouse, and lockemptying system; and provide a means for navigation interests to satisfy themselves as to the acceptability of the proposed plan by observing the model in operation. Tests of modifications are in progress.

\section{(2680) MODEL STUDY OF HURRICANNE TIDES IN} NARRAGANSETT BAY, RHODE ISLAND.

(b) Division Engineer, U. S. Army Engineer Division, New England, Corps of Engineers, Boston, Massachusetts.

(d) Experimental; for design.

(e) A fixed-bed model, 1:1,000 horizontally and 1:l00 vertically, reproduces all of Narragansett Bay and ar adjacent portion of the Atlantic Ocean. An automatic tide generator reproduces normal tides throughout the model, and a separate, manually operated generator reproduces hurricane tides of the desired characteristics at the bay entrance. Numerous barrier plans for prevention of hurricane-tide damage have been proposed. The relative and absolute effectiveness of these plans in reducing hurricane-tide elevations throughout the bay system were determined and the effects of the best plan on such important factors as tidal circulation, pollution, salinity, and shoaling for normal conditions were investigated. Additional hydraulic, salinity, shoaling, and polution studies of a lower bay barrier plan recommended by the Navy were made; however, analysis of the tests results is not complete. Fresh water only was used in the model during tests of the proposed barrier plans, but both salt and fresh water are being used in the tests to determine the effects of the best barrier plan on all significant factors for normal conditions. Model appurtenances consist of automatic tide gages to record both hurricane-tide and normal-tide elevations at critical points, recording salinity meters, recording dye meters for observing pollution and/or flushing characteristics, current velocity meters, and equipment for simulating shoaling of the channels and other navigation facilities.

\section{(2681) SCALE-EFFECT TESTS OF RUBBLE-MOUND BREAK-} WATERS.

(b) Office of the Chief of Engineers, Dept. of the Army, Washington, D. C.

d) Experimental; applied research.

(e) Tests are being conducted by the Beach Erosion Board, under the supervision of the Waterways Experiment station, to investigate the effects of model scale on the results of experimentally determined criteria for the design of rubble-mound breakwaters. Stability tests are being made of a breakwater slope of 1 on $1-1 / 2$ using wave periods of $2.61,3.75,7.87$, and 11.33 seconds. Tests in the Beach Erosion Board wave ume ( 15 feet by 20 feet by 635 feet) are being conducted using a linear scale of $7.5 \quad 1$ based on the tests conducted in the Waterways Experiment Station 5 - by 4- by 119-foot wave flume. Stability tests have also been conducted in the Waterways Experiment Station small wave flume ( 1 foot by 1.5 feet by 94 feet) using a scale of 0.5 to 1 based on tests conducted in the 5 - by 4 - by 119 -foot wave flume. Therefore, data on the stability of rubble-mound breakwaters will be available for three different linear scales, 0.5 to 1,1 to 1 , and 7.5 to 1 . Test data from the Beach Erosion Board wave flume will be correlated with data from the Waterways Experiment Station flumes as soon as calibration of the flume is completed.

(2682) SACRAMENTO BARGE CANAL LOCK MODEL STUDIES, SACRAMENTO RIVER, CALIFORNIA.

(b) District Engineer, U. S. Army Engineer Dist. Sacramento, Corps of Engineers, Sacramento, California.

(d) Experimental; for design.

(e) Sacramento Barge Canal, which will connect Washington Lake Harbor and the Sacramento River, will contain a lock 86 feet wide by 600 feet long with a minimum depth of 13 feet over the sills. Maximum heads of 21 feet with river stage higher than harbor stage, and 3.6 feet with harbor stage the higher are anticipated. Because of expected reversal of head, sector gates were selected for the lock and are to be used to fill and empty the lock. Tests were conducted on a 1:20 model of the lock to assure the adequacy of fllling and emptying the lock by passing flow between the sector gate leaves and around each leaf through the recess.

(f) Completed.

(g) Tests showed that design criteria will be met in that the lock can be filled in 12 minutes under a 12-foot head with hawser stresses on a 4-barge tow at 9-foot draft not exceeding 5 tons. Longer filling times can be tolerated for larger tows or higher heads. For normal-head filling, three gateoperating schedules were developed, the schedule to be used depending on the head, river stage, and tow size and position. For emptying and reverse-head filling, the gates should be opened at the rate of 0.66 degree per minute for all conditions.

(h) "Filling and Emptying Characteristics of Barge Canal Lock, Sacramento River DeepWater Ship Channel Project, California; Hyaraulic Model Investigation." U. S. Army Engineer Waterways Experiment Station Technical Report No. 2-556, August 1960. (Available on loan.)

(2685) MODEL STUDY OF WAVE ACTION, SUPERIOR ENTRY, DULUTH-SUPERIOR HARBOR, LAKE SUPERIOR.

(b) District Engineer, U. S. Army Engineer Dist., St. Paul, Corps of Engineers, St. Paul, Minnesota.

(a) Experimental; for design. 
(e) A 1:150 fixed-bed model was used that reproduced all the navigation approach channel and he breakwater structures as well as the er harbor dock area serving Superior, Wisconsin, and included adjacent lake and shore-line areas to permit reproduction of storm waves from all critical directions. Investigations were made: to determine the reasons for the wind-wave problems that exist and cause ship damage in the vicinity of Superior Entry; and to develop the most effective remedy possible so that navigation and docking hazards now prevailing will be adequately remedied.

(f) Tests completed; final report in preparation.

\section{(2925) ULTRASONIC FLOW MEASUREMENT.}

(b) Office of the Chief of Engineers, Dept. of the Army, Washington, D. C.

(d) Experimental; development.

(e) Various types of ultrasonic equipment have been investigated in a 24-inch by 14-inch conduit, with full and partial flow, to determine the relative accuracy of each type. Tests to date have been concerned with the adjustment and modification of test equipment.

(f) Inactive. It is anticipated that a.lI further work will be accomplished on specific full-scale structures.

(2931) MODEL STUDY OF SOUTHWEST PASS, MISSISSIPPI RIVER.

(b) District Engineer, U. S. Army Engineer District, New Orleans, Corps of Engineers, New Orleans, Louisiana.

(d) Experimental; for design.

(e) To determine the effectiveness of proposed improvement works (jetty extensions, chainnel realignments, and contraction works) in eliminating or reducing the periodic maintenance now required in order for deepdraft vessels to navigate the jetty and bar channels of Southwest Pass, the lower 12 miles of the Pass and the adjacent area of the Gulf of Mexico were reproduced in a fixed-bed model to scale ratios of $1: 500$ horizontally and 1:100 vertically. Tides, tidal currents, littoral currents, and wave action in the Gulf of Mexico, and salt- and fresh-water flows in Southwest Pass and the bar channel were reproduced in the model. Shoaling studies were made by introducing various mixtures of plastic materials into the model to simulate prototype shoaling materials and thus reproduced in the model the patterns and distribution of shoaling that occur in the prototype.

(f) Preparation of final report in progress.

(2932) MODEL STUDY OF HUDSON RIVER, NEW YORK.

(b) District Engineer, U. S. Anmy Engineer District, New York, Corps of Engineers, New York, New York.

(d) Experimental; for design.

(e) A fixed-bed model constructed to linear scales of $1: 100$ vertically and $1: 1,000$ horizontally, is being used to determine the source of material shoaling the Hudson River in the vicinity of Edgewater and Weehawken piers and the most effective means of reducing or eliminating this shoaling. The model reproduces Upper and Lower New York Bays, Raritan Bay, Hudson River to Hyde Park, East River to Throgs Neck, and tributaries flowing into the modeled bodies of water. Provisions are made to reproduce tides, fresh-water discharge, salinity intrusion, and shoaling.

(2941) MODEL STUDIES OF KEYSTONE DAM, ARKANSAS RIVER, OKLAHOMA.

(b) District Engineer, U. S. Army Engineer District, Tulsa, Corps of Engineers, Tulsa Oklahoma.

(d) Experimental; for design.

(e) Several models were used to: determine the adequacy of height, length, and alignment of the spillway abutments and stilling basin training walls; study stilling basin performance with a view to placing the apron at as high an elevation as feasible; develop a satisfactory conduit outlet portal and determine a suitable arrangement of the nine conduits; and check over all hydraulic performance of the structures. A 1:100 general model, a $1: 36$ section model of two full and two half spillway bays including three conduits and the adjoining stilling basin and exit area, and a 1:20 model of one conduit were used in the study.

(f) Completed.

(g) Major changes were made at the right abutment to improve flow conditions in the first few bays of the spillway. Stilling basin elements were refined in section model tests to allow the basin apron to be placed at the highest possible elevation while retaining the jump in the basin at maximum discharge. Tests of the downwardcurving conduit with flaring outlet revealed that the issuing jet would spread in the stilling basin and that no dangerous negative pressures would occur in the conduit outlet.

(h) "Spillway, Stilling Basin, and FloodControl Conduits, Keystone Dam, Arkansas River; Hydraulic Model Investigation." U. S. Army Engineer Waterways Experiment Station Technical Report No. 2-555, August 1960. (Available on loan).

(3232) MODEL STUDY OF FILLING AND EMPTYING SYSTEM, OLD RIVER LOCK, LOUISIANA.

(b) President, Mississippi River Commission, Corps of Engineers, Vicksburg, Mississippi.

(d) Experimental; for design.

(e) Old River lock will be 1,250 by 75 feet with a minimum depth of 13 feet over the sills. Under normal operating conditions, lifts are not expected to exceed 15 feet but provisions were made for a lift of 32 feet which could occur with the low-sill control structure inoperative. Manifold intakes in t.e approach walls lead to longitudinal 
wall culverts which discharge into the lock chamber through side ports at the bottom of the chamber. The discharge manifold consists of two floor laterals with side ports from each of the two longitudinal wall culverts. Reverse tainter valves are used for flow regulation. A 1:25 model was used to determine: (a) adequacy of intake and discharge manifold designs; (b) maximum permissible lock-filling and emptying rates; (c) best location and spacing of side-wall ports; (d) best location of the bulkhead slot below the culvert valves.

(f) Completed.

(g) In the model tests, the original design intake manifold performed satisfactorily; a revised design was developed for the discharge manifold which also was satisfactory. Tests resulted in adoption of 38 ports (19 in each wall) divided into upstream and downstream groups. Best location for the bulkhead slots was 75 feet downstream from the culvert valves. Single-speed valve schedules were developed which maintained hawser stresses on 4 - and 8-barge tows in the lock chamber at about the 5-ton limit for normal and probable maximum stage conditions and a full range of heads. Filling and emptying times under the maximum head of 32 feet were 11.0 and 10.7 minutes, respectively. Flow conditions in the upstream and downstream approaches during both filling and emptying operations were satisfactory.

(h) "Filling and Emptying System, Old River Navigation Lock, Louisiana; Hydraulic Model Investigation." U. S. Army Engineer Waterways Experiment Station Technical Report No. 2-549, June 1960. (Available on loan.)

\section{(3233) MODEI STUDY OF SPILLWAY BULKHEADS, GREENUP} DAM, OHIO RIVER.

(b) District Engineers, U. S. Army Engineer Districts, Huntington and Louisville, Corps of Engineers, Huntington, West Virginia, and Louisville, Kentucky.

(d) Experimental; for design.

(e) A 1:25 model of a solid, girder-type bulkhead with upstream and downstream skin plate and lifting beam was used to determine the vertical forces acting on the bulkhead and lifting beam as they are lowered in flowing water.

(f) Final report in preparation.

(g) Tests of the spillway bulkheads revealed satisfactory performance when latched together in two and three bulkhead units. Maximum downpull did not exceed 25 kips with the units vented and 85 kips when not vented. However, the bulkheads when placed as single units were unstable and tended to oscillate (vertical movement). When oscillation occurred, forces on the unit varied from an uplift of $40 \mathrm{kips}$ to a downpull of 640 kips.

\section{(3235) MODEL STUDY OF PIKE ISLAND LOCKS AND DAM, OHIO RIVER.}

(b) District Engineer, U. S. Army Engineer
District, Pittsburgh, Corps of Engineers, Pittsburgh, Pennsylvania.

(d) Experimental; for design.

(e) A l:120, fixed-bed type, comprehensive model reproducing about 4 miles of the Ohio River and the locks and dam structures, was used to select the most favorable site location by studying approach conditions under various river flows, and to develop modifications required to overcome any undesirable conditions at selected site.

(f) Tests completed; preparation of report in progress.

(3236) MODEL STUDY OF MAXWELL LOCKS AND DAM, MONONGAHELA RIVER, PENNSYLVANIA.

(b) District Engineer, U. S. Army Engineer District, Pittsburgh, Corps of Engineers, Pittsburgh, Pennsylvania.

(d) Experimental; for design.

(e) A I:l20 fixed-bed type, comprehensive model, reproducing about 2.5 miles of the Monongahela River and the locks and dam structures, is being used to study approach conditions under various river flows and methods of operation of control gates; to determine effects of design modification; to develop modifications required to overcome any undesirable conditions; to demonstrate to navigation interests the acceptability of the proposed design from a navigation standpoint.

(f) Suspended.

(3237) MODEL STUDY OF OUTIET WORKS, BLACK BUTTE DAM, STONY CREEK, CALIFORNIA.

(b) District Engineer, U. S. Army Engineer Dist. Sacramento, Corps of Engineers, Sacramento, California.

(a) Experimental; for design.

(e) The single-tunnel outlet works of Black Butte Dam will be required to pass floodcontrol discharges up to a maximum of 22,800 cubic feet per second, and to permit diversion of a maximum of 530 cubic feet per second for irrigation at total flows up to 8,000 cubic feet per second. A 1:16 model, which reproduced 160 feet of the 23-foot-diameter tunnel, the energy dissipator, irrigation diversion outlets, and 560 feet of the exit channel, was used to develop an adequate energy dissipator incorporating the most economical dimensions and to study the effects of various schemes for irrigation diversion on the performance of the energy dissipator as well as to determine the adequacy of these schemes for flow diversion.

(f) Completed.

(g) The design recommended on the basis of the model tests consisted of a combination energy dissipator-irrigation diversion structure. The energy dissipator, with sloping face, performed as a hydraulic jump stilling basin for discharges as high as 8,000 cubic feet per second. At these discharges, tailwater in the stilling basin provided sufficient head for diversion of irrigation releases through four 4.5-foot 
wide by 3.6-foot-high openings in one wall of the stilling basin, with bottom elevation of openings 4 feet above basin floor. At higher discharges the structure performed as a flip bucket and flow passed below the irrigation diversion outlets.

(h) "Outlet Works, Black Butte Dam, Stony Creek, California; Hydraulic Model Investigation." U. S. Army Engineer Waterways Experiment Station Technical Report No. 2-551, July 1960. (Available on loan.)

3238) MODEL STUDY OF EUFAULA DAM, CANADIAN RIVER, OKLAHOMA.

(b) District Engineer, U. S. Army Engineer District, Tulsa, Corps of Engineers, Tulsa, Oklahoma.

(a) Experimental; for design.

(e) A 1:36 section model, reproducing one full bay and two flanking half bays of the 520foot-long, gated spillway, the horizontal stilling basin, and approach and exit channels, was used to determine the adequacy of design of the stilling basin elements, and to investigate pressure conditions on the spillway crest.

(f) Preparation of final report in progress.

3239) MODEL STUDY OF SPILLWAY CREST GATE, STILIING BASIN, AND BULKHEAD, NEW CUMBERLAND LOCKS AND DAM, OHIO RIVER, PENNSYLVANIA.

(b) District Engineer, U. S. Army Engineer District, Pittsburgh, Corps of Engineers, Pittsburgh, Pennsylvania.

(d) Experimental; for design.

(e) A 1:25 section model reproducing 400 feet of the approach area, a portion of the gated spillway crest and stilling basin, and 800 feet of the exit area was used to examine the hydraulic performance of the spillway weir and stilling basin. A second phase of this study involved measurements of hydraulic forces acting on a submergible type spillway tainter gate. A 1:25 model of a trusstype bulkhead with an upstream skin plate and lifting beam was used to determine the vertical forces acting on the bulkhead and lifting beam as they are lowered in flowing water. A l:25 section model reproducing a 25-foot-wide section of the spillway and stilling basin was installed in a glass-sided flume which permitted observation of subsurface basin action.

(f) Final report in preparation.

(g) Supplementary stilling basin tests indicated that the unsatisfactory basin action previously observed in the model could be eliminated if the ratio of head on the spillway to drop from crest to stilling basin was 3.0 or greater. Tests olso indicated that the location of basin elements had no effect on basin action if the ratio of height of baffle to its distance downstream from the spillway toe was 0.15 or less. Tests of the submergible gate revealed satisfactory performance for all conditions investigated. Maximum water load on the gate was 35 kips per hoist and the gate was stable throughout its range of travel. The emergency bulkheads were also satisfactory and the maximum downpull did not exceed 125 kips per hoist.

(3240) MODEL STUDY OF CANACADEA CREEK, HORNELL, NEW YORK.

(b) Department of Public Works, State of New York.

(d) Experimental; for design.

(e) A highway bridge is proposed for construction across Canacadea Creek just upstream from the existing Seneca Street Bridge. In order to pass flood flows under the new briage, the existing Seneca Street Weir, located just upstream from the existing bridge, should be removed and a similar structure constructed just upstream from the proposed bridge. A 1:30 model, which reproduced the pertinent reach of Canacadea Creek, was used to verify freeboard on the channel walls upstream of the proposed weir, and freeboard at the new bridge, at the seneca Street bridge, and at Church Street bridge downstream of the proposed weir.

(f) Completed.

(g) A weir with a crest that slopes laterally from elevation 1159.0 at each side wall to a 20-foot-wide low-flow section at elevation 1156.3 in the center of the channel proved the most feasible of several investigated. At the design discharge this weir resulted in an average water-surface elevation upstream of the weir about 1.0 foot lower than that obtained with the existing weir. The average water surface at the Seneca Street bridge was 0.7 foot higher than that observed with the existing weir, but standing waves were not as pronounced and the peak water-surface elevation was 0.3 foot lower. Ample freeboard obtained at the site of the proposed bridge and at the Church Street bridge.

(h) "Channel Improvements, Canacadea Creek, Hornell, New York; Hydraulic Model Investigation." U. S. Army Engineer Waterways Experiment Station Miscellaneous Paper No. 2-413, December 1960. (Available on loan.)

(3241) STUDY OF SEICHE ACTION, DULUTH-SUPERIOR HARBOR, LAKE SUPERIOR.

(b) District Engineer, U. S. Army Engineer District, St. Paul, Corps of Engineers, St. Paul, Minnesota.

(d) Analytical; for design.

(e) Water-stage records obtained from gages in Duluth-Superior Harbor were analyzed to determine whether seiches are the cause of troublesome and damaging ship movements at loading docks in the harbor, and to provide information needed to design a hydraulic model, if the use of a model study is indicated.

(g) Analysis of prototype stage records showed that troublesome current conditions in the harbor are due to Lake Superior seiches, not Duluth-Superior Harbor seiches. A hydraulic model study of the problem is not believed necessary.

(h) Analysis completed; final report in preparation. 
(3242) MODEL STUDY OF CONNEAUT HARBOR, LAKE ERIE, OHIO.

(b) District Engineer, U. S. Army Engineer Dist., Buffalo, Corps of Engineers, Buffalo, New York.

(d) Experimental; for design.

(e) A 1:125 fixed-bed model was used to determine the influence of seiche currents and short-period wind-wave action in causing damage to ships navigating or berthed in Conneaut Harbor (located on the south shore of Lake Erie about 30 miles southwest of Erie, Pa.). The model reproduced about 7.3 square miles including all the area within the harbor and sufficient adjacent lake area to permit reproduction of storm waves from all critical directions. A circulating system installed in the model permitted simulation of currents through and past the harbor caused by seiches on the lake.

(f) Tests completed; final report in preparation.

(3243) MODEL STUDY OF LOCKS AND DAM NO. 4, MONONGAHELA RIVER.

(b) District Engineer, U. S. Army Engineer District, Pittsburgh, Corps of Engineers, Pittsburgh, Pennsylvania.

(d) Experimental; for design.

(e) A l:120 fixed-bed, comprehensive model, reproducing about 2.5 miles of the Monongahela River and the locks and dam structures will be used to determine the effects of modifications to the existing locks and dam on navigation conditions, and to develop modifications required to overcome any undesirable conditions.

(f) Suspended.

(3244) MODEL STUDIES OF COLUMBIA LOCK AND DAM, CHATTAHOOCHEE RIVER.

(b) District Engineer, U. S. Army Engineer Dist., Mobile, Corps of Engrs., Mobile, Ala.

(d) Experimental; for design.

(e) A 1:100 fixed-bed type, comprehensive model, reproducing about 1.5 miles of the Chattahoochee River and the lock and dam structures was used to study navigation conditions within the lock approaches and the head on lower lock gate during lockemptying operations, and to develop modifications required to overcome any undesirable conditions found. Two section models were also used in the investigation to develop final spillway profiles and stilling basin dimensions: a 1:36 model of the fixed-crest spillway reproducing 250 feet of the approach area, a 36-foot wide portion of the spillway and stilling basin, and 300 feet of the exit area; and a 1:27.2 model of the gated spillway, 400 feet of the approach area, a portion of the spillway crest and stilling basin (one full gate bay and two half piers), and 400 feet of the exit area.

(f) Final reports in preparation.

(g) Tests of the spillway section models indicated that while the spillways performed satisfactorily, the stilling basins provided little or no energy dissipation. In the case of the gated spillway, flow passed over the spillway along the surface of the tailwater or dived over the stilling basin into the exit channel. With the fixed-crest spillway, flow normally does not begin until the tailwater over the basin is fairly deep. In such cases there was no measurable velocity at the spillway toe. Based on these observations, both basins were eliminated from prototype construction. Pressures on the gated spillway were positive for all conditions and instantaneous pressure fluctuations were negligible. Tests on the comprehensive model indicated that because of the location of the lock and dam with respect to the alignment of the channels, arrents moving from along the left bank toward the dam would cross the upper approach to the lock, tending to make navigation conditions for downbound tows difficult. Conditions could be improved by modification of the excavation along the left bank, upstream extension of the guard wall or wing wall at the upper end of the guard wall, and installation of ports in the upper guard wall.

(3579) MODEL STUDY OF PIER SLIP SHOALING, NEW YORK HARBOR.

(b) District Engineer, U. S. Army Engineer District, New York, Corps of Engineers, New York, New York.

(d) Experimental; for design.

(e) The study will be conducted in a section model reproducing that portion of the Hudson River between pier 21 (Duane Street) and West 158th Street, Manhattan, constructed to scales of $1: 100$ vertically and $1: 300$ horizontally, in which the tides, tidal currents, and shoaling of navigation slips will be reproduced. The purpose of the studies is to determine the causes of shoaling in the pier slips in New York Harbor and to develop plans for alleviating this shoaling. Adjustment and verification of the model are in progress.

(3580) MODEL STUDY OF IVIAGARA REMEDIAL WORKS.

(b) District Engineer, U. S. Army Engineer Dist., Buffalo, Corps of Engineers, Buffalo, N. Y.

(d) Experimental; for design.

(e) The hydraulic investigation of the Niagara remedial works was conducted on an existing model, scales of $1: 360$ horizontally and $1: 60$ vertically, used previously to study the preservation and enhancement of the senic spectacle of Niagara Falls. The purpose of this study was to determine the adequacy of the existing control dam at the head of the Cascades to maintain desired watersurface elevations in Chippawa-Grass Island pool under various conditions of diversions for power.

(f) Completed.

(g) Tests showed that either additional sluices will have to be added to the existing 1550foot-long dam or power diversions will have 
to be limited to something less than the maximum permitted by treaty if the desired pool levels are to be maintained. Replacing the present Conners Island power intake on the United States side with a new intake will not affect the number of control dam sluices that will have to be closed to maintain proper pool levels, nor reduce flow in the vicinity of the Three Sisters Islands below that required to preserve the scenic spectacle.

(h) "Restudy of Niagara Remedial Control Dam," Appendix B, to "Preservation and enhancement of Niagara Falls; Hydraulic Model Investigation." U. S. Army Engineer Waterways Experiment Station Technical Memo. 2-411, Appendix B, Sept. 1960. (Available on loan.)

(3581) MODEL STUDY OF LAKE PONTCHARTRAIN, IOUISIANA.

(b) District Engineer, U. S. Army Engineer District, New Orleans, Corps of Engineers, New Orleans, Louisiana.

(d) Experimental; for design.

(e) The investigation is being conducted in a fixed-bed model that reproduces to scales of $1: 2,000$ horizontally and 1:100 vertically, Mississippi Sound west of Grand Island, and Lakes Borgne, Pontchartrain, and Maurepas, together with significant tributaries. The model reproduces the tides, tidal currents, salinities, and freshwater discharges of the prototype. The purpose of the study is to determine the effect of proposed hurricane structures across the connections between Lake Borgne and Lake Pontchartrain upon the hydraulic and salinity regimens of the area landward from the structures.

\section{(3582) ARKANSAS RIVER CHANNEL MODEL.}

(b) District Engineer, U. S. Army Fngineer District, Little Rock, Corps of Engineers, Little Rock, Arkansas.

(d) Experimental; for design.

(e) The Arkansas River project has as one of its major aims the development of river navigation from the Mississippi River to the general area of Tulsa, Oklahoma. The Arkansas River channel model was of the movable-bed type with a horizontal scale of $1: 150$ and a vertical scale of $1: 36$, and reproduced the Arkansas River between miles 140.0 and 151.2. The model study constituted an idealized experimental approach to the solution of sedimentation problems involved in the canalization of the Arkansas River and was designed to investigate problems typical of and to provide results generally applicable to the various reaches of the over-all length of the river to be developed for navigation.

(f) Tests completed; preparation of final report in progress.

(g) Tests indicated that: installation of a large dredge cut without a reduction in sediment load or addition of regulatory works would produce only a temporary effect on channel conditions; use of regulating structures to ease the alignment of the channel within bends would tend to provide a more uniform channel cross section and improve the alignment of the channel over crossings; placing contraction works on convex sand bars would tend to improve the alignment, depth, and shape of the channel opposite the sand bar and eliminate the tendancy for the development of a point bar; minimum channel wiaths required would depend upon the location of the reach with respect to the pool, depths required, sediment load, method of operating the dam, and flow conditions; and depths over crossings could be increased by means of low spur or longitudinal grains in the crossings.

\section{(3583) MODEL STUDIES OF CARLYLE DAM, KASKASKIA} RIVER, ILIINOIS.

(b). District Engineer, U. S. Army Engineer District, St. Louis, Corps of Engineers, St. Louis, Missouri.

(d) Experimental; for design.

(e) A 1:36 comprehensive model was used to verify the spillway and stilling basin performance to determine the best alignment for the approach channel and training walls, the best schedule of gate operation, optimum stilling basin design, and an acceptable downstream training wall design; and to furnish pressure profiles for stability analysis. The model reproduced the structure (less sluices), approrimately 1,650 feet of approach channel, and 950 feet of exit channel.

(f) Tests completed; preparation of final report in progress.

(g) Use of wing dikes in the approach area off each abutment were required to reduce abutment losses and obtain the desired capacity. A stilling basin design of the hydraulic-jump type was developed. Guidance was furnished design personnel on trainingwall heights and shapes, as well as expected pressures and flow lines.

(3584) MODEL STUDIES OF RED ROCK DAM, DES MOINES RIVER, IOWA.

(b) District Engineer, U. S. Army Engineer District, Rock Island, Corps of Engineers, Rock Island, Illinois.

(d) Experimental; for design.

(e) A 1:50 model, reproducing 900 feet of the approach channel above the spillway, an 825-foot-wide section along the dam, the spillway, conduits, stilling basin, and 575 feet of the outlet channel is being used to verify stilling basin and training wall design. The model reproduces the entire spillway and stilling basin, sufficient approach area to assure natural flow conditions over the spillway and at the abutments, and sufficient exit area to permit formation of the natural flow pattern in the exit channel. A 1:16 model of the intersection of the spillway fac, and conduit outlet portal will be used to 
determine armor plate requirements at the outlet portal.

(g) The spillway design discharge was passed at a head of 57 feet with square abutments. Rounding the abutments (radius 7.8 feet) lowered the head to 55 feet at the spillway design discharge, 331,500 cubic feet per second. Bottom-velocity measurements in the upper approach indicated that the embankment near the abutments will be exposed to bottom velocities of about 9 feet per second, thus indicating the need for riprap protection. Stilling basin tests verified baffle pier size, location, and apron elevation.

(3585) MODEL STUDY OF NEW POE LOCK, ST. MARYS RIVER.

(b) District Engineer, U. S. Army Engineer District, Buffalo, Corps of Engineers, Buffalo, New York.

(d) Experimental; for design

(e) A 1:25 pre liminary culvert and single lateral model was used to test flow distribution within the lateral under various operating conditions. The major investigations were conducted in a $1: 25$ comprehensive model reproducing 600 feet of upstream approach, intake manifolds, l,000 feet of lock chamber, culverts, bottom lateral outlet manifolds, and 300 feet of downstream approach. This model included provision for changing the arrangement of bottom laterals, lock length, culvert height, and culvert valve operating schedules, and was used to confirm the suitability of the initial design hydraulic filling and emptying system or to develop improvements in the system. A $1: 12$ culvert valve model was used to study proposed valve design.

(f) Tests completed; preparation of final report in progress.

(g) Tests in the preliminary model established the best lateral design. Tests in the general model established the best lateral arrangement and valve schedules for filling and emptying the lock. Satisfactory flow distribution through the intakes was obtained in the general model. A satisfactory vertically framed culvert tainter valve design was developed in the valve model studies.

\section{(3586) MODEL STUDY OF HOPPER DRAGHEAD.}

(b) District Engineer, U. S. Army Engineer District, Philadelphia, Corps of Engineers, Philadelphia, Pennsylvania.

(d) Experimental; for design.

(e) To develop improved dragheads designed to attain a greater rate of intake of solids when dredging mud and silt mixtures (soft materials) and dredging densely packed, fine sand (hard material), an investigation is being conducted in an 80 by 10 -foot flume containing various types of bed material. The draghead and suction line, constructed to a scale of $1: 6$, are connected to a suction pump mounted on a double carriage that provides travel, both longitudinally and transversely, along the top of the flume.

(g) Preliminary tests have indicated that the model draghead would tend to be more efficient in sand than the prototype because of modifications in the design and operation under more ideal conditions. Tests have also indicated that a mixture of available materials could be used to simulate prototype mud for the draghead test.

(3587) MODEL STUDIES OF JOHN REDMOND DAM, GRAND RIVER, KANSAS.

(b) District Engineer, U. S. Army Engineer District, Tulsa, Corps of Engineers, Tulsa Oklahoma.

(d) Experimental; for design.

(e) A 1:100 model, reproducing 2,900 feet of the approach channel above the spillway, the spillway, stilling basin, and 2,450 feet of the outlet channel, and a $1: 36$ model, reproducing one full bay and two half bays of the spillway and the stilling basin, are being used to study flow conditions in the shallow, curved spillway approach channel; to verify capacity of the structure and adequacy of the stilling basin and exit channel; and to determine minimum requirements for training walls.

(f) Tests completed; final report in preparation.

(g) The spillway design discharge, 577,000 cubic feet per second, was passed at a head of 44 feet, 2.5 feet higher than the computed value. The upper pool elevation was lowered 0.5 foot at the design discharge by rounding the abutments. A rock dike in the right embankment reduced the upper pool another 0.5 foot by reducing the lateral flow at the right abutment. Lowering the depth of approach to half the design head for a distance of 200 feet upstream of the weir crest further improved weir capacity. A rock dike downstream of the left embankment reduced velocities in the eddy impinging against the embankment. Reshaping the weir by continuing the curve to a point 15 feet beneath the crestline reduced back pressure and increased capacity A pier overhang was effective in reducing the water surface profile alongside the piers. A stilling basin of minimum size and necessitating minimum excavation was developed.

(3588) MODEL STUDY OF SPILLWAY, BIG BEND RESERVOIR, MISSOURI RIVER, SOUTH DAKOTA.

(b) District Engineer, U. S. Army Engineer District, Omaha, Corps of Engineers, Omaha, Nebraska.

(d) Experimental; for design.

(e) A 1:60 model, reproducing 2,400 feet of the approach channel, the spillway and stilling basin, and 1,000 feet of the exit channel, was used to determine: velocity and flow characteristics in the approach channel; (2) spillway discharge rating data with emphasis on the effects 
of weir submergence; and (3) stilling basin behavior and exit channel velocity and scour data.

(f) Tests completed; final report in preparation.

(s) Over-all performance of the spillway of original design was marred by turbulence and unequal flow distribution in the spillway bays adjacent to the abutments. Modification to the abutments and realignment of the spur dike near the right abutment corrected these conditions and resulted in excellent hydraulic conditions over the spillway in the chute, and in the stilling basin. The model discharge coefficient (3.58) coincided with computed values. Basin tests revealed that a horizontal stilling basin 194 feet long with two rows of 12-foot-high baffle piers and a lo-foothigh stepped end sill performed the most satisfactorily.

(3589) MODEL STUDY OF SPILLWAY, PIKE ISLAND DAM, OHIO RIVER, WEST VIRGINIA, OHIO.

(b) District Engineer, U. S. Army Engineer District, Omaha, Corps of Engineers, Omaha, Nebraska.

(d) Experimental; for design.

(e) A l:25 section model reproducing 300 feet of the approach area, a portion of the spillway crest and stilling basin, and 600 feet of the exit area was used to examine the hydraulic performance of the spillway and stilling basin.

(f) Tests completed; final report in preparation.

(g) Tests of the original design stilling basin revealed that unsatisfactory basin action occurred at the larger gate openings (above a 6-foot opening). For satisfactory basin action, correct placement of the baffle piers in the basin below the spillway was essential. The most satisfactory basin consisted of a horizontal apron 67 feet long with a single row of 6-foot-high baffle piers located 42 feet below the spillway toe, and a 3-foot-high stepped end sill. Velocities in the exit did not exceed 6 feet per second for normal tailwater conditions.

(3590) MODEL STUDY OF WAVE ACTION, EAST PASSAGE, NARRAGANSETT BAY, RHODE ISLAND.

(b) Division Engineer, U. S. Army Engineer Division, New England, Corps of Engineers, Waltham, Massachusetts.

(a) Experimental; for design.

(e) A 1:150 model is being used to determine the effects of hurricane surge currents, waves, and winds on the operation of an aircraft carrier in East Passage. A barrier across East Passage has been proposed to limit the quantity of water entering Narragansett Bay from hurricane surge, and the model study will examine ship navigation conditions with respect to barrier location and its navigation opening.

(g) A self-propelled, radio-controlled, model aircraft carrier has been constructed dynamically similar to its prototype, and is being used in tests to determine the effects of the proposed barrier on navigation conditions.

MODEL STUDY OF EVERETT DAM, PISCATAQUOG RIVER, NEW HAMPSHIRE.

(b) Division Engineer, U. S. Army Engineer Division, New England, Corps of Engineers, Waltham, Massachusetts.

(d) Experimental; for design.

(e) The investigation was conducted in a 1:36 model that reproduced 350 feet of the approach channel above the spillway, entire spillway width plus 125 feet of the dam on each side, and 700 feet of the discharge channel. The spillway is to be an uncontrolled ogee weir with a crest length of 180 feet. To eliminate excessive rock excavation the weir bucket inverts will be stepped down, varying from elevation 412 to elevation 385. The four different toe elevations below the spillway and the various slopes in the upstream portion of the channel made prediction of flow conditions in the discharge channel uncertain. It was thought that the crossflow from the high toward the low (right) side of the channel might cause serious piling up of flow and overtopping of the right wall. The model was used to determine spillway flow characteristics and the distribution of flow in the discharge channel.

(f) Completed.

(g) Very close agreement between model and computed spillway rating curves was obtained. A small disturbance occurred in the lowest bucket caused by turbulence generated at the abutment wall upstream of the weir crest. Flow conditions in the discharge channel were generally satisfactory in that no significant waves formed and lateral flow from the high to the low buckets was negligible. For all flows tested the water surface was confined to the rock cut and no overtopping occurred.

(h) "Everett Dam Spillway and Discharge Channel, Piscataquog River, New Hampshire; Hydraulic Model Investigation." U. S. Army Engineer Waterways Experiment Station Miscellaneous Paper No. 2-403, July 1960. (Available on loan).

(3592) MODEL STUDY OF TYPICAL NAVIGATION DAM, ARKANSAS RIVER.

(b) District Engineer, U. S. Army Engineer District, Little Rock, Corps of Engineers, Little Rock, Arkansas.

(d) Experimental; for design.

(e) The Arkansas River multipurpose project includes the development of river navigation from the Mississippi River to the general area of Tulsa. Present plans for navigation include construction of several navigation locks and dams. The purpose of the model study are to investigate various problems that occur in the vicinity of the structures. The investigation is being conducted initially on a movable-bed model constmucted to linear scales of $1: 120$ horizontally and 1:40 vertically, reproducing a 15-mile reach of a typical stream 
having characteristics generally similar to reaches of the Arkansas River, including a typical Arkansas River lock and dam structure. Provisions have been made for modifications to reproduce other selected reaches of similar length but different curvatures. The model of each reach studied on the movable-bed model will be converted to a fixed-bed, 1:120 model to study navigation conditions in the approaches to the locks.

(f) Tests suspended; preparation of report in progress.

(g) Tests indicated that: navigation conditions in the upper approach would be affected by high-velocity currents and crosscurrents near the end of the upper guard wall of the lock at the location tested; conditions in the upper approach could be improved by extending the contraction works in the upstream bend to reduce flow across the bar and by moving the lock and dam structure farther downstream; shoaling would occur in the lower approach channel which could be reduced by means of low wing dikes extending from the end of the lower guard wall; the sand bar in the bend upstream would extend toward the dam and tend to reduce flow through the bays near the abutment on the bar side of the channel; deposition would occur over the dam gate sill and in the stilling basin, but the shoaling should not affect the operation of the gates or the stilling basin.

(3593) MODEL STUDY OF SPILLWAY, MAXWELL DAM, MONONGAHELA RIVER, PENNSYLVANIA.

(b) District Engineer, U. S. Army Engineer District, Pittsburgh, Corps of Engineers, Pittsburgh, Pennsylvania.

(d) Experimental; for design.

(e) A 1:25 section model reproducing 200 feet of the approach channel, a portion of the spillway crest and stilling basin, and 300 feet of the exit area was used to examine the hydraulic performance of the spillway weir and stilling basin. A second phase of the study consisted of determining the most efficient and economical stilling basin below Opekiska Dam, a structure similar to Maxwell.

(f) Final report in preparation.

(3594) MODEL STUDY OF RIPRAP REQUIREMENTS FOR R. R. RELOCATION FILIS, ICE HARBOR DAM AND JOHN DAY DAM PROJECTS, WASHINGTON AND OREGON

(b) District Engineer, U. S. Army Engineer District, Walla Walla, Corps of Engineers, Walla Walla, Washington.

(a) Experimental; for design

(e) Tests are being conducted in a 5-foot-wide, 4-foot-deep, and 119-foot-long wave flume, using a linear scale of $1: 12$, model to prototype, to determine the stability of graded riprap, gravel, and rock fill as cover-layer materials for protection of railroad relocation fills. The stability of the different types of cover-layer materials is being determined as a function of depth below still-water level, slope of fill, depth of water, and wave period.

(8) The results of stability tests on three different gradations of riprap material are represented with very good accuracy by the formula

$$
W_{50}=\frac{\gamma_{r} H^{3}}{K_{\Delta}\left(S_{r}-1\right)^{3} \cot \alpha}
$$

Where $W_{50}$ is weight of riprap (50 percent finer than), $\gamma_{\mathrm{r}}$ is the specific weight of riprap material, $H$ is height of selected design wave, $S_{r}$ is the specific gravity of riprap relative to the fluid in which the structure is located $\left(\gamma_{\mathrm{r}} / \gamma_{\mathrm{W}}\right), \alpha$ is the angle of the fill slope, and $K_{\Delta}$ is a dimensionless coefficient.

(3596) HYDRAULIC STUDIES FOR IMPACT ENERGY DISSIPATOR DESIGN.

(b) Office of the Chief of Engineers, Dept., of the Army, Washington, D. C.

(d) Experimental; applied research.

(e) A general investigation to determine the energy loss coefficient of an impact energy dissipator of variable height and depth for varying slopes, diameters, and energy of flows of the upstream conduit will be conducted on a 1.0-foot-diameter impact energy dissipator. The energy of the influx will be determined from measurements of the discharge and the hydraulic gardient. The energy of the efflux will be determined from measurements of the discharge from each of four quadrants. The slope and size of the incoming pipe will be varied to determine the effect of each upon the energy dissipated. For a particular slope and diameter of the incoming pipe and a particular height and depth of the dissipator, the relative energy content of the efflux to the influx will be determined for as great a range of Reynolds numbers as possible to ascertain the effect of Reynolds number upon the energy loss in the dissipator.

(g) Tests conducted thus far indicate that for a particular slope of the incoming pipe there is an optimum depth of the stilling well below the invert of the incoming pipe at which a nearly uniform distribution of the efflux may be obtained. In general, the loss coefficient of the stilling well decreases with increasing Reynolds number. Also, for the same Reynolds number based on the hydraulic radius, the loss coefficient for full pipe inflow is less than that for partial inflow.

\section{(3597) CORRUGATED PIPE ROUGHNESS STUDY}

(b) Office of the Chief of Engineers, Dept. of the Army, and Bureau of Public Roads, Dept. of Commerce, Washington, D. C.

(d) Experimental; applied research.

(e) This is a general investigation to determine a resistance coefficient and the law of velocity distribution for flow in structuralplate corrugated pipe. A fiber-glass test section reproducing a 5-foot diameter 
standard corrugated pipe at a scale of $1: 4$ was tested in order to obtain additional data on the resistance coefficient and velocity distribution and to correlate model work with full-scale tests. Fiber-glass test sections reproducing a 5-foot-, 10-foot-, and 20-foot-diameter structural-plate pipe at scales of $1: 2.2,1: 8$, and $1: 16$, respectively, will be tested to determine the effect of relative roughness upon the resistance coefficient and velocity distribution. The hydraulic gradient and the energy loss through 20- to 80-dianeter lengths of test section will be established by piezometers located at 5-foot intervals. These piezometers will be $1 / 8$ inch in diameter, on center of the crests of the corrugations, and four in number around the periphery of the pipe. Velocity traverses will be made by means of calibrated pitot tubes at several locations along the test section for determination of the velccity distribution.

(g) Tests conducted on the model reproducing standard corrugations at a scale of $1: 4$ have been completed and the results of tests for a range of Reynolds numbers from $4 \times 10^{4}$ to $2 \times 10^{6}$ agree favorably with results of full-scale studies made at Bonneville Hydraulic Laboratory. Results of tests on the models simulating 5-foot-, 10-foot-, and 20-foot-diameter structuralplate pipes indicate maximum Manning's " $n$ " of $0.0310,0.0295$, and 0.0265 , respectively.

(3598) MODEL STUDIES OF CONTAMINATION DISPERSION IN ESTUARIES.

(b) Nuclear Projects Office, Maritime Administration, U. S. Department of Commierce.

(d) Experimental; applied research.

(e) The increasing use of nuclear reactors in the production of automotive power, both on land and sea, presents new problems pertaining to the dispersal of radioactive waste released either accidentally or purposely into rivers, estuaries, and harbors. The Maritime Administration is concerned with the probable dispersion patterns of radioactive matter that might be released in accidents involving nuclearpowered ships. A series of tests was made on several existing models of important estuaries, including the Delaware River, Narragansett Bay, New York Harbor, and Savannah Harbor, in order to obtain data from which dispersion effects could be computed. Tides, tidal currents, salinities and freshwater flow were reproduced for all tests. Methylene blue chloride dye was used to simulate contamination, and the dye releases were generally made at the most adverse time of tide in relation to the potential upstream spread of the contaminant. Water samples were obtained perlodically throughout the contaminated area for spectrophotometer analysis, and in addition, meters which automatically measured and recorded dye concentrations were in continuous operation at strategic locations. Results obtained are expressed as percentages of the initial concentration.

( $\mathrm{g})$ Tests in the New York Harbor and Savannah models have been completed, and the results of the New York Harbor tests are presented in report listed below. The report contains descriptions of test procedures and techniques, and tables and plates presenting the data obtained. Analyses of data will be made and conclusions drawn by Dr. D. W. Pritchard of Johns Hopkins University.

(h) "Contamination Dispersion in Estuaries; Report 3, New York Harbor; Hydraulic Model Investigation. "U. S. Army Engineer Waterways Experiment Station Miscellaneous Paper No. 2-332. (Available on loan.)

(3902) RADIOACTIVE TRACER TESTS OF SEDIMENT, GALVESTON BAY, TEXAS.

(b) District Engineer, U. S. Army Engineer District, Galveston, Corps of Engineers, Galveston, Texas.

(d) Experimental; field investigation.

(e) It is planned to study the movement of sediment in the vicinity of the Galveston Bay jetty by use of radioactive goldimpregnated glass. The glass is ground to the particle size of the natural sediment and will be deposited in the bay on one side of the jetty. It is expected that the tidal action, littoral current, and wind waves will move the material around the jetty into the shipping channel or through the jetty. The path of the activated gold-impregnated glass particles will be traced by instruments from a small boat.

(3903) MODEL STUDY OF WAVE ACTION, HILO HARBOR, HAWAII.

(b) District Engineer, U. S. Army Engineer District, Honolulu, Corps of Engineers, Honolulu, Hawaii.

(d) Experimental; for design.

(e) A l:125 model is proposed to determine the optimum breakwater plan to decrease wave and surge action in Hilo Harbor so that troublesome and damaging ship motion at piers 1, 2, and 3 will be alleviated. To date, prototype instruments to measure wave and surge action at piers 1 and 2 have been obtained with which measurements will be made for use in determining the cause of the problem and in design of the model.

(3904) MODEL STUDY OF DESIGN OF RUBBLE-MOUND BREAKWATER, MORRO BAY, CALIFORNIA.

(b) District Engineer, U. S. Army Engineer District, Los Angeles, Corps of Engineers, Los Angeles, California.

(d) Experimental; for design.

(e) Stability tests were conducted in a concrete wave flume 119 feet long, 5 feet wide, and 4 feet deep, in which a section model of the Morro Bay Harbor breakwater had been constructed to a linear scale of 1:53.7. The study was performed to obtain data from which alternate designs could be developed for repair of the breakwater. 
Design criteria for both the head and trunk of the structure were desired.

(f) Tests completed.

(g) It was found that a considerable portion of the breakwater trunk would be stable under attack of waves 24 feet high (designwave height) if the lower layer was composed of quarrystones weighing 10 to 20 tons placed on a slope of 1 on 2-1/2. Another reach of the structure could be constructed of quarrystones weighing 10 to 30 tons placed on a slope of 1 on $1-3 / 4$. Design of the breakwater head was difficult. However, it was determined that the head should be composed of concrete armor units of special shape, weighing 20 tons, with slopes varying from 1 on $1-1 / 2$ on the seaside to 1 on 3 on the harborside.

(h) "Designs for Rubble-Mound Breakwater Repair, Morro Bay Harbor, Morro Bay, Calif." Preliminary report, U. S. Army Engineer Waterways Experiment Station, Vicksburg, Miss., October 1960. (Available on loan.)

(3905) KELLEYS ISLAND HARBOR STUDY, LAKE ERIE, OHIO.

(b) Ohio State.

(d) Analytical; for design.

(e) An analytical study is being conducted to determine the characteristics of shortperiod wind waves which occur at the site of the proposed Kelleys Island harbor of refuge. Deep-water waves are charted into the position of the harbor entrance by use of refraction diagrams. The resulting data will be used to determine the optimum alinement of the navigation opening, and the need for, and approximate length of a protecting breakwater.

(3906) POWER PLANT TRANSIENTS TESTS, GARRISON AND OAHE DAMS, MISSOURI RIVER, NORTH DAKOTA.

(b) Division Engineer, U. S. Army Engineer Division, Missouri River, and District Engineer, U. S. Army Engineer District, Omaha, Corps of Engineers, Omaha, Nebraska.

(d) Field investigations; applied research and design.

(e) Hydraulic prototype measurements of power plant transients will be made to evaluate results of a comprehensive digital computer study made by the sponsoring offices, and to determine extent operation corresponds with design. General objective is to develop a solution of the entire problem of power plant transients, with primary emphasis on governing stability. For different plant loadings, instantaneous pressure values at a number of locations in the power tunnel, the surge tank system, turbine scroll case, and draft tube will be obtained simultaneously with instantaneous values of tunnel velocity, reservoir and tallwater elevations, turbine speed and gate opening, power output, and other elements (including governor system). Measurements will be recorded on about 90 channels of oscillograph and magnetic tape recorders. Instrumentation and other preparations are nearly complete for tests at Garrison Dam in the spring of 1961. Tests at Oahe Dam probably will be made in the spring of 1962.

(h) "Hydraulic Analysis of Surge Tanks by Digital Computer," by Nicholas Barbarossa (U. S. Army Engineer Division, Missouri River). ASCE Proceedings, Paper No. 1996, April 1959.

\section{(3907) SHOALING PROCESSES.}

(b) Office of the Chief of Engineers, Dept. of the Army, Washington, D. C.

(d) Experimental; applied research.

(e) The annual cost to the Federal Government of maintaining navigable channels in tidal waterways is estimated to be of the order of $\$ 60,000,000$. The corps of Engineers Committee on Tidal Hydraulics has concluded that a thorough study of shoaling processes in tidal waterways would lead to improvements in channel design, dredging, and spoiling practices, and other maintenance techniques which would reduce this large expenditure. The Committee concludes that the following program of research is essential in arriving at the objective of reducing maintenance cost: (a) flume studies to determine the basic laws involved in the movement and deposition of muddy sediments; (b) flume studies to determine effects of repetitive scour and deposition on sedimentation; (c) the development of techniques for using radioactive tracers for observing the movement and deposition of sediments in nature; (d) the development of a simple and accurate instrument for in-place measurement of turbidity; (e) a study of the physical, chemical, and hydraulic factors involved in the stabilization of deposits in navigable channels; ( $f$ ) determination of the effects of flocculation on shoaling; (g) prototype studies aimed at correlation of sedimentation phenomena in tidal waterways with physical, chemical, hydraulic, salinity, and other significant factors; and $(h)$ classification of the sediments which constitute all major repetitive shoals in tidal waterways. Item (a) is being conducted under contract by the University of California. A literature survey of items (e) and ( $f$ ) was conducted by the Waterways Experiment Station; results are reported in Technical Bulletin 4 cited below. Items $(g)$ and $(h)$ are in progress at the Waterways Experiment Station. Items (c) and (d) are being conducted by other than Federal agencies at no cost to the Federal Government. Item (b) is inactive.

(h) "Soil as a Factor in Shoaling Processes, a Literature Review, "Committee on Tidal Hydraulics Technical Bulletin No. 4. June 1960. (Available on loan.)

\section{(3908) ARKANSAS RIVER NAVIGATION MODEL.}

(b) District Engineer, U. S. Army Engineer District, Vicksburg, Corps of Engineers, Vicksburg, Mississippi. 
(a) Experimental; for design.

(e) A fixed-bed model reproducing to scale of 1:600 horizontally and 1:100 vertically about 33 miles of the Mississippi River near the mouths of the White and Arkansas Rivers, 57 miles of the lower Arkansas River, 12 miles of the lower White River, and the major portion of the White-Arkansas River backwater area is being used for the investigation. The model is to be used to demonstrate alternate routes for the entrance to the Arkansas River navigation project, flow patterns, nature of overbank flow, effect of Arkansas-White Cutoff, and problems related to the location and alignment of the navigation entrance to the Arkansas River from the Mississippi River.

(g) Data on stages for various combinations of flow from the three streams, velocity measurements at critical points, and current directions have been obtained under various test conditions for use of design engineers in determining most feasible plan from navigation and economical standpoint.

(3909) MODEL STUDY OF OPOSSUM CREEK LOCKS AND DAM, OHIO RIVER.

(b) District Engineer, U. S. Army Engineer District, Pittsburgh, Corps of Engineers, Pittsburgh, Pennsylvania.

(d) Experimental; for design.

(e) A 1:120, fixed-bed, comprehensive model reproducing about 4 miles of the Ohio River and the lock and dam structures was used to study navigation conditions in the approaches to the locks, determine suitability of the selected site, and develop modifications required to overcome any undesirable conditions found.

(f) Tests completed; final report in preparation.

(g) Tests indicated site to be generally satisfactory. Velocities in the upper approach sill tend to be high, but could be reduced by modification of excavation along the right bank above the lock.

(3910) MODEL STUDY OF LOWER ATCHAFALAYA RIVER BASIN, LOUISIANA.

(b) District Engineer, U. S. Army Engineer District, New Orleans, Corps of Engineers, New Orleans, Louisiana.

(d) Experimental; for design.

(e) The study was conducted on the Mississippi River flood-control model. The model is of the fixed-bed type with a horizontal scale of $1: 2,000$ and a vertical scale of 1:100. It reproduces the Mississippi River from Helena, Ark., to Donaldsonville, La., the Arkansas-White, Yazoo, and RedOuachita backwater areas, the old River Channel from Angola to Barbre Landing, La., the Atchafalaya River and Basin to the Gulf of Mexico, and the Morganza and West Atchafalaya Floodways. The purpose of the investigation was to determine the effects of dredging and side-channel closures on slopes and velocities within the main channel for the development of plans to increase the flood-carrying capacity of the Atchafalaya Basin.

(f) Completed.

(E) Results consisted of data on stages, velocity measurements within the basin, and directions of flow within the various channels and along the overbank for use of design engineers in establishing dredging and side-channel closure program and priorities.

(3911) MODEL STUDY OF MATAGORDA SHIP CHANNEL, TEXAS.

(b) District Engineer, U. S. Army Engineer District, Galveston, Corps of Engineers, Galveston, Texas.

(d) Experimental; for design.

(e) The fixed-bed model, constructed to scale ratios of $1: 1,000$ horizontally and $1: 100$ vertically, reproduces about 800 square miles of prototype area, including all of Matagorda Bay, part of the connecting bay system, and a portion of the Gulf of Mexico adjacent to Pass Cavallo. Tides and tidal currents are reproduced by one primary tide generator and one secondary tide generator, and fresh-water discharges of tributaries, together with the rainfall over the area, are introduced by means of wiers and flowmeters. Salt water is used in the model gulf to reproduce the prototype salinity regimen and provisions have been made for the injection of silt in the model for measurements of deposits on the bed of the model. Studies will be made to determine: (1) the best location for the entrance channel; (2) the best route for the channel from the entrance to Point Comfort; (3) such protective works as may be required in the interests of navigation and maintenance of the channel; and (4) the effects of the deep-draft navigation channel on the salinity regimen of the bay system.

\section{(3912) MODEL STUDY OF GALVESTON BAY, TEXAS.}

(b) District Engineer, U. S. Army Engineer District, Galveston, Corps of Engineers, Galveston, Texas.

(d) Experimental; for design.

(e) A movable-bed model, with scale ratios of 1:500 horizontally and 1:100 vertically will reproduce about 174.5 square miles of prototype area, including a small portion of Galveston Bay and a portion of the Gulf of Mexico extenaing 8 miles north of the north jetty, 6-1/2 miles south of the south jetty, and offshore to about the 50-foot contour of depth. Tides, tidal currents, littoral currents, and wave action in the Gulf of Mexico will be reproduced. Studies will be made to determine: (1) relocation and stabilization of the jetty channel on an alignment and depth suitable for navigation of supertankers; (2) protection of the north jetty from undermining action of tidal currents; (3) shoaling characteristics of the relocated and deepened jetty (inner bar) channel and plans for minimizing shoaling; and (4) shoaling characteristics of the deepened outer bar channel. 
(f) Model under construction.

(3913) MODEL STUDY OF GULF OUTLET CHANNEL, LA.

(b) District Engineer, U. S. Army Engineer District, New Orleans, Corps of Engineers, New Orleans, Louisiana.

(d) Experimental; for design.

(e) The investigation will be conducted in a fixed-bed extension of the Lake

Pontchartrain model and in conjunction with that model study. Reproduced is that area eastward of New Orleans to Breton Sound and south of Lakes Pontchartrain and Borgne to include the connecting waterways between those lakes and the Gulf outlet Channel, now under construction. Scales are $1: 2,000$ horizontal and 1:100 vertical. Tides, tidal currents, salinities, and water exchange through the connecting waterways will be simulated. Purpose of the study is to determine the effect of the channel on the salinity regimens of Lakes Pontchartrain and Borgne, which will be connected to the channel by existing waterways .

(3914) MODEL STUDY FOR MODERNIZATION OF EXISTING LOCK, MCALPINE LOCKS, OHIO RIVER.

(b) District Engineer, U. S. Army Engineer District, Louisville, Corps of Engineers, Louisville, Kentucky.

(d) Experimental; for design.

(e) A l:25 model which reproduces the filling and emptying system is being used to develop feasible modifications which will improve prototype performance.

(3915) MODEL STUDY OF DROP STRUCTURE, GERING VALIEYY PROJECT, GERING VALLEY, NEBRASKA.

(b) District Engineer, U. S. Army Engr. Dist., Omaha, Corps of Engineers, Omaha, Nebraska.

(a) Experimental; for design.

(e) A $1: 12$ model reproducing successively three typical drop structures, adjacent overbank areas and 300 feet of the approach and exit areas will be used to examine the hydraulic performance of the drop structures.

(3916) MODEL STUDY OF OAHE RESERVOIR SPILLWAY, MISSOURI RIVER, SOUTH DAKOTA.

(b) District Engineer, U. S. Army Engr. Dist., Omaha, Curps of Engineers, Omaha, Nebraska.

(d) Experimental; for design.

(e) A 1:50 model reproduces the remote, gated control structure which will serve as spillway for Oahe Dam, along with approximately 3,000 feet of approach and exit channel. The model study is intended to: (1) indicate head losses through structure and in channel, and provide data on flow patterns and velocities; (2) verify discharge data for gate bays; and (3) develop design of stilling basin, and of transition from stilling basin to sloped sides of exit channel.

(g) Results obtained from the model study thus far include water-surface profiles, flow patterns and velocities for different assumed values of Manning's " $n$ " (roughness coefficient) for the exit channel; discharge data; and certain modifications to the stilling basin and exit channel. Large standing wave formations evident in the exit channel of the original design have been reduced, as have bottom velocities caused by sudden releases from the maximum controlled storage pool into the exit channel. A recommended schedule for gate operation has been formulated.

(3917) GENERAI SPILIWAY MODEL TESTS.

(b) Office of the Chief of Engineers, Dept. of the Army, Washington, D. C.

(d) Experimental; for design.

(e) Tests are made on various elements of spillways to develop improved designs and to better define values of coefficients used in design formulas. A serias of tests is being conducted on low weirs to determine optimum shape from a consideration of discharge coefficients and pressures.

(g) From tests made to date, the desirability of a crest shape tangent to the upstream face of the weir has been established.

(3918) MODEL TESTS FOR TYPICAL C AND SF PROJECT STRUCTURE.

(b) District Engineer, U. S. Army Engineer Dis trict, Jacksonville, Corps of Engineers, Jacksonville, Florida.

(d) Experimental; for design.

(e) A 1:16 model, reproducing 384 feet of the approach channel, an 81.33-foot-wide 3-bay structure, the spillway, stilling basin, and 192 feet of the outlet channel, is being used to determine the discharge coefficient and flow conditions of similar project structures having various approach and exit channel elevations for both controlled and uncontrolled flows.

\section{(3919) MODEL STUDY OF ALIEGHENY DAM, ALLEGHENY} RIVER, PENNSYLVANIA.

(b) District Engineer, U. S. Army Engineer District, Pittsburgh, Corps of Engineers, Pittsburgh, Pennsylvania.

(d) Experimental; for design.

(e) A I:36 model reproduces a 375 foot-widesection of the approach, the entire spillway and portions of each abutment, the six low-lever sluices and two high-level sluices, the stilling basin, and a 425-foot-wide section of the exit channel. The model will provide a means for determining sluice design, spray wall heights, and stilling basin design. Welr calibration data and pressures and abutment coefficients will be determined.

U. S. DEPARTMENT OF COMMERCE, BUREAU OF PUBLIC ROADS.

(856) HYDROLOGY OF STORM DRAINAGE SYSTEMS IN URBAN AREAS.

Cooperative with Johns Hopkins University. See page 46. 
(1074) HYDRAULICS OF STILLING BASINS.

Cooperative with Colorado State University. See page 15.

(1591) DETERMINATION OF WATERWAY AREAS.

Cooperative with University of Illinois. See page 38 .

(2066) STUDY OF OPEN CHANNEL CONSTRICTIONS IN A SLOPING FLUME.

Cooperative with Colorado State University. See page 15.

(2435) HYDRAULICS OF PIPE CULVERTS.

Cooperative with the National Bureau of

Standards. See page 159.

(2839) HYDRAUIICS OF RIVER FLOW UNDER ARCH BRIDGES.

Cooperative with Purdue University. See page 72 .

(3041) MAGNITUDE AND FREQUENCY OF FLOODS FROM SMALI WATERSHEDS IN ARID AND SEMI-ARID AREAS.

Cooperative with Colorado State University. See page 19.

(3166) HYDRODYTAMICS OF FLOW INTO CURB INLETS.

Cooperative with Stanford University.

See page 81 .

(3597) CORRUGATED PIPE ROUGHNESS STUDY.

Cooperative with Waterways Experiment

Station. See page 154.

(3699) ANALYTICAL STUDY OF THE MECHANICS OF SCOUR.

Cooperative with Colorado State University. See page 23.

(3700) UNSTEADY FLOW IN A STORM DRAIN.

Cooperative with Colorado State University. See page 23 .

(3701) DEPRESSED CURB OPENING INLET.

Cooperative with Colorado State University. See page 23.

(3705) ANALYTICAL STUDY OF LOCAL SCOUR.

Cooperative with Colorado State University. See page 24.

(3987) HIGHWAY RUNDOWN DRAIN.

Cooperative with the Bureau of Reclamation. See page 178 .

U. S. DEPARTMENT OF COMMERCE, NATIONAL BUREAU OF
STANDARDS, Fluid Mechanics Section.

Inquiries concerning the following projects should be addressed to the Chief, Fluid Mechanics Section, National Bureau of Standards, Washington 25, D. C.

(1478) WIND WAVES.

(b) Office of Naval Research, Dept. of the Navy.

(d) Experimental and theoretical; basic research.

(e) Includes mathematical and experimental studies of (1) wind tides (setup), (2) growth of wind waves, and (3) surface traction of wind on wavy surfaces.

(2435) HYDRAULICS OF PIPE CULVERTS.

(b) Bureau of Public Roads.

(d) Experimental; applied research.

(e) To determine hydraulic characteristics of various types of culvert entrances and to develop inlets of improved design.

(2436) FLOW OVER HYDROPHOBIC MATERIALS.

(b) Office of Naval Research, Dept. of the Navy.

(d) Experimental; applied research.

(e) To determine augmented dissipation of hydrophobic disks and plates oscillated in various fluids.

(h) Report in preparation.

(3250) INERTIAL FORCES IN UNSTEADY FLOW.

(b) Office of Naval Research, Dept. of the Navy.

(d) Experimental; basic research.

(e) Determination of inertia and drag coefficients of cylinders and plates when subjected to a varying monotonically varying flow.

(h) Report in preparation.

(3599) MOTION OF CYLINDERS IN STRATIFIED LAYERS.

(b) Office of Naval Research, Dept. of the Navy.

(d) Theoretical and experimental; basic and applied research.

(e) A study is made of the internal waves produced by the horizontal motion of a cylinder through the liquid. Experiments are made with two liquid layers of different densities and with a liquid with linear density gradient. In the latter case the surface disturbance is also examined.

(h) "Disturbances Due to the Motion of Cylinders in a Liquid with Linear Density Gradient," by L. H. Carpenter and G. H. Keulegan, NBS Report 7007, November 4, 1960.

(3600) DAMPING OF PROGRESSIVE OSCILLATORY INTERNAL WAVES.

(b) Office of Naval Research, Dept. of the Navy.

(d) Theoretical and experimental; basic and applied research.

(e) A study is being made of the velocity and. damping of internal progressive oscillatory waves of a two-layer system.

(h) Report in preparation. 
DEPARTMENT OF COMMERCE, U. S. WEATHER BUREAU.

Inquiries concerning the following projects, except as indicated, ahould be addressed to Mr. William E. Hiatt, Chief, Hydrologic Services Division, U. S. Weather Bureau, Washington 25, D. C.

\section{(1015) MEASUREMENT OF EVAPORATION.}

(b) Laboratory project.

(d) Theoretical and field investigation; applied research.

(e) Studies are directed toward the derivation of reliable procedures for estimating evaporation from reservoirs (existing and proposed) and land surfaces, utilizing readily available meteorological data and pan evaporation observations.

(g) A World Meteorological Organization Work Group on Evaporation Measurement has been requested to recommend a standard evaporation instrument for possible adoption. An experimental pan has been designed as an initial Weather Bureau contribution to the Work Group activities. The pan is made of fiberglas with a diameter of about 14 inches and depth of about $2-1 / 2$ inches, set in a slab of styrofoam 20 inches in diameter and approximately 6 inches thick. A screen made of very thin piano wire with about $3 / 4$ inch grid is installed 1 inch above pan to prevent birds, etc., drinking the water. Pan is set in a wooden platform about 3 feet above ground level. Four of these pans have been constructed. Field testing is being carried on at the Weather Bureau Silver Hill Observatory, Md., Weather Bureau Airport Station at Las Vegas, Nev., and at Lake Overholser near Oklahoma City, Okla. The Weather Bureau Observational Test and Development Center at Silver Hill, Ma., has been closed and relocated at a new site near Dulles International Airport in Virginia. An evaporation observational program will be continued at the new site. A report is being prepared covering the studies made at the Silver Hill location. The evapotranspiration study to develop a basin accounting method for estimating soilmoisture deficiency is continuing. A slightly revised approach of soil-moisture accounting is being tested under varying climatic regimes to determine its usefulness as an index of antecedent soil condition in rainfall-runoff relations.

(h) "The Felt Lake Evaporation Study," by Donala Baker and Ray K. Linsley, Technical Report No. 5, Department of Civil Engineering, Stanford University, April 1960.

\section{(1744) DEVELOPMENT OF RIVER FORECASTING METHODS.}

(b) River Forecast Centers for: Lower Ohio River Basin, Cincinati, Ohio; Upper Ohio River Basin, Pittsburgh, Pa.; Susquehanna and Delaware River Basins, Harrisburg, Pa.; Lower Missouri River Basin, Kansas City, Mo.; Columbia River Basin, Portland, Oreg.; Middle and Upper Mississippi River Basin, St. Louis, Mo.; Arkansas and Red River
Basins, Tulsa, Okla.; New England and Hudson River Basins, Hartford, Conn.; South Atlantic and East Gulf River Basins, Augusta, Ga.; and Middle Atlantic River Basins, Washington, D. C.

(d) Theoretical and field investigation; operation and applied research.

(e) The purpose of these investigations is to develop modern river forecast procedures for all ranges of flow for various streams of each basin. Procedures include: (1) Rainfall-runoff relations involving consideration of the physics of soil moisture, vegetative reception, transpiration, evaporation and geological features of the basins; (2) snowmelt forecasting relations involving consideration of the physics of snow and heat transfer; (3) unit hydrographs; and (4) streamflow routing procedures, based upon adaptations of basic hydraulic principles, using electronic or mechanical analogues.

(g) Forecasting procedures have been developed for key points; refinement of these procedures and development from other basins are underway.

(h) "Snow Melt Floods, Spring 1959, Upper Mississippi Watershed," by Phillip Light, Pub. No. 51, Int. Assn. Sci. Hyaro., 1960. "Extended Low Flow Forecasting Operations on the Mississippi River," by Russell G. Mann and Eugene M. Rasmusson, Pub. No. 51, Int. Assn. Sci. Hydro., 1960.

"Veri Klag Scale for Streamflow Routing," by Delmar J. Taylor, Civ. Eng., Vol. 30, No. $10,1960$.

\section{(1745) WATER SUPPLY FORECASTS FOR WESTERN UNITED} STATES.

(b) Work being conducted in following field offices: River Forecast Center, Portland, Oreg.; Water Supply Forecast Unit, Salt Lake City, Utah; River Forecast Center, Kansas City, Mo.; Weather Bureau Office, Sacramento, Calif.; and River Forecast Center, Windsor Locks, Conn.

(d) Theoretical and field investigation; operation and applied research.

(e) The purpose of these investigations is the development of precipitation-runoff relations for water supply forecasting utilizing statistical methods to correlate precipitation during the winter with runoff during the melting season.

(g) Water Supply Forecasts are prepared for about 350 points in the Western United States. These forecasts of water-year and residual flow are released in Monthly Water Supply Forecast Bulletins, January through May. This research program is of a continuing nature designed to improve and extend the present forecasting service.

(h) "Water Supply Forecasts in Northern New England, "by Charles D. Hopkins, Proc. Eastern Snow Conf., 1959-60.

\section{(1751) MAXIMUM STATION PRECIPITATION.}

(b) Corps of Engineers, Department of the Army. (d) Analysis of data. 
(e) Tabulations of maximum recorded 1-, 2-, 3-, 6-, 12-, and 24-hour precipitation, for automatic recording rain-gage stations, by states.

(h) Twenty-four states completed and published as parts of Weather Bureau Technical Paper No. 15; Arkansas at printers; Oklahoma and Iowa in process.

2437) UNITED STATES STORM CHARACTERISTICS PROJECT.

(b) Soil Conservation Service, Department of Agriculture.

(d) Theoretical and field investigation; applied research and design.

(e) Studies to provide rainfall data for design criteria in estimating required capacities of hydraulic structures. Work includes: (I) Development of a generalized relationship between depth, area, duration and frequency for areas up to 400 square miles, durations of 20 minutes to 24 hours, and return periods from 1 to 100 years;

(2) development of a generalized portrayal of the probable maximum precipitation for areas up to 400 square miles, and durations up to 24 hours in the United States; and (3) combination of (1) and (2) for Puerto Rico, Virgin Islands and Hawaiian Islands.

(h) "Rainfall Intensity-Frequency Regime --

Part 5 -- Great Lakes Region," U. S. Weather Bureau Technical Paper No. 29.

(2438) STORM TIDE PREDICTIONS.

(b) Laboratory projects.

(c) Mr. D. Lee Harris, Office of Meteorological Research, U. S. W. B., Washington 25, D. C.

(d) Theoretical and field investigation; basic and applied research.

(e) The differences between the observed and predicted tides during storms are being studied with the goal of improving the accuracy of storm tide forecasting.

(g) Empirical methods of forecasting these innundations are being developed and used in the Weather Bureau's hurricane and storm warning service. Continued improvement in these forecasts is expected to result from this research.

(2441) HURRICANE RAINFAIL AND ITS QUANTITATIVE FORECASTING .

(b) Corps of Engineers, Department of the Army.

(d) Theoretical and field investigation; applied research and design.

(e) Collection, analysis, and effective presentation of existing data on hurricane rainfall and development of methods of forecasting the intensity and quantity of rainfall from future hurricanes for design of protective works, planning of evacuation procedures, etc.

(h) "On Quantitative Precipitation Forecasting, by C. S. Gilman, et al, U.S.W.B., National Hurricane Research Project Report No. 38, $143 \mathrm{pp}$. , August 1960.

(2442) HURRICANE WIND ANALYSIS.

(b) Corps of Engineers, Department of Army. (d) Theoretical and field investigation; applied research and design.

(e) Development of methods for obtaining detailed wind speeds and directions in hurricanes just above the sea-surface indirectly from available data, which is mostly on land. Also construction by indirect means of detailed analyses of the winds over specific areas of the sea where the energy of the wind develops waves and tides damaging to specific coastal areas.

(h) "Surface Winds Near the Center of Hurricanes (and other cyclones)." U.S.W.B., National Hurricane Research Project Report No. 39, 200 pp., September 1960.

\section{(2943) RADAR BEACON FOR REPORTING RATNFALL.}

(b) Laboratory project.

(d) Experimental; development.

(e) A compact device capable of being installed in relatively remote areas within line of sight of a radar. Activated by a tipping bucket rain gage and pulse signal from the radar, instmment transmits delayed pulse which appears on radarscope indicating accumulated amounts of precipitation. Additional investigations underway for applying beacon principle to the reporting of river and tide stage, and radioactive snow water equivalent gage.

(g) Initial field installation now operational, additional beacons being built.

(2944) PROBABLE MAXIMUM PRECIPITATION OVER CALIF. BASINS.

(b) Corps of Engineers, Department of Army.

(d) Design and applied research.

(e) Estimate of probable maximum precipitation over basins in California based on simple model of wind flow up orographic slopes, checked against December 1955 flood-producing storm, combined with non-orographic storm precipitation.

(g) Estimates furnished sponsor. Methods being refined.

(3251) RAINFAII DISTRIBUTION AS DETERMINED BY RADAR.

(b) U. S. Geological Survey.

(d.) Experimental; applied research.

(e) Using time-lapse film of the radar PPI scope, various methods of determining the areal distribution of rainfall intensity are being tested. A 50-square-mile basin, heavily instrumented with recording rain gages, is used as a control basin. To be used for flood forecasting and storm studies.

(f) Inactive, awaiting data from improved weather search radar being installed in test area.

(3601) STUDY OF TECHNIQUES FOR MEASURING RAINFALL BY REFERENCE TO RADAR ATTENUATION.

(b) Laboratory project in cooperation with Stanford Research Institute.

(d) Experimental; development.

(e) By measuring the attenuation of short wave length radar energy over a fixed course 
and relating it to the measured precipitation along the path of the radar beam, it is hoped that a relationship can be established which will enable a relatively simple instrument to be developed which can monitor areas above damsites and headwaters of streams to alert downstream interests of heavy rainfall.

\section{(3602) EXTENSION OF RATING CURVES.}

(b) Laboratory project.

(d) Theoretical and field investigation; operation and applied research.

(e) The flood forecasting procedures used by the Weather Bureau are primarily based on discharge. However, the flood warnings to be of any value must be in terms of stage (or elevation). This is accomplished by use of U. S. Geological Survey rating curves relating discharge to stage. Rating curves are defined only to the maximum observed stage of record. Therefore, it is imperative to devise a reliable method of extending rating curves in order to issue accurate stage predictions for the record breaking flood.

(g) Progress has been slow and no significant results are available at this time.

(3920) FLOAT-TYPE RESISTANCE RIVER GAGE.

(b) Laboratory project.

(d) Experimental; development.

(e) A device employing a Helipot (multi-turn potentiometer) operated by a float or connected to an existing river gage and linked by wire or radio to an observation point (up to 3 miles by wire and 50 miles by radio). A reading is obtained by balancing the resistance in the system with a similar unit at the observation point. May be operated on AC or DC power.

(g) Initial field installations now operational.

(3921) PUNCHED-TAPE RECORDING, WEIGHING-TYPE PRECIPITATION GAGE WITH TELEMETERING CAPABILITY.

(b) Laboratory project in cooperation with Fisher and Porter Co.

(d) Experimental; development.

(e) A fifteen-inch capacity, weighing-type battery-operated precipitation gage providing a punched tape record which can be machine processed, capable of over one month's unattended operation. Gage so designated that data can be telemetered through use of a "black box" attached to recording mechanism.

(g) Initial gage built and undergoing laboratory tests. Additional gages for field testing being procured.

U. S. DEPARTMENT OF THE INTERIOR, GEOLOGICAL SURVEY.

(1221) STEADY STATE ELECTRIC FLOW NET MODELS.

(b) Laboratory project. (c) Mr. R. R. Bennett, U. S. Geological Survey, Washington 25, D. C.

(d) Applied research.

(e) Preparation of electric flow net models using graphite paper, conductive paints, resistor grids, etc.

(1755) CHARACTERISTICS OF SAND CHANNEL STREAMS.

(b) Laboratory project.

(c) Mr. R. W. Carter, U. S. Geological Survey, Washington 25, D. C.

(d) Field investigation; applied research.

(e) Compilation and analysis of data collected in a 1,900-foot reach of the Elkhorn River in Nebrasks to evaluate bed roughness, extent of scour and fill, and sediment movement.

(g) "Flow Characteristics of Elkhorn RIver, near Waterloo, Nebraska," by E. W. Beckman and L. W. Furness, Water Supply Paper 1498-B, U. S. Geological Survey (to be published in 1961).

(1764) COMBINED PHYSIOGRAPHIC AND HYDRAULIC STUDIES.

(b) Laboratory project.

(c) Dr. Luna B. Leopold, U. S. Geological Survey Washington 25, D. C.

(d) Field and office research.

(e) Hydraulic and physiographic factors controlling overbank flow, slope, and pattern of natural river channels and flood plains.

\section{(1995) COMPARATIVE STUDY OF SOIL MOISTURE EQUTPMENT,}

(b) Laboratory project.

(c) Mr. Irwin Remson, U. S. Geological Survey, Trenton, N. J.

(d) Fleld investigation; applied research.

(e) A comparative study of all commercially available instruments for measuring soil moisture, possible deisgn of new instruments.

(f) Suspended.

(2444) REDESIGN OF PRICE CURRENT METER.

(b) Laboratory project.

(c) Mr. E. G. Barron, U. S. Geological Survey, Columbus 12, Ohio.

(d) Experimental; development.

(e) To design a vane-type rotor for the Price current meter that can be mass-produced with ldentical rating calibration and is little affected by vertical velocity components or proximity to the water surface.

(g) Fifty identical rotors are under test.

\section{(2687) AQUTFER ANALYTICAL METHODS.}

(b) Laboratory project.

(c) Mr. R. H. Brown, U. S. Geological Survey, Washington, D. C.

(d) Analytical; applied research.

(e) To develop more versatile and comprehensive methods of determining and evaluating aquifer and ground-water reservoir hydrologic characteristics.

(f) Suspended. 
(b) Laboratory project.

(c) Mr. J. F. Poland, U. S. Geological Survey, Sacramento, California.

(d) Field investigation; basic and applied research.

(e) To determine the principles and factors involved in the strain, deformation, and compaction of water-bearing rocks resulting chiefly from changes in hydrologic environment.

(h) "Correlation of Atterberg Limits with Geology of Deep Cores From Subsidence Areas in California," by D. A. Morris and A. I. Johnson, in Papers on Solls: Am. Soc. Testing Materials Spec. Tech. Pub. 254, p. 183-187 (1959).

"Hydrologic and Physical Properties of Late Cenozoic Water-bearing Deposits of the Los Banos-Kettleman City Area, Western Fresno County, California," by A. I. Johnson and D. A. Morris, (mimeo.) (1960).

(2689) DIFFUSIONAL PROCESSES AND HYDRODYNAMICS OF SALT-FRESH WATER INTERFACE IN AQUTFERS.

(b) Laboratory project.

(c) Mr. H. H. Cooper, U. S. Geological Survey, Tallahassee, Florida.

(d) Field and laboratory investigation; basic and applied research.

(e) To determine the factors affecting the distribution of salt water in coastal aquifers subject to salt water encroachment.

(2690) MICROSCOPIC FLOW THROUGH POROUS MEDIA.

(b) Laboratory project.

(c) Dr. E. S. Simpson, U. S. Geological Survey, Washington, D. C.

(d) Laboratory investigation; basic research.

(e) To determine the factors affecting the pattern of microscopic flow of water and other liquids through porous media.

(h) Doctoral thesis to be published.

(2692) ANALOG COMPUTER FOR ANALYSIS OF GROUNDWATER FLOW SYSTEMS.

(b) Laboratory project.

(c) Mr. H. E. Skibitzke, U. S. Geological Survey, Phoenix, Arizona.

(d) Theoretical study and instrument development.

(e) Development of the physical and mathematical theory of ground-water flow systems and construction of an analog computer for analyzing ground-water flow systems under transient conditions.

(g) Functions generators being developed.

(2695) CONIINUOUS DISCHARGE RECORDS IN TIDAL STREAMS.

(b) Laboratory project.

(c) Mr. John Shen, U. S. Geological Survey, Washington 25, D. C.

(d) Theoretical; applied research.

(e) To develop methods of obtaining continuous discharge records in tidal streams. considerations will be checked by field observations.

(2698) EVALUATION OF EFFECT OF CHANNEL STORAGE ON PEAK DISCHARGE.

(b) Laboratory project.

(c) Mr. W. D. Mitchell, U. S. Geological Survey, Champaign, Illinois.

(d) Field investigation; basic research.

(e) The objective is to develop parameters that describe the effect of channel storage in an areal correlation of peak flow.

(f) Field investigation completed.

(g.) Report in preparation.

(2700) PARAMETERS OONTROLLING THE SHAPE AND PATTERN OF NATURAL STREAM CHANNELS.

(b) Laboratory project.

(c) Mr. M. G. Wolman, Dr. L. B. Brush, Jr., and Dr. L. B. Leopold, U. S. Geological Survey, Washington 25, D. C.

(d) Basic research.

(e) The effect of discharge, load, grain size, slope, and channel curvature was studied in a small channel free to adjust both bed and side walls.

(h) "Flow Resistance in Sinuous or Irregular Channels" by Luna B. Leopold, Ralph A. Bagnold, M. Gordon Wolman, and Lucien M. Brush, Jr., U. S. Geological Survey Professional Paper 282-D.

"Some Aspects of the Shape of River Meanders," by Ralph A. Bagnold, U. S. Geological Survey Professional Paper 282-E.

\section{(2701) SEDIMENT TRANSPORT INVESTIGATIONS.}

(b) Field project (cooperative with Bureau of Reclamation).

(c) Mr. D. M. Culbertson, U. S. Geological Survey, Lincoln, Nebraska.

(d) Field observations and theoretical analysis.

(e) Field and theoretical investigations of the methods, equipment, and computations used for determining sediment movement; and the theory of sediment transport.

(g) Evaluation of the equal-transit-rate (ETR) method of measuring suspended-sediment discharge indicates the method is satisfactory when properly used. Tests of a new (petrolatum-type) surface bed-material sampler give results that compare favorably with the core-type of sampler. The modified Einstein procedure is adequate for computing total load when water temperature is near freezing. In general, low values of roughness are associated with low temperatures and high sediment loads on Middle Loup River at Dunning, Nebraska.

(h) "Investigations of Some Sedimentation Characteristics of a Sand Bed Stream," by D. W. Hubbell and others, Progress Report No. 1 , open file release.

"Investigations of Some Sedimentation Characteristics of Sand Bed Streams," by D. W. Hubbell, Progress Report No. 2, open file release. 
(2703) EVAPORATION SUPPRESSION.

(b) Cooperative with Texas A, and $M$, and State of Texas.

(c) Mr. G. E. Koberg, U. S. Geological Survey, Denver, Colo.

(d) Field investigation.

(e) The purpose of this project is to develop methods, equipment, and techniques of applying and maintaining a monomolecular film for suppressing evaporation, and to measure the effectiveness of the film in reducing evaporation. Field testing of application techniques of these alkanols has been tried with varying success. Research in this field must continue until reliable methods are developed which are economically feasible in obtaining the maximum evaporation reduction. Both laboratory and field studies will be continued.

(g) Field experiments are continuing near San Antonio, Texas.

(2947) STUDY OF AGGRADATION AND DEGRADATION IN ALLUVIAL CHANNELS.

(b) Laboratory project.

(c) Dr. Lucien M. Brush, Jr., USGS, Washington 25, D. C.

(d) Basic research.

(e) A study of channel and hydraulic parameters associated with aggradation and degradation in Muddy Creek, near Baggs, Wyoming.

(2948) ANALOG MODEL ANALYZER FOR STEADY-STATE GROUND-WATER FLOW PROBLEMS.

(b) Laboratory project.

(c) Mr. R. W. Stallman, U. S. Geological Survey, Denver, Colorado.

(d) Theoretical study and instrument development.

(e) Design and development of a variable-resistance grid analyzer for use in analyzing steady-state ground-water flow problems in which the transmissibility varies in space.

(g) Basic unit completed.

(h) Report in preparation.

(2949) ULTRASONIC FLOW METER.

(b) U. S. Geological Survey.

(c) Mr. E. G. Barron, U. S. Geological Survey, Columbus 12, Ohio.

(d) Experimental; instrument development.

(e) The objective is to measure the average velocity in a natural channel by acoustic means.

(g) Instrument being tested at a field installation.

(2950) SEDIMENT TRANSPORT AND CHANNEL ROUGHNESS IN NATURAL AND ARTIFICIAL CHANNELS.

(b) Laboratory project.

(c) Mr. Thomas Maddock, Jr., U. S. Geological Survey, Washington 25, D. C.

(d) Basic research.

(e) Field and laboratory studies, original and other investigations will be analyzed in terms of sediment movement, channel roughness, shear distribution in channel prism and other effects on shape of natural chan- nels.

(3252) INTERRELATIONS OF LANDFORM MORPHOLOGY, DIRECT STREAM RUNOFF AND GROUND WATER DRAINAGE.

(b) Laboratory project.

(c) Dr. Charles W. Carlston, U. S. Geological Survey, Washington 25, D. C.

(d) Basic research.

(e) Evaluation on the effects of geology on drainage density and ground water drainage; the effects of relief on runoff characteristics; and the relations of drainage densit to direct runoff and ground water drainage.

(h) Report in preparation.

(3253) CHANNEL STABILITY IN AN EPHEMERAL STREAM.

(b) Laboratory project.

(c) Dr. Luna B. Leopold, U. S. Geological Survey, Washington 25, D. C.

(d) Field investigation; basic research.

(e) In an ephemeral stream (arroyo), measurements are being made on the following: Stress on rocks during a flow; movement and location of rocks after flow; extent of scour and fill; movement of bars; and changes in cross sections at certain locations.

\section{(3254) DISPERSION IN NATURAL STREAMS.}

(b) Atomic Energy Commission.

(c) Mr. R. G. Godfrey, U. S. Geological Survey, Washington 25, D. C.

(d) Theoretical and field investigation; basic research.

(e) To measure dispersion and relate dispersal patterns to stream-channel geometry, fluid properties, and flow characteristics.

(g) Field tests continuing.

(3255) ELECTROMAGNETIC FLOW METER.

(b) Laboratory project.

(c) Mr. E. G. Barron, U. S. Geological Survey, Columbus 12, Ohio.

(d) Experimental; instrument design.

(e) To redesign, adapt, and repackage the electromagnetic flow meter now used by the U. S. Navy, to measure velocity in open channels.

(g) Experimental model undergoing field tests.

(3257) MEASUREMENT OF TOTAL SEDIMENT DISCHARGE OF COARSE SEDIMENTS.

(b) Laboratory project.

(c) Mr. D. W. Hubbell, U. S. Geological Survey, Lincoln, Nebraska.

(d) Analytical; applied research.

(e) A review of the types of equipment currently used to measure sediment moving as bed load and the preparation of a report covering criteria for sampler design and use.

(f) Inactive.

(h) Progress report in process of publication.

(3258) TRANSTENT FLOW IN A POROUS MEDIUM.

(b) Laboratory project. 
(c) Mr.W. O. Smith, U. S. Geological Survey, Washington 25, D. C.

(d) Theoretical and experimental; basic research.

(e) To determine validity of Darcy's law under non-steady state conditions of flow:

(g) Data analysis in progress.

(3260) SOIL-MOISTURE EQUIPMENT.

(b) Laboratory project.

(c) Mr. A. I. Johnson, Chief, Hydrologic Laboratory, U. S. G. S., Denver, Colorado.

(a) Laboratory and field investigation; applied research.

(e) Laboratory model and field comparative study of techniques and of various commercially available instruments for measuring soll moisture. New equipment may also be designed as result of study.

(g) Field and laboratory calibrations of neutron meter, tensiometers, moisture blocks and sampling equipment. Evaluation of neutron meter. Design of small-diameter fast-response tensiometer. Library research.

(h) The following reports are in the process of review:

"References on Soil-Moisture Measurement Under Field Conditions, " by A. I. Johnson (mimeo).

"Measurement of Soil Moisture Under Field Conditions" by A. I. Jóhnson, U.S.G.S., Water Supply Paper.

(3261) MODEL STUDY FOR SALT WATER DIFFUSION.

(b) Laboratory study.

(c) Mr. A. I. Johnson, Chief, Hyärologic Lab., U.S.G.S., Denver, Colorado, or Mr. H. H. Cooper Jr., Research Engineer, U.S.G.S., Tallahassee, Florida.

(a) Experimental; applied research.

(e) Model study is being used to study diffusion at the interface between fresh and salt water. Variable movement of interface simulates effects of various amplitudes and periods of tidal action.

(g) Design and construct plastic model and conductivity-recording equipment; one test run with fine-sand size glass beads and one test run of medium sand completed.

(3262) SMALL-DIAMETER OBSERVATION-WELL EQUIPMENT AND TECHNIQUES.

(b) Laboratory project.

(c) Mr. A. I. Johnson, Chief, Hydrologic Laboratory, U.S.G.S., Denver, Colorado.

(d) Laboratory and field investigation; applied research.

(e) Design and evaluate equipment for recording depth-to-water in small-diameter wells; test in model well in laboratory and on ground-water wells under field conditions.

(g) Design and construct model well; construct small-diameter observation wells in field; design and construct equipment to be adapted to water-state recorders on smalldiameter wells; evaluation on model well in progress.

(h) "Powered Float for Recording Water Levels in Wells of Small Dlameter," by F. C. Koopman and W. N. Palmquist, Jr., Water Resources Bulletin (Internal Publ.).

"Evaluation of Equipment for Measurement of Water Level in Small Diameter Wells," by Eugene Shuter and A. I. Johnson, U.S.G.S., Water Supply Paper, (in review).

(3263) SPECIFIC YIELD AND RELATED PROPERTIES.

(b) Cooperative with the State of Califormia.

(c) Mr. A. I. Johnson, Chief, Hydrologic Lab., U.S.G.S., Denver, Colorado.

(d) Laboratory and fleld investigation; basic and applied research.

(e) Theoretical laboratory and field study of specific yield, and related properties, such as moisture equivalent, field capacity, moisture tension, relative permeability and time-drainage relationships, as related to ground-water storage. Evaluation of existing, and possible development of new methods for determining these properties.

(g) Library research; laboratory study in progress or completed, of factors affecting column drainage, centrifuge moisture equivalent, moisture tension and relative permeability.

(h) "Effect of Temperature on Moisture Content as Determined by Centrifuge and Tension Techniques," by R. C. Prill and A. I. Johnson in Papers on Solls: Am. Soc. Testing Materials Spec. Tech. Pub. 254, p. 340-349 (1959).

(3264) SUBSURFACE EXPLORATION EQUIPMENT AND TECHNIQUES.

(b) Laboratory project.

(c) Mr. A. I. Johnson, Chief, Hydrologic Lab., U.S.G.S., Denver, Colorado.

(d) Laboratory and field investigation; applied research.

(e) Evaluate and adapt subsurface exploration equipment and techniques, such as gamma ray and electric loggers, fluid velocity and conductivity loggers, temperature loggers, power augers and core samplers, for solving ground-water occurrence problems.

(g) Portable temperature logger nearly completed; core samplers designed and commercial models procured and compared under field conditions; power augering equipment and techniques evaluated; evaluation in progress of ganmaray, conductivity and temperature logging equipment for salt-water encroachment and waste disposal problems. Library research in progress.

(h) The following reports are in process of review:

"References on Infiltration," by A. I. Johnson (mimeo.)

"Measurement of Infiltration," by A. I. Johnson, U.S.G.S. Water-Supply Paper. "Portable Equipment for Bore-Hole Geophysical Exploration," by A. I. Johnson (mimeo.) (1958).

(3265) INVESTIGATION OF VADOSE FLOW THROUGH HOMOGENEOUS ISOTROPIC MEDIA.

(b) Laboratory project. 
(c) Mr. A. I. Johnson, Chief, Hydrologic Lab., U.S.G.S., Denver, Colorado.

(d) Experimental; basic and applied research.

(e) Laboratory model study of infiltration of fluids from surface pits into a thick unsaturated zone above the water table.

(g) Model tank designed and constructed; several test runs with beads of different particle size completed; library research; test runs photographed by slide and movie.

(h) "Model Study of Infiltration into layered Materials," by W. N. Palmquist, Jr., and A. I. Johnson, presented at Am. Soc. Civil Engineers Annual Convention, Boston, Oct. 10-14, 1960, (multilithed).

Progress report in review. Silent lapse-time. movie on second and third phase of moàl study completed.

\section{(3603) SURFACE FOLLOWER.}

(b) Laboratory project.

(c) Mr. E. G. Barron, USGS, Columbus 12, Ohio.

(d) Experimental; design.

(e) The surface follower is designed to operate a recorder while following the level of the water in a 2-inch vertical pipe. A switch in a "float" closes either the up or down circuit which rotates a drum raising or lowering the float. A shaft input recorder is coupled to the drum.

(g) Production units undergoing field tests.

\section{(3605) MINERALOGY OF FLUVIAI SEDIMENTS.}

(b) Atomic Energy Commission.

(c) Mr. V. C. Kennedy, USGS, Denver, Colorado.

(d) Laboratory and field investigations.

(e) Study of the mineralogy and cation-exchange capacity of fluvial sediments for typical hydrologic and geologic environments.

(3606) STREAM CHANNEL GEOMETRY AS RELATED TO FLOOD FREQUENCY.

(b) Laboratory project.

(c) Mr. F. A. Kilpatrick, U. S. Geological Survey, Atlanta 8, Georgia.

(d) Field investigation; basic research.

(e) The study is pointed toward finding a relation between channel characteristics (bank-full stage, bed slope, etc.) and flood frequency.

(g) Surveys and field investigations are being conducted in channel reaches in the Piedmont.

\section{(3607) BATTERY OPERATED DIGITAL RECORDER.}

(b) Laboratory project.

(c) Mr. E. G. Barron, U. S. Geological Survey, Columbus 12, Ohio.

(d) Field investigation; operation.

(e) To develop a battery operated digital punch to record stream flow data. A shaft rotation input becomes a 16 channel parallel code output on paper tape.

(f) Completed.

(g) Production units being installed.

(3922) ABRUPT CHANNEL ENLARGEMENTS AND THE
INFLUENCE OF BOUNDARY ROUGHNESS.

(b) Georgia Institute of Technology, Atlanta, Georgia.

(c) Prof. C. E. Kindsvater, Georgia Institute of Technology, Atlanta, Georgia.

(d) Experimental; applied research for master's thesis.

(e) To determine the effect of boundary roughness on the total energy loss due to abrupt area-enlargements in natural channels.

(f) Completed.

(g) "Energy Losses Associated with Abrupt Enlargements" by C. E. Kindsvater, WaterSupply Paper 1369-B, U. S. Geological Survey (to be published in 1961).

DISTRIBUTION OF BOUNDARY SHEAR IN OPEN CHANNEL FLOW.

(b) Laboratory project.

(c) Mr. R. W. Carter, U. S. Geological Survey, Washington 25, D. C.

(d) Experimental; applied research.

(e) Shear plates will be used in a flume to measure boundary shear in open-channel flow. If an accurate measure is obtained, the indirect methods of shear determination will be evaluated.

(g) Laboratory study underway.

(3924) GAGING FLOW THROUGH TURBINES.

(b) Atomic Energy Commission.

(c) Mr. B. J. Frederick, U. S. Geological Survey, Oak Ridge, Tennessee.

(d) Experimental; applied research.

(e) To develop a method of rating turbines with use of radioisotopes as a tracer similar to "salt dilution" method.

(f) Test method and instrumentation being designed.

(3925) SURGES IN NATURAL CHANNEIS.

(b) Laboratory project.

(c) Mr. S. E. Rantz, U. S. Geological Survey, Menlo Park, California.

(d) Field investigation; applied research.

(e) To test application of classic wave theory in a natural channel.

(f) Completed.

(g) Report in preparation.

\section{(3926) GAGING OF SHALIOW MOUNTAIN STREAMS.}

(b) Laboratory project.

(c) Mr. R. G. Godfrey, USGS, Washington 25, D. C.

(d) Experimental; applied research.

(e) The use of radioactive tracers for gaging streamflow is feasible. Portable lightweight equipment is needed to sense and record the tracer concentration. Development is underway of a suitable probe to measure flow in shallow mountain streams.

(g) Available equipment being investigated.

(3927) DEPTH-DISCHARGE RELATIONS IN ALIUVIAL STREAMS

(b) Laboratory project.

(c) Mr. D. R. Dawdy, U. S. Geological Survey, 
Phoenix, Arizona.

(d) Field investigation; basic research.

(e) To determine the cause of an abrupt discontinuity in the depth-discharge relation between the dune-bed form and the planebed form in an alluvial stream.

(g) The critical point of discontinuity is dependent upon temperature. The resistance to flow for discharges beyond the discontinuity is related to bed material size.

(h) "Depth-Discharge Relations of Alluvial Channels" by D. R. Dawdy, Water-Supply Paper 1498-C, U. S. Geological Survey (to be published in 1961.)

3928) EFFECT OF URBANIZATION OF PEAK DISCHARGE.

(b) Laboratory project.

(c) Mr. R. W. Carter, U. S. Geological Survey, Washington 25, D. C.

(d) Field investigation; applied research.

(e) To develop a general method of predicting the frequency of flood discharges from urban areas based on all available hydrologic information.

(f) Completed.

(h) Report in preparation.

3929) USE OF AERIAL PHOTOGRAPHS AND MAPS IN HYDROLOGIC STUDIES.

(b) Laboratory project.

(c) Mr. W. J. Schneider, U. S. Geological Survey, , Washington 25, D. C.

(d) Field investigations; applied research.

(e) Objective is to determine possible relationships between basin characteristics and low stream flow for areal studies; and establish criteria for depicting streams on topographic maps to meet needs in hydrologic investigations.

(g) Two pilot areas have been selected. Drainage details on maps and aerial photographs are being compared with observations made on ground.

\section{(3930) FLOODS FROM SMALL AREAS.}

(b) Laboratory project.

(c) Mr. W. D. Mitchell, U. S. Geological Survey, Champaign, Illinois.

(d) Field investigation; applied research.

(e) Purpose is to provide information and develop methods to solve small basin drainage structure design problems.

(g) Data at 50 small basin sites have been collected and hydrograph characteristics determined for 15 of these sites.

(3931) SOURCE OF BASE FLOW OF STREAMS.

(b) Laboratory project.

(c) Mr. F. A. Kilpatrick, U. S. Geological Survey, Washington 25, D. C.

(d) Field investigation; applied research.

(e) Purpose is to define the source, amount and distribution of base flow of streams.

(g) Field data being collected in Yellow River Basin in Georgia.

(3932) AREAL ANALYSIS OF LOW FLOWS. (b) Laboratory project.

(c) Mr. H. C. Riggs, U. S. Geological Survey, Washington 25, D. C.

(d) Field investigation; applied research.

(e) Objective is to develop general expressions relating low flow characteristics of streamflow at one or more sites with the basin characteristics of the area. Purpose is to increase the usefulness of short and intermittent records of streamflow.

(g) The slope of the low-flow frequency curve is related to drainage area, and the slope of the base-flow recession curve. A method of defining the base-flow recession curve is developed.

(h) Report in preparation.

(3933) EVALUATION OF STATISTICAL PROCEDURES IN HYDROLOGY.

(b) Laboratory project.

(c) Dr. N. C. Matalas, U. S. Geological Survey, Washington 25, D. C.

(d) Experimental; applied research.

(e) Objective is to determine the expected values and the variances of the regression parameters in order to develop tests of significance for the regression parameters.

(g) Expected values of regression parameters have been determined. A solution for the variance of the regression coefficient is near completion.

Results show that use of random, dependent data has considerable influence on the variance of the regression coefficient.

(h) "Statistical Analysis of Streamflow Data," by M. B. Fiering, Doctoral Thesis, Harvard University, 1960.

"Distribution of Droughts with Respect to Time," by Dr. N. C. Matalas, U. S. Geological Survey, Washington 25, D. C. (in preparation) 1960.

"Frequency Analyses of Droughts," by Dr. N. C. Matalas, U. S. Geological Survey, (in preparation) 1960, Washington 25, D. C. "Statistical Properties at a Runoff-Effective Precipitation Relationship," by Dr. N. C. Matalas, U. S. Geological Survey, Washington 25, D. C. (in preparation) 1960.

(3934) EXTENDING SMALI-AREA FLOOD RECORDS.

(b) Laboratory project.

(c) Mr. L. B. Peirce, U. S. Geological Survey, Montgomery, Alabama.

(d) Field investigation; applied research.

(e) Purpose is to develop methods, whereby 3or 4-year long records of streamflow can be related to long-term records of storm rainfall, that will provide design information for hydraulic structures in stream channels.

(g) A means of using long-term rainfall records at nearby first-order weather stations, now being devised.

\section{(3935) FLOOD PLAIN ZONING IN SUBURBAN AREAS.}

(b) Laboratory project.

(c) Mr. D. G. Anderson, U. S. Geological Survey, 300 South Payne St., Fairfax, Virginia. 
(d) Field investigation; applied research.

(e) To determine magnitude and frequency of flood discharges from records of short duration and develop a method to describe the water-surface profile for a flood of a given frequency at all points along the stream channel.

(g) Field data being obtalned.

(3936) FLOOD-FREQUENCY RELATIONS WITHIN NEW ENGLAND.

(b) Laboratory project.

(c) Mr. M. A. Benson, USGS, Wash. 25, D. C.

(d) Fleld investigation; applied research.

(e) Objective is to understand the basic causative factors affecting peak flows and to improve the methods of flood-frequency analysis.

(f) Completed.

(g) Historlcal-flood data permitted extension of flood knowledge to 300 years. Multiplecorrelation analysis led to formulas defining annual peak discharges with recurrence intervals from 1.2 to 300 years in terms of 6 variables: 3 topographic, 2 meteorologic and 1 orographic.

(h) "Channel-Slope Factor in Flood-Frequency Analysis," by M. A. Benson, Separate No. 1994, American Society of Civil Engineers, 9 p., 1959. Final report in preparation.

(3937) FLOOD-FREQUENCY RELATIONS IN A SEMIARID AREA.

(b) Laboratory project.

(c) Mr. M. A. Benson, USGS, Washington 25, D. C.

(d) Field investigation; basic research.

(e) Objective is to understand the basic causative factors affecting peak flows and to improve the methods of flood-frequency analysis.

(g) Data on physical and meteorological characteristics have been compiled.

(3938) FREQUENCY OF DEFICIENT DISCHARGE FOR PERIODS OF SELECTED LENGTHS.

(b) Laboratory project.

(c) Mr. J. R. Crippen, USGS, Washington 25, D. C.

(d) Field Investigation; applied research.

(e) Objective is to develop a method of lowflow frequency analysis that can predict comparable results from either a shortterm or a long-term stream-flow record.

(f) Completed.

(g) Report in preparation.

(3939) STUDY OF RADIOACTIVE WASTES, CLINCH RIVER, TENNESSEE.

(b) Atomic Energy Commission.

(c) Mr. P. H. Carrtgan, USGS, Oak Ridge, Tenn.

(d) Field Investigation; applied research.

(e) Purpose is to undertake a comprehensive study of the entry, movement, location and rate of radioactive wastes discharged into the Clinch River by the Oak Ridge National Laboratory.

(g) Methodology under study.

(3940) THE TREND OF RUNOFF AND SEDIMENT YIELD,
BRANDYWINE CREEK BASIN, PENNSYLVANIA AND DELAWARE.

(b) Laboratory project.

(c) Mr. R. O. R. Martin and Mr. H. P. Guy, U. S. Geologlcal Survey, Washington 25, D. C.

(d) Field investigation; applied research.

(e) Objective is to appraise and determine the changes in runoff and sediment yield resulting from changes in land use.

(f) Completed.

(g) Final report in preparation.

(3941) EFFECT OF REFORESTATION ON STREAM FLOW.

(b) Laboratory project.

(c) Mr.W. J. Schneider, USGS, Wash. 25, D. C.

(d) Field investigation; applied research.

(e) Purpose is to define the relation between reforestation and stream flow.

(f) Completed.

(g) Tree growth in reforested areas has reduced total runoff by as much as one-third and peak discharges by as much as one-half in a twenty-five year period.

(h) "A Progress Report on an Investigation of the Influence of Reforestation on Streamflow in State Forests in Central New York, "by G. R. Ayer, USGS, (open-file report) 1949. "Effect of Forest Cover on Snowmelt Runoff," by G. R. Ayer, Proceedings, Eastern Snow Conference, 1960.

"A Program for the Investigation of the Influence of Forests on Stream Flow in the State of New York," by W. P. Cross (unpublished thesis), Ohio State University, Columbus, Ohio, 1935.

"A Geologic and Hydrologic Study at Shackham Watershed, New York State," by D. E. Outlaw, USGS, (open-file report) 1953.

"The Effect of Reforestation on Peak Discharge," by W. J. Schneider, Forest Science (in process of publication) 1961.

(3942) ERRORS IN DISCHARGE MEASUREMENTS.

(b) Laboratory project.

(c) Mr. I. E. Ander son, USGS, Wash. 25, D. C.

(d) Experimental; applied research.

(e) To identify the source, magnitude, distribution, and effect of various errors, in discharge measurements, on the results obtained.

(g) U. S. G. S. Methods satisfactory but less demanding standards yield acceptable results.

(h) Final report in preparation.

(3943) USE OF PRECIPITATION RECORDS IN EXTENDING STREAMFLOW DATA.

(b) Laboratory project.

(c) Mr. R.0. R. Martin, USGS, Wash. 25, D. C.

(d) Field investigation; applied research.

(e) Objective is to develop a practicable method of using the precipitation records to augment short-term streamflow records and to test the extent of the improvement in reliability.

(g) Correlation studies underway.

(3944) AUTOMATIC COMPUTATION OF DAILY DISCHARGE 
RECORDS.

(b) Laboratory project.

(c) Mr. W. L. Isherwood, U. S. Geological Survey, Washington 25, D. C.

(d) Experimental; operation systems.

(e) To develop a practical system of collecting records of river stages in a form suitable for automatic computation through a high speed computer with print out acceptable for offset reproduction.

(8) Operational testing of a digital recorder nearly complete. Field testing of computer program underway. Reproduction system under study.

(3945) STANDARD STATISTICAL ANALYSES OF STREAMFLOW RECORDS.

(b) Laboratory project.

(c) Mr. C. R. Showen, U. S. Geological Survey, Washington 25, D. C.

(d) Experimental; operation.

(e) To develop operational systems and programs for automatic computation of statistical analyses of streamflow records.

(g) Programs for duration tables, low-flow and high-flow summaries for consecutive periods of various time periods now operational.

(3946) MORPHOLOGICAL ANALYSES OF GROUND-WATER DISCHARGE AREAS.

(b) U. S. Geological Survey.

(c) H. E. LeGrand, U. S. Geological Survey, Washington 25, D. C.

(d) Basic research.

(e) Through geologic and hydrologic observations and inferences hypothetical piezometric maps are to be prepared in the environs of stream valleys. Various types of hydrogeological settings are being studied so that a specific stream can be compared with its prototype.

(g) Feasibility evaluation completed.

(3947) PROBLEMS OF CONIRASTING GROUND-WATER MEDIA IN CONSOLIDATED ROCKS.

(b) U. S. Geological Survey.

(c) H. E. LeGrand, U. S. Geological Survey, Washington 25, D. C.

(d) Basic research.

(e) Porous granular material overlies jointed consolidated rock in many parts of the earth, resulting in two contrasting types of media through which water moves. Description of media and hydrologic ramifications with variable geologic conditions and with variable head changes in the piezometric surface are considered for the composite framework.

(h) Geologic and hydrologic data assembled and report in preparation.

(3948) SEDIMENT TRANSPORT PARAMETERS IN SAND BED STREAMS.

(b) Laboratory project.

(c) Mr. J.K. Curbertson, U. S. Geological
Survey, Albuquerque, New Mexico.

(d) Field and office research.

(e) Field and theoretical investigation of sediment transportation in sand bed streams. Specifically included are hydraulic and sediment data for the Rio Grande.

(3949) FACTORS AFFECTING BED-MATERIAL DISCHARGE OF SAND BED STREAMS.

(b) Laboratory project.

(c) Mr. B. R. Colby, U. S. Geological Survey, Lincoln, Nebraska.

(d) Field and office research.

(e) Field and theoretical investigation of bedmaterial discharge of sand bed streams utilizing available sediment-load data for a range of width/depth ratios.

(h) Initial report in preparation.

(3950) MEANDERING VALIEYS IN THE U. S. A.

(b) Laboratory project.

(c) Dr. G. H. Dury, U. S. Geological Survey, Washington 25, D. C.

(d) Field and theoretical investigation; basic research.

(e) Hydrologic and paleoclimatic implications of meandering valleys, in relation to changes of discharge in the Pleistocene.

(3951) HYDROLOGY OF ARID REGIONS.

(b) Laboratory project.

(c) Mr. Gerala G. Parker, USGS, Denver, Colo.

(d) Field investigations; both basic and applied research.

(e) Purpose is to develop a better understanding of the hydrology of arid regions.

(3952) STUDY OF THE MECHANICS OF HILLSLOPE EROSION.

(b) Laboratory project.

(c) Dr. S. A. Schumm, U. S. Geological Survey, Denver, Colo.

(d) Field investigation.

(e) The purpose of this project is to study the mechanics of the erosion of hillslopes under various physical conditions, and to appraise the relative influence of each factor involved in hillslope erosion in semi-arid and arid environments. Studies include quantitative measurements of hillslope erosion and, to the extent possible, measurements of the contributing or related factors. Such information is needed to determine the amount of sediment derived from hillslopes and to provide guidance in planning erosion control measures. Studies are in progress in several areas in eastern and western Colorado and western Utah.

(g) A number of hillslope profiles have been measured and permanently monumented for future re-surveys. A rainfall-simulator infiltrometer has been designed by $I$. S. McQueen for use on several study plots. Soil samples have been obtained and analyzed.

(3953) BASIC RESEARCH IN VEGETATION AND HYDROLOGY. 
(b) Eaboratory project.

(c) Dr. R. S. Sigafoos, U. S. Geological Survey, Arlington, Va.

(d) Field investigation.

(e) The purpose of this project is to study the interrelationship between vegetation and geomorphic processes by comparing qualitative differences in distribution and form of plants with selected geologic and hydrologic variables. This comparison is prerequisite to establishment of methods to measure botanical parameters quantitatively. The immediate objectives will be to identify and map species limited to flood plains, to adjoining uplands, to alluvial fans, terraces, coves and ridges; to study relationship between forest development and flood frequency, and to determine the effect of land use upon changes in vegetation.

(g) Two floods on the Potomac River, the first since the project was started in 1958 exceeded the bank full stage, thus permitting the collection of hydrologic botanical data not available before. Superficial observation suggests that certain herbaceous plants, bluebells, phlox, sweet ciceley, May apple, and others, grow only on flood plain surfaces, higher than the flood having a recurrence interval of 1.5 years. Plant parts, soil, and surface mu-off during a storm were collected for chemical analysis in connection with the interagency strip mine project in Kentucky. Relations of trees to glacial moraines on Mr. Rainier, Washington, are studied in an attempt to develop a geochronology of that area.

(h) "Botanical Evidence of Modern History of Nisqually Glacier, Washington," Professional Paper 398-A, by R. S. Sigafoos and E. L. Hendricks, is being processed.

\section{(3954) CHARACTERISTICS OF GLACIER-FED STREAMS.}

(b) Laboratory project.

(c) Dr. R. K. Fahnestock, U. S. Geological Survey, Fort Collins, Colo.

(d) Field investigation.

(e) The purpose of this project is to study the channel characteristics of streams below active glaciers, especially those carrying substantial amounts of debris which is sorted and transported by meltwater. It should assist developing an understanding of glacial outwash deposits, both present and past, in other areas. This study should also add to both the knowledge of the influence of diurnal fluctuations in flow on the characteristics of alluvial channels and to the knowledge of long term response of stream channels to glacier fluctuations. The project is carried on at White River below Emmons Glacier, Mt. Rainier, Wash., flume studies are carried out at Colorado State University.

(h) U.S.G.S. Professional paper in review.

(3955) DOWNSTREAM EFFECT OF DAMS, DIVERSIONS, AND IRRIGATION DRAINS ON ALLUVIAL CHANNELS.

(b) Laboratory project.

(c) Dr. M. G. Wolman, Johns Hopkins University,
Baltimore, Ma.

(d) Field investigation.

(e) The purpose of the project is to determine the downstream effect the above types of structures exert on alluvial channels. All available data are to be gathered and summarized on channel surveys before and after construction. This will be accomplished insofar as possible by correspondence with State, Federal, and local agencies.

\section{(3956) LONG-TERM HYDROLOGIC TRENDS AS INDICATED} BY GLACIERS.

(b) Laboratory project.

(c) Dr. M. F. Meier, U. S. Geological Survey, Tacoma, Washington.

(d) Field investigation.

(e) The purpose of this project is to learn more of the mechanics of glaciers and to relate ice thickness, velocity, slope, surface water flow, stream-line inclination, and ablation. The hydrology of alpine basins, including snow fields and ice-covered areas, is important because of the relation of climate, precipitation, snow melt and storage effects on the water resources of northern and high-elevation areas. The project consists of a basic research study in fundamental problems of glacier regime, studies of long-term fluctuations in hydrologic factors, and relations between climatic and hydrologic factors. Comparisons will be made between the regime nourishment factors and activity of two similar valley glaciers located in different climatic environments. Primary study area: South Cascade Glacier, Washington.

(3957) THE HYDROLOGY OF A PORTION OF THE HUMBOLDT RIVER VALLEY.

(b) State of Nevada and U. S. Bureau of Reclamation.

(c) Mr. T. W. Robinson, U. S. Geological Survey, Menlo Park, California.

(d) Field investigation.

(e) The purpose of this project is to determine how the available water in Humboldt River valley might better be utilized. The following hydrologic data will be collected and studied: (1) Runoff characteristics and magnitude of use of surface waters; (2) the specific yield of sediments in the flood plain and the magnitude and extent of water-level fluctuations in the groundwater reservoir; (3) the use of water by greasewood and willows; (4) variations in chemical quality of the water in the flood plain; (5) amount of underflow at Comus and Rose Creek to be determined by means of pumping tests of exploratory holes; and (6) amount of ground water from tributary valleys, to be determined on the basis of chemical analyses and low-flow measurements. The General Hydrology Branch has furnished the project leader and will determine the amount of water used by greasewood and willows by use of tanks (lysimeters) similar to those used in the Buckeye project. Site is near Winnemucca, Nevada, in the Humboldt 
River Valley.

(3958) THE EFFECT OF EXPOSURE ON SLOPE MORPHOLOGY.

(b) Laboratory project.

(c) Mr. R. F. Hadley, U. S. Geological Survey, Denver, Colo.

(d) Field investigation.

(e) The purpose of this project is to determine the morphologic and hydrologic differences existing among slopes of various exposures and to measure the resulting effects on erosion, soil moisture, and vegetational cover. Also, the effect of differential exposure on drainage-basin evolution will be investigated. Sites for study are several selected small areas in Wyoming, Colorado, and New Mexico.

(3959) LONG-TERM CHRONOLOGIES ON HYDROLOGIC EVENTS.

(b) Laboratory project.

(c) Mr. W. D. Simons, U. S. Geological Survey, Tacoma, Washington.

(e) The purpose of this project is to provide information on flood and drought frequencies and other critical hydrologic events from the history of major river basins. Data will be sought to evaluate long-term fluctuation in water supply to determine whether or not there has been either an upward or downward trend during the last 2 or 3 centuries. Such data will include crop records, news items, historical records, tree-ring data and lake levels. Efforts will be made to obtain useful data from anthropological research studies in the Pacific Northwest. This study would provide additional knowledge on probable frequency and duration of critical hydrologic events especially droughts for each major river basin. The first investigation would be in the Columbia River basin.

(3960) ANALYSIS OF SURFACE-GROUND WATER RELATIONS, HOP BROOK BASIN, MASSACHUSETTS.

(b) Laboratory project.

(c) Mr. J. C. Kammerer, U. S. Geological Survey, Boston, Mass.

(d) Field investigation.

(e) The purpose of this project is to observe and evaluate some of the interrelated. responses of ground and surface water to conditions and changes of climate and ecology characteristics of the spring, summer, and fall season, with particular reference to 3 or 4 specific sites within the basin, as well as some basinwide effects, such as the changes in upstream limits of the surface-drainage network.

(3961) USE OF WATER BY SALTCEDAR.

(b) Bureau of Reclamation.

(c) Dr. T. E. A. vanHylckama, U. S. Geological Survey, Phoenix, Ariz.

(e) The purpose of this project is to measure the use of ground water by saltcedar in evapotranspirometers and to evaluate these data against those obtained by energy budget and mass transfer methods. Estimates can then be made of the quantity of water salvageable by control or eradication of saltcedar. Large evapotranspirometers have been constructed in an environment of saltcedar and planted at the same density as in the surrounding area. The use of water from these tanks will be measured and the effect of maintaining ground water at different levels studied.

(g) All six tanks have been constructed and 5 have been planted, instrumentation is nearly completed.

\section{(3962) RESEARCH IN PHREATOPHYTES.}

(b) Laboratory project.

(c) Mr. T. W. Robinson, U.S. Geological Survey, Menlo Park, California.

(d) Field investigation.

(e) The purpose of this project is to estimate with reasonable accuracy the quantity and quality of the ground water consumptively wasted and to evaluate the quantity and quality of the water that can be salvaged by control or eradication of the phreatophyte. The fields of study involved in attaining these objectives are: (I) A knowledge of the habitats and life-cycle characteristics of problem phreatophytes; (2) the factors that control their growth, development, and occurrence; (3) the factors that affect their use of ground water; and (4) economic methods for effecting salvage of the water consumptively wasted by phreatophytes. Among others, data are needed on occurrence, which requires mapping of areas and density of growth; relations of occurrence to the quality of the ground water; depth of root penetration; effects of phreatophytes on flood-plain erosion and sedimentary processes; and the annual water consumption for different depths to the water table under different climatic conditions, by species.

\section{(3963) EVAPOTRANSPIRATION THEORY AND MEASUREMENT.}

(b) Laboratory project.

(c) Mr. O. E. Leppanen, U. S. Geological Survey, Phoenix, Arizona.

(d) Field investigation.

(e) The purpose of this project is to study the physical processes involved in evapotrans piration and to develop techniques and equipment for measuring evapotranspiration. The studies encompass an analysis of the physical forces and differential equations describing the transport of momentum, latent heat of evaporation, energy, water vapor, and possibly carbon dioxide in the earth's surface in order to develop practical techniques and instruments for the measurement of evapotranspiration.

(g) The field phase of the project was completed in 1959 and considered highly successful wherein the energy-budget method was used for the direct measurement of evapotranspiration loss from a vegetated land area.

(3964) MECHAIVICS OF EVAPORATION.

(b) Laboratory project. 
(c) Mr. J. S. Meyers, U. S. Geological Survey, Denver, Colorado.

(d) Field investigation.

(e) The purpose of this project is to find ways of simplifying and reducing the costs of data collection for the energy-budget method of evaporation determination. This method has proven to be accurate and reliable. However, it is costly and much simplification is needed before it can be widely used to determine evaporation either from free water surfaces or from bare land surfaces. Data processing has been another costly item; however, the use of high-speed computing machines are expected to reduce this somewhat after more reliability is built into the field-recording systems. The possibility of using avallable Weather Bureau data will be explored.

(g) The energy-budget method of evaporation determination has been developed and has proven much more accurate than the old evaporation pan method. Much remains to be done.

\section{(3965) HYDROLOGIC EFFECT OF VEGETATION MODIFICATION.}

(b) Laboratory project.

(c) Mr. R. C. Culler, U. S. Geological Survey, Tuscon, Arizona.

(d) Field investigation.

(e) The purpose of this project is to evaluate the change in water yield produced by the vegetation modification and to develop a more comprehensible understanding of the function of vegetation, within the hydrologic regime, under semiarid conditions. Substitution of short-rooted grass for deeprooted trees is the basis for this study. The study has been divided into two parts; (1) The determination of the changes in water yield produced by a pinon-juniper eradication program on a drainage area of 200 square miles; and (2) the intensive study of 2 pairs of small watersheds to evaluate the hydrologic processes involved and alterations that occur as a result of vegetation modification. Correlations of runoff, using precipitation will be used for (1). In part (2) an attempt will be made to evaluate the major portions of the hydrologic cycle and to define the interrelationships. Study site is Carrizo and Corduroy Creek basins in the Fort Apache Indian Reservation, Arizona.

(g) Six gaging stations were constructed. The Bureau of Indian Affairs has cleared Corduroy basin of pinon-juniper, and correlations are being computed.

\section{(3966) EFFECTS OF SEDIMENT CHARACTERISTICS ON} FLUVIAL MORPHOLOGY AND HYDRAULICS.

(b) Laboratory project.

(c) Dr. S. A. Schumm, U. S. Geological Survey, Denver, Colorado.

(d) Field investigation.

(e) The purpose of this project is to collect data on the physical properties of sediments forming the perimeter of alluvial channels, and to determine the effect of sediment type on fluvial morphology and hydraulics. The physical and chemical properties of alluvial materials and their relations to and effects upon fluvial morphology are not well enough understood and require considerable research. Basic data are collected at about 200 cross-sectional sites or as many as possible of the following: channel shape, dimensions, gradient, pattern, and roughness; channel and bank vegetation; stream discharge; velocity of flow; suspended and bed sediment loads; and the types of sediment forming the cross-sectional perimeter of the channels.

(3967) STUDY OF AGGRADATION AND DEGRADATION IN STREAM CHANNELS.

(b) Laboratory project.

(c) Dr. S. A. Schumm, U. S. Geological Survey, Denver, Colorado.

(d) Field investigation.

(e) The purpose of this project is to study the mechanics of channel formation in alluvium of semiarid and arid valleys, and sediment deposition in ephemeral stream channels. The physical properties of alluvial materials have not been related satisfactorily to stream channel characteristics. This project involves the relation of sediment types to channel pattern, longitudinal profile, channel shape and roughness, bed-load movement, and variations in discharge, and takes place in several areas in Colorado, Wyoming, Kansas and Nebraska.

(3968) STUDY OF CHANNEL CHARACTERISTICS AND FLOOD PLAIN AGGRADATION TUSAYAN WASHES, ARIZONA.

(b) Laboratory project.

(c) Mr. R. F. Hadley, U. S. Geological Survey, Denver, Colorado.

(d) Field investigation.

(e) The purpose of this project is to determine the physical and hydraulic factors that control channel characteristics in aggrading and degrading alluvial channels in the semiarid and arid Southwest. An understanding of these processes is needed in order to plan conservation practices in a logical and economic fashion. The project includes study of aggradation occurring naturally as well as aggradation induced by channel structures. Studies are in the drainage basins of Polacca, Oraibi, Jeddito, Dinnebito Washes, all tributary to Little Colorado River near Winslow in northeastern Arizona.

(g) Aerial photography of Oraibi wash channel was obtained in June, 1960. Repeat photography to determine changes is planned for interval of 4 to 5 years.

\section{(3969) GENERAL STUDIES OF EROSION AND SEDIMENTATION.}

(b) Laboratory project.

(c) Mr. R. F. Hadley and Mr. N. J. King, U. S. Geological Survey, Denver, Colorado.

(d) Field investigation.

(e) The purpose of this project is to investigate the basic processes of erosion in a semiarid and arid environment. Studies 
fall into three general groups: (I) Quantitative measurements of gully growth, channel widening, and channel erosion;

(2) measurements of rates of upland erosion; and (3) detailed studies of a particular erosional process in a selected area. The quantitative measurements will be utilized to aid in design of soil and water conservation measures. Studies are being made in several areas in Montana, Wyoming, Utah, New Mexico, and Arizona.

\section{(3970) HYDROLOGIC EFFECTS OF URBANIZATION.}

(b) Laboratory project.

(c) Mr. A. O. Waananen, USGS, Menlo Park, Calif.

(d) Field investigation.

(e) The purpose of this project is to evaluate the hydrologic effects of changes in land use associated with development of suburban, industrial and urban communities; also included is a study of hydrologic problems in storm drainage in urban areas. Changes in land use associated with urban development affect local hydrologic factors such as runoff, flood frequency, recharge, channel stability, sediment production and the interrelationship between surface and ground water. Data on streamflow, precipitation, soil moisture and related hydrologic and climatologic data, topographic effects, and geologic, soils, and ecologic information, together with documentation of changes in land use as they occur, are needed for proper evaluation. The study area, San Francisquito Basin at Stanford University, Palo Alto, California.

(3971) THE HYDROLOGY OF PRAIRIE POTHOLES, NORTH AND SOUTH DAKOTA.

(b) Laboratory project.

(c) Mr. G. E. Harbeck, and Mr. J. B. Shjeflo, U. S. Geological Survey, Denver, Color ado.

(a) Field investigation.

(e) The purpose of this project is to determine the water requirements of marsh and pothole areas in the glaciated part of the Dakotas. The Garrison Diversion Project and the Oahe Diversion Project propose to bring irrigation to about a million acres in North and South Dakota, a large portion of which is in the prairie pothole region. It is expected that many potholes will be lost due to land leveling and the construction of drainage systems. Questions arise with regard to the amount of water that will be required to meet the associated water demands from seepage, evaporation, and particularly transpiration from aquatic vegetation.

(g) A set of four potholes was chosen and rejected after geologic examination. A new set has been chosen and instrumentation is under way.

(3972) STUDY OF WATER APPLICATION AND USE ON A RAITE WATERSPREADER IN NORTHEASTERNI MONTANA.

(b) Laboratory project.

(c) Mr. F. A. Branson, Mr. I. S. Mcqueen, Mr. R. F. Miller, USGS, Denver, Colorado. (d) Field investigation.

(e) The purpose of this project is to evaluate the use of a waterspreader on forage yields. Little information is available on amounts of water applied to and used by waterspreaders or on the amounts of water needed for successful waterspreaders. As water becomes more in demand, information on the efficiency of water used by waterspreaders becomes increasingly important. Water applied to the spreader is measured by means of a waterstage recorder which determines the duration of flow through a pipe onto the spreader and by means of a rain gage. Plant measurements are being made by the Montana Agricultural Experiment Station. Study site is the Willow Creek area near Fort Peck, Mont

(g) The spreader site was precalibrated in terms of kinds and quantities of plants present for three years before the waterspreader was constructed. One year of soil moisture records on the spreader and control areas were obtained before water was applied to the spreader.

(3973) STUDY OF PRECIPITATION, RUNOFF AND SEDIMENT YIELD IN CORNFIELD WASH, NEW MEXICO.

(b) Laboratory project.

(c) Mr. Durl E. Burkham, U. S. Geological Survey, Albuquerque, New Mexico.

(d) Field investigation.

(e) The purpose of this project is to obtain hydrologic data for use in the design of soil and water conservation structures and to evaluate the effects of structures on control of flood runoff and erosion. The original study was started in 1951 when the Bureau of Land Management completed construction of reservoirs in an area about 15 miles southwest of Cuba, New Mexico. In the fall of 1957 part of the watersheds were pitted by a mechanical pitter in an attempt to increase infiltration and growth of vegetation.

(h) "Water-Supply Paper 1475-B," reports the results of the first five years, 1951-55.

(3974) LABORATORY STUDY OF THE GROWTH OF MEANDERS IN OPEN CHANNELS.

(b) Laboratory project.

(c) Dr. M. G. Wolman and Mr. Michael Moore, John Hopkins University, Baltimore, Md.

(e) The purpose of this project is to attempt to establish channels having various initial ratios of width to curvature. Each channel pattern will be allowed to develop under controlled conditions of slope and discharge, and the rate of growth and change in pattern will be observed continuously. This study is a continuation of the work begun in the experiments by Leopold, Bagnold, Wolman, and Brush and deal with the energy losses and behavior of curved channels.

\section{(3975) STUDY OF EFFECTS OF GRAZING IN BADGER WASH} AREA, COLORADO.

(b) Laboratory project.

(c) Mr. G. C. Lusby, U. S. Geological Survey, 
Denver, Colorado.

(d) Field investigation.

(e) The purpose of this project is to determine the effects of grazing exclusion in regard to improving vegetation, and reducing damaging floods, upstream erosion and downstream sedimentation. This study was planned and started in 1953 as a cooperative undertaking between the Bureau of Land Management, Forest Service, Bureau of Reclamation, and the Survey. Studies by the Fish and Wildlife Service started a year later. The study by agreement is to run for 20 years. Twenty reservoirs were constructed and records of runoff and sediment are collected on each. The study area is divided into four pairs of areas each with a dam and reservoir. One of each pair is fenced to exclude grazing and the other is left open. Study area is about 8 miles northwest of Mack, Mesa County, Colorado.

(g) Data collection is continuing. Only slight changes have been noted so far. Changes in 40 permanent cross-sections are computed periodically.

\section{(3976) EVALUATION OF SEDIMENT BARRIER ON SHEEP} CREEK, NEAR TROPIC, UTAH.

(b) Laboratory project.

(c) Mr. G. C. Lusby, U. S. Geological Survey, Denver, Colorado.

(d) Field investigation.

(e) The purpose of this study is to test the effectiveness of treatment methods to reduce the high sediment contribution of the Paria River and similar streams. In addition to land-treatment practices, which will be carried out by the Forest Service, National Park Service, Bureau of Land Management and Soil Conservation Service, the Bureau of Reclamation has constructed a small barrier on Sheep Creek. The Survey is to measure the effect of this barrier on runoff and sediment at a site about 7 miles southwest of Tropic, Utah.

(g) A dam was constructed on Sheep Creek.in the Spring of 1960 and sediment samplers were located in three places in Creek bed this summer. There has been no munoff as yet.

\section{(3977) HYDROLOGIC EFFECTS OF SMALL RESERVOIRS.}

(b) Laboratory project.

(c) Mr. F. W. Kennon and Mr. R. W. Stallman, U. S. Geological Survey, Oklahoma City 2, Oklahoma.

(d) Field investigation.

(e) During recent years there has been a great increase in the number of small reservoirs being constructed for stock water supply, irrigation, flood control, recreation, and other uses. The purpose of this project is to evaluate this type of construction in terms of its effect on the hydrology of the area. Similar work has been done in other parts of the West.

(g) Work in progress on Sandstone Creek, Okla., Honey Creek, Texas and several other small watersheds in Texas.
(3978) EFFECTS OF MECHANICAL TREATMENTS ON ARID LAND IN THE WESTERN UNITED STATES.

(b) Laboratory project.

(c) Mr. A. Branson, Mr. I. S. McQueen, and Mr. R. F. Miller, U. S. Geological Survey, Denver, Colorado.

(d) Field investigation.

(e) The purpose of this project is to determine the effects of different mechanical treatments on arid lands. Several small basins on land administered by the Bureau of Land Management in central Montana, eastern New Mexico, and western Colorado, are the study sites. Some reservoirs have been, and others are to be constructed in each of these basins, and runoff and sediment yield is being and has been determined before treatments are applied. Among the treatments applied after precalibration are the following: spike-tooth pitting, eccentric-disc pitting, and contour furrowing (with furrow intervals determined on the basis of computed furrow water-storage capacity). Other measurements made would include: vegetation kinds and quantities before and after treatment, soil-moisture storage and seasonal and annual changes.

(g) Certain areas in Montana and New Mexico are already under study and have been instrumented.

(3979) GENERAL EVALUATION OF SOIL AND MOISTURE TREATMENT PRACTICES.

(b) Laboratory investigation.

(c) Mr. K. R. Melin, U. S. Geological Survey, Denver, Colorado.

(d) Field investigation.

(e) The purpose of this project is to appraise the structures and treatment practices used in soil moisture conservation to determine their effectiveness in accomplishing the purposes for which they were designed. The field studies include maintenance of records on runoff, erosion and sedimentation to determine the effects of the structures or practices at several areas in Colorado, Utah, Arizona, Wyoming, Montana, and New Mexico.

\section{(3980) HYDROLOGY OF DEATH VALLEY.}

(b) Laboratory project.

(c) Mr. T. W. Robinson and Mr. C. B. Hunt, U. S. Geological Survey, Menlo Park, California.

(d) Field investigation.

(e) The purpose of this report is to study the various phases of the hydrology of Death Valley. Data on evaporation, wind movement, humidity and temperature are being obtained under informal agreement with the National Park Service. Relations of plants to salinity and effects of salinity on evapotranspiration also are being investigated.

(3981) PLEISTOCENE LAKES OF THE GREAT BASIN.

(b) Nevada State Engineers.

(c) Mr. C. T. Snyder, U. S. Geological Survey, Menlo Park, California. 
(d) Field investigation.

(e) The purpose of this project is to prepare a map based on data gathered during Soil and Moisture Conservation investigations showing the Pleistocene Lakes in the Great Basin area. Further refinements can now be made to Lakes Lahounta and Bonneville and the associated smaller lakes that existed concurrently. An additional large Pleistocene lake recently discovered is included.

(3982) INTERRELATIONSHIPS BETWEEN ION DISTRIBUTION AND WATER MOVEMENT. IN SOILS AND T'HE ASSOCIATED VEGETATION.

(b) Laboratory project.

(c) Mr. R. F. Miller, U. S. Geological Survey, Denver, Colorado.

(d) Field investigation.

(e) The purpose of this study is to obtain information basic to improvement of water use and vegetation yields on arid lands. These data are needed to evaluate the potential of treatment practices proposed on an extensive scale on the public domain. This study emphasizes the investigation of soil chemistry as it affects the swelling or shrinkage of soils and may have as great an effect of hydrologic characteristics as texture. Study areas are in several 1ocations on public lands in several western states.

(g) Special equipment in place. Data collection now in progress.

(3983) DEVELOPMENT OF FIELD CRITERIA FOR EVALUATING SITES FOR FLOOD WATER SPREADING.

(b) Laboratory project.

(c) Mr. R. F. Miller, U. S. Geological Survey, Denver, Colorado.

(d) Field investigation.

(e) The purpose of this project is to determine field criteria with which to evaluate potential sites before making relatively large expenditures for further developments. Examinations made to date on spreaders in several localities suggest that in addition to adequacy of water available the infiltration characteristics and moisture-holding capacity of the soils are important factors. The kinds and quantities of vegetation growing where water collects naturally on similar soils on or near proposed sites may be a useful indicator of the potentiality of the site after water is applied.

(g) Existing waterspreaders in Montana, Wyoming, Colorado, Utah, New Mexico, and Arizona.

(3984) WATER AND SOIL RELATIONSHIPS AS INDICATED BY PLANT SPECIES OR PLANT COMMUNITIES.

(b) Laboratory project.

(c) Mr. A. Branson, Mr. I. S. McQueen, Mr. R. F. Miller, U. S. Geological Survey, Denver, Colorado.

(d) Field investigation.

(e) The purpose of this project is to determine whether or not phonological development of vegetation differs for communities having the same macroclimate but different soils Plants have been used as indicators of conditions, processes and uses for many years. Where plants can be used as indicators of soll conditions, expensive measurements of physical and chemical properties can be reduced. Plant species or communities may be used as indicators of potential production to be expected from land management and treatment practices. Research sites are near Golden, Colorado. other sites will be selected.

(g) Preliminary work and some mapping has been accomplished.

\section{U. S. DEPARTMENT OF THE INTERIOR, BUREAU OF RECLAMATION.}

Inquiries concerning the following projects should be addressed to Assistant Comissioner and Chief Engineer, Bureau of Reclamation, Denver Federal Center, Denver 25, Colorado.

(1502) STABLE CHANNEL STUDIES--TRACTIVE FORCES REQUIRED TO MOVE NONCOHESIVE MATERIALS.

(f) Tests completed; report in preparation.

(1777) SIPHON SPILLWAY STUDIES.

(b) Laboratory project.

(d) Experimental, laboratory and field investigations; applied research and design.

(e) Develop an improved design for lower priming head and short priming time. Attempts will be made to design a partialization device to regulate the discharge of the siphon by means of a self-regulating air intake, thereby enabling the siphon to operate more or less continuously at reduced flow rather than intermittently at full capacity.

(g) The priming head for minimum operating discharge has been reduced to 25 percent of the head required in standard design; corresponding discharge is about 20 percent of the discharge for standard design. Shape and length of the bucket on the downstream end of the barrel have been proportioned for maximum discharge coefficient. Position and angle of the deflector in the barrel have been determined.

(2455) CASA COLORADA CHANNEL ALINEMENT--MIDDIE RIO GRANDE.

(f) Completed; for further studies of channelization by steel jetties see (3271).

(h) "Use of Steel Jețties for Bank Protection and Channelization in Rivers," by E. J. Carlson and P. F. Enger, Paper 87, August 1956.

(2457) EROSION AND TRACTIVE FORCE STUDY OF UNLINED AND EARTH-LINED CANALS.

(f) Collection of field data and laboratory testing in progress.

(h) "Progress Report No. 3, Canal Erosion and 
Tractive Force Study--Correlation of Laboratory Test Data--Lower-cost Canal Lining Program," by P. F. Enger, J. Merriman, B. A. Prichard, and M. J. Ruffatti, General Report No. 26, July 1960.

(2705) TRINITY DAM-MORNING-GLORY SPILLWAY.

(f) Completed.

(h) "Hydraulic Model Studies of the Trinity Dam Morning-glory Spillway--Trinity River Division--Central Valley Project, Calif.," by W. B. McBirney, Report No. Hyd-447, April 1960.

"Hydraulic Model Studies of the Trinity Dam Spillway Flip Bucket--Central Valley Project, California," by T. J. Rhone, Report No. Hyd-467, August 1960.

\section{(2719) GLEN CANYON DAM SPILLWAY.}

(b) Laboratory project.

(d) Experimental, for design.

(e) The model, built to a scale of $1: 63.5$, includes the tunnel spillways on both sides of the river, the curved arch dam, the outlet works, the powerhouse, and a section of the Colorado River upstream and downstream from the dam.

(f) Report in preparation. The model is being retained to assist in solving river diversion and other problems that arise during the construction period.

(g) Alinements for the excavated spillway approach channels, tunnel transitions between the spillway crest and the inclined tunnel, new type flip buckets in new locations, and other recommended features and procedures have resulted from the studies.

(2724) FRICTION FACTOR TEST IN LARGE PRESSURE CONDUTTS- -WEBER-COULEE SIPHON.

(f) Completed.

(g) Results in good agreement with previously published data.

(h) "Progress Report 1--Friction Factors for Large Conduits Flowing Full--Eklutna, Neversink, and East Delaware Tunnels, Weber Coulee Siphon, San Diego Aqueduct," by J. C. Schuster and R. B. Dexter, Report No. Hyd-460, March 1960.

(2953) STUDIES OF WIND WAVES ON CANALS.

(b) Laboratory project.

(a) Experimental, laboratory and field investigations, applied research and design.

(e) Laboratory and field studies are being conducted to develop relationships to predict erosion produced by surface waves on canal banks.

(f) Field data are being analyzed. Reports in preparation.

(g) Waves have been measured on field canals, and wave characteristics have been correlated with channel characteristics and wind velocity and direction. Laboratory and field concerning the erosion characteristics of waves on earth material from one canal have been conducted and some data have been analyzed.

(2954) GLEN CANYON TUNNEL PLUG OUTLET WORKS.

(f) Completed.

(h) "Air and Hydraulic Model Studies of the Left Diversion Tunnel Outlet Works, " by W. P. Simmons, Jr., Report No. Hyd-468, September 1960.

(2955) CAVITATION IN SUDDEN ENLARGEMENTS DOWNSTREAM FROM GATE VALVES.

(b) Laboratory project.

(d) Experimental; applied research and design.

(e) Tests are being made at heads from 200 to 400 feet to determine the critical cavitation indexes for gate valves operating at partial openings and discharging into pipe sections $1.5,1.75$, and 2.0 times the nominal valve diameter.

(h) Report to be prepared.

(2958) HOLLOW-JET VALVE STILLING BASINS FOR OUTLET WORKS.

(f) Completed.

(h) "Stilling Basin for High Head outlet Works utilizing Hollow-Jet Valve Control (Basin VIII)" by G. I. Beichley and A. J. Peterka, Report No. Hyd-446, April 1960.

(2959) STILLING BASINS FOR SLIDE GATE CONTROLLED OUTLET WORKS.

(b) Laboratory project.

(d) Experimental; applied research and design.

(e) A study to generalize stilling basin dimensions, using either one or two slide gates.

(h) Report to be prepared

(2960) FLAMING GORGE DAM SPILLWAY.

(b) Laboratory project.

(d) Experimental; for design.

(e) A 1:36 scale model has been constructed to develop a satisfactory approach channel, crest section, tunnel transition and spillway, flip bucket, and outlet works.

(g) The model is being retained to help solve any problems that arise during the construction period. A satisfactory structure has been developed having good flow conditions throughout.

(h) Report in preparation.

(3267) CANAL INLET AND OUTLET TRANSTTION STUDIES.

(b) Laboratory project.

(d) Experimental; applied research and design.

(e) Head loss and scour tests are in progress to determine the effects of angle of divergence or convergence from pipe to canal or vice versa, and the effects of the slope and elevation of the pipe with respect to the canal.

(h) Report to be prepared.

(3269) EFFECT OF SHADE PRODUCED BY SUSPENDED SEDIMENTS ON THE GROWTH OF AQUATIC WEEDS. 
(f) Completed.

(h) "Some Effects of Suspended Sediment on Growth of Submersed Pondweeds," by N. E. otto and P. F. Enger, General Laboratory Report No. GEN-27, July 1960.

(3270) SAN ACACIA DIVERSION--HEADWORKS AND SLUICEWAY.

(f) Tests completed

(h) Report in preparation.

(3271) CHANNELIZATION IN ALLUVIAL RIVERS USING STEEL JACKS AND JETTIES.

(f) Tests completed.

(h) Report in preparation.

(3272) NAVAJO DAM SPILLWAY AND AUXILIARY OUTLET WORKS.

(f) Tests completed.

(h) Report in preparation.

(3273) NAVAJO DAM DIVERSION AND OUTLET WORKS STILLING BASIN.

(f) Completed.

(h) "Hydraulic Model Studies of Navajo Dam Diversion and Outlet Works Structures," by G. L. Beichley, Report No. Hyd-457, August 1960.

(3274) CONSTANT HEAD ORIFICE TURNQUT.

(b) Laboratory project.

(d) Experimental; applied research and design.

(e) A 24-inch slide gate turnout is being calibrated by means of a $1: 2$ scale model. Design changes resulting from use of the turnout have necessitated an analysis and calibration of the variables affecting the discharge capacity.

(g) Results show that submergence of the orifice or of the upstream gate of the twogate turnout has a major effect on the discharge coefficient. A calibration for a 9-cfs standard turnout and several comparative calibrations of modified turnouts have been obtained.

(h) Report in preparation.

(3275) FRICTION FACTOR TESTS IN LARGE PRESSURE CONDUITS--EKLUTNA TUNNEL, ALASKA.

(b) Laboratory project.

(d) Experimental, field investigations; for design.

(e) Extension of data to provide information on friction factors for smooth interior finishes of concrete that can be consistently produced with present-day construction methods. A second set of tests was completed in 1960 on the 9-foot-insidediameter concrete-lined tunnel. Head losses were measured over a length of 2,534 diameters. Average velocities of flow were determined from calibrated pressure taps in two turbine scrollcases.

(f) Tests and data analyses are completed. Report on second set of tests in preparation. (g) Data were obtained for 15 test discharges over a Reynolds number range of $4.4 \times 105$ to $5.9 \times 10^{6}$. Friction factors computed from the Darcy-Weisbach equation ranged from 0.020 to 0.011 , respectively; corres ponding Manning " $n$ " values are 0.015 to 0.011 .

(3276) FOSS DAM OUTLET WORKS.

(f) Completed.

(h) "Hydraulic Model Studies of the Foss Dam River Outlet Works Stilling Basin," by D. Colgate, Report No. Hyd-466, August 1960.

(3278) CAVITATION OF CONCRETE SURFACE IRREGULARITIES.

(b) Laboratory project.

(d) Experimental; applied research and design.

(e) The cavitation-producing potential of concrete surface irregularities such as abrupt offsets, protruding filler material, bug holes, etc., is being investigated. The test apparatus employs full-scale velocities and pressures.

(h) "Why Close Tolerances are Necessary Under High-velocity Flow," by J.W. Ball, Report No. Hyd-473, October 1960.

(3280) GLENDO DAM OUTLET WORKS.

(f) Completed.

(h) "Hydraulic Model Studies of Glendo Dam Outlet Works," Missouri River Basin Project, Wyoming," by W. E. Wagner, Report No. Hyd-461 August 1960.

(3281) ISLAND BEND CONTROL GATES.

(f) Completed.

(h) "Hydraulic Model Studies of the Island Bend Control Gate, Snowy Mountains HydroElectric Authority, Australia," by W. P. Simmons, Jr., Report No. Hyd-462, April 1960.

(3608) TWIN BUTTES OUTLET WORKS.

(f) Completed.

(h) "Hydraulic Model Studies of Twin Buttes Dam Outlet Works--San Angelo Project, Texas," by T. J. Rhone, Report No. Hyd-463, May 1960.

(3609) TWIN BUTTES OUTLET WORKS INTAKE STRUCTURE.

(f) Completed

(h) Report in preparation.

(3610) HYDRAULIC DOWNPULL ON HIGH HEAD SLIDE GATES.

(f) Completed.

(h) "Hydraulic Downpull Forces on High Head Gates," by Donald Colgate, and "Air Model Studies of Hydraulic Downpull on Large Gates," by W. P. Simmons, Jr., Journal Hydraulics Division, Proceedings ASCE, November and January 1959.

"Model Studies of Hydraulic Dowmpull Forces that act on the Palisades-type Regulating Slide Gate and the Glendo Fixed Wheel Gate," by W. P. Simmons, Jr., and Donald Colgate, Report No. Hyd-421, February 1957. 
(3611) ADJUSTABLE WEIR.

(b) Laboratory project.

(d) Experimental, laboratory and field investigations, applied research.

(e) Weirs having an adjustable crest height are used for checking water surface levels for upstream water delivery and for water measurement beyond weir. An investigation of the head-discharge capacity of a single 2-foot-crest-length weir has been completed. Extension of the study to include combinations of weirs and those having adjustable crest length is contemplated.

(f) Single weir investigation completed.

(g) Capacity of weir for crest heights greater. than 0.1 foot above fixed blade compares very favorably with standard 2-foot Cipolletti weir.

(h) Report in preparation.

(3612) DISCHARGE COEFFICIENTS FOR RADIAL GATES.

(b) Laboratory project.

(d) Experimental, laboratory and field investigations; applied research.

(e) Radial gates are used extensively in irrigation systems for discharge and water surface level control. Intelligent operation of the systems requires that the rate of flow passing the gated structure be known. Literature research resulted in an analytical approach and adjusted equation for the gate capacity with unsubmerged flow. A model gate was designed and will be installed in the laboratory to obtain data for checking the proposed formula and extending the scope of presently available information.

(f) Model to be constmicted.

\section{(3613) COMPOUND WEIR STUDIES.}

(b) Laboratory project.

(d) Experimental, applied research.

(e) Develop relationships for flows through combined $\mathrm{V}$-notch and rectangular contracted weirs, particularly in the transition range of discharges. Several sizes tested.

(f) Tests completed.

(h) Report is in preparation.

(3614) EXPERIMENTAL STUDY OF SUBCRITICAL FLOW IN CURVED CHANNELS.

(b) Laboratory project.

(d) Experimental; applied research and design.

(e) A fixed-bed, hydraulic model has been constructed to determine the possibility of reduction in scour and deposition in unlined channels due to secondary currents. Preliminary investigations will be conducted by varying the radius of curvature and the central angle.

(3615) TUNNEL SPILLWAY FLIP BUCKETS.

(f) Completed.

(h) "Improved Tunnel Spillway Flip Buckets," by T. J. Rhone and A. J. Peterka, Journal of the Hydraulics Division, American Society of Civil Engineers, Paper 2316, Dec. 1959.

(3985) DISCHARGE CAPACITY OF LARGE CONCRETE-LINED CANALS.

(b) Laboratory project.

(d) Experimental, laboratory and field investigations; applied research and design.

(e) This study is for the purpose of exploring the effects on the hydraulic gradient of the relationship of boundary surface resistance to the cumulative resistance of crossings, inlets, turnouts, checks, and other local items in concrete-lined canals of different sizes, shapes and grades. This study is part of a program to explain why design procedures used successfully for small and medium sizes of canals may not be adequate for large concrete-lined canals on flat slopes.

(3986) MERRITT DAM CANAL OUTLET WORKS.

(b) Laboratory project.

(d) Experimental; for design.

(e) A 1:20 scale model was constructed to develop the design of the outlet works stilling basin and the canal wave suppressor for discharges up to 1,340 second-feet from two 4- by 4foot high-pressure slide gates.

(f) Completed.

(g) A satisfactory stilling basin and wave suppressor in the canal immediately downstream from the basin was developed which provided quiet flow in the concrete-lined canal at the Parshall flume measuring station.

(h) Report in preparation.

\section{(3987) HIGHWAY RUNDOWN DRAIN.}

(b) Bureau of Public Roads.

(d) Experimental; for design.

(e) The studies were concerned with determining the capacity of a highway rundown drain and in developing a satisfactory energy dissipator fabricated from standard corrugated metal pipe components to provide protection against erosion at the exit.

(f) Tests completed.

(g) Tests indicated that the capacity is approximately twice that used in present design practice. Satisfactory protection against erosion at the exit was obtained by using either a standard end section with extensive riprap protection, or a simple, easily fabricated, energy dissipator developed in the laboratory with minimum riprap protection.

(h) Report in preparation.

(3988) YELLOWTAIL DAM OUTLET WORKS.

(b) Laboratory project.

(d) Experimental; for design.

(e) A 1:28 scale model is being constructed to develop a satisfactory stilling basin for the outlet works which is controlled by two 84-inch hollow jet valves. The problem is unusual because of the extreme variations in tail-water elevation for normal operating discharges. 
(f) Tests in progress.

(3989) YELLOWTAIL DAM LIVAY.

(b) Laboratory project.

(d) Experimental; for design.

(e) A 1:50 scale model is being constructed to develop the spillway intake, the tunnel, and the hydraulic jump stilling basin. The basin is designed to still flows up to 12,000 second-feet and flip larger flows up to 92,000 second-feet into the river channel.

(3990) BAFFLED APRON FOR GRAVITY FLOW BYPASS, WILLARD CANAL PUMPING PLANT NO. 1.

(b) Laboratory project.

(d) Experimental; for design.

(e) A 1:10 scale model is being constructed to develop a baffled apron constructed on a 5-1/2:1 slope rather than the usual 2:1 slope. The baffled apron is a chute studded with baffle piers of a height and arrangement to maintain a nonaccelerating flow of water from an upper to a lower level. Since no stilling pool is used at the downstream end of the chute, the height and placement pattern of the baffle piers, the height of the training walls, and the entrance characteristics of the flow are critical factors in the design of a satisfactory apron. Generalized hydraulic design data are available for chutes on a 2:1 slope but no information exists for flatter slopes such as the proposed 5-1/2:1 slope.

(f) Tests in progress.

(3991) SEDIMENT TESTS ON PROTOTYPE DIVERSION DAMS, KAIVAS RIVER BASIN, NEBRASKA-KANSAS.

(b) Laboratory project.

(d) Experimental, field investigation; applied research and design.

(e) Data were taken at 4 diversion dams to determine the effectiveness of the structures in reducing the amount of bed sediment entering the canals. The results will be compared with those from hydraulic model studies.

(g) Data obtained in the field has been partially analyzed.

(3992) SHERMAN OUTLET WORKS.

(b) Laboratory project.

(d) Experimental; for design.

(e) A 1:20 scale model was constructed to develop the design of the stilling basin for discharges up to 1,600 second-feet from two 4- by 5-foot high pressure slide gates.

(f) Completed.

(g) A satisfactory basin was developed to provide quiet flow from the basin into the earth-lined canal.

(h) "Hydraulic Model Studies of Sherman Dam Outlet Works," by G. L. Beichley, Report No. Hyd-455, September 1959.

(3993) SHADEHILL DAM OUTLET WORKS MODIFTCATTON, (b) Laboratory project.

(d) Experimental; for design.

(e) A I:12.52 scale model was constructed to determine the modifications to the structure necessary because of an increased irrigation water demand. Because the outlet works head and discharge were increased materially, flows from the old stllling basin basin were diverted through a bypass pipe into the larger service spillway stilling basin.

(f) Completed.

(g) Baffle piers, a training wall modification, and a wave suppressor were added to the outlet works stilling basin to provide a satisfactory basin for discharges greater than twice the original design capacity. An intake for a 72-inch steel bypass pipe and a specially shaped discharge nozzle were also developed to provide a satisfactory means of discharging the flow from the outlet works basin to the service spillway basin. The nozzle imparts a spinning motion to the water entering the service basin, resulting in greater dispersion and better performance.

(h) "Hydraulic Model Studies of Shadehill Dam Outlet Works Modification," by G. L. Beichley, Report No. Hyd-453, September 1959.

(3994) HYDRAULIC JUMP CHUTE BLOCK AND BAFTIE BLOCK PRESSURES.

(b) Laboratory study.

(d) Experimental; applied research and design.

(e) A conventional hydraulic jump stilling basin with a 2:1 approach slope has been constructed in a 4-foot-wide flume for the purpose of relating chute block and baffle pier pressures to entrance velocity, entrance flow depth, and tail-water elevation.

(f) Tests in progress.

(g) Thus far, maximum subatmospheric pressures on square edged chute blocks have been found to occur on the downstream face of the blocks, near the sides and floor.

(3995) LABORATORY STUDY TO DETERMINE THE EQUILIBRIUM BEACH PROFILE FOR FIGARDEN RESERVOIR SITE--CENTRAL VALIEY PROJECT, CALIFORNIA.

(b) Laboratory project.

(a) Experimental; for design.

(e) The reservoir soil, mean diameter $0.6 \mathrm{~mm}$, was placed on a $1: 1-1 / 2$ slope in a l-foot wide test section. Waves were directed to represent directly approaching onshore waves. Profile data were obtained for determining a dimensionless beach profile in terms of the wave length.

(f) Tests completed.

(g) Previously established parameters were verified and new ones were developed. The study indicates that design curves could be developed to aid in predicting beach profiles of reservoirs.

(h) Report in preparation.

(3996) HIGH HEAD ORIFICE STUDIES. 
(b) Laboratory project.

(d) Experimental; applied research and design.

(e) Tests at heads of 200 to 550 feet are being conducted on concentric circular orifices in a 3-inch-diameter pipeline to determine transient pressures, cavitation characteristics, critical cavitation indexes, and the effect of cavitation on the discharge coefficient.

(f) Tests in progress.

(h) Report to be prepared.

(3997) TWIN BUTTES AUXILIARY OUTLET GATES,

(b) Laboratory project.

(d) Experimental; for design.

(e) A l:15 scale model of a 2-foot highpressure gate and entrance conduit is used to develop a satisfactory bellmouth entrance which must be fitted in a relatively short distance. Calibration curves will also be obtained for the gate which operates under a head of 101 feet.

(f) Tests in progress.

(h) Report to be prepared.

\section{(3998) JET FLOW GATE--TRINITY DAM.}

(b) Laboratory project.

(d) Experimental; for design.

(e) Laboratory tests were made on the most recent design of the jet flow gate to determine operating characteristics, discharge coefficients, and air demand for free discharge and conduit discharge flow conditions. Conduit lengths ranging from 4 to 22 times the gate orifice diameter were used on the $1: 15$ scale model.

(f) Tests completed.

(h) Report in preparation.

\section{U. S. DEPARTMENT OF THE NAVY, DAVID TAYLOR MODEL} BASIN.

Inquirles concerning the following projects should be addressed to the Commanding officer and Director, David Taylor Model Basin, Wash. 7, D. C.

\section{(709) THEORY OF WAVE RESISTANCE.}

(b) Bureau of Ships; David Taylor Model Basin.

(d) Hydrodynamic research.

(e) A mathematical study of the theory of wave resistance for the purpose of establishing methods for extending the theory to the analysis of ship resistance. Studies will include the general theory of waves in liquids and will encompass a review of existing theory and comparisons with existing experimental data.

(g) A symopsis has been written on the application of the theory to the calculations of wave resistance.

Calculations were made to obtain general information about wave resistance of submerged bodies of revolution. The forms considered are ellipsoids, Rankine ovoids, anc a simple family of streamlined bodies. A report of this work is to be published.
(710) RESEARCH ON MAIN INJECTION SCOOPS AND OVERBOARD DISCHARGES.

(b) Bureau of Ships; David Taylor Model Basin.

(d) Experimental and theoretical; applied research.

(e) Investigations to determine the characteristics of injection scoops and discharges to provide design data for use in design of future ships in both high and low speed ranges.

(h) "Boundary Layer Investigation on the USS TIMMERMAN EAGI52 (ex-DD828)," C. I. Sayre and E. J. Duerr, TMB Rept. 1170, Sept. 1960.

\section{(711) CAVITATION RESEARCH.}

(b) Bureau of Ships; David Taylor Model Basin.

(d) Theoretical and experimental; applied research.

(e) Research is being conducted on the mechanism and effects of cavitation phenomena in real and ideal fluids. (1) Linearized theory is being applied to determine cavity shapes and forces in steady flows. (2) Experimental studies of the growth of cavities on hydrofoils are to be made in both steady and unsteady flows (see reference No. 3284). (3) A device is being developed to measure the extent of cavitation on the surface of a hydrodynamic body.

(g) A better correlation between theoretically and experimentally determined cavity shape has been achieved by modifying linearized cavitation theory to include surface tension effects.

(h) "Surface Tension Effects in Two-Dimensional Steady Cavitating Flow," by Dr. S. H. Schot. Paper presented at the November 1960 meeting of the American Physical Society, Division of Fluid Dynamics, Baltimore, Maryland.

(1506) STIMULATION OF TURBULENCE ON SHIP MODELS.

(b) Bureau of Ships; David Taylor Model Basin.

(d) Frictional resistance research.

(e) Development of a turbulence stimulating device which will insure adequate turbulence in the boundary layer over the entire length of any ship model. Empirical and theoretical studies will be conducted to evaluate the relative effectiveness of turbulence rods, trip wires, sand roughness, isolated stubs, noise makers and vibrators. Their relative effectiveness will be calculated by studying the model resistance and the character of the boundary layer flow around ship models as determined by the dye-method, the chemical compound, and the hot-wire survey method.

(f) Suspended.

(g) The work of the previous year was devoted to the study of the stimulating effect of studs and the development of the technique of the chemical compound. The effect of various stimulators on the BSRA model has been established and the evaluations work will compare the results for each stimulator with the results obtained by the English tanks. The evaluation of the stimulators used is still continuing. 
and wavemakers for the purpose of making maneuvering tests on ship models.

(b) Bureau of Ships; David Taylor Model Basin.

(g) Construction contract awarded in May 1956 with a completion date the end of 1960 .

(d) Experimental testing.

(e) Measurements of side forces on propeller, rudder, and hull of a single-screw ship model during successive phases of starting, stopping, and backing maneuvers.

(f) Inactive.

(g) A test program has been formulated. A side-force dynamometer has been designed and completed. Testing is expected to begin when priority considerations permit.

(1521) 36-INCH VARIABLE PRESSURE WATER TUNNEL.

(b) Bureau of Ships; David Taylor Model Basin.

(d) New facility.

(e) Design and construction of a 36-inch variable pressure water tunnel for investigation of propulsion, cavitation, and noise characteristics of propellers as well as tests on sub-surface bodies. Interchangeable test sections of open and closed jet type will be provided. The maximum design speed is 85 fps.

(g) Estimated completion is end of 1960.

(1778) HYDRODYNAMIC NOISE.

(b) Bureau of Ships; David Taylor Model Basin.

(d) Hydrodynamic research.

(e) Investigations of the characteristics of underwater noise associated with various hydrodynamic phenomena such as cavitation, bubble oscillation, turbulence and splashing.

(g) Experimental and theoretical studies have been made of noise produced by cavitation, splashing, oscillating air bubbles, and turbulence.

(1779) TURBULENT BOUNDARY LAYERS.

(b) Bureau of Ships; David Taylor Model Basin.

(d) Theoretical and experimental; applied research.

(e) An experimental investigation of velocity profile and criteria for separation in a turbulent boundary layer with an adverse pressure gradient. Results will be compared with existing theories.

(h) "The Behavior of Incompressible, TwoDimensional Turbulent Boundary Layer with Adverse Pressure Gradient," by P. K. Chang and R. D. Cahn, TMB Report 1416 (in preparation).

(1781) ROTATING-ARM AND MAIEUVERING BASIN.

(b) Bureau of Ships; David Taylor Model Basin.

(d) New facility.

(e) Design and construction of a circular basin of 260-foot diameter with a rotating arm whose radius can be varied from 18 to 120 feet. To be used for towing tests of surface and sub-surface models. Also, design and construction of a maneuvering basin 350 feet long and 230 feet wide, equipped with traveling bridge and towing carriages,

\section{(1783) MATHEMATICAL SHIP LINES.}

(b) Bureau of Ships; David Taylor Model Basin.

(d) Theoretical research.

(e) Development of a suitable method for the mathematical determination of ship lines which can be applied to a wide variety of ship forms especially to those of modern design.

(g) A method has been developed for the mathematical fairing of graphical lines. This is a first step toward the development of of a flexible system of mathematical ship lines. Future work is directed toward the development of a system of mathematical lines which will permit the derivation of a hull form for a given set of parameters.

(h) "Mathematical Ship Surface," by Dr. P. C. Pien, TMB Report 1398, presents progress to date for this project.

\section{(1786) STUDIES OF THE SLAMMING OF SHIPS.}

(b) Bureau of Ships; David Taylor Model Basin.

(d) Experimental and theoretical; basic research.

(e) Computations and measurements of the pressure distribution and impact forces on the bottoms of slamming ships for the purpose of developing design criteria to effect their reduction.

(g) Theoretical methods were developed for evaluating the impact pressures and forces by replacing the original equivalent wedge concept by a serles of elliptical cylinders approximating the ships sections. Such an approach permits an evaluation of the impact pressure at the critical instant of impact. Experimental studies were conducted in regular waves to determine the effect of bow form and hull size on slow induced pressures.

(h) "A. Theoretical Consideration of Impact at Ship Slamming," by K. M. Ochi and M. D. Bledsoe, TMB Report 1321.

"Model Experiments on the Effect of a Bulbous Bow on Ship Slamming," by K. M. Ochi, TMB Report 1360 .

"Experiments on the Effect of Bow Form on Ship Slamming," by K. M. Ochi, TMB Report 1400 .

\section{(1788) WAX DEVELOPNENT.}

(b) David Taylor Model Basin.

(d) Experimental testing.

(e) Development of a wax composition and manufacturing techniques for the manufacture of ship models up to $30 \mathrm{ft}$. on water-line length.

(f) Completed.

(g) The blend developed is entirely suited to the climatic conditions existing in Wash., D. C. The strength of this material is such that all types of models, including submarines, may be constructed and handled with no greater care than is given to corresponding 
wood models. Ninety-one models, varying in length between 19 and $24 \mathrm{ft}$ and in weight between 1,000 and 4,500 lbs., and four $30 \mathrm{ft}$ models have been successfully manufactured and tested since the development of this new wax blend. The introduction of wax model construction technique has resulted in a substantial saving in time and cost of ship model manufacturing at TMB.

\section{(2019) SERIES 60 - PROPELTER EXCITED VIBRATION.}

(b) David Taylor Model Basin and Society of Naval Architects and Marine Engineers.

(d) Experimental basic research.

(e) Measurement of propeller induced vibratory forces on a series of models with variations in stern shape.

(g) The instrumentation and test techniques for measuring the propeller induced vibratory forces on a single screw ship model has been developed sufficiently to obtain repetitive results. Although there is insufficient information available to permit extrapolation to full scale forces, comparison of test results of models of similar type and dimensions appears valid. During the past year tests were conducted of a series of 3 models, based on the $0.70 C_{B}$ Series 60 parent form, with variations in stern section shape from $U$ to $V$.

Measurement of instantaneous pressure has been made on the hull of the USS TIMMERMAN and on the hull of a 30-foot model of that vessel. Preliminary data indicates that the model measurements when similarly extrapolated also produce higher values than were measured on board ship.

(h) "The Effect of Variations in Afterbody Shape Upon Resistance, Power, Wake Distribution and Propeller Excited Vibratory Forces," by G. R. Stuntz, F. C. Pien, W. B. Hinterthan, and N. L. Ficken, Society of Naval Architects and Marine Engineers Paper, November 1960.

\section{(2229) NEAR SURFACE EFFECTS.}

(b) Bureau of Ships; David Taylor Model Basin.

(d) Hyarodynamic research.

(e) A mathematical study of the forces and moments acting on bodies due to the proximity of a free surface. The studies include both the case in which the surface is initially undisturbed and the case in which there are disturbances originating at a distance. Experiments are being conducted to verify the theoretical developments .

(g) Methods were developed for computing the forces and moments acting on bodies of revolution, both due to waves generated by the body itself and to regular trains of waves. Experiments with a spheroid moving under waves largely confirmed the theory except in following seas. The damping forces on a submerged translating ellipsoid which is oscillating in any of its six degrees of freedom have been developed theoretically. (h) "A Note on the Stripwise Damping of a Submerged Spheroid," by J. N. Newman, Journal of Ship Research, Vol. 4, No. 1, pages 8-11 (1960).

(2230) THEORY OF SEAWORTHINESS.

(b) Bureau of Ships; David Taylor Model Basin.

(d) Hydrodynamic research.

(e) A theoretical and experimental study of factors affecting the seaworthiness of ships, for the purpose of developing procedures for predicting their motion. The work is oriented in three directions: (1) Finding the equations of motion of a ship in a seaway, with the forces obtained from solutions of the boundary value potential problem. This approach will provide equations which are valid for transient as well as steady-state oscillatory conditions. (2) Validification of the more common technique of assuming that the longitudinal plane motions can be described by a system of linear second order differential equations with constant frequency dependent coefficients. The coefficients in the equations of motion are determined experimentally, as well as the forces on restrained models in regular waves. The motions of a free model can then be computed and compared with experiments to determine the validity of the theory. (3) Analytical and experimental studies of the damping of ship motions by free surface effects.

(g) A restrained ship model has been towed in regular waves and the force and moment induced by the waves has been mea sured. Comparison of these data with calculations based on the Froude-Krylov hypothesis shows only qualitative agreement. Calculation of damping coefficients has been completed for Series 60 models, yielding generally excellent agreement with forced oscillation experiments.

(h) "The Damping and Wave Resistance of a Pitching and Heaving Ship," J. N. Newman, Journal of Ship Research, Vol. 3, No. I, pages 1-19 (1959).

"A Comparison of Experimental and Theoretical Hydrodynamic Forces and Moments Acting on a Restrained Surface Ship in Regular Waves," A. Gersten, TMB Report 1424.

\section{(2231) HYDRODYNAMIC ROUGHNESS STUDIES.}

(b) Bureau of Ships; David Taylor Model Basin.

(d) Theoretical and experimental; basic and applied research.

(e) Research on methods for analyzing and predicting the frictional resistance of arbitrarily rough surfaces such as the painted surfaces of ship hulls. The geometrical characteristics are to be correlated with the hydrodynamic characteristics.

(g) A new roughness profilometer has been built for use in curved surfaces and which is integrated into a magnetic tape recording system. A theoretical method has been 
devised for predicting the full scale resistance of arbitrarily rough surfaces from tests if model plates with the actual roughness. A high speed towing rig is under design and construction for these tests.

(h) "A Surface Roughness Profilometer," by J. B. Miller, TMB Report 1347, Sept. 1960.

(2232) PRESSURE AND VELOCITY DISTRIBUTIONS ON TWODIMENSIONAL AND AXI-SYMMETRIC THREE-DIMENSIONAL FORMS.

(b) Bureau of Ships; David Taylor Model Basin.

(d) Theoretical; applied research.

(e) Investigate analytic techniques for determining the pressure and velocity distribution on two-dimensional and axi-symmetric three-dimensional forms. The solution is to be amenable to coding for a high speed computor.

(f) Inactive.

(g) This project has been terminated with the delivery of an IBM 704 program for computing pressure and velocity distribution on twodimensional and axisymmetrical three-dimensional forms developed at Douglas Aircraft Co. under a TMB external research contract.

\section{(2235) LIBERTY SHIP SEAWORTHINESS.}

(b) Bureau of Ships; David Taylor Model Basin.

(d) Experimental.

(e) Thorough seaworthiness investigations of a Iiberty Ship and a modified Liberty Ship hull. Full scale trials were conducted during several crossings of the North Atlantic. Speed reduction, ship motion stresses and slaming pressures were investigated.

(g) The motion and stress data obtained for special maneuvers conducted on each of the ships in approximately a State 5 sea have been analyzed and a comparative evaluation made for this particular oceanographic condition. Data obtained in other sea conditions are currently under analysis.

(h) "Seakeeping Trials on Two Modified Liberty Ships - Part I: Performance in a Sea State 5" by M. O. Bledsoe and P. Plaia, TMB Report 1439.

(2236) OSCILLATING PRESSURES IN THE VICINITY OF PROPELLERS.

(b) David Taylor Model Basin.

(d) Experimental and theoretical; applied research.

(e) Studies of the oscillating pressures on boundaries and in the free space produced by propeller operation. The purpose of the work is to determine the magnitude of the hydrodynamic propeller excited vibratory forces acting on ship's hulls and the effect of operating parameters.

(f) Completed.

(g) Experimental results have been completed.

(2237) LIFTING SURFACE THEORY OF PROPELLERS.

(b) Cooperative with Bureau of Ships. (d) Theoretical; applied research.

(e) Studies of the corrections on lifting line theory which arise from the finite extent of the blades.

(f) Application of an approximate lifting surface theory is completed. Development of a rigorous theory currently in progress.

(g) The available results are being applied to propeller design methods.

(2462) PITCH REDUCTION STUDTES.

(b) Bureau of Ships; David Taylor Model Basin.

(d) Experimental and theoretical.

(e) To determine the mechanism of occurrence and basic properties of horizontal hull vibrations induced by anti-pitching fins.

(g) To clarify the mechanism whereby the transverse vibrations are induced, a fiber glass model of the Mariner was tested and the fin loading model motions and hull vibrations recorded. The effect of position of the fin along the hull on the vibration was studied. It was found that the vibrations are the result of an impact on the fin due to collapse of a cavity and/or slamming.

(h) "Effect on Hull Vibrations of Various Bow Anti-Pitching Fin Configurations," by G. P. Stefun and F. M. Schwartz.

"Vibrations Induced by an Anti-Pitching Fin," by K. M. Ochi, TMB Report 1455.

(2463) STUDIES OF LOW ASPECT-RATIO CONTROL SURFACES.

(b) David Taylor Model Basin; Laboratory project.

(d) Experimental investigation; basic research.

(e) Determine the aerodynamic characteristics of a family of low aspect-ratio control surfaces which can be used by the designer of submarines and surface ships.

Phase $I$ is an investigation of a family of all-movable control surfaces. Phase II is an investigation of the same family with plain flaps of different chord length.

(f) Phase I, completed; Phase II, active.

(g) The results of Phase I indicate that many of the aerodynamic characteristics of low aspect-ratio surfaces can be accurately predicted from lifting surface theory.

(h) The results of Phase I and comparisons with lifting surface theory are presented in DTMB Report No. 933.

(b) Bureau of Ships; David Taylor Model Basin.

(d) Experimental and theoretical investigation of the excitations of cavity resonance by fluid flow.

(e) Studies to determine the mechanism of excitation of the cavity resonance by fluid flow past orifice will be undertaken. The experimental investigation will employ the low turbulence wind tunnel and circulating water channel. The amplitude of pressure fluctuations in the cavity will be investigated as function of the size, shape and number of orifices, as well as the turbulence characteristics ir the boundary layer flow.

(h) "Studies of the Mechanism for the Flow 
Induced Cavity Resonance," by M. C. Harrington and W. H. Dunham. Presented at the Fifty-Ninth Meeting of the Acoustical Society of America, Brown University, Providence, Rhode Island, June 1960.

\section{(2471) THEORY OF CONTRA-ROTATING PROPELLERS.}

(b) Cooperative with the Bureau of Ships.

(d) Experimental and theoretical; applied research.

(e) Studies of the theory of contra-rotating propellers without assumptions regarding the orientation of the resultant induced velocity. Open water and water tunnel tests to determine, experimentally, the effect of various propeller parameters.

(g) Application to open water and wake adapted propellers. Latest experiments have shown the performance to be insensitive to spacing between propellers so long as they are operated at their design spacing.

(h) "The Effect of Axial Spacing and Diameter on the Powering Performance of Counterrotating Propellers," by R. Hecker and N. A. McDonald, TMB Report No. 1342, Feb. 1960.

(2472) COOPERATIVE TESTS ON A VICTORY SHIP DESIGN.

(b) David Taylor Model Basin: Skin Friction Committee of the International Towing Tank Conference.

(d) Experimental testing; basic research.

(e) The investigation was authorized by the International Committee on "Scale Effect on Propellers," and on "Self-Propulsion Factors," as part of the international cooperative test program in ship basins. The International Conmittee will compare the results from the various basins and present a report to the coming International Conference. The tests will be carried out with a wax model of scale $1: 23$ equipped with different kinds of stimulators. The friction corrections will be calculated by the various basins according to their methods.

(g) The specified program of model testing has been completed. The required calculation for the power predictions have to be done before the evaluation work can proceed. Results have been reported to the International Towing Conference. A TMB Report is being prepared comparing TMB results with those of other basins.

(2727) THE EFFECT OF HUB DIAMETER ON THE OPTTMUM DISTRIBUTION OF CIRCULATION OF PROPELLERS.

(b) Davia Taylor Model Basin.

(d) Theoretical; applied research.

(e) Studies of the effect of hub diameters on the optimum distribution of circulation. Inactive.

(g) Calculations have been completed.

(2729) HULL FORM RESEARCH WITH A FLEXIBLE MODEL.

(b) David Taylor Model Basin. (d) Development and experimental work.

(e) A flexible model which can be quickly changed to have any fullness and any shape of section area curve is to be developed first. The effect of section area curve parameters, such as $t_{F}, t_{A}, C_{P F}, C_{P A}, L_{E}$, $\mathrm{LX}, \mathrm{X}_{\mathrm{F}}, \mathrm{X}_{\mathrm{A}}$, etc., upon resistance will be systematically investigated by using this flexible model.

(f) Inactive.

(g) The flexible model has been built and experimental test work begun. Thirty resistance tests have been conducted during the past fiscal year. Preliminary work with this flexible model indicates its adaptability for this work is satisfactory. An analysis of the test results has not been completed.

(2730) MOLECULAR-PHYSICAL SKIN EFFECT.

(b) David Taylor Model Basin.

(d) Experimental applied research.

(e) The frictional resistance of a "new" plate consisting of a special molecular coating will be compared with the frictional resistance of a hydraulically smooth brass plate and of a mirror smooth glass plate. The test equipment will be designed and constructed to study wave and spray formation for the determination of the true wetted surface. The plate will be tested with maximum speed of 15.0 knots and with various stimulation devices.

(g) The Nikuradse coated plates have been tested. Significant resistance differences between coated and non-coated plates have been measured on a coated brass plate and an uncoated aluminum plate. Since the contours of the leading and trailing edges of the two plates vary considerably a doubt is raised at whether the coating or the difference in the contours caused the resistance differences. A stainless steel plate having the same contours as the coated brass plate has been constructed and tested. The resistance of this plate has been obtained. and the relation between the coated and uncoated plate will be the subject of an additional report.

\section{(2962) DUTCH DESTROYER SEAKEEPING TRIALS.}

(b) Bureau of Ships; David Taylor Model Basin. (d) Field investigation (Full Scale Trials).

(e) An account of seakeeping trials carried out jointly by the Royal Netherlands Navy and the United States Navy with three destroyers.

(f) Completed.

(g) Measurements were made of motions accelerations, slamming pressures and stresses. These were analyzed to determine the effect of the seaway, of speed and of relative course on these quantities.

(h) "Seakeeping Trials on Three Dutch Destroyers," by M. D. Bledsoe, O. Bussemaker and W. E. Cummins, presented at the Spring Meeting of the Society of Naval Architects and Marine Engineers, May 1960. 


\section{(2967) CONTROL SURFACE FLUTTER.}

(b) Bureau of Ships; David Taylor Model Basin.

(d) Experimental and theoretical; basic investigation.

(e) Experiments are being conducted with a flutter apparatus to determine flutter speeds as a function of inertias, spring and damping constants. The results will be compared with a simplified rudder flutter analysis which can then be applied to design procedures.

(g) Flutter (a self-excited, oscillatory instability) of a small-aspect-ratio foil was produced in water, without free surface effects, at a speed of $20 \mathrm{ft} / \mathrm{sec}$.

(h) "Hydroelastic Instability of a Control Surface," by D. A. Jewell and M. E. McCormick, TMB Report 1442 (in preparation).

(2969) FLOW STUDIES ON THREE-DIMENSIONAL FORMS.

(b) Bureau of Ships; David Taylor Model Basin.

(d) Experimental and theoretical basic research.

(e) Pressure distributions and flow studies have been made in a wind tunnel on several shapes similar to those of certain sonar domes. Data will be used in predicting those conditions of ship speed, yaw and pitch which are conductive to cavitation on sonar domes.

(f) Inactive.

(h) "Pressure Distribution Apout Four Sonar Domes," by R. D. Cahn, report in review.

(2970) STUDIES OF HYDRODYNAMIC LOADING ON BARE AND FAIRED CABLES.

(b) David Taylor Model Basin.

(d) Experimental investigation; basic research.

(e) Measure the tangential and normal hydrodynamic forces acting on a long cylinder towed at various angles to the stream over a range of Reynolas numbers. Tests will be made with various degrees of roughness simulating stranded cable, and various trailing-type fairing designs.

(2971) FUII SCALE TRIAL AND MODEL PREDICTION CORRELATION.

(b) Bureau of Ships; David Taylor Model Basin.

(d) Experimental testing and re-evaluation of existing test data.

(e) The accuracy of full scale power predictions from model test results depends upon the selection of the proper correlation allowance $\left(\Delta C_{f}\right)$ to be used in model calculations. Model tests have been conducted and past correlations have been re-analyzed such that a total of 54 correlations have been completed. An analysis of this data has begun.

(g) Analysis of the completed correlations has begun and is scheduled for completion by January 1, 1961. The presentation of a paper to the Society of Naval Architects and Marine Engineers is projected.

(3282) RADIAL DISTRIBUTION OF PROPELLER THRUST FROM MODEL WAKE MEASUREMENTS. (b) Bureau of Ships; David Taylor Model Basin.

(d) Experimental; applied research.

(e) Information concerning the radial distribution of thrust is needed for a propeller operating behind a submerged body of revolution. The results of theory and experiment are compared. The experimental thrust distribution was obtained from the axial momentum equation by applying appropriate corrections for slip stream rotation and contraction. The theoretical thrust distribution was obtained from the circulation distribution of the propeller with a finite hub.

(f) Completed.

(g) The radial distribution of propeller thrustload coefficient is calculated from experimental wake data obtained from towed and self-propulsion tests on a body of revolution. The experimentally obtained thrust distribution is in excellent agreement with a theoretically calculated distribution. Numerical integration yields a total thrustload coefficient which is in good agreement with propulsion test results.

(3283) FUNDAMENTAL HYDROMECHANICS RESEARCH.

(b) Bureau of Ships; David Taylor Model Basin.

(d) Applied research.

(e) Survey of work carried out under Bureau of Ships Fundamental Hydromechanics Research Program.

(f) Completed.

(g) Survey includes results obtained during the period of 1952 to present.

(3284) UNSTEADY HYDROFOILS.

(b) Bureau of Ships; David Taylor Model Basin.

(d) Experimental and theoretical applied research.

(e) The purpose of this work is to provide hydrofoil design criteria to the Bureau of Ships to be used in designing high speed, seagoing hydrofoil craft. The objective is to determine the steady and unsteady forces on hydrofoils due to heaving and pitching oscillations of the foil and due to encounters with regular head and following waves on the foil when operated in proximity to the free water surface. Both fully wetted and cavitating foil conditions are being studied. This work is related to Hydroelasticity (Reference No. 3285) and Cavitation (Reference No. 7ll) studies.

(g) The unsteady lift force on a flat restrained hydrofoil advancing through regular head and following waves has been measured experimentally. The experimental data has been compared with theoretical data.

(h) "The Unsteady Lift Force on a Restrained Hydrofoil in Regular Waves," by J. M. Steele, Jr. and D. A. Jewell, TMB Report 1408 (in preparation).

\section{(3285) HYDROELASTICITY PROBLEMS.}

(b) Bureau of Ships; David Taylor Model Basin.

(d) Experimental and theoretical; applied research. 
(e) Investigations to determine the conditions which produce hydroelastic instability of oscillatory hydrofoil systems. The effects of speed, frequencies, mass distribution, cavitation, free surface and waves on the system stability will be studied. This work is related to Unsteady Hydrofoils (Reference No. 3284), Cavitation Studies (Reference No. 711), and Control Surface Flutter (Reference No. 2967).

(g) Flutter (a self-excited, oscillatory instability) of a small-aspect-ratio foil was produced in water, without free surface effects, at a speed of $20 \mathrm{ft} / \mathrm{sec}$.

(h) "Hydroelastic Instability of a Control Surface," by D. A. Jewell and M. E. McCormick, TMB Report 1442 (in preparation).

(3286) THEORY OF SUPERCAVITATING PROPELTERS.

(b) Bureau of Ships; David Taylor Model Basin.

(d) Theoretical and experimental; applied research.

(e) Studies and design of propellers designed to operate at high speeds.

(g) The prediction and experimental confirmation of the performance of such propellers have been completed.

(3287) EFFECT OF STERN MODIFICATION TO A SERIES 60 VESSEL, RESISTANCE POWERING, WAKE DISTRIBUTION AND PROPELLER INDUCE VIBRATION.

(b) David Taylor Model Basin; Maritime Administration.

(d) Experimental testing and evaluation of data for basic research.

(e) Models representing specific variations in stern shapes and designed for special instrumentation installation will be buil.t. The basic design will be the Series 60, 0.70 Block Coefficient Parent. Six other forms will be derived having systematic changes in section shapes (from extreme $V$ to extreme $U$ ) and for variation in waterline endings (from fine to blunt). An attempt will be made to develop formulation to mathematically express the stern variations from the parent.

(g) The basic model has been constructed and powering data has been obtained.

(h) "Series 60 - The Effect of Variations in Afterbody Shape Upon Resistance, Power, Wake Distribution and Propeller Excited Vibratory Forces, " by G. R. Stuntz, P. C. Pien, W. B. Hinterthan, and N. L. Ficken, Society of Naval Architects and Marine Engineers Paper, Nov. 1960.

\section{(3288) SHIP STABILIZATION.}

(b) Bureau of Ships; David Taylor Model Basin.

(d) Theoretical; applied research.

(e) The roll response of an AK cargo vessel converted for use as a missile tracking station has been simulated on an analog computer to evaluate the stabilization accomplished by passive anti-rolling tanks. A description of the simulation, the ship responses to regular wave action and some comparison with experimental values pre- sented in the report of the study.

(f) Completed.

(h) "Analog Simulation of a Passive Anti-Rolling Tank System for a Missile-Range Ship," by J. W. Church, TMB Report 1322, May 1959.

(3292) EXPLORATORY STUDIES AND PLANS AT DTMB FOR MODEL TESTS IN 3-DIMENSIONS.

(b) Bureau of Ships; David Taylor Model Basin.

(d) Experimental, basic research.

(e) A new seakeeping test facility is to be in operation in 1961. Techniques for generating irregular short-crested seas and measuring the response of ship models at oblique headings is under development.

(g) Segmented wave generators provide the ability to produce oblique waves. Programming to individual wavemakers results in generation of confused seas of almost any nature. The rectangular basin offers opportunity to test in any relative heading to the waves and even in cross seas. Problems in analysis involve determination of the seaway (in the tank) as a function of frequency and direction. Ship motions in confused seas will be random in nature and will be analyzed by spectrum methods.

(h) "Wave Propagation in the Tenth-Scale Model of the Seakeeping Basin, Part II - Generation of Oblique Waves," by W. Marks, TMB Report in review.

"SEADAC The Taylor Model Basin Seakeeping Data Analysis Center," by W. Marks and P. E. Strausser, TMB Report 1353, July 1960. "SPLASHNIK The David Taylor Model Basin Disposable Wave Buoy," by W. Marks and R. G. Tuckerman, TMB Report 1423 (in preparation).

(3293) RELATION OF HULL FORM TO SEAWORTHINESS AND SPEED MAINTENANCE.

(b) Bureau of Ships; David Taylor Model Basin.

(d) Experimental and theoretical; basic research.

(e) In order to establish meaningful design criteria for ships with minimum motions, dry decks and high sustained sea speed, tests will be conducted to relate ship behavior and speed maintenance to sea state and hull form. The limited model data currently available pertains largely to unrelated forms and speed reduction is not included. Therefore, systematic model tests will be conducted in order to establish the required relations.

(g) A preliminary study of results obtained from various model tests in waves indicates that variations in pitch and heave amplitudes among the different models can be attributed to variations of the average beam-draft ratios in the case of heave, and to variations of the modified displacement-length ratios in the case of pitch.

\section{(3294) SEAWORTHINESS OF HYDROFOIL CRAFT.}

(b) Bureau of Ships, David Taylor Model Basin.

(d) Theoretical research.

(e) A theoretical study of the vertical plane 
motions of a hydrofoil craft in sinusoidal waves.

(g) An earlier theoretical development of the equations of motion for hyarofoil craft has been extended to include unsteadiness and non-linearities. Computer solutions have been obtained for the pitching and heaving motions in sinusoidal waves. Good agreement with an available set of experimental results have been obtained.

\section{(3617) VENTILATED PROPELLER DEVELOPMENT.}

(b) David Taylor Model Basin.

(d) Theoretical and experimental; applied research.

(e) Studies and design of ventilated propellers for operation at intermediate speeds.

(g) Experiments have been completed on the first ventilated propeller.

(3618) PRESSURE DISTRIBUTION ON BLADES OF MARINE PROPELIERS UNDER OPERATING CONDITIONS.

(b) David Taylor Model Basin.

(d) Experimental; applied research.

(e) Experimental determination of the pressure distribution on the blades of marine propellers under operating conditions and comparison with theoretical values obtained from two-dimensional airfoil theory.

(f) Inactive.

(g) Experimentation on one propeller completed.

(h) "Measurement of Pressure Distribution on Blades of Marine Propellers," J. Auslaender. Paper presented at American Towing Tank Conference, Berkeley, California, Aug. 1959.

\section{(3619) VERTICAL AXIS PROPELIER.}

(b) Bureau of Ships; David Taylor Model Basin.

(d) Experimental and theoretical; applied research.

(e) Theoretical and experimental studies of performance characteristics of various types of vertical axis propellers.

(g) First phase of experimental work has been completed.

(h) "Experimental Performance of a Six-Bladed Vertical Axis Propeller," by B. V. Nakonechny, TMB Report 1446, Oct. 1960.

(3620) PROPELLER PERFORMANCE IN UNSTEADY FLOW.

(b) David Taylor Model Basin.

(d) Experimental and theoretical; applied research.

(e) Experimentation to evaluate the effect of various dimensional characteristics on the time dependent propeller forces while operating in waves. Correlation of results with wave theory.

(f) Inactive.

(g) A 16" diameter bronze propeller has been tested in various waves. The thrust and torque coefficients were calculated for the wave crests and wave troughs. The wave velocity from the trochoidal wave theory was applied the advance coefficients.

(3621) STUDY OF BENDING MOMENTS OF A SHIP MODEL

\section{MOVING IN WAVES.}

(b) Bureau of Ships; David Taylor Model Basin.

(d) Theoretical and experimental basic research.

(e) To provide ship designers with more exact information concerning the magnitude of bending moment and shear forces in a ship moving in waves.

(g) Bending moment about the transverse axis and vertical shear forces were measured experimentally in regular head seas and results compared with analytical calculations of motions bending moments and shear forces. The above work was supplemented by additional tests in regular following waves. Results of both tests are being analyzed and a report is being written.

\section{(3622) FLUCTUATING FLOWS.}

(b) Bureau of Ships, David Taylor Model Basin.

(d) Experimental and theoretical basic research.

(e) The mechanism of the fluctuations in the flow about a body in a moving stream will be studied. Correlations of varying forces and motions of the body will be sought. In one experiment a cylinder while being towed will be oscillated at frequencies above and below the frequency of vortex shedding with a view toward an explanation of the lack of spanwise correlation of vortex shedding from rigid cylinders.

\section{(3999) SHIP WAKE CHARACTERISTICS.}

(b) Bureau of Ships; David Taylor Model Basin.

(d) Experimental; Applied Research.

(e) Development of instrumentation for measuring turbulent velocities and thermal microstructure in ship wakes. Measurements will be made to determine the rate of decay and dispersion of wakes.

\section{(4000) DRAG REDUCTION BY BOUNDARY LAYER CONTROL.}

(b) Bureau of Ships; David Taylor Model Basin.

(d) Theoretical and experimental; basic and applied research.

(e) Investigations into feasibility of achieving drag reduction by boundary layer control in applications to naval hydrodynamics. Tests are to be made on flat plates with flexible coatings which delay transition to turbulent flow.

(g) Towing rig under design and construction.

For sponsored projects see the following:

(3026) Ship Resistance in Uniform Waves as a Function of Block Coefficient and Wave Steepness.

(3686) Non-Linear Coupled Ship Motions.

(3717) Pressure Waves Radiated by a Collapsing Cavity.

(3721) Calculation of Three-Dimensional Potential Flows.

(3730) Dynamic Behavior of Ground Effect Vehicles.

(2802) Experimental Study of Wave Mechanics.

(2356) Ship Motions Project. 
(3499) Studies of Hydrofoil Configurations in Regular Waves.

(3504) Experimental Determination of Unsteady Lift and Drag Forces on Dihedral Hydrofoils in Waves.

(3826) Hydrodynamics of Ship Slamming.

(3828) Studies in Hydroelasticity.

(2615) Forces and Moments on Submerged Bodies Below Waves.

(2616) The Blade Frequency Force Generated by a Propeller on a Body of Revolution.

(2866) An Analytic Study of the Pressure Field Near Counterrotating Propellers.

(3171) Analytical Study of the Thrust Deduction of a Single-Screw Thin Ship.

(3173) Hydroelastic Instabilities of Supercavitating Hydrofoils.

(3176) Theory of Lateral Motions of Ships in Waves.

(3509) Theoretical Calculations of the Vibratory Thrust Produced by a Ship Propeller Operating in the Wake of a Hull.

(3512) Blade Frequency Pressure Near an Operating Marine Propeller in a Wake.

(3514) Theoretical and Experimental Investigation of Flutter of Fully-Wetted Hydrofoils.

(3518) The Effect of High Speed on Lateral Ship Stability.

(3829) Development of Sonic Wave Probe for use on Ships.

(3830) Radiation of a Marine Propeller Pressure Wave From Elastic Plate and Cylinder.

(3831) Correlation of Theoretical Results with Experiments on Vibratory Thrust and Pressure.

(3836) Acoustic Excitation of Flat Plates in a Murbulent Boundary Layer.

(3519) Deep-Sea Mooring of Ships in Waves and Currents.

\section{U. S. DEPARTMENT OF THE NAVY, NAVAL BOILER AND} TURBINE LABORATORY.

\section{(2731) EFFECT OF PIPE ROUGHNESS ON ORIFICE METER} ACCURACY.

(b) American Gas Association.

(c) American Gas Association, 420 Lexington Avenue, New York 17, New York.

(d) Experimental, applied research.

(e) To determine the effect of meter tube roughness on the discharge coefficient of orifice meters for tube surfaces varying in roughness from that of run of the mill pipe to bored and honed tubes.

(f) Completed.

(g) Results conclusively indicate that tubes can be honed without affecting their accuracy. In normal metering practice the honing of tubes will not change the coefficient in any pipe size.

(h) "Effect of Pipe Roughness on Orifice Meter Accuracy," by H. S. Bean and J. W. Murdock, Report of Supervising Committee on Four Inch Tests, American Gas Association Research Project NW-20, February 1960.
(3623) HIGH PRESSURE-TEMPERATURE WATER FLOW METER CALIBRATION .

(b) Bureau of Ships; Philadelphia Naval Shipyard (Naval Boiler and Turbine Laboratory).

(c) Mr. J.W. Murdock, Head, Applied Physics Division, Naval Boiler and Turbine Lab.

(d) Experimental; applied research.

(e) A facility is available for calibrating with water at pressures and temperatures up to $2500 \mathrm{psi}$ and $600 \mathrm{~F}$ respectively. Capacity is $100 \mathrm{gpm}$ at maximum pressure and temperature and greater at lower pressures and temperatures. After flowing through the metering section the water is cooled and weighed. The facility is also used to investigate and verify orifice meter coefficients at pressures and temperatures above those at which the coefficients in use were established.

(g) A limited amount of test data indicate good agreement between orifice flow rates obtained by calibration at high pressures and temperatures and those obtained by extrapolating from cold water calibrations. Other meter tests show the need to include suitable corrections for change in shape, size, density, etc.

\section{(3624) INVESTIGATION OF ELBOW FLOW METERS.}

(b) Bureau of Ships; Philadelphia Naval Shipyard; (Naval Boiler and Turbine Laboratory).

(c) Mr. J.W. Murdock, Head, Applied Physics Division, Naval Boiler and Turbine Lab.

(d) Experimental, applied research.

(e) The 90 degree elbow has been proposed for metering flow in shipboard systems. This type meter is attractive since the use of an existing elbow would not require any changes to the piping and would impose no additional pressure drop on the system. The chief drawbacks are large variation in elbows and the lack of an exact relationship between flow and differential pressure. Testing will be limited to the long turn 90 degree, type A elbows of Specification MIL-F-1183 to establish criteria for their installation and use.

\section{(4001) HIGH PRESSURE STEAM AND WATER FLOW TESTS.}

(b) American Society of Mechanical Engineers.

(c) Research Committee on Fluid Meters, American Society of Mechanical Engineers, 29 West Thirty-Ninth Street, New York 18, New York.

(d) Experimental, applied research.

(e) Although the ASME Research Committee on Fluid Meters has sponsored many fundamental research programs dealing with the development of basic constants used with primary elements, hardly any of this work has been done on steam flow at high pressures and temperatures. Neither has research been done on high temperature water flow. Analysis of many tests indicate that the basic calibrations obtained with low temperature water (air and gas) could be extrapolated with high accuracy to the measurement of high pressure and temperature steam and water flow provided suitable corrections were 
made for the change in the shape and size of the primary element, the pipe and the fluid. This procedure has been experimentally verified for steam up to 1250 psi and $950^{\circ} \mathrm{F}$ and for water to $200 \mathrm{psi}$ and $150^{\circ} \mathrm{F}$. Beyond these limits, the metered steam flow produced by a steam generator is sometimes found to exceed the metered feedwater input to the generator.

U. S. NAVAL ORDNANCE TEST STATION,

\section{(3295) FORCED VENTIIATION OF HYDROFOILS.}

(b) Bureau of Naval Weapons, Department of the Navy.

(c) Commander, U. S. Naval Ordnance Test Sta., Attn: T. G. Lang or A. G. Fabula, Code P508 3202 East Foothill Blvd., Pasadena, California.

(d) Experimental and theoretical; basic research.

(e) The hydrodynamic lift, drag, pitching moment and pressure distribution on hydrofoils of various cross-sections from which gas is exhausted are being studied for possible use primarily on torpedoes as a simple means of varying control forces.

(g) Water tunnel tests have been conducted at the California Institute of Technology with various flow rates and, exhaust hole sizes, shapes and arrangements and with exhaust either from one side or from a thick-cutoff trailing edge. For the uniform spanwise exhaust case with full-cavity flow (i.e. with free streamlines extending beyond the trailing edge), thin-airfoil theory has been applied to consider arbitrary exhaust location and cavity pressure.

(h) "Base Vented Hydrofoils," by T. G. Lang. NAVORD 6606 of 19 October 1959.

"Theoretical Lift and Drag on Vented Hydrofoils for Zero Cavity Number and Steady Two-Dimensional Flow, " by A. G. Fabula. NAVORD 7005 of 4 November 1959. "Water Tunnel Tests of Hydrofoils With Forced Ventilation," by T. G. Lang, Dorothy A. Daybell, and K. E. Smith. NAVORD 7008 of 10 November 1959.

"Application of Thin Airfoil Theory to Hydrofoils with Cut-off, Ventilated Trailing Edge," by A. G. Fabula. NAVWEPS 7571, in preparation.

"Water Tunnel Tests of a Base-Vented Hydrofoil Having a Cambered Parabolic Cross Section," by T. G. Lang and Dorothy A. Daybell. NAVWEPS 7584 , in preparation.

\section{(4002) MISSIIE BEHAVIOR DURING WATER EXIT.}

(b) Bureau of Naval Weapons, Navy Department.

(c) Commander, U. S. Naval Ordnance Test Station, Attn: Dr. John G. Waugh, Code P8074, 3202 E. Foothill Blvd., Pasadena, California.

(d) Experimental; basic research.

(e) The purpose of this project is, to study missile water-exit behavior and associated phenomena under different conditions to determine if problems may exist in missile water-exit technology and to establish scaling techniques for modeling misstle water-exit behavior.

(g) A preliminary study was made of the water exit behavior of a momentum-propelled 2inch-diameter hemisphere-head missile under different degrees of cavitation, ranging from fully wetted to fully cavitating, and for a range of trajectory water-exit angles. The results indicate that considerable perturbations in missile pitch and pitch velocity take place at water exit, and it is inferred that problems may exist in missile water-exit technology.

(h) "Underwater Launch and Trajectory Modeling Scaling Techniques," by J. G. Waugh. NAVORD 7029, 15 March 1960.

\section{(4003) UNDULATING HYDROFOIL PROPULSTON.}

(b) Bureau of Naval Weapons, Department of the Navy .

(c) Commander, U. S. Naval Ordnance Test Station Attn: Howard R. Kelly, Code 40606, China Lake, California.

(d) Experimental and theoretical; basic research.

(e) To measure the propulsive force on a thin, two-dimensional hydrofoil, undulating in sinusoidal motion, and compare with theory.

(g) The results to date have shown good agreement with recent theoretical analyses, with positive thrust for high frequency of undulation and negative thrust for low frequencies. Some earlier theory by Smith and Stone has been revised to include the effect of wake vorticity, which had been neglected, and agreement with experiment improved. Power input and propulsion efficiency are also predicted by the theories. Measurement of these quantities is in progress.

(h) "Propulsion With an Undulating Thin Hydrofoil," by Howard R. Kelly, Glenn Bowlus, and A. W. Rentz. NAVWEPS Report, in preparation.

(4004) LIFT AUGMENTATION BY SPANWISE FLUID EJECTION.

(b) Laboratory project.

(c) Commander, U. S. Naval Ordnance Test Station, Attn: John D. Brooks, Code P8040, 3202 East Foothill Blvd., Pasadena, California.

(d) Experimental; applied research.

(e) Purpose of the study was to determine the effect on lift of a fluid jet ejected spanwise from a three-dimensional hydrofoil. The jet acts as a barrier to decrease the end flow around the tips of the foils and thus increases the effective aspect ratio. Jet flow rate, slit width, and hydrofoil aspect ratio were varied. An internal report has been prepared.

(f) Completed.

(g) It was found that the lift for a given angle of attack and stream velocity increases as the jet momentum increases. With the highest jet momentum a lift increase by a factor of five was obtained. 
U. S. DEPT. OF THE NAVY, OFFICE OF NAVAL RESEARCH.

For sponsored projects see the following:

Project

Page

(1548) Special Problems in Hydrodynamics.

(3377) Theoretical Studies in Hydrodynamics.

(3009) Cavitation Similitude.

(3378) Cavitation in Cascades.

(2753) Hydraulic Breakwater.

(3677) Annular Nozzle Ground Effect Machine.

(3684) Propagation of Waves over an Obstacle in Water of Finite Depth.

(3687) Pressure Distributions, Added-Mass, and Damping Coefficients for Cylinders Oscillating in a Free Surface.

(2537) Water Exit Hydroballistics.

(73) Measurement of Turbulence in Flowing Water.

(79) Cavitation.

(81) Mathematical Analysis of Pressure Distribution.

(854) Boundary-Layer Development on Smooth and Rough Surfaces.

(2091) Research on Ship Theory.

(2451) Development of Instruments for Use in Analyzing Aperiodic Signals.

(2792) The Decay of Turbulence in a ZeroMomentum Wake.

(3074) Wake of Zero Momentum Flux.

(3075) Annular Jets in Ground Proximity.

(3429) Jet With Transverse Pressure Gradient.

(3430) Axisymmetric Gravity Waves.

(2801) Interaction of Waves With Floating Bodies.

(2802) Experimental Study of Wake Mechanics.

(3444) Effects of Basin Geometry and Viscous Damping on the Amplitude of Resonant Oscillations in Harbors.

(3445) Characteristics of Cross Waves.

(3463) Behavior of Wakes in Adverse Pressure Gradients.

(3755) Transition from Bubble to slug Flow.

(3756) Entrance Effect in a Two-Phase Slug Flow.

(3759) The Three-Dimensional Boundary Layer in the Vicinity of a Wedge.

(3120) Office of Naval. Research Atmosphere Interaction and Wave Project.

(2374) The Mechanism of Two-Phase Flow of Annular Liquid Films in a Vertical Tube.

(2144) Experimental and Analytical Studies of Hydrofoils.

(3153) Flow About Bodies at Small Cavitation Numbers.

(3821) Strut Interference Effects on Hydrofoil Systems.

(3822) Flow over Vibrating Plates.

(2154) Investigation of Ship Motions.

(3174) Unsteady Lift and Moment on Fully Cavitating Hydrofoils at Zero Cavitation Number.

(3517) Ships of Minimum Wave Resistance.

(3835) Hydrophone Self-Noise Research.

(2870) Model Study of Surge Action in a Port.

1
12

40

40

40

81

41

41

42

42

43

43

43

43

50

51

52

52

56

64

74

79

81

86

88

(3865) Ducted Propellers.

(1478) Wind Waves. 159

(2436) Flow Over Hydrophobic Materials. 159

(3250) Inertial Forces in Unsteady Flow. 159

(3599) Motion on Cylinders in Stratified Layers.

(3600)

Damping of Progressive Oscillatory

Internal Waves.

TENNESSEE VALLEY AUTHORITY, Hydraulic Data Branch.

Inquiries concerning all TVA projects should be addressed to Mr. Albert S. Fry, Hydraulic Data Branch, Tennessee Valley Authority, Knoxville, Tennessee.

Hydraulic Operations and Tests Section.

(731) SOUTH HOLSTON DAM, SURGE TANK MODEL STUDY.

(d) Experimental; for design.

(e) A 1:50 model of the penstock and surge chanber was used to determine (1) the orifice size and characteristic shape to produce favorable pressure and water surface elevations to be expected in the surge chamber; and (2) the operational characteristics of the selected design.

(f) Model studies completed.

(g) With the proper orifice between the riser and the surge chamber as satisfactory results can be obtained as with the differential riser type of surge tank.

(h) Report in preparation.

(758) CHEROKEE DAM, PROTOTYPE CHECK TESTS.

(d) Field investigation; applied research.

(e) Periodic checks and observations will be made on the various hydraulic appurtenances to determine the operating characteristics of the structures and the effect of operation on the structures.

(g) Measurement of pressures in the sluice barrel have been obtained and will be compared with pressures obtained in model tests. The apron and sluice barrels were inspected in 1953 to determine the effect of intermittent operation during the past eleven years.

(h) Report in preparation.

(759) DOUGLAS DAM, PROTOTYPE CHECK TESTS.

(d) Field investigation; applied research.

(e) Periodic checks and observations will be made on the various hydraulic appurtenances to determine the operating characteristics of the structures and the effect of operation on the structure.

(g) Measurement of pressures in the sluice barrel have been obtained and will be compared with pressures obtained in model tests. The apron and sluice barrels were inspected in 1953 to determine the effect of intermittent operation during the past ten years.

(h) Report in preparation.

(762) SOUTH HOLSTON DAM, SURGE TANK PROTOTYPE 
(d) Field investigation; applied research.

(e) The prototype installation was equipped to allow testing in a manner similar to that used in the model studies which established the design. A check on the model accuracy can thus be obtained.

(g) Tests made in February 1951, July and Oct. 1958 at headwater elevations 1630, 1719 , and 1690 , respectively.

(1534) FORT PATRICK HENRY DAM, SPILLWAY MODEL STUDIES.

(d) Experimental; for design.

(e) Tests were conducted on a 1:50 scale and $1: 112.5$ scale model to determine the apron design, training wall dimensions, and other related data.

(f) Model studies completed.

(g) An apron using a single row of rectangular baffle blocks was developed on the 1:50 scale model. This apron was then used in the $1: 112.5$ scale model and the necessary appurtenant structures developed. Of main interest in the developed design was the lack of training walls. Studies to determine the effect of vegetative growth on the island areas below the spillway showed which areas must be kept free of growth and which may be allowed to grow up. Installation completed and instruction manual partially completed and issued.

(h) "Fort Patrick Henry Project Hydraulic Model Studies," Tech. Monograph No. 87, 1960. TVA Treasurer's Office, Knoxville (\$2.50).

(1794) WATTS BAR LOCK PROTOTYPE TESTS.

(d) Field investigation; applied research.

(e) The prototype installation was equipped with piezometers to allow checking of culvert and port pressures and discharges. The culverts and ports were designed from model studies. Thus, measurement on the prototype would provide model-prototype verification data.

(f) Complete field tests were conducted in 1952.

(h) Reduction of data is being completed.

(2241) KINGSTON STEAM PLANT - CONDENSER COOLING WATER CONDUTT LOSS.

(d) Experimental; for design.

(e) Longitudinal interior support was required for 96-inch concrete pipe conduit. A study was made of the relative loss for a sixinch thick vertical concrete wall, I beams separated by $4-1 / 2-i n c h$ pipe columns and I beams separated by streamiined 4-1/2-inch pipe columns.

(g) The results indicated that the loss with the plain struts would be four times that for an unobstmucted pipe, while the loss with the streamlined struts would be two and onehalf times that for plain pipe. Streamlined struts were installed in the prototype.

(h) Laboratory model study report completed; partial field tests performed. (d) Experimental; for design.

(e) The new Wilson lock is 110 feet wide, 675 feet center-to-center pintles with a 100foot maximum lift. A 1:36 scale model of a single transverse lateral with 12 ports was used to determine the proper lateral and port designs. A $1: 16$ scale model of the lock chamber, intake, culverts, gates and other details was used to determine the overall designs.

(f) Laboratory model studies completed.

(g) The basic design for the filling and emptying systems was determined from the model studies. Filling will be achieved through the use of 6 lateral culverts each containing 12 equally spaced ports $3.5 \mathrm{ft}$ high by $1.5 \mathrm{ft}$ wide. The upper three laterals will be fed from the landward main culvert and the lower three laterals by the riverward culvert. At minimum tailwater elevation only $23 \mathrm{ft}$ of water cushion is available at the bottom of the controlling reverse-flow tainter valves. Dangerously low pressures were eliminated by use of a fast initial opening rate followed by a slow rate for the major portion of the opening and by modifications of the valve shape and of the upper seal nose design. A stepped lateral design was found necessary to produce stable flow conditions.

(h) Report on lock filling and emptying system in preparation.

(2973) REVISION TO PRESENT WILSON NAVIGATION LOCK.

(d) Experimental; for design.

(e) Upon completion of tha new Wilson Lock construction, the tailwater in the navigation canal at the dam will be lowered 10 feet. To make the present two-lift lock operable under the new conditions, the lower chamber floor will be lowered 10 feet and a new filling and emptying system provided.

(f) Model studies have been completed to determine the exact hydraulic design to be used in the renovations.

(g) The new filling system consists of a single culvert located on the longitudinal centerline of the lock with ports located near the bottom along both sides. The old valves are much above tailwater elevations; therefore, the culverts above tailwater were reduced in cross-sectional area to minimize the air entrainment problems.

(h) Report in preparation.

(2974) DEVELOPMENT OF IMPACT TUBE-PRESSURE TRANSDUCER TURBULENCE PROBE.

(d) Experimental; applied research in field investigations.

(e) Development of a turbulence probe and auxiliary analog computer for field use.

(f) Development active.

(g) Based on project (578) of Mass. Inst. of Tech., a turbulence probe for use in natural streams is to be developed. An analog computer which will produce autocorrelation factors directly from the 
pressure cell data is also under development.

(3299) WILSON POWERHOUSE EXTENSION, HYDRAULIC MODEL STUDIES.

(d) Experimental for design.

(e) A 1:28.5 scale model of two turbine intakes and one spillway bay was constructed to determine (1) if there is a possibility of air being drawn into the intakes; (2) if changes will be required in the shape of the intake mouths and trash rack arrangement to improve flow conditions; and (3) if the flow through the adjacent spillway bay will effect the flow into the intake.

(f) Model studies completed.

(g) Design requirements in renovating an existing structure made it necessary to locate the turbine intakes closer to the water surface than is normally desirable. The model tests indicated that vortices would form at the intakes and air might be drawn into the units. The vortex action was essentially eliminated by installing a specially designed vortex eliminating structure above the intakes to the units.

(h) Report to be prepared.

\section{(3300) HIWASSEE, PUMP TURBINE RATING.}

(d) Field investigation; operation.

(e) Measurements of the discharge and differential pressures in the pump turbine scroll case have been used to establish the discharge rating for the pump turbine over all operating conditions. The discharge was measured by using Apalachia reservoir as a volumetric tank. Water was both pumped from the reservoir and discharged into the reservoir for a period of 12 hours. The reservoir area was obtained from aerial photographs taken at the beginning and end of each test. Five recording gages were used to measure the reservoir level. From these measurements the volume and corresponding discharge was computed.

(h) Report in preparation.

(3302) WIDOWS CREEK STEAM PLANT, AIR AND GAS DUCT TESTS.

(d) Experimental; for design.

(e) Model studies were conducted to improve flow conditions and reduce pressure losses in the gas duct which will carry gases from the furnace to the smoke stack for a 500mw unit. Calibration of the air foil metering section in the forced-draft fan inlet ducts was also made by model studies.

(f) Model studies completed.

(g) Flow conditions were improved by use of flow straighteners and vanes.

(h) Report in preparation.

(3303) WIDOWS CREEK STEAM PLANT, CONDENSER WATER PUMP TESTS.

(d) Field investigations; operation.

(e) Condenser water pump acceptance tests on three pumps for a $500 \mathrm{MW}$ steam turbine were conducted to determine the flow, head, and power requirements in accordance with the latest ASME test codes for centrifugal pump and hydraulic prime movers modified to use pitometer traverses. Velocity measurements were made in the 9-foot, 6-inch square concrete pump discharge conduit.

(f) Field tests completed.

(h) Report in preparation.

( 3626 ) WHEETER LOCK, HYDRAULIC MODEL STUDIES.

(d) Experimental; for design.

(e) The proposed lock will be 600 feet long by 110 feet wide with a maximum lift of 52 feet. Initial tests to develop a satisfactory filling system were conducted utilizing a $1: 50$ scale model which simulated the basic details of one-half of the lock filling system. A 1:16 scale model of the lock chamber, intake, gates, culverts and other details were used to determine the final design.

(f) The $1: 50$ and $1: 16$ scale model tests were completed.

(g) The filling system developed from the 1:16 scale model tests used 836 eight-inch pipes for discharge. These pipes feed the water directly from the $12.3^{\prime} x 15.5$ ' longitudinal culverts into the lock chamber. Filling of the lock chamber was accomplished in 9.6 minutes. Transverse and longitudinal hawser stresses on the model barges did not exceed 3.3 tons. $1: 2.25$ and $1: 5.78$ scale models of one of the 8 -inch discharge pipes indicated that cavitation effects in the 8-inch discharge pipes can be eliminated by installing a flared entrance constructed from a standard 12"x8" reducer. The model tests indicated that the operation of this lock will be equally as satisfactory as the new Wilson lock design and will provide a more economical design.

(h) Internal reports issued.

(3627) MELTON HILI DAM, HYDRAULIC MODEL STUDIES.

(a) Experimental; for design.

(e) The proposed projects include three spillway bays, a powerhouse with 3 units and a $75^{\prime} \times 400$ ' navigation lock with a maximum lift of 60 feet. A $1: 75$ scale fixed bed model which reproduced the general area, spillway, lock, and powerhouse and a $1: 31$ scale model which reproduced two spillway bays and the powerhouse were constructed to determine the spillway capacity, training wall dimension, lock wall designs, method of operation necessary to provide satisfactory navigation conditions at the lock approaches, spillway pier design and other related hydraulic data.

(g) The final apron design incorporated the use of spillway chute blocks, apron baffle blocks and end sill which made it possible to use a relatively short apron located only 6 feet below the normal river bed level. No training wall extensions beyond, the end of the apron were required. The spillway capacity was increased approximately 9 
percent by modifying the upper lock guide wall design and utilizing sharp pointed pier noses.

(h) Internal reports issued.

(3628) KINGSTON, GAS DUCT MODEL STUDIES.

(d) Experimental; for design.

(e) A comprehensive $1: 16$ scale model study of the gas duct system which carries gases to the stacks has been conducted to (1) reduce pressure losses in the duct system; (2) determine the effect of the flow distribution within the existing duct on the operation of the mechanical fly ash collector; and (3) determine a means of obtaining a uniform velocity distribution through the proposed electrostatic precipitators.

(f) Model studies completed.

(g) Flow conditions were improved and pressure losses reduced in the ducts by use of flow straighteners and vanes. The mechanical collector was found to be an effecient flow distributor and any non-uniformity in the flow approaching it would be removed. A uniform velocity distribution through the electrostatic precipitator was obtained by the use of perforated plates, suitable vaning and flow straighteners in the approach duct.

(h) Report in preparation.

(3629) LOW POWER VHF RADIO GAGES FOR REPORTING RAINFALL AND STREAM LEVEL DATA.

(a) Development.

(e) Transistorized radio components operating from nickel cadmium batteries charged by solar cells will be used. Data in binary coded decimal form will be transmitted by audio tone pulses. Long-term, unattended operation is a primary consideration in design.

(4005) MELTON HILL LOCK, HYDRAULIC MODEL STUDIES.

(a) Experimental; for design.

(e) The proposed lock will be 75 feet wide by 400 feet long with a maximum lift of 60 feet. A 1:16 scale model of the lock chamber, intakes, culverts, gates and other details has been constructed to determine the overall design.

(f) Laboratory model studies started.

(g) Initial design of the filling system has been patterned after the multiport filling system as basically conceived in the Wheeler lock model studies. A total of 438 eight-inch pipe ports were used to discharge the water into the lock chamber from the $8^{\prime} \times 13^{\prime}$ side culverts in the lock walls. Initial tests indicated a lock filling time of 9.5 minutes. Forces measured on the barge during filling or emptying did not exceed 3 tons. Although the testing program has not been completed, it appears that the multiple port filling system will provide good lock operation at Melton Hill.

(4006) COLBERT STEAM PLANT, GAS DUCT MODEL STUDIES. (d) Experimental; for design.

(e) A 1:16 scale plexiglass model of the gas duct extending from the air preheater through the stack was constructed to (1) obtain a uniform velocity distribution at the entrance to the electrostatic precipitator; (2) develop a satisfactory duct system to carry the gas from the electrostatic precipitator to the stack, and (3) reduce headlosses in the duct system. Test results were evaluated by observing smoke traces and from measurements of velocities and pressures at critical locations in the duct system.

(f) General improvements in the operation were accomplished by installing flat plate vanes at the bends in the duct to gride and direct the flow of gas through the duct system. Two perforated plates with $38 \%$ and $50 \%$ of the area open, installed upstream from the electrostatic precipitator, in conjunction with the flat plate guide vanes, made it possible to obtain a uniform velocity distribution at the entrance to and through the electrostatic precipitator. Headlosses in the duct system were reduced by the installation of the flat plate vanes. Vanes installed in the stack opposite the breeching aided in turning the flow up at stack and materially reduced the headlosses.

(h) Report in preparation.

(4007) AIR FOIL METER.

(d) Basic research; for design and MS thesis.

(e) A model study was conducted to develop an air foil metering section for measuring the air flow to the furnaces at large steam plants. Consideration was given to developing an accurate meter which will cause a minimum pressure loss in the system.

(g) The optimum shape of the air foil meter was initially developed from 1:16 scale model tests of the Widows Creek Steam Plant air duct. The air foil as developed consists of a circular nose with a flat, $V$-shaped tail attached to the downstream side. Differential pressures were measured between the front face of the meter and at points 60 to 110 degrees to the left or right. Initial tests using air as the medium of flow developed data for Reynolds Numbers up to $4 \times 10^{4}$. The data were further extended using water as the medium of flow. Reynolds Numbers up to $2 \times 10^{6}$ were obtained with this setup. Data thus far have been obtained for ducts whose ratios of width to height were $2: 1$ and $8: 1$ and for meters whose ratios of meter width to duct width vary between 0.156 and 0.467 . The test results have indicated that the maximum pressure differential occurs when the pressure is measured between the front face of the meter and a point offset $80^{\circ}$ to $85^{\circ}$. Headloss caused by the meter is exceptionally small.

(h) Report being prepared.

(4008) TURBULENCE SCALING.

(d) Basic research. 
(e) No sound theoretical or experimental data are available to indicate the method that should be used for scaling either turbulent induced pressure fluctuations, frequencies or amplitudes as immediately related to flows in lock culverts. As a result a series of tests are being conducted on circular pipes 4, 6 and 24 inches in diameter to establish the correlation factors.

(g) The results of the first series of tests are now being analyzed. The results, although not complete or decisive, indicate the scaling probably follows Froude relationships.

(4009) HALES BAR, LEAKAGE INVESTIGATION.

(d) Field investigation.

(e) Operational records and observations of boils below the Hales Bar Dam indicated that leakage was occurring under the dam. Field measurements were undertaken in 1956 and 1960 to determine the magnitude of the leakage.

(g) The total plant discharge was measured by means of current meters at the highway bridge located 7,000 feet downstream from the dam under the following plant loading conditions: unit 15 operating alone; unit 16 operating alone; and units 15 and 16 operating together. By solving three simultaneous equations based on the three plant loading conditions, the total leakage and turbine discharge was obtained. Twenty-one individual measurements of the discharge indicated a total leakage of 1200 cubic ft per second. Sepcial dye injection equipment was developed for injecting dye into core holes and leakage intake points which were located by divers in the reservoir. From the dye injection tests a map was prepared showing the leakage intake and outlet points and leakage paths. Grouting operations are now being made to stop the leakage.

(4010) WHEELER LOCK OUTLET STUDIES.

(d) Experimental; for design.

(e) A 1:30 scale model study is being conducted to develop a suitable lock culvert outlet design. The consideration under study is the elimination of heavy wave action which would affect navigation and small craft.

(g) Initial model tests utilizing a discharge outlet design consisting of a $20^{\prime}$ diameter vertical outlet pipe surrounded by a skimmer wall structure 103 feet in diameter.

\section{Hydraulic Investigations Section.}

(765) EVAPORATION IN THE TENNESSEE BASIN.

(d) Field investigation; applied research.

(e) To provide data for estimating reservoir losses and derive a general rule, applicable to the Basin, permitting computation of evaporation from pans at six locations in Basin, together with standard meteorological readings.

(h) "Precipitation in Tennessee River Basin," published in monthly and annual bulletins.
(768) PRECIPITATION IN TENNESSEE RIVER BASIN.

(d) Field investigation; basic research.

(e) A comprehensive study of rainfall and other weather phenomena for purposes of water dispatching and improvements in water control; storm studies as related to maximum precipitation, rainfall-runoff, spillway design and operation, etc.

(h) Monthly bulletin, "Precipitation in Tenn. River Basin," also annual summary. In addition, a supplement to the 1959 annual bulletin was published, entitled, "Mean Precipitation in Tennessee River Basin." This contains maps and tables showing mean monthly, flood season, crop season, and annual precipitation data for the Tenn. River Basin and its major watershed subdivisions above and below Chattanooga, together with monthly and annual mean precipitation at stations with 15 or more years of record through 1959. Also published was a supplement to the March 1960 bulletin, entitled, "Snow and Ice Storms of 1959-1960 in Tenn. River Basin." This presents data on the record-breaking storms that occurred during the period Nov. 1959-March 1960. During that period over 150 inches of snow was reported officially, and over 190 inches reported unofficially, in the eastern part of the Basin. A crippling ice storm is reported which struck northeast Ala., northwest Georgia, western North Carolina, and an area of Tenn. roughly within 80 miles of Chattanooga. Millions of dollars in damage were suffered. by forests, buildings, businesses, and utilities.

\section{(769) RESERVOIR AND STREAM TEMPERATURES.}

(d) Field investigation; basic research.

(e) Study of water utilization and water movement as concerns industrial plant locations and stream pollution. Variations in temperature from surface to bottom in reservoirs throughout the year are determined by soundings, and by continuous recording gages in natural streams.

\section{(771) GALTERY DRATNAGE IN LARGE DAMS.}

(d) Field investigations; design.

(e) Weirs are placed in main galleries and drainage measured as check on tightness and stability.

\section{(785) SEDIMENTATION OF EXISTING RESERVOIRS.}

(d) Field investigation; basic research.

(e) Selected ranges in reservoirs are probed and sounded, volumetric samples are collected and analyzed, quantity and distribution of sediment are computed to determine deposition by stream, probable life of reservoir, effect of sediment storage on navigation channels and sedimentation of downstream reservoirs, and probable sedimentation in future reservoirs.

(786) WATER TRAVEL IN NATURAL STREAMS. 
(a) Field investigations; applied research.

(e) Sanitary and chemical changes in water during passage downstream are determined. A given mass of water is identified by electrical conductivity or chemical titration.

(f) No work done in recent years.

(787) MOVEMENT OF WATER THROUGH LARGE RESERVOIRS.

(d) Field investigation; applied research.

(e) Because of slow water travel, samples are collected by traverse through lake.

(f) No work done in recent years.

(g) Water entering a reservoir does not intermix with the rest of the reservoir, but remains as a density current as a result of the difference in temperature between the inflowing water and that in the reservoir. During certain seasons of the year, in Watts Bar Reservoir the cold water released from Norris Reservoir passes upstream along the bottom of the Fmory River arm of the former reservoir.

Hyàrology Section.

(779) MAXIMUM POSSIBLE PRECIPITATION IN TENNESSEE VALIEEY.

(b) Cooperative with U. S. Weather Bureau.

(d) Theoretical; applied research.

(e) Hydrometeorological analysis of large storms with upward adjustments of controlling factors to maximum limits as applied to the Tennessee Valley anà subdivisions.

(g) Results to be published as one of current series of hydrometeorological reports by the U.S.W.B. and cooperating agencies.

(780) PERIODIC EVALUATION OF GROUND-WATER STORAGE.

(a) Theoretical; operation.

(e) By analysis of current records of stream discharge, the volumes of runoff in groundwater and channel storage are determined for use in operation of multi-purpose reservoirs.

(g) Results reported monthly and weekly within the organization.

(2975) SUPPLY AND UTILIZATION OF WATER IN THE TENNESSEE VAITEY.

(c) Mr. Reed A. Elliot, Chief Water Control Planning Engineer, Tennessee Valley Authority, Knoxville, Tennessee.

(a) Assembly and analysis of basic information on water resources and uses, including field investigation of water uses for irrigation, mining operations, industry, and other purposes.

(e) All available data are being analyzed to present a comparison of the water resource of the area with the present and expected 1975 demand upon that resource. Problems of shortage and conflict are being developed and possible solutions suggested.

(g) No widespread shortages exist now or are expected by 1975, although some local shortages on smaller streams, are antici- pated.

(h) Report in preparation.

(3306) COOPERATIVE RESEARCH PROJECT IN WESTERN NORTH CAROLINA.

(b) Project conducted in cooperation with North Carolina State College of Agriculture and Engineering.

(d) To determine water-land relationships for some of the principal soils used for agricultural purposes in western North Carolina under important vegetative covers. Observations include rainfall, runoff, soilmoisture, potential evapotranspiration, and actual evapotranspiration.

(e) A statistically designed rotation of four covers on four small watersheds and a separate evaluation of deep-rooted crop on a fifth watershed.

(f) Field studies of the deep-rooted crop, alfalfa, have been discontinued.

(g) Results to date are summarized in annual reports on the project.

(h) "Hydrology of Small Watersheds in Relation to Various Crop Covers and Soil Characteristics," a pictorial brochure prepared by North Carolina State College and TVA, 1960. "Hydrologic Studies by Electronic Computers in TVA, " by Willard M. Snyder, American Society of Civil Engineers, Proc. 86 (No. HY-2): 1-10, February 1960.

\section{(3307) PARKER BRANCH PILOT WATERSHED RESEARCH} PROJECT.

(b) Project conducted in cooperation with North Carolina State College of Agriculture and Engineering.

(d) To determine the effects upon the hydrology of the watershed of an intensive farm development program designed to give the optimum economic well-being of the people using the land. Rainfall, runoff, suspended and deposited sediment are observed, periodic soils-land-use and inventories are made, and records of income summaries and public and private investments are maintained.

(e) Project activities are divided into calibration, action, and evaluation phases.

(g) Results to date are summarized in annual report on the project.

(h) "An Analysis of the Parker Branch Watershed Project, 1953-1959--a Progress Report," prepared by North Carolina State College and TVA, June 1960.

\section{(3308) WHITE HOLLOW WATERSHED.}

(d) To study the effect of changes in the vegetal cover on a watershed taken out of cultivation on the hydrologic factors of runoff and soil erosion.

(e) Continuous record from 1935 of rainfall, runoff, and suspended sediment, and periodic determination of vegetal cover indexes.

(g) During the 21-year period 1935-1955, the forest cover improvement in the watershed resulted in greater watershed protection with no measurable decrease in water yield, 
no change in volume of either surface runoff or ground-water runoff, marked reductions in summer peak rates of discharge with lesser reductions in winter rates, a prolongation of the period of draining of surface runoff from the channel system, and a 96 percent reduction in the sediment load.

(h) Report in preparation covering the vegetal cover improvement influences upon hydrologic characteristics since 1935.

\section{(3309) PINE TREE BRANCH WATERSHED.}

(a) To determine the effects upon the hydrology of the watershed by reforestation and erosion control measures.

(e) Continuous record from 1941 of rainfall, munoff, ground water, and sediment loads.

(g) During the 19-year period 1941-1959, the cover improvement and erosion control in the watershed resulted in a decrease in surface runoff volumes and an increase in ground-water discharges, marked reductions in summer and winter peak flood discharges, a reduction in overland surface velocities, a prolongation of the period of draining of surface runoff from the channel system, an appreciable decrease in water yield, and $\ni$ 95 percent reduction in sediment load.

(4011) NORTH FORK CITICO CREEK RESEARCH WATERSHED.

(b) Project conducted in cooperation with U.S. Forest Service.

(a) Field investigation; basic research.

(e) To determine the effects of normal, highstandard National Forest Multiple-use management upon the hydrology of the area. Observa tions include rainfall, runoff, air and water temperature, and humidity. Timber inventories, soil surveys, wildlife inventories, and evaluations of soil disturbances will be made. Project activities are divided into calibration, development, and evaluation phases.

(f) Hyarologic measurements were begun in May 1960.

(g) Results will be published in annual reports. 
H. G. ACRES AND COMPANY LIMITED, Hydraulic Lab.

Inquiries concerning the following projects should be addressed to Mr. I. W. McCaig, Hydraulic Engineer, H. G. Acres and Company Limited, Niagara Falls, Canada.

(3630) FRICTION FACTOR TESTS IN LARGE PRESSURE CONDUITS; BERSIMIS NO. I AND CHUTE-DESPASSES HYDRO-ELECTRIC DEVELOPMENTS.

(b) Quebec Hydro-Electric Commission, Aluminum Company of Canada Limited.

(d) Field investigation; design.

(e) For the extension of data on friction in concrete-lined tunnels, an inspection was made of the 3l-foot diameter Bersimis No. 1 tunnel and the 35-foot diameter Chutedes-Passes tunnel. The tunnel surface was classified in six categories. Plaster casts of each type of surface permitted evaluation of construction methods.

(f) Tests to be continued.

(g) Depending on the care taken during construction, the surface roughness of concrete poured against steel forms varied between 0.002 and 0.02 inches. Roughness between 0.005 and 0.01 inches was measured on the screened invert finish by steel trowelling. Finishing with wood floats gave a roughness of between 0.035 and 0.050 . inches.

(3632) VORTEX FORMATION AT INTAKE FOR CHUTE-DESPASSES HYDRO-EIECTRIC DEVELOPMENT.

(b) Aluminum Company of Canada Limited.

(d) Field investigation; design.

(e) Prototype observations of the vortex formation were continued to determine the correlation between the formation of the vortex in the prototype and the model (3312).

(f) Completed.

(g) The investigation has shown that for this type of submerged intake the formation of the vortex in the $1 / 60$ scale model occurs at a Froude number which is 3.5 to 4.5 times the Froude number at which the vortex is formed in the prototype.

\section{(4012) DISCHARGE RATING CURVE FOR TAINTOR GATE.}

(b) Aluminum Company of Canada Limited.

(d) Experimental; operation.

(e) Tests were made on a 1:36 scale model of the spillway, with horizontal apron, to determine the discharge characteristics of the taintor gates.

The tests were carried out for different gate openings and for heads varying from a minimum of 15 feet to the maximum design head of 35 feet.

(f) Completed.

(h) Report was submitted to sponsor.

(4013) SPILLWAY MODEL TEST FOR GRAND RAPIDS DEVELOPMENT.

(b) The Manitoba Hydro-Electric Board.

(d) Experimental; design.

(e) Tests were carried out on two models:
A flume model scale 1:64 to determine the discharge coefficient of the spillway and also to determine the optimum shape of the spillway bucket, and a model of the complete spillway, scale $1: 100$, to determine the erosion pattern downstream from the spillway and around adjacent structures.

(f) Completed.

(g) The tests in the flume showed that the bucket design which caused the least amount of scour had a lip angle of 30 degrees and a radius of 45 feet. Using this design of bucket, the second model showed the most satisfactory layout of spillway and wingwalls.

(h) Report was submitted to sponsor.

UNIVERSITY OF ALBERTA, Hydraulics Laboratory.

(4014) APRON STONE SIZES FOR BRIDGE PIERS IN GRAVEL RIVERS.

(b) Alberta Government Research Council, Dept. of Highways and the University of Alberta.

(c) Dr. T. Blench, Department of Civil Engineering, University of Alberta, Edmonton.

(d) Experimental; basic and applied research; master's thesis.

(e) Investigate in models, the scour of gravel beds and stone aprons round bridge piers and express results according to regime theory criteria.

(g) Scour depth and pier breadth measurements, each made nondimensional by dividing by "zero flood depth" based on bed-factor expected from a river of the same bed material, are related approximately by a fourth root formula; sand bed data of Sir C. C. Inglis (circa 1938) agreed with the relation. The anomalous sheet flow behavior of the gravel bed at low charges did not affect scour behavior at the piers. Initial tests for safe apron stone sizes were made.

(h) "Model Studies of Scour Around Bridge Piers and Stone Aprons," A. N. Varzelioti. Part requirement for degree of $M$. Sc. from the University of Alberta.

(4015) SCOUR ROUND BRIDGE PIERS.

(b) Alberta Government Research Council, Dept. of Highways and the University of Alberta.

(c) Dr. T. Blench, Department of Civil Engineering, University of Alberta, Edmonton.

(d) Experimental; basic and applied research; master's thesis.

(e) To devise equipment for rapid survey of scour at bridge piers during floods.

(f) Completed.

(g) Literature on field measurements was studied. A useable instrument, with auxiliary equipment, was devised and is being put into routine operation.

(h) "A Method for Measurement of Scour at Bridge Piers," E. J. Sanden. Part requirement for degree of M.Sc. from University of Alberta. 


\section{(4016) BED LOAD TRANSPORT.}

(b) University of Alberta.

(c) Dr. T. Blench, Department of Civil Engineering, University of Alberta, Edmonton.

(d) Experimental; basic research; master's thesis.

(e) Collect extracts from literature on bedload transport, examine for relevance to sheet flow in early stages of transport of gravel, investigate experimentally whether the phenomenon is due to small scale of laboratory experiments, note inconsistencies of literature.

(f) Completed. Results transferred to related program.

(g) Literature discordant on discontinuity of functions as flow passes through critical. Experiments gave, by extrapolation, the limit of discharge intensity for $1.7 \mathrm{~mm}$ gravel above which sheet flow would not occur in early stages of transport. Conclusion will be tested in large engineering model.

(h) "A Study of the Bed-Characteristics of 1.70 mm gravel in a Laboratory Flume," Santos Bhattacharya. Part requirement for degree of M.Sc. from University of Alberta.

\section{UNIVERSITY OF BRITISH COLUMBIA, Hydraulics Lab.}

Inquiries concerning the following projects should be addressed to Prof. E. S. Pretious, Dept. of Civil Engineering, Univ . of British Columbia, Vancouver, Canada unless otherwise indicated.

\section{(1044) FRASER RIVER MODEL.}

(b) Hydraulic model studies cooperative with the Department of Public Works of Canada, Vancouver, B.C.

(d) Experimental project to aid engineering studies of navigation requirements involving river regulation and control.

(e) An outdoor erodible-bed tidal river model to study methods for improving and maintaining the navigation channels of the Fraser River estuary. Horizontal scale 1:600, vertical scale 1:70. The model occupies approximately 4 acres of the campus and represents the tide-water reaches of the lower Fraser River extending from its seaward end at the Strait of Georgia to the head of tide water at Sumas, a distance of approximately 60 miles. Pitt River and Pitt Lake ( 30 square miles in area) are subject to tidal influence and are included in the model. Natural tides and river discharges can be synchronized and simulated on the model and are controlled automatically by electronic servo-systems. Sand injection can be controlled automatically as a function of river discharge. Instantaneous water surface slopes can be obtained over the whole model by automatic electrically-recording point gauges situated at controlling points. Natural river sand of appropriate grain size is used for the bed material. (h) Progress and technical reports submitted periodically to the Department of Public Works of Canada.

(4017) NEW HIGHWAY BRIDGE OVER THE COLUMBIA RIVER AT TRAIL, BRITISH COLUMBIA.

(b) Hydraulic laboratory studies cooperative with the Department of Highways, Province of British Columbia.

(d) Experimental project to aid in the design of the most economical type of bridge piers.

(e) Models of two types of bridge piers were investigated; one being a conventional solid pier with semicircular ends while the other consisted of an open-pile footing surmounted by vertical cylindrical shafts. The models were placed on movable beds of sand of suitable coarseness in a steel and glass flume in the hydraulic laboratory. Probable flood flows and water depths at the site were obtained from an analysis of stream flow records and accurately imposed on the models. The progress of the bed scour around the piers was recorded photographicalIy and also by direct measurement. Studies were made to minimize abrasion of the concrete piles in the prototype by boulders moving along the bed, through the use of underwater deflecting structures. Flow patterns around the piers were observed at various water stages and suitable clearance heights recommended for the bridge deck above the water surface.

(f) Completed.

(g) The study showed that the open-pile footing would produce considerably less bed scour than the solid piers. It was shown that underwater deflectors would serve their purpose but would alter the bed-scour pattern.

(h) A report was submitted to the Bridge Engineer's office, Department of Highways, Province of British Columbia.

(4018) NEW C. N. R. FERRY SLIP ON TILBURY ISLAND, FRASER RIVER, BRITISH COLUMBIA.

(b) Hydraulic model studies cooperative with the Canadian National Railways.

(d) Experimental project to aid in the design of a new Ferry Slip on Tilbury Island adjacent to the southerly (left) bank of the Main Channel of the Fraser River, B. C.

(e) An hydraulic model of the proposed new ferry slip was incorporated into the Fraser River Model. Flow-pattern and bed-movement studies were made to determine the scour and shoal conditions around the structures, to ensure the required operational depths without endangering the structures. Recommendations for suitable rock sizes for rockfill foundation structures were made. The proposed preliminary over-all design of the slip was checked in the light of the hydraulic and sedimentation conditions at the site and changes made where necessary to obtain a satisfactory final design.

(f) Completed.

(g) The study showed that the location and alignment of the final design of the ferry 
slip would integrate successfully with the river behavior.

(h) A report was submitted to the office of the District Engineer, British Columbia Dist., Western Region, Canadian National Railways.

4019) HYDRO SYSTEM POWER STUDY.

(b) Govermment of Canada, Dept. of Northern Affairs and National Resources, Water Resources Branch.

(c) Dr. R. F. Hooley, Department of Civil Engineering, Univ. of British Columbia, Canada.

(d) Theoretical research on development of a river system.

(e) A system was devised for use on an Alwac IIIe computer to investigate a river system having any configuration of tributaries. A maximum of seventy-six dams may be studied. The main use of this analysis is in optimizing power flows.

(4020) OPTIMUM CLOSURE OF HYDRAULIC TURBINE GATES.

(b) General research.

(c) Dr. Eugen Ruus, Dept. of Civil Engrg., Univ. of British Columbia, Vancouver, Canada.

(d) Basic research.

(e) To find a turbine gate closure arrangement which would yield the least value of the maximum head rise in a penstock.

(f) Completed.

(g) Due to optimum gate closure a major reduction in water hammer can be achieved. This is particularly true for developments with large head variations.

(h) A paper is being prepared for submission to the Journal of the Power Div. of the Proceedings of the A.S.C.E.

THE HYDRO-ELECTRIC POWER COMMISSION OF ONTARIO, Hydraulic Model Laboratory.

Inquiries concerning the following projects should be addressed to Mr. J. B. Bryce, Hydraulic Engineer, Hydraulic Generation Department, 620 University Avenue, Toronto 2, Ontario, Canada.

(3324) ST. LAWRENCE RIVER MODEL - OGDENSBURG TO LEISHMAN'S POINT.

(b) Ontario Hydro and the Power Authority of the State of New York.

(d) Experimental; for design, development and operation.

(e) A 1:500 × 1:100 scale model of the st. Lawrence River between Ogdensburg and Leishman's Point, a distance of 16.1 miles, was constructed to determine the design of channel enlargements, the location of the Iroquois Control Dam and a plan of river control during construction of the St. Lawrence Power Project.

(f) Work is essentially completed but model is still active.

(g) Channel enlargements were developed which met the criteria stipulated by the International Joint Commission with respect to navigation and ice-forming velocities and the seaway navigation channel was located. The optimum arrangement and location for the Iroquois Control Dam was determined. A plan of river control during construction was developed.

(3325) ST. LAWRENCE RIVER MODEL - OGDEN ISLAND REACH.

(b) Ontario Hydro and Power Authority of the State of New York.

(d) Experimental; for design, development and operation.

(e) A 1:500 x 1:100 scale model of the St. Lawrence River reproducing 7.9 miles of the river between the towns of Iroquois and Morrisburg, was constructed to determine the design of channel enlargements and a plan of river control during construction of the St. Lawrence Power Project.

(f) Work is essentially completed but model is still active.

(g) Channel enlargements were developed which met the ice-forming criteria stipulated by the International Joint Commission and a satisfactory Seaway Navigation channel was located. A plan of river control during construction was developed.

(3326) ST. LAWRENCE RIVER MODEL - DEWATERING AND CLOSURE AREA.

(b) Ontario Hydro and Power Authority of the State of New York.

(d) Experimental; for design, development and operation.

(e) A 1:500 × 1:100 scale model of the St. Lawrence River reproducing 13.8 miles from Cat Island to below the powerhouses was constructed to develop plans for dewatering the Long Sault Dam and the powerhouse and to investigate conditions during the various stages of their construction.

(f) Work is completed but model is still active.

(g) Dewatering diversion channels were designed in detail and a plan of construction developed to preserve the necessary water levels for existing navigation and ensure adequate discharge capacity in the various stages of construction. Velocities in the Seaway Channel were also investigated. The Power Pool filling operation was investigated in detail.

(3330) ST. LAWRENCE POWER PROJECT - COMPREHENSIVE MODEL OF IROQUOIS CONTROL DAM.

(b) Ontario Hydro and the Power Authority of the State of New York.

(d) Experimental; for design, development and operation.

(e) A comprehensive 1:80 scale model, size 130 feet by 54 feet, of the complete Iroquois Control Dam was constructed including $1-1 / 2$ miles of river channel and the downstream approach to the Iroquois lock. Its purpose was to determine a plan of river control during construction, a plan of dewatering, the velocities at the cofferdams during their construction, verification of the performance of energy-dissipating works, and the discharge calibration of the 
sluiceways.

(f) Work is completed and model removed.

(g) The dewatering plans were tested in the model, and the velocities and currents that would occur during construction of the cofferdam were determined. A plan of river control was developed to maintain satisfactory levels and navigation conditions during the construction of the dam. The performance of the energy-dissipating works, which had been developed in a sectional model, was verified. A discharge calibration of the dam was obtained for the construction period and gate opening patterns developed. Performance data for operational use was obtained.

\section{(3333) ST. IAAWENCE RIVER MODEL - TAILRACE AREA.}

(b) Ontario Hydro and the Power Authority of the State of New York.

(d) Experimental; for design.

(e) A 1:160 × 1:80 scale model reproducing 2.5 miles of the St. Lawrence River from above the powerhouses to below Polly's Gut, has been constructed to develop the design of an economic tailrace improvement and a suitable dewatering scheme.

(f) Work essentially completed but model still active.

(g) An economic tailrace enlargement was developed in the model. A cofferdaming plan to dewater much of the enlargement area was devised and the velocities at various stages observed.

\section{(3335) RED ROCK GENERATING STATION MODEL.}

(b) Ontario Hydro-Electric Power Commission.

(d) Experimental; for design.

(e) A 1:60 scale comprehensive model of the sluiceways, powerhouse and upstream and downstream river channel has been constructed to determine the dewatering arrangements for construction, velocities along cofferdams, energy-dissipating works at the sluices, the rating of the diversion sluices, ports and sluiceways, the tailrace excavation, and location of log slide.

(f) Work is essentially completed but model is still active.

(g) Hydraulic design is completed but model is active for problems during construction.

\section{(3643) HEADGATE MODEL.}

(b) Cntario Hydro-Electric Power Commission.

(d) Experimental; as applied research.

(e) A I:24 scale model of a St. Lawrence powerhouse headgate and inlet water passage was built to investigate the hydraulic forces on gates with upstream and downstream skin plates under conditions of horizontal and sloping floors and submerged and free discharge conditions.

(f) Work is essentially completed but model still active.

\section{(3644) OTTER RAPIDS GENERATING STATION MODEL.}

(b) Ontario Hyaro-Electric Power Commission. (d) Experimental; for design.

(e) A 1:72 scale comprehensive model of the sluiceways, powerhouse and upstream and downstream river channels has been constructed to determine the dewatering arrangement for construction, velocities at and along cofferdams, height location and slope of high water channel sluiceway training walls, the rating of the diversion ports and the sluiceways and the tailrace channel enlargement.

(f) Work is essentially completed but model still active.

(3645) DISTORTION MODEL OF NIAGARA CONTROL STRUCTURE.

(b) Ontario Hydro-Electric Power Commission.

(d) Experimental; as applied research.

(e) A sectional model of three of the 100-foot sluices in the Niagara River Control Structure were built of plexiglass so that the effects of distortion of a model structure might be investigated at distortion scales of $5: 1,2-1 / 2: 1$ and undistorted.

(f) Work is completed and model removed.

\section{(3646) PENSTOCK WATER PASSAGES MODEL.}

(b) Ontario Hydro-Electric Power Commission.

(d) Experimental; as experimental research.

(e) A 1:24 scale model of the water passages from the dam face to the circular penstock of an existing unit was built and variations of inlet width, pier length, roof slope, bed height and transition shape were investigated in order to reduce hydraulic losses and to improve performance characteristies.

(f) Work is completed and model removed.

\section{(4021) CAMERON FALLS LOG DRIVING MODEI.}

(b) Ontario Hydro-Electric Power Commission.

(d) Experimental; for design, development and operation.

(e) A 1:24 scale model was constructed of the forebay and the model tested to determine the log driving rates under field conditions, with and without the assistance of flow developers. With the use of three flow developers, the driving rate was more than doubled.

(f) Work completed and model removed.

(g) The design developed was installed in the field and the solution found to be effective during 1960 log driving season.

\section{(4022) LOG CHUTE EXIT MODEL.}

(b) Ontario Hydro-Electric Power Commission.

(d) Experimental; basic research.

(e) A 1:24 model of a log chute exit was constructed with removable end sections, and variations of end section, tailwater level, depth of water and specific gravity of logs were investigated.

(f) Work completed and model removed.

(g) The many variables were tried in various combinations to determine their singular or combined effect on the free passage of 
logs with minimum number hitting the bottom.

(4023) DOUGLAS POINT INTAKE MODEL.

(b) Ontario Hydro-Electric Power Commission.

(d) Experimental; hydraulic design and operation of water intake.

(e) A I:24 model was constructed of the intake, tunnel and forebay of a nuclear generating station. The design of the intake to draw cooling and process water from a lake and to exclude floating ice and vortices as well as the forebay design of the pumping station and operation under pick-up and rejection of the pumping capacity.

(4024) ADAM CREEK CONTROL STRUCTURE MODEL.

(b) Ontario Hydro-Electric Power Commission.

(d) Experimental; hydraulic design and operation.

(e) A 1:60 model was constructed to determine the rollway profile and pressures, piershape, discharge capacity and energy-dissipating works with fixed and movable bed.

\section{(4025) TRASH RACK LOSS STUDY.}

(b) Ontario Hydro-Electric Power Commission.

(d) Experimental; basic research.

(e) A I:12 model was constructed in a flume where hydraulic losses due to shape and number of horizontal members and shape and spacing of vertical members were determined. The effects of angularity to flow were also investigated.

(f) Testing completed and model inactive.

\section{(4026) NIAGARA RIVER MODEL.}

(b) Ontario Hyaro-Electric Power Commission.

(d) Experimental; for design and operation.

(e) An existing 1:250 x 1:50 scale model reproducing five miles of the Niagara River from Buckhorn Island to below the Cataracts is being used to determine the operational characteristics of the Niagara Control Structure under developed conditions. This model was previously used to investigate the remedial works necessary for the preservation and enhancement of Niagara Falls and for the location of the intakes and necessary river improvements of both Ontario Hydro and the Power Authority of the State of New York.

\section{LASALLE HYDRAULIC LABORATORY.}

Inquiries concerning the following projects should be addressed to Mr. E. Pariset, LaSalle Hydraulic Laboratory, 0250 St. Patrick Street, LaSalle, P.Q. Canada.

\section{(3346) MODEL STUDY OF THE CARIILON POWER PROJECT.}

(b) Quebec Hydroelectric Commission.

(d) Experimental; applied research.

(e) A model of the ottawa River at the Carillon Site was built at a scale of $1: 110$ to study the hydraulic problems pertaining to the construction and operation of the Carillon
Project.

Studies have been concentrated on: Economical study of tailrace excavations; effect of surges caused by sudden load acceptance and rejection on navigation conditions at locks; protection of navigation dykes from waves caused by spillway operation.

(f) Hydraulic studies are completed but model is active for eventual problems during construction.

(h) Report submitted to sponsor.

(3650) MONT - LOUIS BREAKWATER.

(b) Department of Public Works.

(d) Experimental research; design.

(e) Study in a 16 foot wide, 60 foot long, wave flume at scale $1 / 60$ of a three dimensional scale model of the Mont Louis Breakwater. This study has shown the necessity of the three dimensional model, as the results obtained are indeed greatly different from those obtained in a previous study on a two dimensional scale model. Locally, the protecting facing required 15 ton tetrapods or quarry blocks weighing 30 tons.

(f) Completed.

(h) Report submitted to sponsor.

(3652) ROCKFIELD AUTOMATIC SEWAGE REGULATOR.

(b) City of Montreal.

(d) Experimental research; design.

(e) Study on a $1 / 24$ scale model of the maximum permanent discharge compatible with flow conditions to be introduced at all times into the collector. The solution studied included automatic sewage regulators with downstream control (patented by the Laboratory) (publication in I.A.H.R. Eighth Congress Montreal 1959).

(f) Completed.

(h) Report submitted to sponsor.

\section{(3655) CARILLON SPILLWAY.}

(b) Quebec Hydroelectric Commission.

(d) Experimental; applied research.

(e) The model built at a scale of $1: 48$ represents four of the fourteen bays of the Carillon Spillway and part of the Powerhouse. The model was used for spillway calibration and to obtain an economic design of the downstream apron and lip. This was designed to prevent scouring below the lip caused by transverse currents initiated by the low trajectory jet.

(f) Completed.

(h) Report submitted to sponsor.

\section{(4027) CARIILON IOCK.}

(b) Quebec Hydroelectric Commission.

(d) Experimental; design.

(e) A 1/20 scale model used to study design problems of the $65 \mathrm{ft}$. lift navigation lock included in the Carillon development on the ottawa River. Electronic recorder used extensively to measure transient pressure fluctuations downstream of the valves 
during operation, and to measure hawser pulls on a model boat. Modifications to the outlet and stilling basin eliminated low pressure difficulties at the emptying valve. Safe operating procedures and characteristics specified.

(f) Completed - model still active for later design purposes.

(h) Report submitted to sponsor.

(4028) CARIILON POWER PLANT - DOWNSTREAM WATER LEVEL FLUCTUATIONS.

(b) Quebec Hyaroelectric Commission.

(d) Theoretical; operation.

(e) Study of the water level fluctuation in the Lake of two Mountains, Lake St. Louis and Montreal Harbour, due to the peak power plant operations.

For the ottawa River Section, downstream of the Power Plant, phenomena of wave propagation in cases of sudden variations of discharge, was studied by the SchnyderBergeron method.

(f) Completed.

(h) Report submitted to sponsor.

(4029) LEMAY RIVER POWER-HOUSE PROJECT-SURGE TANK.

(b) Quebec Hyaroelectric Commission.

(d) Theoretical; design.

(e) Study by the Schnyder-Bergeron method of mass oscillations and damping in the surge tank for different cases of load acceptance and rejection.

(f) Di scontinued.

(h) Preliminary report submitted to sponsor.

(4030) LEMAY RIVER DEVELOPMENT - RESERVOIR UTILIZATION.

(b) Quebec Hyaroelectric Commission.

(d) Theoretical; operation.

(e) This development was considered a possible source of power for construction of the nearby Manicouagan-Site 5 scheme. Maximum power output was determined for complete annual utilization of the reservoir by considering mean, dry and arought year hydrographs.

(f) Discontinued.

(g) Report submitted to sponsor.

(4031) BEAUHARNOIS CANAL WIDENING.

(b) Quebec Hyaroelectric Commission.

(d) Theoretical for improvement of PowerHouse operation. Using topographical survey results, a study was undertaken to determine the gain of head obtained by widening the canal for a length of 70,000 feet where bottom excavation had reached rock.

Study included both summer and winter operation of the power-house.

(f) Completed.

(g) Cost of excavation too high compared to the annual production gain.

(h) Report submitted to sponsor.

(4032) BEAUHARNOIS CANAL ICE COVER. (b) Quebec Hydroelectric Commission.

(d) Theoretical; improvement.

(e) Study of the possibilities to reduce the head losses due to the large thickening of the ice cover upstream of the Beauharnois Power Plant.

(f) Completed.

(g) The thickening of the ice-cover seems to be a result of the excessive thrusts on the ice-cover. To decrease these thrusts several solutions have been studied. Widening or bottom excavation of the canal is too costly. The recommended solution is to provide a longitudinal, median dyke in order to increase the part of the thrust sustained by the banks.

(h) Report submitted to aponsor.

(4033) MANICOUAGAN POWER DEVELOPMENT SITE 5.

(b) Quebec Hydroelectric Commission.

(d) Theoretical; design.

(e) This study was carried out to define the volumes and peak discharges of the spring and autumn floods of probabilities up to $1 / 10,000$.

Only two year's stream-gauging data was available at the site, therefore it was necessary to work on the basis of longer records on neighboring catchments. Statistical correlation and arithmetic methods were used as means of data transfer, and the Gumbel equation was used to determine the discharges for the probabilities required. The slope of the spring flood hydrograph was determined from data available at a gauging station on the same river downstream of the site, then transferred by a unit-flood-peak discharge method.

(f) Completed.

(h) Report submitted to sponsor.

(4034) MANICOUAGAN POWER PLANT - SITE 5 - TEMPORARY DIVERSION.

(b) Quebec Hydroelectric Commission.

(d) Theoretical and experimental; design.

(e) A 1/108 scale model being used to determine the stage-discharge law of the two diversion tunnels proposed. Studies carried out so far include refinements to the intakes and outlets to improve conditions of transition from free surface flow to pressure flow in the tunnels. Law of upstream level vs. discharge takes into account considerable storage in reservoir formed by upstream cofferdam.

(h) Progress report only submitted to sponsor.

(4035) MANICOUAGAN POWER PLANT - SITE 5 - COFFERDAM.

(b) Quebec Hydroelectric Commission.

(d) Theoretical; design.

(e) Preliminary study of cofferdaming of the Manicouagan River. Both toe dumping and horizontal layers construction methods have been considered; the first one seems easier and cheaper.

A more elaborate study will be carried out on a scale model.

(f) Completed. 
(g) Report submitted to sponsor.

(4036) CHEMAINUS HARBOUR.

(b) Department of Public Works.

(d) Theoretical study; design.

(e) A study of the arrival of deep water generated waves in the harbour was carried out by using wave diagrams. This allowed determination of the efficiency of a proposed breakwater, as well as an alternative, more effective project.

(f) Completed.

(h) Report submitted to sponsor.

(4037) SUMMERSIDE HARBOUR - PRINCE EDWARD ISLAND.

(b) Department of Public Works.

(d) Theoretical study; design.

(e) Thio study of Harbour protection and effect of the Queen's Wharf extension has shown that this Harbour is well protected against penetration of swell. Unsatisfactory mooring conditions can be explained by excessive reflections and concentrations of incoming waves.

Some structures are recommended to decrease these effects.

(f) Completed.

(h) Report submitted to sponsor.

(4038) SKINNER'S POND HARBOUR IMPROVEMENTS, PRINCE EDWARD ISLAND.

(b) Department of Public Works.

(d) Theoreretical study; design.

(e) Preliminary study of the protection of the harbour entrance against sand deposit by littoral drift.

The results have shown the usefulness of enlarging the south breakwater, the safest and cheapest method to keep the required clearance at the entrance is to carry out periodic dredging. Field measurements are needed before completing the study.

(f) Completed

(h) Report submitted to sponsor.

(4039) SEWER SIPHON UNDER LACHINE CANAL.

(b) City of Montreal.

(d) Theoretical; design.

(e) Hydraulic design of a low level sewer passing under the Lachine Canal. Special attention was given to prevention of sedimentation in the low lying section of the siphon.

(f) Completed.

(h) Report submitted to sponsor.

(4040) CUROTIE PAPINEAU SEWAGE COLLECTOR FLOW METER.

(b) City of Montreal.

(d) Experimental; design and operation.

(e) Study on a model at a scale $1 / 18$ of solutions to increase the discharge of domestic water toward the interceptor. Study and calibration on the same model of a flow meter for domestic and flood waters. In studied solutions the intercepted discharge is controlled by an automatic sewage regulator with downstream control patented by the Laboratory (publications in I.A.H.R., eighth Congress, Montreal 1959).

(4041) QUEEN MARY TRIBUTARY INTERCEPTION, DROP IN A VERTICAL CONDUTT.

(b) City of Montreal.

(d) Experimental; design.

(e) Study on a $1 / 12$ scale model of the maximum discharge evacuated by a vertical conduit by means of a free surface giratory flow. Adjustment of the transition according to the tributary slope. Standardi zation.

(4042) LAVIGNE PUMPING STATION.

(b) City of Montreal.

(d) Theoretical; design.

(e) Hydraulic design of an automatic pumping station which drains a domestic and storm water sewer. Special attention given to prevention of sedimentation during low discharge seasons.

(f) Completed.

(h) Report submitted to sponsor.

ECOLE POLYTECHNIQUE, Department of Civil Engineering, Hydrodynamics Laboratory.

Inquiries concerning the following projects should be addressed to Professor Raymond Boucher, Director Hydrodynamics Laboratory, Ecole Polytechnique, 2500 Guyard Avenue, Montreal 26, Quebec, Canada.

(4043) STUDY OF THE RELIABILITY AND OPERATION OF BACK-WATER VALVES ON PLUMBING SYSTEMS AGATNST FLOODING BY PUBLIC SEWERS.

(b) City of Montreal, City Planning Department, Inspection Division.

(d) Experimental; applied research.

(e) A full scale three-story plumbing system has been erected in the Hydrodynamics Lab. of Ecole Polytechnique. The diameter of the pluvial column, the soil stack and the drain is $4 \mathrm{in.}$ The drain has many sections of pyrex glass to permit observations at critical points. A system of valves and of cross-connections on the vents lends to various combinations of tests. The backwater valves have a transparent lucite cover to enable visual observations. As air entrainment seems to have a great importance on the venting capacity, the rate of air entrained in the vertical columns is measured at the inlet by means of a hotwire air-meter. Various flooding conditions of the public sewers are simulated by a tank in which the water level can be controlled by gate valves. This research is aimed at determining whether back-water valves can offer home dwellers a reliable protection against flooding due to any overload of combined sewers. If this method is not satisfactory, an improved design of plumbing system may be suggested.

(4044) HYDRAULIC AND MECHANICAL TESTTNG OF A 


\section{6-INCH BUTTERFLY VALVE.}

(b) Dominion Engineering Company Limited

(d) Experimental; for design.

(e) Head losses to be measured across the Butterfly valve as a function of valve opening for discharges from 500 to 10,000 U. S. gpm. Torque determination to be executed throughout opening and closing cycles by means of strain gauge and electronic recorder at same flows as and concurrently with the head loss test, and at zero flow. An endurance test for 10,000 closing and opening cycles is also to be performed on the valve at a discharge of 10,000 U.S. gpm when the valve is fully open. Visual inspection for seat leakage is to be made after 100, 1000, 3,000, 5,000, 8,000 and 10,000 cycles.

NATIONAL RESEARCH COUNCIL, Division of Mechanical Engineering.

Inquiries concerning the following projects should be addressed to Dr. D. C. MacPhail, Director, Div. of Mechanical Engineering, National Research Council, Montreal Road, ottawa, Ontario, Canada.

\section{(3361) RESEARCH ON THE DESIGN OF FISHING BOATS.}

(b) Laboratory project.

(d) Experimental and theoretical to improve design.

(e) This project is being undertaken in cooperation with the Department of Fisheries, Canada, to improve the design and operation of East Coast fishing boats.

(g) A full scale fishing boat constructed to lines produced by the laboratory has shown good performanee. Full scale tests have been carried out on fishing nets to determine the towing forces. Model tests on ships and propellers are continuing.

(4045) PRELIMINARY SURVEY OF ST. LAWRENCE RIVER.

(b) Laboratory project.

(d) Field and theoretical study of tide and current.

(e) A theoretical study of the modification to the tide wave, as it progresses up the St. Lawrence River, has been made on the basis of published data and some field measurements. It is expected that this work will be useful in planning channel improvements for navigation.

(g) The study has shown that the tide wave is strongly modified by a number of restrictions in the river channel and has shown how dredging in various channels has affected water levels and tidal currents. The project is in the preliminary stage and will be continued.

(h) "The Tide in the St. Lawrence River," by H. A. Neu, Paper was presented at the ASCEEIC Meeting in Boston, 11 October 1960.

(4046) DINGWALL HARBOUR, NOVA SCOTIA.

(b) Department of Public Works, Canada. (d) Experimental project for design.

(e) An undistorted scale model, approximately $50 \mathrm{ft}$. by $100 \mathrm{ft}$., to a scale of $1: 80$, has been constructed to study the shoaling problem in the entrance of the harbour which is located on a sandy shore.

(f) Test work almost completed.

(g) Model tests have shown that suitably shaped rubble-mound breakwaters may be constructed so that an outward current will be ireated along the bed to prevent sand from entering the harbour during storms. Maintenance dredging should be reduced considerably.

(h) A report will be prepared for the sponsor.

(4047) BAIE COMEAU, PROVINCE OF QUEBEC.

(b) Department of Public Works, Canada.

(d) Experimental for design.

(e) A $1 / 110$ scale model of the harbour and offshore area has been constructed to study plans for harbour development. The harbour is located on the north shore of the Gulf of St. Lawrence where it is subject to fairly strong wave action. It is therefore essential that harbour developments be designed to provide safe berthing areas for ships. A number of layouts have been tested and the waves in the harbour compared.

(f) Test work almost completed.

(g) Preliminary data issued to the sponsor.

\section{(4048) NORTHUMBERLAND STRATT CAUSEWAY.}

(b) Department of Public Works, Canada.

(d) Experimental for design data.

(e) Proposals have been made to construct a rubble-mound causeway across Northumberland Strait - a distance of $91 / 2$ miles - to link Prince Edward Island with the mainland. Because of the exposed location and the prevalence of large quantities of ice, it is essential that the structure have adequate stability. A 1/30 scale model of a typical cross-section, designed by the consulting engineers, was constructed in the wave flume and tested under a variety of wave and tide conditions.

(h) Preliminary data submitted to the sponsor.

(4049) ETANG DES CAPS.

(b) Department of Public Works, Canada.

(d) Experimental for design.

(e) Etang des Caps is a small fishing settlement on the Magdalen Island, which has no harbour facilities. A model of scale $1 / 80$ has been constructed to develop a rubblemound breakwater arrangement which would be suitable for the exposed location and provide protection for a small group of fishing boats.

(f) Tests almost complete.

(h) A final report will be prepared for the sponsor.

\section{(4050) STUDY OF ICE DRIFT.}

(b) Laboratory project.

(d) Theoretical study.

(e) A theoretical study of the drift of ice in the Gulf of St. Lawrence is being conducted. 
(s) The mechanics of the wind-induced currents have been studied and it has been found that a permanent cyclonic circulation occurs in the Gulf. The combined effects of wind and density fields across Cabot Strait have also been studied. The study indicated a possible theoretical route which could be used by ships during the winter.

(h) A report is being prepared.

(4051) LOCK-FILLING MANIFOLD ANALYSIS.

(b) Laboratory project.

(d) Theoretical; applied research.

(e) As a sequel to lock model experiments conducted to obtain design data for the Seaway locks, an analysis of multiple-port culvert systems is being made. This is an attempt to study lock behavior without using large models. Experimentally determined characteristics of culvert and port components have been applied analytically to a network of lumped impedances but, because of non-linearlity, solution is difficult.

(g) An approximate solution has given filling curve results which are in good agreement with experimental data.

(h) "Some Remarks on the Behavior of Iock Culvert Filling Systems Considering NonLinear Friction," by J. E: Feir. 8th I.A.H.R. Congress, 1959.

\section{ONTARIO AGRICULTURAL COLIEGE.}

\section{(2492) RUNOFF FROM SMALL WATERSHEDS.}

(b) Laboratory project.

(c) Prof. D. F. Witherspoon, Ontario Agricultural College, Guelph, Ontario, Canada.

(d) Experimental; applied research.

(e) The relationship of precipitation and snowmelt to runoff characteristics on four watersheds of 20 acres each, under various land use practices, is being evaluated.

(g) Winter surface runoff from watersheds with good grass-legume cover is greater than from watersheds plowed during the winter season.

(2740) MAIN TILE DRATN SIZES FOR COMPOSITE DRAINAGE OF BROOKSTON CLAY SOIL.

(b) Laboratory project.

(c) Prof. F. R. Hore, Ontario Agricultural College, Guelph, Ontario, Canada.

(d) Field investigation; applied research.

(e) Discharge measurements from lateral tile drains in Brookston clay soil are being made to determine the proper drainage coefficient to use in the design of main tile drains and to determine the effect of lateral tile drain spacing on the drainage rate. Two additional lateral drains were installed in the fall of 1960.

(g) Correlation analysis of drainage rates have been made to determine which drain would best serve as a check to study the effect of the additional lateral drains. (b) Laboratory project.

(c) Prof. R. W. Irwin, Ontario Agricultural College, Guelph, Ontario, Canada.

(d) Field investigation; applied research.

(e) The study is being carried out to establish criteria to be used in the development and operation of the water control program for organic soils. In the investigation, an attempt will be made to establish an hydrologic water balance for the field area by measuring, recording and analyzing so far as possible the evaporation, seepage, transpiration, precipitation, water table elevation and ground water discharge through tile drains.

(g) Data are presently being analyzed.

(3658) THE RESISTIVITY METHOD FOR GROUND WATER EXPLORATION.

(b) Laboratory project.

(c) Prof. D. F. Witherspoon, Ontario Agricultural College, Guelph, Ontario, Canada.

(d) Field investigation; applied research.

(e) The objective is to investigate the application of the resistivity method to subsurface exploration for ground water under the geological conditions found in southern ontario.

(g) Equipment for use in Schlumberger traversing has been designed and tested. Correlative depth sounding traverses have been made near five wells with known logs. A lateral investigation was undertaken to find a buried pre-glacial river bed in the bedrock surface. Initial results indicated that the method shows promise for this type of investigation.

(3659) DROUGHT FREQUENCY ANALYSIS.

(b) Laboratory project.

(c) Prof. H. D. Ayers, Ontario Agricultural College, Guelph, Ontario, Canada.

(d) Experimental; development.

(e) The objective of this analysis is to determine the frequency of droughts in southwestern ontario. This information is to be used in determining the irrigation requirements for specific crops on various soil types. Water budget techniques are to be used and applied to actual meteorological observations in order to calculate the frequency and magnitude of irrigation requirements.

(3660) RAINFALL DEPTH-AREA-INTENSITY RELATIONSHIPS IN CENTRAL ONTARIO.

(b) Laboratory project.

(c) Prof. D. F. Witherspoon, Ontario Agricultural College, Guelph, Ontario, Canada.

(d) Field investigation; applied research.

(e) A dense network of standard and recording rain gauges has been established in the Guelph area with the co-operation of the Meteorological Branch, Department of Transport. The network is over an area of approximately $12 \mathrm{sq}$. miles with an average 
gage density of 1 per sq. mile. The purpose of this study is to obtain detailed information on summer precipitation characteristics for use in the hydrologic design for small drainage basins.

(g) Two years data have been collected. Summer thunder storms show a highly variable areal distribution. One storm over the network varied from 4.53 inches to 0.02 inches depth.

(3661) HYDROLOGIC FACTORS AFFECTING BRIDGE DESIGN.

(b) Laboratory project in cooperation with Ontario Department of Highways and Univ. of Toronto.

(c) Prof. F. R. Hore, Ontario Agricultural College, Guelph, Ontario, Canada.

(d) Experimental; Master's Thesis.

(e) The purpose of this project is to develop satisfactory design criteria for bridges and culverts based on watershed runoff relationships for Ontario. Frequency analysis of existing stream flow data for the province have been carried out. An attempt is being made to correlate watershed characteristics with peak discharge relationships.

(g) A thesis and a report to the ontario Dept. of Highways will be completed in 1961 .

(3662) POTENTIAL EVAPOTRANSPIRATION AND CONSUMPTIVE USE OF WATER BY CROPS.

(b) Laboratory project.

(c) Dr. K. M. King, Department of Soils, Ontario Agricultural College, Guelph, Ontario, Canada.

(d) Field investigation; basic research.

(e) The purpose of this investigation is to evaluate the factors influencing evapotranspiration by the use of a specially designed floating lysimeter. Study is being conducted on the effect of soil moisture on the heat budget and evapotranspiration for crops.

(g) Data are presently being analyzed.

(4052) COVER MATERIALS FOR TILE DRAINS.

(b) Laboratory project.

(c) Prof. F. R. Hore, Ontario Agricultural College, Guelph, Ontario, Canada.

(d) Experimental and field investigation; applied research and Master's Thesis.

(e) This study is being made to determine the effect of several cover materials on soil movement and water discharged into a tile drain. Laboratory studies of some relatively new glass fiber materials have been completed and a field experiment based on those results was installed in the fall of 1960 .

(g) Glass fiber filter material placed above and below the drain proved to be the most effective cover material.

(h) "The Effect of Cover Materials on the Movement of Soil into Tile Drains" by $\mathrm{H}$. C. Tiwari, Thesis on file in Massey Library, Ontario Agricultural College.
(4053) THE WATER YIELD OF SWAMP AREAS.

(b) Laboratory project.

(c) Prof. D. F. Witherspoon, Ontario Agricultural College, Guelph, Ontario, Canada.

(d) Field investigation; Master's Thesis.

(e) A watershed of approximately 900 acres containing a swamp area is being studied to determine the relationship between water shed characteristics and water yield.

(g) Six months' data on water levels, flow records, and precipitation have been collected and analysis has been started.

(4054) RUNOFF FROM FLAT LAND.

(b) Laboratory project in cooperation with Water Resources Division, Department of Northern Affairs and National Resources.

(c) Prof. F. R. Hore, Ontario Agricultural College, Guelph, Ontario, Canada.

(d) Field investigation; applied research.

(e) Several 2 to $10 \mathrm{sq}$. mile flat watersheds of fine-textured soils are to be studied to determine the relationship between precipitation, snowmelt, watershed characteristics and runoff. One watershed has been surveyed and instruments have been installed to determine precipitation and runoff. Hydrologic data on this type of watershed is being sought for the establishment of criteria for the design of hydraulic structures.

\section{(4055) EVAPORATION FROM A SNOW SURFACE.}

(b) Laboratory project.

(c) Prof. D. F. Witherspoon, Ontario Agricultural College, Guelph, Ontario, Canada.

(d) Field investigation; applied research.

(e) Snow evaporation will be measured from a floating lysimeter and basic equations for the heat budget over a snow surface will be developed for estimating snow evaporation and snowmelt. These data will be used in a water balance for experimental watersheds in the Guelph area.

(g) Equipment has been designed and constructed. Initial data will be collected during the winter of 1960-61.

QUEEN'S UNIVERSITY AT KINGSTON, HYDRAULIC LABORATORTES.

(3364) LITTORAI DRIFT AND ITS EFFECT ON THE HARBOURS ON THE NORTH SHORE OF LAKE ONTARIO.

(b) The National Research Council of Canada.

(c) Dr. Bernard Le Mehaute, Department of Civil Engineering, Queen's University at Kingston, Ontario.

(d) Experimental and field; basic and applied.

(e) Field and laboratory (i.e. three dimensional movable bed model of the Harbour of Cobourg) examination of silting due to littoral drift and research of a solution.

(h) "An Introduction to the Mathematical 
Theories of Two-Dimensional Periodic Progressive Gravity Waves," A. Brebner and B. Le Mehaute, Queen's University, C. E. Research Report No. Il (Available from (c)).

(3663) THE CAUSE, GROWTH AND EFFECT OF SECONDARY CURRENTS IN STRATGHT OPEN CHANNEL FLOW.

(c) Prof. R. J. Kennedy, Department of Civil Engineering, Queen's University at Kingston.

(d) Laboratory and Theoertical Investigation for Doctoral Thesis by J. F. Fulton.

(e) An investigation into the mechanism of secondary flow.

(h) Publication pending by $E$. I. C.

(3664) PERIODICAL GRAVITY WAVE MOTION ON DISCONTINUITIES.

(c) Dr. B. Le Mehaute, Department of Civil Engineering, Queen's University at Kingston.

(d) Theoretical analysis of gravity waves on a discontinuity.

(e) Experimental verification.

(h) "Periodical Gravity Waves on a Discontinuity," Published in Journal of ASCE, Hydraulic Div., November 1960.

(3665) THE EFFECT OF AIR-BUBBLING BREAKWATER ON WAVE MASS TRANSPORT.

(b) The National Research Council of Canada.

(c) Dr. A. Brebner, Civil Engineering Department, Queen's University at Kingston.

(d) Experimental laboratory investigation.

(f) Suspended.

(h) "A Laboratory Study of Pneumatic, Breakwaters," T. M. Dick and A. Brebner, Queen's University, C. E. Research Report No. 12 (Available from (c)).

(3666) CRITICAL MASS-TRANSPORT VELOCTTIES FOR PARTICIES OF VARIOUS SIZES.

(b) The National Research Council of Canada.

(c) Dr. A. Brebner, Department of Civil Engineering, Queen's University at Kingston.

(d) Experimental laboratory investigation.

(g) Work to present indicates limiting parameter for validity of Longuett-Higgins Theory.

(h) Publication pending by E. I. C. - A. S. M. E.

(4056) SUBMERGED BREAKWATERS AS A SOLUTION TO HARBOUR DEPOSIT.

(b) The National Research Council of Canada.

(c) Dr. B. Le Mehaute, Department of Civil Engineering, Queen's University at Kingston.

(d) Experimental and theoretical investigation of the possibility of using wave energy to create a scouring and flushing current which would reduce deposition of silt in a harbour.

(g) Promising results in a two-dimensional waveflume and on a three-dimensional basin with movable bed.

(h) Publication Pending by E. I. C. - A. S. M. E.

(4057) THE TRANSPORT OF LOGS OR SUSPENDED SOLIDS THROUGH PIPELINES.

(c) Dr. A. Brebner, Department of Civil Engi- neering, Queen's University at Kingston.

(d) Laboratory Investigation.

(e) A $400 \mathrm{ft}$. length of instrumented 4 inch a.luminum pipe with Perspex Observation Sections being used.

(4058) A THEORETICAL STUDY OF WAVES BREAKING AT AN ANGLE WITH A SHORE.

(b) National Research Council of Canada.

(c) Dr. B. Le Mehaute, Department of Civil

Engineering, Queen's University at Kingston.

(d) Basic theoretical research.

(f) Completed.

(h) Under print in Journal of Americal Geophysical Union, February, 1961.

(4059) A THEORY ON AGITATION IN A HARBOUR.

(b) National Research Council of Canada.

(c) Dr. B. Le Mehaute, Department of Civil Engineering, Queen's University at Kingston.

(d) Basic theoretical research.

(e) A theory using complex number calculus has permitted the evaluation of the agitation in a basin submitted to a given regular wave taking account of the entrance configuration, that is wave-traps, beaches etc.

(f) Completed.

(h) Publication pending by A.S.C.E.

(4060) PROBABILITY OF AGITATION IN A HARBOUR.

(b) National Research Council.

(c) Dr. B. Le Mehaute, Department of Civil Engineering, Queen's University at Kingston.

(d) Basic theoretical research.

(e) Theoretical study on the probability of agitation in a harbour subjected to incident irregular wave motion.

(f) Report in preparation.

(406I) WAVE LENS.

(b) National Research Council.

(c) Dr. B. Le Mehaute, Department of Civil Engineering, Queen's University at Kingston.

(d) Basic theoretical research.

(e) A theoretical study has been made on the possibilities of using a submerged mound to cause a change of direction of incident wave. A direct analogy with a convex lens has been used to study protection of a harbour entrance from agitation. Such a solution is economical only when the wave direction is almost constant.

UNIVERSITY OF TORONTO, Department of Mechanical Engineering.

(1298) DISCHARGE CHARACTERISTICS OF WEIR-TYPE SPILLWAYS.

(b) Laboratory project.

(c) Prof. L. E. Jones, University of Toronto, Toronto 5, Canada.

(d) Experimental; applied research for masters' theses.

(e) A long-term research carried out with a view 
to systematizing discharge characteristics for spillways having various pier spacings and proportions.

(g) Significant correlations obtained via special plotting techniques.

(h) Report in preparation.

(3003) ROUGHINESS PHENOMENA IN OPEN CHANNEL FLOW.

(b) Laboratory project.

(c) Prof. L. E. Jones, University of Toronto, Toronto 5, Canada.

(d) Experimental; applied research for doctoral thesis.

(e) Experimental and theoretical analysis to determine the influence of cross-section geometry on the resistance to flow in conduits. The channel under study is 70 feet long with variable rectanguiar section and uses air as the fluid medium. Extensive tests have been made on head loss and shear stress distribution as a function of shape of section.

(h) Report in preparation.

\section{(3368) DIFFUSION OF GASEOUS PLUMES.}

(b) Laboratory project.

(c) Prof. W D. Baines, University of Toronto, Toronto 5, Canada.

(d) Experimental; basic research for doctoral thesis.

(e) A jet of air is being injected normally into an artificially thickened boundary layer. Mean velocities and turbulence parameters are to be studied.

(g) Photographs of diffusion of a smoke jet show large differences in spreading rates due to velocity gradient and non-isotropy of the turbulent field. Two contra-rotating vortices with horizontal axes are produced due to interaction of jet and mean flow field.

(4062) CHANNEL IMPROVEMENT OF DON RIVER AT YORK MILLS, ONTARIO.

(b) W. O. Chisholm, Agincourt, Ontario, Canada, for Metropolitan Toronto and Region Conservation Authority.

(c) Prof. G. Ross Lord, University of Toronto, Toronto 5, Canada.

(d) Experimental; applied research for design.

(e) Model investigation of optimum spillway configuration.

(f) Completed.

(h) Reported to sponsor.

(4063) STACK HEIGHT DETERMTNATION. (b) Canada Iron Foundries, Limited, Toronto, Canada.

(c) Prof. G. Ross Lord, University of Toronto, Toronto 5, Canada.

(d) Experimental; applied research for design.

(e) Model study in low speed wind tunnel of stack discharge from existing foundry cupola under various conditions of velocity, wind, and stack height, to provide design data to reduce present incidence of downwash in dense industrial area.

(h) Report in preparation.

(4064) EFFECT OF GROINS ON LITTORAL TRANSPORT.

(b) Laboratory project.

(c) Prof. G. Ross Lord, University of Toronto, Toronto 5, Canada.

(d) Experimental; applied research for master's thesis.

(e) The motion of individual sediment particles of various sizes and densities is being studied on a model beach of 1:10 slope built at $45^{\circ}$ to the wave direction. Direction and magnitude of the particle velocities and the effect of groins upon particle motion patterns are being studied.

(g) It has been found that the rate of longshore transport is a maximum in the surf zone and decreases rapidly in the offshore direction. Preliminary tests indicate that groins are most effective if the length extends just beyond the surf zone.

(4065) FLOW AROUND OBJECTS IMMERSED IN A BOUNDARY LAYER.

(b) Laboratory project.

(c) Prof. W. D. Baines, University of Toronto, Toronto 5, Canada.

(d) Experimental; applied research for master's thesis.

(e) An artificial, thick boundary layer has been produced on the floor of a wind tunnel. Pressure distribution and secondary flow phenomena are being studied with respect to walls and cubes on the tunnel floor at various orientations.

(g) A secondary flow down the velocity gradient has been observed on the upstream faces of the object, resulting in higher pressures near the base. A linear combination of pressure coefficient and local velocity provides a fair approximation to the observed distribution. On the downstream faces the pressure distribution is uniform with a very strong secondary flow up the velocity gradient. 
Accelerated motion

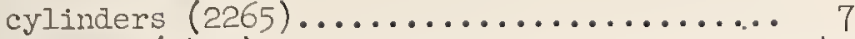

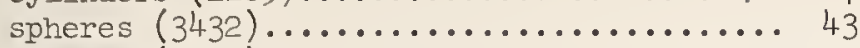

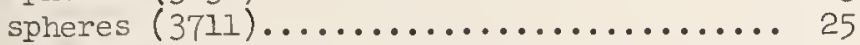

Air entrainment

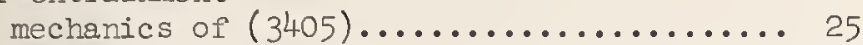

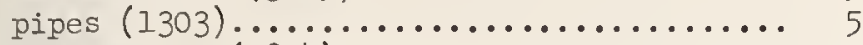

Air-water flow $(1834) \ldots \ldots \ldots \ldots \ldots \ldots \ldots \ldots$

Apparatus

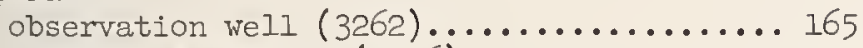

rainfall similator $(2596) \ldots \ldots \ldots \ldots \ldots \ldots . \ldots 71$

rotating arm $(1781) \ldots \ldots \ldots \ldots \ldots \ldots \ldots \ldots 181$

sediment sampler $(194) \ldots \ldots \ldots \ldots \ldots \ldots \ldots . \ldots \ldots$

shallow streamgaging $(3926) \ldots \ldots \ldots \ldots \ldots \ldots . \ldots \ldots$

soil, measurement of hydraulic

conductivity $(3213) \ldots \ldots \ldots \ldots \ldots \ldots \ldots \ldots 12$

spray formation $(2730) \ldots \ldots \ldots \ldots \ldots \ldots \ldots . \ldots \ldots \ldots$

surface follower $(3603) \ldots \ldots \ldots \ldots \ldots \ldots \ldots$

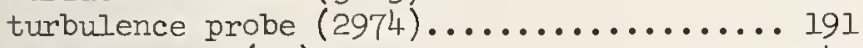

water tunnel $(79) \ldots \ldots \ldots \ldots \ldots \ldots \ldots \ldots \ldots . \ldots \ldots$

water tunnel $(1521) \ldots \ldots \ldots \ldots \ldots \ldots \ldots \ldots 181$

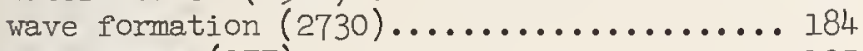

wave gages $(977) \ldots \ldots \ldots \ldots \ldots \ldots \ldots \ldots \ldots . \ldots \ldots \ldots$

Baffle piers

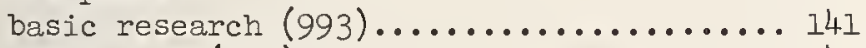

cavitation $(993) \ldots \ldots \ldots \ldots \ldots \ldots \ldots \ldots \ldots . \ldots \ldots \ldots$

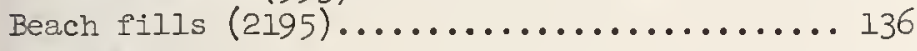

Beaches

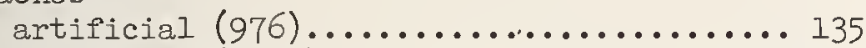

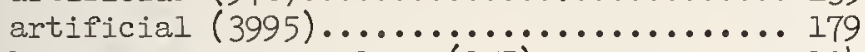

by-passing sand, inlets $(975) \ldots \ldots \ldots \ldots . . .134$

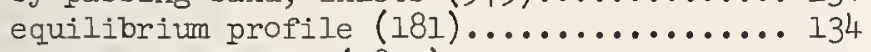

littoral movement $(3897) \ldots \ldots \ldots \ldots \ldots \ldots \ldots . \ldots \ldots$

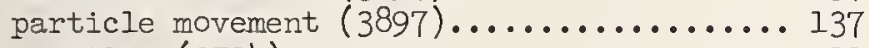

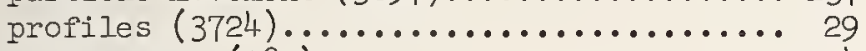

wave action $(181) \ldots \ldots \ldots \ldots \ldots \ldots \ldots . \ldots \ldots . \ldots \ldots$

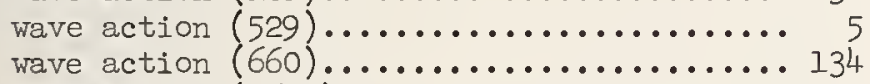

wave action $(1609) \ldots \ldots \ldots \ldots \ldots \ldots \ldots \ldots . \ldots \ldots$

Bibliographies, water measurement (1643)..... 68

Boundary layer $(3788) \ldots \ldots \ldots \ldots \ldots \ldots \ldots . \ldots 6$

Boundary layer

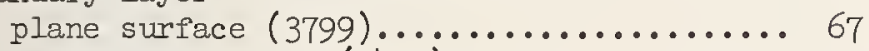

rectangular ducts $(3455) \ldots \ldots \ldots \ldots \ldots \ldots \ldots . \ldots \ldots \ldots \ldots \ldots \ldots \ldots \ldots$

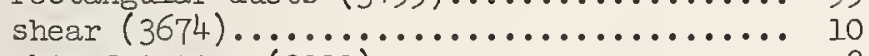

skin friction $(3020) \ldots \ldots \ldots \ldots \ldots \ldots \ldots . \ldots \ldots$

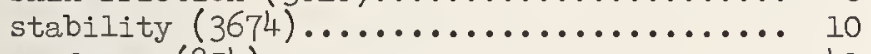

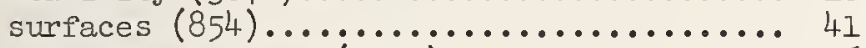

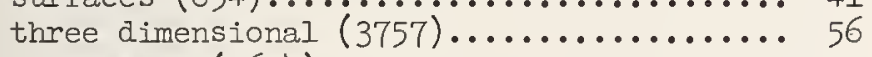

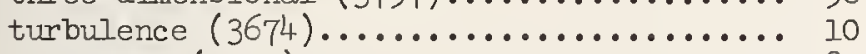

turbulent $(1779) \ldots \ldots \ldots \ldots \ldots \ldots \ldots \ldots \ldots \ldots \ldots 181$

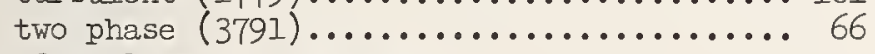

Boundary layer development

effect vibrations (3822)............. 79

Boundary layer flow

submerged bodies $(3481) \ldots \ldots \ldots \ldots \ldots \ldots \ldots 66$

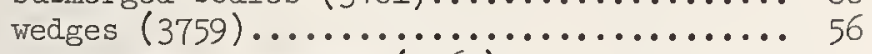

Boundary layer, laminar $(3765) \ldots \ldots \ldots \ldots \ldots \ldots$

Boundary shear stress $(2770) \ldots \ldots \ldots \ldots \ldots \ldots 18$

Breakwaters

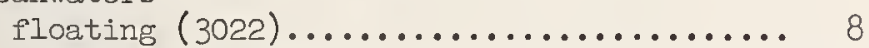

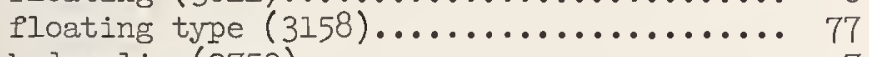

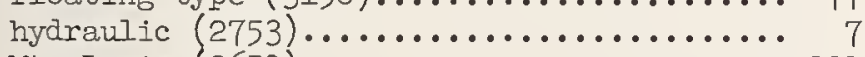

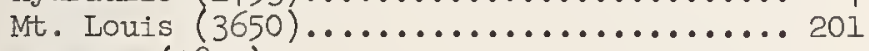

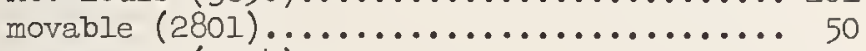

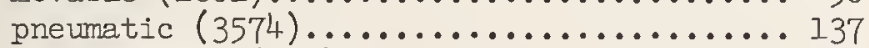

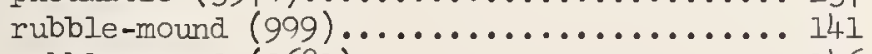

rubble-mound $(2681) \ldots \ldots \ldots \ldots \ldots \ldots \ldots \ldots . \ldots \ldots \ldots$

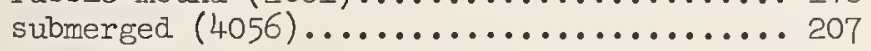

Bridge piers

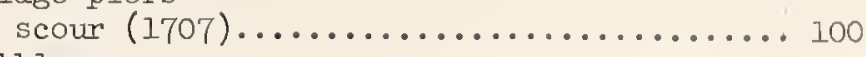
Bubbles

vapor (1548).

Canals

gravity flow bypass (3990)............. 179

irrigation

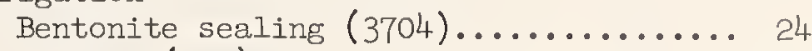

linings $(151) \ldots \ldots \ldots \ldots \ldots \ldots . \ldots \ldots$

linings $(1966) \ldots \ldots \ldots \ldots \ldots \ldots \ldots . \ldots \ldots$

linings

seepage $(1859) \ldots \ldots \ldots \ldots \ldots \ldots \ldots \ldots . \ldots \ldots$

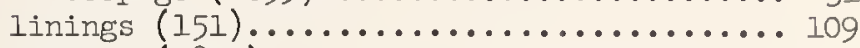

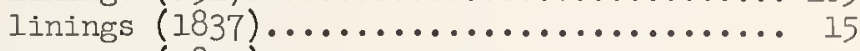

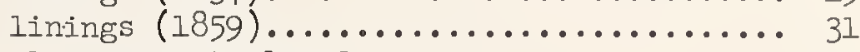

Canals, concrete-lined

discharge capacity $(3985) \ldots \ldots \ldots \ldots \ldots \ldots 178$

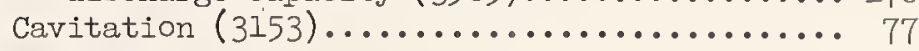

Cavitation

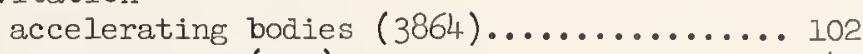

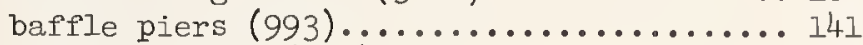

basic research $(993) \ldots \ldots \ldots \ldots \ldots \ldots \ldots . \ldots 141$ basic research

Calif. Inst. of Technology (1548)...... I

David Taylor Model Basin (711)........ 180

Iowa State University (79)........... 40

Waterways Experiment Station $(993) \ldots . . .141$

cascades $(3378) \ldots \ldots \ldots \ldots \ldots \ldots \ldots \ldots . \ldots \ldots$

concrete surface irregularities $(3278) \ldots . . .177$ effect thermal properties (3009).......... gate slots $(993) \ldots \ldots \ldots \ldots \ldots \ldots \ldots \ldots \ldots . . \ldots \ldots 14$

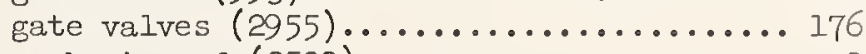
mechanics of $(2502) \ldots \ldots \ldots \ldots \ldots \ldots \ldots$.

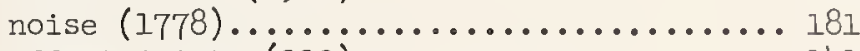

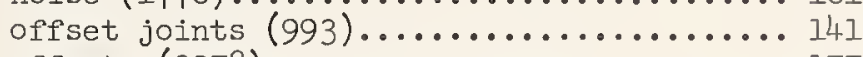

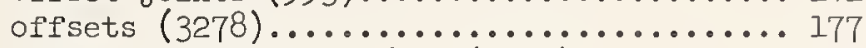

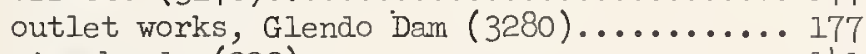
pipe bends $(993) \ldots \ldots \ldots \ldots \ldots \ldots \ldots \ldots \ldots . \ldots \ldots 14$

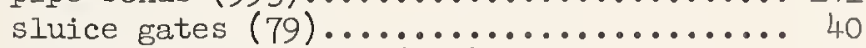

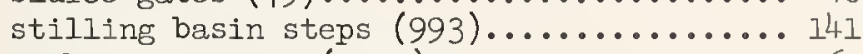

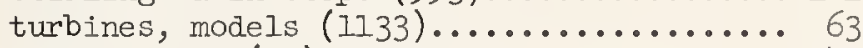

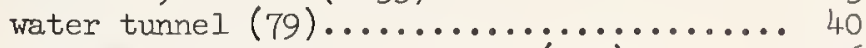

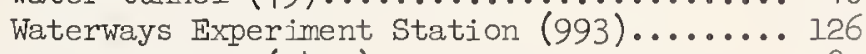

Cavity resonance $(2470) \ldots \ldots \ldots \ldots \ldots \ldots \ldots \ldots . \ldots \ldots$

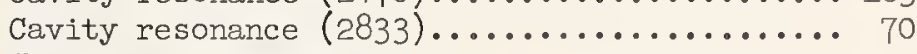

Channel improvement

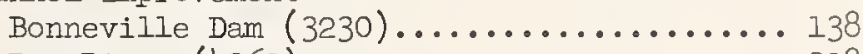

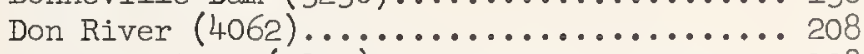

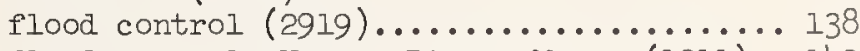
flood control, Hoosic River, Mass. (121i).. 142 flood control, Middle Miss. River (236).... 140

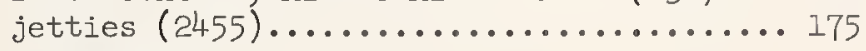
navigation

Delaware River, Pa. (425)........... 141

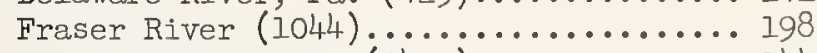

St. Lawrence River (2429) ............... 144 Ogden Island Reach, St. Lawrence River (3325)199 St. Lawrence River (3324).............. 199

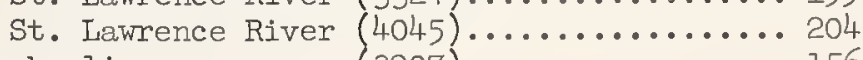

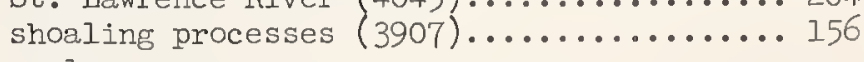
Channels

advance of liquid front (3192)......... 96

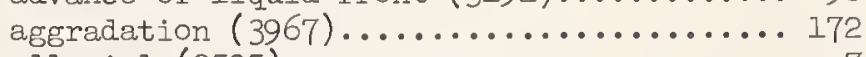

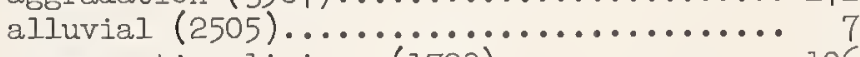
conservation linings $(1723) \ldots \ldots \ldots \ldots \ldots \ldots . \ldots \ldots$ conservation linings $(3804) \ldots \ldots \ldots \ldots \ldots . \ldots 6$

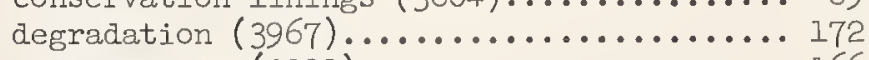
enlargements $(3922) \ldots \ldots \ldots \ldots \ldots \ldots \ldots \ldots \ldots . \ldots \ldots \ldots$ fluctuations $(3792) \ldots \ldots \ldots \ldots \ldots \ldots \ldots \ldots . \ldots \ldots$ 


\section{Channels}

guide vanes in $90^{\circ}$ bends $(3852) \ldots \ldots \ldots . .99$

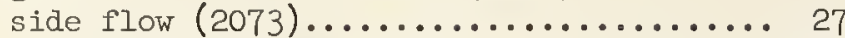
subcritical flows $(3400) \ldots \ldots \ldots \ldots \ldots \ldots . . .20$

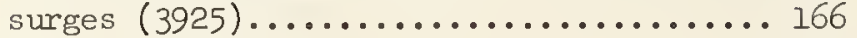

Channels, alluvial

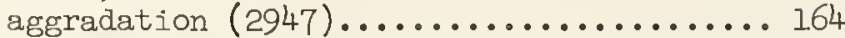

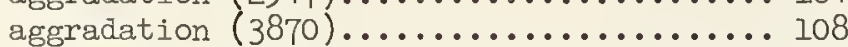

aggradation $(3968) \ldots \ldots \ldots \ldots \ldots \ldots \ldots \ldots 172$

bed roughness $(2514) \ldots \ldots \ldots \ldots \ldots \ldots \ldots . \ldots \ldots$

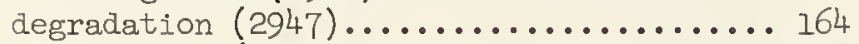

degradation $(3870) \ldots \ldots \ldots \ldots \ldots \ldots \ldots \ldots . \ldots \ldots$

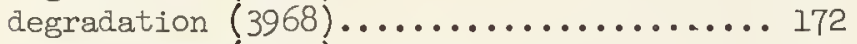

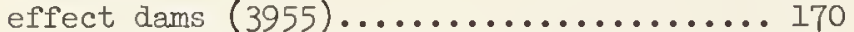

effect diversion $(3955) \ldots . . \ldots \ldots \ldots \ldots . . \ldots 170$

effect irrigation drains (3955)......... 170

hydraulics of $(3034) \ldots \ldots \ldots \ldots \ldots \ldots \ldots . \ldots \ldots$

Channels, curved, subcritical flow (3614)... 178 Channels, steep

surface characteristic $(3824) \ldots \ldots \ldots \ldots 79$

Climatology, Upper Colo. River Basin (3399).. 20

Coefficients

hydrophobic disks and plates (2436)...... 159

Conduits

circular, exit transitions (2543)...... 48

condenser cooling water loss (2241)...... 191

entrance, pressure distribution (3840)... 88

exit pressure distributions (2543)...... 48

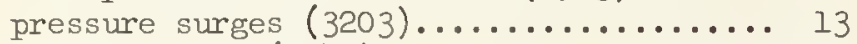

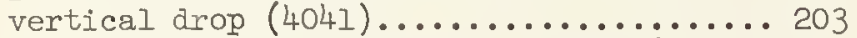

Conduits, non-circular, friction loss (3849). 97

Conduits, pressure

friction factors $(2724) \ldots \ldots \ldots \ldots \ldots . . . .176$

friction factors $(3275) \ldots \ldots \ldots \ldots \ldots \ldots 177$

Conduits, resistance, pressures (3778)...... 61

Contamination dispersion, rivers, harbors

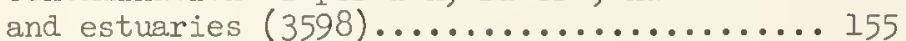

Convection, forced

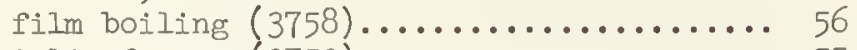

Coriolis forces $(3753) \ldots \ldots \ldots \ldots \ldots \ldots \ldots . \ldots \ldots$

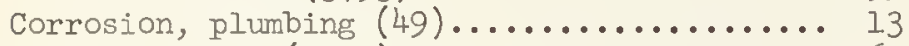

Culvert inlets $(3772) \ldots \ldots . . . \ldots \ldots . . . . .60$

Culvert inlets, circular $(3774) \ldots \ldots \ldots \ldots .60$ Culverts

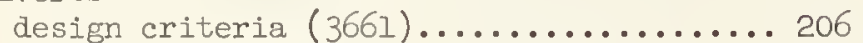
discharge characteristics (2435)........ 159

drop inlet $(111) \ldots \ldots \ldots \ldots \ldots \ldots \ldots \ldots . \ldots \ldots \ldots$

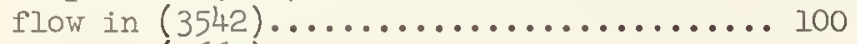

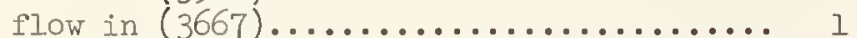

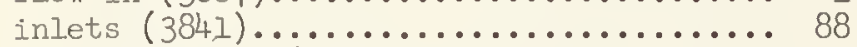

nature of flow $(3376) \ldots \ldots \ldots \ldots \ldots \ldots \ldots$

turbulence scaling $(4008) \ldots \ldots \ldots \ldots \ldots . \ldots 194$

Cylinders

accelerated motion $(2265) \ldots \ldots \ldots \ldots \ldots \ldots$

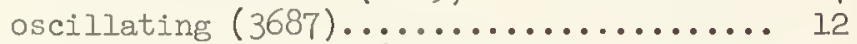

Dams, gallery drainage (771)............. 194

Density currents

salt water intrusion, Delaware River (425) 141

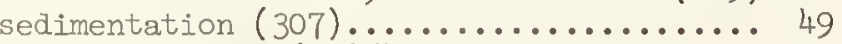

tidal estuaries $(1986) \ldots \ldots \ldots \ldots \ldots \ldots . \ldots 144$

Density, mean

slug flow $(3756) \ldots \ldots \ldots \ldots \ldots \ldots \ldots$

Diffusers

turbulent boundary layer (2320)........ 39

Diffusion

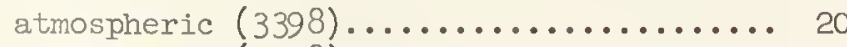

atmospheric $(3708) \ldots \ldots \ldots \ldots \ldots \ldots \ldots \ldots \ldots . \ldots \ldots$

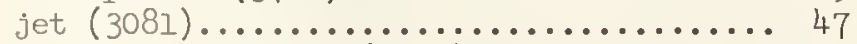

particles in fluid $(1331) \ldots \ldots \ldots \ldots . . . . .30$

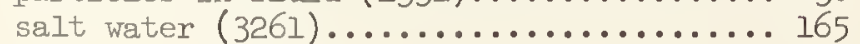

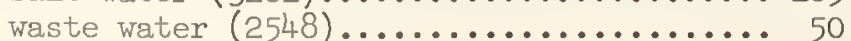

Disks, rotating

resistance of $(3749) \ldots \ldots \ldots \ldots \ldots \ldots \ldots \ldots . \ldots \ldots$

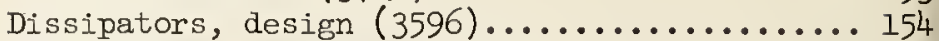

Distillation, sea water $(1554) \ldots \ldots \ldots \ldots \ldots \ldots$

Drag

skin friction $(3143) \ldots \ldots \ldots \ldots \ldots \ldots \ldots . \ldots \ldots$

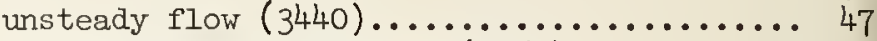

Drag coefficient, cylinders (2265).......... 7

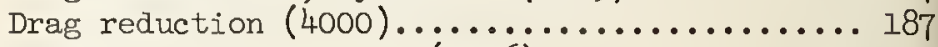

Drag resistance, piers $(2396) \ldots \ldots \ldots \ldots \ldots . . . . . . .91$

Drain tile

depth and spacing $(2330) \ldots \ldots \ldots \ldots \ldots . \ldots 44$

discharge measurements (2740) ............. 205

flow characteristics $(3490) \ldots \ldots \ldots \ldots \ldots \ldots .71$

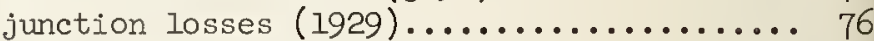

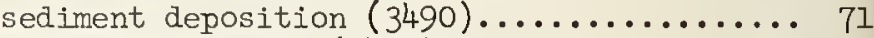

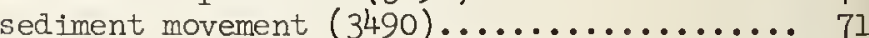

Drain tiles, cover material (4052)......... 206

Drainage

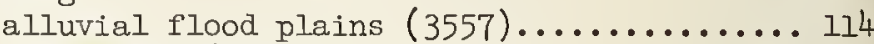

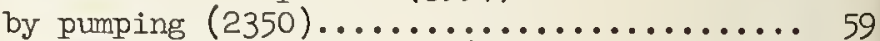

Coachella Valley, Calif. (26)............ 4

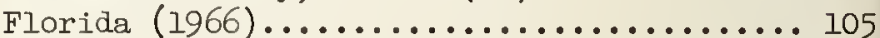

galleries, dams $(771) \ldots \ldots \ldots \ldots \ldots \ldots \ldots . . \ldots \ldots . . \ldots \ldots$

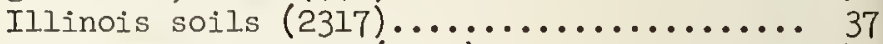

improvement surface $(2333) \ldots \ldots \ldots \ldots \ldots \ldots . \ldots \ldots$

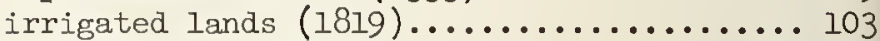

irrigated lands $(1966) \ldots \ldots \ldots \ldots \ldots \ldots . . \ldots 105$

irrigated lands $(3401) \ldots \ldots \ldots \ldots \ldots \ldots \ldots . \ldots \ldots . \ldots \ldots$

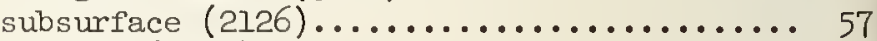

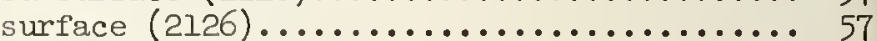

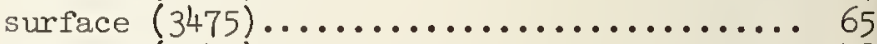

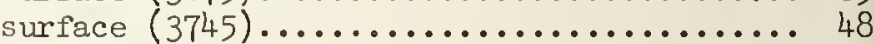

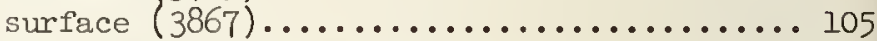

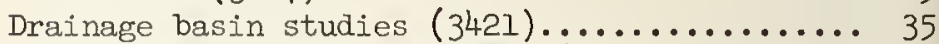

Drainage improvement, surface $(2333) \ldots \ldots \ldots . .45$

Drainage installations, subsurface (3216)..... 112

Drainage systems, design (2504)............ 5

Drains, filter

operational characteristics $(3060) \ldots \ldots \ldots 38$

Drains, subsurface

durability $(2127) \ldots \ldots \ldots \ldots \ldots \ldots \ldots \ldots . \ldots \ldots$

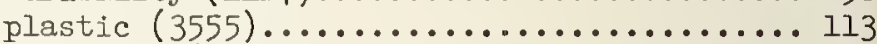

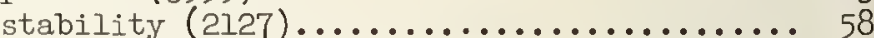

Eddies, effect of boundary geometry (1875).... 41

Embankments (291)...................... 29

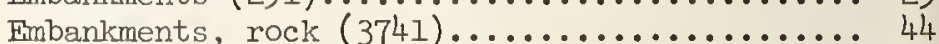

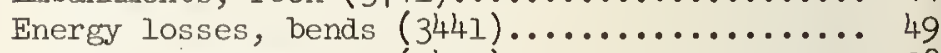

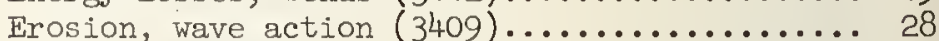

Erosion research

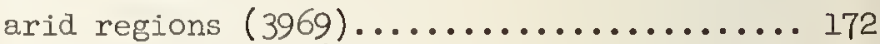

Boca Raton Inlet $(3410) \ldots \ldots \ldots \ldots \ldots \ldots . \ldots 29$

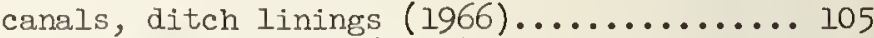

canals, earth lined $(2457) \ldots \ldots \ldots \ldots \ldots \ldots . . \ldots 175$

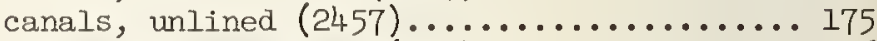

conservation farming $(150) \ldots \ldots \ldots \ldots \ldots \ldots . . . . .106$

conservation farming $(2187) \ldots \ldots \ldots \ldots \ldots . \ldots \ldots \ldots$

curved open channels $(3089) \ldots . . \ldots \ldots \ldots . . . . .51$

dikes $(3744) \ldots \ldots \ldots \ldots \ldots \ldots \ldots \ldots \ldots . \ldots \ldots \ldots$

effect logging $(2912) \ldots \ldots \ldots \ldots \ldots \ldots \ldots . \ldots \ldots$

effects tillage (2597)................ 71

effect vegetation $(261) \ldots \ldots \ldots \ldots \ldots \ldots \ldots \ldots$

forest influences $(380) \ldots \ldots \ldots \ldots \ldots \ldots . \ldots 132$

forest influences 657 ............... 127

Florida inlets $(3413) \ldots \ldots \ldots \ldots \ldots \ldots . \ldots . \ldots 29$

hillslopes (3952).................... 169

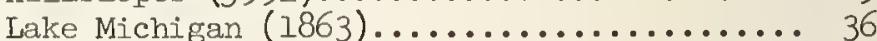

mountain watersheds $(261) \ldots \ldots \ldots \ldots \ldots \ldots . \ldots 125$

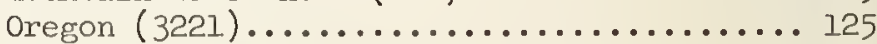

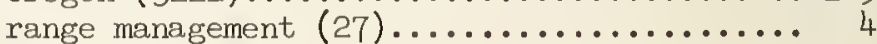

semiarid regions $(3969) \ldots \ldots \ldots \ldots \ldots \ldots \ldots$ 
Erosion research

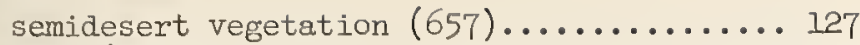

soil $(3424) \ldots \ldots \ldots \ldots \ldots \ldots \ldots \ldots . \ldots \ldots . \ldots \ldots$

Evaporation

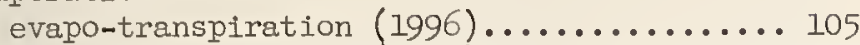

evapo-transpiration $(2188) \ldots \ldots \ldots \ldots \ldots \ldots . \ldots 129$

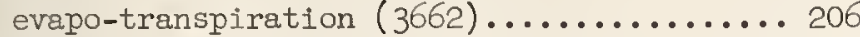

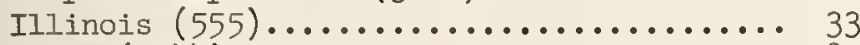

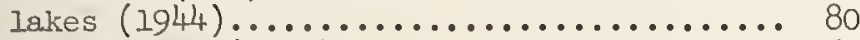

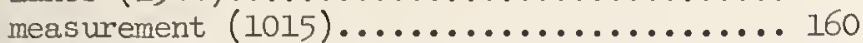

measurement $(2179) \ldots \ldots \ldots \ldots \ldots \ldots \ldots . \ldots \ldots$

measurement $(3881) \ldots \ldots \ldots \ldots \ldots \ldots \ldots \ldots \ldots \ldots \ldots \ldots$

mechanics of $(3964) \ldots \ldots \ldots \ldots \ldots \ldots \ldots \ldots \ldots \ldots$

moving surfaces $(3393) \ldots \ldots \ldots \ldots \ldots \ldots \ldots . \ldots \ldots$

reduction $(2828) \ldots \ldots \ldots \ldots \ldots \ldots \ldots \ldots \ldots$

reduction $(3508) \ldots \ldots \ldots \ldots \ldots \ldots \ldots \ldots . \ldots \ldots . \ldots \ldots$

reservoirs $(765) \ldots \ldots \ldots \ldots \ldots \ldots \ldots \ldots \ldots . \ldots \ldots$

reservoirs $(2180) \ldots \ldots \ldots \ldots \ldots \ldots \ldots \ldots \ldots \ldots . \ldots \ldots$

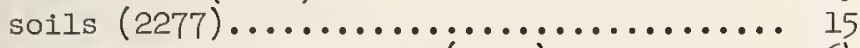

suppression, reservoirs $(2703) \ldots \ldots \ldots \ldots \ldots 164$

urban areas $(564) \ldots \ldots \ldots \ldots \ldots \ldots \ldots \ldots \ldots . . . \ldots \ldots$

watersheds, tennessee Basin (765)........ 194

Evapotranspiration

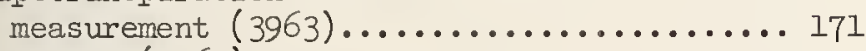

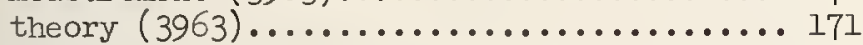

Filtering $(2741) \ldots \ldots \ldots \ldots \ldots \ldots \ldots \ldots \ldots \ldots \ldots$

Filtering, sand $(3844) \ldots \ldots \ldots \ldots \ldots \ldots \ldots . \ldots \ldots$

Filtering, sediments $(3554) \ldots \ldots \ldots \ldots \ldots \ldots \ldots$

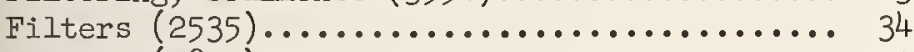

Filters $(2837) \ldots \ldots \ldots \ldots \ldots \ldots \ldots \ldots \ldots \ldots \ldots \ldots . \ldots \ldots$

Fish ladders, dams, John Day (3578)......... 139

Fishway model study

John Day Dam, ladder diffusers (3576)..... 139

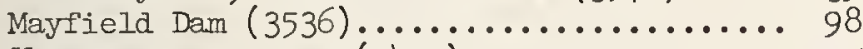

hanapum facilities $(3497) \ldots \ldots \ldots \ldots \ldots \ldots . \ldots \ldots 77$

Flashboards, dynamic forces $(3068) \ldots \ldots \ldots \ldots . . . .42$

Flood control $(3682) \ldots \ldots \ldots \ldots \ldots \ldots \ldots \ldots . \ldots . \ldots 12$

Flood control

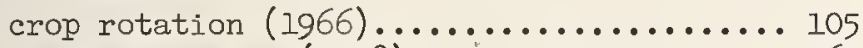

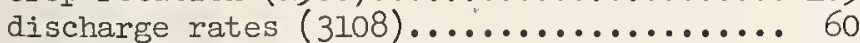

discharge rates $(4033) \ldots . . \ldots \ldots \ldots . . . \ldots 2$

electric flood model $(3385) \ldots \ldots \ldots \ldots \ldots . . \ldots 9$

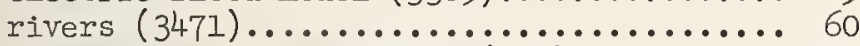

rivers, Mississippi Basin (236)........... 140 structure design $(3930) \ldots \ldots \ldots \ldots \ldots \ldots \ldots 16$

Flood control systems

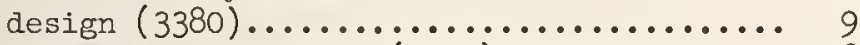

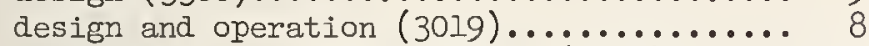

Flood forecasting, rating curves (3602)...... 162 Flood frequency $(3606) \ldots \ldots \ldots \ldots \ldots \ldots \ldots$ Flood frequency

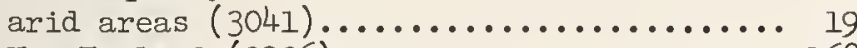

New England $(3936) \ldots \ldots \ldots \ldots \ldots \ldots \ldots . \ldots \ldots$

semiarid areas $(3041) \ldots \ldots \ldots \ldots \ldots \ldots \ldots . \ldots \ldots$

semiarid areas $(3937) \ldots \ldots \ldots \ldots \ldots \ldots \ldots . \ldots \ldots$

urban areas $(3928) \ldots \ldots \ldots \ldots \ldots \ldots \ldots \ldots \ldots . \ldots \ldots$

Flood plane zoning, suburban areas (3935)..... 168 Flood records, small-area (3934)........... 167

Flood routing $(3476) \ldots \ldots \ldots \ldots \ldots \ldots \ldots \ldots . \ldots 6$

Flow

accelerated $(3740) \ldots \ldots \ldots \ldots \ldots \ldots \ldots \ldots . \ldots 4$

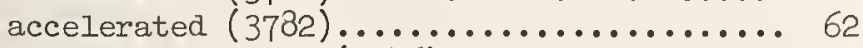

fibre suspensions $(2546) \ldots \ldots \ldots \ldots \ldots \ldots . \ldots \ldots$

fluctuating $(3622) \ldots \ldots \ldots \ldots \ldots \ldots \ldots \ldots \ldots . \ldots \ldots . \ldots \ldots$

free surface $(3720) \ldots \ldots \ldots \ldots \ldots \ldots \ldots \ldots . \ldots 28$

free surface, disturbed $(3414) \ldots \ldots \ldots \ldots . . . . .30$

non-Newtonian $(3390) \ldots \ldots \ldots \ldots \ldots \ldots \ldots . \ldots \ldots$

non-Newtonian $(3482) \ldots \ldots \ldots \ldots \ldots \ldots \ldots . \ldots \ldots 6 . \ldots \ldots$

non-Newtonian fluids $(3781) \ldots \ldots \ldots \ldots \ldots . \ldots 2$

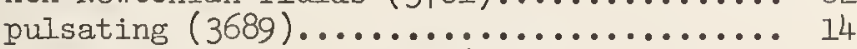

river under arch bridges (2839)......... 72
Flow

single and two-phase in tube $(2374) \ldots \ldots .74$

solid-liquid mixtures (3692)............... 14

steady, viscous $(3148) \ldots \ldots \ldots \ldots \ldots \ldots \ldots . \ldots \ldots \ldots$

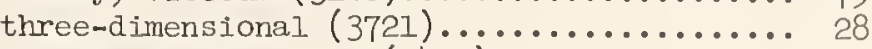

two-phase in venturi $(3403) \ldots \ldots \ldots \ldots \ldots . . \ldots 21$

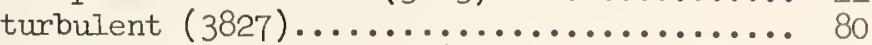

Flow characteristics, foam (3690)........... 14

Flow conditions, Renca Thermal Plant (3862).... 102

Flow, divided, mechanics of $(3743) \ldots \ldots \ldots . . .47$

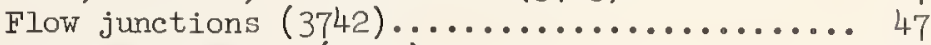

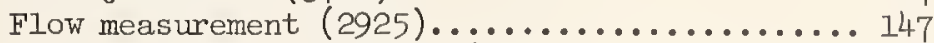

Flow non-steady, viscous $(3148) \ldots \ldots \ldots \ldots \ldots . \ldots \ldots$

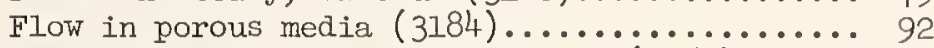

Flow studies, 3-dimensional forms (2969)...... 185

Flow studies, two-phase (3764)........................ 57

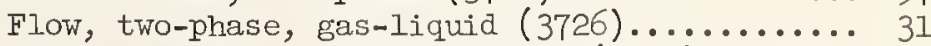

Flow, unsteady, inertial forces (3250)....... 159

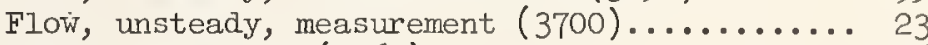

Flows, secondary $(3761) \ldots \ldots \ldots \ldots \ldots \ldots \ldots \ldots . \ldots \ldots$

Fluidization, sand beds (3669)............... 4

Fluid mechanics, educational films (3739).... 44

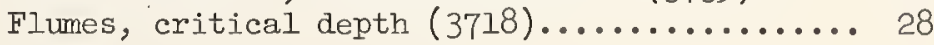

Flumes

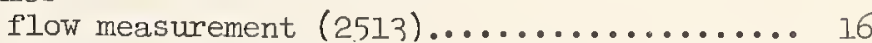

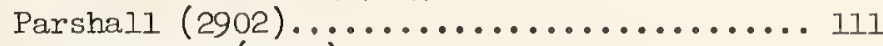

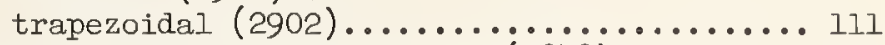

Flumes, metering, calibration (3848)......... 97

Forces, wind-tunnel measurement (2832)....... 70

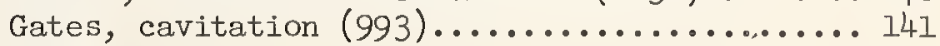

Gates

jet flow $(3998) \ldots \ldots \ldots \ldots \ldots \ldots \ldots \ldots \ldots$

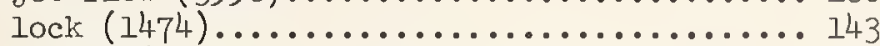

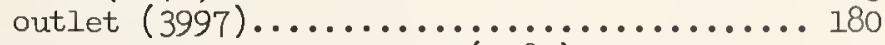

Gates, control, Island Bend (3281)........... 177

Gates, slide, hydraulic downpull (3610)...... 177

Gates, turbine, closure (4020)............. 199

Geohydraulic theory $(3147) \ldots \ldots \ldots \ldots \ldots \ldots . \ldots . \ldots 73$

Ground water

aquifers $(3184) \ldots \ldots \ldots \ldots \ldots \ldots . \ldots \ldots$

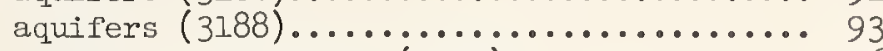

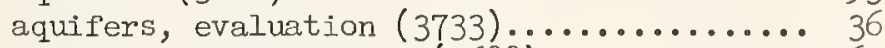

aquifers, mechanies of $(2688) \ldots \ldots \ldots \ldots \ldots . . \ldots 163$

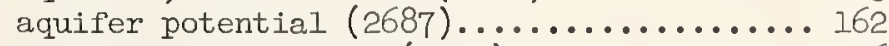

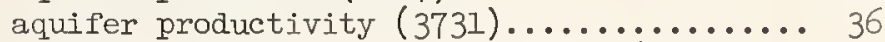

aquifers, salt water encroachment (2689).... 163

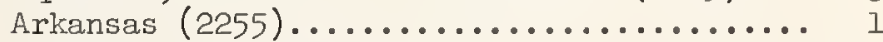

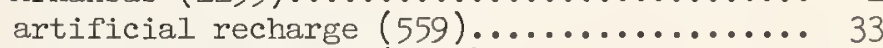

artificial recharge $(1966) \ldots \ldots \ldots \ldots \ldots \ldots$

artificial recharge $(2255) \ldots \ldots \ldots \ldots \ldots \ldots . . . \ldots 1$

artificial recharge $(2315) \ldots \ldots \ldots \ldots \ldots \ldots . \ldots \ldots$

artificial recharge $(3394) \ldots \ldots \ldots \ldots \ldots \ldots . \ldots \ldots$

artificial recharge $(3676) \ldots \ldots \ldots \ldots \ldots \ldots \ldots$

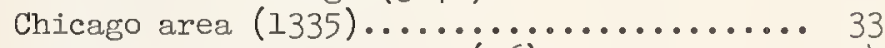

Coachella Valley, Calif. (26)............ 4

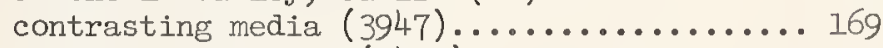

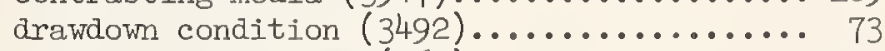

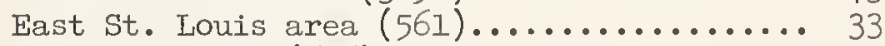

effect forests $(656) \ldots \ldots \ldots \ldots \ldots \ldots \ldots \ldots . \ldots \ldots$

electric flow net $(1221) \ldots \ldots \ldots \ldots \ldots \ldots . \ldots . \ldots 162$

electrical analogue $(2692) \ldots \ldots \ldots \ldots \ldots \ldots . . \ldots 163$

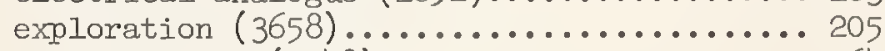

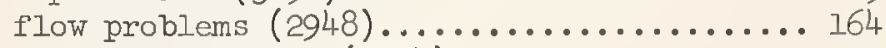

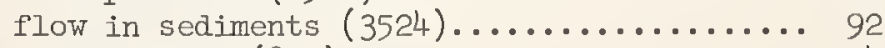

fluctuations $(821) \ldots \ldots \ldots \ldots \ldots \ldots \ldots . \ldots \ldots 14$

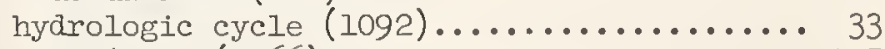

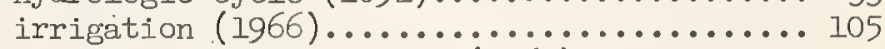

Lower Bijou Basin, Colo. (27El).......... 17

non-homogeneous anistropic flow $(3186) \ldots . . .99$

occurrence problems $(3264) \ldots \ldots \ldots \ldots \ldots . . \ldots 165$

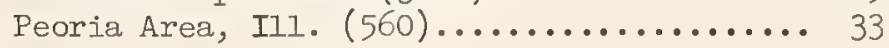


Ground water

Ralston Creek, Iowa (66)............. 40

Rapid Creek, Iowa (68).............. 40

Red River Valley, No. Dak. (32l7)........113

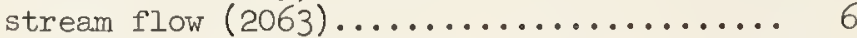

Tennessee Valley $(780) \ldots \ldots \ldots \ldots \ldots \ldots \ldots$

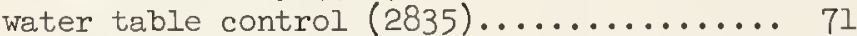

wells, evaluation $(3733) \ldots \ldots \ldots \ldots \ldots \ldots$

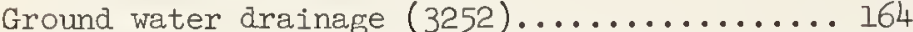

Ground water flow, aquifers (3538)......... 100

Ground water storage $(3263) \ldots \ldots \ldots \ldots \ldots \ldots \ldots$

Gutters, side flow (2073)............. 27

Harbor improvement

Baie Comeau, Que., Canada (4047).......... 204

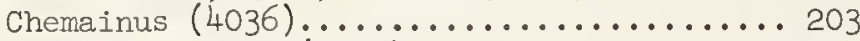

Dingwall Harbor $(4046) \ldots \ldots \ldots \ldots \ldots . \ldots 204$

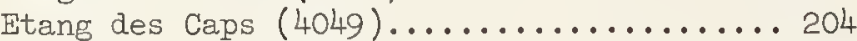

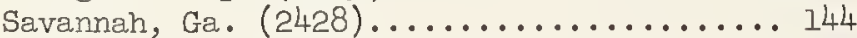

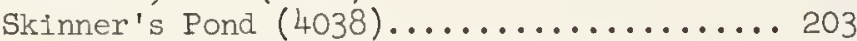

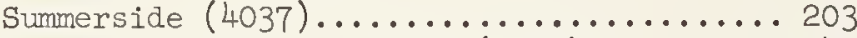

Harbor models, scale effects (1002)......... 142

Harbor study, Kelly's Island, Lake Erie.(3905) 156

Heat transfer

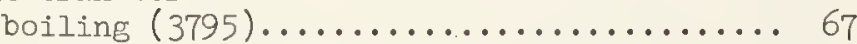

fluidized beds $(3474) \ldots \ldots \ldots \ldots \ldots \ldots \ldots \ldots \ldots$

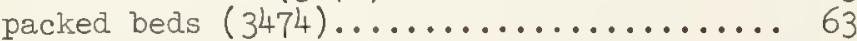

thin liquid films $(3728) \ldots \ldots \ldots \ldots \ldots \ldots . . \ldots 1$

Highway drainage

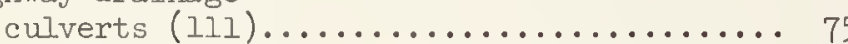

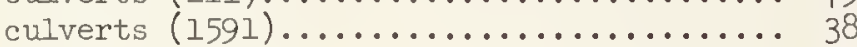

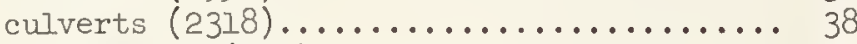

embankments (291).................. 29

energy dissipator $(2318) \ldots \ldots \ldots \ldots \ldots \ldots . \ldots \ldots$

energy dissipators $(3987) \ldots \ldots \ldots \ldots \ldots \ldots . . . . .178$

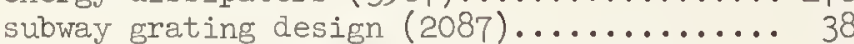

Hydraulic control systems, valves (2335).... 45

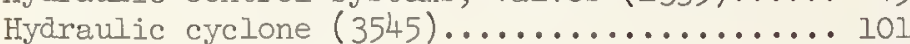

Hydraulic jump $(2161) \ldots \ldots \ldots \ldots \ldots \ldots \ldots \ldots . \ldots 9 . \ldots$

Hydraulic jump $(3994) \ldots . . . \ldots \ldots \ldots . . . . .179$

Hydrodynamic forces

cylinders $(3853) \ldots \ldots \ldots \ldots \ldots \ldots \ldots \ldots . \ldots . \ldots 9 . \ldots \ldots$

underwater bodies $(2746) \ldots \ldots \ldots \ldots \ldots \ldots \ldots$

Hydrodynamics, flow studies $(3377) \ldots \ldots \ldots \ldots . . . . .2$

Hydrofoil craft, seaworthiness $(3294) \ldots \ldots \ldots . . .186$

Hydrofoils

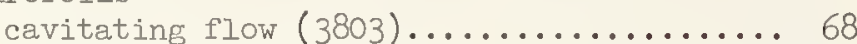

design criteria $(3284) \ldots \ldots \ldots \ldots \ldots \ldots$

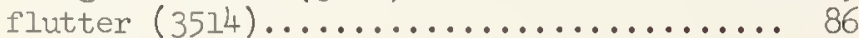

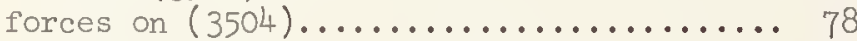

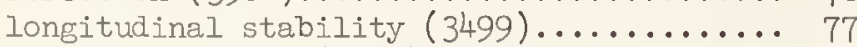

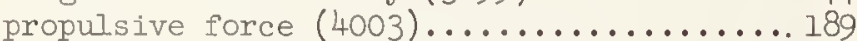

strut interference effects $(3821) \ldots \ldots \ldots \ldots 78$

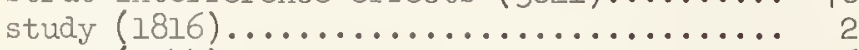

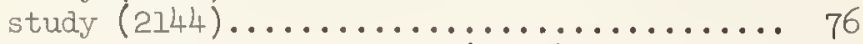

Hydrofoils, models, testing (3828)......... 80

Hydrofoils, submerged, flutter studies (3833). 87

Hydrofoils, supercavitating

forces on $(3174) \ldots \ldots \ldots \ldots \ldots \ldots . \ldots \ldots$

hydroelastic instabilities $(3173) \ldots \ldots \ldots .64$

hydroelastic instabilities $(3834) \ldots \ldots \ldots . . .67$

Hydrologic data, telemetering (3056)........ 32 Hydrologic processes, forest lands (3884).... 120 Hydrologic studies (3929) ............... 167 Hydrologic studies

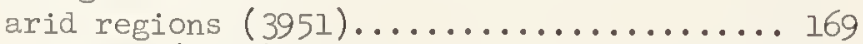

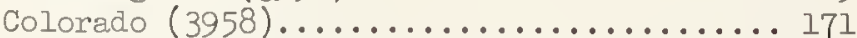

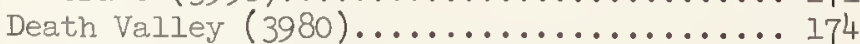

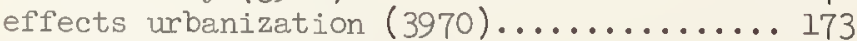
flood frequency $(3953) \ldots \ldots \ldots \ldots \ldots \ldots \ldots . \ldots 170$

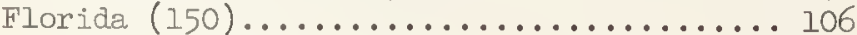

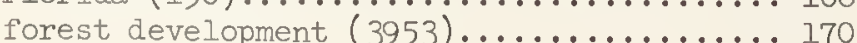

Hydrologic studies

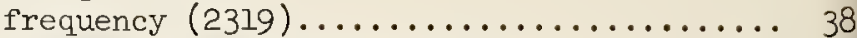

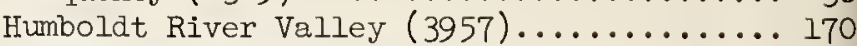

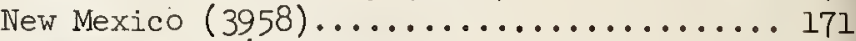

organic soil (3363).................. 205

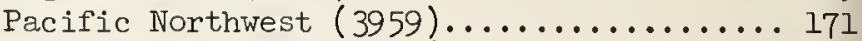

Waller Creek Watershed (2162)............... 91

water yield $(3965) \ldots \ldots \ldots \ldots \ldots \ldots \ldots \ldots . \ldots \ldots \ldots$

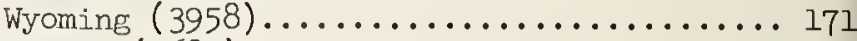

Hydrology $(3682) \ldots \ldots \ldots \ldots \ldots \ldots \ldots \ldots \ldots . \ldots \ldots 12$

Hydrology, statistical procedures (3933)..... 167

Hydromechanics problems

numerical solution $(3491) \ldots \ldots \ldots \ldots \ldots . \ldots 73$

Infiltration

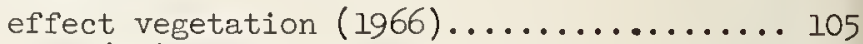

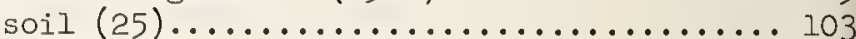

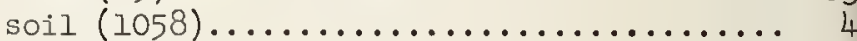

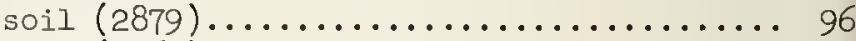

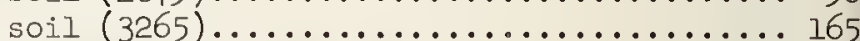

Infiltration studies $(3507) \ldots \ldots \ldots \ldots \ldots \ldots .61$

Inlets

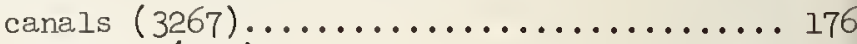

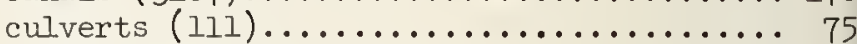

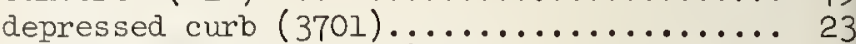

hydrodynamics of flow $(3166) \ldots \ldots \ldots \ldots \ldots .61$

theory $(2088) \ldots \ldots \ldots \ldots \ldots \ldots \ldots \ldots \ldots \ldots \ldots \ldots \ldots \ldots$

Instruments

current meter $(3802) \ldots \ldots \ldots \ldots \ldots \ldots \ldots \ldots .68$

hydrograph, outflow $(3679) \ldots \ldots \ldots \ldots \ldots \ldots 10$

pitot-tube calibration $(3784) \ldots \ldots \ldots \ldots \ldots 63$

precipitation gage, weighing type (3921)... 162

pressure cells (1004).................. 142

pressure fluctuation (2541)........... 42

radar raingage $(2943) \ldots \ldots \ldots \ldots \ldots \ldots \ldots 16 \ldots \ldots \ldots$

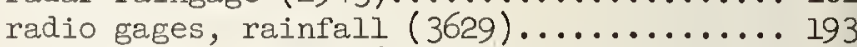

radio gages, stream $(3629) \ldots \ldots \ldots \ldots \ldots \ldots . \ldots \ldots$

river gage, float-type (3920)....................... 162

sediment density gage $(3227) \ldots \ldots \ldots \ldots \ldots \ldots 136$

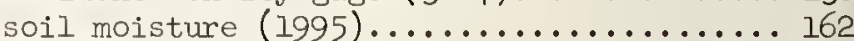

soil moisture $(3260) \ldots \ldots \ldots \ldots \ldots \ldots \ldots \ldots$

sonic wave probe $(3829) \ldots \ldots \ldots \ldots \ldots \ldots . \ldots 87$

streambed analyzer $(3402) \ldots \ldots \ldots \ldots \ldots \ldots . . \ldots 21$

turbulence indicators (2629)........... 91

velocity meter $(1004) \ldots \ldots \ldots \ldots \ldots \ldots \ldots . \ldots . \ldots 142$

water level recorder $(3527) \ldots \ldots \ldots \ldots \ldots . . \ldots 3$

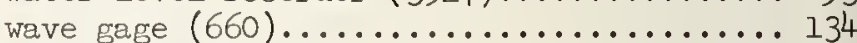

wave gage $(977) \ldots \ldots \ldots \ldots \ldots \ldots \ldots \ldots \ldots \ldots . \ldots \ldots \ldots$

wave gage $(1004) \ldots \ldots \ldots \ldots \ldots \ldots \ldots \ldots . \ldots . \ldots . \ldots$

Intakes

Chute-des-Passes (3632).............. 197

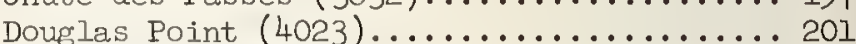

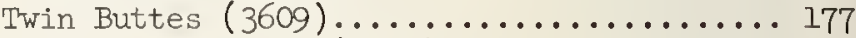

Wilson Powerhouse $(3299)$............... 192

Irrigation

application rates $(3104) \ldots \ldots \ldots \ldots \ldots . \ldots 58$

canals

bentonite sealing (3558)................... 114

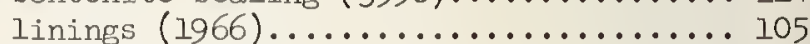

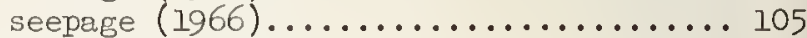

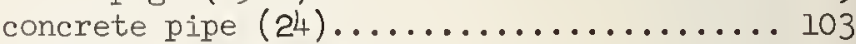

control systems, mechanized (3553)........ 113

control of water $(1966) \ldots \ldots \ldots \ldots \ldots \ldots . \ldots \ldots$

drainage design $(3211) \ldots \ldots \ldots \ldots \ldots \ldots \ldots 112$

drainage studies $(1723) \ldots \ldots \ldots \ldots \ldots \ldots . . . . .106$

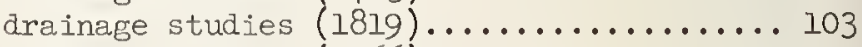

drainage studies $(1966) \ldots \ldots \ldots \ldots \ldots \ldots . \ldots 105$

drainage studies $(2651) \ldots \ldots \ldots \ldots \ldots \ldots \ldots 110$

drainage studies $(3218) \ldots \ldots \ldots \ldots \ldots \ldots \ldots \ldots \ldots$

efficiencies $(2786) \ldots \ldots \ldots \ldots \ldots \ldots \ldots \ldots . \ldots \ldots \ldots . \ldots \ldots \ldots$

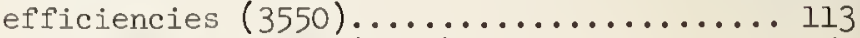

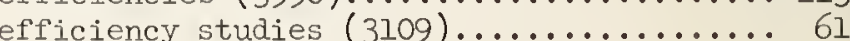


Irrigation

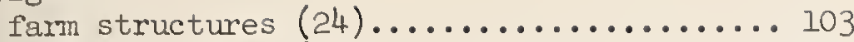

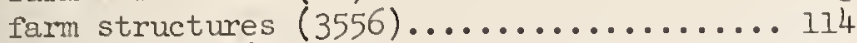

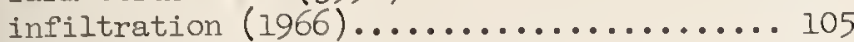

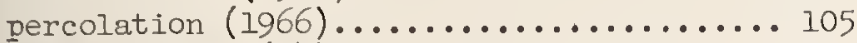

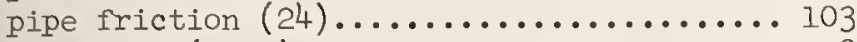

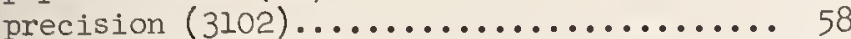

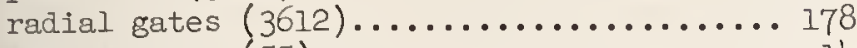

snow surveys $(55) \ldots \ldots \ldots \ldots \ldots \ldots \ldots \ldots \ldots \ldots \ldots$

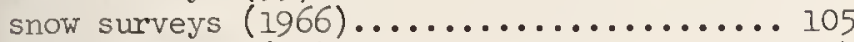

soil moisture $(26) \ldots \ldots \ldots \ldots \ldots \ldots \ldots \ldots \ldots$. 4

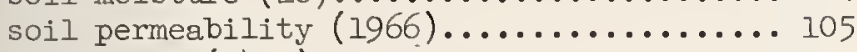

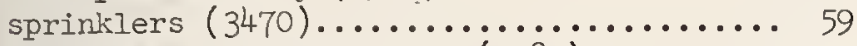

sprinklers, hydraulics of $(3187) \ldots \ldots \ldots \ldots 93$

sprinkling systems $(21) \ldots \ldots \ldots \ldots \ldots \ldots \ldots . \ldots 102$

sprinkling systems (1966)............... 105

structures $(24) \ldots \ldots \ldots \ldots \ldots \ldots \ldots \ldots . \ldots \ldots$

structures, low cost $(3842) \ldots \ldots \ldots \ldots \ldots . . \ldots 4$

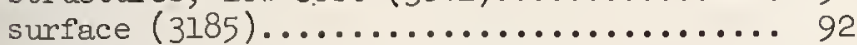

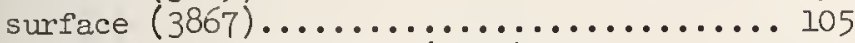

surface, hydraulics of (3552)..............113

surface systems, design of $(3681) \ldots \ldots \ldots . .12$

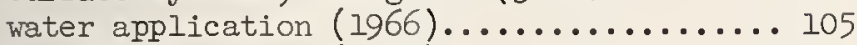

water consumption $(3209) \ldots \ldots \ldots \ldots \ldots \ldots \ldots 11$

water control $(3418) \ldots \ldots \ldots \ldots \ldots \ldots \ldots \ldots . \ldots \ldots$

water measurement $(24) \ldots \ldots \ldots \ldots \ldots \ldots \ldots . \ldots . \ldots 103$

water measurement $(2650) \ldots \ldots \ldots \ldots \ldots \ldots \ldots 110$

water measurement $(3209) \ldots \ldots \ldots \ldots \ldots \ldots \ldots . \ldots \ldots \ldots$

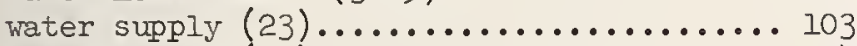

water supply $(27) \ldots \ldots \ldots \ldots \ldots \ldots \ldots \ldots \ldots \ldots$. 4

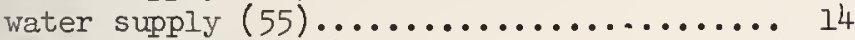

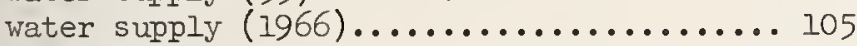

water supply

Santa Barbara Co., Calif. (2653)....... 111

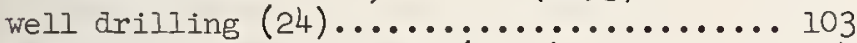

Irrigation systems, surface $(2866) \ldots \ldots \ldots \ldots 104$

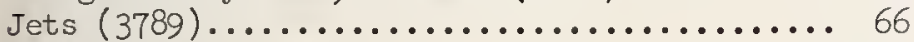

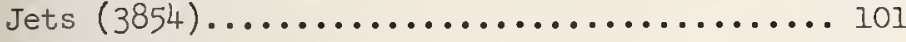

Jets

axisymmetrical flow $(3395) \ldots \ldots \ldots \ldots \ldots \ldots . . \ldots$

mean pressure distributions (3075)....... 43

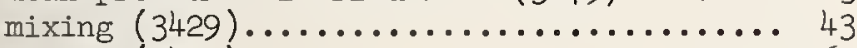

mixing $(3477) \ldots \ldots \ldots \ldots \ldots \ldots \ldots \ldots \ldots . \ldots \ldots$

Jets, annular

mean velocity distributions (3075)....... 43

Jets, submerged

turbulence characteristics (3790)........ 66

Jetties

effect littoral drift (2190)........... 135

effect wave action (529).............. 5

effectiveness $(3271) \ldots \ldots \ldots \ldots \ldots \ldots \ldots \ldots . \ldots \ldots 77$

Liquids, thermodynamics (957).............. 99

Locks

approaches (1738)(1739)

filling, emptying systems

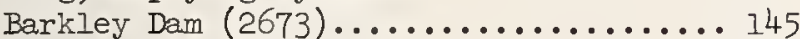

Carillon Lock (4027) ................. 201

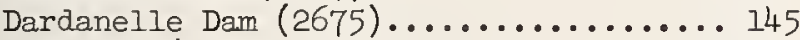

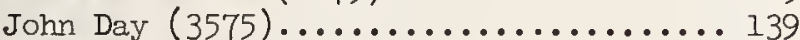

Louisville, Ky. (2678).............. 145

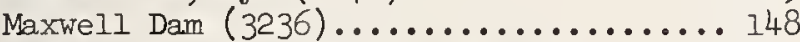

McAlpine Locks Ohio River (3914)....... 158

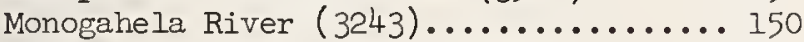

New Poe, St. Marys River (3585)........ 152

old River Lock, La. (3232)........... 147

Sacramento Barge Canal (2682)......... 146

Watts $\operatorname{Bar}(1794) \ldots \ldots \ldots \ldots \ldots \ldots \ldots . . \ldots 191$

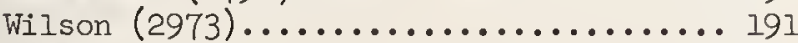

John Day $(2662) \ldots \ldots \ldots \ldots \ldots \ldots \ldots \ldots . . \ldots \ldots 137$

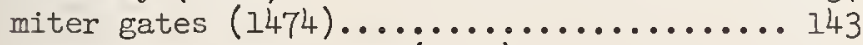

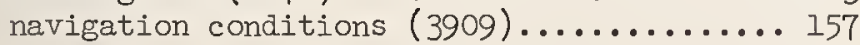

ocks

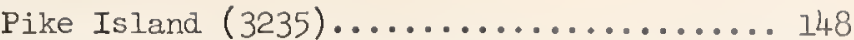

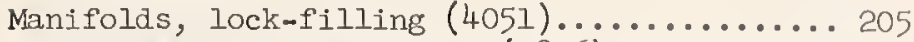
Manifolds, two dimensional (3806).......... 70

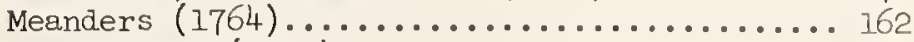

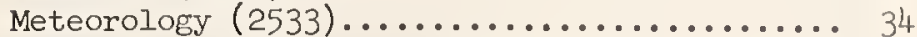
Meteorological observations (2760)......... 17 Meters

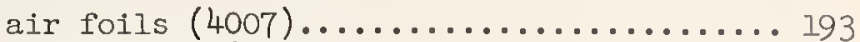

calibration $(124) \ldots \ldots \ldots \ldots \ldots \ldots \ldots \ldots . \ldots \ldots$

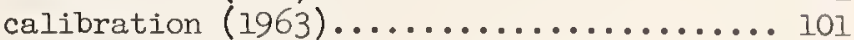

calibration $(3406) \ldots \ldots \ldots \ldots \ldots \ldots \ldots . \ldots \ldots$

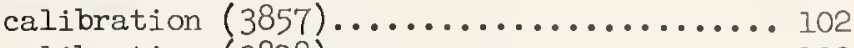

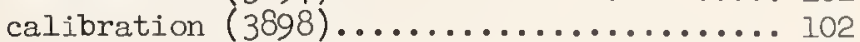

critical flow $(3713) \ldots \ldots \ldots \ldots \ldots \ldots \ldots \ldots . \ldots \ldots$

current, redesign Price(2434)........... 162

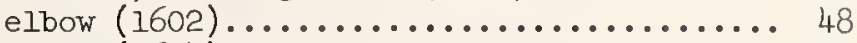

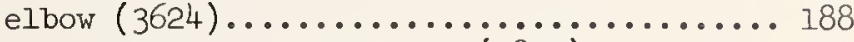

elbow, dynamic similarity (3872)........ 115

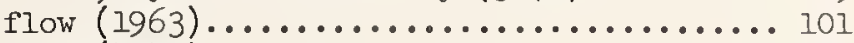

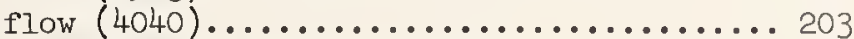

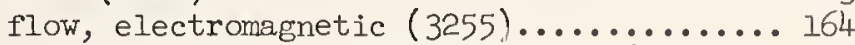

flow, performance characteristics (2769)... 17

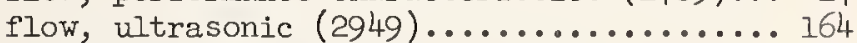

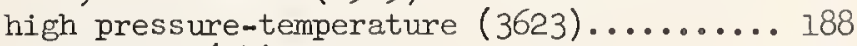

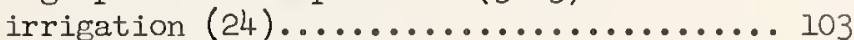

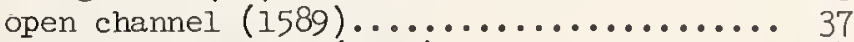

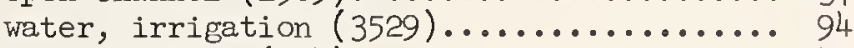

Model distortion $(994) \ldots \ldots \ldots \ldots \ldots . . . \ldots 141$

Model laws, scale effects, harbors (1002)..... 142 Model studies

Adam Creek control structure (4024)....... 201

Arkansas River, navigation dam (3592)..... 153

Arkansas River Channel (3582)........... 151

Arkansas River navigation entrance (3908).. 157 bed scour $(3820) \ldots . \ldots \ldots \ldots \ldots \ldots \ldots . . . \ldots 78$

Canacadea Creek (3240)................ 149

Carillon Power Project (3346)........... 201

Chattahoochee River $(3244) \ldots \ldots \ldots \ldots \ldots . . \ldots 150$

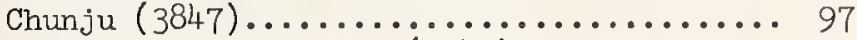

Conneaut Harbor, Ohio (3242)............ 150

breakwater, Morro Bay, Calif. (3904)...... 155 dams

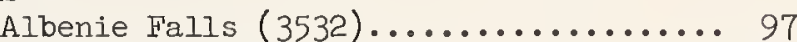

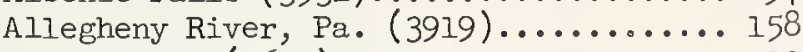
Melton Hill (3627)................ 192 Opossum Creek, Ohio River (3909)....... 157 riprap requirements, Ice Harbor (3594).. 154 Snake River (3577).................. 139 diversion tunnel intake, Guadalupe R. (3547) 101 Duluth-Superior Harbor (3241).......... 149 emptying-filling systems

Melton Hill Lock (4005).............. 193

Wheeler Lock $(3626)$................. 192

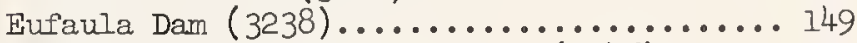
flow patterns, Delaware River (3546)...... 101

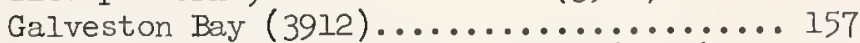
generating station, otter Rapids (3644)...2 200

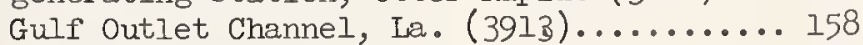
head gates $(3643) \ldots \ldots \ldots \ldots \ldots . \ldots \ldots . . \ldots 200$ head losses in bends $(3441) \ldots \ldots \ldots \ldots . . . .49$ Hudson River, N. Y. (2932)............ 147 hurricane structures

Lake Pontchartrain, La. (3581)........ 151 inlet structures

Uttarbhag Pumping Station (3540)....... 100 Iroquois Control Dam (3320)............ 199 John Day Dam (3901)................... 140 Karadj Re-regulating Dam (3152)......... 77 Kingston, gas duct (3628)............. 193 Lower Atchafalaya River (3910).......... 157 
Model studies

Matagorda Bay (3911)................ 157 McNary Fish Ladder, Columbia River (401)... 137 Necuima River diversion $(3816) \ldots \ldots \ldots \ldots 78$

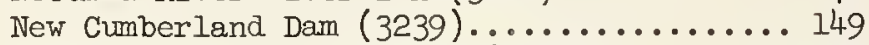
Niagara Control structure $(3645)$......... 200 Niagara Power Project (3859) ............ 102 Niagara Remedial Works (3580)........... 150 Niagara River control Structure (4026)..... 201 Noxon Flume (3533)................. 97 penstock water passages $(3646) \ldots \ldots \ldots . .200$ pier slip shoaling, New York Harbor (3579). 150 pumping plant

Charles River Basin (Boston) (3090)...... 51

Sarasota Bay (3722)................. 29

Red Rock Generating Station (3335)........ 200

St. Lawrence River dewatering and

closure area (3326)................ 199

sluicegates, downpull forces $(3900) \ldots . . .140$ Smith Mountain Hydroelectric

development $(3860) \ldots \ldots \ldots \ldots \ldots \ldots . \ldots 102$

spillways

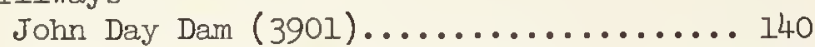

North Hartland Dam, Vt. (2918)........ 138

Oahe Reservoir, Mo. River, S. D. (3916). 158 stream diversion, Smith Mountain (3861).... 102 tailrace improvement, St. Lawrence R.(3333) 200 Wanapum Project, Columbia River (3531).... 97 watershed, arid (3845)................. 95 Model tests, spillways

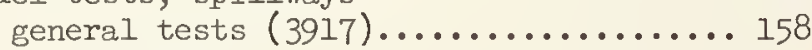

Model verification

pressure measurement

penstocks, South Holston Dam (762)..... 190

sluices, Cherokee Dam (758).......... 190

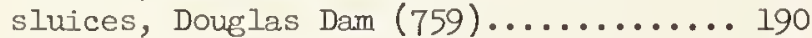

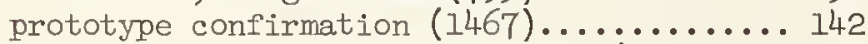
Rocky Reach Site, Columbia River (2631).... 96 Southwest Pass, Miss. River (2931)....... 147

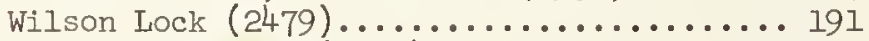
Noise, hydrodynamic $(1778) \ldots \ldots \ldots \ldots \ldots \ldots . . . .181$ Noise, research, hydrophone $(3835) \ldots \ldots \ldots \ldots 88$ Nozzles, annular $(3677) \ldots \ldots \ldots \ldots \ldots \ldots \ldots . \ldots 10$

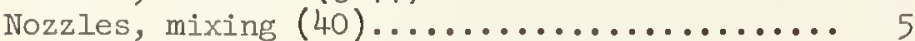
Open channels

boundary shear distribution (3923)....... 166

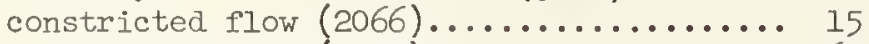
effect discharge $(2700) \ldots \ldots \ldots \ldots \ldots \ldots . \ldots 163$

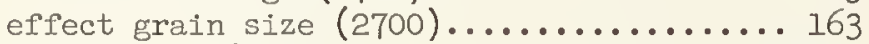
effect load $(2700) \ldots \ldots \ldots \ldots \ldots \ldots \ldots \ldots . \ldots 163$ effect slope $(2700) \ldots \ldots \ldots \ldots \ldots \ldots \ldots . \ldots \ldots$ flow characteristics (3839)............ 88 flow, right angle bends $(3407) \ldots \ldots \ldots \ldots . .28$ free surface effect $(3737) \ldots \ldots \ldots \ldots \ldots \ldots . \ldots$

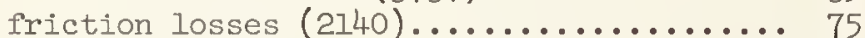

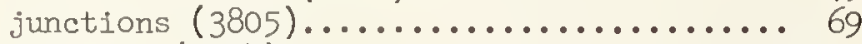

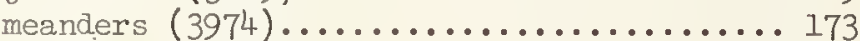
roughness $(3003) \ldots \ldots \ldots \ldots \ldots \ldots . \ldots \ldots . . \ldots 208$

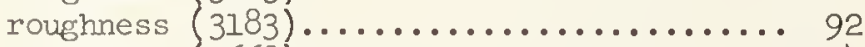
roughness $(3668) \ldots \ldots \ldots \ldots \ldots \ldots \ldots \ldots \ldots \ldots$ secondary flow $(3663) \ldots \ldots \ldots \ldots \ldots \ldots \ldots . \ldots 207$

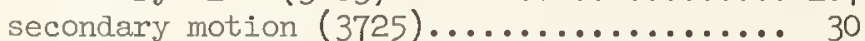
stability $(3253) \ldots \ldots \ldots \ldots \ldots \ldots \ldots \ldots \ldots . \ldots \ldots$

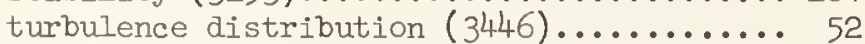
uniform flow $(2529) \ldots \ldots \ldots \ldots \ldots \ldots \ldots \ldots . \ldots \ldots$ velocity distribution (2083)........... 39 velocity distribution $(3433) \ldots \ldots \ldots \ldots \ldots . . \ldots 43$ velocity distribution $(3446) \ldots \ldots \ldots \ldots \ldots . \ldots . \ldots 2$

velocity distribution $(3715) \ldots \ldots \ldots \ldots . . . .26$ Orifice meters

effect pipe roughness (2731)........... 188
Orifice studies

high head (3996)................... 180

Orifices

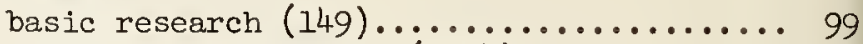

constant head turnout $(3274) \ldots \ldots \ldots \ldots \ldots . . .177$

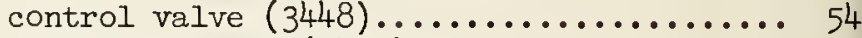

design criteria $(2470) \ldots \ldots \ldots \ldots \ldots \ldots \ldots . \ldots 183$

discharge measurements (2285)........... 27

sharp edge $(3719) \ldots \ldots \ldots \ldots \ldots \ldots \ldots \ldots \ldots . \ldots \ldots$

vortex flow $(1181) \ldots \ldots \ldots \ldots \ldots \ldots \ldots . \ldots 9$

Outlet works

dams

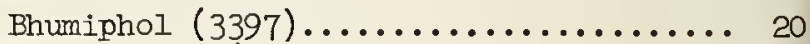

Black Butte $(3237) \ldots \ldots \ldots \ldots \ldots \ldots \ldots . \ldots 148$

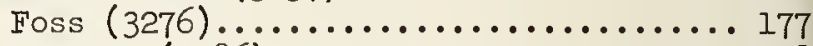

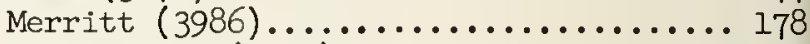

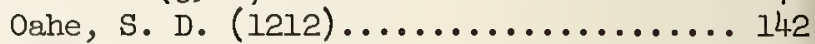

Shadehill (3993).................. 179

Sherman $(3992) \ldots \ldots \ldots \ldots \ldots \ldots \ldots \ldots \ldots \ldots 179$

Yellowtail (3988)................ 178

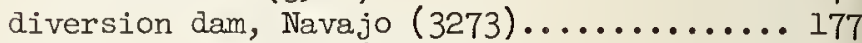

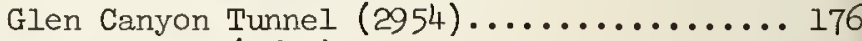

Twin Buttes $(3608) \ldots \ldots \ldots \ldots \ldots \ldots \ldots \ldots . \ldots \ldots$

Outlets

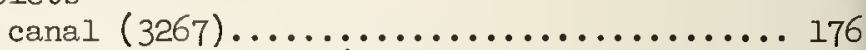

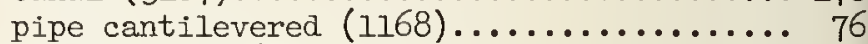

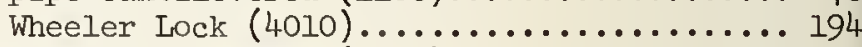

Particle entrainment $(3670) \ldots \ldots \ldots \ldots \ldots \ldots . . . \ldots$

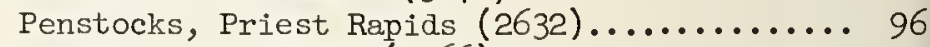

Percolation studies $(1966) \ldots \ldots \ldots \ldots \ldots \ldots \ldots . . \ldots 105$

Percolation studies, California (2181)...... 110 Pipe fittings

bends, elbows (1602)................ 48

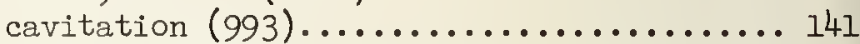

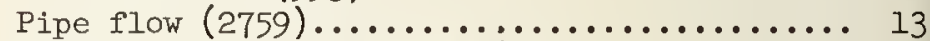

Pipe flow, vortex effects $(3752) \ldots \ldots \ldots \ldots \ldots . \ldots \ldots 5$

Pipe systems, air movement $(3070) \ldots \ldots \ldots \ldots . . .42$

Pipes

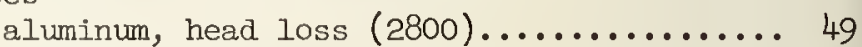

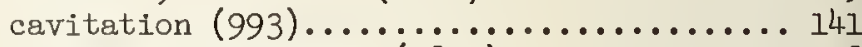

concrete, resistance $(3851) \ldots \ldots \ldots \ldots \ldots . . . . .98$

couplings $(3526) \ldots \ldots \ldots \ldots \ldots \ldots \ldots \ldots . \ldots \ldots$

energy losses $(3066) \ldots \ldots \ldots \ldots \ldots \ldots \ldots . \ldots . \ldots 39$

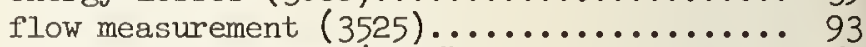

flow straighteners $(3786) \ldots \ldots \ldots \ldots \ldots \ldots . \ldots 3$

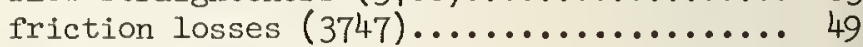

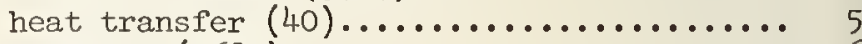

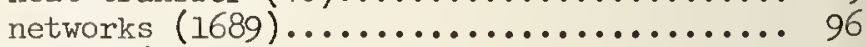

surges $(1303) \ldots \ldots \ldots \ldots \ldots \ldots \ldots \ldots \ldots \ldots . \ldots \ldots$

Pipes, corrugated

roughness study $(3597) \ldots \ldots \ldots \ldots \ldots \ldots 154$

Pipes, flow of mixtures

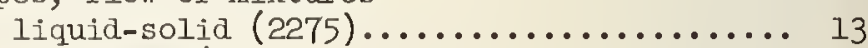

solid-gas $(40) \ldots \ldots \ldots \ldots \ldots \ldots \ldots \ldots \ldots . . . \ldots \ldots$

Pipes, friction

concrete $(24) \ldots \ldots \ldots \ldots \ldots \ldots \ldots \ldots . \ldots \ldots . \ldots \ldots$

fluid-solid mixture $(3773) \ldots \ldots \ldots \ldots \ldots . \ldots . . .60$

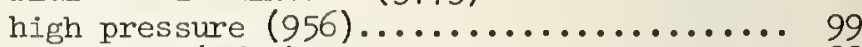
roughness $(2619) \ldots \ldots \ldots \ldots \ldots \ldots \ldots \ldots . \ldots \ldots . \ldots \ldots$ steady and unsteady states $(2614) \ldots \ldots \ldots 81$

Pipes, inclined liquid-solid mixtures (3205)........... 13

Pipes, pressure losses Widows Creek Steam Plant (3302).......... 192

Plumbing

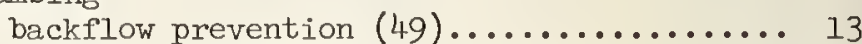

backflow prevention (4043)............. 203

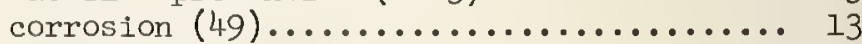

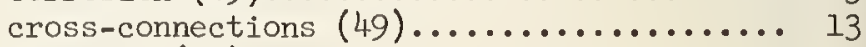

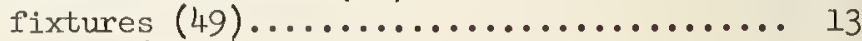
manual $(3688) \ldots \ldots \ldots \ldots \ldots \ldots \ldots \ldots . \ldots \ldots \ldots$ 
Porous media ( 3030$)$

Porous media

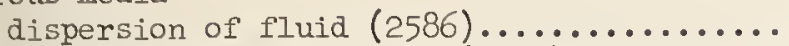

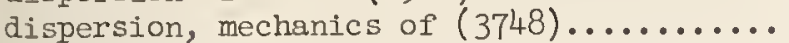

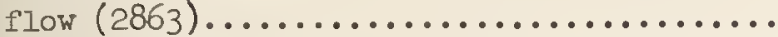

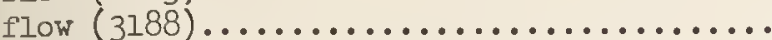

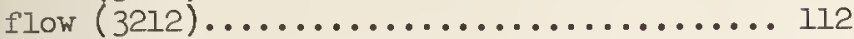

flow $(3258) \ldots \ldots \ldots \ldots \ldots \ldots \ldots \ldots \ldots . \ldots \ldots \ldots$

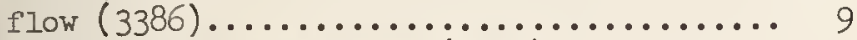

fluid collector systems $(3146) \ldots \ldots \ldots \ldots \ldots 73$

microscopic flow (2690)................. 163

Pressure distribution

basic research $(79) \ldots \ldots \ldots \ldots \ldots \ldots \ldots . . . .40$

basic research $(81) \ldots \ldots \ldots \ldots \ldots \ldots \ldots \ldots . \ldots \ldots \ldots$

tube entrances $(3480) \ldots \ldots \ldots \ldots \ldots \ldots \ldots 6$

Pressure drop, two-phase flow (3727)........ 31

Pressure fluctuation, flat plates (3836)..... 88 Pressure measurement

sluices

Cherokee Dam (758)................. 190

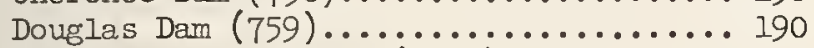

Pressures, cavity collapse (3379).......... 3

Propellers

blade forces $(3754) \ldots \ldots \ldots \ldots \ldots \ldots \ldots \ldots$

blade frequency pressure (3512)......... 85

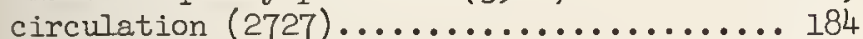

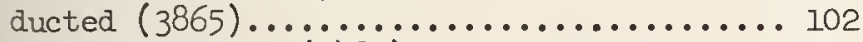

flow distortion $(3487) \ldots \ldots \ldots \ldots \ldots \ldots \ldots . \ldots \ldots$

performance, unsteady flow $(3620) \ldots \ldots \ldots \ldots 187$ pressure distribution, blades (3618)...... 187 sound level generation (3830)........... 87

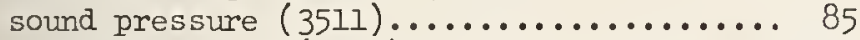
supercavitating $(3286) \ldots \ldots \ldots \ldots \ldots \ldots \ldots . \ldots \ldots$ theoretical thrust distribution (3282).... 185

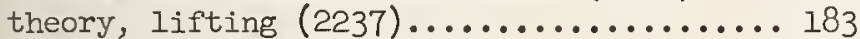
thrust deduction (3509)............... 85 thrust deduction study $(3171) \ldots \ldots \ldots \ldots . . .64$ transient forces $(2616) \ldots \ldots \ldots \ldots \ldots \ldots . \ldots . \ldots . \ldots 3$ ventilated $(3617) \ldots \ldots \ldots \ldots \ldots \ldots \ldots \ldots \ldots \ldots$ vertical axis, performance

characteristics (3619).............. 187

Prototype check tests

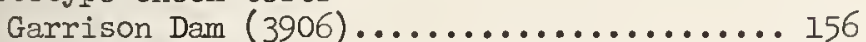

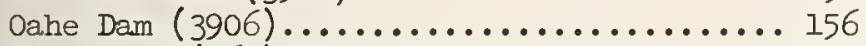

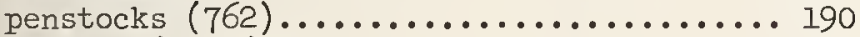

sluices $(758)(759) \ldots \ldots \ldots \ldots \ldots \ldots \ldots . \ldots \ldots$

Pumps

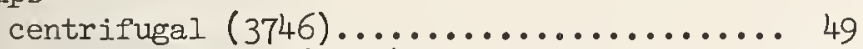

condenser water $(3303)$.................. 192

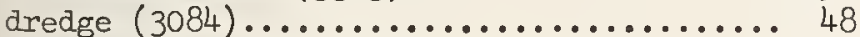

impeller design $(3442) \ldots \ldots \ldots \ldots \ldots \ldots . \ldots \ldots$

jet, for sediment $(3673) \ldots \ldots \ldots \ldots \ldots \ldots \ldots . \ldots \ldots$

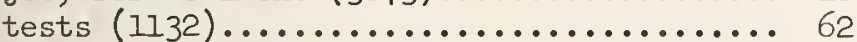

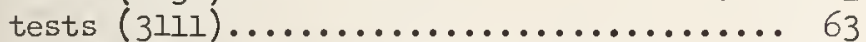

turbine model tests $(3300) \ldots \ldots \ldots \ldots \ldots \ldots . . \ldots 192$

Pumps, dredging, hopper draghead (3586)...... 152

Rainfall

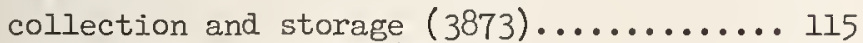

depth-area-intensity $(3660) \ldots \ldots \ldots \ldots \ldots \ldots . .205$

effect canopy cover $(3472) \ldots \ldots \ldots \ldots \ldots .61$

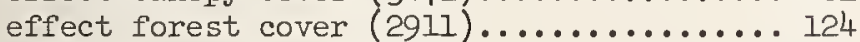

effect forest cover $(3882) \ldots \ldots \ldots \ldots \ldots \ldots 118$

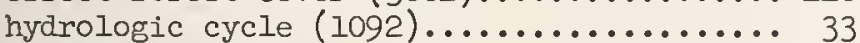

intensity $(3058) \ldots \ldots \ldots \ldots \ldots \ldots \ldots \ldots . \ldots \ldots . \ldots \ldots$

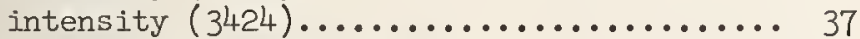

intensity hurricane $(2441) \ldots \ldots \ldots \ldots . . . \ldots 161$

Lake Michigan (3423)................ 36

maximum $(779) \ldots \ldots \ldots \ldots \ldots \ldots \ldots . . \ldots \ldots . . \ldots \ldots$

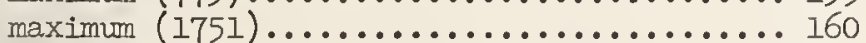

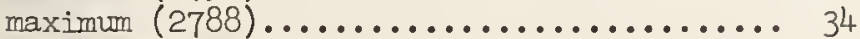

rainfall-runoff $(68) \ldots \ldots \ldots \ldots \ldots \ldots \ldots \ldots . \ldots \ldots$
Rainfall

rainfall-runoff $(564) \ldots \ldots \ldots \ldots \ldots \ldots \ldots \ldots \ldots \ldots$

rainfall-runoff $(768) \ldots \ldots \ldots \ldots \ldots \ldots \ldots$

rainfall-runoff $(1078) \ldots \ldots \ldots \ldots \ldots \ldots . \ldots \ldots$

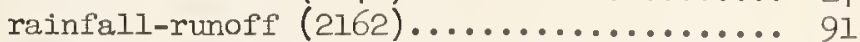

rainfall-runoff $(2561) \ldots \ldots \ldots \ldots \ldots \ldots \ldots \ldots \ldots \ldots \ldots$

rainfall-runoff $(3808) \ldots \ldots \ldots \ldots \ldots \ldots \ldots \ldots \ldots \ldots \ldots \ldots$

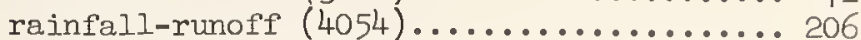

rainfall-runoff relations (368).................... 99

rainfall-runoff relations (2397).......... 91

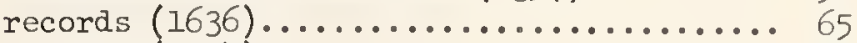

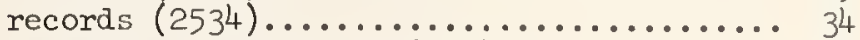

Tennessee River Basin (768)............. 194

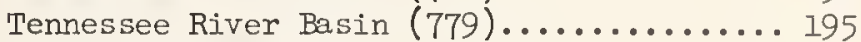

Rainfall measurements, radar (3601)......... 161

Rainfall, research

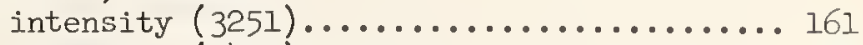

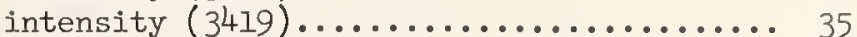

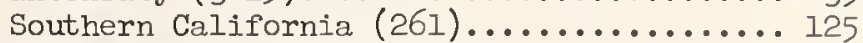

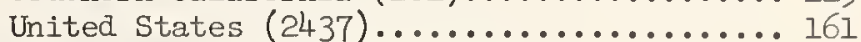

Range management practices (27)............ 4

Reservoirs

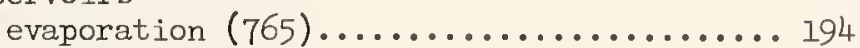

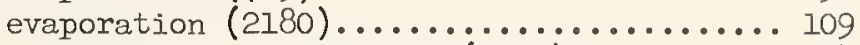

evaporation, retardation (2532)........... 34

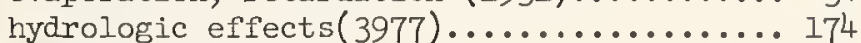

LeMay River development (4030)........... 202

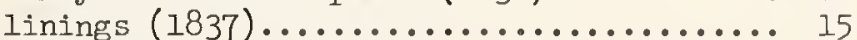

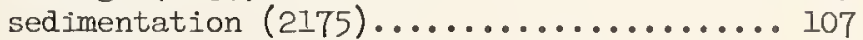

sedimentation, measurements (2334)....... 45

silting, Illinois $(552) \ldots \ldots \ldots \ldots \ldots . \ldots . \ldots 32$

silting, temperature gaging (769)........ 194

silting, Tennessee River (785)........... 194

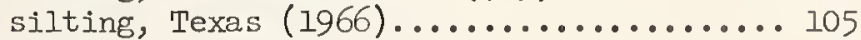

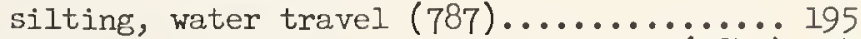

Resistance coefficient, friction factor (3843) 94

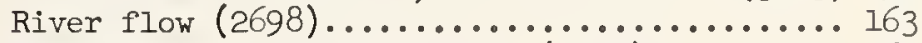

River regime characteristics (3031)........ 69

Roughness

artificial channels (2950)............. 164

artificial

flow of water $(3383) \ldots \ldots \ldots \ldots \ldots \ldots \ldots$

surface $(2328) \ldots \ldots \ldots \ldots \ldots \ldots \ldots \ldots . . . \ldots \ldots$

surface, $\operatorname{drag}(854) \ldots \ldots \ldots \ldots . . . \ldots . . . . .41$

effect of water temperature $(1988) \ldots \ldots \ldots . .144$

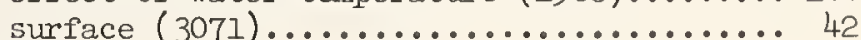

Runoff

annual, Upper Colo. River Basin (3710)....

Brandywine Creek Basin (3940)............

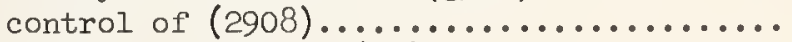

denudation effects $(23) \ldots \ldots \ldots \ldots \ldots \ldots . . . . .103$

denudation effects $(27) \ldots \ldots \ldots \ldots \ldots \ldots \ldots$

effect of forest $(377) \ldots \ldots \ldots \ldots \ldots \ldots \ldots . . .127$

effect of forest $(656) \ldots \ldots \ldots \ldots \ldots \ldots \ldots . \ldots \ldots \ldots$

effects tillage $(2597) \ldots \ldots \ldots \ldots \ldots \ldots \ldots . \ldots 71$

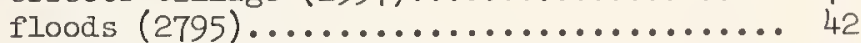

hydrologic cycle (1092)............... 33

infiltration determinations $(2795) \ldots \ldots \ldots 42$

rainfall-runoff $(564) \ldots \ldots \ldots \ldots \ldots \ldots \ldots \ldots \ldots \ldots \ldots \ldots$

rainfall-runoff $(856) \ldots \ldots \ldots \ldots \ldots \ldots \ldots . \ldots \ldots$

rainfall-runoff $(959) \ldots \ldots \ldots \ldots \ldots \ldots . \ldots \ldots$

rainfall-runoff $(1078) \ldots \ldots \ldots \ldots \ldots \ldots \ldots \ldots \ldots \ldots \ldots$

rainfall-runoff $(1723) \ldots \ldots \ldots \ldots \ldots \ldots . \ldots \ldots$

rainfall-runoff $(1744)(1745) \ldots \ldots \ldots \ldots . \ldots \ldots$

rainfall-runoff $(2162) \ldots \ldots \ldots \ldots \ldots \ldots . \ldots . \ldots$

rainfall-runoff $(2165) \ldots \ldots \ldots \ldots \ldots \ldots . \ldots \ldots$

rainfall-runoff $(2331) \ldots \ldots \ldots \ldots \ldots \ldots \ldots 44$

rainfall-runoff $(2334) \ldots \ldots \ldots \ldots \ldots \ldots . \ldots \ldots$

rainfall-runoff $(2795) \ldots \ldots \ldots \ldots \ldots \ldots \ldots . \ldots \ldots$

rajnfall-runoff, peak rates $(3698) \ldots \ldots \ldots . . .22$

rainfall-runoff relations (2397).......... 91 
Runoff

rainfall-runoff, New Mexico and Wash.(3973) 173

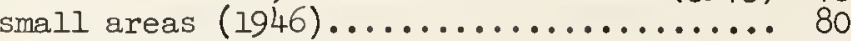

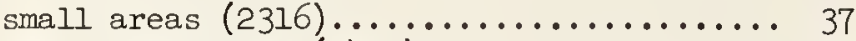
small watersheds $(2492) \ldots \ldots \ldots \ldots \ldots \ldots . \ldots 205$ small watersheds $(2841) \ldots \ldots \ldots \ldots \ldots \ldots \ldots . \ldots \ldots$

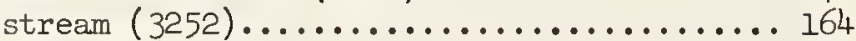

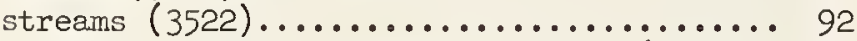
surface, hydraulic characteristics (3559).. 114 urban areas $(564) \ldots \ldots \ldots \ldots \ldots \ldots \ldots \ldots \ldots . \ldots \ldots$ urban areas $(856) \ldots \ldots \ldots \ldots \ldots \ldots \ldots \ldots \ldots . \ldots \ldots$

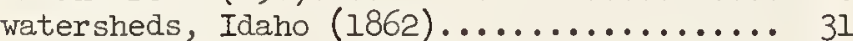

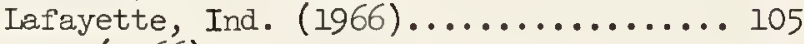

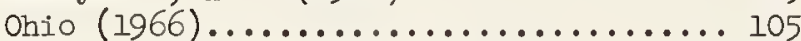

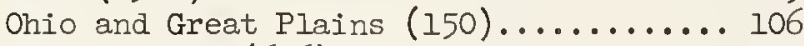

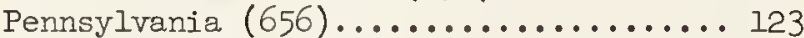
Ralston Creek, Iowa (66)........... 40 Rapid Creek, Iowa (68).............. 40 Tennessee River Valley (780).......... 195

Salt water intrusion

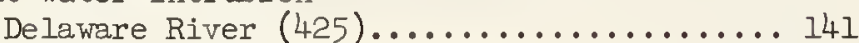

Florida (1966)......................... 105

Sand traps

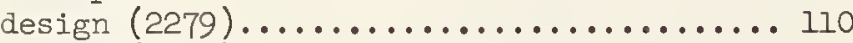

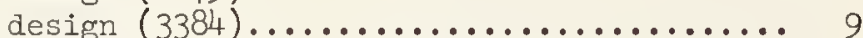

Sand-water mixtures, shear $(2062) \ldots \ldots \ldots \ldots .6$ Scour

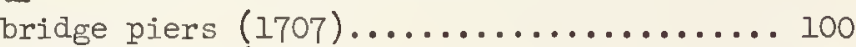

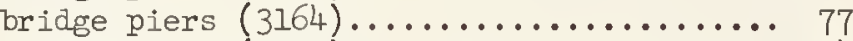

bridge piers $(3705) \ldots \ldots \ldots \ldots \ldots \ldots \ldots . \ldots \ldots 24$

bridge piers $(4014) \ldots \ldots \ldots \ldots \ldots \ldots \ldots \ldots . \ldots \ldots 7$

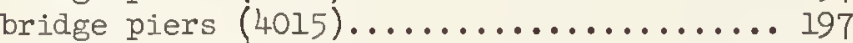

bridge piers $(4017) \ldots \ldots \ldots \ldots \ldots \ldots \ldots \ldots 19$

bulkheads $(3898) \ldots \ldots \ldots \ldots \ldots \ldots \ldots \ldots \ldots \ldots$

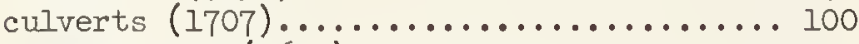

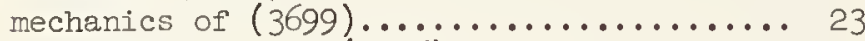

riprap protection $(3496) \ldots \ldots \ldots \ldots \ldots \ldots . \ldots \ldots$

seawalls $(3898) \ldots \ldots \ldots \ldots \ldots \ldots \ldots \ldots \ldots \ldots \ldots$

Sediment

bed load, measurement (3257)...................... 164 Brandywine Creek Basin (3940)............ 168

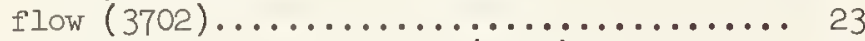
radioactive tracer tests $(3902) \ldots \ldots \ldots \ldots . . \ldots 155$ Sediment barrier, Sheep Creek, Utah (3976).... 174 Sediment, cohesive

scour resistance $(2874) \ldots \ldots \ldots \ldots \ldots \ldots \ldots, 91$

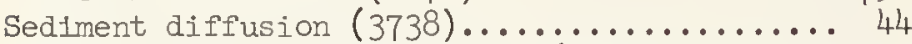
sediment load, variability of $(3767) \ldots \ldots \ldots . . .58$ Sediment particle size, distribution (3431)... 43 Sediment particles, velocities (4064).......208 Sediment research, diversion dams

Kansas River Basin (3991)............. 179

Sediment studies

Arkansas River (3503)................ 78

New Mexico and Washington $(3973) \ldots \ldots \ldots . . . . . .173$

Sediment transport $(3675) \ldots \ldots \ldots \ldots \ldots \ldots \ldots 10$

Sediment transport $(3871) \ldots \ldots \ldots \ldots \ldots \ldots \ldots . \ldots 108$

Sediment transport

artificial channels (2950).............. 164

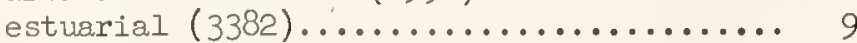

natural channels $(2950) \ldots \ldots \ldots \ldots \ldots \ldots . \ldots 164$

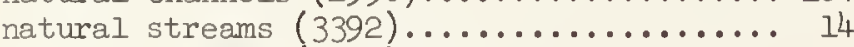

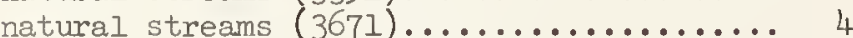

Sediment transportation $(2748) \ldots \ldots \ldots \ldots \ldots \ldots . . . \ldots \ldots$

Sediment transportation

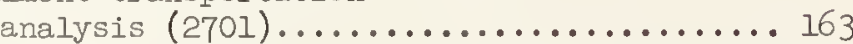

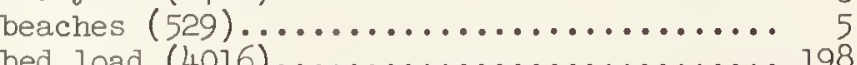

bed load $(4016)$................................ 198

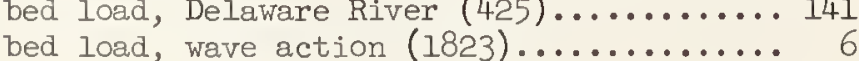

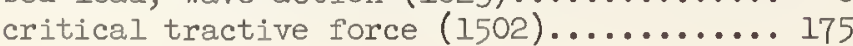

Sediment transportation

density currents (307)

measurement (194).

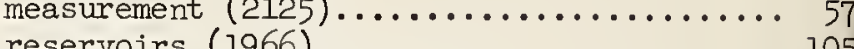

resistance to flow $(3105) \ldots \ldots \ldots \ldots \ldots \ldots \ldots . \ldots \ldots \ldots$

roughness elements $(3105) \ldots \ldots \ldots \ldots \ldots \ldots \ldots . \ldots \ldots$

sand bed streams $(3948) \ldots \ldots \ldots \ldots \ldots \ldots \ldots . \ldots 169$

suspended load

measurement $(194) \ldots \ldots \ldots \ldots \ldots \ldots \ldots . \ldots 79$

measurement $(1966) \ldots \ldots \ldots \ldots \ldots \ldots 105$

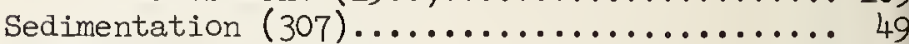

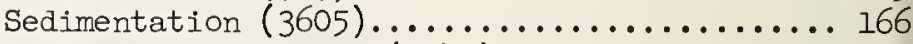

Sedimentation basins $(3541) \ldots \ldots \ldots \ldots \ldots \ldots 100$

Sedimentation

reservoirs $(552) \ldots \ldots \ldots \ldots \ldots \ldots \ldots \ldots \ldots . \ldots \ldots \ldots$

reservoirs $(785) \ldots \ldots \ldots \ldots \ldots \ldots \ldots \ldots \ldots . \ldots \ldots \ldots$

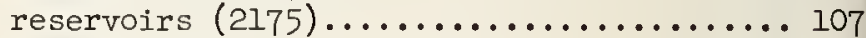

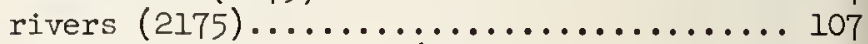

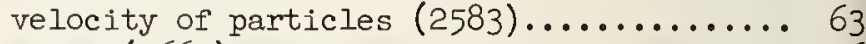

waves $(2660) \ldots \ldots \ldots \ldots \ldots \ldots \ldots \ldots \ldots . \ldots \ldots \ldots$

Sediments

tagged by radioactive minerals (2755)..... 8

Seepage

canal linings $(1859) \ldots \ldots \ldots \ldots \ldots \ldots \ldots$. 31

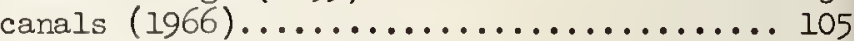

sheeted excavation $(3493) \ldots \ldots \ldots \ldots \ldots . \ldots 73$

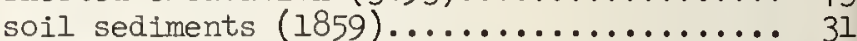

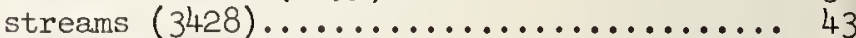

Servomechanisms $(3207) \ldots \ldots \ldots \ldots \ldots \ldots \ldots . \ldots \ldots . \ldots \ldots$

Servomechanisms $(3435) \ldots \ldots \ldots \ldots \ldots \ldots \ldots \ldots . \ldots \ldots$

Servomechanisms $(3436) \ldots \ldots \ldots \ldots \ldots \ldots \ldots . \ldots \ldots$

Servomechanisms, hydraulic $(3494) \ldots \ldots \ldots \ldots 73$

Sewer outfalls, ocean $(3678) \ldots \ldots \ldots \ldots \ldots \ldots . . . .10$

Sewerage system, design (4039)............ 203

Sewerage systems, design criteria $(3438) \ldots \ldots 46$

Ships

bending moment (2387)......................... 82

bending moment $(2393) \ldots \ldots \ldots \ldots \ldots \ldots \ldots . \ldots . \ldots . \ldots . \ldots . \ldots 2$

bending moment $(2865) \ldots \ldots \ldots \ldots \ldots \ldots \ldots \ldots . \ldots \ldots$

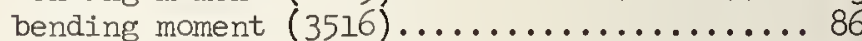

bending moment $(3621) \ldots \ldots \ldots \ldots \ldots \ldots \ldots \ldots \ldots \ldots \ldots \ldots \ldots$

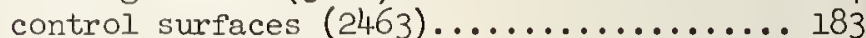

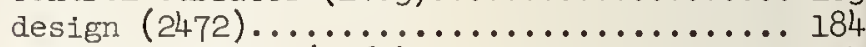

fishing, design $(3361) \ldots \ldots \ldots \ldots \ldots \ldots 204$

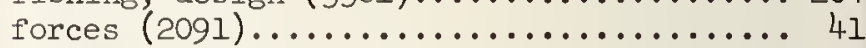

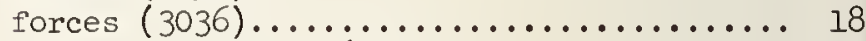

forces, on bodies $(2229) \ldots \ldots \ldots \ldots \ldots \ldots . . . . .182$

hull form research $(2729) \ldots \ldots \ldots \ldots \ldots \ldots 184$

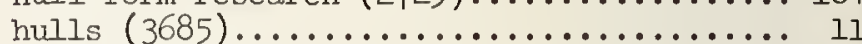

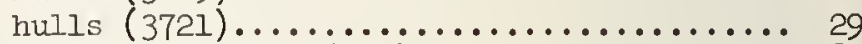

injection scoops $(710) \ldots \ldots \ldots \ldots \ldots \ldots \ldots 180$

lateral motions in waves $(3176) \ldots \ldots \ldots \ldots 85$

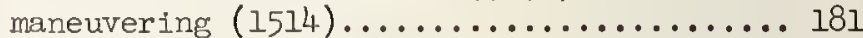

mathematical lines $(1783) \ldots \ldots \ldots \ldots \ldots \ldots . \ldots \ldots 1$

model techniques $(1788) \ldots \ldots \ldots \ldots \ldots \ldots \ldots 18 \ldots \ldots \ldots$

model testing facility $(3292) \ldots \ldots \ldots \ldots \ldots . . . \ldots 186$

models

towing test maneuvering basin (1781)... 181

turbulence stimulation (1506).......... 180 moments $(3036) \ldots \ldots \ldots \ldots \ldots \ldots \ldots \ldots \ldots . \ldots \ldots \ldots . \ldots \ldots \ldots$

moorings $(3519) \ldots \ldots \ldots \ldots \ldots \ldots \ldots . \ldots \ldots$

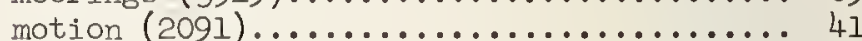

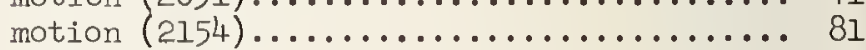

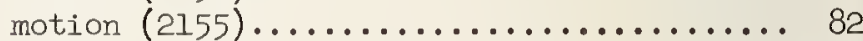

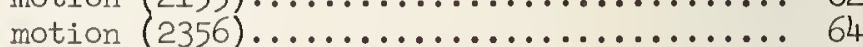

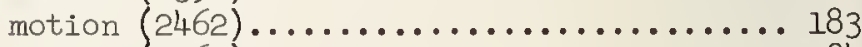

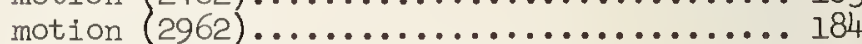

motion $(3686) \ldots \ldots \ldots \ldots \ldots \ldots \ldots \ldots \ldots \ldots \ldots \ldots$

motions, restraint of $(3035) \ldots \ldots \ldots \ldots \ldots 18$

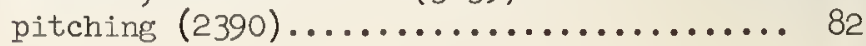


Ships

pressure distribution (2232)........... 183

pressure field (3831)............... 87

propellers

contra-rotating $(2471) \ldots \ldots \ldots \ldots \ldots 184$

counter-rotating $(2866) \ldots \ldots \ldots \ldots . . . . . .63$

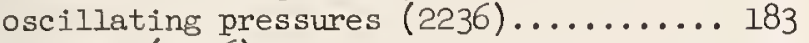

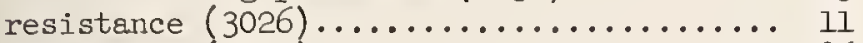

resistance $(3515) \ldots \ldots \ldots \ldots \ldots \ldots \ldots \ldots . \ldots \ldots$

resistance $(3517) \ldots \ldots \ldots \ldots \ldots \ldots \ldots \ldots$

resistance

frictional (2231) ............... 182

models $(901) \ldots \ldots \ldots \ldots \ldots \ldots \ldots \ldots \ldots \ldots . \ldots \ldots$

theory $(709) \ldots \ldots \ldots \ldots \ldots \ldots \ldots \ldots \ldots \ldots . \ldots \ldots$

seaworthiness $(2230) \ldots \ldots \ldots \ldots \ldots \ldots \ldots \ldots . \ldots 182$

seaworthiness $(2235) \ldots \ldots \ldots \ldots \ldots \ldots \ldots \ldots \ldots$

seaworthiness $(3293) \ldots \ldots \ldots \ldots \ldots \ldots \ldots \ldots \ldots$

slamming $(1786) \ldots \ldots \ldots \ldots \ldots \ldots \ldots \ldots \ldots \ldots \ldots$

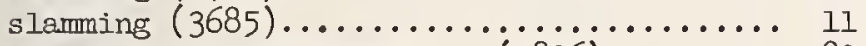

slamming, hydrodymamics of $(3826) \ldots \ldots \ldots . . .80$

stability $(3024) \ldots \ldots \ldots \ldots \ldots \ldots \ldots \ldots \ldots \ldots$

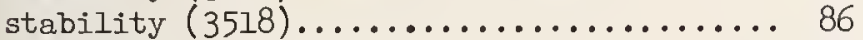

stabilization $(3288) \ldots \ldots \ldots \ldots \ldots \ldots \ldots \ldots . \ldots \ldots$

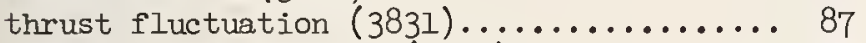

velocity distribution (2232)............ 150

vibration (2019)................... 182

wake characteristics (3999)............ 187

Shore processes $(2192) \ldots \ldots \ldots \ldots \ldots \ldots \ldots \ldots . \ldots 135$

Shore protection

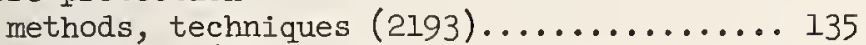

structures $(529) \ldots \ldots \ldots \ldots \ldots \ldots \ldots \ldots \ldots$

Silting

harbors north shore of Lake Ontario (3364). 206 reservoirs

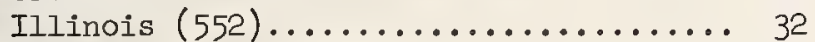

Tennessee Valley $(785) \ldots . . . \ldots \ldots . . . . .194$

Siphons

irrigation $(24) \ldots \ldots \ldots \ldots . \ldots \ldots . . \ldots \ldots$

pumping plants $(1475) \ldots \ldots \ldots \ldots \ldots \ldots . \ldots \ldots$

sluice gates

cavitation (79)................... 40

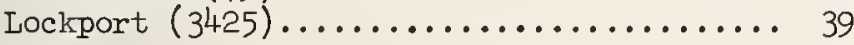

Sluiceways

dams

San Acacia (3270) . . . . . . . . . . . . . 177

dams, pressure measurement

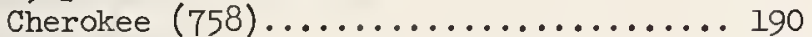

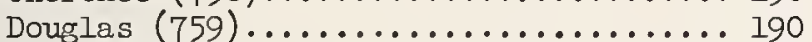

Snow surveys $(3888) \ldots \ldots \ldots \ldots \ldots \ldots \ldots \ldots \ldots \ldots \ldots 121$

Snow surveys $(3895) \ldots \ldots \ldots \ldots \ldots \ldots \ldots \ldots \ldots 131$

Snow surveys

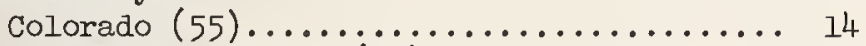

runoff forecasting $(55) \ldots \ldots \ldots \ldots \ldots \ldots . \ldots \ldots . \ldots \ldots$

runoff forecasting $(1966) \ldots \ldots \ldots \ldots \ldots \ldots \ldots$

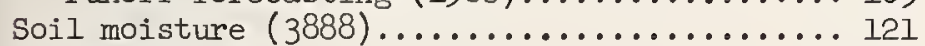

Soil moisture

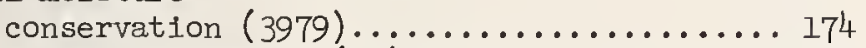

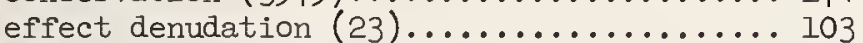

effect timber cutting $(377) \ldots \ldots \ldots \ldots \ldots . . . . . . .127$

evaporation $(2277) \ldots \ldots \ldots \ldots \ldots \ldots \ldots \ldots . \ldots \ldots \ldots$

forest influences $(380) \ldots \ldots \ldots \ldots \ldots \ldots . \ldots 132$

forest influences $(657) \ldots \ldots \ldots \ldots \ldots \ldots \ldots 127$

forest influences $(2188)(2420) \ldots . . \ldots \ldots . .129$

measurement $(261) \ldots \ldots \ldots \ldots \ldots \ldots \ldots \ldots \ldots . \ldots \ldots$ movement $(1058) \ldots \ldots \ldots \ldots \ldots \ldots \ldots \ldots . \ldots \ldots$

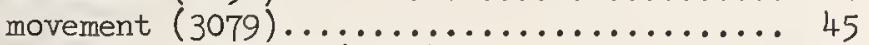
prediction method $(3226) \ldots \ldots \ldots \ldots \ldots \ldots . \ldots 134$ semidesert vegetation $(657) \ldots \ldots \ldots \ldots \ldots \ldots 127$ Southern California (261)............. 125

Spheres

accelerated motion (3432) illways

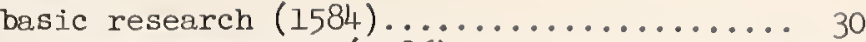

Big Bend Reservoir (3586)............. 152

Brokopondo hydroelectric project (3817).... 78 bulkhead, Greenup Dam (3233)............ 148 Carillon (3655).......................... 201 dams

Carlyle, Kaskaskia River (3583)........ 151

Chief Joseph (3085)............... 48

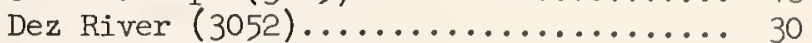

Everett, Piscataqua River (3591)....... 153

Flaming Gorge (2960).............. 176

Fort Patrick Henry (1534)........... 191

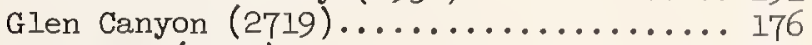

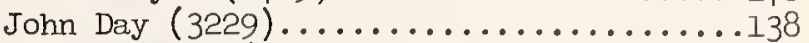

John Redmond (3587) ............... 152

Lower Monumental (3899)............. 140

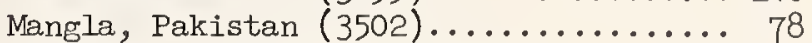

Markland, Ohio River (1739)........... 143

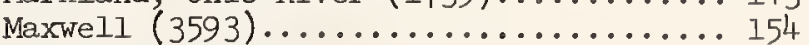

Mission $(3160) \ldots \ldots \ldots \ldots \ldots \ldots \ldots . \ldots . \ldots . \ldots 77$

Otesco $(3548) \ldots \ldots \ldots \ldots \ldots \ldots \ldots \ldots . \ldots \ldots 1$

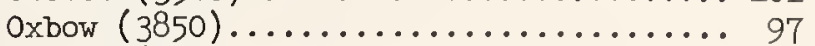

Peters (2151)................... 81

Pike Island, Ohio River (3589)......... 153

Red Rock, Des Moines River (3584)...... 151

Trinity $(2705) \ldots \ldots \ldots \ldots \ldots \ldots \ldots . \ldots . \ldots 176$

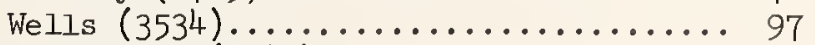

Yellowtail (3989).................. 179

discharge characteristics, taintor

gates (4012)..................... 197

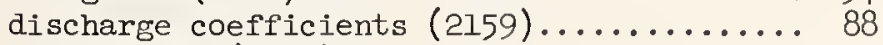

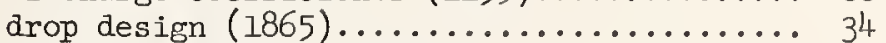

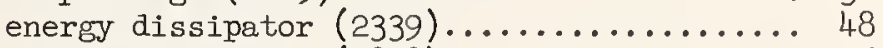

energy dissipator $(2878) \ldots \ldots \ldots \ldots \ldots \ldots$

Grand Rapids Development (4013)............ 197

Ice Harbor, stop log (2921)............ 138

profiles $(3768) \ldots \ldots \ldots \ldots \ldots \ldots \ldots \ldots \ldots \ldots . \ldots \ldots \ldots$

Rend Lake $(3061) \ldots \ldots \ldots \ldots \ldots \ldots \ldots \ldots . \ldots \ldots$

reservoirs, Pearl River (3501).............. 77

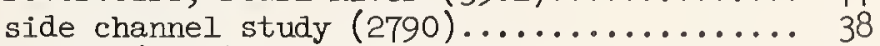

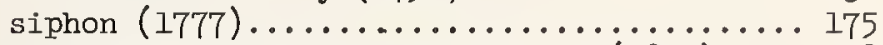

South Saskatchewan River Project (3819).... 78

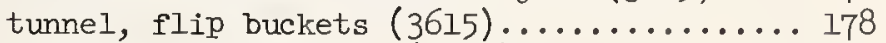

Wanapum Power Project (3156)........... 77

weir type (1298).................... 207

Wilson Powerhouse (3299)............... 192

Sprinkling systems

jets, distribution (21).............. 102

Spur dikes, design criteria (3086).......... 48

Stability

dynamic $(3730) \ldots \ldots \ldots \ldots \ldots \ldots \ldots \ldots \ldots \ldots$

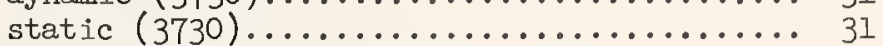

stilling basins

Big Bend Reservoir (3588)............. 152 dams

John Redmond (3587) ............... 152

Keystone $(2941) \ldots \ldots \ldots \ldots \ldots \ldots \ldots . \ldots \ldots . . \ldots \ldots$

Markland, Ohio River (1739)........... 143

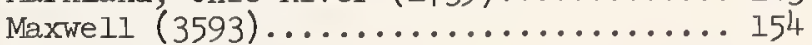

IVavajo $(3272) \ldots \ldots \ldots \ldots \ldots \ldots \ldots \ldots \ldots . \ldots \ldots \ldots$

Plke Island, Ohio River (3589)........ 153

design $(1074) \ldots \ldots \ldots \ldots \ldots \ldots \ldots \ldots . . \ldots \ldots$

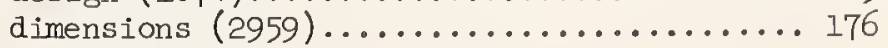
diversion dam

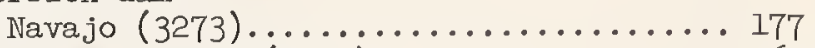

effects water jet $(3775) \ldots \ldots \ldots \ldots \ldots \ldots \ldots 6 . \ldots \ldots$

erosion below $(1987) \ldots \ldots \ldots \ldots \ldots \ldots . \ldots \ldots$

hollow-jet valve $(2958) \ldots \ldots \ldots \ldots \ldots \ldots . \ldots 176$

Stratified flow

mechanics of $(307) \ldots \ldots \ldots . . . . . .49$ 
Stratified flow, mixing (2T91).......... 42

Stream gaging

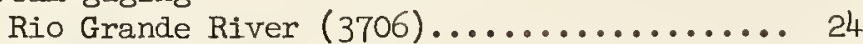

Tennessee Valley $(769)$................. 194 Streamflow

effect reforestation (3941)...........................

low flow characteristics (3078)......... 45

Streamflow forecasts $(1744)(1745) \ldots \ldots \ldots \ldots . . \ldots 160$

Streamflow forecasts

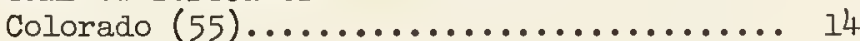

snow surveys $(55) \ldots \ldots \ldots \ldots \ldots \ldots \ldots \ldots . \ldots \ldots$

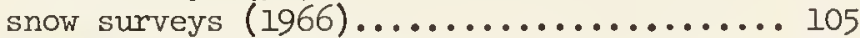

Streamflow gaging $(3894) \ldots \ldots \ldots \ldots \ldots \ldots \ldots 131$

Streamflow, low flows, duration (3420)...... 35

Streamflow, low flows, frequency $(3420) \ldots . . .35$

Streamflow records, statistical analyses(3945) 169

Streamflow variations $(3716) \ldots \ldots \ldots \ldots . . . . .27$

Streams

depth-discharge relations (3927)......... 167

discharge measurements $(3942) \ldots \ldots \ldots \ldots . . .168$

discharge patterns $(3949) \ldots \ldots \ldots \ldots \ldots . . \ldots 169$

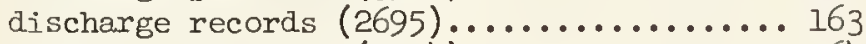

dispersal patterns $(3254) \ldots \ldots \ldots \ldots \ldots \ldots . \ldots \ldots$

effect logging $(969) \ldots \ldots \ldots \ldots \ldots \ldots \ldots \ldots . \ldots \ldots$

effects logging $(3535) \ldots \ldots \ldots \ldots \ldots \ldots . \ldots . \ldots 9$

glacier-fed $(3954) \ldots \ldots \ldots \ldots \ldots \ldots \ldots \ldots . \ldots \ldots$

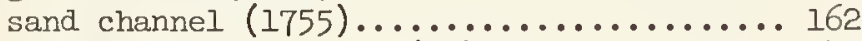

stage discharge, Iowa $(67) \ldots \ldots \ldots \ldots . . .40$

water quality $(786) \ldots \ldots \ldots \ldots \ldots \ldots \ldots \ldots \ldots \ldots$

Structures

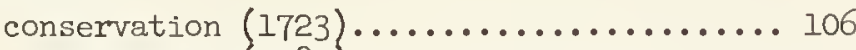

conservation $(2789) \ldots \ldots \ldots \ldots \ldots \ldots \ldots \ldots \ldots \ldots \ldots$

drainage $(2789) \ldots \ldots \ldots \ldots \ldots \ldots \ldots \ldots \ldots . \ldots \ldots . \ldots \ldots$

flow stabilization $(3672) \ldots \ldots \ldots \ldots \ldots . . . \ldots 9$

sewer, drop (3161)................. 77

Structures, drop, Gering Valley, Nebr. (3915). 158

Submerged bodies, forces (2615)........... 83

Submerged bodies, moments (2615).......... 83

Submerged bodies, pressure distribution

theoretical analyses $(81) \ldots \ldots \ldots \ldots \ldots \ldots$

Surge tanks

LeMay River Project (4029)............... 202

South Holston Dam (731)................. 90

Surges, New England South Shore (2868)...... 89

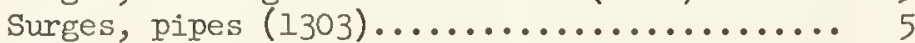

Surges, elastic tube

dissipation rate $(3080)$

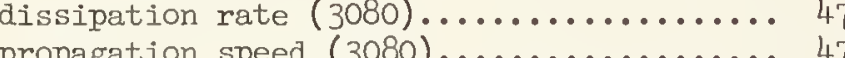

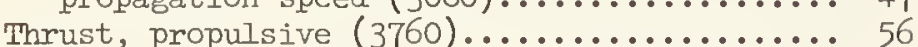

Tidal estuaries, salinity intrusion (3751)... 53

Tidal flow, channels

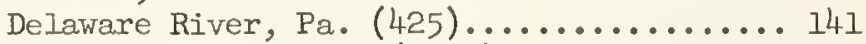

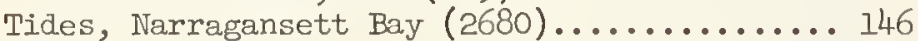
Tides

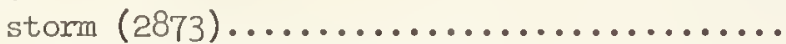

storm and hurricane $(3412) \ldots \ldots \ldots \ldots \ldots \ldots$

storm prediction $(2438) \ldots \ldots \ldots \ldots \ldots \ldots . . \ldots 16$

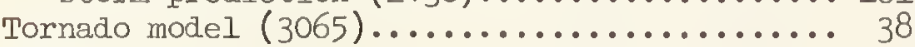

Transition

supercritical velocities (2386).................. 76

vertical tubes $(3755) \ldots \ldots \ldots \ldots \ldots \ldots \ldots . \ldots \ldots$

Tubes $(3689) \ldots \ldots \ldots \ldots \ldots \ldots \ldots \ldots \ldots \ldots \ldots . \ldots \ldots \ldots$

Turbine characteristics

computer representation $(3762) \ldots \ldots \ldots \ldots 56$

Turbines

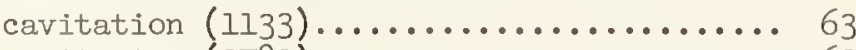

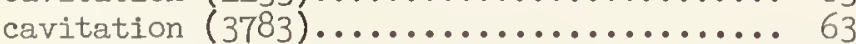

flow gaging $(3924) \ldots \ldots \ldots \ldots \ldots \ldots \ldots \ldots \ldots \ldots$

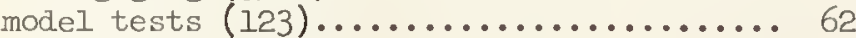

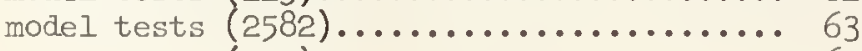

performance $(123) \ldots \ldots \ldots \ldots \ldots \ldots . . . \ldots . . . .62$
Turbines

tests $(3111)$

(3)

tip clearance $(3763) \ldots \ldots \ldots \ldots \ldots \ldots \ldots$

vane moments $(896) \ldots \ldots \ldots \ldots \ldots \ldots \ldots \ldots \ldots \ldots$

velocity profile ( 3785$)$,

Turbulence

boundary layer (3798)

created by fish $(3537)$.

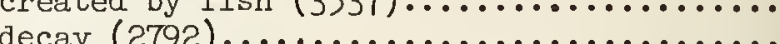

diffusion ( 3709 )

gas phase, two-pha

measurement, apparatus $(73) \ldots \ldots \ldots \ldots \ldots \ldots$

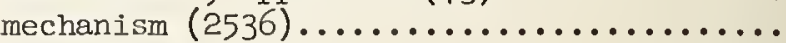

mechanism of $(2840)$

rough surfaces $(3427) \ldots \ldots \ldots \ldots \ldots \ldots \ldots$

stimulation (1506).

structure (3813)

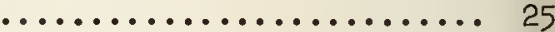

water measurements $(3486) \ldots \ldots \ldots \ldots \ldots \ldots . \ldots \ldots$

Turbulence control, screens (3495).......... 74

Turbulence entrainment $(3670) \ldots \ldots \ldots \ldots \ldots .4$

Turbulence levels, measurement of (3539)..... 100

Turbulence, generation

pulsating viscous flow (3780)

Turbulent flow, corners (3812).................. 62

Valves

butterfly $(1603) \ldots \ldots \ldots \ldots \ldots \ldots \ldots . \ldots . \ldots 48$

butterfly $(4044) \ldots \ldots \ldots \ldots \ldots \ldots . \ldots . \ldots 204$

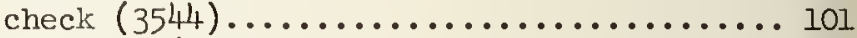

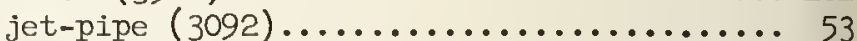

Valves, butterfly

cavitation characteristic (3777)........61

torque characteristic $(3777) \ldots \ldots \ldots \ldots \ldots 6$..........

Velocities

mass-transport (3666)..................207

Velocities, low

measurement of $(3082) \ldots \ldots \ldots \ldots \ldots \ldots . \ldots 4$

Velocity distribution

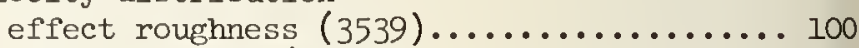

tube entrances $(3480) \ldots \ldots \ldots \ldots \ldots \ldots \ldots . \ldots 6$

Velocity measurement $(3074) \ldots \ldots \ldots \ldots \ldots \ldots . . .43$

Velocity measurement

electro-magnetic $(73) \ldots \ldots \ldots \ldots \ldots \ldots . . . .40$

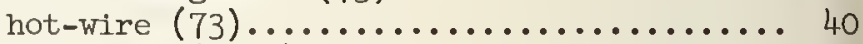

Virtual mass $(2064) \ldots \ldots \ldots \ldots \ldots \ldots \ldots \ldots \ldots . \ldots \ldots$

Virtual mass $(3779) \ldots \ldots \ldots \ldots \ldots \ldots \ldots \ldots \ldots \ldots . \ldots \ldots$

Virtual mass $(3782) \ldots \ldots \ldots \ldots \ldots \ldots \ldots \ldots \ldots . \ldots \ldots$

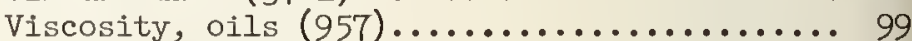

Vortex flow $(3434) \ldots \ldots \ldots \ldots \ldots \ldots \ldots \ldots . \ldots \ldots 4 . \ldots \ldots \ldots$

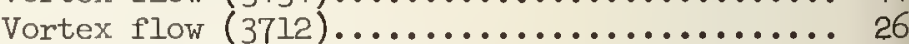

Vortex formation $(3776) \ldots \ldots \ldots \ldots \ldots \ldots \ldots . \ldots 1$

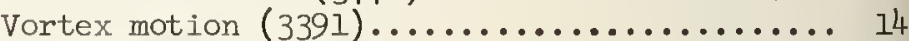

Vortex shedding $(2802) \ldots \ldots \ldots \ldots \ldots \ldots \ldots \ldots . \ldots 1$

Vortices, standing $(3766) \ldots \ldots \ldots \ldots \ldots \ldots \ldots \ldots$

Wake shapes, surface contours $(3169) \ldots \ldots \ldots . . . .83$

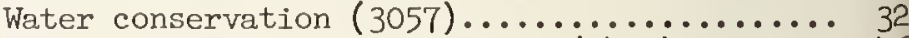

Water consumption, residential $(3437) \ldots \ldots \ldots .46$

Water, consumptive use (1966)................ 105

Water consumptive use

irrigated crops (2177)..........................

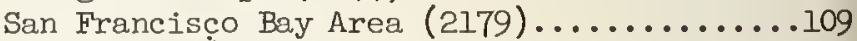

vegetation $(3560) \ldots \ldots \ldots \ldots \ldots \ldots \ldots \ldots \ldots$

Water control facilities, design (1723)...... 106

Water distribution systems, rate of flow (342) 35 Water exit

ellipsoidal bodies $(2537) \ldots \ldots \ldots \ldots \ldots . . .40$

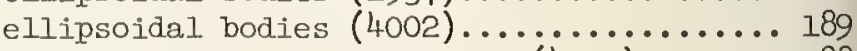

Water flow tests, high pressure $(4001) \ldots . . . .188$ Water hammer

high friction condition (3771)..........

59 
vater management, subsoil (3563).......... 118 vater measurement

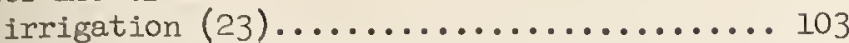

irrigation $(24) \ldots \ldots \ldots \ldots \ldots \ldots \ldots \ldots \ldots . \ldots \ldots$

irrigation $(26) \ldots \ldots \ldots \ldots \ldots \ldots \ldots \ldots \ldots . \ldots \ldots \ldots$

stream flow $(67) \ldots \ldots \ldots \ldots \ldots \ldots \ldots \ldots \ldots . \ldots \ldots$

technique development $(3124) \ldots \ldots \ldots \ldots \ldots 68$

Water movement, unsaturated soil (3868)...... 106

Water relations, surface-ground (3960)...... 171

Water resources

development $(3680) \ldots \ldots \ldots \ldots \ldots \ldots \ldots \ldots \ldots . \ldots \ldots$

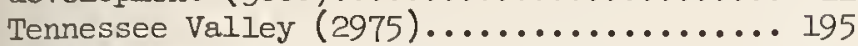

Water supplies

Colo. River Basin of Nevada (2652)........ 111

Water use

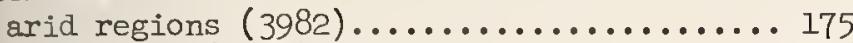

industrial $(3734) \ldots \ldots \ldots \ldots \ldots \ldots \ldots . \ldots \ldots$

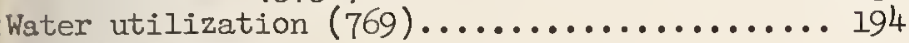

Waters, surface

characteristics (3059).

Watershed management

Albuquerque, N. M. (3570)(3571)......... 130

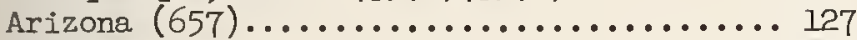

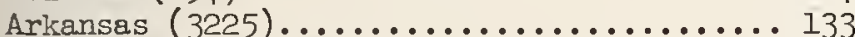

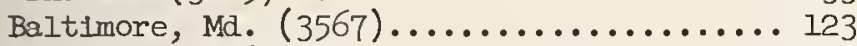

Beaver Creek (2913)................... 130

Continental Divide (377)............... 127

Grand Junction, Colo. (2657) ............. 129

Lake State research program (3885)......... 120

Laramie, Wyo. (3569)................. 130

Laramie, Wyo. (3891) (3892)(3893) . . . . . . . . 131

Michigan $(3890) \ldots \ldots \ldots \ldots \ldots \ldots \ldots \ldots \ldots \ldots . \ldots \ldots$

Newark, N. J. (3568) ................. 124

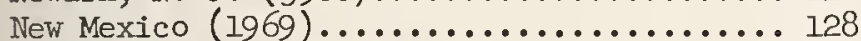

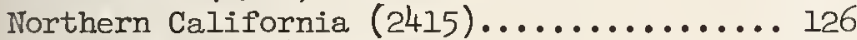

Northern Minn. (3887) .................. 121

Pennsylvania $(656)(2910) \ldots \ldots \ldots \ldots \ldots \ldots . \ldots 123$

research (2658)..................... 129

Southeastern United States $(380) \ldots . . \ldots \ldots . .132$

Southeastern Wisconsin $(3889)$............ 121

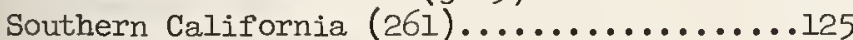

Tallahatchee Research Center (2914)....... 133

Trout Creek Colo. (3223)............... 130

Wayne County, Pa. (966)............... 123

Watershed-range management

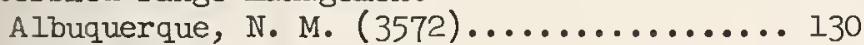

Albuquerque, N. M. $(3573) \ldots \ldots \ldots \ldots \ldots \ldots 131$

Watershed studies

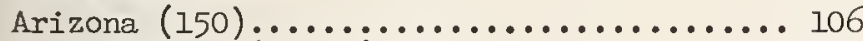

Beaver Creek (3222)(3224) .............. 130

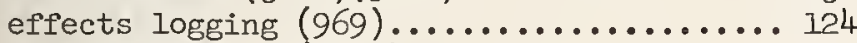

effects logging $(2654) \ldots \ldots \ldots \ldots \ldots \ldots \ldots \ldots$

Florida $(150) \ldots \ldots \ldots \ldots \ldots \ldots \ldots \ldots . \ldots \ldots \ldots$

forest influences $(377)$.............. 127

forest influences $(380) \ldots \ldots \ldots \ldots \ldots \ldots \ldots . \ldots 132$

forest influences $(656)(966)(1188) \ldots \ldots \ldots . . .123$

hydrologic cycle $(1764) \ldots \ldots \ldots \ldots \ldots \ldots . . . . .162$

hydrologic cycle $(2162) \ldots \ldots \ldots \ldots \ldots \ldots \ldots . . \ldots 1$

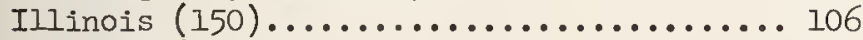

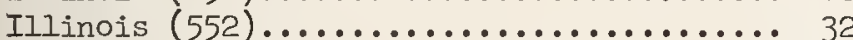

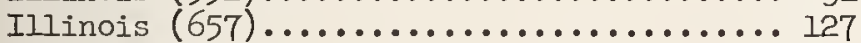

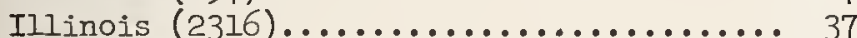

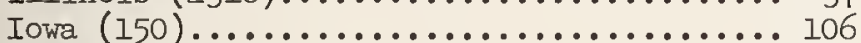

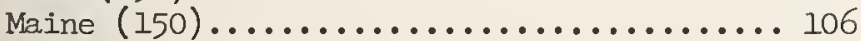

management $(261) \ldots \ldots \ldots \ldots \ldots \ldots \ldots \ldots \ldots \ldots . \ldots \ldots$

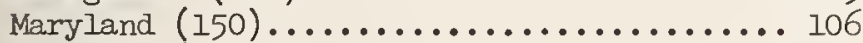

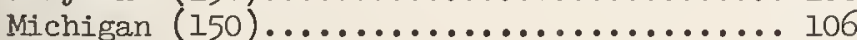

Nebraska $(150) \ldots \ldots \ldots \ldots \ldots \ldots \ldots \ldots \ldots . \ldots \ldots . . \ldots \ldots$

New Jersey $(150) \ldots \ldots \ldots \ldots \ldots \ldots \ldots \ldots . . \ldots \ldots$

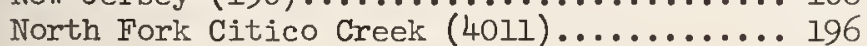

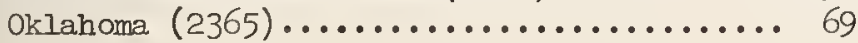

atershed studies

Parker Branch (3307)................ 195

Pine Tree $(3309) \ldots \ldots \ldots \ldots \ldots \ldots . \ldots . \ldots . \ldots 196$

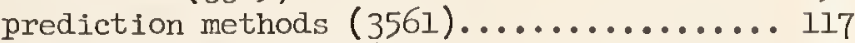

Ralston Creek, Iowa $(66) \ldots . . . \ldots \ldots . . . .40$

Rapid Creek, Iowa (68).............. 40 rehabilitation depleted slopes (3562)..... 118

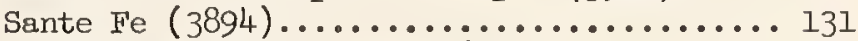

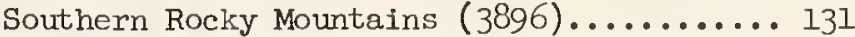

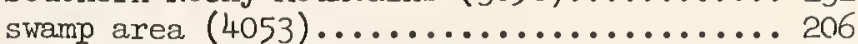

Tennessee River Valley (768)............ 194

Tennessee River Valley (780)............ 195

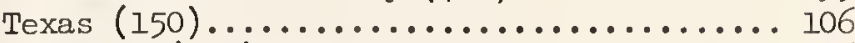

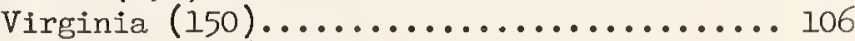

White Hollow $(3308) \ldots \ldots \ldots \ldots \ldots \ldots \ldots \ldots$

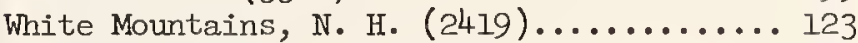

Wisconsin $(150) \ldots \ldots \ldots \ldots \ldots \ldots . \ldots \ldots . \ldots \ldots$

Yazoo River, Miss. (3869)............... 108

Wave absorbers, evaluation of $(3818) \ldots \ldots \ldots 78$

Wave action

beaches $(181) \ldots \ldots \ldots \ldots \ldots \ldots \ldots \ldots . \ldots \ldots \ldots$

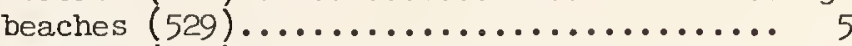

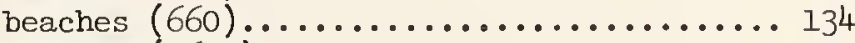

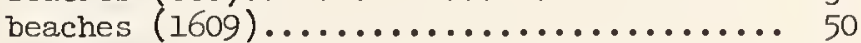

breakwaters

harbors, Duluth-Superior (2685)....... 146

rubble-mound (999)................. 141

East Passage, Narragansett Bay (3590)..... 153

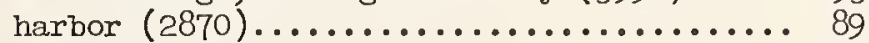

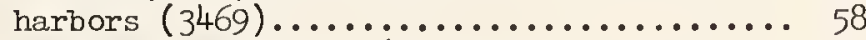

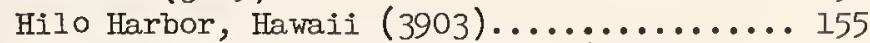

Northumberland Strait Causeway (4048)...... 204

shore protection works (529)........... 5

Wave forces

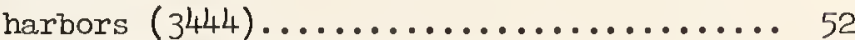

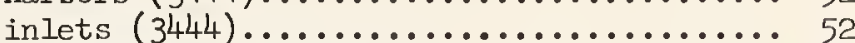

moored objects $(3750) \ldots \ldots \ldots \ldots \ldots \ldots \ldots \ldots$

Wave forecasting

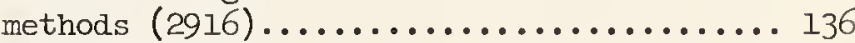

methods $(3520) . . . \ldots \ldots \ldots . . . \ldots . . . . .90$

Wave propagation

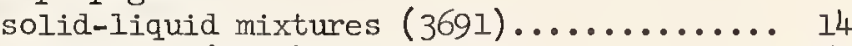

Wave research $(2357) \ldots \ldots \ldots \ldots \ldots \ldots \ldots \ldots \ldots . \ldots \ldots$

Wave setup, beaches $(3228) \ldots \ldots \ldots \ldots \ldots \ldots \ldots 137$

Wave studies $(3120) \ldots \ldots \ldots \ldots \ldots \ldots \ldots \ldots \ldots . \ldots . \ldots 6$

Waves

forces, submerged structures (2659)...... 136

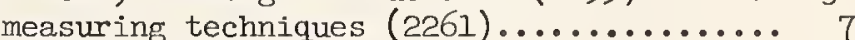

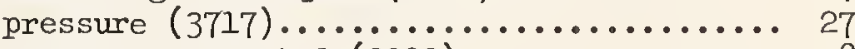

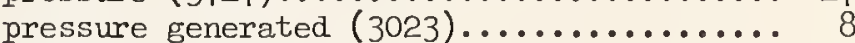

propagation $(3684) \ldots \ldots \ldots \ldots \ldots \ldots \ldots \ldots \ldots$

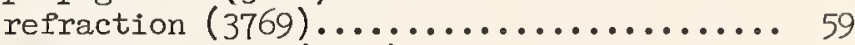

reproduction of $(3029) \ldots \ldots \ldots \ldots \ldots \ldots \ldots . . . \ldots 11$

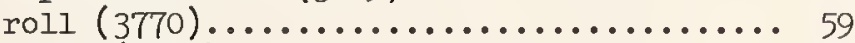

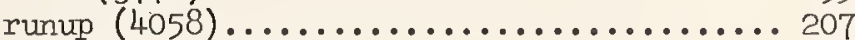

runup, shore structures $(2661) \ldots \ldots \ldots \ldots . . . .136$

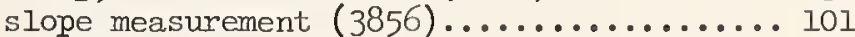

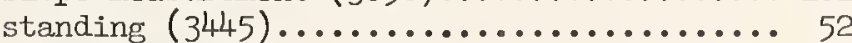

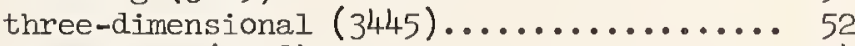

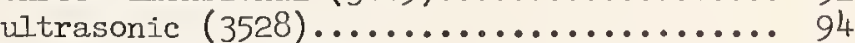

wind generated $(3855) \ldots \ldots \ldots \ldots \ldots \ldots \ldots \ldots$

Waves, gravity

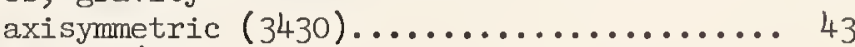

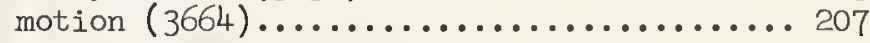

Waves, internal

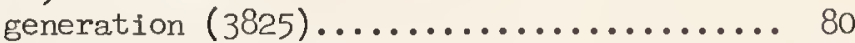

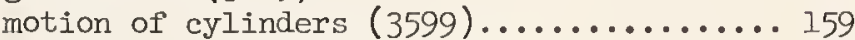

propagation $(3825) \ldots \ldots \ldots \ldots \ldots \ldots \ldots . \ldots . \ldots . \ldots$

Waves, internal progressive oscillatory

damping $(3600)$........................ 159

Waves, surface, characteristics (660)........ 134 
Waves, surface

energy losses (2298).................. 29

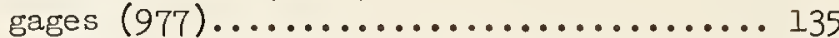

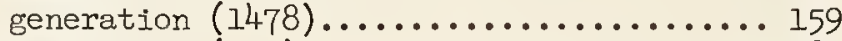

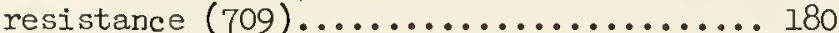

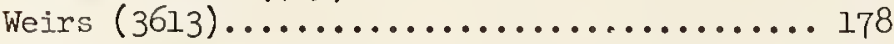

Weirs

basic research (149)............... 99

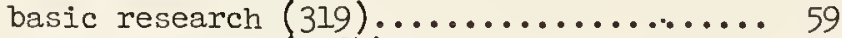

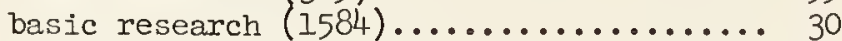

basic research $(2578) \ldots \ldots \ldots \ldots \ldots \ldots \ldots \ldots . \ldots \ldots$

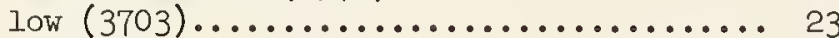

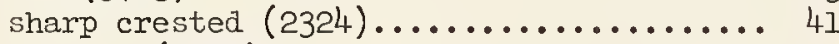

V-notch $(1709) \ldots \ldots \ldots \ldots \ldots \ldots \ldots . . \ldots \ldots$
Weirs, adjustable Wells

discharge capacity (3611)............. 178

construction $(2576) \ldots \ldots \ldots \ldots \ldots \ldots \ldots . \ldots \ldots$

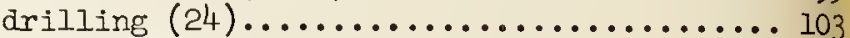

Wells, irrigation

sediment retention $(3215) \ldots \ldots \ldots \ldots \ldots \ldots 112$

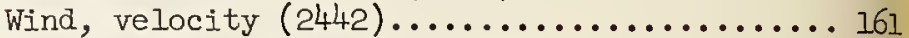

Wind and water behavior $(3051) \ldots . \ldots \ldots \ldots . .29$

Wind tides

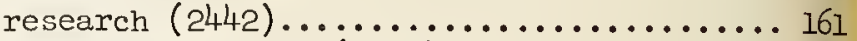

Wind tunnel facility $(3707) \ldots \ldots \ldots \ldots \ldots . . . . . . .24$

Wind waves

canals (2953).......................... 176 
Luther H. Hodges, Secretary

NATIONAL BUREAU OF STANDARDS

A. V. Astin, Director

\section{THE NATIONAL BUREAU OF STANDARDS}

The scope of activities of the National Bureau of Standards at its major laboratories in Washington, D.C., and Boulder, Colorado, is suggested in the following listing of the divisions and sections engaged in technical work. In general, each section carries out specialized research, development, and engineering in the field indicated by its title. A brief description of the activities, and of the resultant publications, appears on the inside of the front cover.

\section{WASHINGTON, D.C.}

Electricity. Resistance and Reactance. Electrochemistry. Electrical Instruments. Magnetic Measurements. Dielectrics.

Metrology. Photometry and Colorimetry. Refractometry. Photographic Research. Length. Engineering Metrology. Mass and Scale. Volumetry and Densimetry.

Heat. Temperature Physics. Heat Measurements. Cryogenic Physics. Equation of State. Statistical Physics.

Radiation Physics. X-Ray. Radioactivity. Radiation Theory. High Energy Radiation. Radiological Equipment. Nucleonic Instrumentation. Neutron Physics.

Analytical and Inorganic Chemistry. Pure Substances. Spectrochemistry. Solution Chemistry. Standard Reference Materials. Applied Analytical Research.

Mechanics. Sound. Pressure and Vacuum. Fluid Mechanics. Engineering Mechanics. Rheology. Combustion Controls.

Organic and Fibrous Materials. Rubber. Textiles. Paper. Leather. Testing and Specifications. Polymer Structure. Plastics. Dental Research.

Metallurgy. Thermal Metallurgy. Chemical Metallurgy. Mechanical Metallurgy. Corrosion. Metal Physics. Electrodeposition.

Mineral Products. Engineering Ceramics. Glass. Refractories. Enameled Metals. Crystal Growth. Physical Properties Constitution and Microstructure.

Building Research. Structural Engineering. Fire Research. Mechanical Systems. Organic Building Materials. Codes and Safety Standards. Heat Transfer. Inorganic Building Materials.

Applied Mathematics. Numerical Analysis. Computation. Statistical Engineering. Mathematical Physics. Data Processing Systems. Components and Techniques. Digital Circuitry. Digital Systems. Analog Systems. Applications Engineering.

Atomic Physics. Spectroscopy. Infrared Spectroscopy. Solid State Physics. Electron Physics. Atomic Physics.

Instrumentation. Engineering Electronics. Electron Devices. Electronic Instrumentation. Mechanical Instruments. Basic Instrumentation.

Physical Chemistry. Thermochemistry. Surface Chemistry. Organic Chemistry. Molecular Spectroscopy. Molecular Kinetics. Mass Spectrometry. Molecular Structure and Radiation Chemistry.

- Office of Weights and Measures.

\section{BOULDER, COLO.}

Cryogenic Engineering. Cryogenic Equipment. Cryogenic Processes. Properties of Materials. Gas Liquefaction.

Ionosphere Research and Propagation. Low Frequency and Very Low Frequency Research. Ionosphere Research. Prediction Services. Sun-Earth Relationships. Field Engineering. Radio Warning Service.

Radio Propagation Engineering. Data Reduction Instrumentation. Radio Noise. Tropospheric Measurements. Tropospheric Analysis. Propagation-Terrain Effects. Radio-Meteorology. Lower Atmosphere Physics.

Radio Standards. High Frequency Electrical Standards. Radio Broadcast Service. Radio and Microwave Materials. Atomic Frequency and Time Interval Standards. Electronic Calibration Center. MillimeterWave Research. Microwave Circuit Standards.

Radio Systems. High Frequency and Very High Frequency Research. Modulation Research. Antenna Research. Navigation Systems. Space Telecolnmunications.

Upper Atmosphere and Space Physics. Upper Atmosphere and Plasma Physics. Ionosphere and Exosphere Scatter. Airglow and Aurora. Ionospheric Radio Astronomy. 


\section{Hydraulic Research in the United States}

Guides to projects conducted by various hydraulic and hydrologic laboratories in the United States and Canada during 1951, 1952, 1953, 1954, 1955, 1956, 1957, 1958, and 1959. Project reports cover work done at 85 private or State laboratories in the United States, 24 Federal laboratories, and 10 Canadian laboratories. These publications outline individual projects on nearly 200 subjects in the field.

Order:

NBS Miscellaneous Publication 201, Hydraulic Research in the United States, 1951, 190 pages. Price: $\$ 1.25$.

NBS Miscellaneous Publication 205, Hydraulic Research in the United States, 1952, 200 pages. Price: $\$ 1.00$.

NBS Miscellaneous Publication 208, Hydraulic Research in the United States, 1953, 215 pages. Price: $\$ 1.25$.

NBS Miscellaneous Publication 210, Hydraulic Research in the United States, 1954, 207 pages. Price: $\$ 1.25$.

NBS Miscellaneous Publication 218, Hydraulic Research in the United States, 1956, 216 pages. Price: $\$ 1.50$.

NBS Miscellaneous Publication 224, Hydraulic Research in the United States, 1958, 168 pages. Price: $\$ 1.25$.

NBS Miscellaneous Publication 227, Hydraulic Research in the United States, 1959, 188 pages. Price: $\$ 1.25$.

NBS Miscellaneous Publication 231, Hydraulic Research in the United States, 1960, 190 pages. Price: $\$ 1.00$. 